\title{
Efeito dos envelhecimentos termo-oxidativo e foto-oxidativo sobre propriedades reológicas de ligantes asfálticos modificados
}

Dissertação apresentada ao Departamento de Engenharia de Transportes da Escola de Engenharia de São Carlos, da Universidade de São Paulo, como parte dos requisitos para obtenção do título de Mestre em Engenharia Civil.

Área de Concentração: Infraestrutura de Transportes

Orientador: Prof. Associado Adalberto Leandro Faxina

São Carlos

Novembro 
AUTORIZO A REPRODUÇÃO E DIVULGAÇÃO TOTAL OU PARCIAL DESTE TRABALHO, POR QUALQUER MEIO CONVENCIONAL OU ELETRÔNICO, PARA FINS DE ESTUDO E PESQUISA, DESDE QUE CITADA A FONTE.

Ficha catalográfica preparada pela Seção de Tratamento da Informação do Serviço de Biblioteca - EESC-USP

\footnotetext{
N244e Efeito dos envelhecimentos termo-oxidativo e fotooxidativo sobre propriedades reológicas de ligantes asfálticos modificados. / Thalita Cristina Brito Nascimento; orientador Adalberto Leandro Faxina. São Carlos, 2015.

Dissertação (Mestrado) - Programa de Pós-Graduação em Engenharia de Transportes e Área de Concentração em Infraestrutura de Transporte -- Escola de Engenharia de São Carlos da Universidade de São Paulo, 2015.

1. Envelhecimento a curto prazo 2. Envelhecimento a longo prazo. 3. Radiação ultravioleta. 4. Ligantes asfálticos modificados. I. Título.
} 


\section{FOLHA DE JULGAMENTO}

Candidata: Engenheira THALITA CRISTINA BRITO NASCIMENTO.

Título da dissertação: "Efeito dos envelhecimentos termo-oxidativo e fotooxidativo sobre propriedades reológicas de ligantes asfálticos modificados".

Data da defesa: 13/11/2015

\section{Comissão Julgadora:}

Prof. Associado Adalberto Leandro Faxina (Orientador)

(Escola de Engenharia de São Carlos/EESC)

Profa. Dra. Ana Paula Furlan

(Escola de Engenharia de São Carlos/EESC)

Prof. Dr. Benedito Coutinho Neto

(Instituto Federal do Pará/IFPA)

\section{Resultado:}

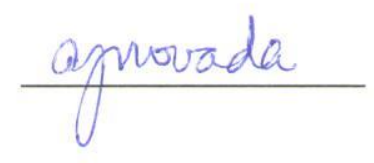

Aprovada

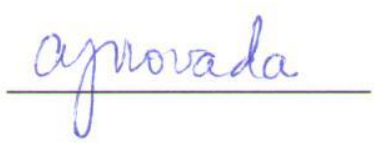

Coordenador do Programa de Pós-Graduação em Engenharia de Transportes: Prof. Associado Paulo Cesar Lima Segantine

Presidente da Comissão de Pós-Graduação:

Prof. Associado Paulo Cesar Lima Segantine 

A minha mãe Marina Brito, pelo apoio incondicional. 



\section{AGRADECIMENTOS}

A Deus por minha vida, minha família, minha fé, pelos sonhos colocados no meu coração e por me permitir lutar por eles, pela força nos momentos difíceis, por todo amor e misericórdia.

A minha mãe Marina, por todo empenho, dedicação e paciência, por ser minha base e meu porto seguro. Ao meu pai João Vianey, por torcer por mim e me apoiar sempre. Ao meu irmão Marcus, por ser um exemplo para mim de pessoa batalhadora e honesta. A minha cunhada Kelly, pela amizade e pelo meu sobrinho João Luiz, que está trazendo ao mundo para a alegria da família.

Ao professor Adalberto Leandro Faxina, por ter aceitado me orientar e ter desempenhado seu papel com excelência. Por ter sido presente, compreensivo, dedicado e por todo aprendizado que pude adquirir com ele ao longo desses anos.

À Escola de Engenharia de São Carlos - EESC e à Coordenação de Aperfeiçoamento de Pessoal de Nível Superior - CAPES.

Aos professores do STT por todo conhecimento transmitido. Ao professor Glauco Fabri por todo aprendizado que tive na monitoria (PAE). Aos funcionários do STT por viabilizarem e facilitarem nosso percurso acadêmico. A dona Benê, por seu café e carinho diário. Ao Antonio Carlos Gigante, Paulo Toyama, João Pereira Filho, Aline Vale e Ygor Mello por todo apoio nas atividades de laboratório.

À professora Sandra de Aguiar Soares e sua equipe da Universidade Federal do Ceará, por ter possibilitado a realização dos ensaios químicos e por toda presteza que tiveram comigo.

Ao professor Benedito Coutinho Neto e professora Maísa Tobias, por terem me inspirado e apoiado, ainda na graduação, na minha escolha profissional.

Às amigas do Pará Karla, Maiara e Natália, por nosso laço de amizade que, independente da distância, continua firme. Pelas visitas, momentos de alegria e descontração.

Aos colegas de orientação Andressa, Lucas, Matheus e Javier, por toda ajuda que me deram, por nossas trocas de conhecimento e discussões.

Aos amigos do STT e de São Carlos, com quem compartilhei tantos momentos bons. Vocês tornaram meus dias leves, felizes e agradáveis, cada um com seu jeito particular: Andressa, Bruno, Murilo, Angélica, Diego Camargo, Artur, Monique, Fernando Piva, Cassiano, Andrea, Marcela, Maria José, Iara, Miguel, Felipe, Lucas, Igor, Thiago, Heymar, Fábio, Mateus Silva, Júlia, Diogo e Alysson. 

NASCIMENTO, T. C. B. Efeito dos envelhecimentos termo-oxidativo e foto-oxidativo sobre propriedades reológicas de ligantes asfálticos modificados. 2015. 274 p. Dissertação (Mestrado) Escola de Engenharia de São Carlos, Universidade de São Paulo, São Carlos, 2015.

O envelhecimento dos ligantes asfálticos possui uma grande influência sobre as propriedades mecânicas das misturas asfálticas. As especificações atuais limitam determinados índices ou parâmetros de envelhecimento, visando contornar o endurecimento excessivo do ligante asfáltico, porém, não levam em conta o efeito da radiação ultravioleta (UV). O objetivo deste trabalho é avaliar o efeito dos envelhecimentos termo-oxidativo e foto-oxidativo sobre as propriedades reológicas de um CAP puro e 11 ligantes asfálticos modificados, incluindo polímeros elastoméricos e plastoméricos, borracha moída de pneus e ácido polifosfórico, incluindo também combinações destes aditivos. Os ligantes asfálticos, com classificação por grau de desempenho PG 76-XX, preparados com base em um CAP 50-70 com classificação PG 64-22, foram previamente envelhecidos a curto prazo na estufa RTFO e posteriormente submetidos ao envelhecimento foto-oxidativo em uma estufa UV sob dois níveis de radiação, $0,68 \mathrm{~W} / \mathrm{m}^{2}$ e $1,00 \mathrm{~W} / \mathrm{m}^{2}$, por um período de $240 \mathrm{~h}$. Para efeitos de comparação dos resultados, as mesmas amostras foram submetidas ao envelhecimento termo-oxidativo na estufa PAV. As amostras virgens e envelhecidas a curto prazo foram caracterizadas por meio de ensaios empíricos. Os resíduos obtidos nos envelhecimentos foram submetidos a ensaios no reômetro de cisalhamento dinâmico (DSR). Propriedades reológicas dos ligantes asfálticos foram analisadas por meio de curvas-mestre e do ensaio de fadiga LAS. Algumas amostras foram caracterizadas quimicamente por meio de espectroscopia no infravermelho (FTIR), cromatografia por permeação em gel (GPC) e do fracionamento SARA. Para a maioria das amostras os procedimentos PAV e UV a $0,68 \mathrm{~W} / \mathrm{m}^{2}$ apresentam certa equivalência, em termos da capacidade de alterar as propriedades reológicas analisadas. O ligante asfáltico que mostrou ser menos sensível ao envelhecimento PAV foi o $\mathrm{CAP}+\mathrm{SBR}$, o que demonstrou ser menos sensível ao envelhecimento $\mathrm{UV}$ a $0,68 \mathrm{~W} / \mathrm{m}^{2}$ foi o $\mathrm{CAP}+\mathrm{EVA}$, e o que demonstrou menor sensibilidade ao envelhecimento $\mathrm{UV}$ a $1,00 \mathrm{~W} / \mathrm{m}^{2}$ foi o $\mathrm{CAP}+\mathrm{SBS}$. O CAP+SBS+PPA foi a amostra que apresentou maior sensibilidade ao envelhecimento PAV e UV a $1,00 \mathrm{~W} / \mathrm{m}^{2}$.

Palavras-chave: Envelhecimento a curto prazo. Envelhecimento a longo prazo. Radiação ultravioleta. Ligantes asfálticos modificados. 



\section{NASCIMENTO, T. C. B. Effect of termo-oxidative and ultraviolet aging on the rheological properties} of modified asphalt binders. 274 p. Thesis (Master of Transportation Engineering) - São Carlos School of Engineering, University of São Paulo, São Carlos, 2015.

Aging of the asphalt binders has a great influence on the mechanical properties of asphalt mixtures. The current specifications establish limits for some indexes or aging parameters in an attempt to avoid the excessive hardening of the asphalt binder; however, they do not take into account the effects of ultraviolet (UV) irradiation. The objective of this study is to analyze the impact of thermo-oxidative and UV aging methods on the rheological properties of a base asphalt cement (AC) and 11 formulations prepared with additives, i. e., elastomeric and plastomeric polymers, ground tire rubber and polyphosphoric acid. Combinations these additives were also included in the study. The modified asphalt binders are graded as PG-76 XX in the Superpave specification, whereas the 50-70 base AC is graded as PG 64-22 in the same specification. The materials were first aged in the rolling thin-film oven (RTFO), and then submitted to photo-oxidative aging in an UV oven at two irradiation levels $\left(0.68 \mathrm{~W} / \mathrm{m}^{2}\right.$ and $\left.1.00 \mathrm{~W} / \mathrm{m}^{2}\right)$ for $240 \mathrm{~h}$. For comparison purposes, these formulations were also subjected to thermo-oxidative aging in the pressurized aging vessel (PAV). The unaged and short-term aged samples were characterized by means of empirical tests. The residues obtained in the RTFOT, PAV e UV aging methods were tested in the dynamic shear rheometer (DSR). The rheological properties of asphalt binders were analyzed by means of master curves and the linear amplitude sweep (LAS) fatigue test. Some samples were chemically characterized by the Fourier transform infrared spectroscopy (FTIR), the gel permeation chromatography (GPC) and the SARA fractionation techniques. The PAV and the UV procedures at $0.68 \mathrm{~W} / \mathrm{m}^{2}$ show some similarities for many formulations in terms of the ability to change their rheological properties. The AC+SBR was found to be less sensitive to PAV aging than the other studied binders, whereas the AC+EVA was the less sensitive material to UV aging at $0.68 \mathrm{~W} / \mathrm{m}^{2}$ and the AC+SBS showed the lowest sensitivity to UV aging at $1.00 \mathrm{~W} / \mathrm{m}^{2}$. The AC+SBS+PPA was the most sensitive formulation to PAV and UV aging at $1.00 \mathrm{~W} / \mathrm{m}^{2}$.

Keywords: Short-term aging. Long-term aging. Ultraviolet irradiation. Modified asphalt binders. 



\section{LISTA DE TABELAS}

Tabela 2.1- Distribuição da irradiância solar (média anual) que atinge o topo da atmosfera (FREDERICK et al., 1989)

Tabela 2.2 - Principais variáveis do envelhecimento UV abordada por alguns autores

Tabela $4.1-$

Quantas vezes $\mathrm{G}^{*}$ virgem aumentou ou diminuiu em relação aos valores referentes ao ligante asfáltico de base, a $25^{\circ} \mathrm{C}$

Tabela 4.2 - Quantas vezes $\mathrm{G}^{*}$ RTFOT aumentou ou diminuiu em relação aos valores referentes ao ligante asfáltico de base, a $25^{\circ} \mathrm{C}$

Tabela 4.3 - Quantas vezes $G^{*}$ PAV aumentou ou diminuiu em relação aos valores referentes ao ligante asfáltico de base, a $25^{\circ} \mathrm{C}$

Tabela 4.4 - Quantas vezes $\mathrm{G}^{*} \mathrm{UV} 0,68 \mathrm{~W} / \mathrm{m}^{2}$ aumentou ou diminuiu em relação aos valores referentes ao ligante asfáltico de base, a $25^{\circ} \mathrm{C}$

Tabela $4.5-$

Quantas vezes $\mathrm{G}^{*} \mathrm{UV} 1,00 \mathrm{~W} / \mathrm{m}^{2}$ aumentou ou diminuiu em relação aos valores referentes ao ligante asfáltico de base, a $25^{\circ} \mathrm{C}$

Tabela 4.6 - Ordenamento dos ligantes asfálticos modificados em relação ao CAP 50/70 puro, com base nos valores de $\mathrm{G}^{*}$ a $25^{\circ} \mathrm{C}$

Tabela 4.7 - $\quad$ Quantas vezes $\boldsymbol{\delta}$ virgem aumentou ou diminuiu em relação aos valores referentes ao ligante asfáltico de base, a $25^{\circ} \mathrm{C}$

Tabela $4.8-$

Quantas vezes $\boldsymbol{\delta}$ RTFOT aumentou ou diminuiu em relação aos valores referentes ao ligante asfáltico de base, a $25^{\circ} \mathrm{C}$

Tabela 4.9 - Quantas vezes $\boldsymbol{\delta}$ PAV aumentou ou diminuiu em relação aos valores referentes ao ligante asfáltico de base, a $25^{\circ} \mathrm{C}$

Tabela 4.10 - Quantas vezes $\boldsymbol{\delta}$ UV 0,68 W/m² aumentou ou diminuiu em relação aos valores referentes ao ligante asfáltico de base, a $25^{\circ} \mathrm{C}$

Tabela 4.11 - Quantas vezes $\boldsymbol{\delta}$ UV 1,00 W/m² aumentou ou diminuiu em relação aos valores referentes ao ligante asfáltico de base, a $25^{\circ} \mathrm{C}$

Tabela 4.12 - Ordenamento dos ligantes asfálticos modificados em relação ao CAP 50/70 puro, com base nos valores de $\delta$

Tabela 4.13 - Quantas vezes $G^{*}$ aumentou ou diminuiu e quantos graus $\delta$ aumentou ou diminuiu devido aos envelhecimentos a longo prazo no PAV e na estufa UV em relação ao CAP 50/70 puro envelhecido no RTFO, a $25^{\circ} \mathrm{C}$

Tabela 4.14- Quantas vezes $G^{*}$ aumentou ou diminuiu e quantos graus $\delta$ aumentou ou diminuiu devido aos envelhecimentos a longo prazo no PAV e na estufa UV em relação ao CAP 50/70+PPA envelhecido no RTFO, a $25^{\circ} \mathrm{C}$

Tabela 4.15 - Quantas vezes $G^{*}$ aumentou ou diminuiu e quantos graus $\delta$ aumentou ou diminuiu devido aos envelhecimentos a longo prazo no PAV e na estufa UV em relação ao CAP 50/70+borracha envelhecido no RTFO, a $25^{\circ} \mathrm{C}$

Tabela 4.16- Quantas vezes $G^{*}$ aumentou ou diminuiu e quantos graus $\delta$ aumentou ou diminuiu devido aos envelhecimentos a longo prazo no PAV e na estufa UV em relação ao CAP 50/70+borracha+PPA envelhecido no RTFO, a $25^{\circ} \mathrm{C}$

Tabela 4.17- Quantas vezes $G^{*}$ aumentou ou diminuiu e quantos graus $\delta$ aumentou ou diminuiu devido aos envelhecimentos a longo prazo no PAV e na estufa UV em relação ao CAP 50/70+SBS envelhecido no RTFO, a $25^{\circ} \mathrm{C}$ 
Tabela 4.18 - Quantas vezes $\mathrm{G}^{*}$ aumentou ou diminuiu e quantos graus $\delta$ aumentou ou diminuiu devido aos envelhecimentos a longo prazo no PAV e na estufa UV em relação ao CAP 50/70+SBS+PPA envelhecido no RTFO, a $25^{\circ} \mathrm{C}$

Tabela 4.19 - Quantas vezes $G^{*}$ aumentou ou diminuiu e quantos graus $\delta$ aumentou ou diminuiu devido aos envelhecimentos a longo prazo no PAV e na estufa UV em relação ao CAP 50/70+EVA envelhecido no RTFO, a $25^{\circ} \mathrm{C}$

Tabela 4.20 - Quantas vezes $G^{*}$ aumentou ou diminuiu e quantos graus $\delta$ aumentou ou diminuiu devido aos envelhecimentos a longo prazo no PAV e na estufa UV em relação ao CAP 50/70+EVA+PPA envelhecido no RTFO, a $25^{\circ} \mathrm{C}$

Tabela 4.21 - Quantas vezes $G^{*}$ aumentou ou diminuiu e quantos graus $\delta$ aumentou ou diminuiu devido aos envelhecimentos a longo prazo no PAV e na estufa UV em relação ao CAP 50/70+PE envelhecido no RTFO, a $25^{\circ} \mathrm{C}$

Tabela 4.22 - Quantas vezes $\mathrm{G}^{*}$ aumentou ou diminuiu e quantos graus $\delta$ aumentou ou diminuiu devido aos envelhecimentos a longo prazo no PAV e na estufa UV em relação ao CAP 50/70+PE+PPA envelhecido no RTFO, a $25^{\circ} \mathrm{C}$

Tabela 4.23 - Quantas vezes $G^{*}$ aumentou ou diminuiu e quantos graus $\delta$ aumentou ou diminuiu devido aos envelhecimentos a longo prazo no PAV e na estufa UV em relação ao CAP 50/70+SBR envelhecido no RTFO, a $25^{\circ} \mathrm{C}$

Tabela 4.24 - Quantas vezes $G^{*}$ aumentou ou diminuiu e quantos graus $\delta$ aumentou ou diminuiu devido aos envelhecimentos a longo prazo no PAV e na estufa UV em relação ao CAP 50/70+SBR+PPA envelhecido no RTFO, a $25^{\circ} \mathrm{C}$

Tabela 4.25 - Ordenamentos finais da sensibilidade ao envelhecimento nos três níveis de envelhecimento a longo prazo e ordenamento geral da sensibilidade ao envelhecimento, à luz dos valores de $\mathrm{G}^{*} \mathrm{e} \delta \mathrm{a} 25^{\circ} \mathrm{C}$

Tabela 4.26 - Variações de $\mathrm{G}^{*}, \delta, \mathrm{G}^{*} / \operatorname{sen} \delta$ e $\mathrm{G}^{*} . \operatorname{sen} \delta$ dos ligantes asfálticos modificados em relação aos valores do 50/70 puro, a $10 \mathrm{rad} / \mathrm{s}$, em função da temperatura, na condição PAV

Tabela 4.27 - Variações de $G^{*}, \delta, G^{*} / \operatorname{sen} \delta$ e $G^{*}$.sen $\delta$ dos ligantes asfálticos modificados em relação aos valores do 50/70 puro, a $10 \mathrm{rad} / \mathrm{s}$, em função da temperatura, na condição UV a $0,68 \mathrm{~W} / \mathrm{m}^{2}$

Tabela 4.28 - Variações de $G^{*}, \delta, G^{*} / \operatorname{sen} \delta$ e $G^{*}$.sen $\delta$ dos ligantes asfálticos modificados em relação aos valores do 50/70 puro, a $10 \mathrm{rad} / \mathrm{s}$, em função da temperatura, na condição de envelhecimento a longo prazo na estufa UV a 1,00 W/m²

Tabela 4.29 - Variações de $G^{*}, \delta, G^{*} / \operatorname{sen} \delta$ e $G^{*}$.sen $\delta$ do CAP 50/70 puro nas condições PAV e UV em relação aos valores do material envelhecido a curto prazo, a 10 $\mathrm{rad} / \mathrm{s}$, em função da temperatura

Tabela 4.30 - Variações de $\mathrm{G}^{*}, \delta, \mathrm{G}^{*} / \operatorname{sen} \delta$ e $\mathrm{G}^{*} . \operatorname{sen} \delta$ do CAP 50/70-PPA nas condições PAV e UV em relação aos valores do material envelhecido a curto prazo, a 10 $\mathrm{rad} / \mathrm{s}$, em função da temperatura

Tabela 4.31 - Variações de $\mathrm{G}^{*}, \delta$, $\mathrm{G}^{*} / \operatorname{sen} \delta$ e $\mathrm{G}^{*}$.sen $\delta$ do CAP 50/70-borracha nas condições PAV e UV em relação aos valores do material envelhecido a curto prazo, a 10 $\mathrm{rad} / \mathrm{s}$, em função da temperatura

Tabela 4.32 - Variações de $\mathrm{G}^{*}, \delta, \mathrm{G}^{*} / \operatorname{sen} \delta$ e $\mathrm{G}^{*}$.sen $\delta$ do CAP 50/70-borracha-PPA nas condições PAV e UV em relação aos valores do material envelhecido a curto prazo, a $10 \mathrm{rad} / \mathrm{s}$, em função da temperatura 
Tabela 4.33 - Variações de $\mathrm{G}^{*}, \delta$, $\mathrm{G}^{*} / \operatorname{sen} \delta$ e $\mathrm{G}^{*}$.sen $\delta$ do CAP 50/70-SBS nas condições PAV e UV em relação aos valores do material envelhecido a curto prazo, a 10 $\mathrm{rad} / \mathrm{s}$, em função da temperatura

Tabela 4.34- Variações de $\mathrm{G}^{*}, \delta, \mathrm{G}^{*} / \operatorname{sen} \delta$ e $\mathrm{G}^{*}$.sen $\delta$ do CAP 50/70-SBS-PPA nas condições PAV e UV em relação aos valores do material envelhecido a curto prazo, a $10 \mathrm{rad} / \mathrm{s}$, em função da temperatura

Tabela 4.35 - Variações de $\mathrm{G}^{*}, \delta, \mathrm{G}^{*} / \operatorname{sen} \delta$ e $\mathrm{G}^{*}$.sen $\delta$ do CAP 50/70-EVA nas condições PAV e UV em relação aos valores do material envelhecido a curto prazo, a 10 $\mathrm{rad} / \mathrm{s}$, em função da temperatura

Tabela 4.36 - Variações de $G^{*}, \delta, G^{*} / \operatorname{sen} \delta$ e $G^{*}$.sen $\delta$ do CAP 50/70-EVA-PPA nas condições PAV e UV em relação aos valores do material envelhecido a curto prazo, a $10 \mathrm{rad} / \mathrm{s}$, em função da temperatura

Tabela 4.37 - Variações de $\mathrm{G}^{*}, \delta, \mathrm{G}^{*} / \operatorname{sen} \delta$ e $\mathrm{G}^{*}$.sen $\delta$ do CAP 50/70-PE nas condições PAV e UV em relação aos valores do material envelhecido a curto prazo, a $10 \mathrm{rad} / \mathrm{s}$, em função da temperatura

Tabela 4.38 - Variações de $G^{*}, \delta, G^{*} / \operatorname{sen} \delta$ e $G^{*}$.sen $\delta$ do CAP 50/70-PE-PPA nas condições PAV e UV em relação aos valores do material envelhecido a curto prazo, a 10 $\mathrm{rad} / \mathrm{s}$, em função da temperatura

Tabela 4.39 - Variações de $\mathrm{G}^{*}, \delta, \mathrm{G}^{*} / \operatorname{sen} \delta$ e $\mathrm{G}^{*}$.sen $\delta$ do CAP 50/70-SBR nas condições PAV e UV em relação aos valores do material envelhecido a curto prazo, a 10 $\mathrm{rad} / \mathrm{s}$, em função da temperatura

Tabela 4.40 - Variações de $G^{*}, \delta, G^{*} / \operatorname{sen} \delta$ e $G^{*}$.sen $\delta$ do CAP 50/70-SBR-PPA nas condições PAV e UV em relação aos valores do material envelhecido a curto $\mathrm{prazo}$, a $10 \mathrm{rad} / \mathrm{s}$, em função da temperatura

Tabela 4.41 - Ordenamento baseado nos índices de envelhecimento das Tabelas de 4.29 a 4.40

Tabela $4.42-$

Ordenamento baseado nos índices de envelhecimento PAV das Tabelas de 4.29 a 4.40

Tabela 4.43 - Ordenamento final baseado nos índices de envelhecimento UV a $0,68 \mathrm{~W} / \mathrm{m}^{2}$ das Tabelas de 4.29 a 4.40

Tabela 4.44 - Ordenamento final baseado nos índices de envelhecimento UV a 1,00 W/m² das Tabelas de 4.29 a 4.40

Tabela 4.45 - Ordenamento final baseado nos índices de envelhecimento PAV, UV a 0,68 $\mathrm{W} / \mathrm{m}^{2}$ e UV a $1,00 \mathrm{~W} / \mathrm{m}^{2}$ das Tabelas de 4.29 a 4.40

Tabela 4.46 - Parâmetro de tolerância ao dano $\mathrm{a}_{\mathrm{f}}(\mathrm{mm})$ no ensaio LAS a $25^{\circ} \mathrm{C}$ - os dados referentes às condições RTFOT e PAV foram obtidos de Nuñez (2013)

Tabela 4.47 - Ordenamento do parâmetro de tolerância ao dano $\mathrm{a}_{\mathrm{f}}(\mathrm{mm})$ no ensaio LAS a $25^{\circ} \mathrm{C}$, por condição envelhecida

Tabela 4.48 - Valores do coeficiente $\mathrm{A}_{35}$ dos modelos de fadiga a $25^{\circ} \mathrm{C}$ - os dados referentes às condições RTFOT e PAV foram obtidos de Nuñez (2013)

Tabela 4.49 - Valores do coeficiente $\mathrm{B}$ dos modelos de fadiga - os dados referentes às condições RTFOT e PAV foram obtidos de Nuñez (2013)

Tabela 4.50 - Modelos de fadiga dos ligantes asfálticos - os modelos referentes às condições RTFOT e PAV foram obtidos de Nuñez (2013) 
Tabela 4.51 - Estimativa do número de repetições do eixo padrão para $3 \%$ e $30 \%$ de deformação, com base no modelo de fadiga, das amostras na condição RTFOT a $25^{\circ} \mathrm{C}$ (NUÑEZ, 2013)

Tabela 4.52 - Estimativa do número de repetições do eixo padrão para $3 \%$ e $30 \%$ de deformação, com base no modelo de fadiga, das amostras na condição PAV a $25^{\circ} \mathrm{C}$ (NUÑEZ, 2013)

Tabela 4.53 - Estimativa do número de repetições do eixo padrão para $3 \%$ e $30 \%$ de deformação, com base no modelo de fadiga, das amostras na condição UV a $0,68 \mathrm{~W} / \mathrm{m}^{2}$ a $25^{\circ} \mathrm{C}$ (NUÑEZ, 2013)

Tabela 4.54 - Estimativa do número de repetições do eixo padrão para $3 \%$ e $30 \%$ de deformação, com base no modelo de fadiga, das amostras na condição UV a $1,0 \mathrm{~W} / \mathrm{m}^{2}$ a $25^{\circ} \mathrm{C}$ (NUÑEZ, 2013)

Tabela 4.55 - Áreas de absorbância de carbonila e sulfóxido dos CAPs analisados nas condições envelhecidas

Tabela 4.56 - Resultados GPC dos CAP puro e CAP+PPA virgens e envelhecidos a curto e a longo prazos

Tabela 4.57 - Principais frações SARA (\%) do CAP 50/70 puro na condição virgem e envelhecidos a curto e a longo prazos

Tabela 4.58 - Principais frações SARA (\%) do CAP 50/70+PPA na condição virgem e envelhecidos a curto e a longo prazos

Tabela 4.59 - Índice de instabilidade coloidal do CAP puro e do CAP+PPA, nas condições virgem e envelhecida a curto e a longo prazos (PAV e UV)

Tabela 5.1 - Posições médias dos ligantes asfálticos por requisitos de interesse, incluindo todas as condições de envelhecimento - longo prazo na estufa PAV e longo prazo na estufa UV $\left(0,68\right.$ e $\left.1,00 \mathrm{~W} / \mathrm{m}^{2}\right)$

Tabela 5.2 - Parâmetros de fadiga por condição de envelhecimento - destaques 206 


\section{LISTA DE FIGURAS}

Figura 2.1 - Representação esquemática da análise de composição química de um ligante [Whiteoak (1991) apud Tonial (2001)]

Figura 2.2 - Representação da estrutura coloidal do ligante asfáltico [Yen (1991) apud Leite (1999)]

Figura 2.3 - Espectro da radiação solar que atinge o topo da atmosfera e ao nível do mar. Ref. UNEP, 1987 (OKUNO e VILELA, 2005)

Figura $2.4-$ Esquema do princípio do GPC (DURAND et al. 2012)

Figura $3.1-$

Câmara UV utilizada para simulação do envelhecimento a longo prazo fotooxidativo

Figura 3.2 - Esquema do funcionamento da câmara UV [Fonte: Q-Lab (http://www.qlab.com)]

Figura 3.3 - Bandejas contendo os filmes de ligante asfáltico, antes e depois do envelhecimento UV

Figura $3.4-$ Modelo de fadiga (JOHNSON, 2010)

Figura $3.5-$

Incremento de deformação no ensaio LAS (JOHNSON, 2010) e incremento de deformação no ensaio LAS modificado (HINTZ, 2012), respectivamente

Figura $3.6-$ Ilustração do cálculo das áreas de carbonila e sulfóxido (OLIVEIRA, 2015) _

Figura $3.7-$ Esquema geral de um ensaio GPC (DARANGA, 1999)

Figura $3.8-$ Curva de calibração - ensaio GPC 76

Figura 4.1 Penetração das amostras virgens

Figura $4.2-$ Penetração das amostras envelhecidas a curto prazo

Figura $4.3-$ Graus de modificação com base nos valores de penetração

Figura 4.4 Penetração retida

Figura $4.5-$ Ponto de amolecimento das amostras virgens

Figura $4.6-$

Ponto de amolecimento das amostras envelhecidas a curto prazo

Figura $4.7-$ Graus de modificação com base nos valores de ponto de amolecimento

Figura $4.8-$ Aumento do ponto de amolecimento

Figura $4.9-$ Perda de massa

Figura $4.10-$

Efeito dos envelhecimentos a curto prazo no RTFO e a longo prazo nas estufas PAV e UV sobre G*: CAP 50/70 puro

Figura 4.11 - Efeito dos envelhecimentos a curto prazo no RTFO e a longo prazo nas estufas PAV e UV sobre G*: CAP 50/70+PPA

Figura 4.12 - Efeito dos envelhecimentos a curto prazo no RTFO e a longo prazo nas estufas PAV e UV sobre G*: CAP 50/70+borracha

Figura 4.13 - Efeito dos envelhecimentos a curto prazo no RTFO e a longo prazo nas estufas PAV e UV sobre G*: CAP 50/70+borracha+PPA

Figura 4.14 - Efeito dos envelhecimentos a curto prazo no RTFO e a longo prazo nas estufas PAV e UV sobre G*: CAP 50/70+SBS 
Figura 4.15 - Efeito dos envelhecimentos a curto prazo no RTFO e a longo prazo nas estufas PAV e UV sobre G*: CAP 50/70+SBS+PPA

Figura 4.16 - Efeito dos envelhecimentos a curto prazo no RTFO e a longo prazo nas estufas PAV e UV sobre G*: CAP 50/70+EVA

Figura 4.17 - Efeito dos envelhecimentos a curto prazo no RTFO e a longo prazo nas estufas PAV e UV sobre G*: CAP 50/70+EVA+PPA

Figura 4.18 - Efeito dos envelhecimentos a curto prazo no RTFO e a longo prazo nas estufas PAV e UV sobre G*: CAP 50/70+PE

Figura 4.19 - Efeito dos envelhecimentos a curto prazo no RTFO e a longo prazo nas estufas PAV e UV sobre G*: CAP 50/70+PE+PPA

Figura 4.20 - Efeito dos envelhecimentos a curto prazo no RTFO e a longo prazo nas estufas PAV e UV sobre G*: CAP 50/70+SBR

Figura $4.21-$ Efeito dos envelhecimentos a curto prazo no RTFO e a longo prazo nas estufas PAV e UV sobre G*: CAP 50/70+SBR+PPA

Figura 4.22 - Efeito dos envelhecimentos a curto prazo no RTFO e a longo prazo nas estufas PAV e UV sobre $\delta$ : CAP 50/70 puro

Figura 4.23 - Efeito dos envelhecimentos a curto prazo no RTFO e a longo prazo nas estufas PAV e UV sobre $\delta$ : CAP 50/70+PPA

Figura 4.24 - Efeito dos envelhecimentos a curto prazo no RTFO e a longo prazo nas estufas PAV e UV sobre $\delta$ : CAP 50/70+borracha

Figura 4.25 - Efeito dos envelhecimentos a curto prazo no RTFO e a longo prazo nas estufas PAV e UV sobre $\delta$ : CAP 50/70+borracha+PPA

Figura 4.26 - Efeito dos envelhecimentos a curto prazo no RTFO e a longo prazo nas estufas PAV e UV sobre $\delta$ : CAP 50/70+SBS

Figura 4.27 - Efeito dos envelhecimentos a curto prazo no RTFO e a longo prazo nas estufas PAV e UV sobre $\delta$ : CAP 50/70+SBS+PPA

Figura 4.28 - Efeito dos envelhecimentos a curto prazo no RTFO e a longo prazo nas estufas PAV e UV sobre $\delta$ : CAP 50/70+EVA

Figura 4.29 - Efeito dos envelhecimentos a curto prazo no RTFO e a longo prazo nas estufas PAV e UV sobre $\delta$ : CAP 50/70+EVA+PPA

Figura 4.30 - Efeito dos envelhecimentos a curto prazo no RTFO e a longo prazo nas estufas PAV e UV sobre $\delta$ : CAP 50/70+PE

Figura 4.31 - Efeito dos envelhecimentos a curto prazo no RTFO e a longo prazo nas estufas PAV e UV sobre $\delta$ : CAP 50/70+PE+PPA

Figura 4.32 - Efeito dos envelhecimentos a curto prazo no RTFO e a longo prazo nas estufas PAV e UV sobre $\delta$ : CAP 50/70+SBR

Figura 4.33 - Efeito dos envelhecimentos a curto prazo no RTFO e a longo prazo nas estufas PAV e UV sobre $\delta$ : CAP 50/70+SBR+PPA

Figura 4.34 - Determinação do valor do parâmetro $\mathrm{a}_{\mathrm{f}}$ na temperatura de $25^{\circ} \mathrm{C}$ para o CAP $50 / 70$ puro envelhecido na estufa UV a $0,68 \mathrm{~W} / \mathrm{m}^{2}$ - os dados referentes às condições RTFOT e PAV foram obtidos de Nuñez (2013)

Figura 4.35 - Estimativa da vida de fadiga em função da deformação na condição de envelhecimento a curto prazo e temperatura de $25^{\circ} \mathrm{C}$ - dados fornecidos por Nuñez (2013) 
Figura 4.36 - Estimativa da vida de fadiga em função da deformação na condição de envelhecimento a longo prazo PAV e temperatura de $25^{\circ} \mathrm{C}$ - dados fornecidos por Nuñez (2013)

Figura 4.37 - Estimativa da vida de fadiga em função da deformação na condição de envelhecimento a longo prazo UV a $0,68 \mathrm{~W} / \mathrm{m}^{2}$ e temperatura de $25^{\circ} \mathrm{C}$

Figura 4.38 - Estimativa da vida de fadiga em função da deformação na condição de envelhecimento a longo prazo UV a $1,00 \mathrm{~W} / \mathrm{m}^{2}$ e temperatura de $25^{\circ} \mathrm{C}$

Figura 4.39 - Estimativa de vida de fadiga - CAP 50/70 puro [dados referentes aos materiais nas condições RTFOT e PAV obtidos de Nuñez (2013]

Figura 4.40 - Estimativa de vida de fadiga - CAP+PPA [dados referentes aos materiais nas condições RTFOT e PAV obtidos de Nuñez (2013]

Figura 4.41 - Estimativa de vida de fadiga - CAP+borracha [dados referentes aos materiais nas condições RTFOT e PAV obtidos de Nuñez (2013]

Figura 4.42 - Estimativa de vida de fadiga - CAP+borracha+PPA [dados referentes aos materiais nas condições RTFOT e PAV obtidos de Nuñez (2013]

Figura 4.43 - Estimativa de vida de fadiga - CAP+SBS [dados referentes aos materiaisnas condições RTFOT e PAV obtidos de Nuñez (2013]

Figura 4.44 - Estimativa de vida de fadiga - CAP+SBS+PPA [dados referentes aos materiais nas condições RTFOT e PAV obtidos de Nuñez (2013]

Figura 4.45 - Estimativa de vida de fadiga - CAP+EVA [dados referentes aos materiais nas condições RTFOT e PAV obtidos de Nuñez (2013]

Figura 4.46 - Estimativa de vida de fadiga - CAP+EVA+PPA [dados referentes aos materiais nas condições RTFOT e PAV obtidos de Nuñez (2013]

Figura 4.47 - Estimativa de vida de fadiga - CAP+PE [dados referentes aos materiais nas condições RTFOT e PAV obtidos de Nuñez (2013]

Figura 4.48 - $\quad$ Estimativa de vida de fadiga $-\mathrm{CAP}+\mathrm{PE}+\mathrm{PPA}$ [dados referentes aos materiais nas condições RTFOT e PAV obtidos de Nuñez (2013]

Figura 4.49 - Estimativa de vida de fadiga - CAP+SBR [dados referentes aos materiais nas condições RTFOT e PAV obtidos de Nuñez (2013]

Figura 4.50 - Estimativa de vida de fadiga - CAP+SBR+PPA [dados referentes aos materiais nas condições RTFOT e PAV obtidos de Nuñez (2013]

Figura 4.51 - Ordenamento dos valores de $\mathrm{N}_{\mathrm{f}}$ obtidos do ensaio LAS para baixos níveis de deformação (3\%) [dados nas condições RTFOT e PAV obtidos de Nuñez (2013)]

Figura 4.52 - $\quad$ Ordenamento dos valores de $\mathrm{N}_{\mathrm{f}}$ obtidos do ensaio LAS para altos níveis de deformação (30\%) [dados nas condições RTFOT e PAV obtidos de Nuñez (2013)]

Figura 4.53 - $\quad$ Espectro do FTIR do CAP puro nas condições de envelhecimentos a curto prazo (RTFOT) e a longo prazos (PAV, UV 0,68 W/m² e UV 1,00 W/m²)

Figura 4.54 - Espectro do FTIR do CAP+PPA nas condições de envelhecimentos a curto prazo (RTFOT) e a longo prazos (PAV, UV 0,68 W/m² e UV 1,00 W/m²)

Figura 4.55 - Espectro do FTIR do CAP+SBS nas condições de envelhecimentos a curto prazo (RTFOT) e a longo prazos (PAV, UV 0,68 W/m² e UV 1,00 W/m²)

Figura 4.56 - Soma das áreas de carbonila e sulfóxido dos CAPs analisados envelhecidos_ 
Figura 4.58 - Cromatograma do CAP 50/70+PPA virgem e envelhecido a curto e a longo prazos

Figura 4.59 - Variação das frações SARA do CAP puro virgem e envelhecidos a curto e a longos prazos

Figura 4.60 - Variação das frações SARA do CAP+PPA virgem e envelhecidos a curto e a longos prazos

Figura 5.1 - Ordenamento final da sensibilidade à radiação PAV - posição média mais baixa indicando material menos sensível

Figura 5.2 - Ordenamento final da sensibilidade à radiação UV $\left(0,68 \mathrm{~W} / \mathrm{m}^{2}\right)$ - posição média mais baixa indicando material menos sensível

Figura 5.3 - Ordenamento final da sensibilidade à radiação UV $\left(1,00 \mathrm{~W} / \mathrm{m}^{2}\right)$ - posição média mais baixa indicando material menos sensível

Figura 5.4 - Ordenamento final da sensibilidade aos envelhecimentos PAV, UV a 0,68 $\mathrm{W} / \mathrm{m}^{2}$ e UV $1,00 \mathrm{~W} / \mathrm{m}^{2}$

Figura A. 1- Curva-mestre de G* da mistura 50/70-PPA em relação ao CAP puro: condição virgem

Figura A. 2 - Curva-mestre de $G^{*}$ da mistura 50/70-borracha em relação ao CAP puro: condição virgem

Figura A. 3 - Curva-mestre de $\mathrm{G}^{*}$ da mistura 50/70-borracha-PPA em relação ao CAP puro: condição virgem

Figura A. 4 - Curva-mestre de $\mathrm{G}^{*}$ da mistura 50/70-SBS em relação ao CAP puro: condição virgem

Figura A. 5 - Curva-mestre de $\mathrm{G}^{*}$ da mistura 50/70-SBS-PPA em relação ao CAP puro: condição virgem

Figura A. 6 - Curva-mestre de $\mathrm{G}^{*}$ da mistura 50/70-EVA em relação ao CAP puro: condição virgem

Figura A. 7 - Curva-mestre de $\mathrm{G}^{*}$ da mistura 50/70-EVA-PPA em relação ao CAP puro: condição virgem

Figura A. 8 - Curva-mestre de G* da mistura 50/70-PE em relação ao CAP puro: condição virgem

Figura A. 9 - Curva-mestre de $G^{*}$ da mistura 50/70-PE-PPA em relação ao CAP puro: condição virgem

Figura A. 10 - Curva-mestre de G* da mistura 50/70-SBR em relação ao CAP puro: condição virgem

Figura A. 11 - Curva-mestre de $\mathrm{G}^{*}$ da mistura 50/70-SBR-PPA em relação ao CAP puro: condição virgem

Figura A. 12 - Curva-mestre de $\mathrm{G}^{*}$ da mistura 50/70-PPA em relação ao CAP puro: condição RTFOT

Figura A. 13 - Curva-mestre de $\mathrm{G}^{*}$ da mistura 50/70-borracha em relação ao CAP puro: condição RTFOT

Figura A. 14 - Curva-mestre de G* da mistura 50/70-borracha-PPA em relação ao CAP puro: condição RTFOT

Figura A. 15 - Curva-mestre de $\mathrm{G}^{*}$ da mistura 50/70-SBS em relação ao CAP puro: condição RTFOT 
Figura A. 16 - Curva-mestre de G* da mistura 50/70-SBS-PPA em relação ao CAP puro: condição RTFOT

Figura A. 17 - Curva-mestre de $\mathrm{G}^{*}$ da mistura 50/70-EVA em relação ao CAP puro: condição RTFOT

Figura A. 18 - Curva-mestre de $\mathrm{G}^{*}$ da mistura 50/70-EVA-PPA em relação ao CAP puro: condição RTFOT

Figura A. 19 - Curva-mestre de G* da mistura 50/70-PE em relação ao CAP puro: condição RTFOT

Figura A. 20 - Curva-mestre de $\mathrm{G}^{*}$ da mistura 50/70-PE-PPA em relação ao CAP puro: condição RTFOT

Figura A. 21 - Curva-mestre de $\mathrm{G}^{*}$ da mistura 50/70-SBR em relação ao CAP puro: condição RTFOT

Figura A. 22 - Curva-mestre de $\mathrm{G}^{*}$ da mistura 50/70-SBR-PPA em relação ao CAP puro: condição RTFOT

Figura A. 23 - Curva-mestre de $\mathrm{G}^{*}$ da mistura 50/70-PPA em relação ao CAP puro: condição PAV

Figura A. 24 - Curva-mestre de $G^{*}$ da mistura 50/70-borracha em relação ao CAP puro: condição PAV

Figura A. 25 - Curva-mestre de $\mathrm{G}^{*}$ da mistura 50/70-borracha-PPA em relação ao CAP puro: condição PAV

Figura A. 26 - Curva-mestre de G* da mistura 50/70-SBS em relação ao CAP puro: condição PAV

Figura A. 27 - Curva-mestre de $G^{*}$ da mistura 50/70-SBS-PPA em relação ao CAP puro: condição PAV

Figura A. 28 - Curva-mestre de $\mathrm{G}^{*}$ da mistura 50/70-EVA em relação ao CAP puro: condição PAV

Figura A. 29 - Curva-mestre de $\mathrm{G}^{*}$ da mistura 50/70-EVA-PPA em relação ao CAP puro: condição PAV

Figura A. 30 - Curva-mestre de $\mathrm{G}^{*}$ da mistura 50/70-PE em relação ao CAP puro: condição PAV

Figura A. 31 - Curva-mestre de $G^{*}$ da mistura 50/70-PE-PPA em relação ao CAP puro: condição PAV

Figura A. 32 - Curva-mestre de G* da mistura 50/70-SBR em relação ao CAP puro: condição PAV

Figura A. 33 - Curva-mestre de $G^{*}$ da mistura 50/70-SBR-PPA em relação ao CAP puro: condição PAV

Figura A. 34 - Curva-mestre de G* da mistura 50/70-PPA em relação ao CAP puro: UV a $0,68 \mathrm{~W} / \mathrm{m}^{2}$

Figura A. 35 - Curva-mestre de $\mathrm{G}^{*}$ da mistura 50/70-borracha em relação ao CAP puro: condição UV a $0,68 \mathrm{~W} / \mathrm{m}^{2}$

Figura A. 36 - Curva-mestre de G* da mistura 50/70-borracha-PPA em relação ao CAP puro: condição UV a $0,68 \mathrm{~W} / \mathrm{m}^{2}$

Figura A. 37 - Curva-mestre de $\mathrm{G}^{*}$ da mistura 50/70-SBS em relação ao CAP puro: condição $\mathrm{UV}$ a $0,68 \mathrm{~W} / \mathrm{m}^{2}$ 
Figura A. 38 - Curva-mestre de $G^{*}$ da mistura 50/70-SBS-PPA em relação ao CAP puro: condição UV a $0,68 \mathrm{~W} / \mathrm{m}^{2}$

Figura A. 39 - Curva-mestre de $G^{*}$ da mistura 50/70-EVA em relação ao CAP puro: condição UV a $0,68 \mathrm{~W} / \mathrm{m}^{2}$

Figura A. 40 - Curva-mestre de G* da mistura 50/70-EVA-PPA em relação ao CAP puro: condição UV a $0,68 \mathrm{~W} / \mathrm{m}^{2}$

Figura A. 41 - Curva-mestre de $\mathrm{G}^{*}$ da mistura 50/70-PE em relação ao CAP puro: condição UV a $0,68 \mathrm{~W} / \mathrm{m}^{2}$

Figura A. 42 - Curva-mestre de $\mathrm{G}^{*}$ da mistura 50/70-PE-PPA em relação ao CAP puro: condição UV a $0,68 \mathrm{~W} / \mathrm{m}^{2}$

Figura A. 43 - Curva-mestre de $\mathrm{G}^{*}$ da mistura 50/70-SBR em relação ao CAP puro: condição $\mathrm{UV}$ a $0,68 \mathrm{~W} / \mathrm{m}^{2}$

Figura A. 44 - Curva-mestre de $\mathrm{G}^{*}$ da mistura 50/70-SBR-PPA em relação ao CAP puro: condição UV a $0,68 \mathrm{~W} / \mathrm{m}^{2}$

Figura A. 45 - Curva-mestre de $G^{*}$ da mistura 50/70-PPA em relação ao CAP puro: UV a $1,00 \mathrm{~W} / \mathrm{m}^{2}$

Figura A. 46 - Curva-mestre de $\mathrm{G}^{*}$ da mistura 50/70-borracha em relação ao CAP puro: condição UV a $1,00 \mathrm{~W} / \mathrm{m}^{2}$

Figura A. 47 - Curva-mestre de $\mathrm{G}^{*}$ da mistura 50/70-borracha-PPA em relação ao CAP puro: condição UV a $1,00 \mathrm{~W} / \mathrm{m}^{2}$

Figura A. 48 - Curva-mestre de $\mathrm{G}^{*}$ da mistura 50/70-SBS em relação ao CAP puro: condição $\mathrm{UV}$ a $1,00 \mathrm{~W} / \mathrm{m}^{2}$

Figura A. 49 - Curva-mestre de $\mathrm{G}^{*}$ da mistura 50/70-SBS-PPA em relação ao CAP puro: condição UV a $1,00 \mathrm{~W} / \mathrm{m}^{2}$

Figura A. 50 - Curva-mestre de $\mathrm{G}^{*}$ da mistura 50/70-EVA em relação ao CAP puro: condição UV a $1,00 \mathrm{~W} / \mathrm{m}^{2}$

Figura A. 51 - Curva-mestre de $\mathrm{G}^{*}$ da mistura 50/70-EVA-PPA em relação ao CAP puro: condição UV a $1,00 \mathrm{~W} / \mathrm{m}^{2}$

Figura A. 52 - Curva-mestre de $\mathrm{G}^{*}$ da mistura 50/70-PE em relação ao CAP puro: condição $\mathrm{UV}$ a $1,00 \mathrm{~W} / \mathrm{m}^{2}$

Figura A. 53 - Curva-mestre de $\mathrm{G}^{*}$ da mistura 50/70-PE-PPA em relação ao CAP puro: condição UV a $1,00 \mathrm{~W} / \mathrm{m}^{2}$

Figura A. 54 - Curva-mestre de $\mathrm{G}^{*}$ da mistura 50/70-SBR em relação ao CAP puro: condição $\mathrm{UV}$ a $1,00 \mathrm{~W} / \mathrm{m}^{2}$

Figura A. 55 - Curva-mestre de $\mathrm{G}^{*}$ da mistura 50/70-SBR-PPA em relação ao CAP puro: condição UV a $1,00 \mathrm{~W} / \mathrm{m}^{2}$

Figura A. 56 - Curva-mestre de $\delta$ do 50/70-PPA em relação ao CAP puro: condição virgem

Figura A. 57 - Curva-mestre de $\delta$ da mistura 50/70-borracha em relação ao CAP puro: condição virgem

Figura A. 58 - Curva-mestre de $\delta$ da mistura 50/70-borracha-PPA em relação ao CAP puro: condição virgem

Figura A. 59 - Curva-mestre de $\delta$ da mistura 50/70-SBS em relação ao CAP puro: condição virgem 
Figura A. 60 - Curva-mestre de $\delta$ da mistura 50/70-SBS-PPA em relação ao CAP puro: condição virgem

Figura A. 61 - Curva-mestre de $\delta$ da mistura 50/70-EVA em relação ao CAP puro: condição virgem

Figura A. 62 - Curva-mestre de $\delta$ da mistura 50/70-EVA-PPA em relação ao CAP puro: condição virgem

Figura A. 63 - Curva-mestre de $\delta$ da mistura 50/70-PE em relação ao CAP puro: condição virgem

Figura A. 64 - Curva-mestre de $\delta$ da mistura 50/70-PE-PPA em relação ao CAP puro: condição virgem

Figura A. 65 - Curva-mestre de $\delta$ da mistura 50/70-SBR em relação ao CAP puro: condição virgem

Figura A. 66 - Curva-mestre de $\delta$ da mistura 50/70-SBR-PPA em relação ao CAP puro: condição virgem

Figura A. 67 - Curva-mestre de $\delta$ da mistura 50/70-PPA em relação ao CAP puro: condição RTFOT

Figura A. 68 - Curva-mestre de $\delta$ da mistura 50/70-borracha em relação ao CAP puro: condição RTFOT

Figura A. 69 - Curva-mestre de $\delta$ da mistura 50/70-borracha-PPA em relação ao CAP puro: condição RTFOT

Figura A. 70 - Curva-mestre de $\delta$ da mistura 50/70-SBS em relação ao CAP puro: condição RTFOT

Figura A. 71 - Curva-mestre de $\delta$ da mistura 50/70-SBS-PPA em relação ao CAP puro: condição RTFOT

Figura A. 72 - Curva-mestre de $\delta$ da mistura 50/70-EVA em relação ao CAP puro: condição RTFOT

Figura A. 73 - Curva-mestre de $\delta$ da mistura 50/70-EVA-PPA em relação ao CAP puro: condição RTFOT

Figura A. 74 - Curva-mestre de $\delta$ da mistura 50/70-PE em relação ao CAP puro: condição RTFOT

Figura A. 75 - Curva-mestre de $\delta$ da mistura 50/70-PE-PPA em relação ao CAP puro: condição RTFOT

Figura A. 76 - Curva-mestre de $\delta$ da mistura 50/70-SBR em relação ao CAP puro: condição RTFOT

Figura A. 77 - Curva-mestre de $\delta$ da mistura 50/70-SBR-PPA em relação ao CAP puro: condição RTFOT

Figura A. 78 - Curva-mestre de $\delta$ da mistura 50/70-PPA em relação ao CAP puro: condição PAV

Figura A. 79 - Curva-mestre de $\delta$ da mistura 50/70-borracha em relação ao CAP puro: condição PAV

Figura A. 80 - Curva-mestre de $\delta$ da mistura 50/70-borracha-PPA em relação ao CAP puro: condição PAV 
Figura A. 81 - Curva-mestre de $\delta$ da mistura 50/70-SBS em relação ao CAP puro: condição PAV

Figura A. 82 - Curva-mestre de $\delta$ da mistura 50/70-SBS-PPA em relação ao CAP puro: condição PAV

Figura A. 83 - Curva-mestre de $\delta$ da mistura 50/70-EVA em relação ao CAP puro: condição PAV

Figura A. 84 - Curva-mestre de $\delta$ da mistura 50/70-EVA-PPA em relação ao CAP puro: condição PAV

Figura A. 85 - Curva-mestre de $\delta$ da mistura 50/70-PE em relação ao CAP puro: condição PAV

Figura A. 86 - Curva-mestre de $\delta$ da mistura 50/70-PE-PPA em relação ao CAP puro: condição PAV

Figura A. 87 - Curva-mestre de $\delta$ da mistura 50/70-SBR em relação ao CAP puro: condição PAV

Figura A. 88 - Curva-mestre de $\delta$ da mistura 50/70-SBR-PPA em relação ao CAP puro: condição PAV

Figura A. 89 - Curva-mestre de $\delta$ da mistura 50/70-PPA em relação ao CAP puro: condição $\mathrm{UV}$ a $0,68 \mathrm{~W} / \mathrm{m}^{2}$

Figura A. 90 - Curva-mestre de $\delta$ da mistura 50/70-borracha em relação ao CAP puro: condição UV a $0,68 \mathrm{~W} / \mathrm{m}^{2}$

Figura A. 91 - Curva-mestre de $\delta$ da mistura 50/70-borracha-PPA em relação ao CAP puro: condição UV a $0,68 \mathrm{~W} / \mathrm{m}^{2}$

Figura A. 92 - Curva-mestre de $\delta$ da mistura 50/70-SBS em relação ao CAP puro: condição $\mathrm{UV}$ a $0,68 \mathrm{~W} / \mathrm{m}^{2}$

Figura A. 93 - Curva-mestre de $\delta$ da mistura 50/70-SBS-PPA em relação ao CAP puro: condição UV a $0,68 \mathrm{~W} / \mathrm{m}^{2}$

Figura A. 94 - Curva-mestre de $\delta$ da mistura 50/70-EVA em relação ao CAP puro: condição $\mathrm{UV}$ a $0,68 \mathrm{~W} / \mathrm{m}^{2}$

Figura A. 95 - Curva-mestre de $\delta$ da mistura 50/70-EVA-PPA em relação ao CAP puro: condição UV a $0,68 \mathrm{~W} / \mathrm{m}^{2}$

Figura A. 96 - Curva-mestre de $\delta$ da mistura 50/70-PE em relação ao CAP puro: condição UV a $0,68 \mathrm{~W} / \mathrm{m}^{2}$

Figura A. 97 - Curva-mestre de $\delta$ da mistura 50/70-PE-PPA em relação ao CAP puro: condição UV a $0,68 \mathrm{~W} / \mathrm{m}^{2}$

Figura A. 98 - Curva-mestre de $\delta$ da mistura 50/70-SBR em relação ao CAP puro: condição UV a $0,68 \mathrm{~W} / \mathrm{m}^{2}$

Figura A. 99 - Curva-mestre de $\delta$ da mistura 50/70-SBR-PPA em relação ao CAP puro: condição UV a $0,68 \mathrm{~W} / \mathrm{m}^{2}$

Figura A. 100 - Curva-mestre de $\delta$ da mistura 50/70-PPA em relação ao CAP puro: condição $\mathrm{UV}$ a $1,00 \mathrm{~W} / \mathrm{m}^{2}$

Figura A. 101 - Curva-mestre de $\delta$ da mistura 50/70-borracha em relação ao CAP puro: condição UV a $1,00 \mathrm{~W} / \mathrm{m}^{2}$ 
Figura A. 102 - Curva-mestre de $\delta$ da mistura 50/70-borracha-PPA em relação ao CAP puro: condição UV a $1,00 \mathrm{~W} / \mathrm{m}^{2}$

Figura A. 103 - Curva-mestre de $\delta$ da mistura 50/70-SBS em relação ao CAP puro: condição $\mathrm{UV}$ a $1,00 \mathrm{~W} / \mathrm{m}^{2}$

Figura A. 104 - Curva-mestre de $\delta$ da mistura 50/70-SBS-PPA em relação ao CAP puro: condição UV a $1,00 \mathrm{~W} / \mathrm{m}^{2}$

Figura A. 105 - Curva-mestre de $\delta$ da mistura 50/70-EVA em relação ao CAP puro: condição $\mathrm{UV}$ a $1,00 \mathrm{~W} / \mathrm{m}^{2}$

Figura A. 106 - Curva-mestre de $\delta$ da mistura 50/70-EVA-PPA em relação ao CAP puro: condição UV a $1,00 \mathrm{~W} / \mathrm{m}^{2}$

Figura A. 107 - Curva-mestre de $\delta$ da mistura 50/70-PE em relação ao CAP puro: condição $\mathrm{UV}$ a $1,00 \mathrm{~W} / \mathrm{m}^{2}$

Figura A. 108 - Curva-mestre de $\delta$ da mistura 50/70-PE-PPA em relação ao CAP puro: condição UV a $1,00 \mathrm{~W} / \mathrm{m}^{2}$

Figura A. 109 - Curva-mestre de $\delta$ da mistura 50/70-SBR em relação ao CAP puro: condição $\mathrm{UV}$ a $1,00 \mathrm{~W} / \mathrm{m}^{2}$

Figura A. 110 - Curva-mestre de $\delta$ da mistura 50/70-SBR-PPA em relação ao CAP puro: condição UV a $1,00 \mathrm{~W} / \mathrm{m}^{2}$ 



\section{LISTA DE SÍMBOLOS}

$\mathrm{C}=\mathrm{O} \quad$ Grupos carbonila

$\mathrm{N}_{2} \quad$ Nitrogênio

$\mathrm{O}_{2} \quad$ Oxigênio

$\mathrm{NO}_{2} \quad$ Dióxido de nitrogênio

$\mathrm{SO}_{2} \quad$ Dióxido de enxofre

$\mathrm{TiO}_{2} \quad$ Dióxido de titânio

$\mathrm{CeO}_{2} \quad$ Dióxido de cério

HDL Hidróxido duplo lamelar

SDS Dodecil sulfato de sódio

SDSO Sulfonato dodecil de sódio

G* Módulo complexo de cisalhamento em regime oscilatório

$\delta \quad$ Ângulo de fase

G*/sen $\delta$ Parâmetro de deformação permanente

$\mathrm{G}^{*} \cdot \operatorname{sen}(\delta) \quad$ Parâmetro de fadiga

$\mathrm{N}_{\mathrm{f}} \quad$ Número de ciclos à falha por fadiga

A, B Parâmetros da vida de fadiga

$\mathrm{CS}_{2} \quad$ Dissulfeto de carbono

THF Tetrahidrofurano

af Parâmetro da análise de tolerância ao dano no ensaio LAS

$\gamma \quad$ Deformação cisalhante aplicada

$\mathrm{S}=\mathrm{O} \quad$ Sulfóxidos

Mw Massa molar ponderal 



\title{
LISTA DE SIGLAS E ABREVIAÇÕES
}

\author{
AASHTO "American Association of State Highway and Transportation Officials" \\ ANP Agência Nacional do Petróleo, Gás Natural e Biocombustíveis \\ ASTM "American Society for Testing and Materials" \\ BPR "Bureau of Public Roads" \\ CAP Cimento Asfáltico de Petróleo \\ DNIT Departamento Nacional de Infraestrutura de Transportes \\ DSR Reômetro de cisalhamento dinâmico \\ EVA Copolímero de etileno acetato de vinila \\ FID "flame ionization detection" \\ FTIR Espectroscopia no Infravermelho por Transformada de Fourier \\ GPC Cromatografia por Permeação em Gel \\ IC Índice de estabilidade coloidal \\ ISL "Instrumentation Scientifique de Laboratoire" \\ LAS Varredura de amplitude linear \\ LMS "large molecular size" \\ PAV Ensaio em vaso pressurizado, material envelhecido a longo prazo \\ PE Polietileno \\ PG Grau de desempenho \\ PPA Ácido polisfosfórico \\ RCAT "rolling cylinder aging test" \\ REPLAN Refinaria de Paulínia (SP) \\ RMFO "rolling microfilm oven test" \\ RTFO Estufa utilizada no envelhecimento a curto prazo \\ RTFOT Ensaio da estufa de filme fino rotativo, material envelhecido a curto prazo \\ SARA Fracionamento em saturados, aromáticos, resinas e asfaltenos \\ SBR Borracha de estireno-butadieno
}


SBS Copolímero de estireno-butadieno-estireno

SEC Cromatografia de exclusão de tamanho

SHRP "Strategic Highway Research Program"

STOA "short-term oven aging"

STT Departamento de Engenharia de Transportes

TFAAT "thin film accelerated test"

TFOT "thin film oven test"

TODT "tild-oven durability test"

UNEP Programa das Nações Unidas para o Ambiente

UV Radiação ultravioleta

VECD Dano contínuo viscoelástico 
1. INTRODUÇÃO............................................................................................................33

1.1 Objetivos _ 35

1.2 Estrutura da dissertação __ 35

2. REVISÃO BIBLIOGRÁFICA......................................................................................... 37

2.1 Ligante asfáltico: características e composição___ 37

2.2 Envelhecimento de ligantes asfálticos _ 40

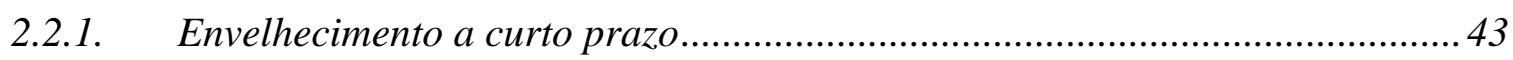

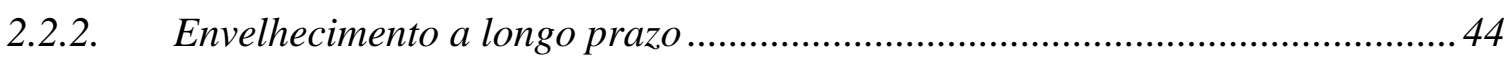

2.3 Ligantes asfálticos modificados e o efeito do envelhecimento _ 45

2.4 Radiação ultravioleta (UV): considerações gerais __ 46

2.5 Envelhecimento ultravioleta: princípio foto-oxidativo _ 49

2.5.1. Técnicas de envelhecimento UV abordadas na literatura .................................51

2.6 Estudo do envelhecimento UV em misturas asfálticas __ 55

2.7 Comparação das simulações de envelhecimento em laboratório com o envelhecimento de campo ___ 56

2.8 Técnicas utilizadas para análise de envelhecimento dos ligantes asfálticos _ 57

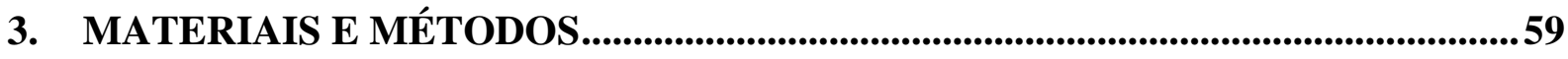

3.1 Materiais _ 59

3.2 Formulações _ 60

3.3 Ensaios empíricos para caracterização dos ligantes asfálticos _ 61

3.4 Procedimentos de envelhecimento dos ligantes asfálticos _ 62

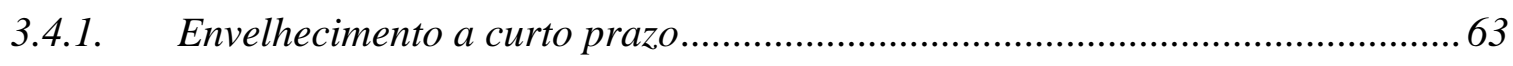

3.4.2. Envelhecimento a longo prazo termo-oxidativo...............................................6 63

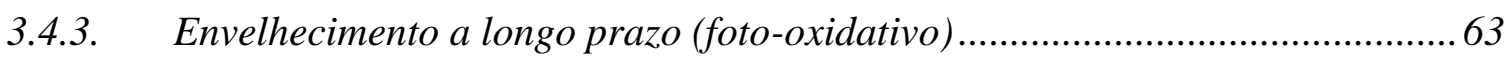

3.5 Propriedades reológicas monitoradas _ 67

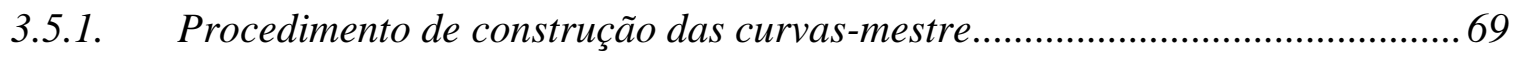

3.5.2. Ensaio de Varredura de Amplitude Linear (LAS)...........................................6 69

3.6 Análises Químicas _ 73

3.6.1. Espectroscopia no Infravermelho por Transformada de Fourier (FTIR)......... 74 
3.6.2. Cromatografia por Permeação em Gel - GPC .............................................. 75

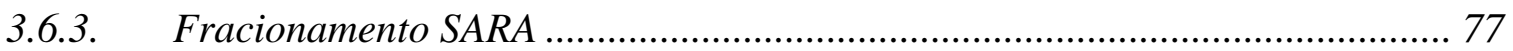

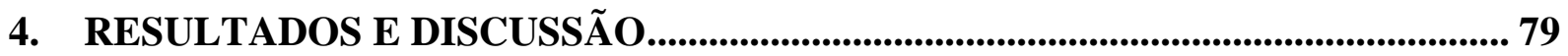

4.1 Ensaios de caracterização dos ligantes asfálticos virgens e envelhecidos a curto prazo__ 79

4.2 Efeito dos diferentes níveis de envelhecimento___ 93

4.2.1. Efeito dos modificadores sobre a rigidez e a elasticidade dos ligantes asfálticos

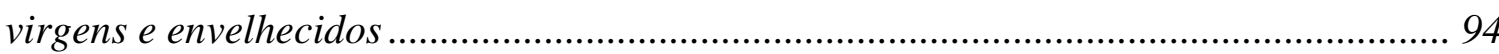

4.2.2. Efeito dos diferentes níveis de envelhecimento sobre a rigidez e a elasticidade dos ligantes asfálticos............................................................................................. 112

4.2.3. Efeitos dos componentes dos níveis de envelhecimento sobre o comportamento termossensível dos ligantes asfálticos ....................................................................... 142

4.3 Ensaio de varredura de amplitude linear (LAS) _ 164

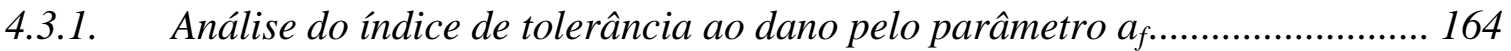

4.3.2. Análise baseada na teoria de dano contínuo viscoelástico (VECD).............. 168

4.4 Análises Químicas __ 187

4.4.1. Caracterização estrutural por FTIR........................................................... 187

4.4.2. Cromatografia por Permeação em Gel (GPC) ........................................... 190

4.4.3. Fracionamento SARA (Saturados, Aromáticos, Resinas e Asfaltenos) .......... 193

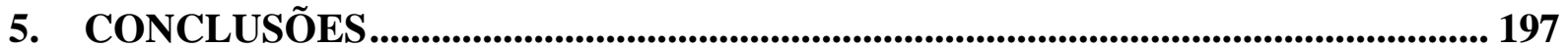

5.1 Introdução 197

5.2 Efeitos dos envelhecimentos a curto e a longo prazos com base nas curvasmestre _ 197

5.3 Vida de fadiga — 200

5.4 Caracterização química dos ligantes asfálticos___ 201

5.5 Considerações Finais__ 202

5.6 Sugestões para trabalhos futuros 204

REFERÊNCIAS BIBLIOGRÁFICAS .................................................................................. 209

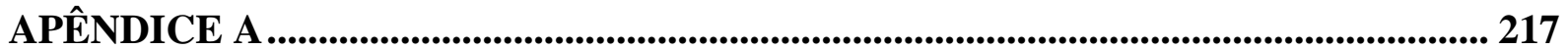

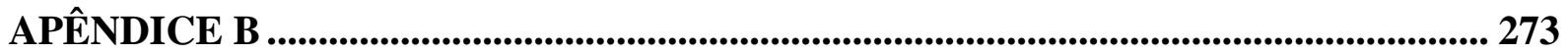




\section{INTRODUÇÃO}

O CAP (Cimento Asfáltico de Petróleo) é um material termossuscetível e que sofre transformações químicas quando exposto ao ar e à água, levando-o a um processo de envelhecimento por oxidação. O envelhecimento dos ligantes asfálticos é um fenômeno natural, que tem início na fase de construção das camadas asfálticas executadas a quente e que se desenvolve mais lentamente ao longo da vida útil do pavimento. A principal consequência do envelhecimento é o endurecimento do ligante asfáltico, expresso no aumento do seu módulo complexo, que favorece a resistência à deformação permanente nos primeiros meses após a construção, mas que pode desfavorecer a resistência à fadiga quando este fenômeno se dá por deformação controlada. Dada a sua influência sobre as propriedades reológicas dos ligantes asfálticos, o envelhecimento tem sido objeto de estudos ao longo das últimas décadas, com o intuito de tentar incluir alguns critérios de controle nas especificações destes materiais.

Em especificações mais elaboradas, como a especificação Superpave para ligantes asfálticos, a problemática do envelhecimento está, aparentemente, bem modelada. Esta especificação prescreve a simulação do envelhecimento a curto prazo, ocorrido na fase de construção da camada asfáltica, por meio do ensaio em estufa de filme fino rotativo (RTFOT), e o envelhecimento a longo prazo, que se dá lentamente ao longo da vida útil do pavimento, por meio do ensaio em vaso pressurizado (PAV). Tais técnicas de envelhecimento acelerado, além de várias outras listadas na literatura, são orientadas pelo princípio da simulação termo-oxidativa, que se baseia na aplicação de temperatura e pressão, combinada com exposição a algum gás (ar ou oxigênio), durante um determinado intervalo de tempo. A radiação ultravioleta (UV), orientada pelo princípio da simulação foto-oxidativa e que tem efeito inegavelmente expressivo sobre a oxidação do ligante asfáltico, normalmente é desconsiderada pelas especificações, incluindo a brasileira.

Tendo em vista a pequena quantidade de pesquisas acerca do efeito da radiação ultravioleta sobre o envelhecimento oxidativo dos ligantes asfálticos, este estudo visa quantificar os efeitos da radiação UV sobre as propriedades reológicas de ligantes asfálticos, como o módulo complexo $\left(\mathrm{G}^{*}\right)$ e o ângulo de fase $(\delta)$. Em virtude do uso gradativamente crescente dos ligantes asfálticos modificados, faz-se necessário avaliar como a radiação ultravioleta afeta as propriedades reológicas destes materiais, na tentativa de indicar quais são 
menos sensíveis ao envelhecimento foto-oxidativo. A opção pelo estudo de propriedades reológicas está baseada em uma das principais conclusões do programa de pesquisas SHRP (Strategic Highway Research Program) de que é mais promissor relacionar as propriedades físicas e não químicas dos ligantes asfálticos ao desempenho das misturas em campo (ANDERSON et al., 1994).

Foram avaliados 12 ligantes asfálticos (CAP puro mais 11 modificados), todos com classificação por grau de desempenho PG 76-XX, preparados com base em um CAP 50-70 com classificação PG 64-22, previamente envelhecidos a curto prazo na estufa RTFO. Os modificadores empregados foram a borracha de pneu moída, o SBS, o EVA, o polietileno, o SBR e o ácido polifosfórico (PPA). Foram analisadas cinco formulações do tipo $\mathrm{CAP}+$ modificador e cinco formulações do tipo CAP+modificador+PPA, além do CAP+PPA e do CAP puro. Os ligantes asfálticos envelhecidos a curto prazo foram expostos a dois níveis diferentes de radiação UV e os resíduos obtidos foram submetidos a ensaios no reômetro de cisalhamento dinâmico (DSR). Os resultados obtidos foram comparados aos das amostras envelhecidas a curto e a longo prazos, nas estufas RTFO e PAV, sem a aplicação da radiação UV. Algumas amostras foram submetidas também a ensaios químicos, na tentativa de analisar o comportamento dos ligantes asfálticos perante o processo de envelhecimento oxidativo.

Foram monitoradas propriedades fundamentais dos ligantes asfálticos, por estarem associadas ao desempenho do pavimento, já que o programa SHRP concluiu que as propriedades empíricas de ligantes asfálticos não se correlacionam bem com o desempenho das misturas no campo (ANDERSON et al., 1994), além de não detectarem precisamente o efeito dos modificadores (ABDELRAHMAN e CARPENTER, 1999). O monitoramento de propriedades fundamentais dos ligantes asfálticos é uma forma de atribuir fundamentação científica sólida ao estudo, uma vez que tais propriedades advêm das teorias tradicionais de elasticidade, viscoelasticidade, viscosidade, mecânica do contínuo e mecânica da fratura.

A análise por meio das curvas-mestre proporciona elementos para a avaliação não apenas dos efeitos dos diferentes níveis de envelhecimento e dos diferentes modificadores, mas também os efeitos de diferentes temperaturas e velocidades de tráfego (frequências), o que amplia o campo de aplicação dos resultados aqui apresentados. 


\subsection{Objetivos}

Os objetivos deste estudo são:

1. quantificar o efeito da radiação ultravioleta sobre as propriedades reológicas de ligantes asfálticos modificados previamente envelhecidos a curto prazo em estufa RTFO;

2. comparar os efeitos do envelhecimento foto-oxidativo (UV) com os efeitos do envelhecimento termo-oxidativo (PAV) à luz de propriedades reológicas dos ligantes asfálticos previamente envelhecidos em estufa RTFO;

3. analisar o efeito do envelhecimento dos ligantes asfálticos à luz de ensaios químicos;

4. classificar os ligantes asfálticos modificados em função da menor sensibilidade ao envelhecimento UV e recomendar formulações adequadas para cada nível de radiação UV estudado; e

5. propor um procedimento para envelhecimento sob radiação ultravioleta para ligantes asfálticos.

\subsection{Estrutura da dissertação}

O Capítulo 1 apresenta o tema abordado neste trabalho e a sua relevância, bem como os objetivos pretendidos com este estudo e a estrutura da dissertação.

O Capítulo 2 apresenta a revisão bibliográfica abordando as características e composição dos ligantes asfálticos, considerações gerais sobre a radiação ultravioleta (UV) e os diversos aspectos do envelhecimento de ligantes asfálticos.

O Capítulo 3, materiais e métodos, apresenta os materiais utilizados nesta pesquisa e os ensaios de caracterização, reológicos e químicos, aos quais as amostras foram submetidos. Apresenta também os procedimentos de envelhecimentos a curto prazo e a longo prazos abordados neste experimento. 
O Capítulo 4 apresenta os resultados dos ensaios de caracterização (penetração e ponto de amolecimento), das propriedades monitoradas por meio de curvas-mestre, do ensaio de Varredura de Amplitude Linear (LAS) e dos ensaios químicos (espectroscopia no infravermelho por transformada de Fourier - FTIR, fracionamento SARA e Cromatografia por Permeação em Gel - GPC) aos quais algumas amostras foram submetidas. Neste capítulo, são também discutidos os resultados.

No Capítulo 5 encontram-se as principais conclusões obtidas neste trabalho, muitas delas apresentadas com o auxílio dos ordenamentos aos quais as 12 amostras foram submetidas.

No Apêndice A encontram-se as curvas-mestres que não foram apresentadas no corpo do trabalho e no Apêndice B encontra-se a proposta de procedimento de envelhecimento de ligantes asfálticos puros e modificados em estufa UV, bem como uma proposta de procedimento de análise dos efeitos do envelhecimento UV, utilizando curvasmestre, tendo por base as técnicas que foram desenvolvidas neste estudo. 


\section{REVISÃO BIBLIOGRÁFICA}

Este capítulo aborda as características e composição dos ligantes asfálticos, além do histórico e das pesquisas relacionadas ao envelhecimento a curto e a longo prazo dos mesmos. Apresenta conceitos gerais a respeito da radiação ultravioleta (UV), as pesquisas que simulam o envelhecimento de ligantes asfálticos exposto a radiação UV e as técnicas utilizadas para análise dos resultados.

\subsection{Ligante asfáltico: características e composição}

O ligante asfáltico é um produto obtido por meio da destilação de alguns tipos de petróleo bruto. No Brasil, o ligante asfáltico utilizado em pavimentação é conhecido como Cimento Asfáltico de Petróleo (CAP). Este possui a propriedade de ser um adesivo termoviscoplástico: semi-sólido a temperaturas baixas, viscoelástico a temperaturas ambiente e líquido a altas temperaturas (BERNUCCI et al., 2008). Tais propriedades são importantes para os ligantes asfálticos, tendo em vista que estes devem ser usinados e bombeados a altas temperaturas (cerca de $160^{\circ} \mathrm{C}$ ), ser suficientemente rígidos para suportar o tráfego nas altas temperaturas do pavimento $\left(50^{\circ} \mathrm{C}\right.$, por exemplo), evitando assim o surgimento de deformação permanente, e ao mesmo tempo, devem ser elásticos a temperaturas intermediárias e baixas (negativas em alguns países), para resistir às fissuras por fadiga e de origem térmica, respectivamente (LESUEUR, 2002).

Read e Whiteoak (2003) referem-se ao ligante asfáltico como um material que possui na maior parte de sua constituição moléculas de hidrocarbonetos e uma pequena quantidade de heteroátomos (enxofre, nitrogênio e oxigênio), além de traços de metais como vanádio, níquel, ferro, magnésio e cálcio. Mesmo com sua composição química complexa, é possível separar o asfalto em dois grandes grupos: os asfaltenos e os maltenos. As micelas de asfaltenos possuem alto peso molecular e encontram-se dispersas ou dissolvidas em um meio oleoso de baixo peso molecular (maltenos). Os maltenos são subdivididos em aromáticos, 
saturados e resinas. Essa composição química (saturados, aromáticos, resinas e asfaltenos) é denominada SARA.

Os asfaltenos são separados por precipitação com n-heptano. Os maltenos são solúveis em n-heptano e separados por cromatografia de adsorção. A figura 2.1 apresenta um esquema da análise da composição química do ligante asfáltico.

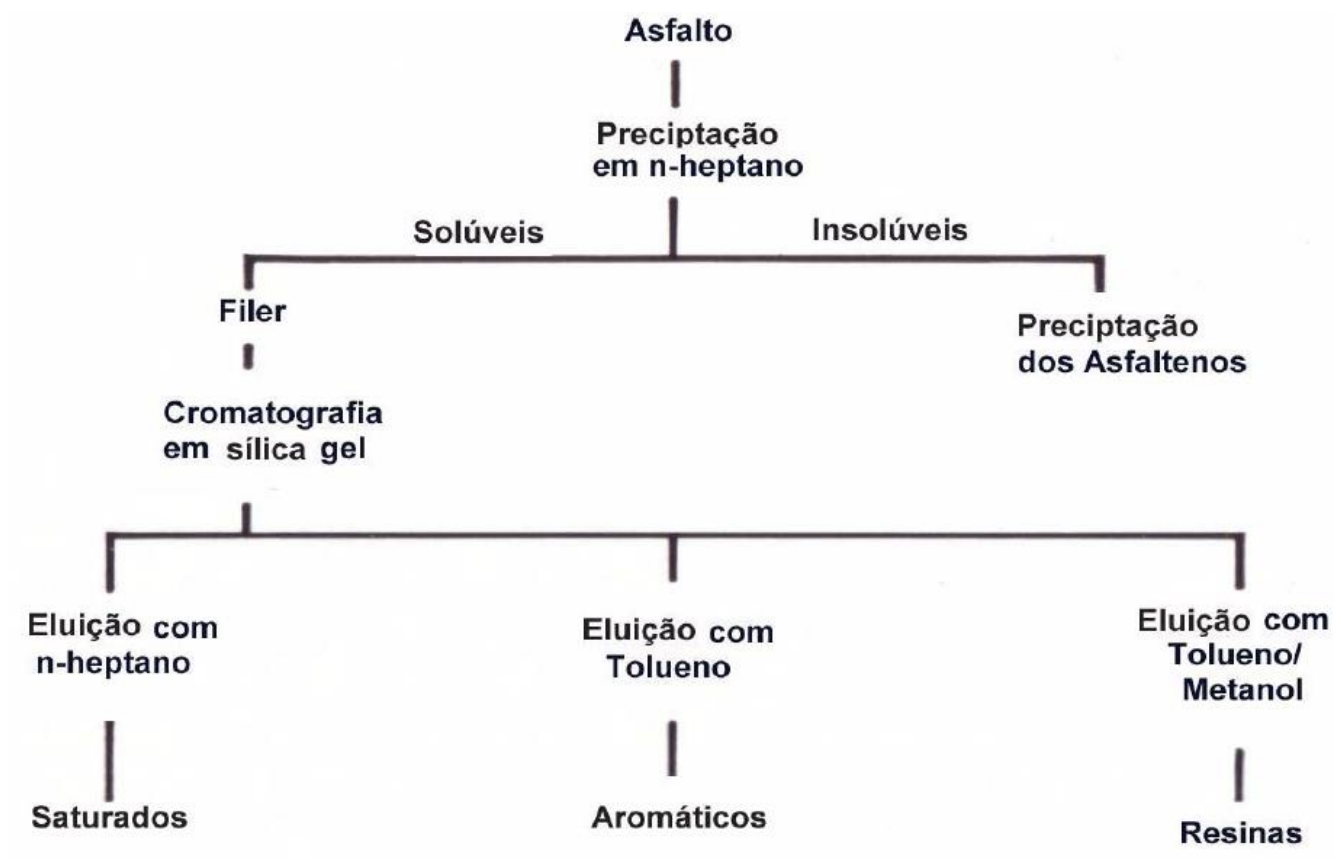

Figura 2.1 - Representação esquemática da análise de composição química de um ligante [Whiteoak ${ }^{1}$ (1991) apud Tonial (2001)]

Yen $(1991)^{2}$ apud Leite (1999) exemplifica esse modelo de estrutura do ligante asfáltico por meio da Figura 2.2, onde o CAP é um sistema coloidal composto por micelas de asfaltenos em suspensão e peptizadas por resinas em meio oleoso, ou seja, saturados e aromáticos, formando o equilíbrio entre moléculas, micelas e aglomerados.

\footnotetext{
${ }^{1}$ WHITEOAK, D., 1991, The SHELL Bitumen Handbook. 1 ed. reprinted - Inglaterra, SHELL.

${ }^{2}$ YEN T.F - Asphaltene/Resin plus oil interconversion: an investigation into coloidal model of asphaltenes

- Proceedings of Workshop - The chemical components and structure of asphaltic materials - Rome 1991.
} 


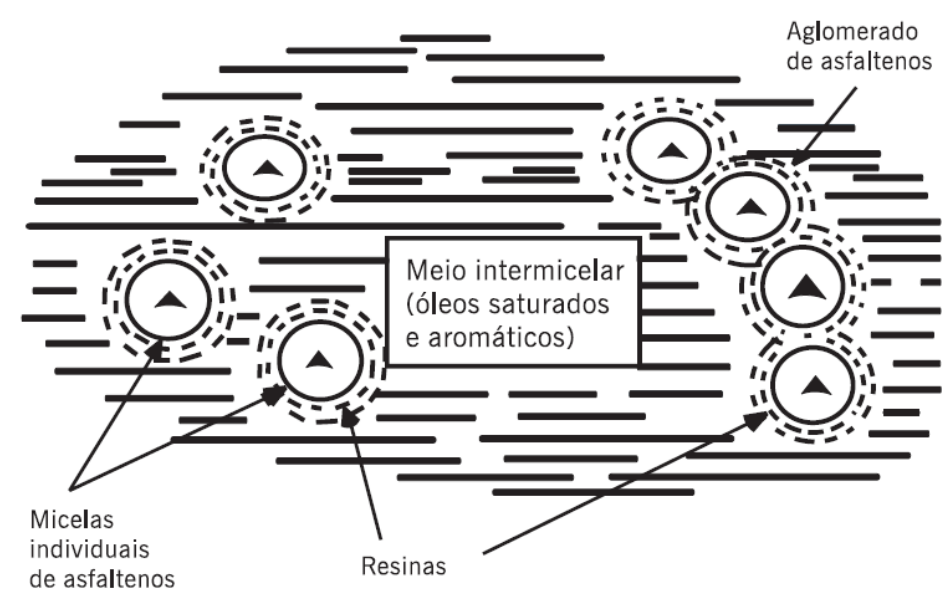

\section{Figura 2.2 - Representação da estrutura coloidal do ligante asfáltico [Yen ${ }^{3}(1991)$ apud Leite (1999)]}

De acordo com Read e Whiteoak (2003), as principais frações do ligante asfáltico possuem as seguintes características:

1. os asfaltenos representam a parte sólida e o seu aumento nos ligantes asfálticos está associado ao endurecimento do CAP, tornando-o mais viscoso, com uma menor penetração e maior ponto de amolecimento. Representam uma quantidade entre 5 e $25 \%$ na constituição do ligante asfáltico;

2. as resinas são solúveis em n-heptano. São compostos sólidos ou semi-sólidos. Suas proporções em conjunto com os asfaltenos determinam o comportamento do CAP como solução (SOL) ou como gelatina (GEL);

3. os aromáticos são líquidos viscosos de baixo peso molecular e representam a maior parte do meio de dispersão para os asfaltenos. Estão presentes em cerca de 40 a $65 \%$ da constituição do ligante asfáltico;

4. os saturados são óleos viscosos não-polares com peso molecular médio similar aos dos aromáticos. Representam de 5 a $20 \%$ da composição química do ligante asfáltico.

\footnotetext{
${ }^{3}$ YEN T.F - Asphaltene/Resin plus oil interconversion: an investigation into coloidal model of asphaltenes - Proceedings of Workshop - The chemical components and structure of asphaltic materials - Rome 1991.
} 
Baseado na sua estrutura coloidal (GIAVARINI et al., 2000), os asfaltos podem ser divididos em três tipos distintos. Asfaltos do tipo SOL se comportam como fluidos newtonianos e tem uma estrutura coloidal com a presença de micelas que não interagem. Asfaltos do tipo SOL-GEL apresentam efeitos elásticos apenas nos estágios iniciais de deformação e tem uma estrutura coloidal com a presença de supermicelas e grandes supermicelas. Asfaltos do tipo GEL têm alta resiliência e uma estrutura coloidal tridimensional, com extensiva interação intermolecular. A maioria dos resíduos de vácuo e os asfaltos para pavimentação são do tipo SOL-GEL, ao passo que os asfaltos oxidados ou soprados são do tipo GEL.

Apesar do modelo da estrutura coloidal do ligante asfáltico de Yen ser bem aceito pela comunidade científica, pesquisadores do "Strategic Highway Research Program" (SHRP) caracterizam quimicamente o asfalto de forma diferente. Segundo Jones (1992), o asfalto consiste de duas famílias de moléculas funcionais denominadas polar e apolar, onde a "compatibilidade" de suas frações ou o grau em que podem dissolver-se uma na outra é controlada pela aromaticidade relativa das duas frações.

\subsection{Envelhecimento de ligantes asfálticos}

O envelhecimento de ligantes asfálticos tem sido tratado como um aspecto de relevância na relação entre as propriedades reológicas do ligante asfáltico e o comportamento mecânico das misturas asfálticas. O nível de severidade das condições às quais o ligante asfáltico é submetido, durante as operações de usinagem e de compactação e também ao longo da vida útil do pavimento, provoca um enrijecimento natural do material, que prejudica o comportamento mecânico da mistura asfáltica. Atualmente, as especificações de ligantes asfálticos têm avançado na direção de classificar o material com base em seu comportamento reológico após o envelhecimento. $\mathrm{Na}$ especificação Superpave, o ligante asfáltico é classificado com base nas propriedades reológicas do material virgem e também envelhecido a curto e a longo prazos. A especificação brasileira de ligantes asfálticos exige o monitoramento da penetração, do ponto de amolecimento e da ductilidade, após o 
envelhecimento a curto prazo, além de controlar a perda percentual de massa provocada pelo envelhecimento.

Como resultado do programa SHRP, duas práticas de envelhecimento foram incorporadas à especificação Superpave. A primeira emprega a estufa de filme fino rotativo (RTFO) para simular o envelhecimento a curto prazo dos ligantes asfálticos, durante as operações de usinagem e de compactação. A segunda emprega a estufa pressurizada (PAV) para simular o envelhecimento a longo prazo de ligantes asfálticos de pista. A especificação Superpave exige que o ligante asfáltico seja envelhecido a curto prazo, antes de se monitorar as propriedades reológicas associadas à deformação permanente, e seja envelhecido a curto e a longo prazos, a fim de se monitorar as propriedades reológicas a baixas temperaturas e associadas à fadiga. $\mathrm{O}$ procedimento empregando cilindro rotativo (RCAT) também vem sendo utilizado em pesquisas, especialmente na Europa, representando uma alternativa promissora no estudo do envelhecimento, pois combina, em um mesmo procedimento de laboratório, os efeitos desse fenômeno, a curto e longo prazos.

O envelhecimento dos ligantes asfálticos é um fenômeno complexo, por promover alterações de natureza física e química destes materiais, que está diretamente associado a mecanismos de ruína da camada asfáltica, como a desagregação e o trincamento por fadiga ou de origem térmica (HUANG et al., 1996). É tradicionalmente dividido em duas fases: o envelhecimento a curto prazo, associado à exposição ao ar e ao calor durante a usinagem e a compactação da mistura asfáltica, e o envelhecimento a longo prazo, que se desenvolve ao longo da vida útil da camada asfáltica. Dada a sua influência sobre as propriedades reológicas dos ligantes asfálticos, o envelhecimento tem sido objeto de estudos ao longo das últimas décadas, com o intuito de tentar incluir alguns critérios de controle nas especificações destes materiais.

O envelhecimento de ligantes asfálticos é um fenômeno que combina os efeitos da volatilização de suas frações mais leves e de reações químicas de seus componentes com oxigênio. Durante as operações de usinagem e compactação, o ligante asfáltico envelhece por volatilização e por oxidação. Durante a vida de serviço, a oxidação é considerada o principal mecanismo de envelhecimento, induzido pela exposição ao ar e a radiação solar (BUTTON et al., 1993; ANDERSON et al., 1994; HUH e ROBERTSON, 1996; ABBAS et al., 2002). 
Com o envelhecimento, os ligantes asfálticos se tornam mais rígidos nas temperaturas de ocorrência de deformação permanente e de trincas por fadiga, apresentando maiores valores de módulo complexo $\left(\mathrm{G}^{*}\right)$, além de mais quebradiços a baixas temperaturas e menos adesivos (GARRICK, 1995; ABBAS et al., 2002). Mesmo assim, o envelhecimento não é absolutamente prejudicial: ligantes asfálticos mais duros são mais resistentes à deformação permanente, no entanto, sob temperaturas intermediárias e baixas, materiais mais duros se tornam mais suscetíveis ao trincamento por fadiga e de origem térmica (ANDERSON et al., 1994). Por outro lado, o envelhecimento aumenta ligeiramente a elasticidade do ligante asfáltico, o que favorece suas resistências à deformação permanente, à fadiga e ao trincamento térmico.

Penetração, ductilidade, ponto de amolecimento e viscosidade estão entre as medidas de consistência mais comuns na avaliação do envelhecimento. A maior parte dos estudos de durabilidade de ligantes asfálticos, feitos até há poucos anos, estava completamente baseada em medidas empíricas. Redução da penetração e da ductilidade e aumento do ponto de amolecimento eram usados como indicadores do envelhecimento. Penetração e ductilidade eram medidas sob várias temperaturas e valores limites foram propostos para indicar o nível de envelhecimento para o qual seriam esperadas trincas no pavimento. Porém, estas características podem não proporcionar uma representação adequada da natureza complexa das propriedades viscoelásticas do ligante asfáltico ou mesmo das alterações provocadas pelo envelhecimento. Por serem medidas empíricas por natureza, não podem ser relacionadas, seja de forma exata ou mesmo aproximada, a qualquer propriedade reológica fundamental do material. O uso de parâmetros viscoelásticos, como módulo complexo e ângulo de fase, é a forma mais adequada de se caracterizar as mudanças provocadas pelo envelhecimento (ANDERSON et al., 1994).

Dentre os principais fatores intervenientes sobre o envelhecimento dos ligantes asfálticos estão as características do próprio ligante asfáltico e o seu teor ótimo na mistura asfáltica, a natureza dos agregados minerais e sua composição granulométrica, o volume de vazios da mistura asfáltica, fatores relacionados à produção, a temperatura e o tempo. Todos estes fatores operam simultaneamente, tornando o envelhecimento dos ligantes asfálticos um processo bastante complexo (LU e ISACSSON, 2002). 


\subsubsection{Envelhecimento a curto prazo}

No envelhecimento a curto prazo, volatilização e oxidação ocorrem em paralelo. A volatilização é um fenômeno predominantemente físico, que se expressa na perda de componentes voláteis do ligante asfáltico e é normalmente avaliada à luz de medidas de perda de massa. Já a oxidação é um fenômeno de natureza química, com consequências mais complexas sobre o comportamento reológico do ligante asfáltico e, por esta razão, de mais difícil mensuração. À medida que o ligante asfáltico oxida (WOO et al., 2008), grupos carbonila $(\mathrm{C}=\mathrm{O})$ se formam, o que aumenta a polaridade e a tendência de associação com outros compostos polares. À medida que tais associações são estabelecidas, são formados asfaltenos menos solúveis e que apresentam comportamento de sólido. Esta mudança de composição resulta em aumento da viscosidade e das propriedades elásticas do ligante asfáltico (HALSTEAD, 1985, LIN et al., 1996, PETERSEN et al., 1993). O resultado final (WOO et al., 2008) é um material que sofre grandes aumentos de tensão quando deforma (alta rigidez elástica) e simultaneamente não pode aliviar a tensão por fluxo (alta viscosidade), levando a um revestimento que é quebradiço e suscetível aos trincamentos por fadiga e de origem térmica.

Os esforços em compreender os mecanismos pelos quais se dá o envelhecimento dos ligantes asfálticos e das misturas asfálticas remontam ao início do século 19 e começaram a ser registrados na literatura por volta da década de 1960 (Bell, 1989). Há mais de 50 anos, Traxler (1961) listou cinco fatores intervenientes sobre o endurecimento sofrido pelos ligantes asfálticos, na seguinte ordem de importância: oxidação, volatilização, tempo (relacionado à reestruturação molecular), polimerização induzida por exposição à radiação solar e polimerização induzida pelo calor. Dois anos depois, Traxler (1963) listou 15 fatores intervenientes sobre o endurecimento sofrido pelos ligantes asfálticos. Mesmo naquela época, estes autores destacaram a necessidade de maior experimentação a fim de compreender os efeitos de tais fatores. Mais recentemente, Peterson (1984) listou três principais fatores sobre o endurecimento do ligante asfáltico nas misturas asfálticas: perda de óleos por volatilização e absorção, mudanças na composição do ligante asfáltico devidas à reação com oxigênio atmosférico e reestruturação molecular (endurecimento estérico). 
Segundo Bell (1989), os primeiros estudos do envelhecimento de ligantes asfálticos empregaram a técnica do aquecimento estendido e a maior parte destes estudos foi patrocinada pelo Bureau of Public Roads (BPR) dos Estados Unidos. Welborn (1979) cita o trabalho de Dow (1903) como o primeiro a submeter o ligante e a mistura asfáltica a aquecimento estendido. Quase 40 anos depois, Lewis e Welborn (1940) introduziram o "thin film oven test" (TFOT), incorporado às especificações da AASHTO em 1959 e da ASTM em 1969. Modificações posteriores levaram ao desenvolvimento do atualmente utilizado "rolling thin film oven test" (RTFOT), pelo California Division of Highways, sendo a primeira descrição deste procedimento apresentada por Hveem et al. (1963) e sua incorporação feita pela ASTM em 1970. Em 1994, com o lançamento da especificação Superpave, o programa SHRP especificou o RTFOT como ensaio para avaliação do efeito do calor e do ar, correspondente ao que se denominou como "envelhecimento a curto prazo". Paralelamente, outros ensaios foram desenvolvidos (BELL, 1989):

- "Shell microfilm test" (Griffin et al., 1955);

- "rolling microfilm oven test" (RMFO) (SCHMIDT e SANTUCCI, 1969);

- "tilt-oven durability test (TODT) (KEMP e PREDOEHL, 1981; MCHATTIE, 1983), ambos modificações do RTFOT e

- "thin film accelerated test (TFAAT) (PETERSON, 1989).

Contudo, o RTFOT tem sido o ensaio mais utilizado em estudos para simulação do envelhecimento a curto prazo de ligantes asfálticos.

\subsubsection{Envelhecimento a longo prazo}

Em paralelo ao desenvolvimento de estudos para simular o envelhecimento durante a usinagem e a compactação da mistura asfáltica, outros estudos focaram a oxidação do ligante asfáltico, mais diretamente associada ao envelhecimento que ocorre ao longo da vida útil da camada asfáltica. Nicholson (1937) e Raschig e Doyle (1937) realizaram os primeiros estudos utilizando a técnica de sopragem para simular a oxidação sofrida pelos ligantes asfálticos. Muitos anos depois, Lee (1973) propôs o envelhecimento do resíduo do TFOT em vaso 
pressurizado a oxigênio. Edler et al. (1985) e Kim et al. (1986) realizaram estudos posteriores, nesta mesma linha.

Mais recentemente, o programa SHRP desenvolveu a estufa PAV (pressure aging vessel) para simular o denominado "envelhecimento a longo prazo", agora utilizando ar sintético em vez de oxigênio puro, durante a pressurização. Neste procedimento, o resíduo obtido do RTFOT é submetido à pressão e temperatura durante um determinado intervalo de tempo. Uma alternativa ao PAV da especificação Superpave é o "rolling cylinder aging test" (RCAT), que simula o envelhecimento a longo prazo utilizando o resíduo do RTFOT, empregando oxigênio mas sem pressurização.

\subsection{Ligantes asfálticos modificados e o efeito do envelhecimento}

A modificação de ligantes asfálticos busca alcançar alguns benefícios, tais como o aumento da durabilidade do pavimento e a otimização da manutenção do mesmo. No entanto, a adição de modificadores, como os polímeros, requer cautela, pois as unidades moleculares dos polímeros são maiores do que as maiores moléculas dos ligantes asfálticos, o que pode gerar problemas de homogeneidade quando misturados (DURAND et al., 2012).

Um dos modificadores mais estudado é o copolímero SBS, sendo utilizado muitas vezes combinado com outros modificadores. Zhang et al. (2011a) pesquisaram as influências dos envelhecimentos (a curto e longo prazo) na viscosidade dinâmica, utilizando um reômetro de tensão controlada; estabilidade térmica, utilizando um analisador termogravimétrico "TA Instruments" modelo SDT2960 e a evolução estrutural dos ligantes asfálticos envelhecidos, por meio de espectroscopia de infravermelho. Os asfaltos foram modificados com SBS e SBS+enxofre. Constataram que a adição de enxofre foi positiva no que se refere à viscosidade dinâmica e a estabilidade térmica, mas as propriedades melhoradas declinaram após o envelhecimento, tornando-se mais negativas com a intensidade do envelhecimento.

Lu e Isacsson (1998) também analisaram o envelhecimento de ligantes asfálticos modificados com SBS. O procedimento de envelhecimento foi simulado por meio dos ensaios de TFOT e RTFOT. Foi observado que o envelhecimento resulta na degradação do polímero 
SBS e oxidação do ligante asfáltico. Em todos os casos avaliados por estes pesquisadores, os ligantes asfálticos modificados envelhecidos apresentaram melhores propriedades reológicas que os CAPs de base envelhecidos. A espectroscopia FTIR "Fourier Transform InfraRed" indicou que o SBS pode atuar como antioxidante na formação de sulfóxidos, mas pode não impedir a formação de carbonilas. De acordo com Petersen and Glaser (2011), os sulfóxidos também são grupos facilmente identificados na oxidação do asfalto, mas receberam pouca atenção no passado. Atualmente, sua formação tem sido considerada um importante fator para entender o endurecimento oxidativo dos asfaltos.

Para Mouillet et al. (2014) uma das problemáticas atuais, no que se refere aos procedimentos existentes de simulação do envelhecimento de ligantes asfálticos, é que as técnicas utilizadas foram desenvolvidas para ligantes asfálticos não modificados, necessitando de reavaliação, tendo em vista que o comportamento dos ligantes asfálticos modificados pode ser diferente dos puros, como constataram Lu et al. (2008). Estes últimos pesquisadores citados compararam três procedimentos: RTFOT seguido de PAV a $100^{\circ} \mathrm{C}$ por 8 a $48 \mathrm{~h}$; RTFOT seguido de PAV a $75^{\circ} \mathrm{C}$ por 48 a $220 \mathrm{~h}$ e RCAT a $163^{\circ} \mathrm{C}$ por 17 a $140 \mathrm{~h}$. Concluíram que tais simulações foram equivalentes, em se tratando de ligantes asfálticos puros, porém quando realizadas com ligantes asfálticos modificados com SBS, os resultados foram significativamente diferentes no que se refere à cinética do envelhecimento.

\subsection{Radiação ultravioleta (UV): considerações gerais}

A radiação solar que atinge a superfície da Terra consiste de uma componente direta e uma componente difusa (DIFFEY, 1977). A componente direta não sofre alteração em sua direção original ao atravessar a atmosfera terrestre, ao passo que a componente difusa é espalhada pelos gases que a compõem e também por conta da presença de poeira e das nuvens. De acordo com Okuno e Vilela (2005), suas contribuições são iguais ao meio dia, já ao amanhecer e ao entardecer a componente difusa é maior.

O espectro eletromagnético é formado por ondas eletromagnéticas que possuem comprimentos de ondas que variam numa faixa bastante ampla. A radiação UV se encontra na região conhecida como óptica, bem como a radiação infravermelha e a luz visível. A unidade 
utilizada para o comprimento de onda na região da radiação UV é o nanômetro (nm), que é usado para pequenos comprimentos e que equivale a $10^{-9} \mathrm{~m}$. A radiação UV compreende a faixa de comprimento de 100 a $400 \mathrm{~nm}$. O sistema de grandeza e a unidade relativos à radiação UV é o radiométrico, em que a grandeza correspondente chama-se radiância (fluxo radiante por unidade de área projetada do radiador por unidade de ângulo sólido, cuja unidade é $\left.W \cdot m^{-2} \cdot s r^{-1}\right)$. A exposição à radiação UV, quando contínua, é quantificada em termos de irradiância, ou seja, o fluxo radiante que atinge uma superfície dividido pela área dessa superfície. Pode ser chamada também de densidade de fluxo radiante e sua unidade é $\mathrm{W} / \mathrm{m}^{2}$ (OKUNO e VILELA, 2005).

Frederick et al. (1989) apresentam a distribuição espectral da irradiância solar, medida no topo da atmosfera terrestre, conforme a Tabela 2.1 e na Figura 2.3 pode ser observado o espectro da radiação solar que atinge o topo da atmosfera e ao nível do mar, tendo como referência o Programa das Nações Unidas para o Ambiente (UNEP). Como pode ser observado, as regiões da luz visível e do infravermelho representam a maior parte das emissões solares, ao passo que a radiação UVC é praticamente toda removida pela absorção eficiente do oxigênio molecular e do ozônio. De acordo com Diffey (1977), os valores do coeficiente de absorção do ozônio aumentam rapidamente com a diminuição do comprimento de onda, assim, praticamente não há radiação com comprimento de onda inferior a $295 \mathrm{~nm}$ que atingem a superfície da Terra. Estudos utilizando dados de satélites e medidores de superfície têm mostrado decréscimo do ozônio em nível global. Dessa forma, sua redução significativa pode implicar no aumento no fluxo UV na superfície da Terra (KIRCHHOFF et al., 2000).

Tabela 2.1- Distribuição da irradiância solar (média anual) que atinge o topo da atmosfera (FREDERICK et al., 1989)

\begin{tabular}{ccc}
\hline Faixa de comprimento de onda & Irradiância $\left(\mathbf{W} / \mathbf{m}^{2}\right)$ & \% do total \\
\hline UVm) & 6,4 & 0,5 \\
UVB $(280-320)$ & 21,1 & 1,5 \\
UVA $(320-400)$ & 85,7 & 6,3 \\
Visível $(400-700)$ & 532,0 & 38,9 \\
Infravermelho $(>700)$ & 722,0 & 52,8 \\
\hline
\end{tabular}




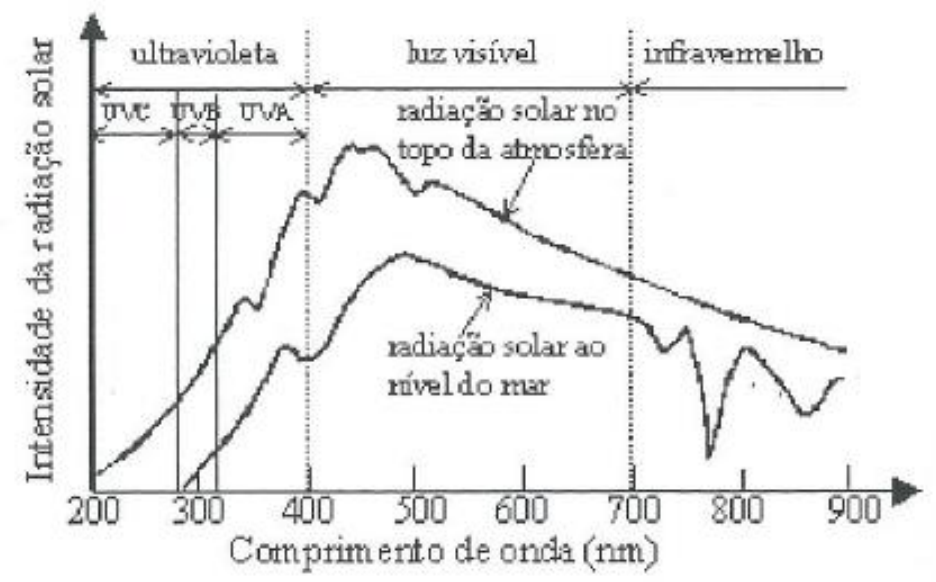

Figura 2.3 - Espectro da radiação solar que atinge o topo da atmosfera e ao nível do mar. Ref. UNEP, 1987 (OKUNO e VILELA, 2005)

A radiação solar que atinge a superfície da Terra é atenuada pela atmosfera. De acordo com Diffey (2002), a qualidade e quantidade da radiação UV são modificadas à medida que atravessam a atmosfera. Na estratosfera, camada localizada entre 10 e $50 \mathrm{~km}$ (aproximadamente) acima do nível do mar, as principais interações são a absorção pelo ozônio e dispersão por moléculas, tais como o nitrogênio $\left(\mathrm{N}_{2}\right)$ e o oxigênio $\left(\mathrm{O}_{2}\right)$. Na troposfera, camada localizada de 0 a $10 \mathrm{~km}$ (aproximadamente) acima do nível do mar, a absorção por poluentes tais como ozônio, dióxido de nitrogênio $\left(\mathrm{NO}_{2}\right)$ e dióxido de enxofre $\left(\mathrm{SO}_{2}\right)$, espalhamento por partículas e as nuvens são os principais processos atenuantes da radiação UV.

Okuno e Vilela (2005) citam outros fatores que afetam a irradiância espectral da radiação $\mathrm{UV}$, tais como:

- hora do dia (irradiância de 70 a $80 \%$ entre 9 e 15 horas);

- estação do ano;

- latitude geográfica (fluxo de radiação UV diminui com o aumento da distância ao Equador);

- altitude (fluxo de radiação UV aumenta cerca de $6 \%$ a cada $1 \mathrm{~km}$ de aumento na altitude), e

- reflexão na superfície (neve reflete cerca de 30\%, areia cerca de $25 \%$, superfícies terrestres e marítimas menos de $7 \%$ de radiação UV). 
Conhecer quanto de radiação UV chega a Terra é importante para diversas áreas de conhecimento, porém diversos fatores tornam essa mensuração difícil. Além das muitas variáveis que interferem na coleta de dados (o ângulo solar zenital, altitude em relação ao nível do mar, nebulosidade, entre outros), Kirchhoff et al. (2000) citam as dificuldades instrumentais e o fato da intensidade UV ser relativamente pequena e de rápida variação com o comprimento de onda. Dessa forma, obter dados confiáveis requer um longo prazo de observações.

\subsection{Envelhecimento ultravioleta: princípio foto-oxidativo}

Outro fator relevante sobre o envelhecimento do ligante asfáltico é a radiação ultravioleta. A influência da radiação solar sobre os ligantes asfálticos é conhecida há muito tempo (DURRIEU et al., 2007): em 1822, Niepce desenvolveu uma técnica de tratamento de um filme fino de ligante asfáltico com luz. Um dos primeiros estudos visando simular o efeito da radiação solar foi realizado por Vallerga et al. (1957), utilizando radiação ultravioleta e infravermelho. Estudos subsequentes foram apresentados por Traxler (1963) e Edler et al. (1985).

Mais recentemente, Yamaguchi et al. (2004) irradiaram os componentes do ligante asfáltico separadamente com raios ultravioleta a fim de avaliar este mecanismo de envelhecimento e confirmaram que os saturados e os aromáticos são convertidos em resinas e asfaltenos, resultando em grupos carbonila (grupos funcionais que contêm oxigênio), embora os saturados e os aromáticos sejam convertidos por mecanismos diferentes. Estes autores adicionaram negro de fumo ao ligante asfáltico e constataram que este fíler previne a conversão de saturados em carbonilas por ação da radiação UV.

Yu et al. (2010) verificaram que o emprego de organo-montmorilonita, de hidróxido de magnésio e de cal mostraram-se eficientes em minimizar o efeito da radiação UV. Estes últimos autores concluíram que maiores tempos de exposição à radiação provocaram maior envelhecimento, que o aumento do teor de fíler reduz o efeito da radiação e que a organomontmorilonita se mostrou mais eficiente que o hidróxido de magnésio. Zhang et al. (2011b) verificaram que a organo-montmorilonita também pode melhorar a resistência ao 
envelhecimento por radiação ultravioleta de ligantes asfálticos modificados com SBS. Nesta linha, Ye et al. (2006) constataram que o SBR também é um ótimo aditivo para reforçar a resistência do ligante asfáltico à radiação UV.

Liao et al. (2008) avaliaram o efeito da adição de nano- $\mathrm{TiO}_{2}$, de $\mathrm{CeO}_{2}$ e de negro de fumo ao ligante asfáltico. Concluíram que, embora o nano- $\mathrm{TiO}_{2}$ e o $\mathrm{CeO}_{2}$ sejam bons absorvedores de radiação UV, são também oxidantes fortes, que podem acelerar o envelhecimento do ligante asfáltico se adicionados em concentrações superiores às ideais. Estes autores observaram também que o negro de fumo é um bom agente anti-UV e que sua concentração ideal deve ser de 0,8\% em massa. Sun et al. (2011) também adicionaram ao ligante asfáltico vários teores de nano-TiO2. Seus resultados mostraram que com $5 \%$ as propriedades antirradiação UV são melhoradas.

Segundo Ma et al. (2008), a radiação ultravioleta tem influência significativa sobre os componentes, a estrutura e as propriedades dos ligantes asfálticos. Após o envelhecimento UV, as frações genéricas são transformadas de moléculas leves em moléculas maiores, indicando aumento da associação molecular. Além disso, grupos funcionais típicos como carbonilas e sulfoxidos aparecem após a radiação UV e a quantidade destes grupos aumenta com o aumento do tempo de exposição à radiação UV. Os autores indicam que após a radiação UV, as propriedades mecânicas dos ligantes asfálticos envelhecidos se aproximam das de um sólido e a suscetibilidade térmica diminui, devido ao aumento da viscosidade e do índice de penetração. Os autores também verificaram aumento do módulo complexo e redução do ângulo de fase devidos ao envelhecimento por radiação UV.

Umas das principais deficiências das técnicas normatizadas de envelhecimento acelerado em laboratório (RTFOT e PAV) é a ausência da simulação do efeito da radiação ultravioleta, por se admitir que apenas a parte superior da camada de rolamento, que sofre a incidência direta da radiação, seja afetada. Conforme estudos de Petersen (1998), no início da vida últil do pavimento, a oxidação penetra, significativamente, apenas cerca de $1 \mathrm{~cm}$ do pavimento. No entanto, o envelhecimento dos ligantes asfálticos devido à radiação ultravioleta é um processo evidente e naturalmente incontornável que exige a realização de estudos aprofundados. Embora afete a camada asfáltica apenas superficialmente, a radiação UV facilita a oxidação do ligante asfáltico nesta região. 


\subsubsection{Técnicas de envelhecimento UV abordadas na literatura}

Estabelecer as condições de ensaio de laboratório ideais, que correspondam com o real envelhecimento do revestimento asfáltico na vida útil em serviço tem sido um grande desafio para a comunidade científica, pois são muitas as variáveis envolvidas neste processo. Dessa forma, cada pesquisador estabeleceu sua própria técnica arbitrando o nível de radiação, temperatura, tempo de ensaio, espessura do filme asfáltico, entre outras, que julgam ser pertinentes, não existindo um padrão a ser seguido nas pesquisas realizadas nesta área.

Com o intuito de resumir as técnicas abordadas pelos pesquisadores consultados para a realização deste trabalho, a Tabela 2.2 apresenta as principais informações acerca dos procedimentos para simulação do envelhecimento UV. Os campos das informações não mencionadas, ou não encontradas, não foram preenchidos.

Tabela 2.2 - Principais variáveis do envelhecimento UV abordada por alguns autores

\begin{tabular}{|c|c|c|c|c|c|c|}
\hline Autor (es) & Procedimento & $\begin{array}{l}\text { Espessura } \\
\text { do filme } \\
\text { asfáltico }\end{array}$ & $\begin{array}{l}\text { Intensidade da } \\
\text { radiação UV } \\
\left(\mathbf{W} / \mathbf{m}^{2}\right)\end{array}$ & $\begin{array}{l}\text { Comprimento } \\
\text { de onda (nm) }\end{array}$ & $\begin{array}{c}\text { Temperatura } \\
\left({ }^{\circ} \mathrm{C}\right)\end{array}$ & $\begin{array}{c}\text { Tempo de } \\
\text { exposição } \\
\text { UV } \\
\text { aproxi- } \\
\text { mado (h) }\end{array}$ \\
\hline $\begin{array}{l}\text { Yamaguchi } \\
\text { et al., } 2005\end{array}$ & $\begin{array}{l}\text { Envelhecimento } \\
\text { UV de ligante } \\
\text { asfáltico após } \\
\text { TFOT }\end{array}$ & $\begin{array}{c}0,05 ; 0,10 ; \\
0,20 ; 0,50 \mathrm{e} \\
1,00\end{array}$ & 78,00 & 300 a 400 & 60 & 48 \\
\hline $\begin{array}{l}\text { Silva et al., } \\
\quad 2005\end{array}$ & $\begin{array}{l}\text { Envelhecimento } \\
\text { UV de ligante } \\
\text { asfáltico após } \\
\text { RTFOT }\end{array}$ & 2,00 & 0,77 & - & 60 & 24 a 840 \\
\hline $\begin{array}{c}\text { Durrieu et } \\
\text { al., } 2007\end{array}$ & $\begin{array}{l}\text { Envelhecimento } \\
\text { UV de ligante } \\
\text { asfáltico após } \\
\text { RTFOT }\end{array}$ & 0,01 & 0,77 & 340 & 60 & 170 \\
\hline $\begin{array}{c}\text { Yi-Qiu et al., } \\
2007 \mathrm{a}\end{array}$ & $\begin{array}{l}\text { Envelhecimento } \\
\text { UV de ligante } \\
\text { asfáltico }\end{array}$ & - & - & - & 73 & 9 \\
\hline $\begin{array}{l}\text { Yi-Qiu et al., } \\
\text { 2007b }\end{array}$ & $\begin{array}{l}\text { Envelhecimento } \\
\text { UV de misturas } \\
\text { asfálticas }\end{array}$ & - & - & - & 73 & 48 \\
\hline $\begin{array}{l}\text { Wu et al., } \\
2008 \mathrm{a}\end{array}$ & $\begin{array}{c}\text { Envelhecimento } \\
\text { de ligante } \\
\text { asfáltico ao ar } \\
\text { livre após RTFOT }\end{array}$ & 0,05 a 0,20 & 12,00 & 300 a 400 & $20 \pm 15$ & $\begin{array}{c}744 \\
\text { (verão) }\end{array}$ \\
\hline
\end{tabular}


conclusão

\begin{tabular}{|c|c|c|c|c|c|c|}
\hline Autor (es) & Procedimento & $\begin{array}{l}\text { Espessura } \\
\text { do filme } \\
\text { asfáltico } \\
\text { (mm) }\end{array}$ & $\begin{array}{c}\text { Intensidade da } \\
\text { radiação UV } \\
\left(\mathbf{W} / \mathbf{m}^{2}\right)\end{array}$ & $\begin{array}{l}\text { Comprimento } \\
\text { de onda (nm) }\end{array}$ & $\begin{array}{c}\text { Temperatura } \\
\left({ }^{\circ} \mathbf{C}\right)\end{array}$ & $\begin{array}{c}\text { Tempo de } \\
\text { exposição } \\
\text { UV } \\
\text { aproxi- } \\
\text { mado (h) }\end{array}$ \\
\hline $\begin{array}{l}\text { Wu et al., } \\
2008 b\end{array}$ & $\begin{array}{l}\text { Envelhecimento } \\
\text { UV de ligante } \\
\text { asfáltico após } \\
\text { RTFOT }\end{array}$ & $\begin{array}{l}0,05 ; 0,10 \\
0,20 \text { e } 0,50\end{array}$ & 20,00 & 360 & 60 & 432 \\
\hline $\begin{array}{c}\text { Yu et al., } \\
2009\end{array}$ & $\begin{array}{l}\text { Envelhecimento } \\
\text { UV de ligante } \\
\text { asfáltico }\end{array}$ & 2,00 & - & 340 & 80 & Até 432 \\
\hline $\begin{array}{c}\text { Yu et al., } \\
2010\end{array}$ & $\begin{array}{l}\text { Envelhecimento } \\
\text { UV de ligante } \\
\text { asfáltico após } \\
\text { RTFOT }\end{array}$ & 1,25 & 100,00 & 365 & 55 & 24 a 48 \\
\hline $\begin{array}{c}\text { Wu et al., } \\
2010\end{array}$ & $\begin{array}{l}\text { Envelhecimento } \\
\text { UV de ligante } \\
\text { asfáltico após } \\
\text { RTFOT }\end{array}$ & $\begin{array}{l}0,05 ; 0,10 \\
0,15 \text { e } 0,20\end{array}$ & $\begin{array}{c}95,00 ; 139,00 \\
173,00 \mathrm{e} \\
200,00\end{array}$ & 360 & 45,65 e 80 & 48 \\
\hline $\begin{array}{l}\text { Zhang et al., } \\
2011 \mathrm{~b}\end{array}$ & $\begin{array}{l}\text { Envelhecimento } \\
\text { UV de ligante } \\
\text { asfáltico após } \\
\text { TFOT }\end{array}$ & 2,00 & 8,00 & - & 80 & 288 \\
\hline $\begin{array}{l}\text { Mouillet et } \\
\text { al., } 2014\end{array}$ & $\begin{array}{l}\text { Envelhecimento } \\
\text { UV de misturas } \\
\text { asfálticas }\end{array}$ & 10,00 & 0,72 & 340 & 44 & 3200 \\
\hline $\begin{array}{l}\text { Liu et al., } \\
2014\end{array}$ & $\begin{array}{l}\text { Envelhecimento } \\
\text { UV de ligante } \\
\text { asfáltico após } \\
\text { TFOT }\end{array}$ & 1,25 & 100,00 & - & 50 & 192 \\
\hline $\begin{array}{l}\text { Xu et al., } \\
2015\end{array}$ & $\begin{array}{c}\text { Envelhecimento } \\
\text { UV de ligante } \\
\text { asfáltico após } \\
\text { TFOT }\end{array}$ & - & 12,00 & 365 & 60 & 216 \\
\hline $\begin{array}{l}\text { Zeng et al., } \\
2015\end{array}$ & $\begin{array}{c}\text { Envelhecimento } \\
\text { UV de ligante } \\
\text { asfáltico após } \\
\text { TFOT }\end{array}$ & 1,20 & 5,00 & 365 & 30,60 e 70 & 480 \\
\hline
\end{tabular}

A técnica utilizada por Yamaguchi et al. (2005), com o uso de lâmpadas de arco de xenônio corresponde, segundo os autores, à exposição ao ar livre por 2 meses. Estes autores analisaram os efeitos da espessura do filme asfáltico, do comprimento de onda e da adição de negro de fumo ao ligante asfáltico e constataram que películas mais finas apresentam maior módulo complexo, viscosidade mais baixa e aumento da produção de carbonilas, que representa um indicador da degradação oxidativa. Com relação aos comprimentos de onda 
testados, confirmaram que a irradiação ultravioleta entre 300 e $400 \mathrm{~nm}$ causa grave fotodegradação no asfalto e que nessa faixa de comprimento de onda, o negro de fumo ajuda a evitar a fotodegradação perto da superfície, onde os danos são mais graves.

A deterioração de um pavimento está relacionada com o envelhecimento do ligante asfáltico, sendo a radiação UV um importante iniciador de reações que ocorrem na superfície do ligante asfáltico, formando uma camada oxidada e quebradiça. Silva et al. (2005) envelheceram dois ligantes, quimicamente distintos em radiação UV e verificaram que apresentaram mecanismos de envelhecimento diferentes. Sob radiação UV, a presença de vanádio na composição química dos ligantes asfálticos agiu como um fotocatalisador na formação de aglomerados de macromoléculas na superfície do material. No programa SHRP A-384, Bell et al. (1994) também especulam que o vanádio pode ser um catalisador, que contribui para a rápida oxidação dos asfaltos.

Muitos estudos mostraram que o envelhecimento foto-oxidativo por radiação UV produz efeitos distintos dos envelhecimentos termo-oxidativos no RTFOT e no PAV (Airey, 2003). Isto indica que o envelhecimento resultante da exposição fotoquímica não pode ser perfeitamente reproduzido pelo envelhecimento termo-oxidativo, particularmente para ligantes asfálticos que sejam suscetíveis ao envelhecimento UV e localizados em regiões em que a radiação solar é alta. É necessário combinar técnicas de envelhecimento fotoquímico com procedimento de aquecimento estendido e de oxidação a fim de simular o envelhecimento a longo prazo em campo dos pavimentos asfálticos nestas regiões (WU et al., 2010).

Yi-Qiu et al. (2007a), por exemplo, compararam o envelhecimento térmico RTFOT com o envelhecimento UV de ligantes asfálticos e observaram respostas diferentes, quando submetidos aos ensaios de caracterização reológicos e químicos realizados. Com o mesmo intuito de comparação do envelhecimento térmico-oxidativo e foto-oxidativo, $\mathrm{Wu}$ et al. (2010), avaliaram o processo de envelhecimento pelo aumento do grupo funcional carbonilas e pelo aumento da viscosidade. No envelhecimento foto-oxidativo, foram utilizados vários níveis de irradiação e várias temperaturas. Os resultados mostraram que o envelhecimento UV teve um efeito significativo sobre as propriedades dos ligantes asfálticos, especialmente quando a espessura do filme asfáltico era inferior a $150 \mu \mathrm{m}$. Observaram ainda que o nível de 
intensidade de irradiação UV teve influência significativa sobre o nível de foto-oxidação do ligante asfáltico.

Zeng et al. (2015) estudaram a influência que as temperaturas geralmente arbitradas nestes testes têm sobre os resultados do envelhecimento UV. Para isto, submeteram resíduos do TFOT a 3 temperaturas $\left(30^{\circ} \mathrm{C}, 50^{\circ} \mathrm{C}\right.$ e $\left.70^{\circ} \mathrm{C}\right)$ e concluíram que a temperatura menor que $50^{\circ} \mathrm{C}$ pode ser ignorada, mas quando atinge $70^{\circ} \mathrm{C}$, a taxa de oxidação do asfalto e a taxa de deterioração do modificador SBS aumentam.

Outra forma também utilizada por alguns pesquisadores de analisar os efeitos do envelhecimento UV sobre as propriedades dos ligantes asfálticos é a sua exposição direta ao ar livre, substituindo assim o uso de estufas UV. Wu et al. (2008a) compararam, utilizando DSR e FTIR, o envelhecimento clássico RTFOT+PAV de filmes de ligantes asfálticos com o envelhecimento ao ar livre no verão. As amostras foram montadas e colocadas sobre o telhado de um edifício na cidade de Wuhan (China). Foi colocada uma placa de vidro com transmitância de $70 \%$ sobre as amostras, com espaçamento de $5 \mathrm{~mm}$. Os resultados mostraram que o efeito da fotodegradação diminuiu à medida que a espessura dos filmes asfálticos aumentou; que a rede de polímeros é gradualmente destruída com o envelhecimento e que ainda assim, os ligantes modificados com SBS exibiram melhores propriedades reológicas que o CAP puro. Em outro estudo Wu et al. (2008b) compararam o envelhecimento de um ligante asfáltico puro em estufa UV e ao ar livre. Constataram forte correlação entre os resultados no DSR dos dois procedimentos.

Levando em consideração os aspectos das modificações, envelhecimento UV e fadiga, o trabalho de Liu et al. (2014) aborda a influência de hidróxidos duplos lamelares (HDL) nas propriedades de fadiga de misturas asfálticas. Os resultados mostraram, entre outros, que a mistura contendo ligante asfáltico modificado com HDL apresentou melhor resistência à fadiga quando comparada com a mistura contendo CAP puro e que os ligantes asfálticos contendo HDL tiveram melhor resistência à oxidação e à radiação UV do que os não modificados. Xu et al. (2015) utilizaram HDL orgânicos intercalados com dodecil sulfato de sódio (SDS) e sulfonato dodecil de sódio (SDSO) sintetizados com o objetivo de melhorar a compatibilidade entre o HDL e o ligante asfáltico. Constataram que após o envelhecimento $\mathrm{UV}$, as alterações nas propriedades físicas e reológicas dos ligantes modificados com HDL 
orgânico são menores que as dos ligantes modificados com HDL, indicando que estes primeiros são superiores no combate ao envelhecimento UV.

\subsection{Estudo do envelhecimento UV em misturas asfálticas}

Alguns pesquisadores vêm estudando o envelhecimento foto-oxidativo dos CAPs nas misturas asfálticas, pois além das transformações químicas que o ligante asfáltico sofre, são analisadas também sua relação com os agregados, volume de vazios, espessuras do filme que recobre o agregado, bem como outras variáveis que tornam o processo do envelhecimento mais complexo ainda. Bell et al. (1994) sugerem que a susceptibilidade ao envelhecimento de misturas asfálticas é dependente do agregado mineral. Porém, o efeito do ligante asfáltico é mais significativo. Segundo este autores, o fenômeno do envelhecimento a curto prazo parece está relacionado à adesão do ligante asfáltico ao agregado. Uma hipótese é a de que quanto maior a adesão, maior é a mitigação do envelhecimento.

Yi-Qiu et al. (2007b) simularam o envelhecimento UV de misturas asfálticas semicompactadas e constaram uma tendência de queda da taxa de fluência na maior parte das misturas. Lee et al. (2008) compararam o RTFOT com o método utilizado para simulação do envelhecimento a curto prazo de misturas asfálticas, o "short-term oven aging" (STOA), em que a mistura é aquecida solta. Os resultados, analisados por meio de Cromatografia por Permeação em Gel (GPC), mostraram que o método RTFOT teve menor efeito de envelhecimento sobre os ligantes asfálticos do que o método STOA para misturas asfálticas preparadas em laboratório. Considerando ainda o envelhecimento da mistura asfáltica, Lee et al. (2009) compararam quatro condições de envelhecimento a curto prazo e constataram que o procedimento que tinha a maior temperatura e o maior tempo causou o maior aumento nos índices de "large molecular size" (LMS), verificado por meio de GPC. Observaram ainda que, ao envelhecer as misturas asfálticas a $154^{\circ} \mathrm{C}$ por 2 horas e a $135^{\circ} \mathrm{C}$ por 4 horas, não houve diferenças significativas para nove ligantes asfálticos testados nas misturas asfálticas.

Mouillet et al. (2014) estudaram a influência da radiação UV no envelhecimento de misturas asfálticas contendo ligantes asfálticos modificados com copolímero SBS. Ao compararem o envelhecimento térmico com o envelhecimento UV, constataram que este 
último pode ser considerado dominante para a produção de carbonilas, o desaparecimento das ligações duplas de butadieno do SBS e o aumento da rigidez do ligante asfáltico. Dentro da mistura, a radiação UV aumentou a taxa de oxidação. Constataram ainda que a evolução do envelhecimento "in loco" por 44 meses é melhor avaliada pelo processo de foto-oxidação do que por termo-oxidação. Dessa forma, a radiação UV pode afetar as propriedades do ligante asfáltico da camada de revestimento mais fortemente que a simulação PAV, o que os levam a acreditar que o ensaio PAV provavelmente subestime a real evolução do ligante asfáltico dentro da mistura que compõe a camada de revestimento do pavimento.

\subsection{Comparação das simulações de envelhecimento em laboratório com o envelhecimento de campo}

Uma das dificuldades dos estudos de simulação do envelhecimento de ligantes e misturas asfálticas, como já mencionado, é estabelecer parâmetros que correspondam ao envelhecimento de campo. As técnicas já consolidadas possuem estimativas de tempo de envelhecimento, mas que podem variar com as características presentes em cada revestimento executado, por isso, alguns autores têm feito estudos nesta linha de comparação. Durrieu et al. (2007) compararam as técnicas de envelhecimento clássico (RTFOT+PAV), o envelhecimento real de um pavimento em serviço depois de 12 e 26 meses e o envelhecimento quando exposto à radiação UV em um forno de intemperismo, após ensaio RTFOT. De acordo com a espectroscopia de infravermelho - FTIR, este trabalho mostra que para todos os ligantes testados, o mesmo nível de envelhecimento, como o que é simulado pelo PAV, é alcançado em 10 horas de exposição aos raios UV após o RTFOT. Os autores concluíram ainda, que o nível do envelhecimento "in loco" de um ligante asfáltico modificado com polímero SBS atinge o envelhecimento simulado no PAV após 12 meses de vida útil do pavimento.

No estudo de Lu et al. (2008), ao compararam o envelhecimento de campo com o laboratorial (RTFOT, PAV e "rotating cylinder aging test" RCAT)verificaram que os ligantes asfálticos extraídos de revestimentos após 10-30 anos de serviço exibiam um grau de endurecimento por envelhecimento relativamente baixos. Para estes pesquisadores, uma das 
hipóteses é que o baixo grau de envelhecimento de campo pode ser atribuído ao baixo volume de vazios nas misturas. Seus resultados mostraram que os asfaltos envelhecidos em campo apresentaram um nível mais elevado de sulfóxidos, mas menor nível de carbonilas, quando comparados com os envelhecimentos simulados em laboratório.

\subsection{Técnicas utilizadas para análise de envelhecimento dos ligantes asfálticos}

As principais análises abordadas neste trabalho, utilizadas com o auxílio de curvasmestre e ensaio de Varredura de Amplitude Linear (LAS), estão relacionadas à reologia dos ligantes asfálticos. De acordo com Schramm (2006) reologia é a ciência que estuda a influência de tensões e deformações de corpos sólidos, líquidos ou gasosos. O reômetro de cisalhamento dinâmico (DSR) é um dos equipamentos utilizados para medir propriedades reológicas de ligantes asfálticos, onde a amostra preenche o espaço entre duas placas paralelas (gap) e é submetida a um cisalhamento por um tempo determinado.

Do ponto de vista reológico, as curvas-mestre permitem a análise do comportamento do ligante asfáltico virgem e envelhecido, quanto à rigidez e a elasticidade. A comparação dos dados fornece subsídios para interpretar qual procedimento de envelhecimento é mais severo, levando em consideração o comportamento reológico do material. Já o ensaio de fadiga LAS é importante tendo em vista que o envelhecimento pode prejudicar as características de resistência à fadiga. Em ensaios realizados por Bahia et al. (1999), em algumas amostras o dano por fadiga aumenta após o envelhecimento no PAV, em especial, sob baixos níveis de deformação.

Do ponto de vista químico, uma das técnicas muito difundidas é o GPC, também conhecido como cromatografia de exclusão de tamanhos (SEC), que de acordo com Durand et al. (2012), consiste em separar as moléculas de acordo com o seu tamanho, por injeção de uma solução de amostra através de uma matriz porosa. As moléculas maiores fluem livremente na coluna, com a mesma velocidade do solvente, enquanto que as moléculas menores se prendem aos poros da matriz. O tempo de retenção é inversamente proporcional ao logaritmo do peso molecular. Os resultados podem ser utilizados para comparar os ligantes asfálticos conforme uma variedade de critérios: peso molecular médio; intensidade do pico, 
que pode ser associado à presença de compostos aromáticos, forma da curva, que é uma informação qualitativa sobre a distribuição de peso molecular e a porcentagem de compostos cujo peso molecular é acima ou abaixo de um limite estipulado. A Figura 2.4 apresenta um esquema do princípio do GPC.

De acordo com Zhao et al. (2014), pesquisas em asfaltos utilizando GPC remontam da década de 60. Vários pesquisadores utilizaram o GPC para correlacionar seus resultados com os resultados obtidos em ensaios reológicos utilizando o DSR.
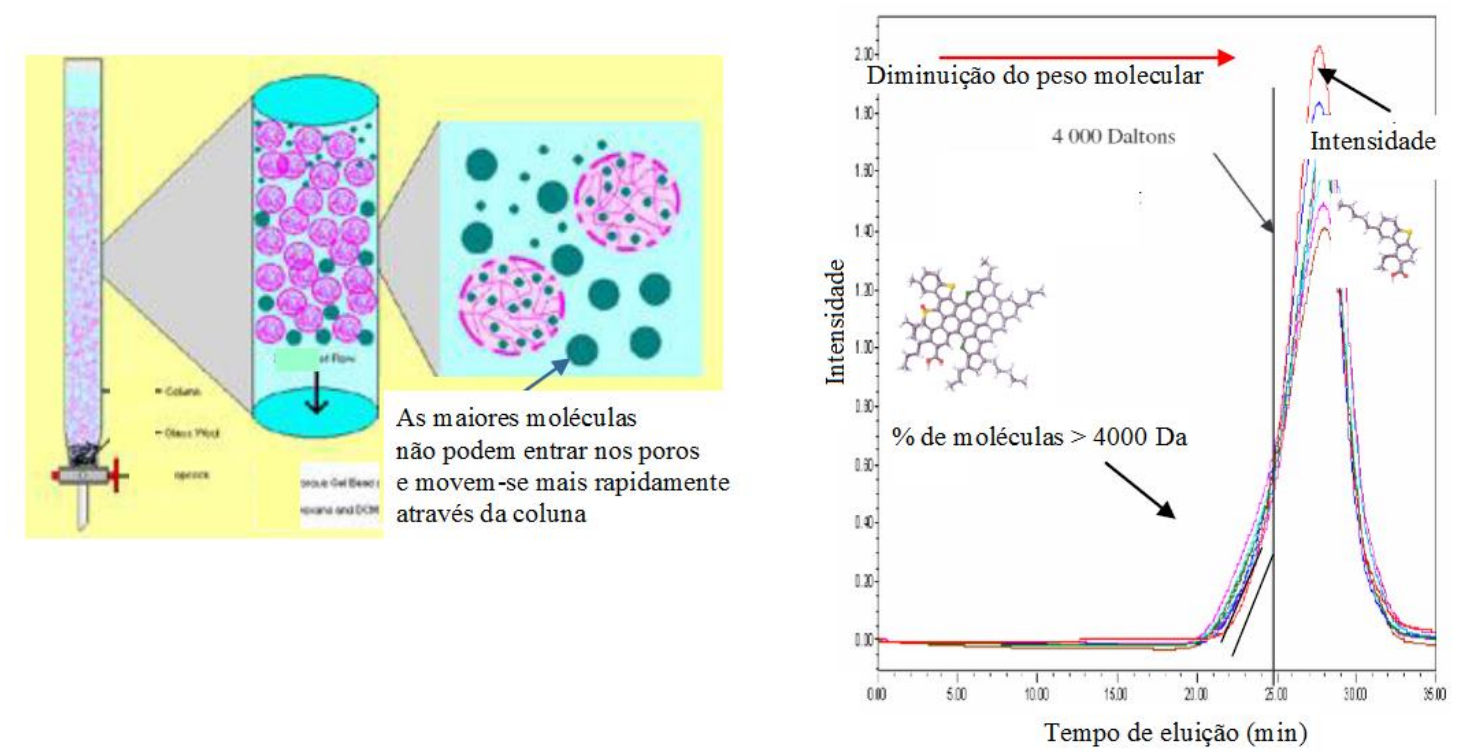

Figura 2.4 - Esquema do princípio do GPC (DURAND et al. 2012)

O FTIR, muito utilizado para analisar as alterações químicas dos ligantes asfálticos, permite a obtenção de espectros por meio da interação da radiação infravermelha com a matéria. As informações sobre as ligações químicas presentes são analisadas nos espectros conforme as posições, intensidade, largura e formato das bandas (OLIVEIRA, 2005). É uma técnica bastante utilizada nos estudos de envelhecimento. Lamontagne et al. (2001) compararam os resultados do envelhecimento clássico RTFOT+PAV com o envelhecimento natural do ligante asfáltico no pavimento por meio de espectroscopia FTIR. Herrington et al. (2014) mediram o grau de oxidação de amostras expostas ao envelhecimento a longo prazo ao ar livre, em termos da formação de grupos carbonilas contendo produtos de reação determinados por FTIR. 


\section{MATERIAIS E MÉTODOS}

Este capítulo é destinado à apresentação dos materiais utilizados nesta pesquisa, bem como os métodos empregados na realização dos ensaios de laboratório. Foram estudados 11 ligantes asfálticos modificados, nas condições virgem e envelhecida (curto prazo no RTFOT, longo prazo no PAV e longo prazo na estufa ultravioleta), aos quais se soma o CAP puro, por meio de ensaios reológicos e químicos.

A preparação das amostras, os ensaios de caracterização, os procedimentos de envelhecimento e os ensaios reológicos foram realizados no Laboratório de Estradas e no Laboratório de Ligantes Asfálticos do Departamento de Engenharia de Transportes (STT) da Escola de Engenharia de São Carlos (EESC) da Universidade de São Paulo (USP). Os ensaios químicos foram realizados no Laboratório de Mecânica dos Pavimentos (LMP) e no Laboratório de Polímeros (LABPOL) da Universidade Federal do Ceará - UFC.

\subsection{Materiais}

Na produção dos ligantes asfálticos modificados foram utilizados:

1. o CAP 50/70, fornecido pela Replan-Petrobras e de classificação PG 64-22;

2. a borracha de pneu moída, fornecida pela empresa Ecija Comércio Exportação e Importação de Produtos Ltda, resultante do processo de trituração de bandas de rodagem de pneus de veículos de passeio e com partículas passantes na peneira $n^{\circ}$ 30 ;

3. o PPA de designação comercial Innovalt E-200, fornecido pela Innophos Inc. dos Estados Unidos;

4. o SBS tipo TR-1101, adquirido da Kraton e fornecido pela Betunel, dotado das seguintes características técnicas: teor de poliestireno de $31 \%$, densidade igual a 0,94, resistência à tração de $33 \mathrm{MPa}$ e alongamento na ruptura igual a $880 \%$; 
5. o SBR tipo Solprene 1205, adquirido da Dynasol e fornecido pela Betunel, dotado das seguintes características técnicas: teor de estireno de $25 \%, 0,1 \%$ de insolúveis e densidade igual a 0,93 ;

6. o EVA tipo HM 728, adquirido da Politeno e fornecido pelo CENPES-Petrobras, dotado das seguintes características técnicas: teor de acetato de vinila igual a $28 \%$, ponto de fusão de $77^{\circ} \mathrm{C}$ e temperatura de amolecimento Vicat igual a $49^{\circ} \mathrm{C}$; e

7. o PE tipo UB160-C de baixa densidade, produzido pela Unipar.

\subsection{Formulações}

As formulações dos ligantes asfálticos e suas respectivas condições de processamento estão detalhadas na Tabela 3.1. As formulações foram escolhidas em um estudo prévio objetivando a obtenção de ligantes asfálticos modificados de classificação PG 76-XX, que corresponde a dois graus acima do PG do CAP puro (PG 64-22). As formulações contendo borracha, borracha+PPA, SBS e SBS+PPA foram preparadas em misturador de alto cisalhamento. As demais foram preparadas em misturador de baixo cisalhamento. Para as formulações com PPA, o ácido foi adicionado na fase final do processamento, conforme indicado na Tabela 3.1. 
Tabela 3.1 - Formulações dos ligantes asfálticos e variáveis de processamento

\begin{tabular}{|c|c|c|c|c|c|c|c|}
\hline \multirow[b]{2}{*}{$\begin{array}{l}\text { Nomenclatura } \\
\text { da amostra }\end{array}$} & \multirow{2}{*}{$\begin{array}{c}\text { Modificador } \\
\text { (es) } \\
\text { utilizado (s) }\end{array}$} & \multicolumn{3}{|c|}{ Teores (em \%) } & \multirow[b]{2}{*}{$\begin{array}{c}\text { Rotação } \\
\text { (rpm) }\end{array}$} & \multirow[b]{2}{*}{$\begin{array}{l}\text { Temperatura } \\
\left({ }^{\circ} \mathbf{C}\right)\end{array}$} & \multirow[b]{2}{*}{$\begin{array}{c}\text { Tempo } \\
(\text { min) }\end{array}$} \\
\hline & & CAP & Polímero & PPA & & & \\
\hline $50 / 70$ & - & 100,0 & - & - & - & - & - \\
\hline PPA & PPA & 98,8 & - & 1,2 & 300 & 130 & 30 \\
\hline borracha & borracha & 86,0 & 14,0 & - & 4.000 & 190 & 90 \\
\hline borracha $+\mathrm{PPA}$ & $\begin{array}{l}\text { borracha e } \\
\text { PPA }\end{array}$ & 88,5 & 11,0 & 0,5 & 4.000 & 190 & $\begin{array}{c}120 \\
\text { PPA } \\
\text { aos } 90\end{array}$ \\
\hline SBS & SBS & 95,5 & 4,5 & - & 4.000 & 180 & 120 \\
\hline $\mathrm{SBS}+\mathrm{PPA}$ & SBS e PPA & 96,5 & 3,0 & 0,5 & 4.000 & 180 & $\begin{array}{c}120, \\
\text { PPA } \\
\text { aos } 60\end{array}$ \\
\hline EVA & EVA & 92,0 & 8,0 & - & 300 & 180 & 120 \\
\hline $\mathrm{EVA}+\mathrm{PPA}$ & EVA e PPA & 96,6 & 3,0 & 0,4 & 300 & 180 & $\begin{array}{c}120 \\
\text { PPA } \\
\text { aos } 90\end{array}$ \\
\hline $\mathrm{PE}$ & polietileno & 94,0 & 6,0 & - & 440 & 150 & 120 \\
\hline $\mathrm{PE}+\mathrm{PPA}$ & $\begin{array}{l}\text { polietileno e } \\
\text { PPA }\end{array}$ & 96,5 & 3,0 & 0,5 & 400 & 150 & $\begin{array}{c}120 \\
\text { PPA } \\
\text { aos } 60\end{array}$ \\
\hline SBR & SBR & 94,5 & 5,5 & - & 400 & 180 & 120 \\
\hline $\mathrm{SBR}+\mathrm{PPA}$ & SBR e PPA & 96,0 & 3,5 & 0,5 & 300 & 180 & $\begin{array}{c}120 \\
\text { PPA } \\
\text { aos } 90\end{array}$ \\
\hline
\end{tabular}

\subsection{Ensaios empíricos para caracterização dos ligantes asfálticos}

Os ensaios empíricos de caracterização dos ligantes asfálticos foram realizados com as amostras virgens e envelhecidas a curto prazo (RTFOT). Tais amostras foram submetidas ao ensaio de penetração (ASTM D5) e de ponto de amolecimento (ASTM D36).

Por meio do ensaio de penetração, verifica-se a consistência do ligante asfáltico expressa como a distância em décimos de milímetros que uma agulha padrão penetra verticalmente a amostra sob carregamento de 100 gramas, a um tempo de 5 segundos, na temperatura de $25^{\circ} \mathrm{C}$. São efetuadas, no mínimo, três medidas, tendo como resultado a média das mesmas. Valores de penetração baixos indicam elevada rigidez do material, ao passo que, 
valores de penetração altos indicam que o material apresenta maior elasticidade. Neste ensaio foi utilizado um penetrômetro universal semiautomático fornecido pela Solotest.

O ensaio de ponto de amolecimento é útil por indicar a tendência de um material fluir sob elevadas temperaturas encontradas em serviço. Neste ensaio, a amostra é condicionada em dois anéis metálicos que são aquecidos a uma taxa controlada em um banho de água destilada, enquanto cada anel suporta uma esfera metálica. O ponto de amolecimento é a média das temperaturas obtidas no momento em que a amostra toca a placa do fundo. $\mathrm{O}$ equipamento utilizado foi o fornecido pela ISL (Instrumentation Scientifique de Laboratoire), modelo RB 36-5G.

\subsection{Procedimentos de envelhecimento dos ligantes asfálticos}

O processo de envelhecimento dos ligantes asfálticos tem início no momento em que existe o contato da mistura asfáltica com o ar, ainda na fase da usinagem e compactação. Para simular esta primeira fase, denominada envelhecimento a curto prazo, foi empregado o ensaio “rolling thin film oven test" (RTFOT), conforme método ASTM D2872-97, para simular a segunda fase do envelhecimento do ligante asfáltico, que se dá durante a vida em serviço da mistura, denominada envelhecimento a longo prazo, foi utilizado o "pressure aging vessel" (PAV), ensaio termo-oxidativo normatizado conforme a especificação ASTM 6521-03a. Porém, como tal especificação não leva em consideração a radiação ultravioleta (UV), a que o revestimento asfáltico está exposto diariamente durante o período de projeto das rodovias, outra simulação de envelhecimento a longo prazo foi utilizada, por meio da exposição de um filme asfáltico em uma estufa de irradiação UV (ensaio foto-oxidativo). Nos dois procedimentos de envelhecimento a longo prazo empregados, as amostras utilizadas foram previamente envelhecidas a curto prazo na estufa RTFO. 


\subsubsection{Envelhecimento a curto prazo}

O envelhecimento dos ligantes asfálticos a curto prazo foi realizado em uma estufa de filme fino rotativo (RTFO), da marca Matest Paralelamente ao envelhecimento, foi realizado o balanço de massa empregando balança analítica com precisão de décimo de milésimo de grama. A estufa RTFO é uma estufa de convecção com aquecimento elétrico, dotada de um termostato capaz de manter a temperatura de $163 \pm 0,5^{\circ} \mathrm{C}$ e de um carrossel com aberturas para conter firmemente presos 8 frascos de vidro na posição horizontal. A velocidade de rotação do carrossel deve ser de $15 \pm 0,2$ rotações/min. Um bico de ar é posicionado na parte inferior da estufa para injetar ar aquecido dentro dos frascos, a uma vazão de $4.000 \pm 200 \mathrm{ml} / \mathrm{min}$. Em cada frasco são vertidos $35 \mathrm{~g}$ de ligante asfáltico e o tempo do ensaio é de 85 minutos.

\subsubsection{Envelhecimento a longo prazo termo-oxidativo}

O envelhecimento a longo prazo (termo-oxidativo) do resíduo envelhecido no RTFO foi efetuado em uma estufa de vaso pressurizado (PAV) da marca Prentex modelo 9300. A estufa de vaso pressurizado é um equipamento composto basicamente de uma câmara pressurizada, dotada de controladores, medidores e registradores de pressão e de temperatura. A câmara do PAV contém um raque com capacidade para dez pratos de aço inoxidável do tipo TFOT, nos quais as amostras são envelhecidas por $20 \mathrm{~h}$ na temperatura de $100{ }^{\circ} \mathrm{C}$ sob pressão de 2,1 MPa. Uma estufa de vácuo foi utilizada para a retirada de bolhas das amostras após o condicionamento. Depois de coletado e homogeneizado, o resíduo envelhecido a longo prazo foi empregado nos ensaios de caracterização reológica.

\subsubsection{Envelhecimento a longo prazo (foto-oxidativo)}

A simulação do envelhecimento dos ligantes asfálticos devido à radiação ultravioleta ainda não é disciplinada por uma norma. O procedimento aqui empregado é o comumente 
mencionado na literatura, sendo composto basicamente pela exposição à radiação UV de um filme asfáltico, a fim de simular a espessura do filme asfáltico que recobre o agregado mineral. As espessuras do filme asfáltico, calculadas multiplicando a massa do ligante asfáltico (30 gramas) pela densidade de cada CAP (segundo método DNIT ME 193-96) e dividida pela área da bandeja $\left(688 \mathrm{~cm}^{2}\right)$, podem ser visualizadas na Tabela 3.2.

\begin{tabular}{ccc} 
Tabela 3.2 - Espessuras dos filmes asfálticos utilizados no envelheciment \\
\cline { 2 - 2 } ligante asfáltico & densidade $\left(\mathbf{g} / \mathbf{c m}^{\mathbf{3}}\right)$ & $\begin{array}{c}\text { espessura do filme } \\
(\mathbf{m m})\end{array}$ \\
\hline CAP puro & 1,004 & 0,44 \\
CAP+PPA & 1,010 & 0,44 \\
CAP+borracha & 1,017 & 0,44 \\
CAP+borracha+PPA & 1,009 & 0,44 \\
CAP+SBS & 1,003 & 0,44 \\
CAP+SBS+PPA & 0,996 & 0,43 \\
CAP+EVA & 0,987 & 0,43 \\
CAP+EVA+PPA & 1,001 & 0,44 \\
CAP+PE & 0,997 & 0,43 \\
CAP+PE+PPA & 1,003 & 0,44 \\
CAP+SBR & 0,999 & 0,44 \\
CAP+SBR+PPA & 0,989 & 0,43 \\
\hline
\end{tabular}

O equipamento empregado foi o da marca Q-LAB modelo Q-SUN Xe-3, também utilizado na simulação do efeito da radiação solar sobre diversos materiais. A câmara possui três lâmpadas de arco de xenônio que reproduzem o espectro completo da luz solar, incluindo radiação ultravioleta, luz visível e radiação infravermelha. A luz emitida pelas lâmpadas é devidamente filtrada por filtros UV, escolhidos neste experimento para simular a luz solar direta do meio-dia no verão, fazendo uma correlação com a exposição ao ar livre natural. $\mathrm{O}$ equipamento possui sensores de controle da irradiância, bem como da temperatura do ar da câmara e do painel onde ficam depositadas as bandejas com as amostras. Na Figura 3.1 podese visualizar a câmara UV utilizada neste procedimento, com o detalhe do painel em que foi possível acompanhar os níveis de irradiação de cada lâmpada, o comprimento de onda e as temperaturas do ensaio. A câmara utilizada tem a possibilidade de pulverizar água sobre os materiais testados, a fim de simular os efeitos associados das intempéries, porém, este recurso não foi utilizado neste trabalho. O esquema do funcionamento interno da câmara pode ser observado na Figura 3.2. 


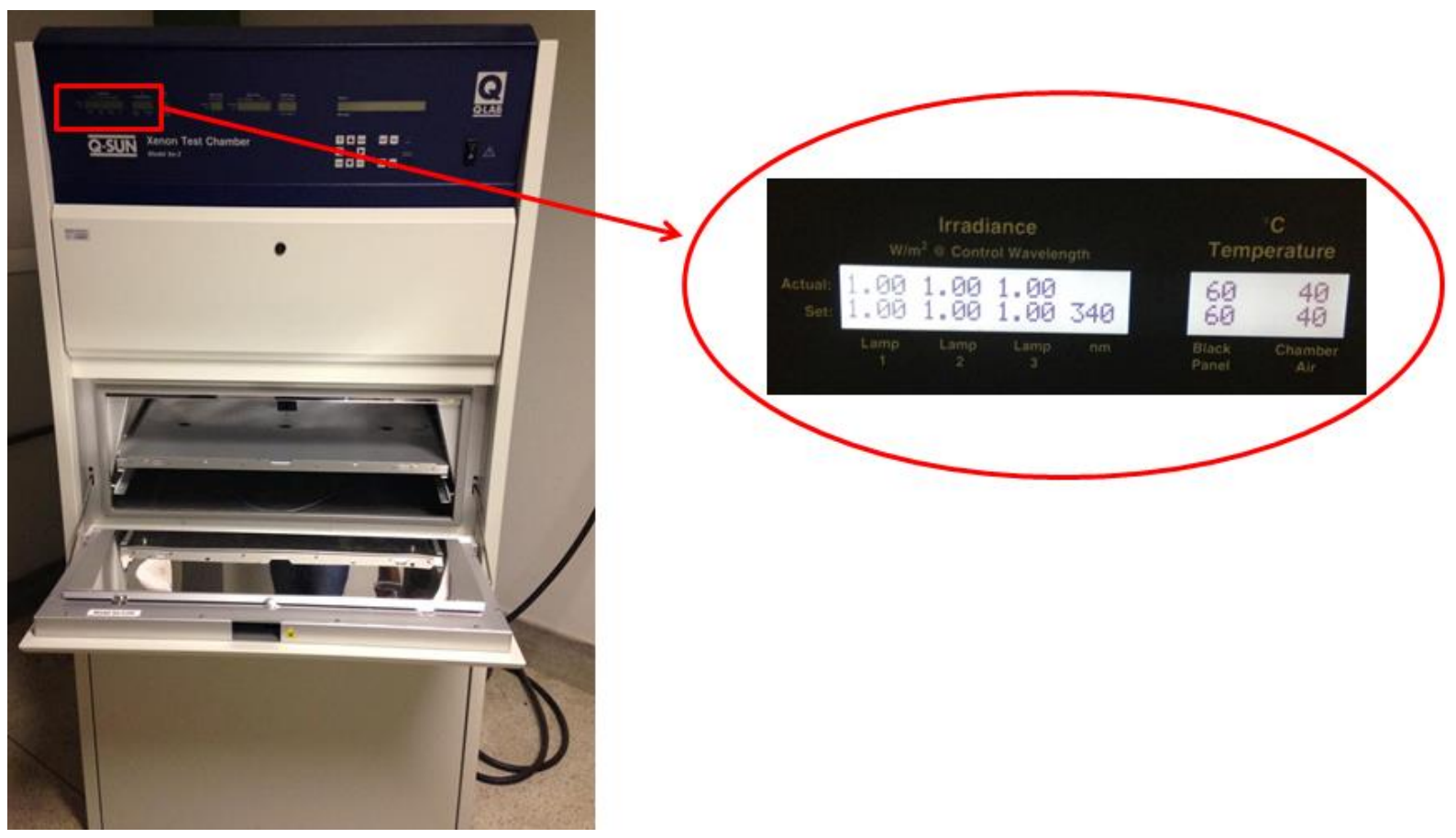

Figura 3.1 - Câmara UV utilizada para simulação do envelhecimento a longo prazo foto-oxidativo

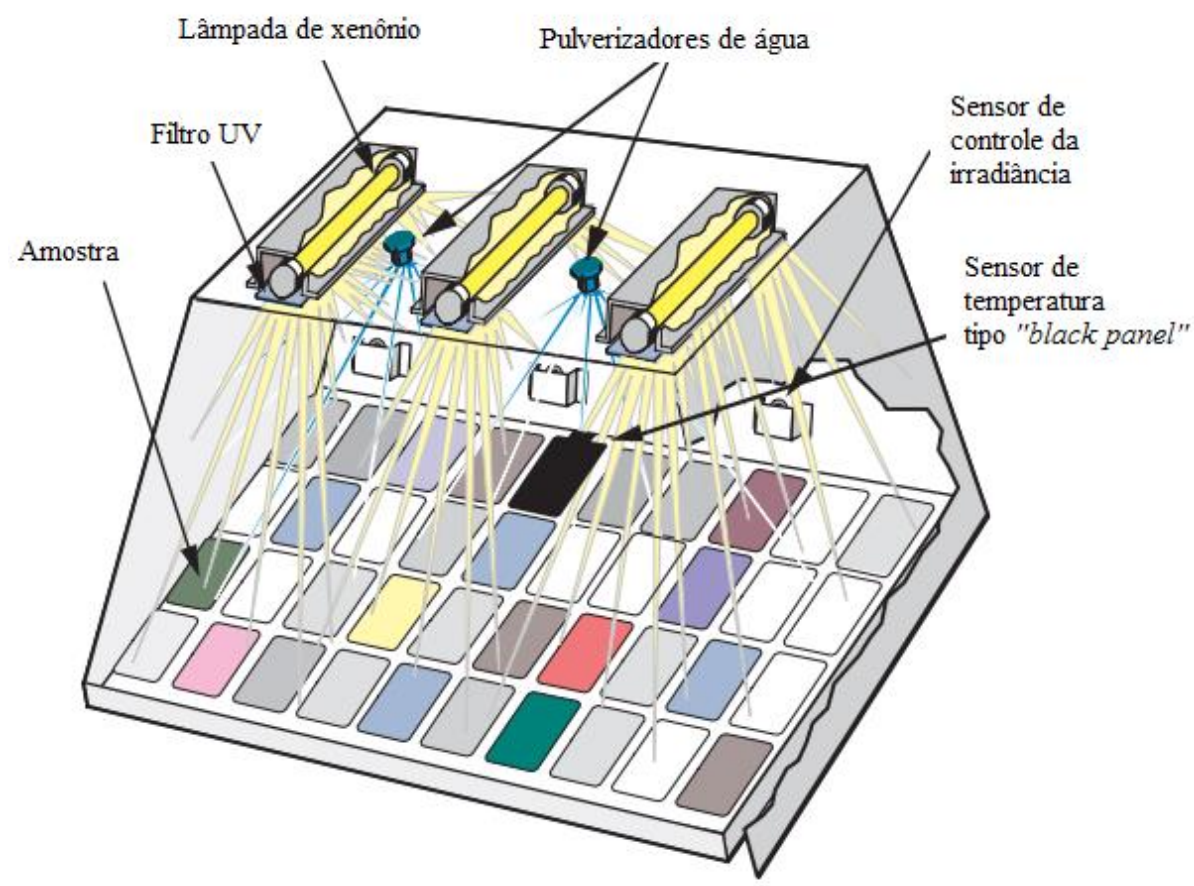

Figura 3.2 - Esquema do funcionamento da câmara UV [Fonte: Q-Lab (http://www.qlab.com)] 
O pavimento está exposto a algumas horas de radiação solar máxima por dia, que varia, entre outros fatores, de acordo com a estação do ano e a presença de nuvens. A simulação do envelhecimento UV, utilizando uma câmara como a empregada neste experimento, permite que a amostra esteja sujeita a esta exposição máxima 24 horas por dia, acelerando o processo de degradação do ligante asfáltico. Os níveis de radiação empregados nesta pesquisa foram de $0,68 \mathrm{~W} / \mathrm{m}^{2}$ (indicado pela fabricante da câmara como a intensidade aproximada de luz solar ao meio-dia no verão) e $1,00 \mathrm{~W} / \mathrm{m}^{2}$ no comprimento de onda de 340 nm, que equivale, segundo Frederick et al. (1989), aos raios UVA.

O tempo de exposição do filme na câmara UV foi de 10 dias $(240$ h), chegando-se ao final do experimento a um nível de irradiação de $163,2 \mathrm{~W} / \mathrm{m}^{2}\left(0,68 \mathrm{~W} / \mathrm{m}^{2}\right.$ x $\left.240 \mathrm{~h}\right)$ e $240 \mathrm{~W} / \mathrm{m}^{2}$ $\left(1,00 \mathrm{~W} / \mathrm{m}^{2} \mathrm{x} 240 \mathrm{~h}\right)$. As temperaturas utilizadas buscaram simular as altas temperaturas que o pavimento está exposto em serviço, que foram de $60{ }^{\circ} \mathrm{C}$ no painel metálico e de $40{ }^{\circ} \mathrm{C}$ na temperatura do ar da câmara.

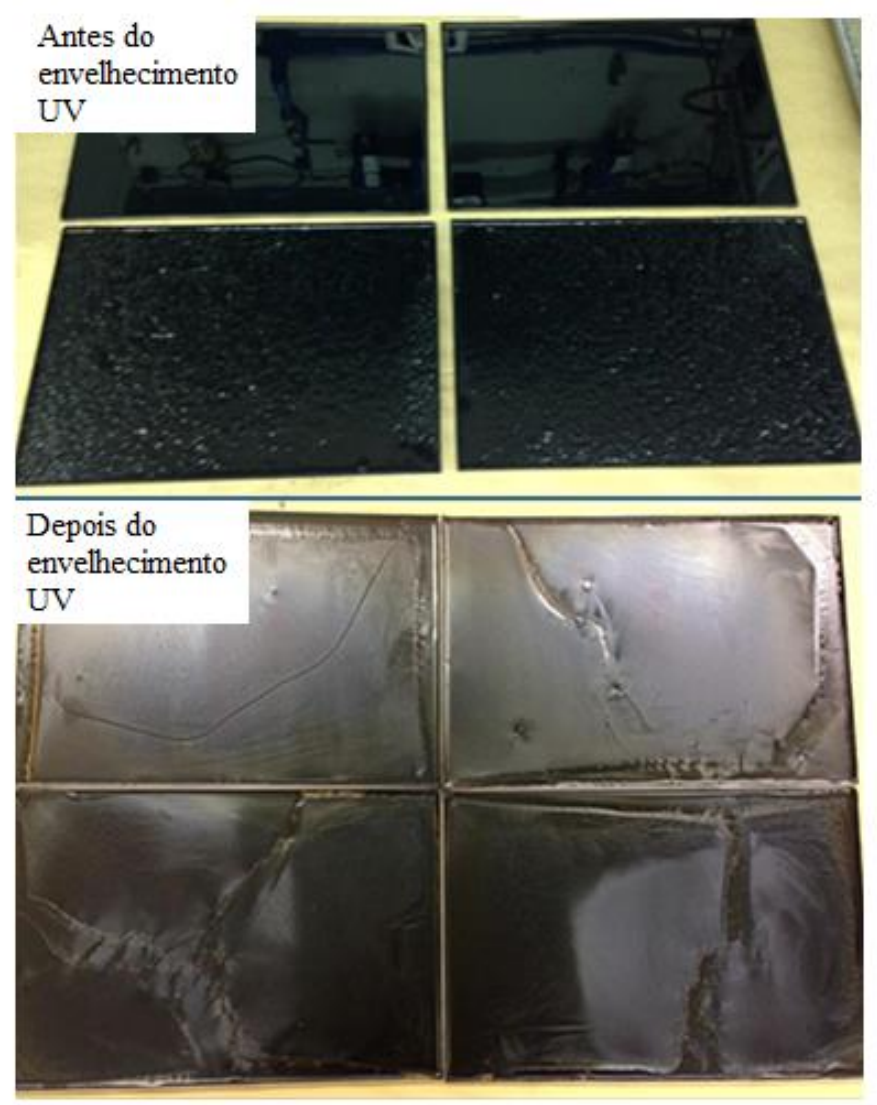

Figura 3.3 - Bandejas contendo os filmes de ligante asfáltico, antes e depois do envelhecimento UV 
As bandejas metálicas utilizadas para a colocação das amostras medem 21,5 x $32 \mathrm{~cm}$, cada uma. A quantidade de amostra por bandeja foi de $30 \mathrm{~g}$ de ligante asfáltico, distribuído uniformemente por toda a área da mesma, conforme pode ser observado na Figura 3.3. Depois de coletado e homogeneizado, o resíduo envelhecido sob radiação UV foi empregado nos ensaios reológicos.

\subsection{Propriedades reológicas monitoradas}

Em virtude do pequeno volume de material obtido nos ensaios de envelhecimento foto-oxidativo, foram realizados apenas ensaios cuja quantidade de amostra fosse pequena. Foram monitorados o módulo complexo $\left(\mathrm{G}^{*}\right)$ e o ângulo de fase $(\delta)$, sob diferentes condições de temperatura e de frequência de carregamento. Estas propriedades foram monitoradas, utilizando-se um reômetro de cisalhamento dinâmico (DSR), modelo AR 2000ex da TA Instruments, nos ligantes asfálticos na condição virgem, envelhecido a curto prazo na estufa RTFO, envelhecido a longo prazo na estufa PAV (resíduo após RTFOT) e envelhecido a longo prazo na estufa UV (resíduo após RTFOT).

Dada a dificuldade em se obterem quantidades maiores do resíduo envelhecido sob radiação UV, propriedades tradicionais como penetração, ponto de amolecimento, retorno elástico, resiliência e ductilidade não puderam ser determinadas.

Em relação ao monitoramento de propriedades fundamentais de ligantes asfálticos, a especificação Superpave recomenda ensaios de laboratório nas diversas faixas de temperatura a que os ligantes asfálticos estão submetidos no decorrer da vida útil do pavimento. Para temperaturas altas, nas quais o afundamento de trilha de roda é um defeito típico, foram monitorados o módulo complexo $\left(\mathrm{G}^{*}\right)$ e ângulo de fase $(\delta)$ conforme o procedimento ASTM D7175-05. Para temperaturas intermediárias, nas quais as trincas por fadiga ocorrem, foram também monitorados $\mathrm{G}^{*}$ e $\delta$, segundo esta mesma norma.

O módulo complexo é a medida da resistência total do ligante asfáltico à deformação quando exposto a pulsos repetidos de tensões de cisalhamento e o ângulo de fase é um indicador da quantidade relativa de deformação recuperável e não-recuperável do ligante 
asfáltico. Em conjunto, estas propriedades permitem avaliar a rigidez do ligante asfáltico, estipulando limites mínimos de resistência à deformação permanente $\left(\mathrm{G}^{*} / \mathrm{sen} \delta>1,0 \mathrm{kPa}\right.$ e 2,2 $\mathrm{kPa}$, respectivamente, para amostras virgens e envelhecidas a curto prazo) e máximos para a perda de elasticidade, a fim de prevenir o aparecimento de trincas por fadiga $\left(\mathrm{G}^{*} \operatorname{sen} \delta<5.000\right.$ $\mathrm{kPa}$, após envelhecimento a longo prazo).

A especificação Superpave também estabelece que propriedades fundamentais sejam obtidas de ligantes asfálticos envelhecidos a curto prazo (ASTM D2872-97) e a longo prazo (ASTM D6521-03a). No procedimento de envelhecimento a curto prazo, é possível quantificar a porcentagem de massa volatilizada, simulando o envelhecimento do ligante asfáltico ocorrido durante a usinagem e a compactação das misturas asfálticas. No envelhecimento a longo prazo, é simulado o envelhecimento dos ligantes asfálticos após 5 a 10 anos de vida em serviço, permitindo avaliar a resistência do material à oxidação.

Para a construção das curvas-mestre, foram monitorados o módulo complexo e o ângulo de fase dos ligantes asfálticos, sob diferentes temperaturas e frequências de carregamento, conforme procedimento apresentado em Bechara et al. (2008). A curva-mestre é uma representação do perfil reológico dos materiais, que descreve o desenvolvimento de uma propriedade reológica qualquer em função da frequência de carregamento. Graças ao princípio de superposição tempo-temperatura, os efeitos da frequência e da temperatura podem ser intercambiados, permitindo a análise do comportamento reológico do material, em termos de rigidez e de elasticidade, ao longo de uma faixa ampla de frequências e de temperaturas típicas que ocorrem nos pavimentos.

As curvas-mestre e as curvas do fator de deslocamento horizontal versus temperatura, em conjunto, permitem a separação dos efeitos do tempo e da temperatura sobre a resposta reológica. Estes recursos possibilitam uma avaliação rigorosa do comportamento reológico dos ligantes asfálticos, pois separam os efeitos do tempo e da temperatura, normalmente confundidos pelas propriedades empíricas. 


\subsubsection{Procedimento de construção das curvas-mestre}

O procedimento usado para a composição das curvas-mestre foi o seguinte: (1) uma amostra foi submetida à varredura de tensão, nas temperaturas de $52,64,76$ e $88{ }^{\circ} \mathrm{C}$, na frequência de $10 \mathrm{rad} / \mathrm{s}$, empregando geometria de $25 \mathrm{~mm}$ de diâmetro e distância entre placas de $1,0 \mathrm{~mm}$, a fim de determinar a tensão que solicita o material, em cada temperatura, na faixa de viscoelasticidade linear; (2) outra amostra foi submetida à varredura de tensão, a 40, 28, 16 e $4{ }^{\circ} \mathrm{C}$, a $10 \mathrm{rad} / \mathrm{s}$, empregando geometria de $8 \mathrm{~mm}$ de diâmetro e distância entre placas de 2,0 mm; (3) uma amostra foi submetida à varredura de frequência, entre 0,1 e $100 \mathrm{rad} / \mathrm{s}, \mathrm{a}$ 52, 64, 76 e $88^{\circ} \mathrm{C}$, nas tensões obtidas em (1) com geometria de $25 \mathrm{~mm}$ e distância entre placas de $1,0 \mathrm{~mm}$; (4) outra amostra foi submetida à varredura de frequência, entre 0,1 e $100 \mathrm{rad} / \mathrm{s}, \mathrm{a} 40$, 28, 16 e $4{ }^{\circ} \mathrm{C}$, nas tensões obtidas em (2), com geometria de $8 \mathrm{~mm}$ e distância entre placas de $2,0 \mathrm{~mm}$; e (5) a curva-mestre foi composta na temperatura de referência de $25^{\circ} \mathrm{C}$.

\subsubsection{Ensaio de Varredura de Amplitude Linear (LAS)}

Uma das principais características do ligante asfáltico envelhecido é o seu endurecimento, expresso pelo aumento do seu módulo complexo $\left(\mathrm{G}^{*}\right)$. Isto favorece a resistência à deformação permanente, nos primeiros anos após a construção, mas pode prejudicar a vida de fadiga, quando este fenômeno se dá por deformação controlada. Quando se tem fadiga por deformação controlada, CAPs mais moles têm vida de fadiga maior e CAPs mais duros têm vida de fadiga menor. Com o intuito de explorar de forma mais aprofundada as características de fadiga dos ligantes asfálticos envelhecidos, foram feitos ensaios de Varredura de Amplitude Linear (LAS).

Os ensaios foram realizados conforme norma da AASHTO TP 101-12-UL. As condições do ensaio foram fixas: temperatura de $25^{\circ} \mathrm{C}$ e amostras envelhecidas a curto e a longo prazos. A temperatura adotada para o ensaio foi de $25^{\circ} \mathrm{C}$, pois tem sido uma temperatura bastante utilizada pelos pesquisadores (BAHIA et al., 2001; SHENOY, 2002; MARTONO et al., 2007). Todos os ensaios foram realizados em duplicata a fim de garantir uma variabilidade menor que $15 \%$. É importante relatar aqui a dificuldade de se obter uma 
variabilidade menor que $15 \%$ neste ensaio. O que se pôde constatar durante a realização destes ensaios foi que quanto mais rígida a amostra, mais difícil é obter um nível satisfatório de repetibilidade.

O LAS é empregado para avaliar a capacidade do ligante asfáltico em resistir aos dano por fadiga, por meio de carregamentos cíclicos de amplitude crescente, a fim de acelerar o dano. Tal ensaio, proposto por Johnson (2010), é realizado em um reômetro de cisalhamento dinâmico (DSR), utilizando a geometria de $8 \mathrm{~mm}$ e um espaçamento entre as placas paralelas de $2 \mathrm{~mm}$.

O ensaio é feito com a aplicação de carregamento cíclico reverso, dividido em duas fases:

1) varredura de frequência de 0,2 a $30 \mathrm{~Hz}$, com $0,1 \%$ de deformação, para determinar as propriedades reológicas na região de viscoelasticidade linear. Nesta fase são gravados o módulo complexo $\left(\mathrm{G}^{*}\right)$ e o ângulo de fase $(\delta)$ em cada frequência, e

2) varredura de amplitude, com incremento linear na amplitude de deformação, variando de 0 a $30 \%$ ao longo de 3100 ciclos de carga, no intervalo de tempo de 300 segundos e a uma frequência de $10 \mathrm{~Hz}$. Nesta fase, picos de deformação cisalhante e picos de tensão de cisalhamento são gravados a cada 10 ciclos de carga (1 segundo), juntamente com o módulo complexo $\left(\mathrm{G}^{*}\right)$ e o ângulo de fase $(\delta)$.

Os resultados obtidos na varredura de frequência e na varredura de amplitude de deformação são utilizados em um modelo de fadiga derivado da relação entre a carga aplicada e a vida de fadiga do material (Figura 3.4), segundo equação 3.1. Esta Equação é utilizada em misturas e ligantes asfálticos por apresentar boa relação entre a carga aplicada e a vida de fadiga $\left(\mathrm{N}_{\mathrm{f}}\right)$ : 


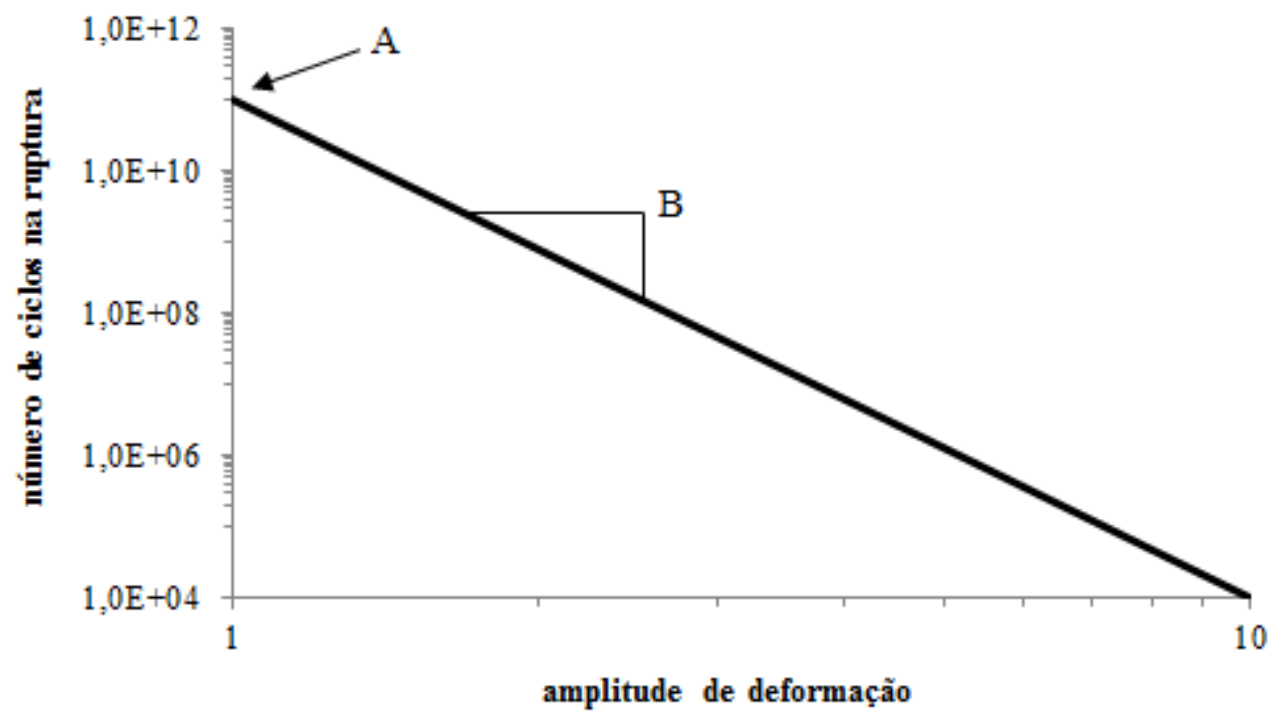

Figura 3.4 - Modelo de fadiga (JOHNSON, 2010)

$\mathrm{N}_{\mathrm{f}}=\mathrm{A}\left(\gamma_{\mathrm{MÁX}}\right)^{\mathrm{B}}$

em que A e B são parâmetros que dependem das características do material e $\gamma_{\text {máx }}$ é a deformação máxima esperada para a estrutura do pavimento.

O parâmetro B é calculado de acordo com a equação 3.2:

$B=2 \alpha$

sendo $\alpha$ dado por:

$\alpha=\frac{1}{m}$

onde $m$ a inclinação da reta do gráfico $\log$-log do módulo de armazenamento $\left(\mathrm{G}^{*}\right.$.cos $\left.\delta\right)$ versus frequência.

O parâmetro A é calculado de acordo com a equação 3.4:

$$
A=\frac{f\left(D_{f}\right)^{k}}{k\left(\left.\pi\right|_{D} C_{1} C_{2}\right)^{\alpha}}
$$

onde $\mathrm{f}$ é a frequência $(10 \mathrm{~Hz}), \mathrm{D}_{\mathrm{f}}$ é o valor de $\mathrm{D}(\mathrm{t})$ na falha, $\mathrm{I}_{\mathrm{D}}$ é o valor inicial de $\mathrm{G}^{*}$.sen $\delta$, em $\mathrm{MPa}$, do intervalo de amplitude de deformação de $1,0 \%$ e k é definido com a equação 3.5 : 
$\mathrm{k}=1+\left(1-\mathrm{C}_{2}\right) \alpha$

Os coeficientes $\mathrm{C}_{0}, \mathrm{C}_{1}$ e $\mathrm{C}_{2}$ podem ser determinados linearizando o modelo ajustado para a relação $\mathrm{G}^{*}$.sen $\delta$ versus $\mathrm{D}(\mathrm{t})$ (equação 3.6), onde $\mathrm{D}(\mathrm{t})$ é o dano acumulado na amostra, calculado de acordo com a equação 3.7:

$G^{*} \operatorname{sen} \delta=C_{0}-C_{1}(D)^{C_{2}}$

$D(t)=\sum_{i=1}^{N}\left[\pi I_{D} \gamma_{0}^{2}\left(G^{*} \cdot \operatorname{sen} \delta_{i-1}-G^{*} \operatorname{sen} \delta_{i}\right)\right]^{\frac{\alpha}{1+\alpha}}\left(t_{i}-t_{i-1}\right)^{\frac{1}{1+\alpha}}$

A seleção de um bom critério de falha por trincas por fadiga para misturas asfálticas e ligantes asfálticos vêm sendo o assunto de muita discussão. O critério tradicional mais aceito é o de redução de 50\% do módulo inicial. No entanto, Johnson (2010) observou que a redução de $35 \%$ no valor de $\mathrm{G}^{*}$.sin $\delta$ proporciona uma correlação razoável entre os resultados do ensaio de varredura de tempo e do LAS. Por esta razão, o valor de $\mathrm{D}(\mathrm{t})$ pode ser calculado utilizando a equação 3.8 :

$D(t)=0,35\left(\frac{C_{0}}{C_{1}}\right)^{\frac{1}{C_{2}}}$

Em sua tese de doutorado, Hintz (2012) sugere a modificação do formato da sequência de amplitude de deformação, aumentando-a linearmente em cada ciclo de carga, como pode ser observado na Figura 3.5 (b). No formato apresentado por Johnson (2010), a amplitude de deformação aumenta na forma de degraus, como pode ser visualizado na Figura 3.8 (a). 


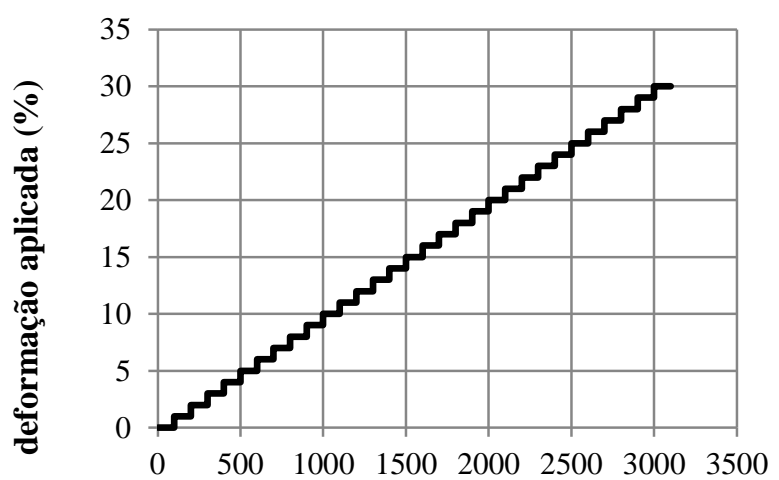

ciclo de carregamento

(a)

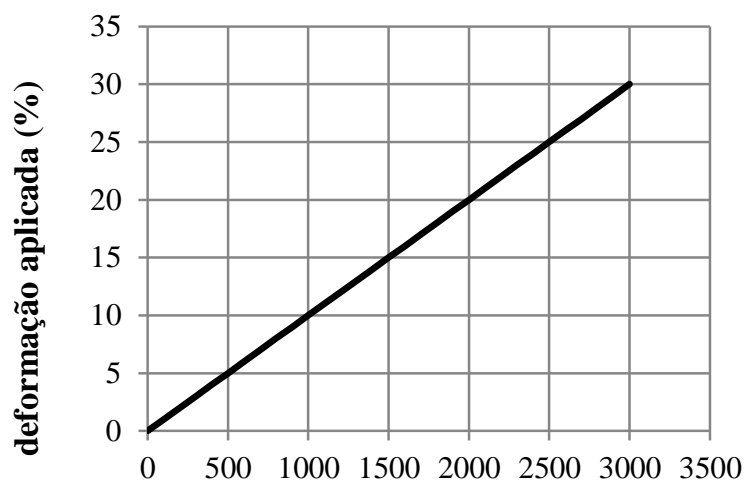

ciclo de carregamento

(b)

Figura 3.5 - Incremento de deformação no ensaio LAS (JOHNSON, 2010) e incremento de deformação no ensaio LAS modificado (HINTZ, 2012), respectivamente

Em 2013, foi lançada a norma utilizada nas análises de fadiga do presente trabalho (AASHTO TP 101-12-UL), norma esta em que a modificação de carregamento proposta por Hintz (2012) foi empregada. Assim, a norma passou a ter a análise de dano contínuo viscoelástico proposta por Johnson (2010) e a análise de tolerância ao dano, proposta por Hintz (2012). Tais análises foram adotadas neste trabalho e apresentadas no Capítulo 4. Detalhes dos procedimentos de ensaio e cálculos foram abordados em Pamplona (2013) e Nuñez (2013).

\subsection{Análises Químicas}

Este item apresenta os procedimentos dos ensaios químicos realizados com algumas amostras, com o intuito de obter uma visão mais aprofundada do que acontece nas estruturas moleculares dos ligantes asfálticos quando passam pelo processo de envelhecimento. Não houve tempo hábil e nem disponibilidade de equipamentos que possibilitassem submeter todas as amostras aos procedimentos que se seguem, ficando para trabalhos futuros a complementação deste estudo. 


\subsubsection{Espectroscopia no Infravermelho por Transformada de Fourier (FTIR)}

O endurecimento dos ligantes asfálticos está relacionado às mudanças de composição que acontece durante o envelhecimento que se dá em usina e em campo, que envolve a conversão de aromáticos em asfaltenos e o aumento nos grupos funcionais das carbonilas e sulfóxidos (QIN et al., 2014). Por meio da espectroscopia no infravermelho por transformada Fourier (FTIR), é possível identificar os compostos formados na oxidação. O ensaio foi realizado com o objetivo de localizar no espectro os picos de carbonila (número de onda 1700 $\mathrm{cm}^{-1}$ ) e sulfóxido (número de onda $1030 \mathrm{~cm}^{-1}$ ), pois, de acordo com a literatura, estas são as principais bandas que indicam o envelhecimento oxidativo do CAP (LAMONTAGNE et al., 2001, QUIN et al., 2014, OLIVEIRA, 2015).

Para a obtenção dos espectros de FTIR, foi utilizado um espectrômetro Shimadzu, modelo IR-Prestige-21, em uma faixa de 4000 a $400 \mathrm{~cm}^{-1}$, com 50 varreduras em média e 4 $\mathrm{cm}^{-1}$ de resolução, em uma célula própria para líquidos. O dissulfeto de carbono $\left(\mathrm{CS}_{2}\right)$ foi adotado como solvente, por possuir alta capacidade de absorção de CAP. Foi utilizada uma concentração de 0,5 g de CAP para $10 \mathrm{ml}$ de solvente. As amostras utilizadas neste ensaio foram o CAP 50/70 puro, o CAP 50/70+PPA e o CAP 50/70+SBS, todas envelhecidas a curto e a longo prazos, com exceção do CAP 50/70+SBS, cuja amostra envelhecida na condição UV $0,68 \mathrm{~W} / \mathrm{m}^{2}$ não está presente.

Os resultados foram analisados levando em consideração que o aumento das áreas de carbonila e sulfóxido está associado ao envelhecimento oxidativo do ligante asfáltico. Estas áreas foram calculadas por meio do software Origin 6.0. Para o cálculo das áreas, foram traçadas linhas de base entre as bandas de interesse, conforme pode ser observado na Figura 3.6. 


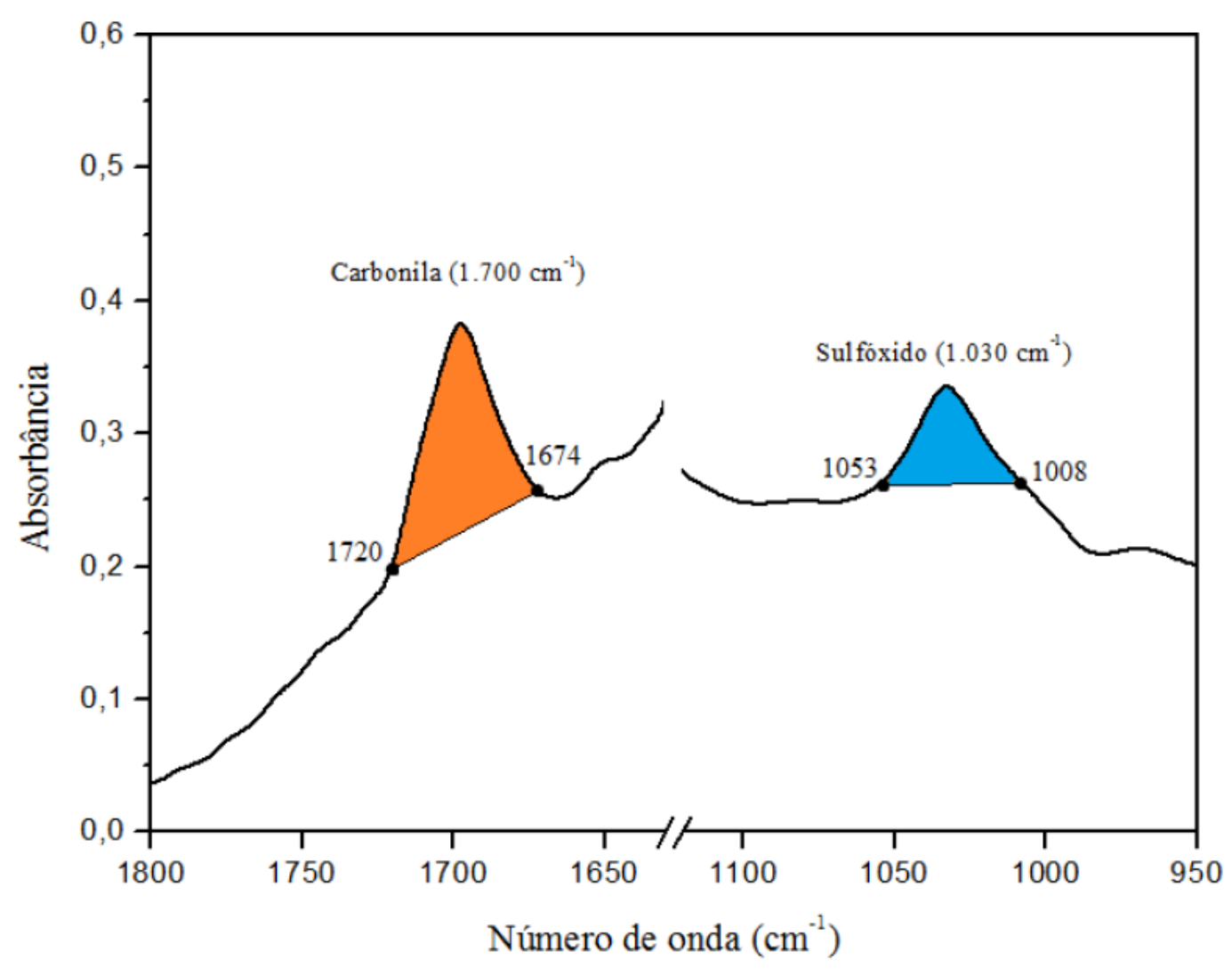

Figura 3.6 - Ilustração do cálculo das áreas de carbonila e sulfóxido (OLIVEIRA, 2015)

\subsubsection{Cromatografia por Permeação em Gel-GPC}

A cromatografia por permeação em gel (GPC) é um método utilizado para determinação da distribuição de massa molar. Neste trabalho, o GPC foi utilizado para indicar as variações de massa molar que ocorrem com as modificações dos ligantes asfálticos, mas principalmente com os envelhecimentos aos quais as amostras foram submetidas.

Neste ensaio, a amostra é injetada no fluxo contínuo do solvente através de uma coluna porosa responsável pela separação das moléculas, de acordo com o tamanho. Fluem primeiramente as moléculas maiores, entrando num detector. Por meio de um cromatograma de permeação em gel, o detector mostra a resposta em função do volume da solução que passa pela coluna (volume de eluição). Utilizando um cromatograma de referência, é possível obter a massa molar em um dado volume de retenção. A Figura 3.7 apresenta um esquema geral de um ensaio GPC. 


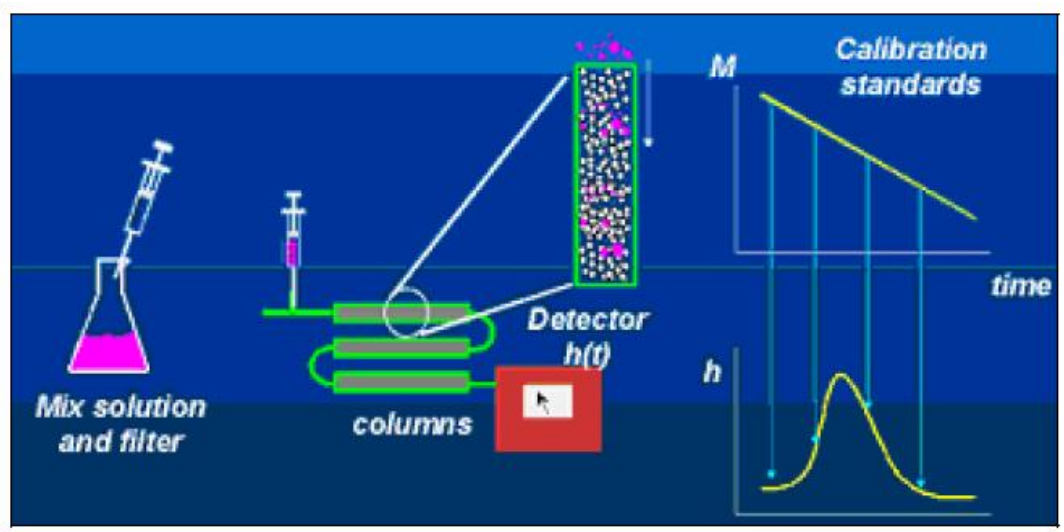

Figura 3.7 - Esquema geral de um ensaio GPC (DARANGA, 1999)

O perfil cromatográfico foi determinado em um cromatógrafo SHIMADZU LC10AD com detector de índice de refração RID-10A a $40{ }^{\circ} \mathrm{C}$. A análise foi realizada utlizando uma coluna phenomenex phenogel linear 7,8 x $300 \mathrm{~mm}$, fase móvel tetrahidrofurano (THF), fluxo de $1,0 \mathrm{~mL} / \mathrm{min}$ e o volume de amostra injetada foi de $20 \mu \mathrm{L}$. A curva de calibração, visualizada na Figura 3.8, foi elaborada com soluções de poliestireno em THF na concentração de $0,1 \%(\mathrm{~m} / \mathrm{v})$ utilizando os padrões com as seguintes massas molares $\left(1,3 \times 10^{3}\right.$; $\left.1,34 \times 10^{4} ; 5,0 \times 10^{4} ; 5,75 \times 10^{5} ; 9,0 \times 10^{5} ; 2 \times 10^{6} \mathrm{~g} / \mathrm{mol}\right)$. As amostras foram preparadas em THF na concentração de $0,8 \%(\mathrm{~m} / \mathrm{v})$.

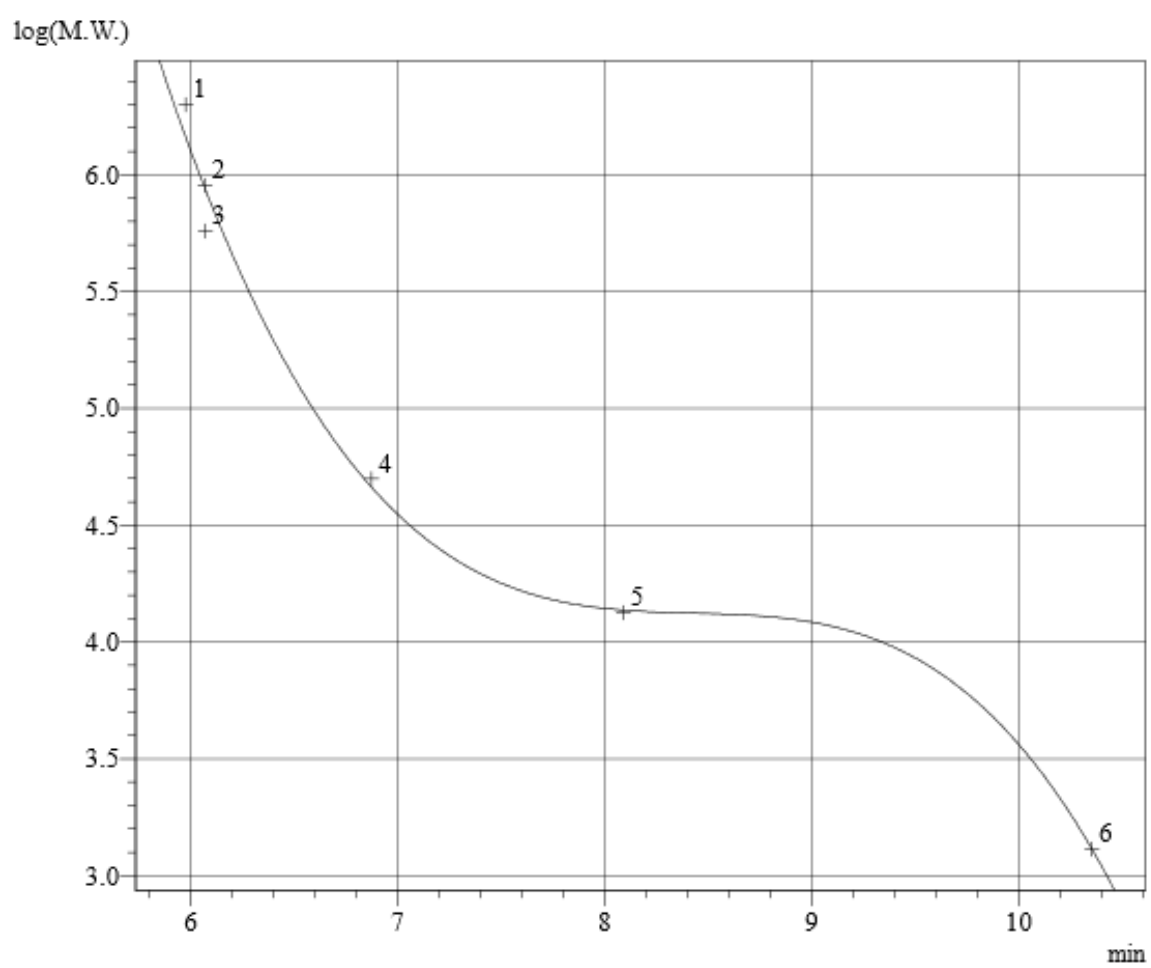

Figura 3.8 - Curva de calibração - ensaio GPC 


\subsubsection{Fracionamento SARA}

O fracionamento SARA é uma técnica que separa as principais frações dos ligantes asfálticos: saturados, asfaltenos, resinas e aromáticos. Representa um meio importante para observar a evolução da composição química do ligante asfáltico ao longo dos processos de envelhecimento sofridos. O ensaio foi realizado conforme a norma ASTM D 4124/1991, utilizando um cromatógrafo Iastrocan MK-6 com sistema de detecção FID (flame ionization detection) e nas mesmas condições do trabalho de Oliveira (2015): fluxos de $\mathrm{H}_{2}$ e ar de 160 $\mathrm{mL} / \mathrm{min}$ e $2 \mathrm{~mL} / \mathrm{min}$, respectivamente, velocidade de varredura de $30 \mathrm{~s} / \mathrm{rod}$, sensibilidade de $50 \mathrm{mV}$ e em 3 réplicas.

Por meio do fracionamento SARA é possível calcular o Índice de Estabilidade Coloidal (IC), proposto por Gaestel et al. (1971), usado para caracterizar o equilíbrio coloidal entre as fases (Equação 3.2). Para Glita (1988) ${ }^{4}$ apud Silva (2005), IC menor que 0,1, representam ligantes asfálticos pouco estruturados (SOL), IC maior que 0,5 representam ligantes asfálticos bem estruturados (GEL) e resultados entre 0,1 e 0,5 representam CAPs com comportamentos intermediários.

$\mathrm{IC}=\frac{\mathrm{S}+\mathrm{A}}{\mathrm{R}+\mathrm{Ar}}$

onde:

$\mathrm{S}=$ Saturados

A $=$ Asfaltenos

$\mathrm{R}=$ Resinas

$\mathrm{Ar}=$ Aromáticos

\footnotetext{
${ }^{4}$ GLITA S. Contribution à l'étude physico-chimie des bitumes. Havre, 1988. Thèse (Doctorat en Sciences) Faculté des Sciences et Techniques de l'Université du Havre.
} 



\section{RESULTADOS E DISCUSSÃO}

Este capítulo é destinado à apresentação dos resultados dos ensaios de laboratório realizados com os ligantes asfálticos e está dividido em três partes. Na primeira parte deste capítulo, são apresentados os resultados referentes aos ensaios de penetração e de ponto de amolecimento realizados com os ligantes asfálticos apenas nas condições virgem e envelhecida a curto prazo.

$\mathrm{Na}$ segunda parte do capítulo, são apresentados os resultados das propriedades reológicas monitoradas com o uso do reômetro de cisalhamento dinâmico (DSR), empregadas na construção de curvas- mestre. Nesta fase, foram analisadas as amostras nas condições virgem, envelhecida a curto prazo (RTFOT) e envelhecida a longo prazo por meio de procedimentos termo-oxidativo (PAV) e foto-oxidativo (UV). Além das curvas-mestre, são apresentados também os resultados das análises de características de fadiga dos ligantes asfálticos envelhecidos a curto prazo na estufa RTFO e a longo prazo nas estufas PAV e UV, por meio do ensaio de varredura de amplitude linear (LAS).

Na terceira parte do capítulo, são apresentados os resultados dos ensaios químicos, aos quais algumas amostras foram submetidas a fim de complementar o estudo realizado. Os ensaios químicos realizados foram a análise de espectroscopia na região de infravermelho (FTIR), o fracionamento SARA e o ensaio de Cromatografia por Permeação em Gel (GPC).

\subsection{Ensaios de caracterização dos ligantes asfálticos virgens e envelhecidos a curto prazo}

A Figura 4.1 apresenta um comparativo dos valores de penetração das amostras virgens. A adição dos diferentes modificadores provoca, em termos gerais, redução da penetração virgem, indicando que os ligantes asfálticos modificados se tornaram mais rígidos que o CAP a $25^{\circ} \mathrm{C}$. Embora todos os ligantes asfálticos modificados apresentem o mesmo PG 
e, consequentemente, rigidez comparável, à exceção do CAP puro, o efeito das modificações é sentido de maneira altamente expressiva na temperatura de $25^{\circ} \mathrm{C}$.

$\mathrm{O}$ polímero que mais afetou a penetração foi o polietileno (amostra CAP+PE), provocando a redução da penetração de 58 para $25\left(10^{-1} \mathrm{~mm}\right)$, ao passo que a menor variação da penetração é a obtida para o CAP+borracha, em que a penetração cai de 58 para $48\left(10^{-1}\right.$ $\mathrm{mm}$ ). Ordenando os demais ligantes asfálticos modificados em relação ao CAP, observa-se que o CAP+PE+PPA é o segundo mais rígido (a penetração cai de 58 para 32), seguido do $\mathrm{CAP}+\mathrm{EVA}+\mathrm{PPA}$, do $\mathrm{CAP}+\mathrm{SBS}+\mathrm{PPA}$ e do CAP+PPA, os três com penetração em torno de 36. Em seguida vem o CAP+SBR (39), seguido pelo CAP+borracha+PPA (42), depois pelo CAP+SBS (44), depois pelo CAP+EVA (46) e finalmente pelo CAP+SBS+PPA (47).

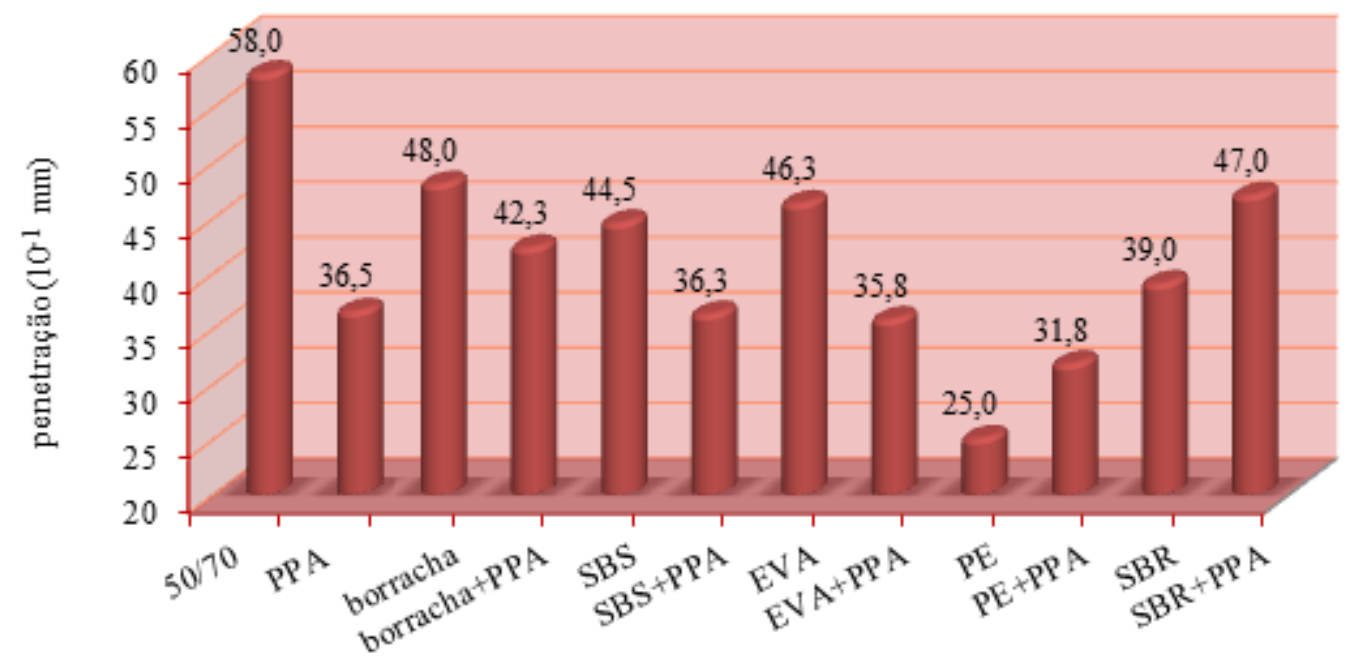

Figura 4.1 - Penetração das amostras virgens

Dadas as proporções dos modificadores empregadas na formulação do CAP+PPA, $\mathrm{CAP}+\mathrm{SBS}+\mathrm{PPA}$ e CAP+EVA+PPA, as penetrações virgens obtidas são comparáveis, o que demonstra que do ponto de vista de penetração, estas três formulações são equivalentes, muito embora sejam modificadores de ações substancialmente distintas. Nas proporções empregadas, uma formulação com um elastômero (SBS) e PPA tem penetração comparável à de uma formulação com um plastômero (EVA) e PPA, e ambas têm penetração comparável a uma formulação apenas com PPA. As formulações CAP+EVA, CAP+SBR+PPA e asfaltoborracha, com penetrações de 46, 47 e 48, respectivamente, também apresentam certo grau de equivalência, muito embora os modificadores tenham natureza distinta: valores de penetração 
equivalentes são obtidos para formulações com borracha, com um plastômero (EVA) e com um elastômero (SBR).

A Figura 4.2 mostra um comparativo dos valores de penetração das amostras envelhecidas a curto prazo. $\mathrm{O}$ envelhecimento a curto prazo altera substancialmente o quadro descrito anteriormente no que se refere ao efeito dos modificadores sobre a penetração. Da mesma maneira que para as amostras virgens, as duas formulações com polietileno (CAP+PE e CAP+PE+PPA) sofrem as maiores reduções de penetração (20 e 23, respectivamente), porém, desta vez, o CAP+SBR é a formulação que menos sofre redução da penetração. A penetração deste ligante asfáltico (37) é maior que a do CAP puro (31). As amostras envelhecidas que sofrem menor redução da penetração, depois do CAP+SBS são o CAP puro (31) e o CAP+SBS+PPA (32). Em seguida, vêm o CAP+borracha (29), o $\mathrm{CAP}+$ borracha+PPA, o $\mathrm{CAP}+\mathrm{SBS}$, o $\mathrm{CAP}+\mathrm{SBS}+\mathrm{PPA}$ e o $\mathrm{CAP}+\mathrm{EVA}$, com penetração da ordem de 26, seguidos pelo CAP+PPA e pelo CAP+EVA+PPA, com penetração de $24\left(10^{-1}\right.$ $\mathrm{mm})$.

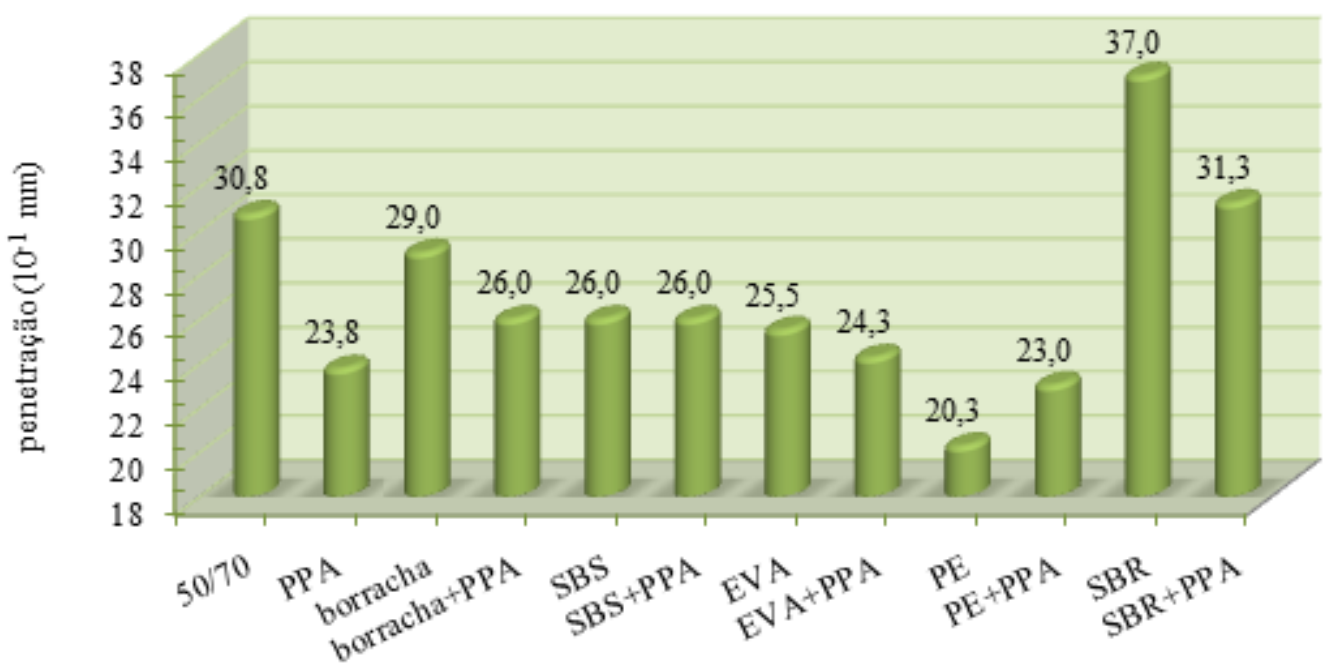

Figura 4.2 - Penetração das amostras envelhecidas a curto prazo

Dentre as amostras envelhecidas, o $\mathrm{CAP}+\mathrm{SBR}$ e o $\mathrm{CAP}+\mathrm{SBR}+\mathrm{PPA}$ são os únicos a apresentar penetração superior ao CAP puro. Interessante observar que, dentre as amostras virgens, todas apresentaram penetração inferior à do CAP puro. Isto destaca o efeito positivo da adição de polímeros ao CAP: na extensão em que reduções menores da penetração são 
indicadores de menor sensibilidade ao envelhecimento, alguns materiais podem ser empregados também para melhorar a resistência ao envelhecimento a curto prazo do CAP.

Do ponto de vista de formulação e tomando por base as amostras envelhecidas, o CAP puro e o $\mathrm{CAP}+\mathrm{SBR}+\mathrm{PPA}$ são comparáveis em termos de penetração, muito embora sejam compostos com materiais de natureza distinta. Outro grupo de formulações com valores de penetração comparáveis é o formado pelo CAP+borracha+PPA, CAP+SBS, $\mathrm{CAP}+\mathrm{SBS}+\mathrm{PPA}$ e CAP+EVA, com penetração em torno de 26. Muito embora sejam ligantes asfálticos modificados de natureza bastante distinta, sendo um composto por uma mescla de polímeros (borracha moída), outro um elastômero (SBS) e outro um plastômero (EVA), suas penetrações são equivalentes. Outra equivalência é observada entre o CAP+PPA e o CAP+EVA+PPA, com penetração em torno de 24.

As Figuras 4.1 e 4.2 são um bom exemplo de como o envelhecimento pode afetar diferentemente os comportamentos reológicos de ligantes asfálticos aditivados com diferentes modificadores. Embora partam da mesma classificação PG, obtida a temperaturas elevadas, a rigidez, em uma temperatura típica de ocorrência de trincamento por fadiga, varia substancialmente com o tipo de modificador e com a condição da amostra (virgem ou envelhecida). Penetrações equivalentes eram observadas para dois grupos de amostras virgens: o primeiro formado pelo $\mathrm{CAP}+\mathrm{PPA}$, pelo $\mathrm{CAP}+\mathrm{SBS}+\mathrm{PPA}$ e pelo $\mathrm{CAP}+\mathrm{EVA}+\mathrm{PPA}$ e o outro grupo composto pelo CAP+EVA, pelo CAP+SBR+PPA e pelo asfalto-borracha. Já para as amostras envelhecidas a curto prazo, outros dois grupos são observados: um formado pelo CAP puro e pelo $\mathrm{CAP}+\mathrm{SBR}+\mathrm{PPA}$ e um outro grupo composto pelo $\mathrm{CAP}+$ borracha+PPA, pelo $\mathrm{CAP}+\mathrm{SBS}$, pelo $\mathrm{CAP}+\mathrm{SBS}+\mathrm{PPA}$ e pelo $\mathrm{CAP}+\mathrm{EVA}$.

Em relação à modificação com ácido polifosfórico, a amostra CAP+PPA sofreu redução substancial da penetração tanto virgem quanto envelhecida. Quando se observam os pares formulados com o mesmo polímero (com e sem PPA), percebe-se que a adição de PPA à formulação provocou redução da penetração virgem apenas nas formulações com borracha, SBS e EVA e levou ao aumento da penetração virgem nas formulações com polietileno e com SBR. No caso das amostras envelhecidas a curto prazo, a incorporação do PPA aos ligantes asfálticos modificados com polímeros levou à redução da penetração também das formulações com borracha e com EVA, sem alteração da penetração no caso da formulação com SBS, e ao 
aumento da penetração no caso das formulações com PE e com SBR, como também observado para as amostras virgens.

Dadas suas características químicas, o efeito do ácido é o de enrijecer o ligante asfáltico, porém, nas situações em que foi combinado com outros polímeros, ocorreu redução da proporção de polímero de maneira a acomodar a incorporação do ácido e manter a rigidez da formulação em um grau PG 76-XX. O aumento da penetração observado para as formulações $\mathrm{CAP}+\mathrm{PE}+\mathrm{PPA}$ e $\mathrm{CAP}+\mathrm{SBR}+\mathrm{PPA}$ se deve à redução do teor de polímero ou de borracha moída. Ainda não existe um número grande de estudos sobre a adição de ácido polifosfórico a ligantes asfaltos modificados, mas uma pesquisa anterior (FAXINA E SALOMON, 2010) mostra a redução da penetração, tanto virgem quanto envelhecida, do CAP, do CAP modificado com resíduo de óleo de xisto, do asfalto-borracha e do asfaltoborracha modificado com resíduo de óleo de xisto, após a adição de PPA, considerando amostras nas quais se acrescentou o ácido mantendo os teores originais dos outros modificadores.

A Figura 4.3 mostra os graus de modificação para a penetração das amostras virgens e envelhecidas e permite inferir que o envelhecimento a curto prazo destaca o efeito dos modificadores em amenizar o efeito do envelhecimento. Exceções a esta constatação são apenas o CAP+SBS e o CAP+EVA. Como os graus de modificação são obtidos como a relação entre a penetração do ligante asfáltico modificado pela penetração do CAP puro, se o CAP sofre uma redução maior da penetração que os CAPs modificados, maiores graus de modificação serão obtidos para as amostras envelhecidas, o que destaca o papel dos modificadores em amenizar o efeito do envelhecimento a curto prazo. Em linhas gerais, o envelhecimento provoca um aumento do grau de modificação de 0,1 a 0,2 , porém chega a 0,3 para o $\mathrm{CAP}+\mathrm{PE}$ e a 0,5 para o $\mathrm{CAP}+\mathrm{SBR}$, indicando que a maioria das aditivações estudadas colabora em evitar o enrijecimento excessivo do CAP após o envelhecimento a curto prazo.

A Figura 4.4 traz os valores de penetração retida. As penetrações retidas de todos os ligantes asfálticos modificados são superiores à do CAP. O maior ganho em penetração retida é o obtido para o CAP+SBR $(95 \%)$ e o menor ganho é o obtido para o CAP+EVA (55\%). Seguem o CAP+SBS, em termos de aumento da penetração retida, o CAP+PE (81\%), o $\mathrm{CAP}+\mathrm{SBS}+\mathrm{PPA}$ e o $\mathrm{CAP}+\mathrm{PE}+\mathrm{PPA}$, com penetração retida da ordem de 75\%, o CAP+PPA, o 
$\mathrm{CAP}+\mathrm{EVA}+\mathrm{PPA}$ e o $\mathrm{CAP}+\mathrm{SBR}+\mathrm{PPA}$, com penetração retida entre 65 e $68 \%$, e por fim o $\mathrm{CAP}+$ borracha, o CAP+borracha+PPA e o CAP+SBS, com penetração retida entre 58 e $62 \%$.

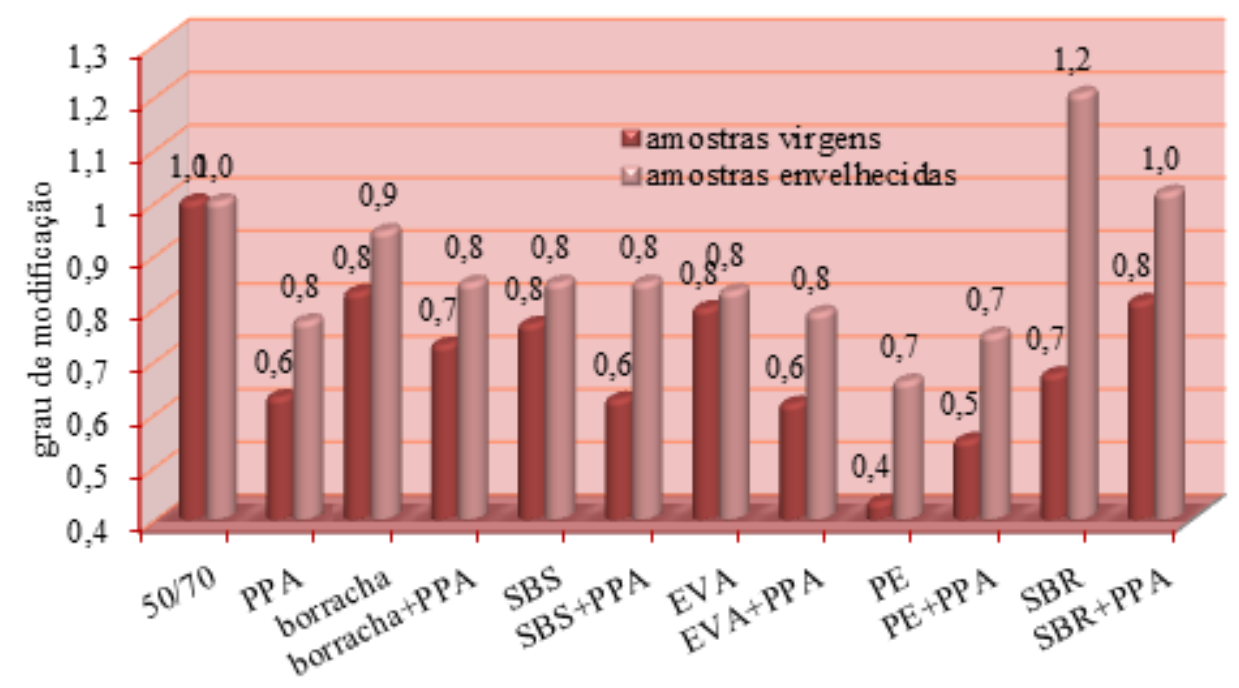

Figura 4.3 - Graus de modificação com base nos valores de penetração

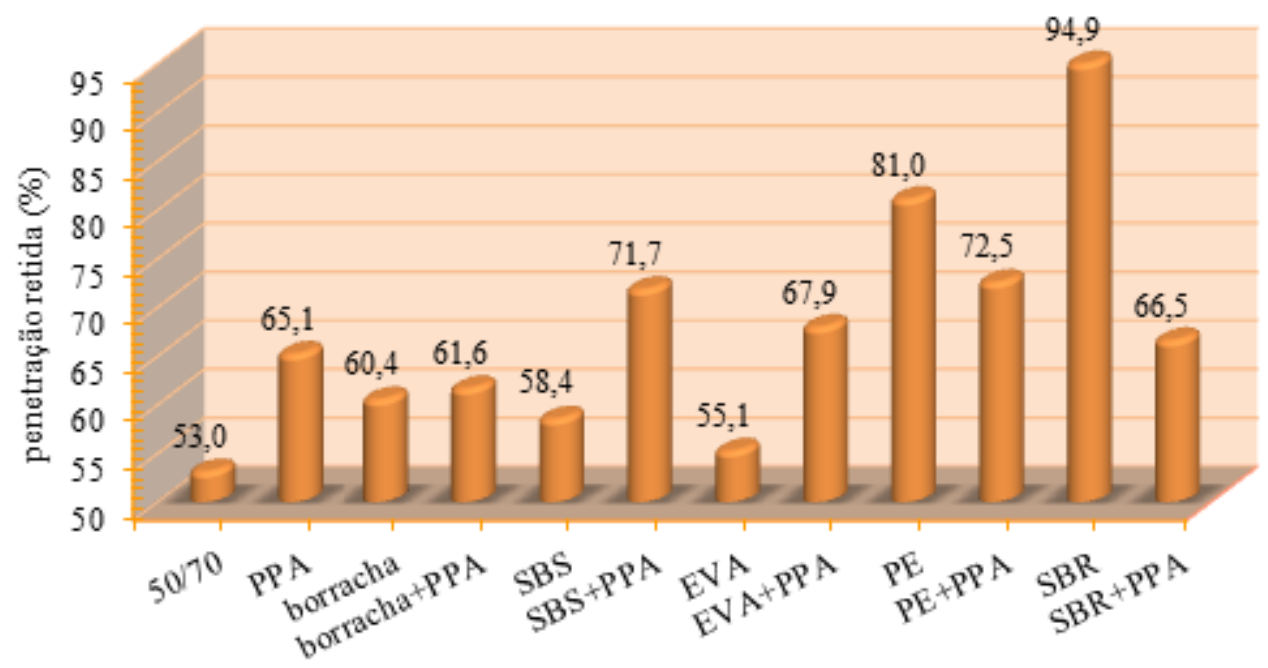

Figura 4.4 - Penetração retida

Admitindo a penetração retida como um indicador da sensibilidade dos ligantes asfálticos ao envelhecimento a curto prazo, os ligantes asfálticos modificados com SBR e com PE, sem a adição de PPA, se mostram mais adequados, à luz deste parâmetro. A adição de PPA aos ligantes asfálticos com SBR e PE provoca reduções substanciais da penetração retida. Já no caso dos ligantes asfálticos compostos com SBS e com EVA, a adição de PPA levou a aumentos substanciais da penetração retida. No caso dos asfaltos-borracha, a adição 
de PPA aumentou pouco a penetração retida. Curioso também observar que o CAP modificado apenas com PPA apresentou ganho de penetração retida superior ao $\mathrm{CAP}+$ borracha, ao $\mathrm{CAP}+$ borracha+PPA, ao $\mathrm{CAP}+\mathrm{SBS}$, ao $\mathrm{CAP}+\mathrm{EVA}$ e equivalente ao $\mathrm{CAP}+\mathrm{SBR}+\mathrm{PPA}$.

Na extensão em que é válida a aplicação dos limites de penetração retida mínima especificados pelo Regulamento Técnico 03/2005 da ANP a ligantes asfálticos modificados, dois valores têm que ser considerados nesta análise: a penetração retida mínima de $55 \%$ para os ligantes asfálticos com penetração entre 50 e $70(0,1 \mathrm{~mm})$, faixa na qual se enquadra o CAP puro, e $60 \%$ para os materiais com penetração entre 30 e $45(0,1 \mathrm{~mm})$, faixa na qual se enquadram todos os demais ligantes asfálticos modificados à exceção do CAP+PE, cuja penetração é inferior a 30 . No limite de $55 \%$, não se enquadra o próprio CAP puro, cuja penetração retida é $53 \%$. No limite de $60 \%$, não se enquadram o CAP+SBS e o CAP+EVA, cujas penetrações retidas são 58 e $55 \%$.

A Figura 4.5 traz um comparativo dos valores de ponto de amolecimento das amostras virgens e a Figura 4.6 expõe os resultados para as amostras envelhecidas a curto prazo. As aditivações, em linhas gerais, aumentaram o ponto de amolecimento das amostras virgens e das envelhecidas a curto prazo, indicando que os ligantes asfálticos modificados enrijecem mais que o CAP puro. Embora todos os modificados apresentem o mesmo PG e, consequentemente, rigidez comparável, à exceção do CAP puro, o efeito das modificações é sentido de maneira altamente expressiva sobre o ponto de amolecimento: os valores para os ligantes asfálticos modificados variam entre 56 e 67 para os virgens e entre 65 e 71 para os envelhecidos. 


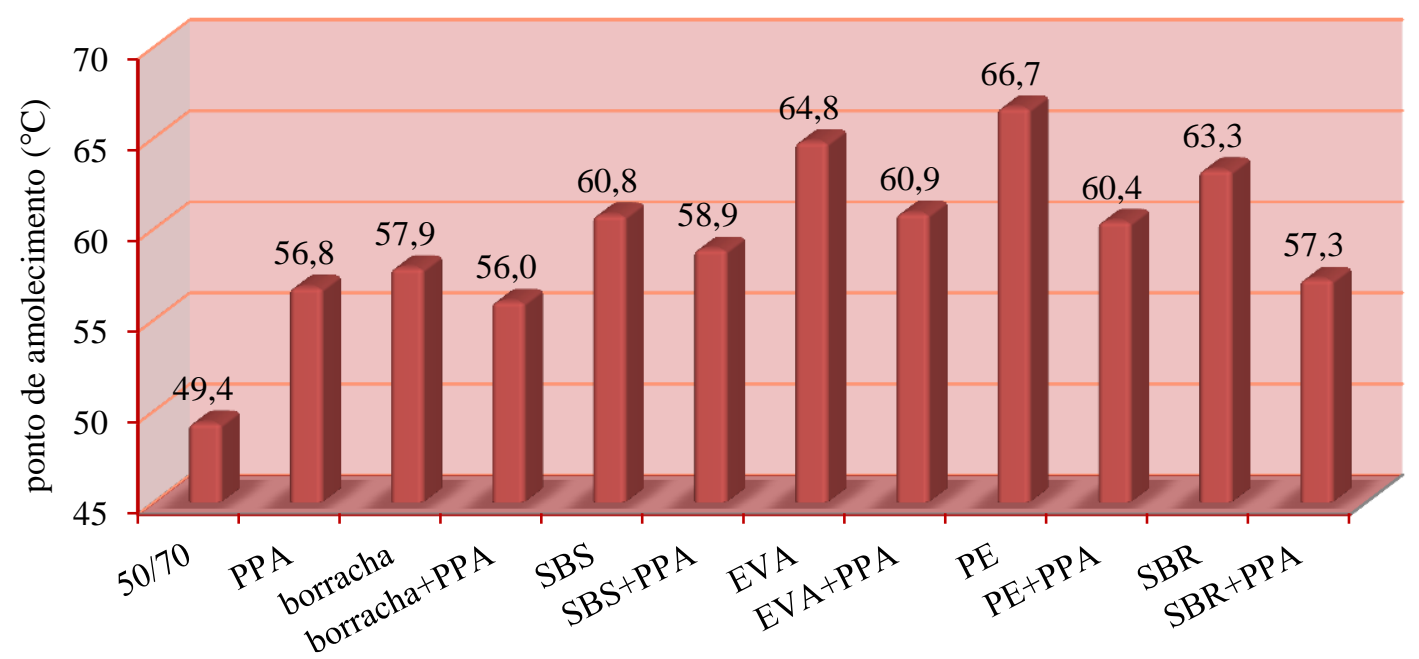

Figura 4.5 - Ponto de amolecimento das amostras virgens

Dentre as amostras virgens, os maiores endurecimentos são observados para as formulações com os plastômeros sem PPA (PE e EVA), com pontos de amolecimento de 67 e 65, respectivamente. Em seguida vem o $\mathrm{CAP}+\mathrm{SBR}$, com valor da ordem de 63. Duas formulações apresentam ponto de amolecimento de 61: o CAP+SBS e o CAP+EVA+PPA. Em seguida vêm o CAP+PE+PPA (60), o CAP+SBS+PPA (59), o CAP+borracha (58), seguidos pelo $\mathrm{CAP}+\mathrm{PPA}$ e o $\mathrm{CAP}+\mathrm{SBR}+\mathrm{PPA}$, com pontos de amolecimento comparáveis (57) e, por último, o CAP+borracha+PPA, com menor ponto de amolecimento entre os ligantes asfálticos modificados virgens.

No caso das amostras envelhecidas a curto prazo (Figura 4.6), os maiores endurecimentos foram verificados para o CAP+EVA+PPA (70) e para o CAP+EVA e o CAP+PE, ambos com ponto de amolecimento de 69. Na sequência, aparecem o CAP+PPA e o $\mathrm{CAP}+\mathrm{PE}+\mathrm{PPA}$, com ponto de amolecimento de 67, seguidos pelo $\mathrm{CAP}+\mathrm{SBS}+\mathrm{PPA}$, o $\mathrm{CAP}+\mathrm{SBR}$ e o $\mathrm{CAP}+\mathrm{SBR}+\mathrm{PPA}$, com ponto de amolecimento de 66, e finalmente o CAP+borracha, o CAP+borracha+PPA e o $\mathrm{CAP}+\mathrm{SBS}$, com os menores pontos de amolecimento (65) em relação ao CAP puro (56). O envelhecimento a curto prazo minimiza a diferença entre pontos de amolecimento das diferentes formulações, tornando o efeito dos modificadores menos distinto: os pontos de amolecimento dos ligantes asfálticos modificados virgens variam entre 56 e 67 (11 graus) ao passo que a variação entre os materiais modificados envelhecidos está entre 65 e 71 (6 graus). 


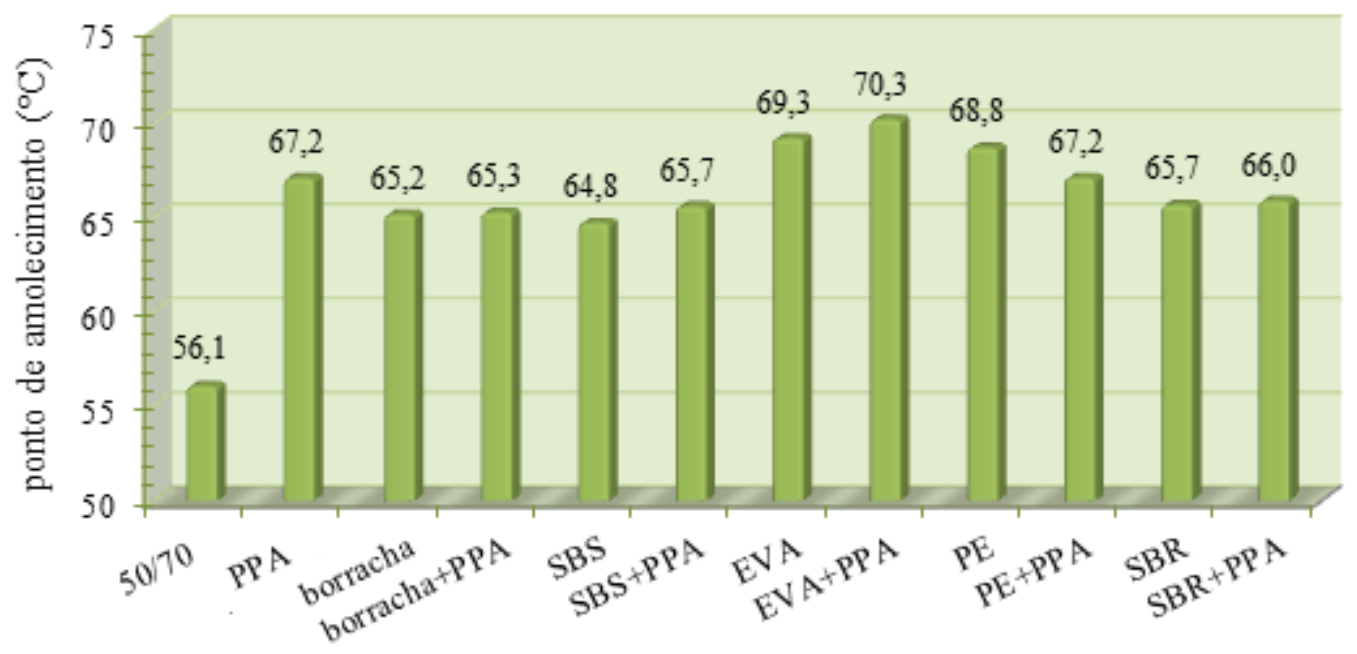

Figura 4.6 - Ponto de amolecimento das amostras envelhecidas a curto prazo

Em relação à modificação com PPA, a amostra CAP+PPA sofreu aumento substancial do ponto de amolecimento tanto virgem quanto envelhecido. Quando se observam os pares formulados com o mesmo polímero (com e sem PPA), percebe-se que a adição de PPA à formulação provocou redução do ponto de amolecimento virgem do CAP+borracha, do $\mathrm{CAP}+\mathrm{SBS}$, do CAP+EVA, do CAP+PE e do CAP+SBR. No caso das amostras envelhecidas a curto prazo, a incorporação do PPA aos ligantes asfálticos modificados com polímeros levou a uma ligeira redução do ponto de amolecimento do CAP+PE e a um ligeiro aumento do ponto de amolecimento do $\mathrm{CAP}+\mathrm{SBS}$ e do CAP+EVA. A adição de PPA ao $\mathrm{CAP}+$ borracha e ao $\mathrm{CAP}+\mathrm{SBR}$ não levou ao aumento do ponto de amolecimento. Há que se ter em mente que a adição do PPA sempre está acompanhada da redução do teor de polímero ou de borracha moída, o que justifica a redução do ponto de amolecimento observado nas formulações $\mathrm{CAP}+$ polímero+PPA ou $\mathrm{CAP}+$ borracha+PPA virgens.

A Figura 4.7 mostra os graus de modificação com base nos valores de ponto de amolecimento das amostras virgens e envelhecidas. Observa-se que o grau de endurecimento provocado pelas aditivações se manteve após o envelhecimento para a maioria das formulações. São exemplos o CAP+PPA, o CAP+borracha, o CAP+borracha+PPA, o $\mathrm{CAP}+\mathrm{SBS}+\mathrm{PPA}$, o CAP+EVA+PPA, o CAP+PE+PPA e o CAP+SBR+PPA. São exceções o $\mathrm{CAP}+\mathrm{SBS}$, o $\mathrm{CAP}+\mathrm{EVA}$, o $\mathrm{CAP}+\mathrm{PE}$ e o $\mathrm{CAP}+\mathrm{SBR}$, cujos graus de modificação sofrem redução com o envelhecimento. O primeiro grupo corresponde às formulações que são pouco sensíveis ao envelhecimento no que se refere ao enrijecimento provocado pelas aditivações e, à exceção do CAP+borracha, todas elas apresentam PPA nas suas composições. Já o segundo 
grupo contém formulações cujo efeito das aditivações é minimizado pelo envelhecimento a curto prazo e é composto por formulações sem PPA.

A Figura 4.8 traz os valores de incremento do ponto de amolecimento. Os maiores incrementos do ponto de amolecimento são observados para o CAP+PPA (10), seguido pelo $\mathrm{CAP}+$ borracha+PPA, o CAP+EVA+PPA e o CAP+SBR+PPA (9). Com aumento de ponto de amolecimento da ordem de 7 graus aparecem o CAP puro, o CAP+borracha, o CAP+SBS+PPA e o CAP+PE+PPA. Os menores aumentos do ponto de amolecimento são obtidos para o CAP+SBS e o CAP+EVA (da ordem de 4 graus) e para o CAP+PE e o CAP+SBR (da ordem de 2 graus). Apenas o CAP+SBS, o CAP+EVA, o CAP+PE e o $\mathrm{CAP}+\mathrm{SBR}$ apresentaram incrementos do ponto de amolecimento inferior ao obtido para o CAP puro.

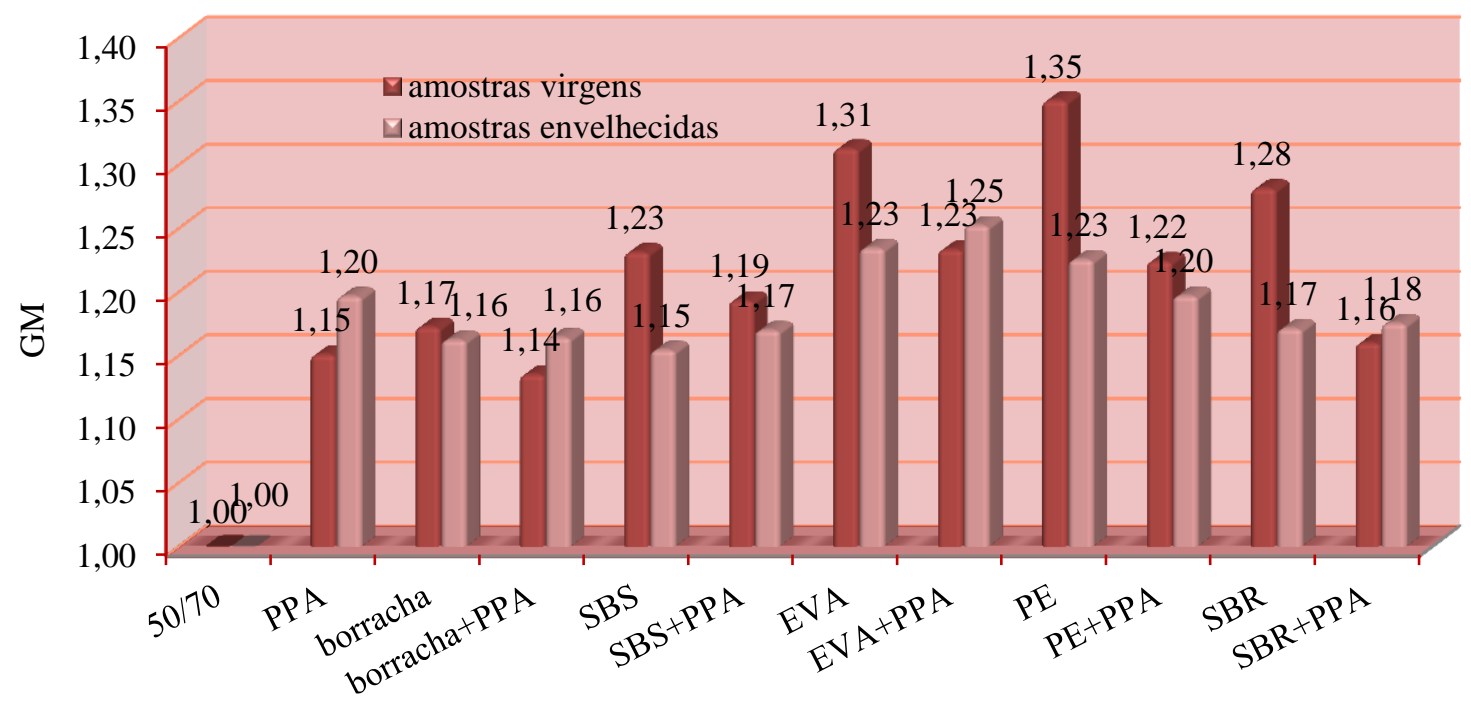

Figura 4.7 - Graus de modificação com base nos valores de ponto de amolecimento 


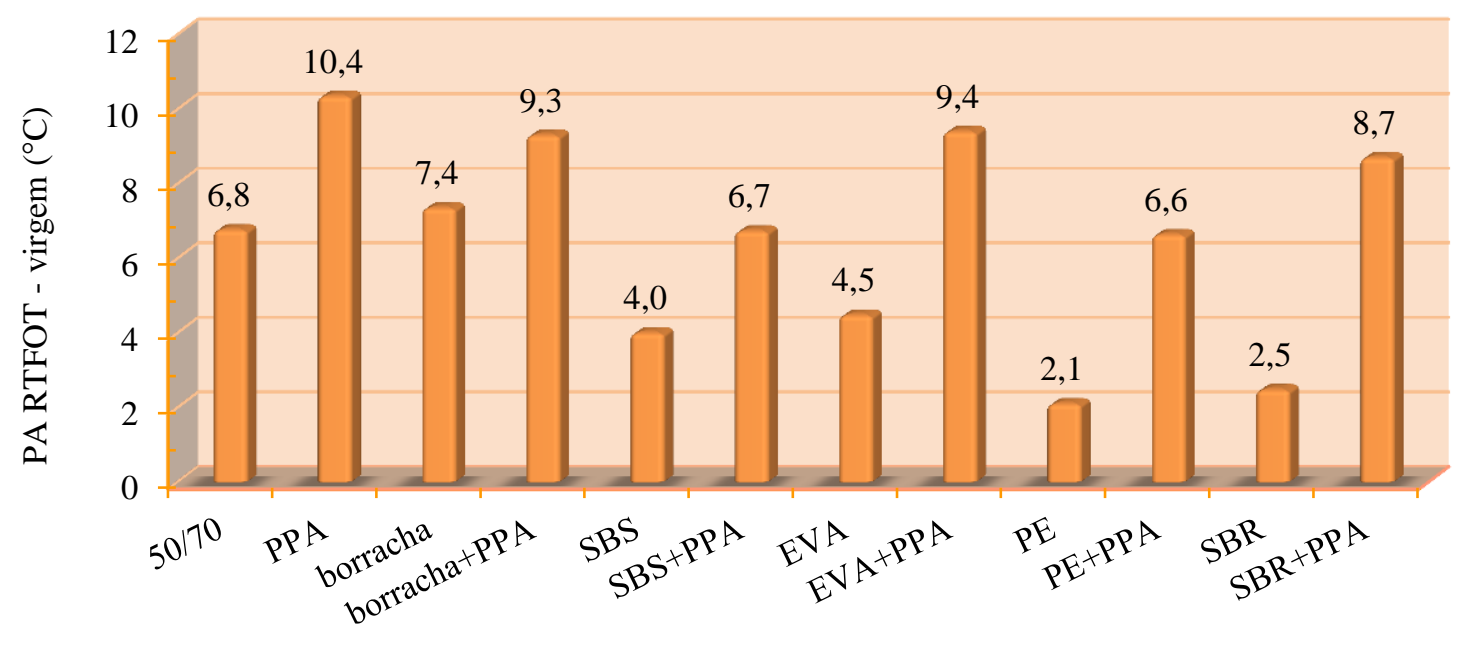

Figura 4.8 - Aumento do ponto de amolecimento

Na extensão em que é válida a aplicação do limite de incremento de ponto de amolecimento de $8^{\circ} \mathrm{C}$ especificado pelo Regulamento Técnico 03/2005 da ANP a ligantes asfálticos modificados, quatro das 12 formulações não seriam adequadas: o CAP+PPA, o $\mathrm{CAP}+$ borracha+PPA, o $\mathrm{CAP}+\mathrm{EVA}+\mathrm{PPA}$ e o $\mathrm{CAP}+\mathrm{SBR}+\mathrm{PPA}$. As quatro formulações contêm ácido polifosfórico e os resultados aqui obtidos estão de acordo com os relatos da literatura acerca da tendência enrijecedora deste modificador. Embora tal efeito enrijecedor seja positivo do ponto de vista da contribuição que um ligante asfáltico mais duro tem sobre a resistência à deformação permanente da mistura asfáltica, valores altos de incremento de ponto de amolecimento também revelam uma maior sensibilidade do ligante asfáltico ao envelhecimento. Nestas condições, a contribuição do ligante asfáltico à resistência à fadiga por deformação controlada da mistura asfáltica também seria prejudicada, já que ligantes asfálticos mais moles são desejáveis no controle deste tipo de mecanismo de ruptura dos pavimentos asfálticos.

Os valores de penetração e de ponto de amolecimento das amostras virgens não permitem afirmar que as formulações contendo plastômeros enrijeceram mais o CAP que os elastômeros, porém os dados das amostras envelhecidas sim. No caso da penetração virgem, o $\mathrm{CAP}+\mathrm{PE}$, o $\mathrm{CAP}+\mathrm{PE}+\mathrm{PPA}$ e o $\mathrm{CAP}+\mathrm{EVA}+\mathrm{PPA}$ apresentaram menores valores, mas o $\mathrm{CAP}+\mathrm{EVA}$ apresentou penetração maior que o $\mathrm{CAP}+\mathrm{SBS}$ e que o $\mathrm{CAP}+\mathrm{SBR}$. Já para a penetração RTFOT, as formulações com SBS e SBR, com ou sem PPA, apresentaram penetrações maiores que as contendo EVA e PE, com ou sem PPA. 
No caso do ponto de amolecimento virgem, as formulações CAP+EVA e CAP+PE apresentaram maiores valores, porém as formulações $\mathrm{CAP}+\mathrm{EVA}+\mathrm{PPA}$ e $\mathrm{CA}+\mathrm{PE}+\mathrm{PPA}$ apresentaram valores comparáveis ao do $\mathrm{CAP}+\mathrm{SBS}$, inferiores ao $\mathrm{CAP}+\mathrm{SBR}$ e ligeiramente superiores ao $\mathrm{CAP}+\mathrm{SBS}+\mathrm{PPA}$ e ao $\mathrm{CAP}+\mathrm{SBR}+\mathrm{PPA}$. Já para o ponto de amolecimento RTFOT, as formulações contendo SBS e SBR, com ou sem PPA, apresentaram pontos de amolecimento maiores que as contendo EVA e PE, com ou sem PPA. O envelhecimento destaca os efeitos destes dois tipos de polímero, indicando que os plastômeros enrijecem mais o CAP que os elastômeros após o RTFOT.

A Figura 4.9 traz os valores de perda de massa. O CAP puro, o CAP+SBS e o CAP+PE apresentaram perdas de massa comparáveis (em torno de 0,10\%). Já o $\mathrm{CAP}+\mathrm{EVA}+\mathrm{PPA}$ e o $\mathrm{CAP}+\mathrm{SBR}$ apresentaram perdas de massa inferiores ao CAP puro. Boa parte das formulações apresentou perdas de massa superiores à do CAP puro, com valores entre 0,20 e 0,30\%, dentre elas o CAP+PPA, o CAP+borracha, o CAP+borracha+PPA, o $\mathrm{CAP}+\mathrm{SBS}+\mathrm{PPA}, \quad \mathrm{o} \quad \mathrm{CAP}+\mathrm{EVA}, \quad \mathrm{o} \quad \mathrm{CAP}+\mathrm{PE}+\mathrm{PPA}$ e $\quad$ o $\mathrm{CAP}+\mathrm{SBR}+\mathrm{PPA} . \quad \mathrm{O}$ CAP+borracha+PPA apresentou a maior perda de massa $(0,30)$ e o CAP+EVA+PPA apresentou a menor $(0,06 \%)$. Três formulações apresentaram perdas de massa idênticas (0,20\%): CAP+SBS+PPA, CAP+EVA e o CAP+PE+PPA.

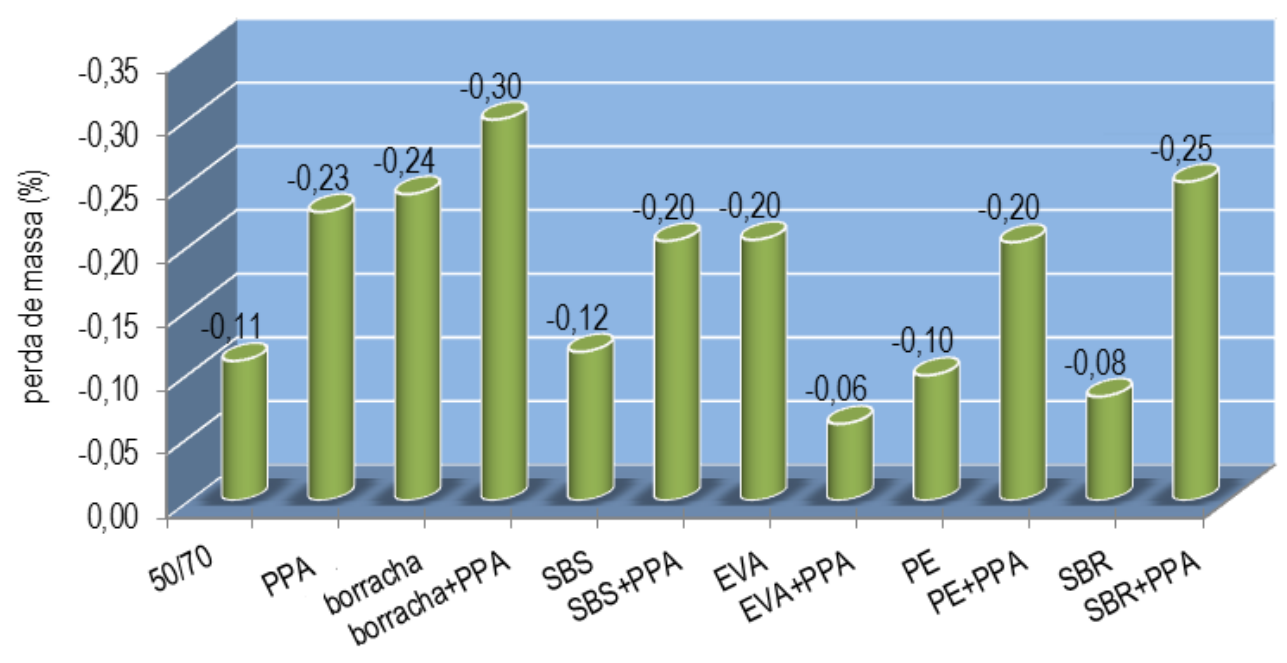

Figura 4.9 - Perda de massa

$\mathrm{Na}$ extensão em que é válida a aplicação do limite de perda de massa de 0,5\% especificado pelo Regulamento Técnico 03/2005 da ANP a ligantes asfálticos modificados, todos seriam adequados do ponto de vista de perda de massa. Embora algumas aditivações 
tenham aumentado a perda de massa, nenhuma delas superou 0,30\%. Destaque deve ser dado ao $\mathrm{CAP}+\mathrm{EVA}+\mathrm{PPA}$ e ao $\mathrm{CAP}+\mathrm{SBR}$ pela redução de perda de massa obtida para estas formulações em relação ao CAP.

Com base nos itens destacados anteriormente, as seguintes conclusões podem ser listadas:

- Embora as aditivações visassem o mesmo PG, os valores de penetração e de ponto de amolecimento variaram expressivamente, tanto entre as amostras virgens quanto as envelhecidas a curto prazo;

- as aditivações provocaram, em linhas gerais, redução da penetração e aumento do ponto de amolecimento tanto das amostras virgens quanto das envelhecidas a curto prazo; com exceção do $\mathrm{CAP}+\mathrm{SBR}$ envelhecido, que forneceu penetração superior à do CAP puro e a amostra $\mathrm{CAP}+\mathrm{SBR}+\mathrm{PPA}$ envelhecida, que forneceu penetração semelhante à do CAP puro;

- a formulação que sofreu maior redução da penetração na condição virgem foi o $\mathrm{CAP}+\mathrm{PE}$; dentre as amostras envelhecidas, a que sofreu menor redução da penetração foi o CAP+SBR (apresentou penetração maior que o CAP puro) e a que sofreu maior redução foi novamente o $\mathrm{CAP}+\mathrm{PE}$;

- o envelhecimento distingue os efeitos de plastômeros e elastômeros, indicando que os plastômeros enrijecem mais o CAP que os elastômeros, após o RTFOT;

- em linhas gerais, a incorporação de PPA aos ligantes asfálticos modificados por polímeros levou à redução da penetração, tanto a virgem quanto a envelhecida a curto prazo, das formulações com borracha e EVA, e ao aumento da penetração das formulações com PE e SBR;

- a adição de PPA às formulações provocou redução do ponto de amolecimento virgem do $\mathrm{CAP}+$ borracha, do $\mathrm{CAP}+\mathrm{SBS}$, do $\mathrm{CAP}+\mathrm{EVA}$, do $\mathrm{CAP}+\mathrm{PE}$ e do $\mathrm{CAP}+\mathrm{SBR}$ e teve efeito pouco expressivo sobre o ponto de amolecimento das amostras envelhecidas;

- as penetrações retidas dos ligantes asfálticos modificados são maiores que a do CAP puro;

- as formulações CAP+SBR e CAP+PE apresentaram as maiores penetrações retidas (95 e $81 \%$ ) ao passo que o CAP+PPA apresentou a menor penetração retida (55\%); 
- o CAP puro, o CAP+SBS e o CAP+EVA não se enquadram nos limites mínimos de penetração retida do Regulamento Técnico 03/2005 da ANP;

- os maiores incrementos do ponto de amolecimento foram observados para o $\mathrm{CAP}+\mathrm{PPA}\left(10^{\circ} \mathrm{C}\right)$, seguido pelo $\mathrm{CAP}+$ borracha+PPA, o $\mathrm{CAP}+\mathrm{EVA}+\mathrm{PPA}$ e o $\mathrm{CAP}+\mathrm{SBR}+\mathrm{PPA}\left(9^{\circ} \mathrm{C}\right)$; os menores incrementos foram obtidos para o $\mathrm{CAP}+\mathrm{SBS}$ e o $\mathrm{CAP}+\mathrm{EVA}$ (da ordem de $4^{\circ} \mathrm{C}$ ) e para o $\mathrm{CAP}+\mathrm{PE}$ e o CAP+SBR (da ordem de $2^{\circ} \mathrm{C}$ );

- apenas o $\mathrm{CAP}+\mathrm{SBS}$, o $\mathrm{CAP}+\mathrm{EVA}$, o $\mathrm{CAP}+\mathrm{PE}$ e o $\mathrm{CAP}+\mathrm{SBR}$ apresentaram incrementos do ponto de amolecimento inferiores ao obtido para o CAP puro;

- o CAP+PPA, o CAP+borracha+PPA, o CAP+EVA+PPA e o CAP+SBR+PPA não se enquadram no limite de incremento do ponto de amolecimento do Regulamento Técnico 03/2005 da ANP;

- o CAP+borracha+PPA apresentou a maior perda de massa $(0,30)$;

- todos os ligantes asfálticos são adequados do ponto de vista de perda de massa, admitido o limite de 0,5\% especificado pelo Regulamento Técnico 03/2005 da ANP;

- a avaliação do efeito do envelhecimento a curto prazo, à luz dos requisitos do Regulamento Técnico 03/2005 da ANP referentes ao incremento do ponto de amolecimento, à penetração retida e à perda de massa, indica que o CAP+SBR e o CAP+PE são duas das melhores formulações, já que apresentam maior penetração retida, menor incremento de ponto de amolecimento e menor perda de massa. 


\subsection{Efeito dos diferentes níveis de envelhecimento}

O Strategic Highway Research Program (SHRP) introduziu a medida do módulo complexo $\left(\mathrm{G}^{*}\right)$ e do ângulo de fase $(\delta)$ dos ligantes asfálticos, no domínio da viscoelasticidade linear, por se tratarem de propriedades reológicas que guardam alguma relação lógica com determinadas propriedades mecânicas das misturas asfálticas associadas aos referidos defeitos do pavimento asfáltico. Medidas pontuais destas propriedades ou medidas obtidas em diferentes frequências de carregamento e temperaturas, posteriormente combinadas na forma de curvasmestre, têm sido rotineiramente empregadas na caracterização reológica dos ligantes asfálticos.

$\mathrm{O}$ aumento de rigidez, expresso pelo aumento de $\mathrm{G}^{*}$, normalmente favorece as resistências à deformação permanente e à fadiga por tensão controlada e prejudica as resistências à fadiga por deformação controlada e de origem térmica. $\mathrm{O}$ aumento da elasticidade, expresso pela redução de $\delta$, via de regra, favorece a durabilidade das camadas asfálticas, já que a capacidade de recuperação elástica e de relaxação de tensões contribui para o aumento das resistências à deformação permanente, à fadiga e ao trincamento térmico. Do ponto de vista de sensibilidade ao envelhecimento, aumentos expressivos de $\mathrm{G}^{*}$ e reduções expressivas de $\delta$ seriam indicativos de alta sensibilidade do material, embora tais variações possam incrementar a contribuição do ligante asfáltico sobre a resistência da mistura asfáltica a um dado mecanismo de ruptura do pavimento e reduzi-la em relação a outro mecanismo.

As curvas-mestre têm sido amplamente empregadas na caracterização reológica de materiais asfálticos, permitindo a avaliação do comportamento reológico dos materiais ao longo de uma ampla faixa de frequências de carregamento, que, devido ao princípio de superposição tempo-temperatura, têm correspondência com as temperaturas em que a deformação permanente, o trincamento por fadiga e o trincamento por origem térmica ocorrem no pavimento.

A construção de uma curva-mestre de um material qualquer exige que tal material atenda o princípio de superposição tempo-temperatura. A adequação a este princípio se verifica pela necessidade apenas de fatores de deslocamento horizontal, log a[T], para a composição de curvas-mestre bem ajustadas, o que revela o comportamento termorreologicamente simples do material em questão. No caso de ajustes ruins, seria 
necessário aplicar fatores de deslocamento verticais, revelando o comportamento termorreologicamente complexo do material.

A lógica do procedimento de análise em curso pressupõe a aplicabilidade do princípio de superposição tempo-temperatura aos ligantes asfálticos em questão, baseada nas conclusões do programa SHRP. Por outro lado, os ajustes ruins nas curvas-mestre de $\delta$ parecem indicar que tal princípio, embora validado para ligantes asfálticos convencionais, ou pouco modificados, não seja plenamente válido para alguns dos ligantes asfálticos modificados avaliados neste experimento em certas condições de envelhecimento.

O princípio de superposição tempo-temperatura implica na equivalência de efeitos provocados pelas variáveis temperatura e tempo sobre as propriedades reológicas dos ligantes asfálticos. Para os materiais aos quais este princípio se aplica, a redução da frequência de aplicação de carga tem um efeito sobre o comportamento reológico do material que equivale a um certo aumento de temperatura. Em condições normais, o dano provocado por um veículo pesado trafegando em velocidade bem baixa em uma temperatura intermediária seria equivalente ao dano provocado por este mesmo veículo trafegando em uma velocidade mais alta e em uma temperatura mais alta. Esta lógica de equivalência será empregada nesta análise, já que as curvas-mestre são construídas em função da frequência e não da temperatura.

\subsubsection{Efeito dos modificadores sobre a rigidez e a elasticidade dos ligantes asfálticos} virgens e envelhecidos

As curvas-mestre de $G^{*}$ e $\delta$ dos ligantes asfálticos modificados em comparação com a curva-mestre do ligante asfáltico de base, nas diversas condições (virgem, curto prazo, longo prazo no PAV e longo prazo na estufa UV) são apresentadas no Apêndice A. São apresentadas neste item apenas as tabelas contendo relações entre as propriedades empregadas na construção das curvas-mestres. As curvas-mestre foram construídas na temperatura de referência de $25^{\circ} \mathrm{C}$ e por esta razão todas as análises decorrentes dos dados destas curvas são feitas apenas nesta temperatura. A análise em outras temperaturas é possível, mas exige a geração de novas curvas-mestre nas temperaturas de interesse. 
A adição dos modificadores, seja isoladamente ou combinados, promove alterações substanciais do perfil reológico do ligante asfáltico de base, nas proporções em que foram empregados. Tais alterações devem ser avaliadas do ponto de vista de quanto contribuem ou prejudicam as resistências aos principais defeitos dos pavimentos asfálticos: deformação permanente, fadiga e trincamento térmico.

A fim de quantificar o enrijecimento provocado pelos modificadores na condição virgem e nos diversos níveis de envelhecimento, as Tabelas de 4.1 a 4.5 mostram a variação de $\mathrm{G}^{*}$ dos ligantes asfálticos modificados comparativamente ao ligante asfáltico de base, em função da frequência de carregamento, a $25^{\circ} \mathrm{C}$, respectivamente para as amostras virgens, envelhecidas a curto prazo (RTFOT) e envelhecidas a longo prazo (PAV, UV a 0,68 W/m² e UV a $1,00 \mathrm{~W} / \mathrm{m}^{2}$ ). A variação de $\mathrm{G}^{*}$ é expressa em termos de quantas vezes $\mathrm{G}^{*}$ aumentou ou diminuiu por conta da adição dos modificadores, em relação aos valores de rigidez do asfalto de base (50/70 puro). Valores acima de 1,0 indicam enrijecimento em relação ao asfalto de base e valores inferiores a 1,0 indicam que o ligante asfáltico é menos rígido que o de referência. Por meio das médias obtidas ao longo do espectro de frequências, pode-se observar quantas vezes a rigidez média da amostra aumentou ou diminuiu, quando comparada ao CAP de base, ou seja, é possível comparar o potencial de cada formulação em aumentar a rigidez do ligante asfáltico de base, a $25^{\circ} \mathrm{C}$. É importante destacar que os ordenamentos das amostras realizados ao longo deste capítulo não empregaram tais médias e sim a média dos ordenamentos em cada frequência. 
Tabela 4.1 - Quantas vezes G* virgem aumentou ou diminuiu em relação aos valores referentes ao ligante asfáltico de base, a $25^{\circ} \mathrm{C}$

\begin{tabular}{|c|c|c|c|c|c|c|c|c|c|c|c|c|}
\hline \multirow{2}{*}{ amostras } & \multicolumn{11}{|c|}{ frequência $(\mathrm{rad} / \mathrm{s})$} & \multirow{2}{*}{ Média } \\
\hline & $10^{-5}$ & $10^{-4}$ & $10^{-3}$ & $10^{-2}$ & $10^{-1}$ & $10^{0}$ & $10^{1}$ & $10^{2}$ & $10^{3}$ & $10^{4}$ & $10^{5}$ & \\
\hline $50 / 70$ & 4,9 & 49,2 & 487,0 & $4,7.10^{3}$ & $3,9.10^{4}$ & $2,8.10^{5}$ & $1,7.10^{6}$ & $8,0.10^{6}$ & $2,8.10^{7}$ & $7,5.10^{7}$ & $1,6.10^{8}$ & \\
\hline PPA & 7,5 & 7,1 & 5,8 & 4,2 & 3,1 & 2,2 & 1,6 & 1,2 & 1,0 & 0,9 & 0,9 & 3,2 \\
\hline borracha & 4,2 & 3,5 & 3,0 & 2,1 & 1,3 & 0,9 & 0,7 & 0,6 & 0,6 & 0,6 & 0,6 & 1,6 \\
\hline borracha-PPA & 5,7 & 5,3 & 4,4 & 2,7 & 1,6 & 1,1 & 0,8 & 0,7 & 0,6 & 0,6 & 0,6 & 2,2 \\
\hline SBS & 3,2 & 3,0 & 2,8 & 2,1 & 1,5 & 1,2 & 1,0 & 0,9 & 0,9 & 0,9 & 0,8 & 1,7 \\
\hline SBS-PPA & 4,8 & 4,6 & 4,0 & 2,7 & 1,8 & 1,4 & 1,1 & 1,0 & 0,9 & 0,8 & 0,8 & 2,2 \\
\hline EVA & 1,1 & 1,1 & 1,1 & 0,8 & 0,6 & 0,5 & 0,4 & 0,4 & 0,5 & 0,6 & 0,7 & 0,7 \\
\hline EVA-PPA & 4,9 & 4,4 & 3,6 & 2,5 & 1,7 & 1,2 & 1,0 & 0,8 & 0,8 & 0,8 & 0,8 & 2,0 \\
\hline $\mathrm{PE}$ & 5,9 & 5,0 & 4,5 & 3,7 & 2,9 & 2,4 & 2,0 & 1,6 & 1,4 & 1,3 & 1,2 & 2,9 \\
\hline PE-PPA & 5,3 & 4,6 & 3,9 & 3,0 & 2,3 & 1,9 & 1,5 & 1,3 & 1,2 & 1,1 & 0,0 & 2,4 \\
\hline SBR & 4,5 & 4,2 & 3,5 & 2,5 & 1,9 & 1,5 & 1,2 & 1,0 & 0,9 & 0,8 & 0,8 & 2,1 \\
\hline SBR-PPA & 4,1 & 4,0 & 3,3 & 2,5 & 1,9 & 1,5 & 1,2 & 1,0 & 1,0 & 0,9 & 0,9 & 2,0 \\
\hline
\end{tabular}


Tabela 4.2 -Quantas vezes G* RTFOT aumentou ou diminuiu em relação aos valores referentes ao ligante asfáltico de base, a $25^{\circ} \mathrm{C}$

\begin{tabular}{|c|c|c|c|c|c|c|c|c|c|c|c|c|}
\hline \multirow{2}{*}{ amostras } & \multicolumn{11}{|c|}{ frequência (rad/s) } & \multirow{2}{*}{ média } \\
\hline & $10^{-5}$ & $10^{-4}$ & $10^{-3}$ & $10^{-2}$ & $10^{-1}$ & $10^{0}$ & $10^{1}$ & $10^{2}$ & $10^{3}$ & $10^{4}$ & $10^{5}$ & \\
\hline $50 / 70$ & 15,4 & 153,5 & $1,5.10^{3}$ & $1,2.10^{4}$ & $9,1.10^{4}$ & $5,7.10^{5}$ & $3,0.10^{6}$ & $1,2.10^{7}$ & $3,9.10^{7}$ & $9,6.10^{7}$ & $2,0.10^{8}$ & \\
\hline PPA & 10,9 & 8,6 & 5,8 & 3,7 & 2,5 & 1,7 & 1,3 & 1,0 & 0,9 & 0,9 & 0,9 & 3,5 \\
\hline borracha & 6,0 & 5,0 & 3,4 & 2,1 & 1,3 & 0,9 & 0,7 & 0,6 & 0,6 & 0,5 & 0,6 & 2,0 \\
\hline borracha-PPA & 7,9 & 6,7 & 4,2 & 2,5 & 1,4 & 1,0 & 0,8 & 0,7 & 0,6 & 0,5 & 0,5 & 2,4 \\
\hline SBS & 4,7 & 4,3 & 3,6 & 2,4 & 1,6 & 1,4 & 1,2 & 1,0 & 0,9 & 0,8 & 0,8 & 2,1 \\
\hline SBS-PPA & 9,3 & 7,9 & 5,7 & 3,5 & 2,4 & 1,7 & 1,3 & 1,1 & 0,9 & 0,8 & 0,8 & 3,2 \\
\hline EVA & 9,6 & 7,8 & 5,3 & 3,1 & 1,4 & 0,8 & 0,5 & 0,4 & 0,4 & 0,5 & 0,5 & 2,8 \\
\hline EVA-PPA & 13,0 & 9,5 & 5,7 & 3,2 & 2,1 & 1,3 & 1,0 & 0,8 & 0,7 & 0,7 & 0,8 & 3,5 \\
\hline $\mathrm{PE}$ & 5,3 & 4,7 & 3,9 & 3,2 & 2,5 & 2,1 & 1,7 & 1,4 & 1,2 & 1,1 & 1,0 & 2,6 \\
\hline PE-PPA & 7,1 & 6,0 & 4,5 & 3,2 & 2,3 & 1,7 & 1,3 & 1,1 & 1,0 & 0,9 & 0,9 & 2,7 \\
\hline SBR & 4,4 & 3,8 & 2,8 & 2,1 & 1,5 & 1,2 & 1,0 & 0,9 & 0,7 & 0,7 & 0,6 & 1,8 \\
\hline SBR-PPA & 10,0 & 7,4 & 5,0 & 3,3 & 2,3 & 1,6 & 1,3 & 1,0 & 0,9 & 0,8 & 0,8 & 3,1 \\
\hline
\end{tabular}


Tabela 4.3 - Quantas vezes G* PAV aumentou ou diminuiu em relação aos valores referentes ao ligante asfáltico de base, a $25^{\circ} \mathrm{C}$

\begin{tabular}{|c|c|c|c|c|c|c|c|c|c|c|c|c|}
\hline \multirow{2}{*}{ amostras } & \multicolumn{11}{|c|}{ frequência $(\mathrm{rad} / \mathrm{s})$} & \multirow{2}{*}{ média } \\
\hline & $10^{-5}$ & $10^{-4}$ & $10^{-3}$ & $10^{-2}$ & $10^{-1}$ & $10^{0}$ & $10^{1}$ & $10^{2}$ & $10^{3}$ & $10^{4}$ & $10^{5}$ & \\
\hline $50 / 70$ & 6,2 & 64,6 & 638,7 & $5,5.10^{3}$ & $4,0.10^{4}$ & $2,7.10^{5}$ & $1,3.10^{6}$ & $5,7.10^{6}$ & $1,8.10^{7}$ & $4,8.10^{7}$ & $1,1.10^{8}$ & \\
\hline PPA & 28,3 & 20,5 & 11,8 & 6,4 & 3,8 & 2,1 & 1,6 & 1,2 & 1,0 & 0,9 & 0,9 & 7,1 \\
\hline borracha & 5,1 & 3,8 & 2,7 & 1,6 & 0,9 & 0,6 & 0,5 & 0,4 & 0,4 & 0,4 & 0,5 & 1,5 \\
\hline borracha-PPA & 10,1 & 5,7 & 3,0 & 1,7 & 1,1 & 0,8 & 0,7 & 0,6 & 0,6 & 0,6 & 0,6 & 2,3 \\
\hline SBS & 4,1 & 3,8 & 3,6 & 2,7 & 1,8 & 1,5 & 1,2 & 1,1 & 1,0 & 0,9 & 0,8 & 2,0 \\
\hline SBS-PPA & 19,4 & 15,4 & 10,3 & 5,9 & 3,4 & 2,2 & 1,7 & 1,3 & 1,1 & 1,0 & 0,9 & 5,7 \\
\hline EVA & 19,7 & 14,2 & 8,7 & 5,3 & 3,0 & 1,6 & 1,0 & 0,7 & 0,6 & 0,6 & 0,6 & 5,1 \\
\hline EVA-PPA & 29,4 & 20,0 & 11,5 & 6,3 & 3,6 & 2,3 & 1,5 & 1,1 & 0,9 & 0,8 & 0,8 & 7,1 \\
\hline $\mathrm{PE}$ & 4,0 & 3,8 & 3,4 & 3,0 & 2,4 & 1,8 & 1,6 & 1,3 & 1,2 & 1,1 & 1,0 & 2,2 \\
\hline PE-PPA & 15,0 & 12,5 & 8,7 & 5,7 & 3,8 & 2,4 & 1,7 & 1,3 & 1,1 & 1,0 & 1,0 & 4,9 \\
\hline SBR & 21,9 & 16,1 & 11,5 & 7,9 & 6,1 & 4,3 & 3,3 & 2,3 & 1,8 & 1,5 & 1,3 & 7,1 \\
\hline SBR-PPA & 9,8 & 7,8 & 5,0 & 3,1 & 2,0 & 1,5 & 1,1 & 0,8 & 0,7 & 0,7 & 0,6 & 3,0 \\
\hline
\end{tabular}


Tabela 4.4 - Quantas vezes G* UV 0,68 W/m² aumentou ou diminuiu em relação aos valores referentes ao ligante asfáltico de base, a $25^{\circ} \mathrm{C}$

\begin{tabular}{|c|c|c|c|c|c|c|c|c|c|c|c|c|c|}
\hline \multirow[t]{2}{*}{ amostras } & \multicolumn{12}{|c|}{ frequência (rad/s) } & \multirow{2}{*}{ Média } \\
\hline & $10^{-6}$ & $10^{-5}$ & $10^{-4}$ & $10^{-3}$ & $10^{-2}$ & $10^{-1}$ & $10^{0}$ & $10^{1}$ & $10^{2}$ & $10^{3}$ & $10^{4}$ & $10^{5}$ & \\
\hline $50 / 70$ & 4,7 & 48,8 & 468,7 & $4,2.10^{3}$ & $3,1.10^{4}$ & $2,0.10^{5}$ & $1,1.10^{6}$ & $4,8 \cdot 10^{6}$ & $1,6.10^{7}$ & $4,3 \cdot 10^{7}$ & $9,6.10^{7}$ & $1,9 \cdot 10^{8}$ & \\
\hline PPA & 24,6 & 18,8 & 12,2 & 6,8 & 4,0 & 2,9 & 2,0 & 1,4 & 1,2 & 1,1 & 1,0 & 1,0 & 6,4 \\
\hline borracha & 37,0 & 23,6 & 12,2 & 5,5 & 2,7 & 1,7 & 1,1 & 0,8 & 0,6 & 0,6 & 0,5 & 0,6 & 7,2 \\
\hline $\begin{array}{l}\text { borracha- } \\
\text { PPA }\end{array}$ & 22,3 & 16,8 & 10,0 & 5,0 & 2,7 & 1,7 & 1,1 & 0,8 & 0,7 & 0,7 & 0,6 & 0,7 & 5,3 \\
\hline SBS & 6,2 & 5,6 & 4,8 & 3,5 & 2,4 & 2,1 & 1,6 & 1,3 & 1,1 & 1,0 & 0,9 & 0,8 & 2,6 \\
\hline SBS-PPA & 21,7 & 17,2 & 12,5 & 7,0 & 4,2 & 3,0 & 2,1 & 1,5 & 1,2 & 1,1 & 1,0 & 0,9 & 6,1 \\
\hline EVA & 57,2 & 41,1 & 25,6 & 10,1 & 4,6 & 2,3 & 1,3 & 0,9 & 0,7 & 0,7 & 0,7 & 0,7 & 12,2 \\
\hline EVA-PPA & 12,3 & 9,7 & 7,0 & 4,4 & 2,7 & 1,8 & 1,3 & 1,0 & 0,8 & 0,8 & 0,8 & 0,8 & 3,6 \\
\hline PE & 6,0 & 5,5 & 5,1 & 4,5 & 3,6 & 3,0 & 2,3 & 1,7 & 1,4 & 1,2 & 1,1 & 1,0 & 3,0 \\
\hline PE-PPA & 14,3 & 12,4 & 9,8 & 6,9 & 5,0 & 3,6 & 2,6 & 1,9 & 1,5 & 1,3 & 1,2 & 1,1 & 5,1 \\
\hline SBR & 4,0 & 3,8 & 3,0 & 2,3 & 1,7 & 1,3 & 1,1 & 1,0 & 0,9 & 0,8 & 0,8 & 0,8 & 1,8 \\
\hline SBR-PPA & 14,6 & 10,9 & 7,2 & 4,3 & 2,9 & 2,3 & 1,6 & 1,2 & 1,0 & 0,9 & 0,9 & 0,9 & 4,1 \\
\hline
\end{tabular}


Tabela 4.5 - Quantas vezes G* UV 1,00 W/m² aumentou ou diminuiu em relação aos valores referentes ao ligante asfáltico de base, a $25^{\circ} \mathrm{C}$

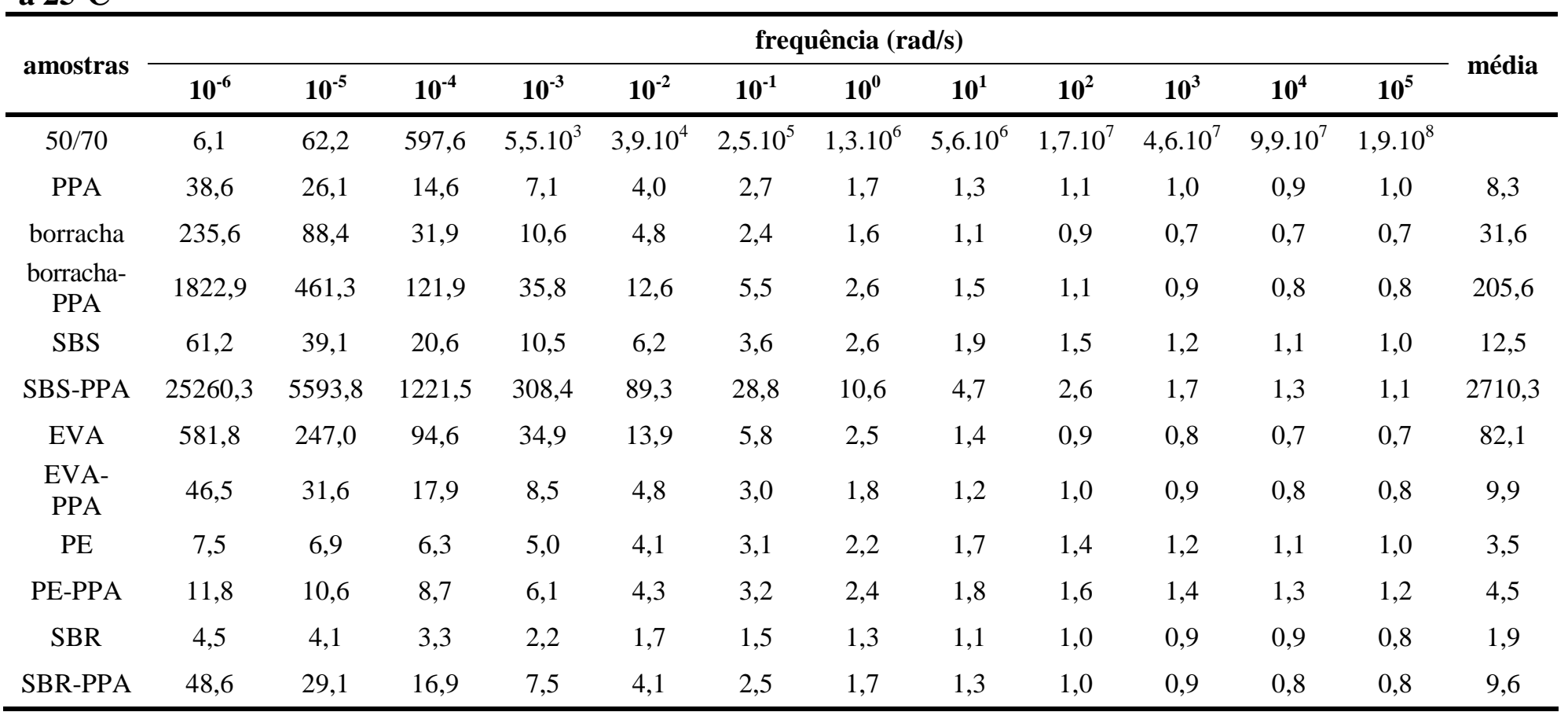


A Tabela 4.6 apresenta um ordenamento das amostras nas condições virgens e envelhecidas, no qual foi considerada a sensibilidade de cada amostra ao envelhecimento com base no critério de aumento de rigidez $\left(\mathrm{G}^{*}\right)$ a $25^{\circ} \mathrm{C}$. Primeiramente, foi feito um ordenamento de todas as amostras por frequência de carregamento e depois foi feita uma média aritmética dos posicionamentos que cada amostra obteve em cada frequência, chegando à sequência apresentada abaixo (da melhor para a pior), considerando que a pior condição é a do enrijecimento excessivo do ligante asfáltico. Os materiais destacados em negrito na primeira linha das tabelas são os menos sensíveis ao envelhecimento (enrijeceram menos) e os presentes na última linha das tabelas são os mais sensíveis ao envelhecimento (enrijeceram mais).

Tabela 4.6 - Ordenamento dos ligantes asfálticos modificados em relação ao CAP 50/70 puro, com base nos valores de $\mathrm{G}^{*}$ a $25^{\circ} \mathrm{C}$

\begin{tabular}{cccccccccc}
\hline \multirow{2}{*}{ Virgem } & \multicolumn{8}{c}{ Após envelhecimento } \\
\cline { 3 - 10 } EVA & $\mathbf{1 , 4 5}$ & borracha & $\mathbf{2 , 2 7}$ & borracha & $\mathbf{1 , 1 8}$ & SBR & $\mathbf{2 , 6 7}$ & SBR & $\mathbf{2 , 5 8}$ \\
norracha & 2,36 & SBR & 3,27 & $\begin{array}{c}\text { borracha- } \\
\text { PPA }\end{array}$ & 2,45 & $\begin{array}{c}\text { borracha- } \\
\text { PPA }\end{array}$ & 3,92 & borracha & 4,00 \\
SBS & 4,18 & EVA & 3,36 & SBR-PPA & 4,09 & borracha & 4,08 & SBR-PPA & 4,33 \\
borracha- & 5,09 & borracha- & 3,73 & SBS & 4,27 & EVA-PPA & 4,08 & PPA & 4,67 \\
PPA & PPA & & & & & & \\
EVA-PPA & 5,09 & SBS & 5,09 & EVA & 5,00 & SBS & 4,75 & EVA-PPA & 4,83 \\
SBR-PPA & 6,27 & EVA-PPA & 6,55 & PE & 6,27 & SBR-PPA & 5,75 & PE & 5,58 \\
SBR & 6,36 & SBR-PPA & 7,27 & EVA-PPA & 7,64 & EVA & 6,75 & EVA & 6,50 \\
SBS-PPA & 6,36 & PE-PPA & 7,91 & SBS-PPA & 7,82 & PE & 7,33 & PE-PPA & 6,75 \\
PE-PPA & 8,18 & PE & 8,45 & PE-PPA & 8,27 & PPA & 8,33 & borracha- & 7,83 \\
PPA & 10,18 & SBS-PPA & 8,82 & PPA & 8,55 & SBS-PPA & 8,83 & SBS & 8,00 \\
PE & $\mathbf{1 0 , 4 5}$ & PPA & $\mathbf{9 , 2 7}$ & SBR & $\mathbf{1 0 , 4 5}$ & PE-PPA & $\mathbf{9 , 5 0}$ & SBS-PPA & $\mathbf{1 0 , 9 2}$ \\
\hline
\end{tabular}

Analisando a Tabela 4.6, verifica-se que o ligante asfáltico modificado que sofreu menor enrijecimento pela adição dos modificadores, na condição virgem, quando comparado ao CAP 50/70 puro, foi o CAP+EVA. No sentido contrário, a amostra que mais enrijeceu foi o CAP+PE. Ao se comparar o nível de enrijecimento sofrido por um dado ligante asfáltico modificado com o enrijecimento sofrido pelo seu par aditivado com PPA, observa-se que a 
adição de ácido polifosfórico (PPA) nos ligantes asfálticos modificados resultou em aumento da rigidez, exceto no caso do ligante asfáltico modificado com PE e com SBR, na condição virgem.

Quando as amostras foram submetidas aos procedimentos de envelhecimento, o comportamento dos ligantes asfálticos, no que se refere à rigidez, mudou expressivamente. Destacam-se dentre os que menos enrijeceram o CAP+borracha, quando envelhecido a curto prazo no RTFO e a longo prazo no PAV, e o CAP+SBR, quando envelhecido a longo prazo na estufa UV, nos dois níveis de radiação. Os piores, ou seja, os que sofreram maior aumento da rigidez quando envelhecidos, foram o $\mathrm{CAP}+\mathrm{PPA}$ (curto prazo no $\mathrm{RTFO}$ ), o $\mathrm{CAP}+\mathrm{SBR}$ (longo prazo no PAV), o CAP+PE+PPA (longo prazo na estufa UV a $0,68 \mathrm{~W} / \mathrm{m}^{2}$ ) e o $\mathrm{CAP}+\mathrm{SBS}+\mathrm{PPA}$ (longo prazo na estufa UV a $1,00 \mathrm{~W} / \mathrm{m}^{2}$ ).

A fim de quantificar o efeito das aditivações sobre a elasticidade das amostras, as Tabelas de 4.7 a 4.11 mostram a variação do ângulo de fase $(\delta)$ dos ligantes asfálticos modificados comparativamente ao ligante asfáltico de base, em função da frequência de carregamento, a $25^{\circ} \mathrm{C}$, respectivamente, para as amostras virgens, envelhecidas a curto prazo no RTFO e envelhecidas a longo prazo no PAV e na estufa UV a 0,68 e a $1,00 \mathrm{~W} / \mathrm{m}^{2}$.

A variação de $\delta$ é expressa em termos de quantos graus aumentaram ou diminuíram em função da adição dos modificadores, em relação aos valores de $\delta$ do ligante asfáltico de base. Valores negativos indicam que o ligante asfáltico modificado é mais elástico que o de referência e valores positivos indicam que o ligante asfáltico modificado é menos elástico que o de referência. Diferentemente da análise realizada com os valores de $G^{*}$, em que foram obtidas relações, no caso do ângulo de fase foram obtidas diferenças entre os valores de $\delta$ dos ligantes asfálticos modificados e os do CAP puro. Por meio das médias obtidas ao longo do espectro de frequências, pode-se observar quantos graus o ângulo de fase aumentou ou diminuiu, em comparação ao CAP de base, ou seja, é possível comparar o potencial de cada formulação em aumentar a elasticidade do ligante asfáltico de base, a $25^{\circ} \mathrm{C}$. 
Tabela 4.7 - Quantas vezes $\delta$ virgem aumentou ou diminuiu em relação aos valores referentes ao ligante asfáltico de base, $a^{\circ} \mathrm{C}$

\begin{tabular}{|c|c|c|c|c|c|c|c|c|c|c|c|c|}
\hline \multirow{2}{*}{ amostras } & \multicolumn{11}{|c|}{ frequência $(\mathrm{rad} / \mathrm{s})$} & \multirow{2}{*}{ média } \\
\hline & $10^{-5}$ & $10^{-4}$ & $10^{-3}$ & $10^{-2}$ & $10^{-1}$ & $10^{0}$ & $10^{1}$ & $10^{2}$ & $10^{3}$ & $10^{4}$ & $10^{5}$ & \\
\hline $50 / 70$ & 89,9 & 89,3 & 86,8 & 83,7 & 79,4 & 73,8 & 67,2 & 58,0 & 48,3 & 39,1 & 30,9 & \\
\hline PPA & $-9,0$ & $-13,8$ & $-15,3$ & $-16,5$ & -15 & $-12,7$ & $-9,9$ & $-6,3$ & $-2,7$ & 0,3 & 2,5 & $-8,9$ \\
\hline borracha & $-3,6$ & $-9,1$ & $-15,5$ & $-19,2$ & $-17,4$ & $-13,7$ & $-7,4$ & 0,4 & 6,6 & 10,2 & 10,5 & $-5,3$ \\
\hline $\begin{array}{l}\text { borracha- } \\
\text { PPA }\end{array}$ & $-4,0$ & $-10,5$ & $-16,8$ & $-20,0$ & $-17,8$ & $-14,9$ & $-8,7$ & $-1,4$ & 4,4 & 8,0 & 9,7 & $-6,5$ \\
\hline SBS & $-1,9$ & $-4,0$ & $-8,1$ & $-13,5$ & $-10,2$ & $-7,3$ & $-1,1$ & 2,3 & 3,5 & 4,0 & 4,0 & $-2,9$ \\
\hline SBS-PPA & $-2,7$ & $-8,4$ & $-14,9$ & $-16,4$ & $-12,9$ & $-9,8$ & $-4,4$ & $-0,3$ & 2,7 & 4,3 & 5,1 & $-5,2$ \\
\hline EVA & $-0,3$ & $-1,4$ & $-6,1$ & $-12,6$ & $-13,0$ & $-9,0$ & $-3,0$ & 5,5 & 11,6 & 16,5 & 17,4 & 0,5 \\
\hline EVA-PPA & $-5,6$ & $-10,8$ & $-14,9$ & $-16,1$ & $-15,2$ & $-12,8$ & $-8,8$ & $-2,9$ & 2,8 & 7,0 & 9,2 & $-6,2$ \\
\hline $\mathrm{PE}$ & $-4,4$ & $-4,4$ & $-5,2$ & $-7,5$ & $-8,0$ & $-7,2$ & $-8,0$ & $-7,9$ & $-7,0$ & $-5,9$ & $-4,7$ & $-6,4$ \\
\hline PE-PPA & $-4,4$ & $-7,0$ & $-9,0$ & $-10,2$ & $-9,7$ & $-8,3$ & $-6,9$ & $-4,8$ & $-3,1$ & $-1,8$ & $-1,0$ & $-6,0$ \\
\hline SBR & $-5,3$ & $-9,2$ & $-10,1$ & $-11,4$ & $-10,3$ & $-9,1$ & $-8,7$ & $-7,7$ & $-6,7$ & $-5,7$ & $-4,6$ & $-8,1$ \\
\hline SBR-PPA & $-3,6$ & $-8,8$ & $-10,8$ & $-11,7$ & $-10,1$ & $-8,1$ & $-6,1$ & $-3,8$ & $-1,5$ & $-0,4$ & 0,4 & $-5,9$ \\
\hline
\end{tabular}


Tabela 4.8 - Quantas vezes $\delta$ RTFOT aumentou ou diminuiu em relação aos valores referentes ao ligante asfáltico de base, a $25^{\circ} \mathrm{C}$

\begin{tabular}{|c|c|c|c|c|c|c|c|c|c|c|c|c|}
\hline \multirow{2}{*}{ amostras } & \multicolumn{11}{|c|}{ frequência $(\mathrm{rad} / \mathrm{s})$} & \multirow{2}{*}{ média } \\
\hline & $10^{-5}$ & $10^{-4}$ & $10^{-3}$ & $10^{-2}$ & $10^{-1}$ & $10^{0}$ & $10^{1}$ & $10^{2}$ & $10^{3}$ & $10^{4}$ & $10^{5}$ & \\
\hline $50 / 70$ & 90,0 & 89,6 & 87,8 & 83,8 & 79,1 & 74,0 & 68,5 & 61,7 & 53,1 & 44,4 & 36,3 & \\
\hline PPA & $-17,3$ & $-21,2$ & $-24,5$ & $-22,4$ & $-19,8$ & $-17,4$ & $-14,2$ & $-9,9$ & $-5,2$ & $-0,9$ & 2,4 & $-13,7$ \\
\hline borracha & $-6,3$ & $-14,0$ & $-20,8$ & $-22,4$ & $-20,5$ & $-18,2$ & $-13,7$ & $-9,5$ & $-5,1$ & $-1,6$ & 0,4 & $-12,0$ \\
\hline $\begin{array}{l}\text { borracha- } \\
\text { PPA }\end{array}$ & $-7,7$ & $-16,4$ & $-23,0$ & $-23,0$ & $-20,7$ & $-18,7$ & $-15,2$ & $-10,7$ & $-6,5$ & $-2,8$ & 0,4 & $-13,1$ \\
\hline SBS & $-1,6$ & $-4,5$ & $-11,0$ & $-16,0$ & $-15,1$ & $-10,3$ & $-7,1$ & $-4,5$ & $-3,1$ & $-1,7$ & $-1,5$ & $-6,9$ \\
\hline SBS-PPA & $-3,9$ & $-10,2$ & $-18,1$ & $-21,0$ & $-17,8$ & $-13,8$ & $-10,7$ & $-7,1$ & $-3,2$ & $-0,6$ & 1,7 & $-9,5$ \\
\hline EVA & $-3,1$ & $-8,6$ & $-18,8$ & $-40,6$ & $-33,5$ & $-26,1$ & $-18,5$ & $-14,8$ & $-7,7$ & $-2,2$ & 0,7 & $-15,7$ \\
\hline EVA-PPA & $-16,0$ & $-22,5$ & $-24,8$ & $-24,0$ & $-21,4$ & $-18,0$ & $-15,0$ & $-10,0$ & $-4,6$ & 1,0 & 5,2 & $-13,6$ \\
\hline $\mathrm{PE}$ & $-4,5$ & $-5,6$ & $-6,7$ & $-7,8$ & $-7,6$ & $-8,0$ & $-9,0$ & $-9,6$ & $-9,0$ & $-7,3$ & $-6,0$ & $-7,4$ \\
\hline PE-PPA & $-4,6$ & $-9,1$ & $-13,4$ & $-14,4$ & $-14,2$ & $-12,3$ & $-10,5$ & $-8,3$ & $-5,6$ & $-3,3$ & $-1,8$ & $-8,9$ \\
\hline SBR & $-5,4$ & $-10,9$ & $-14,2$ & $-16,3$ & $-12,7$ & $-10,8$ & $-10,1$ & $-9,5$ & $-8,3$ & $-6,9$ & $-5,7$ & $-10,1$ \\
\hline SBR-PPA & $-12,1$ & $-16,6$ & $-19,4$ & $-18,6$ & $-16,7$ & $-14,4$ & $-12,6$ & $-10,4$ & $-7,2$ & $-4,4$ & $-2,5$ & $-12,3$ \\
\hline
\end{tabular}


Tabela 4.9 - Quantas vezes $\delta$ PAV aumentou ou diminuiu em relação aos valores referentes ao ligante asfáltico de base, a $25^{\circ} \mathrm{C}$

\begin{tabular}{cccccccccccccc}
\hline \multirow{2}{*}{ amostras } & \multicolumn{10}{c}{ frequência $(\mathbf{r a d} / \mathbf{s})$} & \multicolumn{1}{c}{ média } \\
\cline { 2 - 10 } & $\mathbf{1 0}^{-5}$ & $\mathbf{1 0}^{-4}$ & $\mathbf{1 0}^{-3}$ & $\mathbf{1 0}^{-2}$ & $\mathbf{1 0}^{-1}$ & $\mathbf{1 0}^{\mathbf{0}}$ & $\mathbf{1 0}^{\mathbf{1}}$ & $\mathbf{1 0}^{\mathbf{2}}$ & $\mathbf{1 0}^{\mathbf{3}}$ & $\mathbf{1 0}^{\mathbf{4}}$ & $\mathbf{1 0}^{\mathbf{5}}$ & \\
\hline 50/70 & 89,7 & 87,3 & 83,2 & 78,1 & 71,4 & 65,8 & 59,9 & 53,4 & 45,5 & 38,6 & 32,0 & \\
PPA & $-24,3$ & $-27,8$ & $-27,3$ & $-23,3$ & $-18,5$ & $-14,9$ & $-11,3$ & $-7,7$ & $-2,8$ & 0,4 & 3,6 & $-14,0$ \\
borracha & $-16,0$ & $-22,8$ & $-23,7$ & $-21,0$ & $-15,4$ & $-12,1$ & $-7,9$ & $-4,0$ & $-0,4$ & 2,0 & 3,9 & $-10,7$ \\
borracha-PPA & $-25,7$ & $-28,7$ & $-28,5$ & $-24,7$ & $-17,2$ & $-14,0$ & $-11,2$ & $-7,0$ & $-3,2$ & $-0,1$ & 2,7 & $-14,3$ \\
SBS & $-2,8,0$ & $-5,4$ & $-10,9$ & $-14,0$ & $-10,0$ & $-6,7$ & $-4,8$ & $-3,2$ & $-2,5$ & $-1,7$ & $-1,1$ & $-5,7$ \\
SBS-PPA & $-14,6$ & $-21,6$ & $-24,5$ & $-21,2$ & $-15,9$ & $-13,6$ & $-11,2$ & $-8,6$ & $-5,3$ & $-3,2$ & $-1,3$ & $-12,8$ \\
EVA & $-32,0$ & $-33,5$ & $-35,5$ & $-30,6$ & $-24,5$ & $-21,4$ & $-16,2$ & $-11,1$ & $-6,0$ & $-1,0$ & 2,2 & $-19,1$ \\
EVA-PPA & $-25,7$ & $-30,1$ & $-27,7$ & $-23,2$ & $-19,4$ & $-16,4$ & $-13,1$ & $-9,0$ & $-3,4$ & 0,8 & 4,4 & $-14,8$ \\
PE & $-2,8$ & $-3,8$ & $-5,4$ & $-7,1$ & $-6,5$ & $-6,4$ & $-7,2$ & $-8,6$ & $-7,4$ & $-6,3$ & $-5,1$ & $-6,1$ \\
PE-PPA & $-12,3$ & $-17,8$ & $-19,2$ & $-18,1$ & $-14,7$ & $-12,8$ & $-10,9$ & $-8,5$ & $-5,3$ & $-3,0$ & $-1,0$ & $-11,2$ \\
SBR & $-13,7$ & $-16,1$ & $-16,2$ & $-14,7$ & $-11,4$ & $-9,9$ & $-9,0$ & $-8,3$ & $-6,8$ & $-5,5$ & $-4,5$ & $-10,6$ \\
SBR-PPA & $-20,3$ & $-23,1$ & $-22,3$ & $-19,7$ & $-15,2$ & $-13,6$ & $-11,8$ & $-9,1$ & $-6,0$ & $-3,6$ & $-1,7$ & $-13,3$ \\
\hline
\end{tabular}


Tabela 4.10 - Quantas vezes $\delta$ UV $0,68 \mathrm{~W} / \mathrm{m}^{2}$ aumentou ou diminuiu em relação aos valores referentes ao ligante asfáltico de base, a $25^{\circ} \mathrm{C}$

\begin{tabular}{cccccccccccccc}
\hline & \multicolumn{10}{c}{ frequência $(\mathbf{r a d} / \mathbf{s})$} \\
\cline { 2 - 12 } & $\mathbf{1 0}^{-\mathbf{6}}$ & $\mathbf{1 0 ^ { - 5 }}$ & $\mathbf{1 0}^{-4}$ & $\mathbf{1 0}^{-3}$ & $\mathbf{1 0}^{-2}$ & $\mathbf{1 0}^{-1}$ & $\mathbf{1 0}^{\mathbf{0}}$ & $\mathbf{1 0}^{\mathbf{1}}$ & $\mathbf{1 0}^{\mathbf{2}}$ & $\mathbf{1 0}^{\mathbf{3}}$ & $\mathbf{1 0}^{\mathbf{4}}$ & $\mathbf{1 0}^{\mathbf{5}}$ & média \\
\hline 50/70 & 89,2 & 87,8 & 84,0 & 78,4 & 72,6 & 67,0 & 60,7 & 54,2 & 46,0 & 39,0 & 32,4 & 26,7 \\
PPA & $-19,4$ & $-24,2$ & $-25,2$ & $-22,4$ & $-19,0$ & $-15,4$ & $-12,2$ & $-8,6$ & $-4,0$ & $-1,2$ & 1,5 & 2,9 & $-12,3$ \\
borracha & $-36,8$ & $-34,9$ & $-33,4$ & $-27,4$ & $-24,9$ & $-19,0$ & $-16,2$ & $-13,1$ & $-8,7$ & $-4,7$ & $-1,8$ & 0,7 & $-18,3$ \\
borracha-PPA & $-24,4$ & $-29,6$ & $-29,4$ & $-25,7$ & $-19,0$ & $-16,9$ & $-12,2$ & $-7,5$ & $-2,7$ & 0,3 & 2,7 & 4,2 & $-13,4$ \\
SBS & $-5,0$ & $-11,4$ & $-16,9$ & $-14,6$ & $-10,4$ & $-8,2$ & $-6,9$ & $-6,4$ & $-5,3$ & $-4,2$ & $-3,6$ & $-2,9$ & $-8,0$ \\
SBS-PPA & $-9,9$ & $-16,7$ & $-20,5$ & $-19,8$ & $-15,9$ & $-13,8$ & $-11,6$ & $-10,0$ & $-6,9$ & $-4,9$ & $-3,5$ & $-2,4$ & $-11,3$ \\
EVA & $-31,9$ & $-31,7$ & $-34,1$ & $-38,5$ & $-31,1$ & $-23,5$ & $-16,1$ & $-29,2$ & 0,0 & 0,0 & 0,0 & 0,0 & $-19,7$ \\
EVA-PPA & $-13,7$ & $-19,5$ & $-21,0$ & $-19,9$ & $-17,5$ & $-14,3$ & $-10,9$ & $-7,1$ & $-2,2$ & 1,3 & 4,5 & 6,0 & $-9,5$ \\
PE & $-2,4$ & $-4,1$ & $-5,2$ & $-6,5$ & $-7,3$ & $-10,5$ & $-11,8$ & $-11,9$ & $-9,6$ & $-7,3$ & $-5,6$ & $-4,5$ & $-7,2$ \\
PE-PPA & $-6,0$ & $-10,8$ & $-13,6$ & $-13,8$ & $-13,4$ & $-12,6$ & $-11,4$ & $-10,6$ & $-8,1$ & $-6,2$ & $-5,0$ & $-4,0$ & $-9,6$ \\
SBR & $-8,0$ & $-12,3$ & $-12,1$ & $-11,0$ & $-8,5$ & $-6,8$ & $-5,8$ & $-5,9$ & $-4,4$ & $-3,7$ & $-3,4$ & $-3,0$ & $-7,1$ \\
SBR-PPA & $-17,6$ & $-21,3$ & $-20,6$ & $-17,7$ & $-14,6$ & $-12,4$ & $-10,3$ & $-8,7$ & $-5,9$ & $-3,9$ & $-2,6$ & $-1,6$ & $-11,4$ \\
\hline
\end{tabular}


Tabela 4.11 _ Quantas vezes $\delta$ UV $1,00 \mathrm{~W} / \mathrm{m}^{2}$ aumentou ou diminuiu em relação aos valores referentes ao ligante asfáltico de base, a $25^{\circ} \mathrm{C}$

\begin{tabular}{|c|c|c|c|c|c|c|c|c|c|c|c|c|c|}
\hline \multirow{2}{*}{ amostras } & \multicolumn{12}{|c|}{ frequência ( $\mathrm{rad} / \mathrm{s})$} & \multirow{2}{*}{ média } \\
\hline & $10^{-6}$ & $10^{-5}$ & $10^{-4}$ & $10^{-3}$ & $10^{-2}$ & $10^{-1}$ & $10^{0}$ & $10^{1}$ & $10^{2}$ & $10^{3}$ & $10^{4}$ & $10^{5}$ & \\
\hline $50 / 70$ & 89,1 & 87,2 & 82,8 & 77,4 & 71,1 & 65,5 & 59,8 & 52,7 & 44,5 & 37,6 & 31,2 & 25,7 & \\
\hline PPA & $-25,8$ & $-28,5$ & $-27,8$ & $-24,1$ & $-20,1$ & $-16,2$ & $-13,4$ & $-8,8$ & $-4,0$ & $-0,6$ & 2,4 & 3,8 & $-13,6$ \\
\hline borracha & $-40,3$ & $-40,4$ & $-36,1$ & $-34,1$ & $-26,7$ & $-20,1$ & $-18,7$ & $-13,5$ & $-8,7$ & $-4,2$ & $-0,1$ & 2,6 & $-20,0$ \\
\hline borracha-PPA & 0,0 & $-48,1$ & $-46,6$ & $-39,7$ & $-31,0$ & $-28,6$ & $-24,5$ & $-18,4$ & $-13,0$ & $-7,3$ & $-2,3$ & 1,0 & $-21,5$ \\
\hline SBS & $-27,9$ & $-29,1$ & $-27,2$ & $-23,5$ & $-20,4$ & $-18,1$ & $-16,8$ & $-14,1$ & $-10,3$ & $-7,1$ & $-5,0$ & $-3,3$ & $-16,9$ \\
\hline SBS-PPA & $-57,0$ & $-65,0$ & $-52,5$ & $-47,4$ & $-43,3$ & $-38,5$ & $-34,2$ & $-28,4$ & $-20,7$ & $-15,4$ & $-9,7$ & $-5,2$ & $-34,8$ \\
\hline EVA & $-39,0$ & $-40,0$ & $-38,5$ & $-35,0$ & $-36,3$ & $-31,0$ & $-30,6$ & $-22,9$ & $-14,8$ & $-9,4$ & $-5,3$ & 0,0 & $-25,2$ \\
\hline EVA-PPA & $-31,5$ & $-32,6$ & $-29,7$ & $-28,8$ & $-24,1$ & $-20,5$ & $-16,9$ & $-12,0$ & $-7,0$ & $-2,5$ & 1,3 & 3,3 & $-16,8$ \\
\hline PE & $-3,0$ & $-5,0$ & $-6,8$ & $-8,1$ & $-8,8$ & $-11,4$ & $-13,2$ & $-12,1$ & $-9,6$ & $-7,4$ & $-5,7$ & $-4,9$ & $-8,0$ \\
\hline PE-PPA & $-5,2$ & $-9,4$ & $-11,4$ & $-12,3$ & $-11,2$ & $-10,7$ & $-10,7$ & $-9,7$ & $-7,6$ & $-5,8$ & $-4,5$ & $-4,0$ & $-8,5$ \\
\hline SBR & $-8,3$ & $-11,8$ & $-11,8$ & $-10,7$ & $-7,9$ & $-6,0$ & $-5,9$ & $-4,9$ & $-3,6$ & $-2,7$ & $-2,2$ & $-1,9$ & $-6,5$ \\
\hline SBR-PPA & $-31,7$ & $-31,5$ & $-28,8$ & $-24,3$ & $-19,4$ & $-17,4$ & $-15,0$ & $-11,8$ & $-7,6$ & $-4,6$ & $-2,5$ & $-1,4$ & $-16,3$ \\
\hline
\end{tabular}


Como o aumento da elasticidade, expresso pela redução dos valores de $\delta$ do ligante asfáltico, é sempre favorável ao comportamento mecânico da mistura asfáltica, é viável apontar um ordenamento dos materiais, indicando quais formulações proporcionaram maior aumento da elasticidade ao ligante asfáltico de base e quais proporcionaram menos (ou nenhum) aumento da elasticidade. A Tabela 4.12 apresenta tais ordenamentos das amostras virgens e envelhecidas, considerando o posicionamento da melhor para a pior.

Tabela 4.12 - Ordenamento dos ligantes asfálticos modificados em relação ao CAP 50/70 puro, com base nos valores de $\delta$

\begin{tabular}{|c|c|c|c|c|c|c|c|c|c|}
\hline \multicolumn{2}{|c|}{ Virgem } & \multicolumn{8}{|c|}{ Após envelhecimento } \\
\hline & & \multicolumn{2}{|c|}{ RTFOT } & \multicolumn{2}{|c|}{ PAV } & \multicolumn{2}{|c|}{ UV $0,68 \mathrm{~W} / \mathrm{m}^{2}$} & \multicolumn{2}{|c|}{ UV $1,00 \mathrm{~W} / \mathrm{m}^{2}$} \\
\hline PPA & 3,09 & $\begin{array}{c}\text { borracha- } \\
\text { PPA }\end{array}$ & 3,55 & EVA & 2,27 & SBR & 3,58 & SBR & 2,58 \\
\hline SBR & 4,27 & EVA & 4,27 & EVA-PPA & 4,36 & SBS & 4,33 & PPA & 3,25 \\
\hline $\begin{array}{l}\text { borracha- } \\
\text { PPA }\end{array}$ & 4,64 & EVA-PPA & 4,55 & SBR-PPA & 4,64 & EVA-PPA & 4,33 & PE-PPA & 3,83 \\
\hline EVA-PPA & 4,64 & SBR-PPA & 4,55 & $\begin{array}{c}\text { borracha- } \\
\text { PPA }\end{array}$ & 5,09 & $\mathrm{PE}$ & 5,67 & $\mathrm{PE}$ & 4,58 \\
\hline borracha & 5,91 & PPA & 5,00 & PPA & 5,45 & SBR-PPA & 5,67 & EVA-PPA & 5,33 \\
\hline $\mathrm{PE}$ & 6,09 & borracha & 5,55 & SBS-PPA & 5,45 & PE-PPA & 6,00 & SBR-PPA & 5,50 \\
\hline PE-PPA & 6,18 & SBR & 6,27 & SBR & 6,73 & PPA & 6,25 & SBS & 6,33 \\
\hline SBR-PPA & 6,55 & PE & 7,36 & PE-PPA & 7,00 & $\begin{array}{l}\text { borracha- } \\
\text { PPA }\end{array}$ & 6,33 & borracha & 6,75 \\
\hline SBS-PPA & 6,55 & PE-PPA & 7,45 & $\mathrm{PE}$ & 7,45 & SBS-PPA & 6,50 & $\begin{array}{c}\text { borracha- } \\
\text { PPA }\end{array}$ & 7,75 \\
\hline SBS & 8,55 & SBS-PPA & 8,00 & borracha & 8,09 & EVA & 8,17 & EVA & 9,08 \\
\hline EVA & 9,55 & SBS & 9,45 & SBS & 9,45 & borracha & 9,17 & SBS-PPA & 11,00 \\
\hline
\end{tabular}

Analisando a Tabela 4.12, verifica-se que o ligante asfáltico que obteve o melhor posicionamento na condição virgem, no que se refere ao aumento da elasticidade medida por meio do ângulo de fase, foi o CAP+PPA, ou seja, o CAP+PPA sofreu maior aumento de elasticidade, quando comparado ao CAP 50/70 puro. O de pior posicionamento, na condição virgem, foi o CAP+EVA. Pode-se perceber ainda que a adição de ácido polifosfórico nos ligantes asfálticos modificados com polímeros (incluindo a borracha) aumentou a elasticidade 
no caso dos CAPs com borracha, EVA e SBS. Já os CAPs modificados com SBR+PPA e PE+PPA não tiveram ganho de elasticidade tão substancial quanto seus respectivos pares sem PPA.

Quando as amostras foram submetidas aos procedimentos de envelhecimento, o comportamento dos ligantes asfálticos, no que se refere à elasticidade, mudou significativamente. Destacam-se dentre os que sofreram maiores ganhos de elasticidade o $\mathrm{CAP}+$ borracha+PPA, quando envelhecido a curto prazo no RTFO, o CAP+EVA, quando envelhecido a longo prazo no PAV e o $\mathrm{CAP}+\mathrm{SBR}$, quando envelhecido a longo prazo na estufa UV, em ambos os níveis de radiação. Vale lembrar que em relação a G* o CAP+SBR também teve destaque por apresentar o maior aumento da rigidez nos dois níveis de radiação UV. Os que menos sofreram aumento de elasticidade quando envelhecidos foram o $\mathrm{CAP}+\mathrm{SBS}$, quando envelhecido no RTFO e no PAV, o CAP+borracha, quando envelhecido na estufa UV a $0,68 \mathrm{~W} / \mathrm{m}^{2}$, e o $\mathrm{CAP}+\mathrm{SBS}+\mathrm{PPA}$, quando envelhecido na estufa UV a 1,00 $\mathrm{W} / \mathrm{m}^{2}$.

Com base nos itens destacados anteriormente, as seguintes conclusões podem ser listadas:

- Os efeitos das modificações impostas se expressam pelos desvios das curvas-mestre dos ligantes asfálticos modificados em relação à curva-mestre do CAP puro;

- embora todos os ligantes asfálticos apresentem o mesmo grau de desempenho, cada modificador afeta o comportamento reológico do ligante asfáltico de base de uma maneira particular;

- a principal alteração do comportamento reológico dos materiais é o aumento da rigidez nas frequências baixas (correspondentes às temperaturas altas), visível tanto nas amostras virgens quanto nas envelhecidas a curto e a longo prazos, exceto para a formulação CAP+EVA na condição virgem; na condição de baixas frequências, notouse um aumento de rigidez bastante acentuado para o CAP+borracha+PPA e o CAP+SBS+PPA após envelhecimento UV a 1,00 W/m²;

- nas temperaturas baixas (correspondentes às frequências altas), o efeito das modificações é menos efetivo, notando-se equivalência entre os valores de $\mathrm{G}^{*}$ dos ligantes asfálticos modificados e do CAP puro; no entanto, algumas amostras não apresentaram tal equivalência tanto na condição virgem, quanto nas condições 
envelhecidas (em todos os níveis), como o CAP+borracha, o CAP+borracha+PPA e o CAP+EVA; outras amostras apresentaram tal equivalência na condição virgem, porém quando envelhecidas os valores de $\mathrm{G}^{*}$ foram menores, como no caso do $\mathrm{CAP}+\mathrm{SBR}$ (RTFOT e UV, nos dois níveis de radiação), do CAP+SBR+PPA (PAV e $\mathrm{UV}$ a $1,00 \mathrm{~W} / \mathrm{m}^{2}$ ) e do CAP+EVA+PPA (UV a $\left.0,68 \mathrm{~W} / \mathrm{m}^{2}\right)$;

- a aditivação com os modificadores aqui estudados contribui, de maneira geral, com o aumento da resistência à deformação permanente das misturas asfálticas, dado o aumento substancial da rigidez dos ligantes asfálticos modificados nas temperaturas altas e também ao ligeiro ganho de elasticidade expresso pela redução dos valores de ângulo de fase;

- no que se refere à resistência ao trincamento de origem térmica, as curvas-mestre também apontam que nenhum prejuízo foi imposto ao ligante asfáltico de base pelas aditivações e que, em alguns casos, tal resistência foi incrementada, dada a redução da rigidez nas frequências altas, em particular para as amostras envelhecidas a longo prazo;

- a resistência à fadiga por deformação controlada pode ser prejudicada pelo enrijecimento excessivo do ligante asfáltico e, neste sentido, as amostras foram ordenadas das que menos enrijeceram para as que mais enrijeceram (os ordenamentos consideraram todo o espectro de frequências, a $25^{\circ} \mathrm{C}$ ); verificou-se que o ligante asfáltico modificado que sofreu menor enrijecimento pela adição dos modificadores, na condição virgem, quando comparado ao CAP 50/70 puro, foi o $\mathrm{CAP}+\mathrm{EVA}$; no sentido contrário, a amostra que mais enrijeceu foi o $\mathrm{CAP}+\mathrm{PE}$; quando as amostras foram submetidas aos procedimentos de envelhecimento, o comportamento dos ligantes asfálticos, no que se refere à rigidez, mudou expressivamente; destacam-se dentre os que menos enrijeceram o CAP+borracha (RTFOT e PAV) e o CAP+SBR (UV, nos dois níveis de radiação); os que sofreram maior aumento da rigidez quando envelhecidos foram o CAP+PPA (RTFOT), o CAP+SBR (PAV), o CAP+PE+PPA (UV a $0,68 \mathrm{~W} / \mathrm{m}^{2}$ ) e o CAP+SBS+PPA (UV a $1,00 \mathrm{~W} / \mathrm{m}^{2}$ );

- as aditivações, de maneira geral, provocaram aumento da elasticidade do ligante asfáltico de base, indicado pela redução dos valores de $\delta$ dos ligantes asfálticos modificados, tanto na condição virgem quanto nas envelhecidas; 
- em alguns casos, os ajustes das curvas-mestre de $\delta$ não são bons, o que pode indicar algum desvio do princípio de superposição tempo-temperatura das amostras analisadas;

- o aumento da elasticidade é favorável ao aumento das resistências à deformação permanente, à fadiga e ao trincamento de origem térmica das misturas asfálticas e, neste sentido, as amostras foram ordenadas considerando que maiores aumentos de $\delta$ (em módulo) equivalem à melhor condição, e menores aumentos de $\delta$ (em módulo) à pior condição; na condição virgem, destacou-se o CAP+PPA, com o melhor posicionamento, e o CAP+EVA, com o pior posicionamento; quando envelhecidas, destacam-se dentre os que sofreram maiores ganhos de elasticidade 0 CAP+borracha+PPA (RTFOT), o CAP+EVA (PAV) e o CAP+SBR (UV, nos dois níveis de radiação); os que menos sofreram aumento de elasticidade quando envelhecidos foram o CAP+SBS (RTFOT e PAV), o CAP+borracha (UV a 0,68 $\mathrm{W} / \mathrm{m}^{2}$ ), e o CAP+SBS+PPA (UV a $\left.1,00 \mathrm{~W} / \mathrm{m}^{2}\right)$;

- ao se comparar o nível de enrijecimento sofrido por um dado ligante asfáltico modificado com o enrijecimento sofrido pelo seu par aditivado com PPA (por meio das médias ao longo do espectro de frequências, a $25^{\circ} \mathrm{C}$ ), observa-se que a adição de ácido polifosfórico (PPA) nos ligantes asfálticos modificados resultou, de uma maneira geral, em aumento da rigidez, exceto no caso do CAP+PE (condição virgem), do CAP+SBR (condição virgem e envelhecida no PAV), do CAP+borracha (envelhecido no UV a 0,68 W/m²) e do CAP+EVA (envelhecido nos dois níveis de UV); e

- em termos da contribuição do PPA para o ganho de elasticidade (considerando a média das maiores reduções dos valores de $\delta$ obtidos a $25^{\circ} \mathrm{C}$ ) dos materiais virgens, envelhecidos a curto prazo e envelhecidos a longo prazo, observa-se que todas as formulações com polímero (incluindo a borracha) apresentaram aumento de elasticidade com a adição de PPA, à exceção do $\mathrm{CAP}+\mathrm{PE}$ e do $\mathrm{CAP}+\mathrm{SBR}$ (condição virgem), do CAP+EVA (em todas as condições envelhecidas) e do CAP+borracha (envelhecido no UV a $0,68 \mathrm{~W} / \mathrm{m}^{2}$ ). 
4.2.2. Efeito dos diferentes níveis de envelhecimento sobre a rigidez e a elasticidade dos ligantes asfálticos

As Figuras de 4.10 a 4.21 mostram o efeito dos envelhecimentos a curto prazo (RTFOT) e a longo prazos (PAV e UV) sobre os valores de $\mathrm{G}^{*}$, em comparação com as amostras virgens, das amostras 50/70 puro, 50/70-PPA, 50/70-borracha, 50/70-borracha-PPA, 50/70-SBS, 50/70-SBS-PPA, 50/70-EVA, 50/70-EVA-PPA, 50/70-PE, 50/70-PE-PPA, 50/70SBR, 50/70-SBR-PPA, respectivamente.

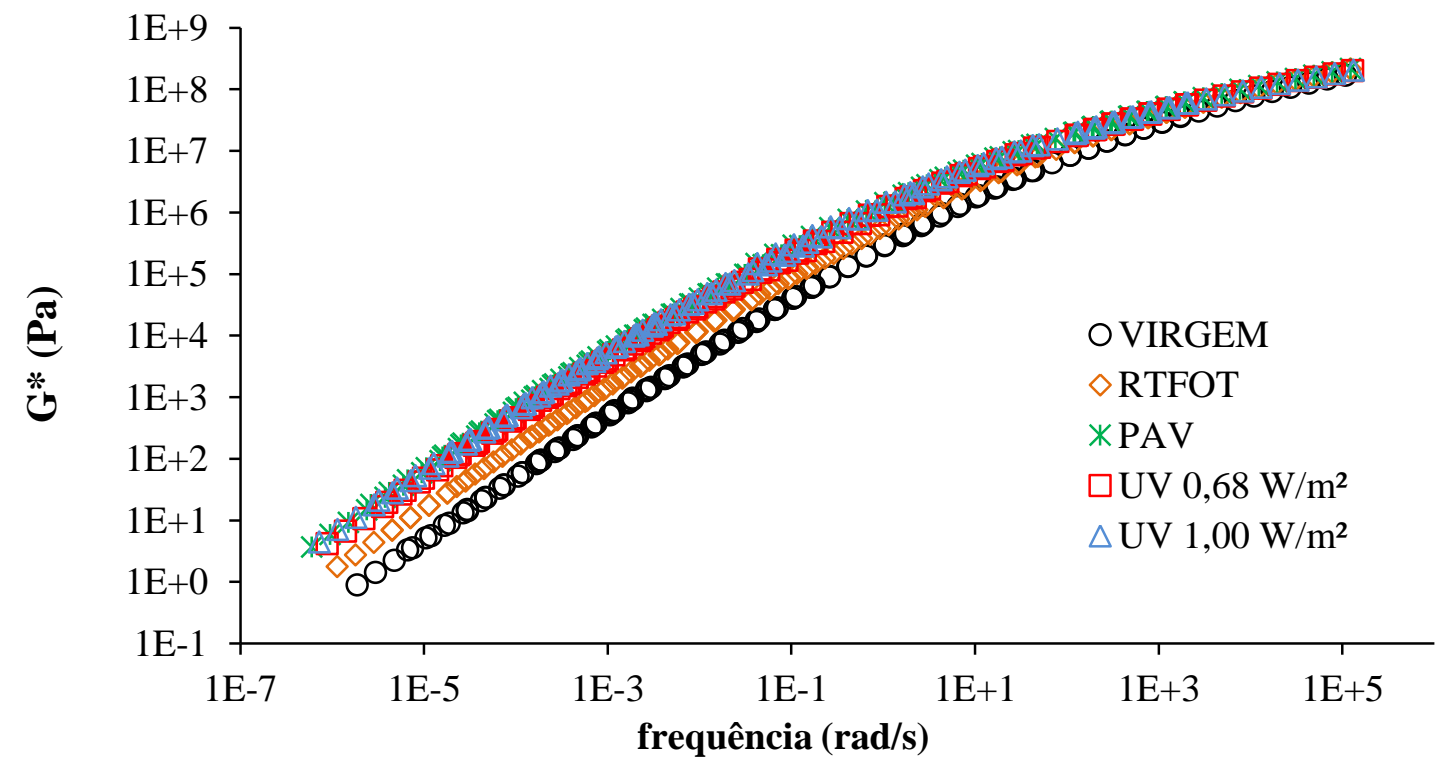

Figura 4.10 - Efeito dos envelhecimentos a curto prazo no RTFO e a longo prazo nas estufas PAV e UV sobre G*: CAP 50/70 puro 


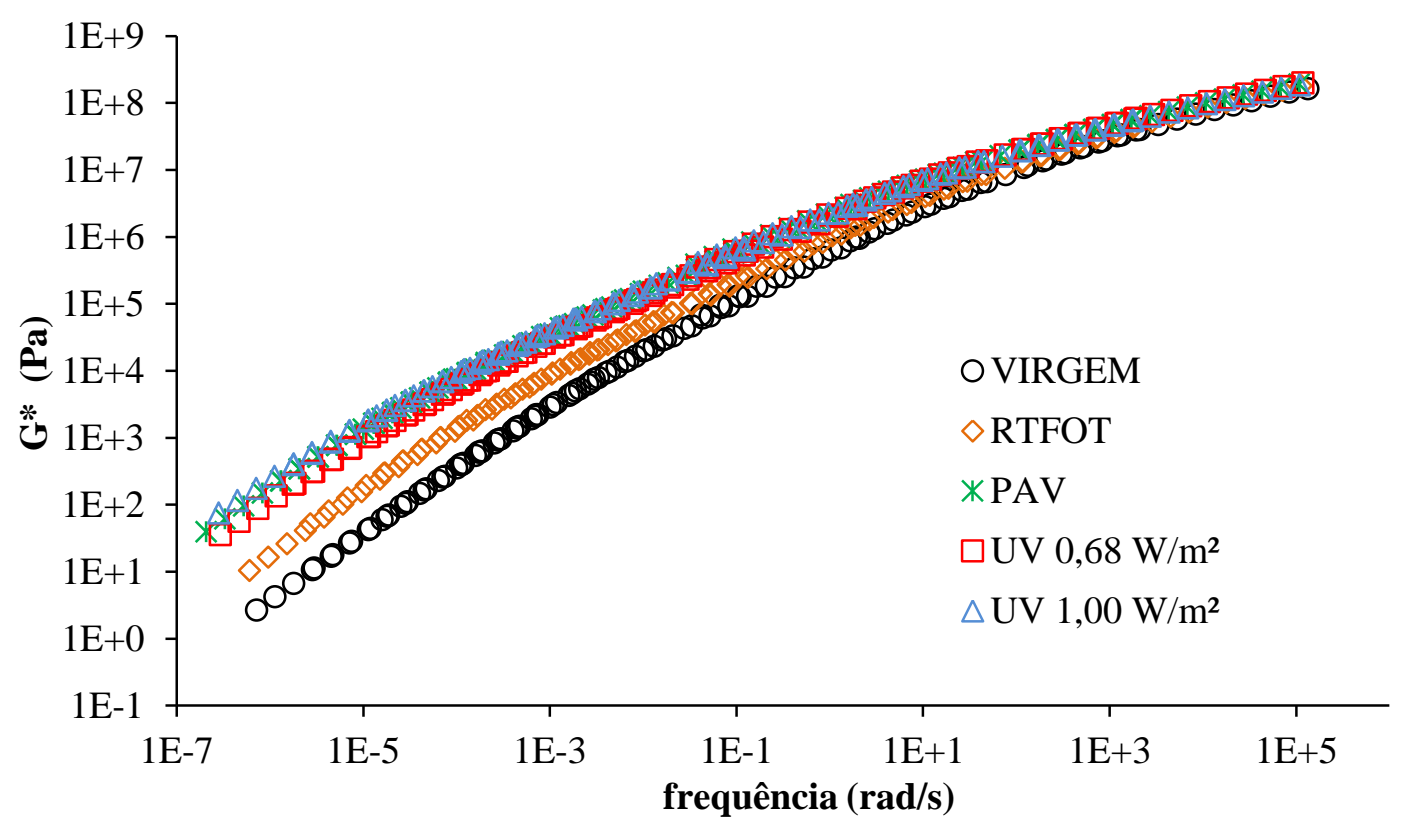

Figura 4.11 - Efeito dos envelhecimentos a curto prazo no RTFO e a longo prazo nas estufas PAV e UV sobre G*: CAP 50/70+PPA

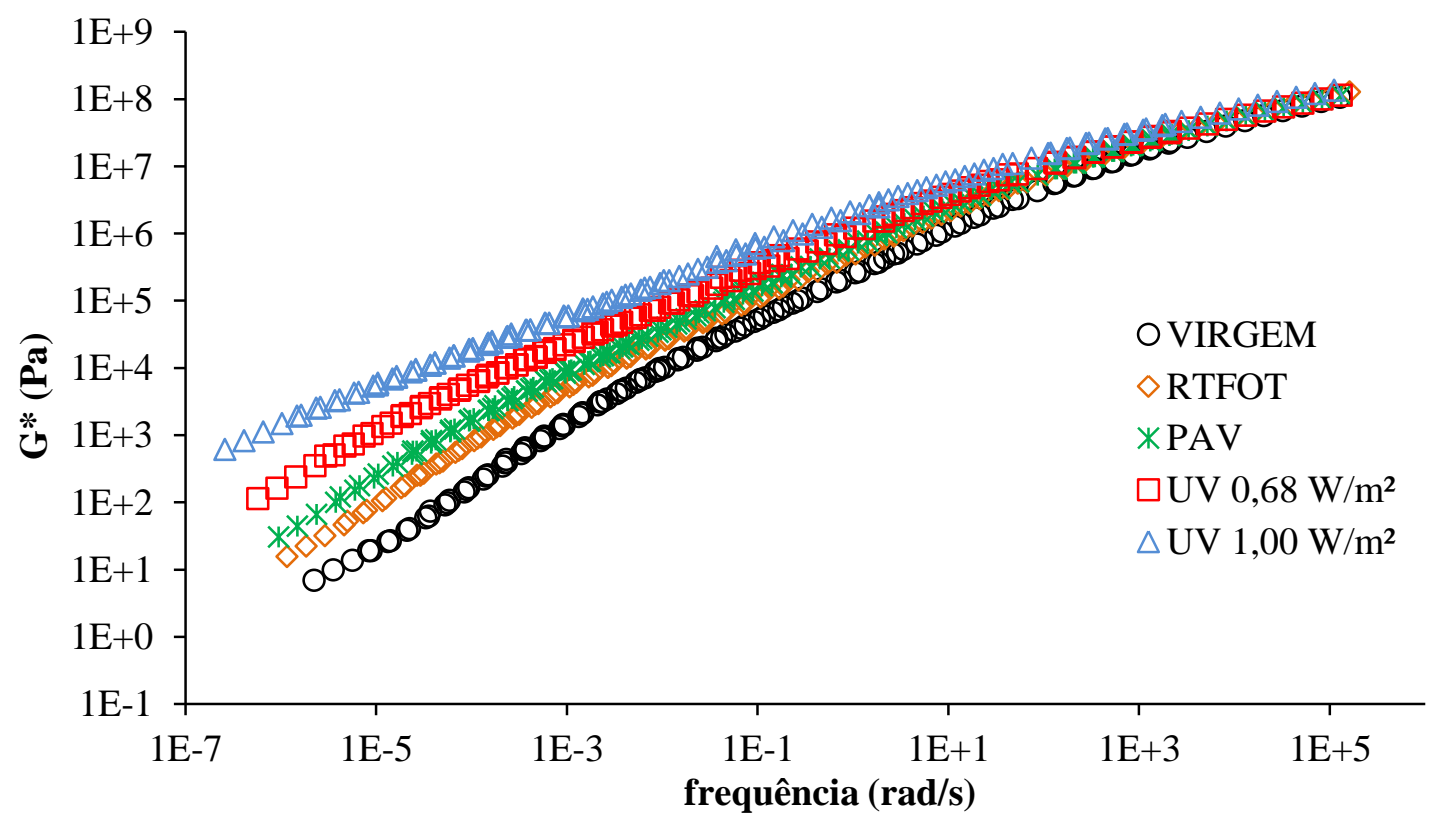

Figura 4.12 - Efeito dos envelhecimentos a curto prazo no RTFO e a longo prazo nas estufas PAV e UV sobre G*: CAP 50/70+borracha 


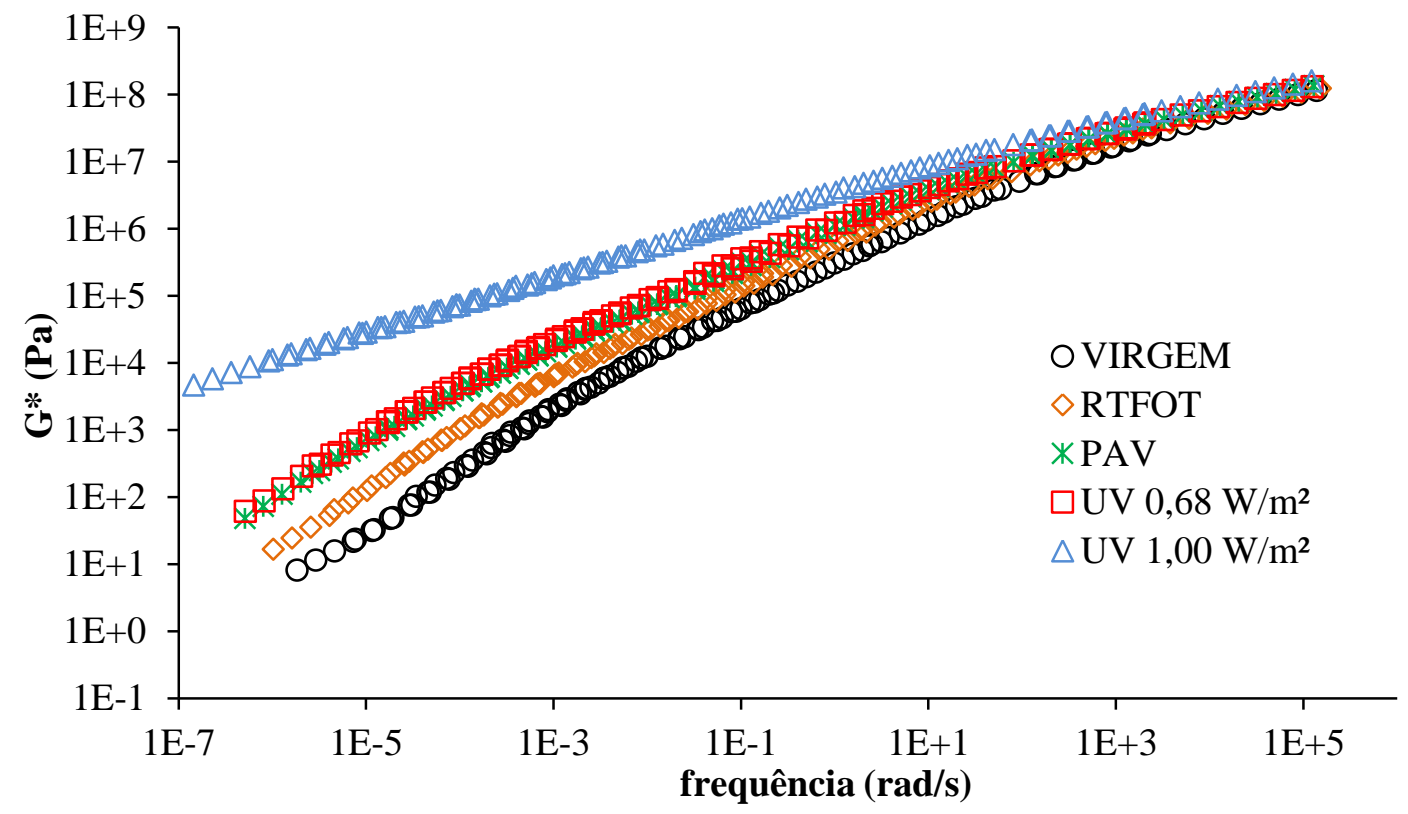

Figura 4.13 - Efeito dos envelhecimentos a curto prazo no RTFO e a longo prazo nas estufas PAV e UV sobre G*: CAP 50/70+borracha+PPA

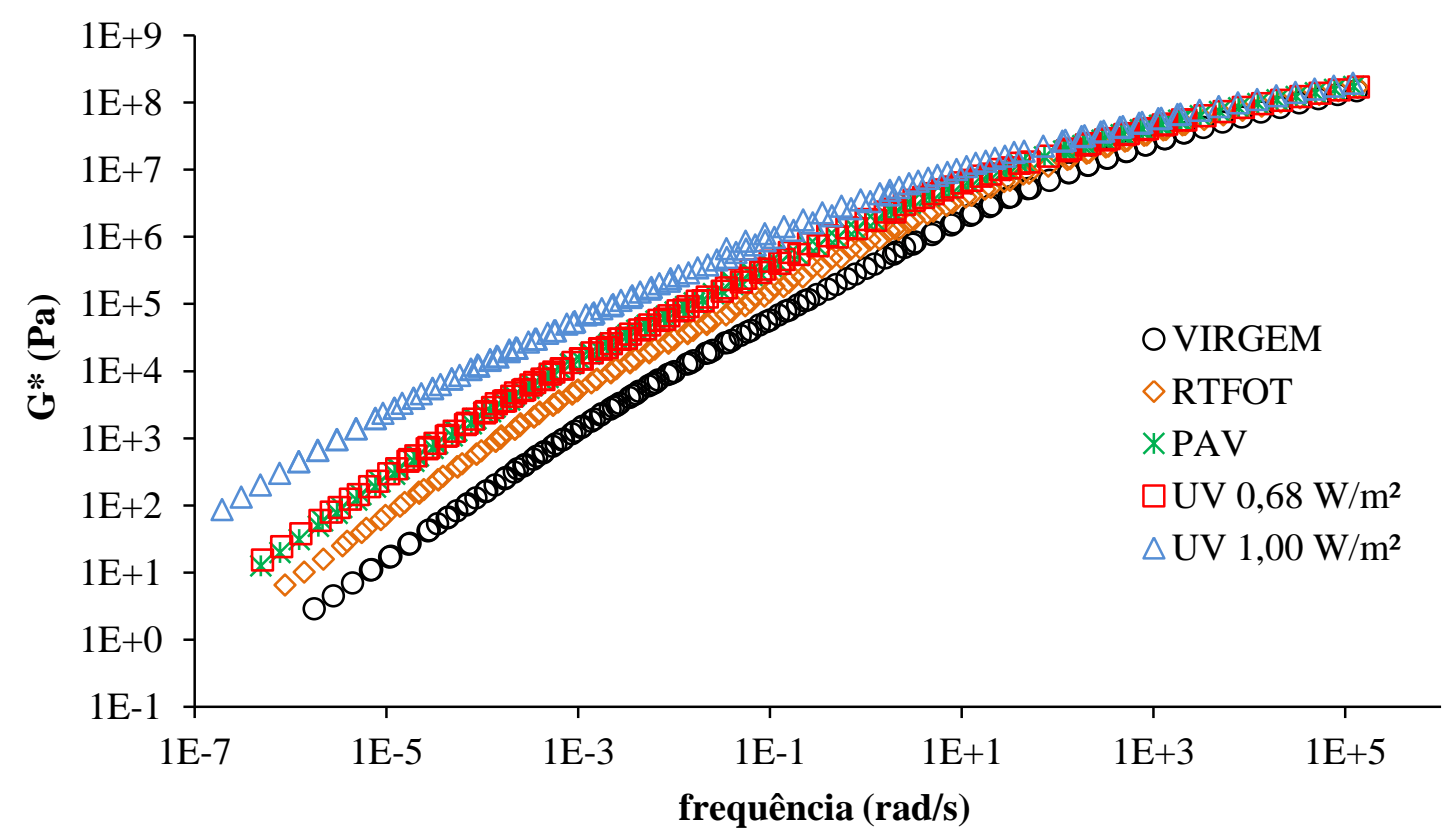

Figura 4.14 - Efeito dos envelhecimentos a curto prazo no RTFO e a longo prazo nas estufas PAV e UV sobre G*: CAP 50/70+SBS 


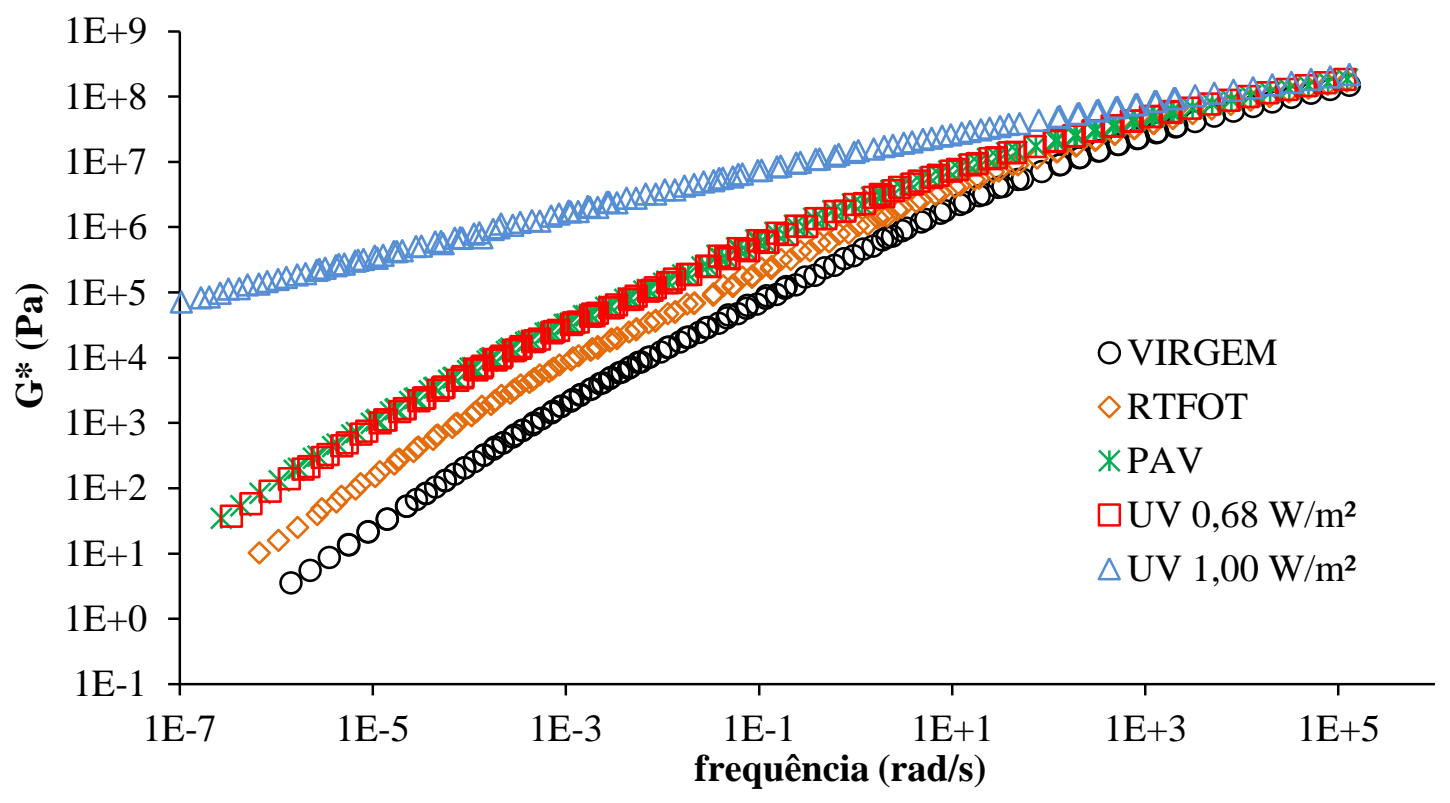

Figura 4.15 -Efeito dos envelhecimentos a curto prazo no RTFO e a longo prazo nas estufas PAV e UV sobre G*: CAP 50/70+SBS+PPA

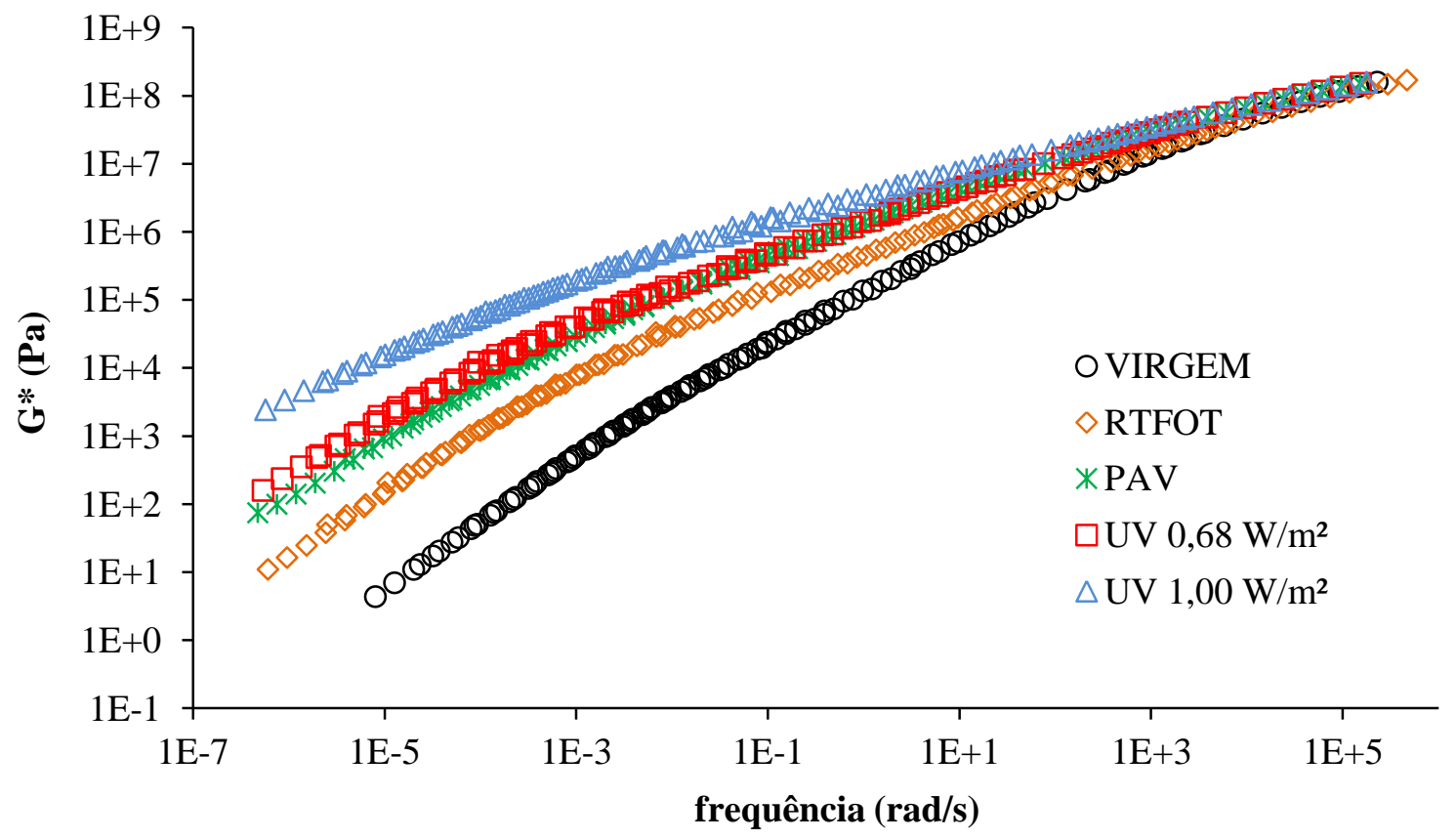

Figura 4.16 -Efeito dos envelhecimentos a curto prazo no RTFO e a longo prazo nas estufas PAV e UV sobre G*: CAP 50/70+EVA 


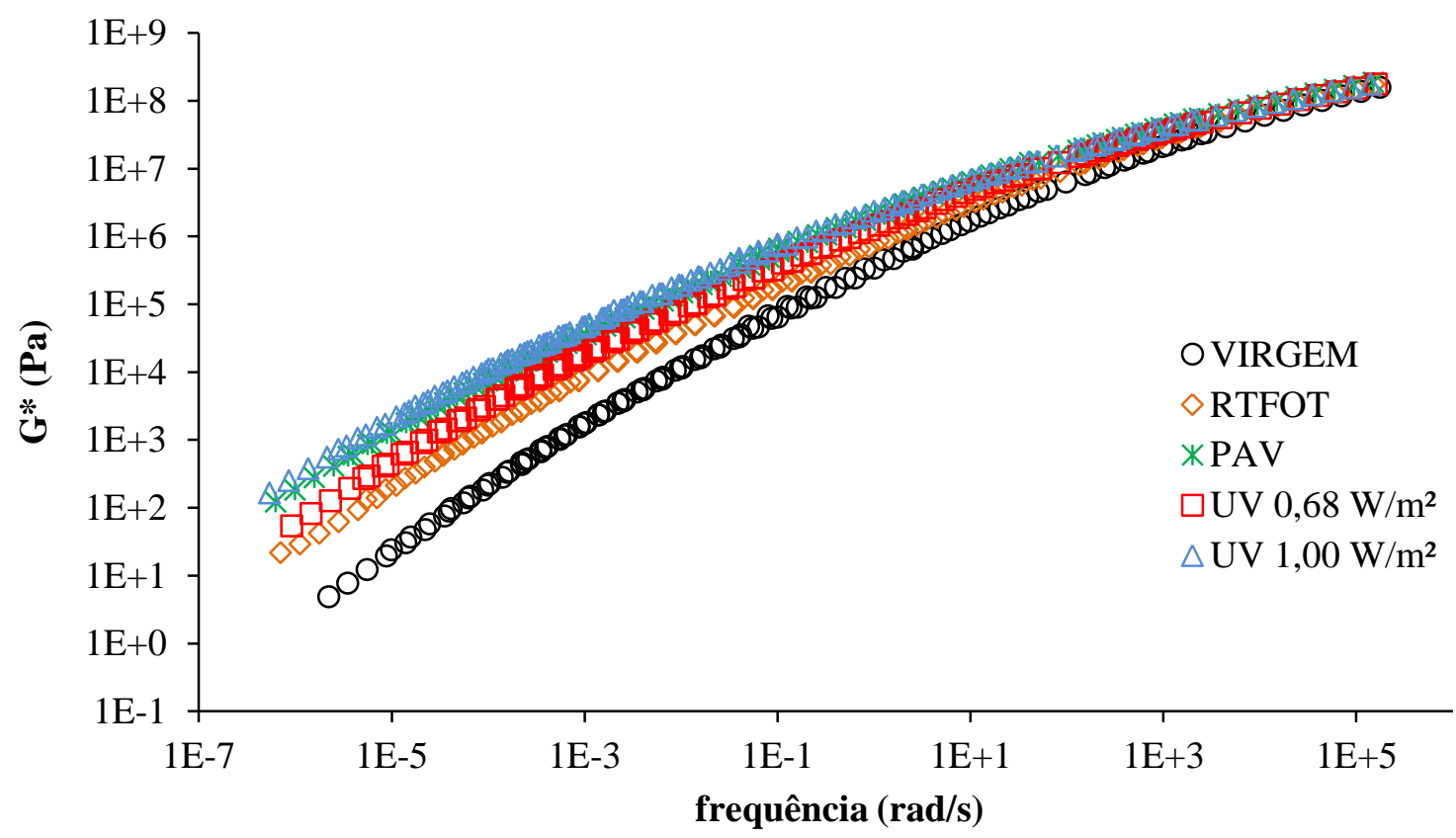

Figura 4.17 - Efeito dos envelhecimentos a curto prazo no RTFO e a longo prazo nas estufas PAV e UV sobre G*: CAP 50/70+EVA+PPA

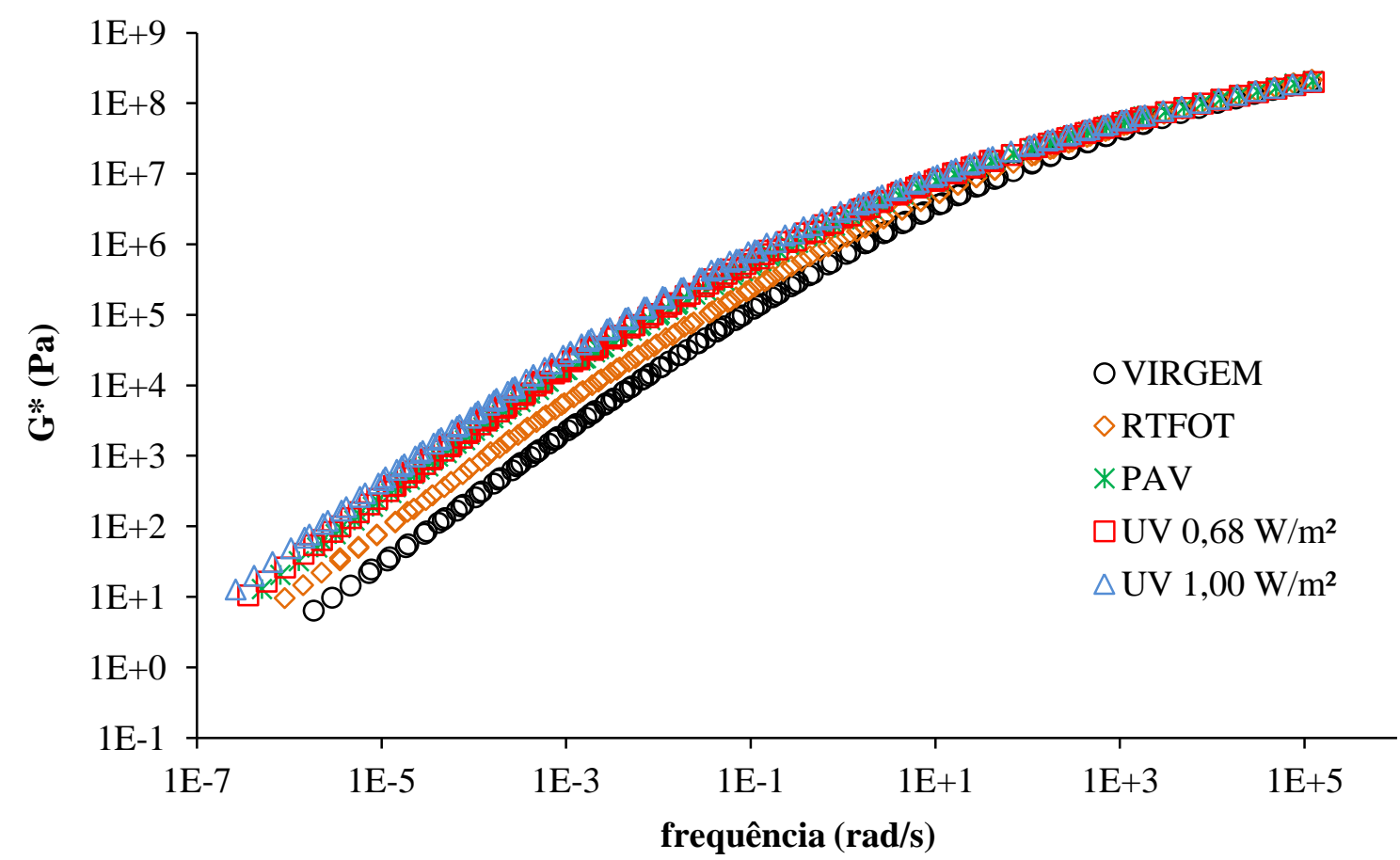

Figura 4.18 - Efeito dos envelhecimentos a curto prazo no RTFO e a longo prazo nas estufas PAV e UV sobre G*: CAP 50/70+PE 


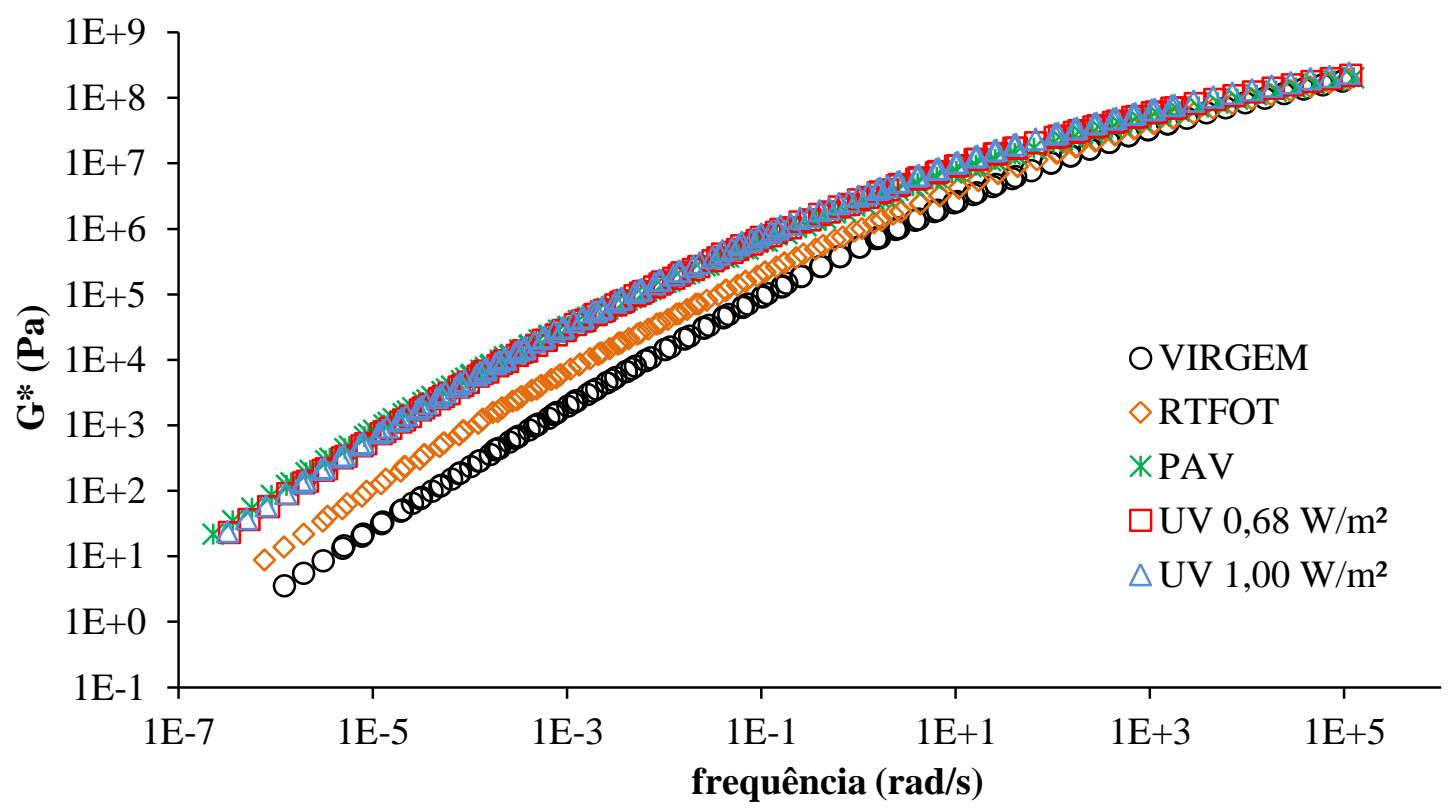

Figura 4.19 - Efeito dos envelhecimentos a curto prazo no RTFO e a longo prazo nas estufas PAV e UV sobre G*: CAP 50/70+PE+PPA

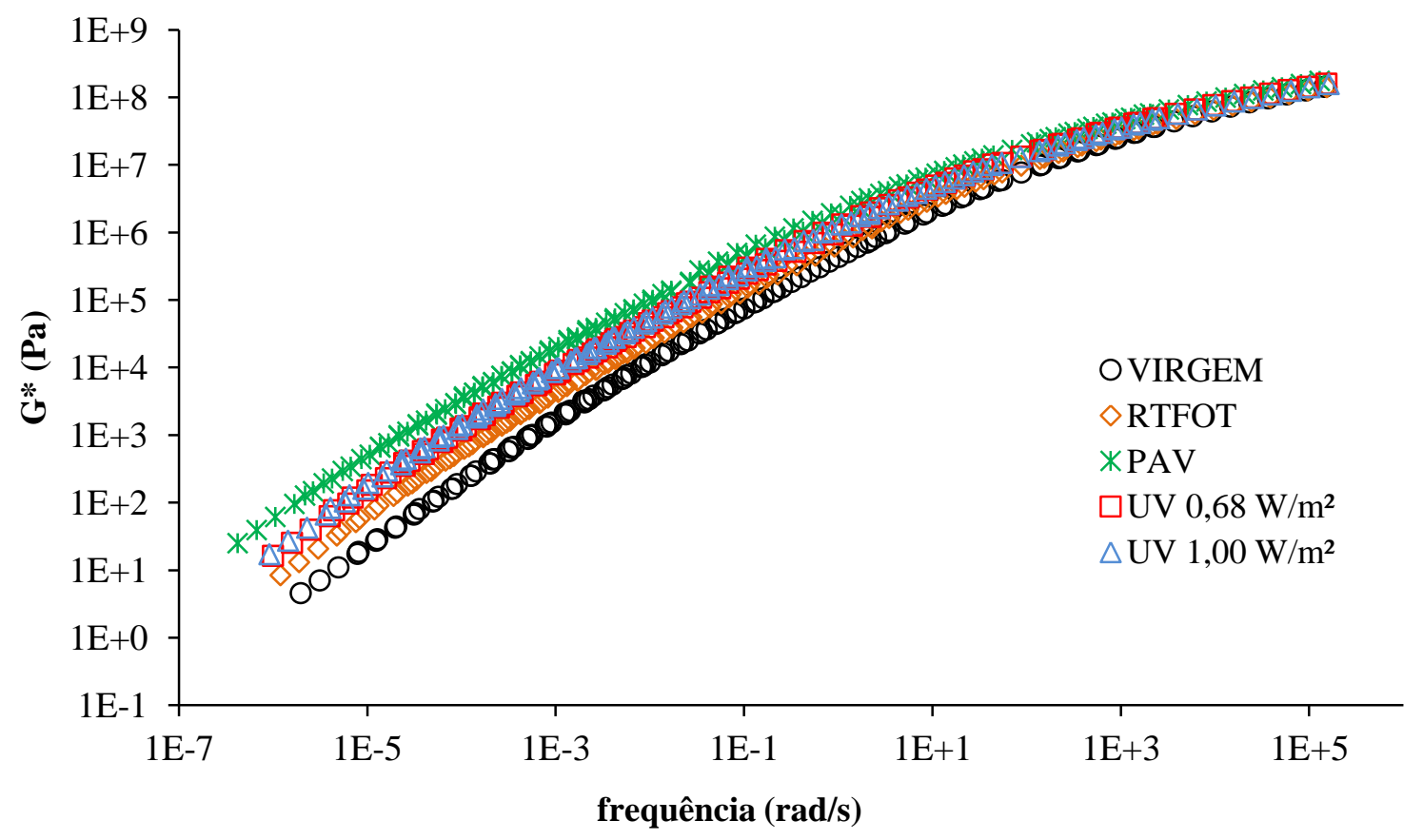

Figura 4.20 - Efeito dos envelhecimentos a curto prazo no RTFO e a longo prazo nas estufas PAV e UV sobre G*: CAP 50/70+SBR 


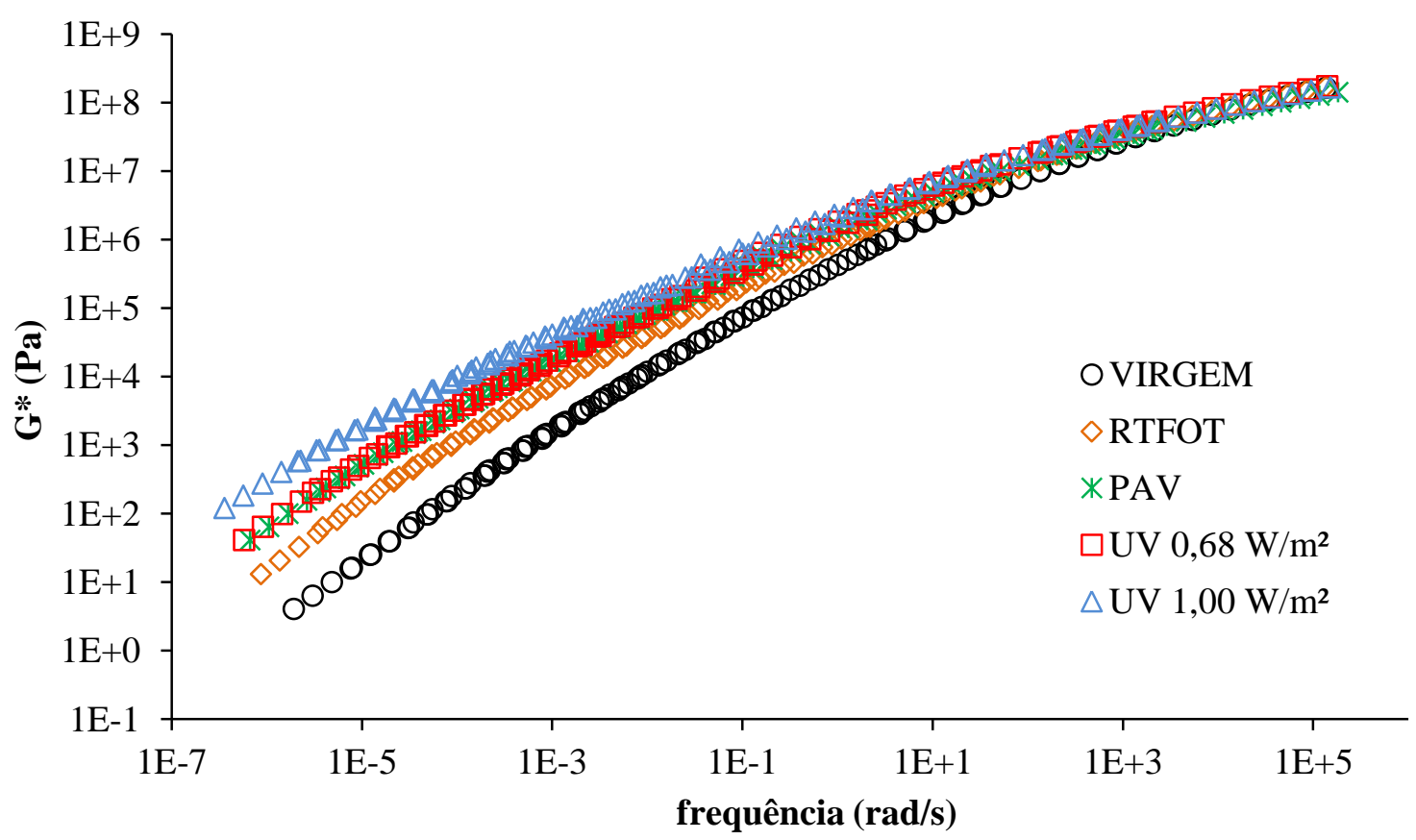

\section{Figura 4.21 - Efeito dos envelhecimentos a curto prazo no RTFO e a longo prazo nas estufas PAV e UV sobre G*: CAP 50/70+SBR+PPA}

A principal alteração do comportamento reológico dos materiais é o aumento da rigidez nas frequências baixas (correspondentes às temperaturas altas), visível tanto nas amostras envelhecidas a curto prazo quanto nas envelhecidas a longo prazo. Nas temperaturas baixas (correspondentes às frequências altas), o efeito dos níveis de envelhecimento é menos efetivo, notando-se equivalência entre os valores de $\mathrm{G}^{*}$ dos ligantes asfálticos virgens e envelhecidos nas quatro condições. $\mathrm{O}$ envelhecimento é responsável por alterações substanciais do comportamento reológico dos materiais, com maior ou menor intensidade, dependendo da formulação.

No geral, nas frequências baixas, o módulo complexo $\left(\mathrm{G}^{*}\right)$ dos materiais envelhecidos a curto prazo no RTFOT sofre aumento com relação ao CAP virgem, mas não mais que os CAPs envelhecidos a longo prazos, o que era esperado. Em algumas curvasmestre de $\mathrm{G}^{*}$ ficou claro que, nas frequências baixas, os ligantes asfálticos que mais enrijeceram foram os CAPs envelhecidos a longo prazo na estufa UV a $1,00 \mathrm{~W} / \mathrm{m}^{2}$, no caso dos CAPs modificados com borracha, borracha+PPA, SBS, SBS+PPA, EVA e SBR+PPA.

As Figuras de 4.22 a 4.33 mostram o efeito dos envelhecimentos a curto e a longo prazo sobre os valores de $\delta$, em comparação com as amostras virgens, das amostras 50/70 
puro, 50/70-PPA, 50/70-borracha, 50/70-borracha-PPA, 50/70-SBS, 50/70-SBS-PPA, 50/70EVA， 50/70-EVA-PPA， 50/70-PE， 50/70-PE-PPA， 50/70-SBR， 50/70-SBR-PPA, respectivamente.

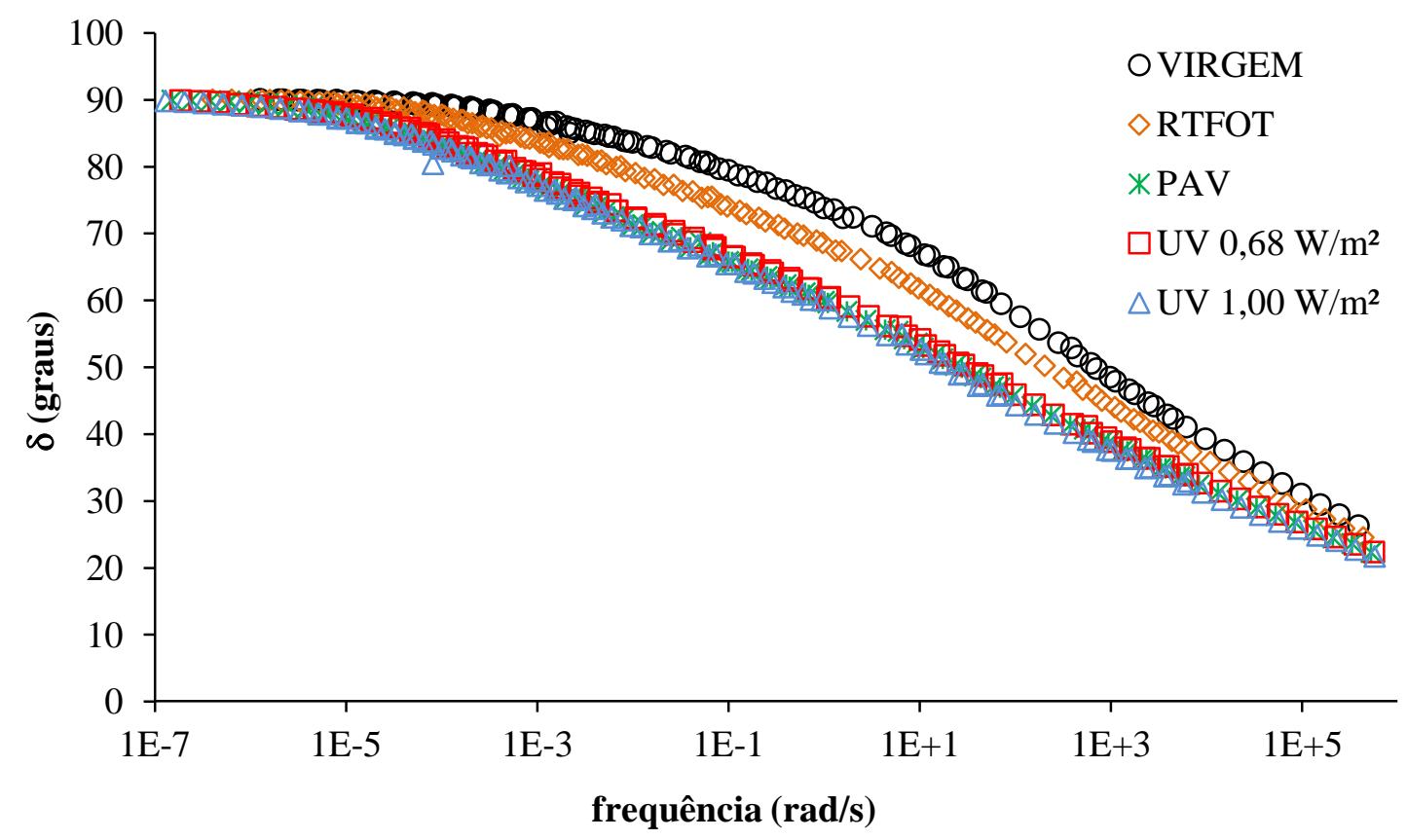

Figura 4.22 - Efeito dos envelhecimentos a curto prazo no RTFO e a longo prazo nas estufas PAV e UV sobre $\delta:$ CAP 50/70 puro

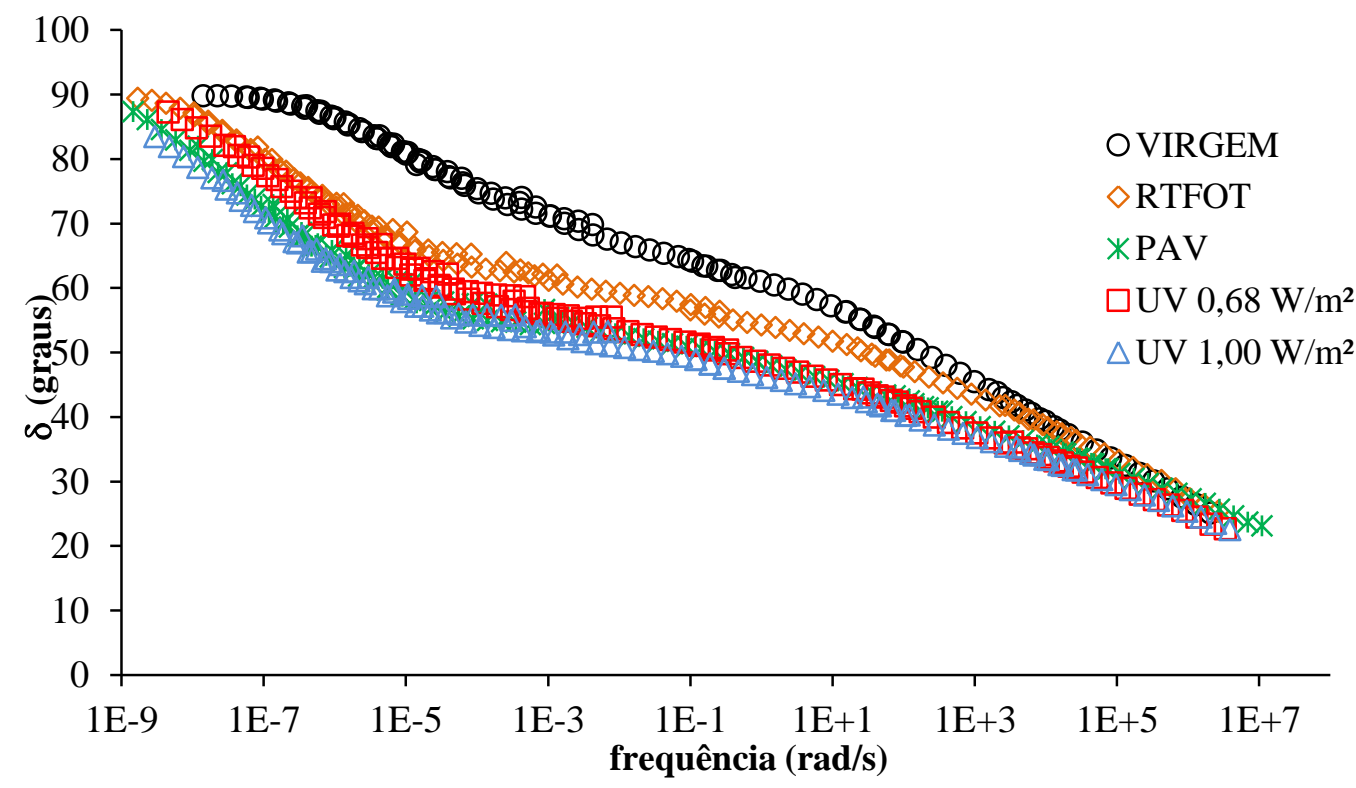

Figura 4.23 - Efeito dos envelhecimentos a curto prazo no RTFO e a longo prazo nas estufas PAV e UV sobre $\delta$ : CAP 50/70+PPA 


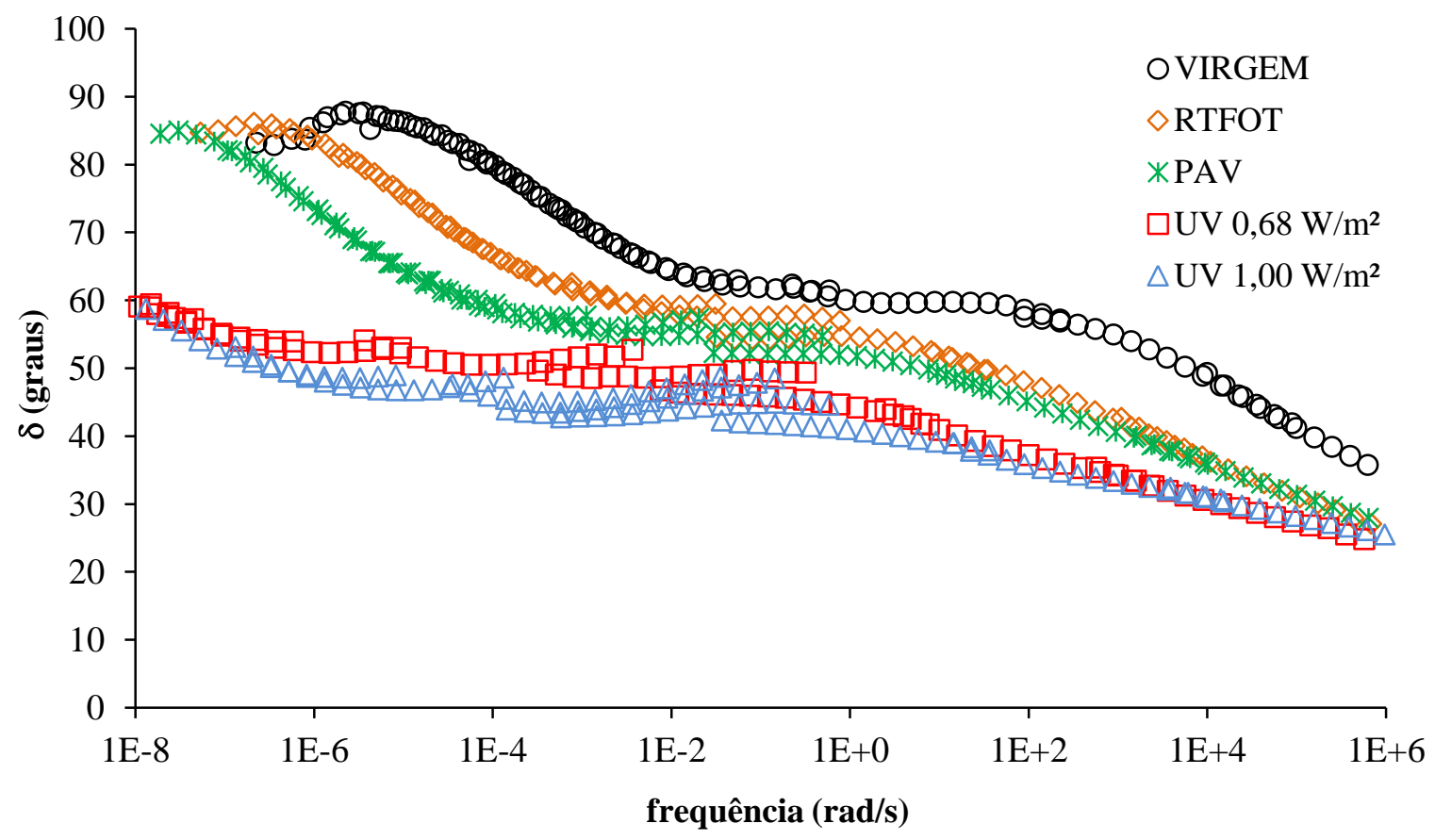

Figura 4.24 - Efeito dos envelhecimentos a curto prazo no RTFO e a longo prazo nas estufas PAV e UV sobre $\delta$ : CAP 50/70+borracha

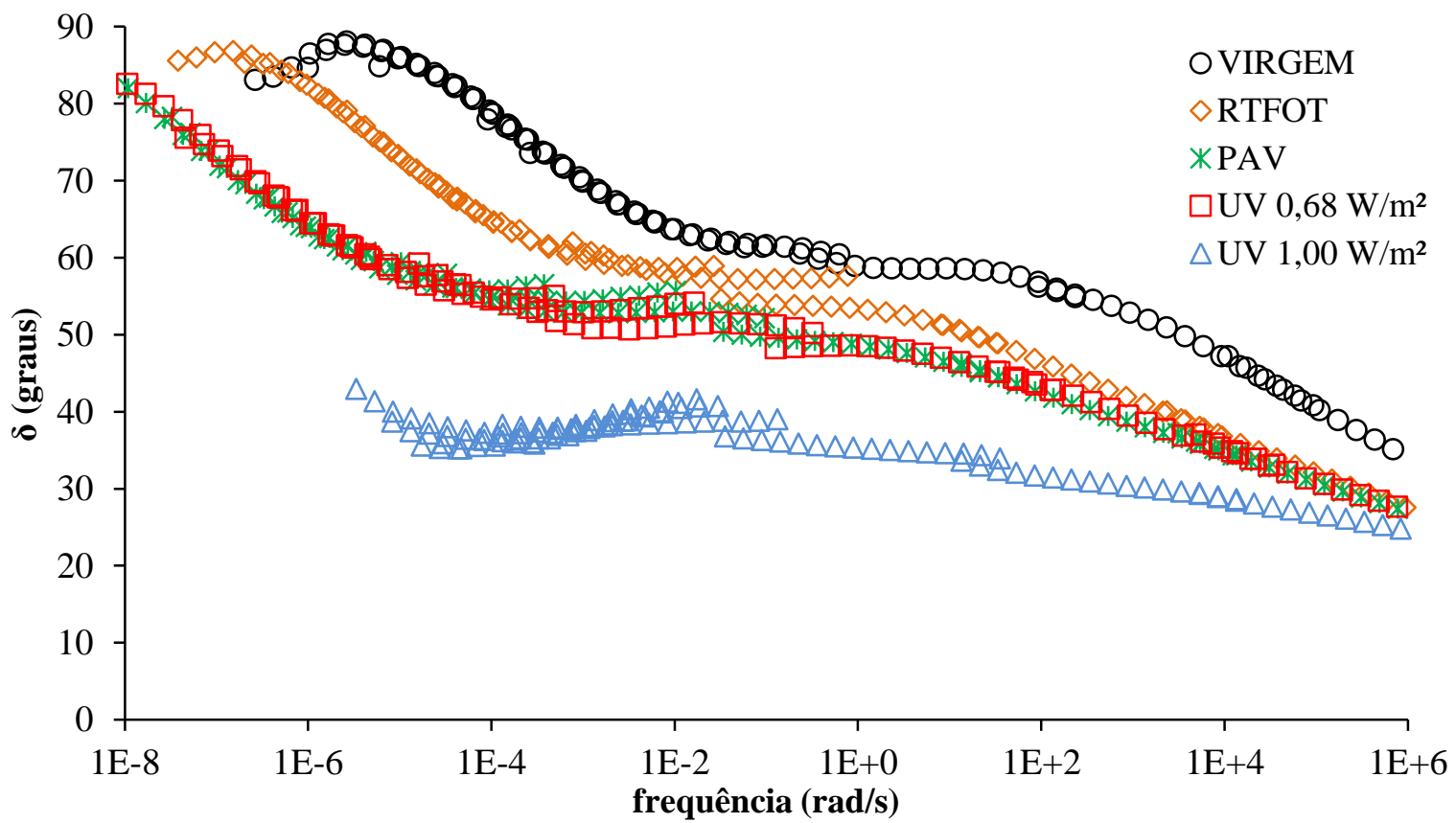

Figura 4.25 - Efeito dos envelhecimentos a curto prazo no RTFO e a longo prazo nas estufas PAV e UV sobre $\delta$ : CAP 50/70+borracha+PPA 


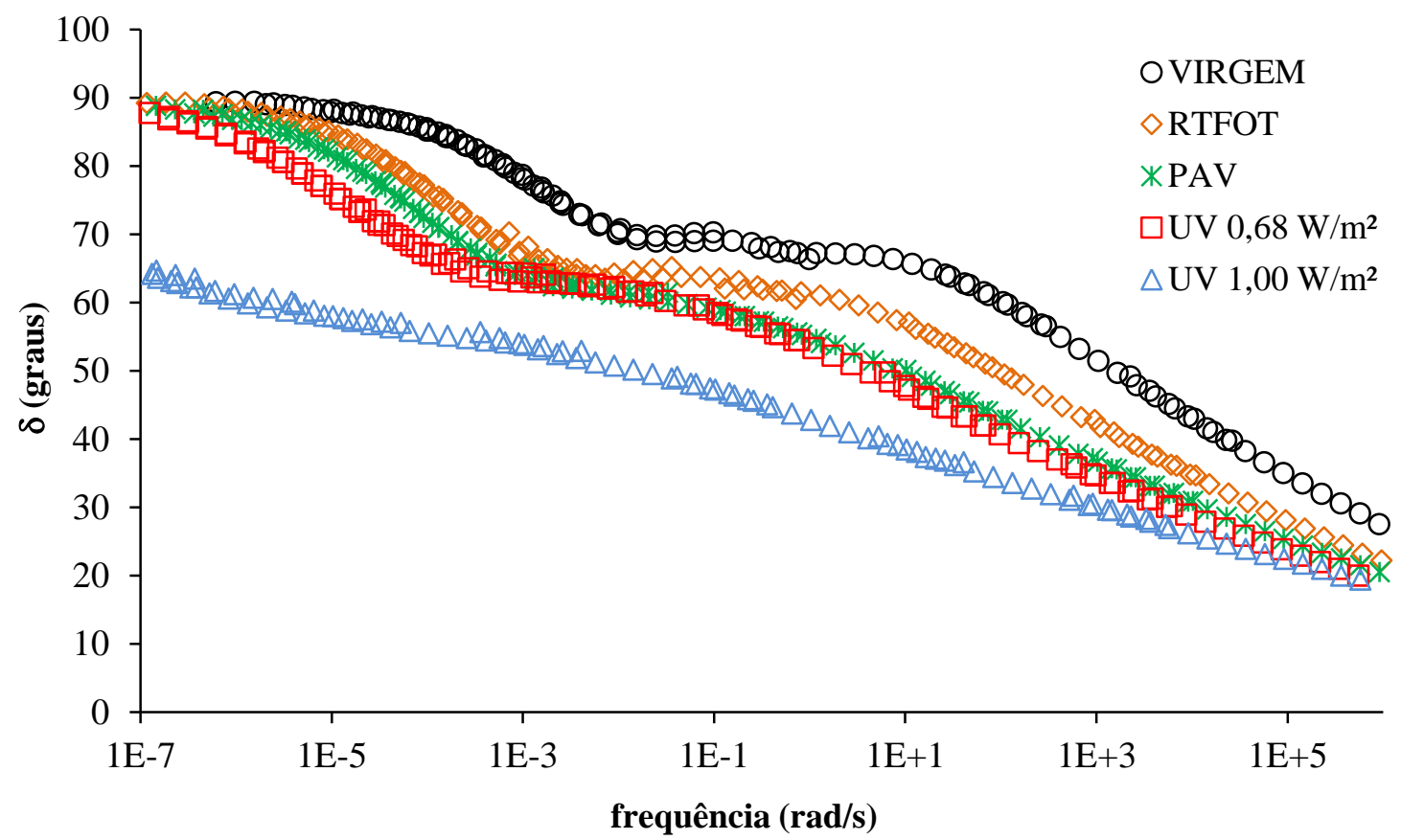

Figura 4.26 - Efeito dos envelhecimentos a curto prazo no RTFO e a longo prazo nas estufas PAV e UV sobre $\delta$ : CAP 50/70+SBS

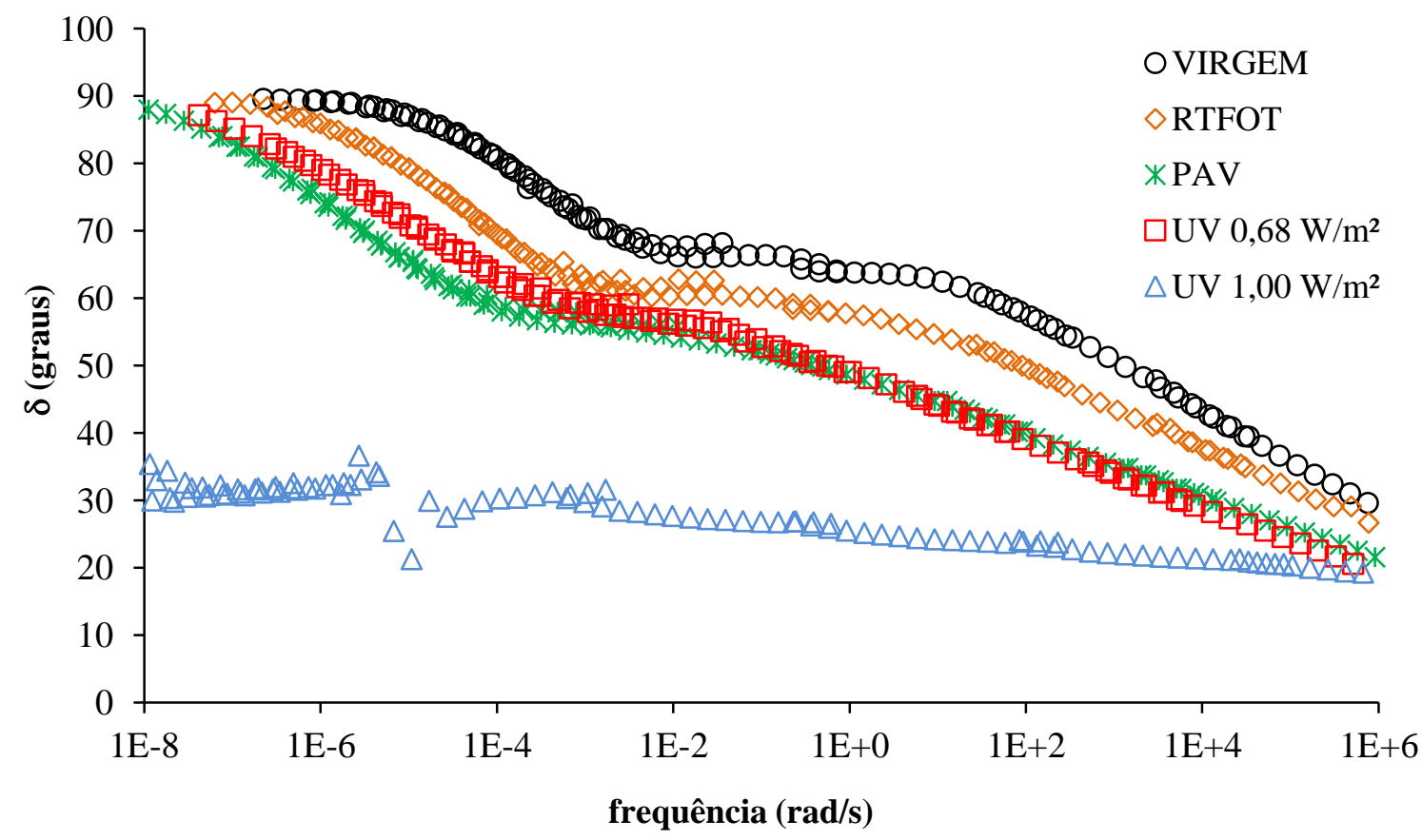

Figura 4.27 - Efeito dos envelhecimentos a curto prazo no RTFO e a longo prazo nas estufas PAV e UV sobre $\delta$ : CAP 50/70+SBS+PPA 


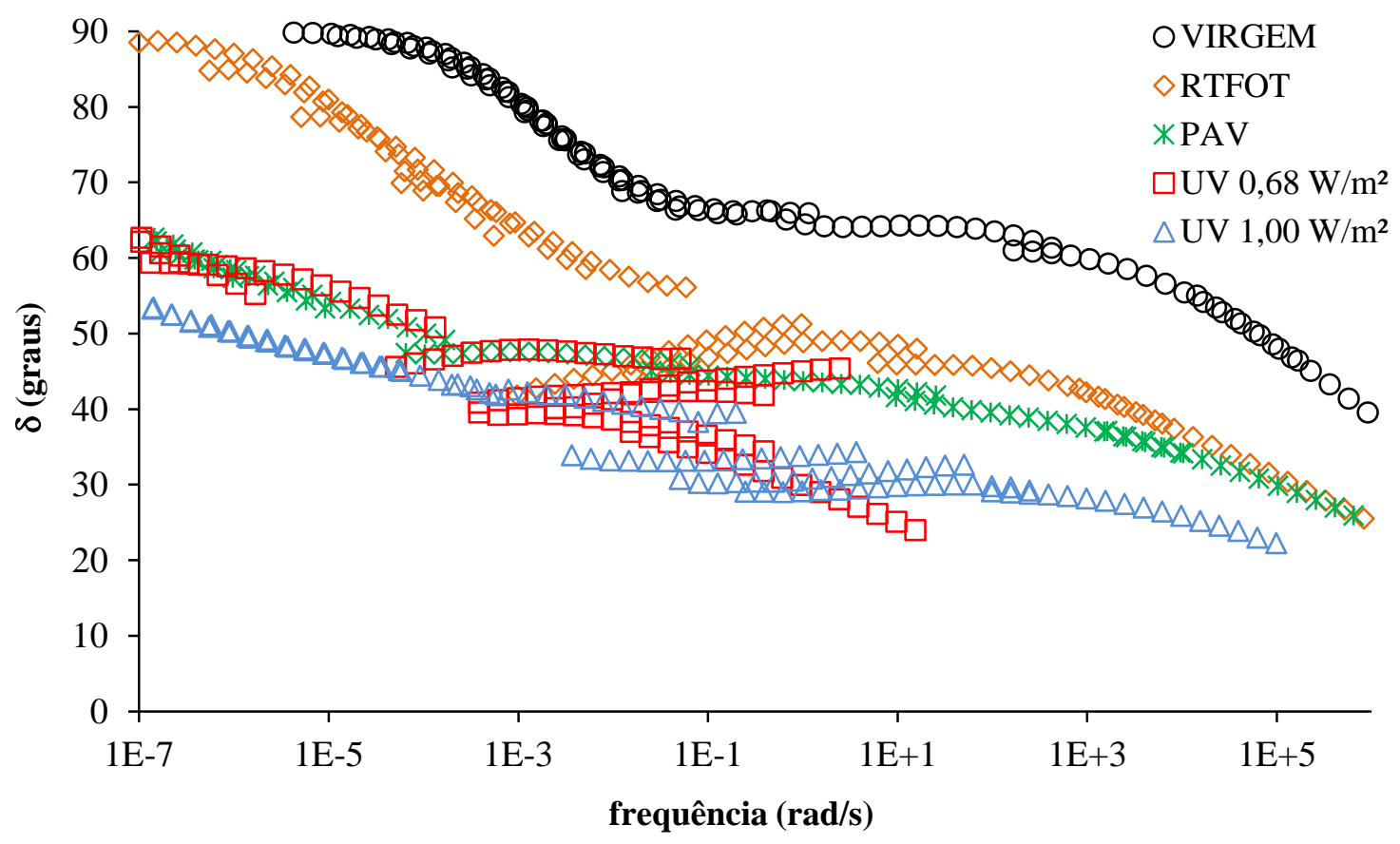

Figura 4.28 - Efeito dos envelhecimentos a curto prazo no RTFO e a longo prazo nas estufas PAV e UV sobre $\delta$ : CAP 50/70+EVA

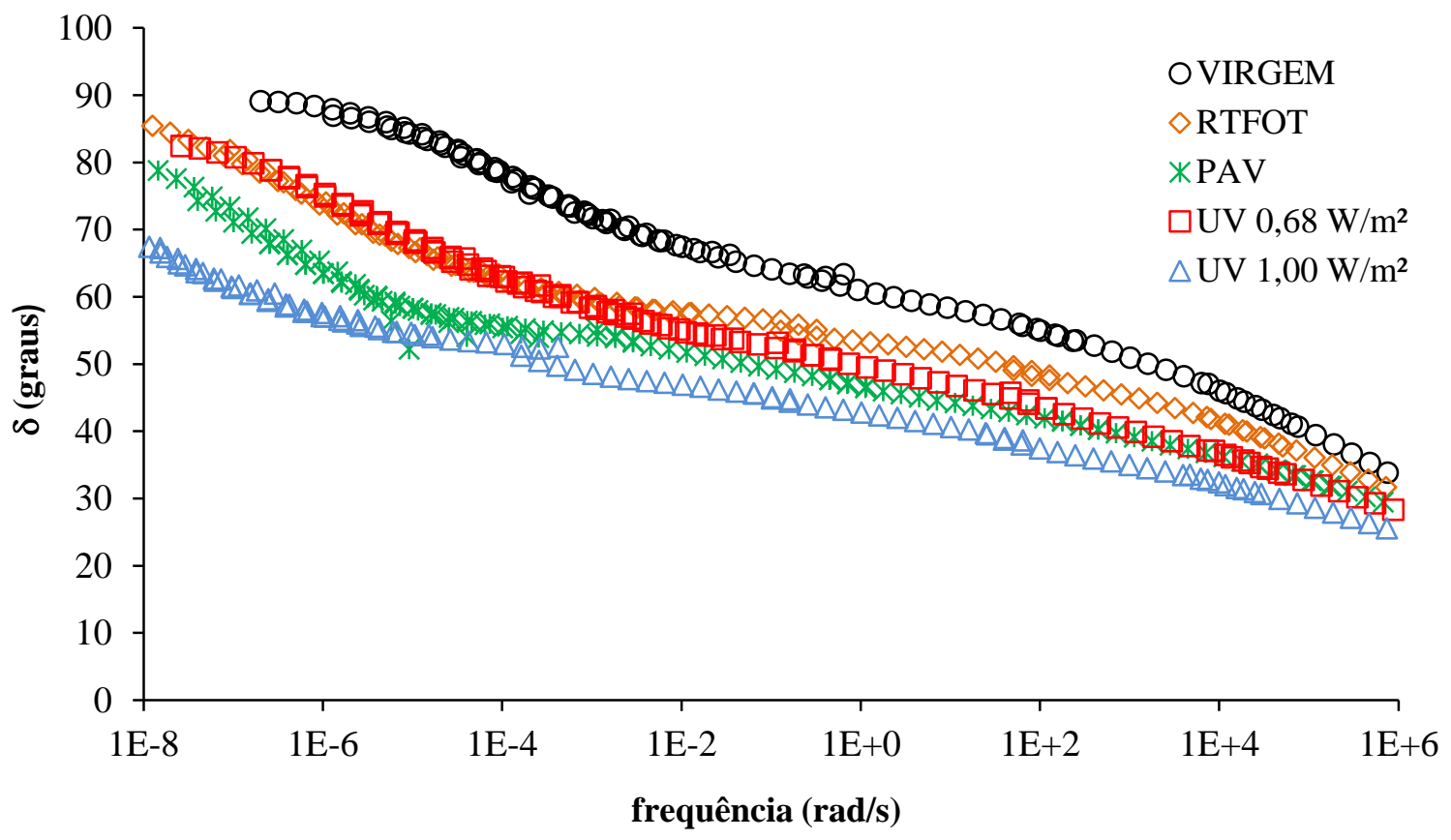

Figura 4.29 - Efeito dos envelhecimentos a curto prazo no RTFO e a longo prazo nas estufas PAV e UV sobre $\delta$ : CAP 50/70+EVA+PPA 


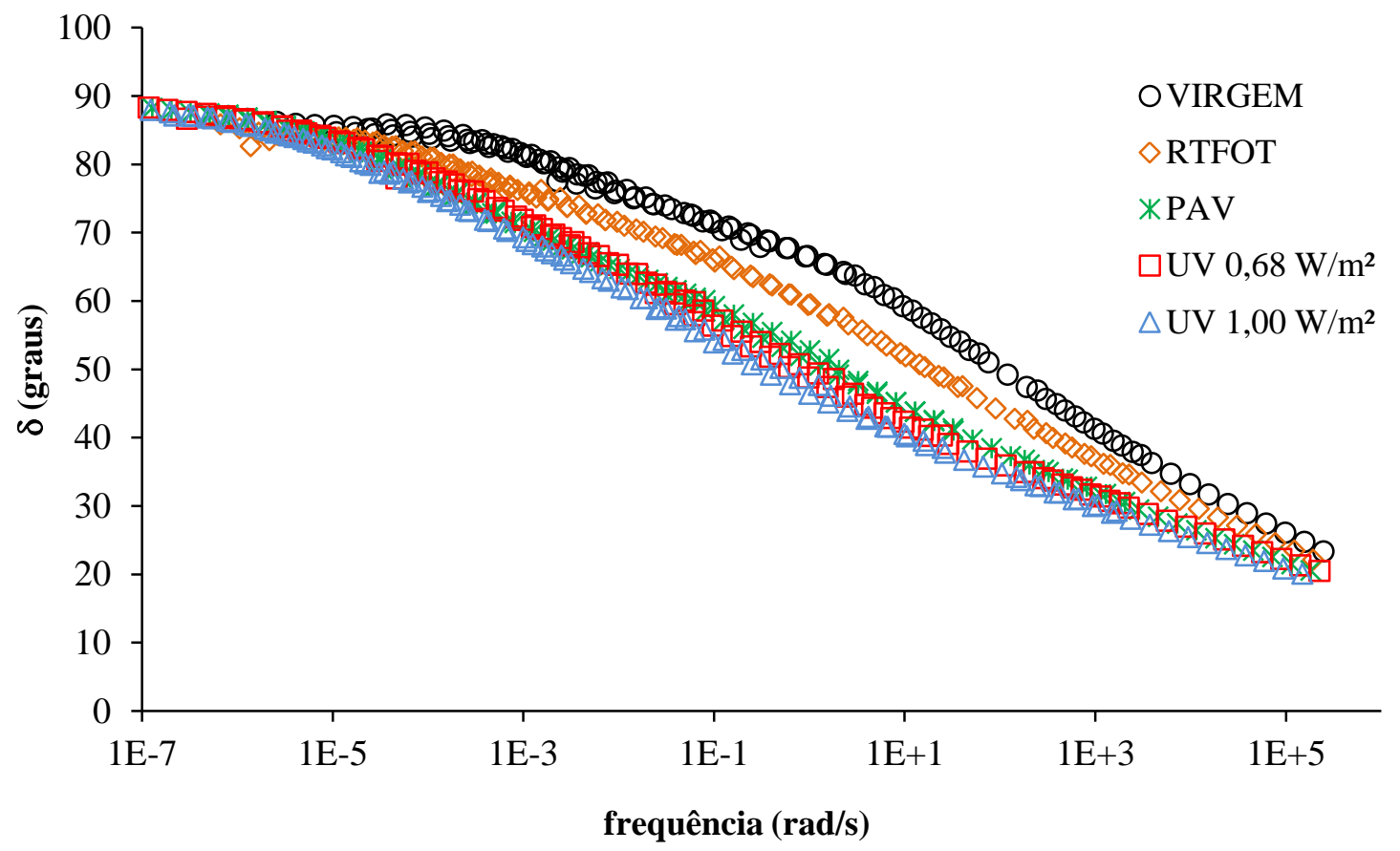

Figura 4.30 - Efeito dos envelhecimentos a curto prazo no RTFO e a longo prazo nas estufas PAV e UV sobre $\delta$ : CAP 50/70+PE

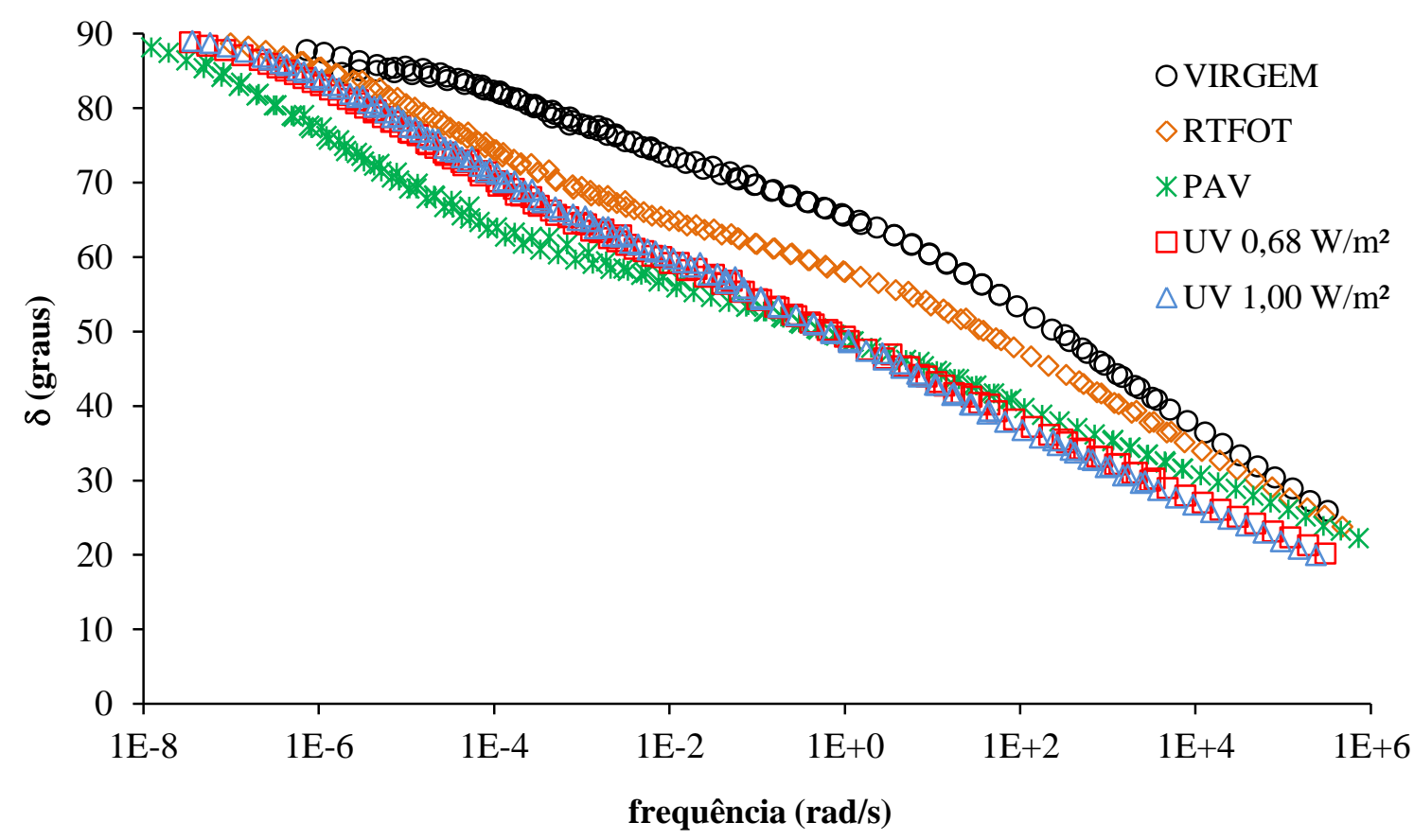

Figura 4.31 - Efeito dos envelhecimentos a curto prazo no RTFO e a longo prazo nas estufas PAV e UV sobre $\delta$ : CAP 50/70+PE+PPA 


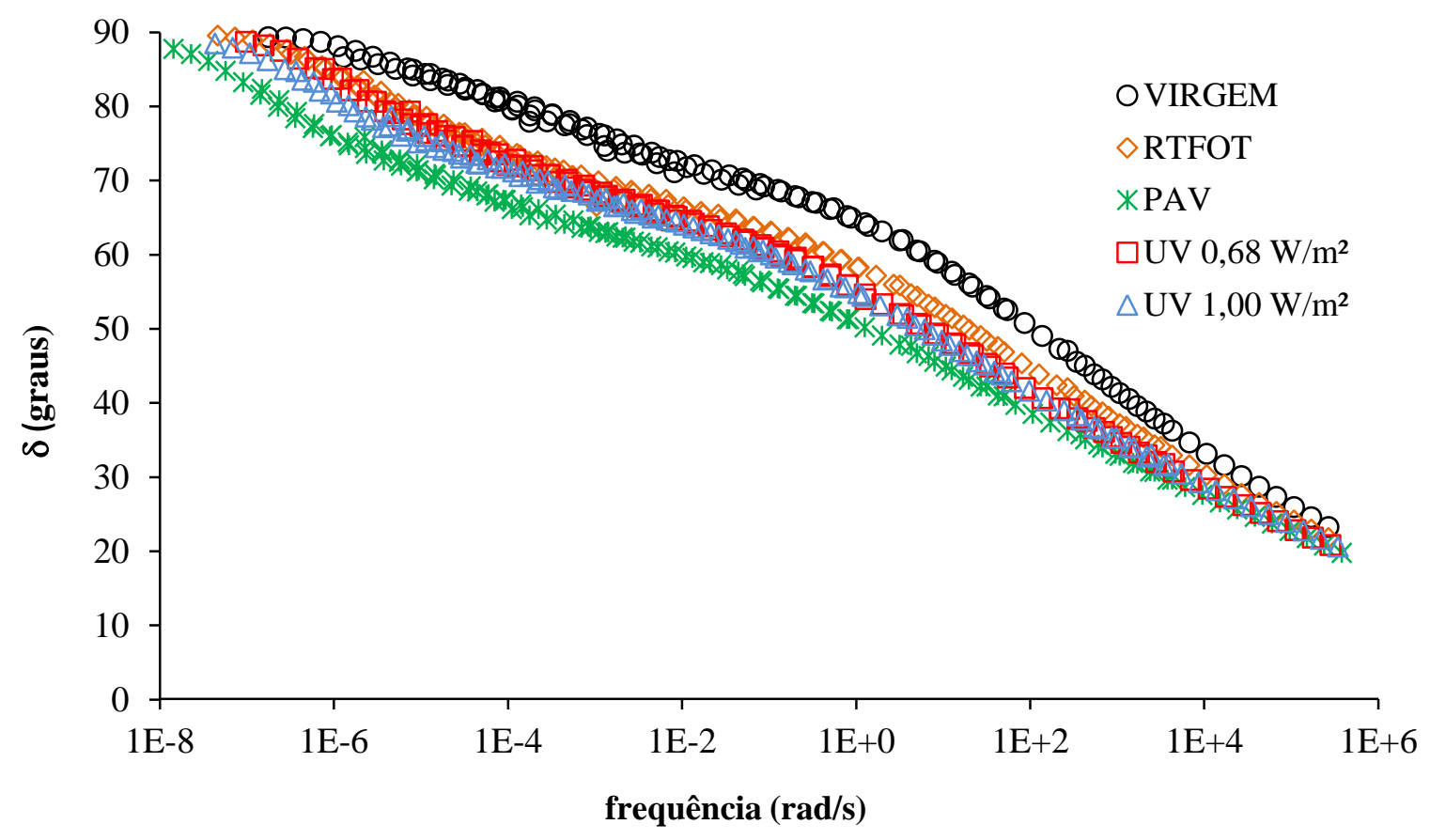

Figura 4.32 - Efeito dos envelhecimentos a curto prazo no RTFO e a longo prazo nas estufas PAV e UV sobre $\delta$ : CAP 50/70+SBR

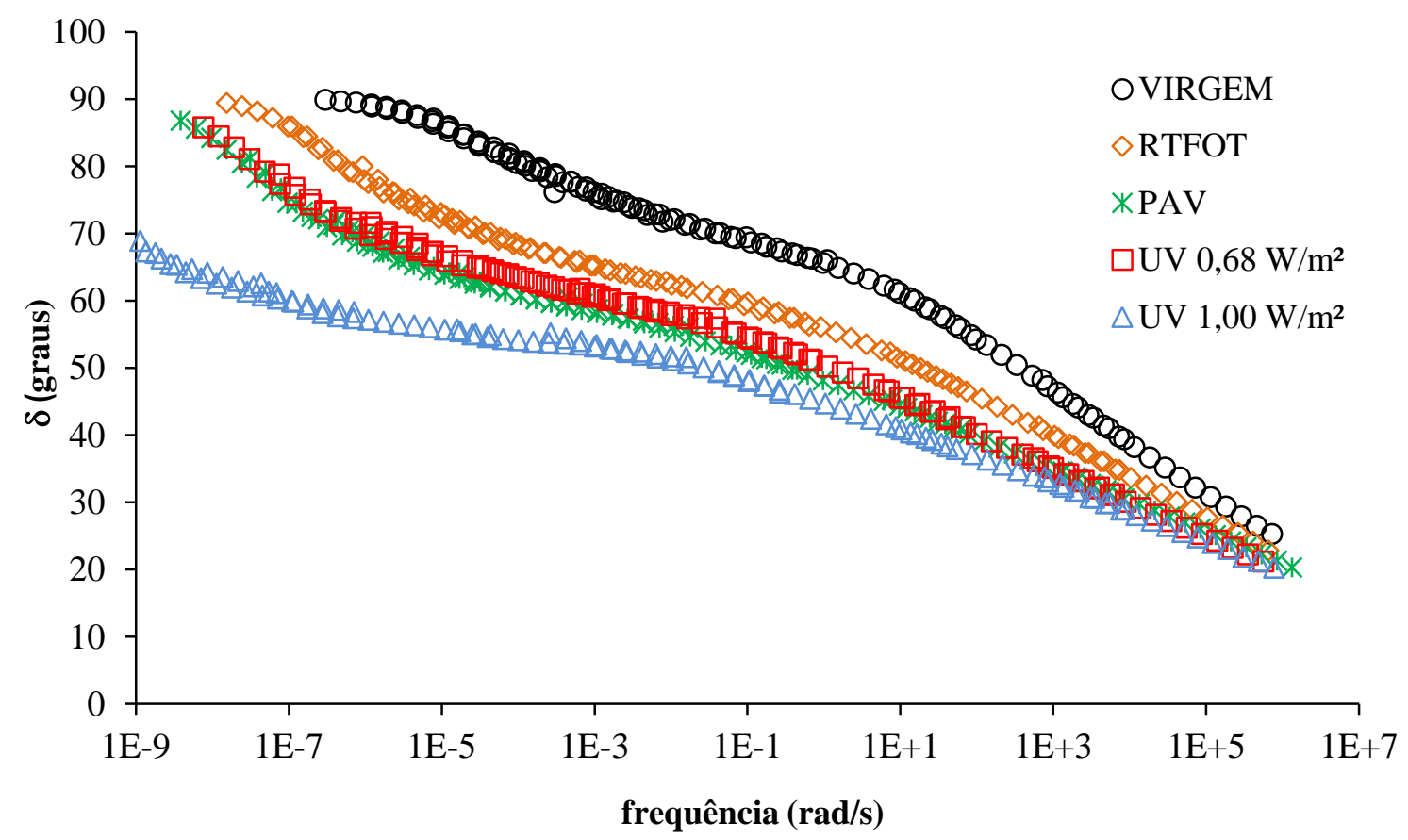

Figura 4.33 - Efeito dos envelhecimentos a curto prazo no RTFO e a longo prazo nas estufas PAV e UV sobre $\delta$ : CAP 50/70+SBR+PPA 
Os envelhecimentos a curto prazo e a longo prazo provocaram, em linhas gerais, aumento da rigidez (aumento dos valores de $G^{*}$ ) e da elasticidade (redução dos valores de $\delta$ ) dos ligantes asfálticos avaliados. Tais variações são particulares para cada tipo de ligante asfáltico e afetam diferentemente as propriedades mecânicas das misturas asfálticas: a resistência à deformação permanente é favorecida pelo enrijecimento e pelo aumento de elasticidade provocados pelo envelhecimento a curto prazo, porém, as resistências à fadiga por deformação controlada e ao trincamento de origem térmica são prejudicadas pelo enrijecimento provocado pelo envelhecimento a longo prazo. $\mathrm{O}$ aumento de elasticidade provocado pelo envelhecimento, por sua vez, ameniza o efeito negativo que o envelhecimento tem sobre a rigidez nas temperaturas de fadiga e de trincamento térmico.

A fim de quantificar os efeitos do envelhecimentos a longo prazo sobre as propriedades reológicas dos ligantes asfálticos envelhecidos a curto prazo, as Tabelas de 4.13 a 4.24 mostram a variação de $\mathrm{G}^{*}$ e de $\delta$ do ligante asfáltico puro e dos ligantes asfálticos modificados, nas condições PAV, UV a $0,68 \mathrm{~W} / \mathrm{m}^{2}$ e UV a $1,00 \mathrm{~W} / \mathrm{m}^{2}$, comparativamente ao respectivo ligante asfáltico envelhecido no RTFOT, em função da frequência de carregamento, $\mathrm{a} 25^{\circ} \mathrm{C}$.

Essa comparação é feita em relação ao CAP envelhecido no RTFOT, tendo em vista que, antes de ser submetido aos três procedimentos de envelhecimento a longo prazo, o ligante asfáltico passa pelo procedimento de envelhecimento a curto prazo. Os valores de $\mathrm{G}^{*}$ e $\delta$ presentes na primeira linha das tabelas correspondem à condição envelhecida a curto prazo (RTFOT), ao passo que os valores presentes nas linhas subjacentes indicam quantas vezes $\mathrm{G}^{*}$ e $\delta$ aumentaram ou diminuíram, por conta do envelhecimento a longo prazo, em comparação com os valores obtidos no RTFOT. Valores de $\mathrm{G}^{*}$ acima de 1,0 indicam enrijecimento em relação ao ligante asfáltico de referência (RTFOT) e valores inferiores a 1,0 indicam que o ligante asfáltico envelhecido a longo prazo é menos rígido que o de referência. Valores negativos de $\delta$ indicam que o ligante asfáltico envelhecido é mais elástico que o de referência e valores positivos indicam que o ligante asfáltico envelhecido é menos elástico que o de referência.

Por meio das médias simples obtidas ao longo do espectro de frequências, é possível quantificar o aumento ou a diminuição que o envelhecimento a longo prazo provocou sobre a rigidez e a elasticidade do CAP, quando comparado à condição envelhecida a curto prazo. Porém, 
a análise que mostra qual envelhecimento é mais severo foi feita considerando o ordenamento médio em todas as frequências, calculado com base no ordenamento de 1 a 3 feito para cada frequência. No caso das análises da variação de $\mathrm{G}^{*}$, a posição mais próxima a 3 representa a condição de envelhecimento mais severa, pois o procedimento de envelhecimento causou um maior aumento da rigidez do ligante asfáltico, indicando uma maior sensibilidade do mesmo. Quando o ordenamento é próximo a 1, para uma determinada condição de envelhecimento, temse que dentre as três condições, esta foi a que menos provocou variação na rigidez de um determinado material. Nas análises de $\delta$, a posição do ordenamento mais próxima a 1 indica que tal procedimento de envelhecimento provocou maior aumento na elasticidade (maior redução de $\delta$ em módulo), e quanto mais próximo de 3, menor foi o aumento da elasticidade. 
Tabela 4.13 - Quantas vezes $G^{*}$ aumentou ou diminuiu e quantos graus $\delta$ aumentou ou diminuiu devido aos envelhecimentos a longo prazo no PAV e na estufa UV em relação ao CAP 50/70 puro envelhecido no $\mathrm{RTFO}$, a $25^{\circ} \mathrm{C}$

\begin{tabular}{|c|c|c|c|c|c|c|c|c|c|c|c|c|c|c|c|}
\hline \multirow{2}{*}{ condição } & \multicolumn{13}{|c|}{ frequência angular (rad/s) } & \multirow{2}{*}{ média } & \multirow{2}{*}{$\begin{array}{c}\text { ordenamento } \\
\text { médio }\end{array}$} \\
\hline & $10^{-6}$ & $10^{-5}$ & $10^{-4}$ & $10^{-3}$ & $10^{-2}$ & $10^{-1}$ & $10^{0}$ & $10^{1}$ & $10^{2}$ & $10^{3}$ & $10^{4}$ & $10^{5}$ & $10^{6}$ & & \\
\hline \multicolumn{16}{|c|}{$\mathrm{G}^{*}$ [quantas vezes aumentou ou diminuiu] } \\
\hline RTFOT & - & $1,5.10$ & $1,5.10^{2}$ & $1,5.10^{3}$ & $1,2.10^{4}$ & $9,1.10^{4}$ & $5,7.10^{5}$ & $3,0.10^{6}$ & $1,2 \cdot 10^{7}$ & $3,9.10^{7}$ & $9,6.10^{7}$ & $2,0.10^{8}$ & - & & \\
\hline PAV & - & 4,2 & 4,2 & 3,7 & 3,3 & 3,0 & 2,3 & 1,9 & 1,5 & 1,3 & 1,1 & 1,0 & - & 2,5 & 2,82 \\
\hline $\begin{array}{c}\text { UV } 0,68 \\
\text { W/m² }\end{array}$ & - & 3,2 & 3,1 & 2,8 & 2,5 & 2,2 & 1,9 & 1,6 & 1,3 & 1,1 & 1,0 & 0,9 & - & 2,0 & 1,00 \\
\hline $\begin{array}{c}\text { UV 1,00 } \\
\text { W/m² }\end{array}$ & - & 4,0 & 3,9 & 3,7 & 3,2 & 2,8 & 2,3 & 1,9 & 1,4 & 1,2 & 1,0 & 0,9 & - & 2,4 & 2,18 \\
\hline \multicolumn{16}{|c|}{$\delta$ [quantos graus aumentou ou diminuiu] } \\
\hline RTFOT & 90,0 & 89,6 & 87,8 & 83,8 & 79,1 & 74,0 & 68,5 & 61,7 & 53,1 & 44,4 & 36,3 & 29,0 & - & & \\
\hline PAV & $-0,3$ & $-2,3$ & $-4,6$ & $-5,7$ & $-7,8$ & $-8,2$ & $-8,6$ & $-8,3$ & $-7,5$ & $-5,8$ & $-4,3$ & $-2,5$ & - & $-5,5$ & 2,08 \\
\hline $\begin{array}{c}\text { UV } 0,68 \\
\text { W/m² }\end{array}$ & $-0,8$ & $-1,8$ & $-3,7$ & $-5,4$ & $-6,5$ & $-7,1$ & $-7,8$ & $-7,5$ & $-7,1$ & $-5,4$ & $-3,8$ & $-2,3$ & - & $-4,9$ & 2,92 \\
\hline $\begin{array}{c}\text { UV 1,00 } \\
\text { W/m }\end{array}$ & $-0,9$ & $-2,4$ & $-5,0$ & $-6,4$ & $-8,0$ & $-8,6$ & $-8,7$ & $-9,0$ & $-8,5$ & $-6,8$ & $-5,1$ & $-3,3$ & - & $-6,0$ & 1,00 \\
\hline
\end{tabular}


Tabela 4.14 - Quantas vezes $G^{*}$ aumentou ou diminuiu e quantos graus $\delta$ aumentou ou diminuiu devido aos envelhecimentos a longo prazo no PAV e na estufa UV em relação ao CAP 50/70+PPA envelhecido no RTFO, a $25^{\circ} \mathrm{C}$

\begin{tabular}{|c|c|c|c|c|c|c|c|c|c|c|c|c|c|c|c|}
\hline \multirow{2}{*}{ condição } & \multicolumn{13}{|c|}{ frequência angular (rad/s) } & \multirow{2}{*}{ média } & \multirow{2}{*}{$\begin{array}{c}\text { ordenamento } \\
\text { médio }\end{array}$} \\
\hline & $10^{-6}$ & $10^{-5}$ & $10^{-4}$ & $10^{-3}$ & $10^{-2}$ & $10^{-1}$ & $10^{0}$ & $10^{1}$ & $10^{2}$ & $10^{3}$ & $10^{4}$ & $10^{5}$ & $10^{6}$ & & \\
\hline \multicolumn{16}{|c|}{$\mathrm{G}^{*}$ [quantas vezes aumentou ou diminuiu] } \\
\hline RTFOT & $1,7.10$ & $1,7.10^{2}$ & $1,3.10^{3}$ & $8,5.10^{3}$ & $4,6.10^{4}$ & $2,3 \cdot 10^{5}$ & $9,6.10^{5}$ & $3,8.10^{6}$ & $1,2.10^{7}$ & $3,4 \cdot 10^{7}$ & $8,2.10^{7}$ & $1,7 \cdot 10^{8}$ & & & \\
\hline PAV & 10,3 & 7,9 & 5,7 & 4,1 & 3,3 & 2,5 & 2,3 & 1,8 & 1,5 & 1,3 & 1,2 & 1,1 & - & 3,6 & 2,00 \\
\hline $\begin{array}{c}\text { UV } 0,68 \\
\text { W/m² }\end{array}$ & 6,8 & 5,5 & 4,3 & 3,3 & 2,7 & 2,6 & 2,2 & 1,8 & 1,5 & 1,3 & 1,2 & 1,1 & - & 2,9 & 1,67 \\
\hline $\begin{array}{c}\text { UV 1,00 } \\
\text { W/m² }\end{array}$ & 13,9 & 9,7 & 6,6 & 4,6 & 3,5 & 3,0 & 2,3 & 1,8 & 1,5 & 1,3 & 1,1 & 1,1 & - & 4,2 & 2,33 \\
\hline \multicolumn{16}{|c|}{$\delta$ [quantos graus aumentou ou diminuiu] } \\
\hline RTFOT & 72,7 & 68,3 & 63,2 & 61,4 & 59,3 & 56,7 & 54,3 & 51,8 & 47,8 & 43,5 & 38,7 & 33,5 & 27,7 & & \\
\hline PAV & $-7,4$ & $-8,8$ & $-7,4$ & $-6,6$ & $-6,4$ & $-5,7$ & $-5,8$ & $-6,2$ & $-5,1$ & $-4,5$ & $-3,0$ & $-2,0$ & $-0,1$ & $-5,3$ & 2,54 \\
\hline $\begin{array}{c}\text { UV 0,68 } \\
\text { W/m² }\end{array}$ & $-2,9$ & $-4,8$ & $-4,4$ & $-5,4$ & $-5,7$ & $-5,1$ & $-5,8$ & $-6,3$ & $-5,9$ & $-5,7$ & $-4,7$ & $-3,9$ & $-2,4$ & $-4,8$ & 2,38 \\
\hline $\begin{array}{c}\text { UV 1,00 } \\
\text { W/m² }\end{array}$ & $-9,4$ & $-9,7$ & $-8,2$ & $-8,1$ & $-8,3$ & $-7,4$ & $-7,9$ & $-7,9$ & $-7,3$ & $-6,4$ & $-5,2$ & $-3,9$ & $-2,2$ & $-7,1$ & 1,08 \\
\hline
\end{tabular}


Tabela 4.15 - Quantas vezes $G^{*}$ aumentou ou diminuiu e quantos graus $\delta$ aumentou ou diminuiu devido aos envelhecimentos a longo prazo no PAV e na estufa UV em relação ao CAP 50/70+borracha envelhecido no RTFO, a $25^{\circ} \mathrm{C}$

\begin{tabular}{|c|c|c|c|c|c|c|c|c|c|c|c|c|c|c|c|}
\hline \multirow{2}{*}{ condição } & \multicolumn{13}{|c|}{ frequência angular ( $\mathrm{rad} / \mathrm{s})$} & \multirow{2}{*}{ média } & \multirow{2}{*}{$\begin{array}{c}\text { ordenamento } \\
\text { médio }\end{array}$} \\
\hline & $10^{-6}$ & $10^{-5}$ & $10^{-4}$ & $10^{-3}$ & $10^{-2}$ & $10^{-1}$ & $10^{0}$ & $10^{1}$ & $10^{2}$ & $10^{3}$ & $10^{4}$ & $10^{5}$ & $10^{6}$ & & \\
\hline \multicolumn{16}{|c|}{$\mathrm{G}^{*}$ [quantas vezes aumentou ou diminuiu] } \\
\hline RTFOT & - & $9,3.10$ & $7,7.10^{2}$ & $5,0.10^{3}$ & $2,5 \cdot 10^{4}$ & $1,1.10^{5}$ & $4,9.10^{5}$ & $2,1.10^{6}$ & $7,2.10^{6}$ & $2,1.10^{7}$ & $5,1.10^{7}$ & $1,1.10^{8}$ & - & & \\
\hline PAV & - & 2,6 & 2,2 & 1,7 & 1,5 & 1,3 & 1,3 & 1,2 & 1,1 & 1,0 & 1,0 & 1,0 & - & 1,4 & 1,00 \\
\hline $\begin{array}{c}\text { UV } 0,68 \\
\text { W/m² }\end{array}$ & - & 12,4 & 7,4 & 4,6 & 3,3 & 2,9 & 2,3 & 1,8 & 1,4 & 1,1 & 1,0 & 1,0 & - & 3,6 & 2,00 \\
\hline $\begin{array}{c}\text { UV 1,00 } \\
\text { W/m }\end{array}$ & - & 59,2 & 24,7 & 11,7 & 7,5 & 5,3 & 4,2 & 2,8 & 2,0 & 1,6 & 1,3 & 1,2 & - & 11,0 & 3,00 \\
\hline \multicolumn{16}{|c|}{$\delta$ [quantos graus aumentou ou diminuiu] } \\
\hline RTFOT & 83,7 & 75,5 & 66,9 & 61,4 & 58,7 & 55,8 & 54,8 & 52,2 & 47,9 & 42,7 & 36,7 & 31,3 & 26,5 & & \\
\hline PAV & $-10,1$ & $-11,0$ & $-7,5$ & $-4,2$ & $-2,7$ & $-2,1$ & $-2,8$ & $-2,8$ & $-2,8$ & $-2,1$ & $-0,7$ & 0,2 & 0,6 & $-3,7$ & 3,00 \\
\hline $\begin{array}{c}\text { UV } 0,68 \\
\text { W/m² }\end{array}$ & $-31,3$ & $-22,6$ & $-16,3$ & $-10,3$ & $-11,0$ & $-7,9$ & $-10,3$ & $-11,2$ & $-10,7$ & $-8,5$ & $-6,1$ & $-3,8$ & 0,0 & $-11,5$ & 1,85 \\
\hline $\begin{array}{c}\text { UV } 1,00 \\
\text { W/m }\end{array}$ & $-34,9$ & $-28,7$ & $-20,3$ & $-18,1$ & $-14,3$ & $-10,4$ & $-13,7$ & $-13,0$ & $-12,1$ & $-9,4$ & $-5,6$ & $-2,9$ & $-0,9$ & $-14,2$ & 1,15 \\
\hline
\end{tabular}


Tabela 4.16 - Quantas vezes $G^{*}$ aumentou ou diminuiu e quantos graus $\delta$ aumentou ou diminuiu devido aos envelhecimentos a longo prazo no PAV e na estufa UV em relação ao CAP 50/70+borracha+PPA envelhecido no $\mathrm{RTFO}$, a $25^{\circ} \mathrm{C}$

\begin{tabular}{|c|c|c|c|c|c|c|c|c|c|c|c|c|c|c|c|}
\hline \multirow{2}{*}{ condição } & \multicolumn{13}{|c|}{ frequência angular (rad/s) } & \multirow{2}{*}{ média } & \multirow{2}{*}{$\begin{array}{c}\text { ordenamento } \\
\text { médio }\end{array}$} \\
\hline & $10^{-6}$ & $10^{-5}$ & $10^{-4}$ & $10^{-3}$ & $10^{-2}$ & $10^{-1}$ & $10^{0}$ & $10^{1}$ & $10^{2}$ & $10^{3}$ & $10^{4}$ & $10^{5}$ & $10^{6}$ & & \\
\hline \multicolumn{16}{|c|}{$\mathrm{G}^{*}[$ quantas vezes aumentou ou diminuiu] } \\
\hline RTFOT & - & $1,2.10^{2}$ & $1,0.10^{3}$ & $6,1.10^{3}$ & $3,0.10^{4}$ & $1,3 \cdot 10^{5}$ & $5,9.10^{5}$ & $2,4.10^{6}$ & $8,0.10^{6}$ & $2,3 \mathrm{E}+07$ & $5,3.10^{7}$ & $1,1.10^{8}$ & - & & \\
\hline PAV & - & 5,4 & 3,5 & 2,7 & 2,2 & 2,3 & 1,8 & 1,5 & 1,3 & 1,2 & 1,2 & 1,1 & - & 2,2 & 1,08 \\
\hline $\begin{array}{c}\text { UV } 0,68 \\
\text { W/m }\end{array}$ & - & 6,8 & 4,6 & 3,4 & 2,7 & 2,6 & 2,0 & 1,7 & 1,4 & 1,3 & 1,2 & 1,1 & - & 2,6 & 1,92 \\
\hline $\begin{array}{c}\text { UV 1,00 } \\
\text { W/m² }\end{array}$ & - & 235,9 & 71,3 & 31,9 & 16,5 & 10,7 & 5,9 & 3,5 & 2,4 & 1,8 & 1,5 & 1,4 & - & 34,8 & 3,00 \\
\hline \multicolumn{16}{|c|}{$\delta$ [quantos graus aumentou ou diminuiu] } \\
\hline RTFOT & 82,3 & 73,1 & 64,7 & 60,8 & 58,5 & 55,4 & 53,3 & 51,0 & 46,5 & 41,6 & 36,7 & 32,0 & 27,4 & & \\
\hline PAV & $-18,4$ & $-14,5$ & $-10,1$ & $-7,3$ & $-4,3$ & $-3,5$ & $-4,7$ & $-4,6$ & $-4,2$ & $-3,1$ & $-2,0$ & $-1,2$ & $-0,5$ & $-6,0$ & 2,38 \\
\hline $\begin{array}{c}\text { UV 0,68 } \\
\text { W/m² }\end{array}$ & $-17,5$ & $-14,9$ & $-10,1$ & $-8,1$ & $-4,9$ & $-5,3$ & $-4,8$ & $-4,3$ & $-3,3$ & $-2,4$ & $-1,5$ & $-1,1$ & $-0,1$ & $-6,0$ & 2,46 \\
\hline $\begin{array}{c}\text { UV 1,00 } \\
\text { W/m }\end{array}$ & 0 & $-34,0$ & $-28,5$ & $-23,0$ & $-18,4$ & $-18,5$ & $-18,1$ & $-16,6$ & $-14,9$ & $-11,4$ & $-7,8$ & $-5,3$ & $-2,8$ & $-15,3$ & 1,15 \\
\hline
\end{tabular}


Tabela 4.17 - Quantas vezes $G^{*}$ aumentou ou diminuiu e quantos graus $\delta$ aumentou ou diminuiu devido aos envelhecimentos a longo prazo no PAV e na estufa UV em relação ao CAP 50/70+SBS envelhecido no RTFO, a $25^{\circ} \mathrm{C}$

\begin{tabular}{|c|c|c|c|c|c|c|c|c|c|c|c|c|c|c|c|}
\hline \multirow{2}{*}{ condição } & \multicolumn{13}{|c|}{ frequência angular (rad/s) } & \multirow{2}{*}{ média } & \multirow{2}{*}{$\begin{array}{c}\text { ordenamento } \\
\text { médio }\end{array}$} \\
\hline & $10^{-6}$ & $10^{-5}$ & $10^{-4}$ & $10^{-3}$ & $10^{-2}$ & $10^{-1}$ & $10^{0}$ & $10^{1}$ & $10^{2}$ & $10^{3}$ & $10^{4}$ & $10^{5}$ & $10^{6}$ & & \\
\hline \multicolumn{16}{|c|}{$\mathrm{G}^{*}$ [quantas vezes aumentou ou diminuiu] } \\
\hline RTFOT & 7,4 & $7,2.10$ & $6,6.10^{2}$ & $5,2 \cdot 10^{3}$ & $2,9.10^{4}$ & $1,5.10^{5}$ & $7,8.10^{5}$ & $3,6.10^{6}$ & $1,2.10^{7}$ & $3,5.10^{7}$ & $7,9.10^{7}$ & $1,5.10^{8}$ & - & & \\
\hline PAV & 3,4 & 3,5 & 3,5 & 2,8 & 2,5 & 2,7 & 2,2 & 1,7 & 1,4 & 1,2 & 1,1 & 1,1 & - & 2,3 & 1,58 \\
\hline $\begin{array}{c}\text { UV } 0,68 \\
\text { W/m² }\end{array}$ & 4,0 & 3,8 & 3,4 & 2,8 & 2,5 & 2,8 & 2,2 & 1,7 & 1,4 & 1,2 & 1,1 & 1,0 & - & 2,3 & 1,42 \\
\hline $\begin{array}{c}\text { UV } 1,00 \\
\mathrm{~W} / \mathbf{m}^{2}\end{array}$ & 50,9 & 34,0 & 18,8 & 11,0 & 8,4 & 6,1 & 4,4 & 2,9 & 2,0 & 1,6 & 1,3 & 1,2 & - & 11,9 & 3,00 \\
\hline \multicolumn{16}{|c|}{$\delta$ [quantos graus aumentou ou diminuiu] } \\
\hline RTFOT & 88,4 & 85,0 & 76,8 & 67,8 & 64,0 & 63,7 & 61,4 & 57,3 & 49,9 & 42,6 & 34,8 & 28,1 & - & & \\
\hline PAV & $-1,5$ & $-3,1$ & $-4,6$ & $-3,6$ & $-2,6$ & $-4,5$ & $-6,4$ & $-7,0$ & $-6,9$ & $-5,7$ & $-3,9$ & $-2,8$ & - & $-4,4$ & 2,92 \\
\hline $\begin{array}{c}\text { UV } 0,68 \\
\text { W/m }\end{array}$ & $-4,2$ & $-8,7$ & $-9,6$ & $-4,0$ & $-1,9$ & $-5,0$ & $-7,6$ & $-9,5$ & $-9,2$ & $-7,9$ & $-6,0$ & $-4,4$ & - & $-6,5$ & 2,08 \\
\hline $\begin{array}{c}\text { UV 1,00 } \\
\text { W/m }\end{array}$ & $-27,2$ & $-26,9$ & $-21,2$ & $-13,8$ & $-13,3$ & $-16,3$ & $-18,4$ & $-18,6$ & $-15,7$ & $-12,2$ & $-8,6$ & $-5,7$ & - & $-16,5$ & 1,00 \\
\hline
\end{tabular}


Tabela 4.18 - Quantas vezes $G^{*}$ aumentou ou diminuiu e quantos graus $\delta$ aumentou ou diminuiu devido aos envelhecimentos a longo prazo no PAV e na estufa UV em relação ao CAP 50/70+SBS+PPA envelhecido no RTFO, a $25^{\circ} \mathrm{C}$

\begin{tabular}{|c|c|c|c|c|c|c|c|c|c|c|c|c|c|c|c|}
\hline \multirow{2}{*}{ condição } & \multicolumn{13}{|c|}{ frequência angular $(\mathrm{rad} / \mathrm{s})$} & \multirow{2}{*}{ média } & \multirow{2}{*}{$\begin{array}{c}\text { ordenament } \\
\text { médio }\end{array}$} \\
\hline & $10^{-6}$ & $10^{-5}$ & $10^{-4}$ & $10^{-3}$ & $10^{-2}$ & $10^{-1}$ & $10^{0}$ & $10^{1}$ & $10^{2}$ & $10^{3}$ & $10^{4}$ & $10^{5}$ & $10^{6}$ & & \\
\hline \multicolumn{16}{|c|}{$\mathrm{G}^{*}[$ quantas vezes aumentou ou diminuiu] } \\
\hline RTFOT & $1,5.10$ & $1,4.10^{2}$ & $1,2.10^{3}$ & $8,4 \cdot 10^{3}$ & $4,2.10^{4}$ & $2,1.10^{5}$ & $9,6.10^{5}$ & $3,9.10^{6}$ & $1,3 \cdot 10^{7}$ & $3,5 \cdot 10^{7}$ & $8,1.10^{7}$ & $1,6.10^{8}$ & - & & \\
\hline PAV & 8,0 & 7,0 & 5,4 & 3,8 & 3,2 & 2,8 & 2,3 & 1,9 & 1,5 & 1,3 & 1,2 & 1,1 & - & 3,3 & 1,58 \\
\hline $\begin{array}{c}\text { UV } 0,68 \\
\text { W/m } / \mathbf{m}^{2}\end{array}$ & 6,8 & 5,9 & 4,8 & 3,5 & 3,1 & 2,8 & 2,3 & 1,8 & 1,5 & 1,3 & 1,2 & 1,1 & - & 3,0 & 1,42 \\
\hline $\begin{array}{c}\text { UV 1,00 } \\
\mathrm{W} / \mathbf{m}^{2}\end{array}$ & 10351,8 & 2437,7 & 600,4 & 200,6 & 83,6 & 33,9 & 14,7 & 6,5 & 3,6 & 2,2 & 1,6 & 1,3 & - & 1144,8 & 3,00 \\
\hline \multicolumn{16}{|c|}{$\delta$ [quantos graus aumentou ou diminuiu] } \\
\hline RTFOT & 86,1 & 79,4 & 69,6 & 62,8 & 61,3 & 60,2 & 57,8 & 54,7 & 49,8 & 43,7 & 37,9 & 32,1 & 26,4 & & \\
\hline PAV & $-11,0$ & $-13,6$ & $-11,0$ & $-5,9$ & $-5,8$ & $-8,0$ & $-9,1$ & $-9,8$ & $-9,6$ & $-8,4$ & $-7,2$ & $-5,9$ & $-4,9$ & $-8,5$ & 2,38 \\
\hline $\begin{array}{c}\text { UV } 0,68 \\
\text { W/m } / \mathbf{m}^{2}\end{array}$ & $-6,7$ & $-8,3$ & $-6,1$ & $-4,3$ & $-4,7$ & $-7,0$ & $-8,7$ & $-10,4$ & $-10,8$ & $-9,7$ & $-9,0$ & $-7,7$ & 0 & $-7,2$ & 2,62 \\
\hline $\begin{array}{c}\text { UV 1,00 } \\
\text { W/m } \mathbf{m}^{2}\end{array}$ & $-54,0$ & $-57,1$ & $-39,4$ & $-32,8$ & $-33,5$ & $-33,3$ & $-32,2$ & $-30,4$ & $-26,0$ & $-21,5$ & $-16,5$ & $-11,6$ & $-7,2$ & $-30,4$ & 1,00 \\
\hline
\end{tabular}


Tabela 4.19 - Quantas vezes $G^{*}$ aumentou ou diminuiu e quantos graus $\delta$ aumentou ou diminuiu devido aos envelhecimentos a longo prazo no PAV e na estufa UV em relação ao CAP 50/70+EVA envelhecido no RTFO, a $25^{\circ} \mathrm{C}$

\begin{tabular}{|c|c|c|c|c|c|c|c|c|c|c|c|c|c|c|c|}
\hline \multirow{2}{*}{ condição } & \multicolumn{13}{|c|}{ frequência angular ( $\mathrm{rad} / \mathrm{s})$} & \multirow{2}{*}{ média } & \multirow{2}{*}{$\begin{array}{c}\text { ordenamento } \\
\text { médio }\end{array}$} \\
\hline & $10^{-6}$ & $10^{-5}$ & $10^{-4}$ & $10^{-3}$ & $10^{-2}$ & $10^{-1}$ & $10^{0}$ & $10^{1}$ & $10^{2}$ & $10^{3}$ & $10^{4}$ & $10^{5}$ & $10^{6}$ & & \\
\hline \multicolumn{16}{|c|}{$\mathrm{G}^{*}$ [quantas vezes aumentou ou diminuiu] } \\
\hline RTFOT & $1,7.10$ & $1,5.10^{2}$ & $1,2.10^{3}$ & $7,8.10^{3}$ & $3,8.10^{4}$ & $1,3 \cdot 10^{5}$ & $4,4 \cdot 10^{5}$ & $1,6.10^{6}$ & $5,4 \cdot 10^{6}$ & $1,7.10^{7}$ & $4,5 \cdot 10^{7}$ & $1,0.10^{8}$ & - & & \\
\hline PAV & 7,3 & 6,2 & 4,6 & 3,7 & 3,2 & 3,4 & 3,1 & 2,5 & 2,1 & 1,7 & 1,5 & 1,3 & - & 3,4 & 1,17 \\
\hline $\begin{array}{c}\text { UV } 0,68 \\
\text { W/m² }\end{array}$ & 16,1 & 13,6 & 9,9 & 5,4 & 3,7 & 3,5 & 3,2 & 2,6 & 2,1 & 1,7 & 1,5 & 1,3 & - & 5,4 & 1,83 \\
\hline $\begin{array}{c}\text { UV 1,00 } \\
\text { W/m² }\end{array}$ & 213,7 & 104,5 & 46,9 & 24,5 & 14,4 & 11,4 & 7,5 & 4,7 & 3,0 & 2,1 & 1,6 & 1,3 & - & 36,3 & 3,00 \\
\hline \multicolumn{16}{|c|}{$\delta$ [quantos graus aumentou ou diminuiu] } \\
\hline RTFOT & 86,9 & 80,9 & 69,0 & 43,2 & 45,6 & 48,0 & 50,0 & 47,0 & 45,4 & 42,2 & 37,0 & 31,1 & - & & \\
\hline PAV & $-29,3$ & $-27,1$ & $-21,4$ & 4,3 & 1,2 & $-3,5$ & $-6,3$ & $-4,7$ & $-5,9$ & $-4,7$ & $-2,8$ & $-1,2$ & - & $-8,4$ & 2,33 \\
\hline $\begin{array}{c}\text { UV } 0,68 \\
\text { W/m² }\end{array}$ & $-29,6$ & $-24,8$ & $-19,1$ & $-3,3$ & $-4,1$ & $-4,4$ & $-5,4$ & $-21,9$ & 0 & 0 & 0 & 0 & - & $-9,4$ & 2,42 \\
\hline $\begin{array}{c}\text { UV 1,00 } \\
\text { W/m }\end{array}$ & $-36,8$ & $-33,7$ & $-24,7$ & $-0,8$ & $-10,8$ & $-13,5$ & $-20,9$ & $-17,1$ & $-15,6$ & $-14,0$ & $-11,2$ & 0 & - & $-16,6$ & 1,17 \\
\hline
\end{tabular}


Tabela 4.20 - Quantas vezes $G^{*}$ aumentou ou diminuiu e quantos graus $\delta$ aumentou ou diminuiu devido aos envelhecimentos a longo prazo no PAV e na estufa UV em relação ao CAP 50/70+EVA+PPA envelhecido no RTFO, a $25^{\circ} \mathrm{C}$

\begin{tabular}{|c|c|c|c|c|c|c|c|c|c|c|c|c|c|c|c|}
\hline \multirow{2}{*}{ condição } & \multicolumn{13}{|c|}{ frequência angular (rad/s) } & \multirow{2}{*}{ média } & \multirow{2}{*}{$\begin{array}{c}\text { ordenamento } \\
\text { médio }\end{array}$} \\
\hline & $10^{-6}$ & $10^{-5}$ & $10^{-4}$ & $10^{-3}$ & $10^{-2}$ & $10^{-1}$ & $10^{0}$ & $10^{1}$ & $10^{2}$ & $10^{3}$ & $10^{4}$ & $10^{5}$ & $10^{6}$ & & \\
\hline \multicolumn{16}{|c|}{$\mathrm{G}^{*}$ [quantas vezes aumentou ou diminuiu] } \\
\hline RTFOT & $2,7.10$ & $2,0.10^{2}$ & $1,5.10^{3}$ & $8,3.10^{3}$ & $3,9.10^{4}$ & $1,9.10^{5}$ & $7,7.10^{5}$ & $3,0.10^{6}$ & $9,6.10^{6}$ & $2,8.10^{7}$ & $7,1.10^{7}$ & $1,5.10^{8}$ & - & & \\
\hline PAV & 6,8 & 6,5 & 5,1 & 4,2 & 3,7 & 3,4 & 2,7 & 2,1 & 1,7 & 1,4 & 1,2 & 1,1 & - & 3,3 & 2,25 \\
\hline $\begin{array}{c}\text { UV } 0,68 \\
\text { W/m² }\end{array}$ & 2,1 & 2,4 & 2,3 & 2,2 & 2,1 & 1,9 & 1,7 & 1,6 & 1,4 & 1,2 & 1,1 & 1,0 & - & 1,7 & 1,00 \\
\hline $\begin{array}{c}\text { UV 1,00 } \\
\text { W/m² }\end{array}$ & 10,6 & 9,9 & 7,4 & 5,6 & 4,8 & 4,1 & 3,0 & 2,2 & 1,7 & 1,4 & 1,2 & 1,1 & - & 4,4 & 2,75 \\
\hline \multicolumn{16}{|c|}{$\delta$ [quantos graus aumentou ou diminuiu] } \\
\hline RTFOT & 73,9 & 67,0 & 62,9 & 59,8 & 57,8 & 56,1 & 53,5 & 51,7 & 48,5 & 45,3 & 41,5 & 36,5 & 31,0 & & \\
\hline PAV & $-10,0$ & $-9,8$ & $-7,5$ & $-4,8$ & $-5,8$ & $-6,6$ & $-6,7$ & $-7,3$ & $-6,3$ & $-6,0$ & $-5,1$ & $-3,7$ & $-2,2$ & $-6,3$ & 2,15 \\
\hline $\begin{array}{c}\text { UV } 0,68 \\
\text { W/m² }\end{array}$ & 1,5 & 1,3 & 0,1 & $-1,3$ & $-2,6$ & $-3,4$ & $-3,7$ & $-4,7$ & $-4,8$ & $-5,1$ & $-4,6$ & $-3,9$ & $-2,8$ & $-2,6$ & 2,85 \\
\hline $\begin{array}{c}\text { UV 1,00 } \\
\text { W/m }\end{array}$ & $-16,4$ & $-12,4$ & $-9,9$ & $-11,1$ & $-10,7$ & $-11,1$ & $-10,6$ & $-11,0$ & $-11,0$ & $-10,3$ & $-9,1$ & $-7,6$ & $-5,8$ & $-10,5$ & 1,00 \\
\hline
\end{tabular}


Tabela 4.21 - Quantas vezes $G^{*}$ aumentou ou diminuiu e quantos graus $\delta$ aumentou ou diminuiu devido aos envelhecimentos a longo prazo no PAV e na estufa UV em relação ao CAP 50/70+PE envelhecido no RTFO, a $25^{\circ} \mathrm{C}$

\begin{tabular}{|c|c|c|c|c|c|c|c|c|c|c|c|c|c|c|c|}
\hline \multirow{2}{*}{ condição } & \multicolumn{13}{|c|}{ frequência angular ( $\mathrm{rad} / \mathrm{s})$} & \multirow{2}{*}{ média } & \multirow{2}{*}{$\begin{array}{c}\text { ordenamento } \\
\text { médio }\end{array}$} \\
\hline & $10^{-6}$ & $10^{-5}$ & $10^{-4}$ & $10^{-3}$ & $10^{-2}$ & $10^{-1}$ & $10^{0}$ & $10^{1}$ & $10^{2}$ & $10^{3}$ & $10^{4}$ & $10^{5}$ & $10^{6}$ & & \\
\hline \multicolumn{16}{|c|}{$\mathrm{G}^{*}$ [quantas vezes aumentou ou diminuiu] } \\
\hline RTFOT & $1,1.10$ & $8,2.10$ & $7,2.10^{2}$ & $5,7.10^{3}$ & $3,9.10^{4}$ & $2,3.10^{5}$ & $1,2.10^{6}$ & $5,0.10^{6}$ & $1,7.10^{7}$ & $4,7.10^{7}$ & $1,1.10^{8}$ & $2,0.10^{8}$ & - & & \\
\hline PAV & 2,4 & 3,0 & 3,0 & 2,9 & 2,5 & 2,2 & 1,8 & 1,5 & 1,3 & 1,1 & 1,0 & 1,0 & - & 2,0 & 1,42 \\
\hline $\begin{array}{c}\text { UV } 0,68 \\
\text { W/m² }\end{array}$ & 2,7 & 3,3 & 3,3 & 3,3 & 2,8 & 2,6 & 2,0 & 1,6 & 1,3 & 1,1 & 1,0 & 0,9 & - & 2,2 & 1,67 \\
\hline $\begin{array}{c}\text { UV 1,00 } \\
\text { W/m² }\end{array}$ & 4,4 & 5,3 & 5,2 & 4,8 & 4,1 & 3,4 & 2,5 & 1,8 & 1,4 & 1,2 & 1,0 & 1,0 & - & 3,0 & 2,92 \\
\hline \multicolumn{16}{|c|}{$\delta$ [quantos graus aumentou ou diminuiu] } \\
\hline RTFOT & 85,5 & 84,0 & 81,1 & 76,0 & 71,6 & 66,0 & 59,5 & 52,1 & 44,1 & 37,0 & 30,3 & 24,1 & - & & \\
\hline PAV & 1,4 & $-0,5$ & $-3,3$ & $-5,0$ & $-6,7$ & $-6,6$ & $-6,8$ & $-7,3$ & $-6,0$ & $-4,8$ & $-3,4$ & $-2,2$ & - & $-4,3$ & 2,58 \\
\hline $\begin{array}{c}\text { UV } 0,68 \\
\text { W/m² }\end{array}$ & 1,3 & $-0,3$ & $-2,2$ & $-4,1$ & $-6,2$ & $-9,5$ & $-10,6$ & $-9,8$ & $-7,7$ & $-5,4$ & $-3,5$ & $-1,9$ & - & $-5,0$ & 2,42 \\
\hline $\begin{array}{c}\text { UV 1,00 } \\
\text { W/m² }\end{array}$ & 0,7 & $-1,7$ & $-5,0$ & $-6,7$ & $-9,3$ & $-12,0$ & $-13,0$ & $-11,4$ & $-9,1$ & $-6,9$ & $-4,9$ & $-3,2$ & - & $-6,9$ & 1,00 \\
\hline
\end{tabular}


Tabela 4.22 - Quantas vezes $G^{*}$ aumentou ou diminuiu e quantos graus $\delta$ aumentou ou diminuiu devido aos envelhecimentos a longo prazo no PAV e na estufa UV em relação ao CAP 50/70+PE+PPA envelhecido no RTFO, a $25^{\circ} \mathrm{C}$

\begin{tabular}{|c|c|c|c|c|c|c|c|c|c|c|c|c|c|c|c|}
\hline \multirow{2}{*}{ condição } & \multicolumn{13}{|c|}{ frequência angular (rad/s) } & \multirow{2}{*}{ média } & \multirow{2}{*}{$\begin{array}{c}\text { ordenamento } \\
\text { médio }\end{array}$} \\
\hline & $10^{-6}$ & $10^{-5}$ & $10^{-4}$ & $10^{-3}$ & $10^{-2}$ & $10^{-1}$ & $10^{0}$ & $10^{1}$ & $10^{2}$ & $10^{3}$ & $10^{4}$ & $10^{5}$ & $10^{6}$ & & \\
\hline \multicolumn{16}{|c|}{$\mathrm{G}^{*}$ [quantas vezes aumentou ou diminuiu] } \\
\hline RTFOT & $1,1.10$ & $1,1.10^{2}$ & $9,1.10^{2}$ & $6,7 \cdot 10^{3}$ & $3,9.10^{4}$ & $2,0.10^{5}$ & $9,6.10^{5}$ & $3,9.10^{6}$ & $1,3 \cdot 10^{7}$ & $3,9 \cdot 10^{7}$ & $9,1.10^{7}$ & $1,8.10^{8}$ & - & & \\
\hline PAV & 8,3 & 7,4 & 6,1 & 4,7 & 4,0 & 3,2 & 2,4 & 1,9 & 1,5 & 1,3 & 1,1 & 1,0 & - & 3,6 & 1,58 \\
\hline $\begin{array}{c}\text { UV } 0,68 \\
\text { W/m² }\end{array}$ & 6,0 & 5,6 & 5,0 & 4,3 & 4,0 & 3,6 & 2,9 & 2,3 & 1,8 & 1,5 & 1,3 & 1,2 & - & 3,3 & 1,67 \\
\hline $\begin{array}{c}\text { UV 1,00 } \\
\text { W/m² }\end{array}$ & 6,4 & 6,1 & 5,7 & 5,0 & 4,4 & 4,0 & 3,2 & 2,6 & 2,0 & 1,6 & 1,4 & 1,2 & - & 3,6 & 2,75 \\
\hline \multicolumn{16}{|c|}{$\delta$ [quantos graus aumentou ou diminuiu] } \\
\hline RTFOT & 85,4 & 80,5 & 74,4 & 69,4 & 64,9 & 61,7 & 58,0 & 53,4 & 47,5 & 41,1 & 34,5 & 28,2 & - & & \\
\hline PAV & $-8,1$ & $-11,0$ & $-10,5$ & $-9,4$ & $-8,2$ & $-8,6$ & $-9,0$ & $-8,5$ & $-7,3$ & $-5,6$ & $-3,5$ & $-1,8$ & - & $-7,6$ & 1,83 \\
\hline $\begin{array}{c}\text { UV } 0,68 \\
\text { W/m² }\end{array}$ & $-2,2$ & $-3,5$ & $-3,9$ & $-4,8$ & $-5,7$ & $-7,3$ & $-8,7$ & $-9,8$ & $-9,6$ & $-8,4$ & $-7,0$ & $-5,5$ & - & $-6,4$ & 2,08 \\
\hline $\begin{array}{c}\text { UV 1,00 } \\
\text { W/m² }\end{array}$ & $-1,5$ & $-2,6$ & $-2,9$ & $-4,2$ & $-4,9$ & $-7,0$ & $-8,9$ & $-10,4$ & $-10,5$ & $-9,3$ & $-7,8$ & $-6,5$ & - & $-6,4$ & 2,08 \\
\hline
\end{tabular}


Tabela 4.23 - Quantas vezes $G^{*}$ aumentou ou diminuiu e quantos graus $\delta$ aumentou ou diminuiu devido aos envelhecimentos a longo prazo no PAV e na estufa UV em relação ao CAP 50/70+SBR envelhecido no RTFO, a $25^{\circ} \mathrm{C}$

\begin{tabular}{|c|c|c|c|c|c|c|c|c|c|c|c|c|c|c|c|}
\hline \multirow{2}{*}{ condição } & \multicolumn{13}{|c|}{ frequência angular (rad/s) } & \multirow{2}{*}{ média } & \multirow{2}{*}{$\begin{array}{c}\text { ordenamento } \\
\text { médio }\end{array}$} \\
\hline & $10^{-6}$ & $10^{-5}$ & $10^{-4}$ & $10^{-3}$ & $10^{-2}$ & $10^{-1}$ & $10^{0}$ & $10^{1}$ & $10^{2}$ & $10^{3}$ & $10^{4}$ & $10^{5}$ & $10^{6}$ & & \\
\hline \multicolumn{16}{|c|}{$\mathrm{G}^{*}$ [quantas vezes aumentou ou diminuiu] } \\
\hline RTFOT & - & $6,8.10$ & $5,8 \cdot 10^{2}$ & $4,1.10^{3}$ & $2,5.10^{4}$ & $1,4 \cdot 10^{5}$ & $6,9.10^{5}$ & $3,1.10^{6}$ & $1,0.10^{7}$ & $2,9.10^{7}$ & $6,6.10^{7}$ & $1,3.10^{8}$ & - & & \\
\hline PAV & - & 7,2 & 5,7 & 4,7 & 3,7 & 3,3 & 2,7 & 2,3 & 1,9 & 1,6 & 1,4 & 1,3 & - & 3,2 & 3,00 \\
\hline $\begin{array}{c}\text { UV } 0,68 \\
\text { W/m² }\end{array}$ & - & 2,8 & 2,4 & 2,3 & 2,0 & 1,9 & 1,8 & 1,5 & 1,3 & 1,2 & 1,1 & 1,1 & - & 1,8 & 1,00 \\
\hline $\begin{array}{c}\text { UV 1,00 } \\
\text { W/m² }\end{array}$ & - & 3,8 & 3,4 & 3,0 & 2,6 & 2,8 & 2,4 & 1,9 & 1,6 & 1,5 & 1,3 & 1,3 & - & 2,3 & 2,00 \\
\hline \multicolumn{16}{|c|}{$\delta$ [quantos graus aumentou ou diminuiu] } \\
\hline RTFOT & 84,5 & 78,7 & 73,6 & 67,5 & 66,5 & 63,2 & 58,4 & 52,2 & 44,7 & 37,4 & 30,5 & 24,4 & - & & \\
\hline PAV & $-8,6$ & $-7,5$ & $-6,6$ & $-4,0$ & $-6,5$ & $-7,2$ & $-7,5$ & $-7,1$ & $-6,0$ & $-4,4$ & $-3,0$ & $-1,7$ & - & $-5,8$ & 1,00 \\
\hline $\begin{array}{c}\text { UV } 0,68 \\
\text { W/m² }\end{array}$ & $-3,3$ & $-3,2$ & $-1,7$ & 0,0 & $-2,3$ & $-3,0$ & $-3,5$ & $-3,8$ & $-3,2$ & $-2,2$ & $-1,5$ & $-0,7$ & - & $-2,4$ & 2,92 \\
\hline $\begin{array}{c}\text { UV 1,00 } \\
\text { W/m }\end{array}$ & $-3,7$ & $-3,3$ & $-2,6$ & $-0,7$ & $-3,3$ & $-3,7$ & $-4,5$ & $-4,3$ & $-3,8$ & $-2,6$ & $-1,6$ & $-0,6$ & - & $-2,9$ & 2,08 \\
\hline
\end{tabular}


Tabela 4.24 - Quantas vezes $G *$ aumentou ou diminuiu e quantos graus $\delta$ aumentou ou diminuiu devido aos envelhecimentos a longo prazo no PAV e na estufa UV em relação ao CAP 50/70+SBR+PPA envelhecido no RTFO, a $25^{\circ} \mathrm{C}$

\begin{tabular}{|c|c|c|c|c|c|c|c|c|c|c|c|c|c|c|c|}
\hline \multirow{2}{*}{ condição } & \multicolumn{13}{|c|}{ frequência angular (rad/s) } & \multirow{2}{*}{ média } & \multirow{2}{*}{$\begin{array}{c}\text { ordenamento } \\
\text { médio }\end{array}$} \\
\hline & $10^{-6}$ & $10^{-5}$ & $10^{-4}$ & $10^{-3}$ & $10^{-2}$ & $10^{-1}$ & $10^{0}$ & $10^{1}$ & $10^{2}$ & $10^{3}$ & $10^{4}$ & $10^{5}$ & $10^{6}$ & & \\
\hline \multicolumn{16}{|c|}{$\mathrm{G}^{*}$ [quantas vezes aumentou ou diminuiu] } \\
\hline RTFOT & $1,5.10$ & $1,5.10^{2}$ & $1,1.10^{3}$ & $7,4 \cdot 10^{3}$ & $4,1.10^{4}$ & $2,1.10^{5}$ & $9,4.10^{5}$ & $3,8.10^{6}$ & $1,2.10^{7}$ & $3,4 \cdot 10^{7}$ & $7,8.10^{7}$ & $1,6.10^{8}$ & - & & \\
\hline PAV & 4,1 & 3,3 & 2,8 & 2,3 & 2,0 & 1,9 & 1,5 & 1,3 & 1,1 & 0,9 & 0,8 & 0,8 & - & 1,9 & 1,00 \\
\hline $\begin{array}{c}\text { UV } 0,68 \\
\text { W/m }\end{array}$ & 4,6 & 3,5 & 3,0 & 2,5 & 2,2 & 2,2 & 1,9 & 1,6 & 1,3 & 1,2 & 1,1 & 1,0 & - & 2,2 & 2,17 \\
\hline $\begin{array}{c}\text { UV 1,00 } \\
\text { W/m }\end{array}$ & 19,9 & 11,8 & 8,9 & 5,5 & 4,0 & 3,0 & 2,4 & 1,9 & 1,5 & 1,2 & 1,1 & 1,0 & - & 5,2 & 2,83 \\
\hline \multicolumn{16}{|c|}{$\delta$ [quantos graus aumentou ou diminuiu] } \\
\hline RTFOT & 77,8 & 72,9 & 68,4 & 65,2 & 62,4 & 59,6 & 55,9 & 51,3 & 45,8 & 40,0 & 33,8 & 27,8 & - & & \\
\hline PAV & $-8,5$ & $-8,7$ & $-7,5$ & $-6,7$ & $-6,3$ & $-7,4$ & $-7,8$ & $-7,0$ & $-6,3$ & $-5,0$ & $-3,6$ & $-2,1$ & - & $-6,4$ & 2,17 \\
\hline $\begin{array}{c}\text { UV } 0,68 \\
\text { W/m² }\end{array}$ & $-6,3$ & $-6,5$ & $-5,0$ & $-4,4$ & $-4,5$ & $-5,0$ & $-5,5$ & $-5,8$ & $-5,7$ & $-4,9$ & $-4,0$ & $-2,8$ & - & $-5,0$ & 2,83 \\
\hline $\begin{array}{c}\text { UV 1,00 } \\
\text { W/m }\end{array}$ & $-20,4$ & $-17,2$ & $-14,3$ & $-12,0$ & $-10,7$ & $-11,5$ & $-11,2$ & $-10,4$ & $-8,9$ & $-7,0$ & $-5,2$ & $-3,5$ & - & $-11,0$ & 1,00 \\
\hline
\end{tabular}


Considerando os ordenamentos médios obtidos para cada procedimento de envelhecimento a longo prazo, em cada amostra, verifica-se que em 10 das 12 amostras, ou seja $83,33 \%$, o procedimento de envelhecimento a longo prazo que mais proporcionou o aumento da rigidez do ligante asfáltico foi o UV a $1,00 \mathrm{~W} / \mathrm{m}^{2}$. Tomando, por exemplo, a Tabela 4.24, dentre as três condições de envelhecimento, a UV 1,0 W/m² é a que ficou mais mal posicionada $(2,83)$, indicando que este nível de envelhecimento é o que mais provocou variação de G*. O mesmo se deu para outras nove amostras.

As amostras restantes (CAP 50/70 puro e CAP+SBR) obtiveram maior incremento da rigidez no procedimento PAV. Dentre os procedimentos que menos afetaram a rigidez, está o PAV para $50 \%$ das amostras (CAP+borracha, CAP+borracha+PPA, CAP+EVA, $\mathrm{CAP}+$ polietileno, $\mathrm{CAP}+$ polietileno+PPA e $\mathrm{CAP}+\mathrm{SBR}+\mathrm{PPA}$ ) e o $\mathrm{UV}$ a $0,68 \mathrm{~W} / \mathrm{m}^{2}$ para as demais amostras (CAP 50/70 puro, CAP+PPA, CAP+SBS, CAP+SBS+PPA, CAP+EVA+PPA e $\mathrm{CAP}+\mathrm{SBR})$.

Analisando os ordenamentos médios com relação ao ângulo de fase, observa-se que $83,33 \%$ das amostras (10 das 12) apresentaram maior sensibilidade ao envelhecimento UV a $1,00 \mathrm{~W} / \mathrm{m}^{2}$, isto é, os ligantes asfálticos ganharam mais elasticidade neste procedimento de envelhecimento e, por este ser um ponto positivo tanto no que se refere à deformação permanente quanto à fadiga, estas amostras ficaram com a melhor posição do ordenamento. As amostras restantes (CAP+polietileno+PPA e CAP+SBR) apresentaram maior ganho de elasticidade quando submetidas ao envelhecimento no PAV. Do ponto de vista do menor incremento na elasticidade, foi obtida a seguinte distribuição: 58,33\% das amostras (CAP 50/70 puro, CAP+borracha+PPA, CAP+SBS+PPA, CAP+EVA, CAP+EVA+PPA, CAP+SBR e $\mathrm{CAP}+\mathrm{SBR}+\mathrm{PPA})$ envelhecidas no $\mathrm{UV}$ a $0,68 \mathrm{~W} / \mathrm{m}^{2} ; 33,33 \%$ das amostras (CAP+PPA, CAP+borracha, CAP+SBS e CAP+polietileno) envelhecidas no PAV e 8,33\% (1 amostra) apresentou ordenamento médio igual para os dois níveis de envelhecimento UV (CAP+polietileno+PPA). Os resultados indicaram que os procedimentos PAV e UV 0,68 W/m² apresentam certa equivalência em termos da capacidade de alterar as propriedades analisadas $\left(\mathrm{G}^{*}\right.$ e $\left.\delta\right)$. 
Foi feito ainda um ordenamento das formulações em função da sensibilidade ao envelhecimento com base nos índices de envelhecimento apresentados nas Tabelas de $4.13 \mathrm{a}$ 4.24. Foi feito, primeiramente, um ordenamento de todos os ligantes asfálticos em cada frequência de carregamento e uma média simples final foi obtida com base nos ordenamentos médios em cada frequência. Do ponto de vista de rigidez, admitiu-se que as formulações mais sensíveis são aquelas que apresentaram maiores incrementos de módulo e, do ponto de vista de elasticidade, as mais sensíveis são as que apresentaram menores incrementos de $\delta$. $O$ posicionamento final das formulações foi o seguinte (da melhor para a pior):

- sensibilidade ao envelhecimento a longo prazo PAV à luz dos incrementos de $\mathrm{G}^{*}$ (menores incrementos, melhor): CAP+borracha (1,36), CAP+SBR+PPA $(1,73)$, $\mathrm{CAP}+\mathrm{PE}(3,27), \mathrm{CAP}+$ borracha+PPA $(4,91), \mathrm{CAP}+\mathrm{SBS}(4,91), \mathrm{CAP} 50 / 70$ puro $(6,45)$, CAP+SBS+PPA (7,64), CAP+PPA (8,45), CAP+PE+PPA $(8,82), \mathrm{CAP}+\mathrm{EVA}(9,82)$, CAP+EVA+PPA $(9,91)$ e CAP+SBR $(10,73)$;

- sensibilidade ao envelhecimento a longo prazo UV a $0,68 \mathrm{~W} / \mathrm{m}^{2}$ à luz dos incrementos de $\mathrm{G}^{*}$ (menores incrementos, melhor): CAP+EVA+PPA $(2,55)$, CAP 50/70 puro $(3,36)$, $\mathrm{CAP}+\mathrm{SBR} \quad(3,36), \mathrm{CAP}+\mathrm{SBR}+\mathrm{PPA} \quad(3,82), \mathrm{CAP}+\mathrm{PE} \quad(3,91), \mathrm{CAP}+\mathrm{SBS} \quad(6,09)$, CAP+borracha+PPA (7,73), CAP+borracha (7,82), CAP+PPA (7,91), CAP+SBS+PPA $(8,91)$, CAP+PE+PPA $(10,73)$ E CAP+EVA $(11,82)$;

- sensibilidade ao envelhecimento a longo prazo UV a $1,00 \mathrm{~W} / \mathrm{m}^{2}$ à luz dos incrementos de $\mathrm{G}^{*}$ (menores incrementos, melhor): CAP 50/70 puro $(1,64)$, CAP+PE $(3,18)$, $\mathrm{CAP}+\mathrm{PPA}(3,55), \mathrm{CAP}+\mathrm{SBR}(3,91), \mathrm{CAP}+\mathrm{SBR}+\mathrm{PPA}(4,18), \mathrm{CAP}+\mathrm{EVA}+\mathrm{PPA}(5,91)$, $\mathrm{CAP}+\mathrm{PE}+\mathrm{PPA}(6,64), \mathrm{CAP}+\mathrm{SBS}(7,82), \mathrm{CAP}+$ borracha $(8,18), \mathrm{CAP}+$ borracha+PPA $(10,55)$, CAP+EVA $(10,64)$ e CAP+SBS+PPA $(11,82)$;

- sensibilidade ao envelhecimento a longo prazo PAV à luz do aumento de elasticidade (maiores incrementos, melhor): $\mathrm{CAP}+\mathrm{SBS}+\mathrm{PPA}(2,42), \mathrm{CAP}+\mathrm{PE}+\mathrm{PPA}(3,75), \mathrm{CAP}$ 50/70 puro (5,00), CAP+EVA+PPA (5,25), CAP+SBR+PPA $(5,67), \mathrm{CAP}+\mathrm{PE}(7,42)$, $\mathrm{CAP}+\mathrm{SBR} \quad(7,50), \quad \mathrm{CAP}+\mathrm{SBS} \quad(7,67), \quad \mathrm{CAP}+\mathrm{PPA} \quad(7,83), \mathrm{CAP}+\mathrm{EVA} \quad(7,83)$, CAP+borracha+PPA $(7,92)$, e CAP+borracha $(9,75)$;

- sensibilidade ao envelhecimento a longo prazo UV a $0,68 \mathrm{~W} / \mathrm{m}^{2}$ à luz do aumento de elasticidade (maiores incrementos, melhor): CAP+borracha $(2,17), \mathrm{CAP}+\mathrm{SBS}+\mathrm{PPA}$ 
(3,67), CAP+PE+PPA (4,58), CAP+SBS (5,92), CAP+PPA (6,08), CAP 50/70 puro (6,50), $\mathrm{CAP}+\mathrm{PE} \quad(6,67), \mathrm{CAP}+$ borracha+PPA (7,00), $\mathrm{CAP}+\mathrm{SBR}+\mathrm{PPA} \quad(7,25)$, CAP+EVA (7,58), CAP+EVA+PPA $(9,75)$ e CAP+SBR $(10,83)$;

- sensibilidade ao envelhecimento a longo prazo UV a $1,00 \mathrm{~W} / \mathrm{m}^{2}$ à luz do aumento de elasticidade (maiores incrementos, melhor): CAP+SBS+PPA $(1,00), \mathrm{CAP}+\mathrm{SBS}(3,50)$, CAP+borracha+PPA (3,92), CAP+EVA (4,33), CAP+borracha $\quad(5,33)$, $\mathrm{CAP}+\mathrm{EVA}+\mathrm{PPA}(5,83), \mathrm{CAP}+\mathrm{SBR}+\mathrm{PPA}(6,83), \mathrm{CAP}+\mathrm{PE}(8,58), \mathrm{CAP}+\mathrm{PE}+\mathrm{PPA}$ $(8,58)$, CAP+PPA $(9,00)$, CAP puro $(9,75)$ e CAP+SBR $(11,33)$.

Os ordenamentos finais por procedimento de envelhecimento, obtidos pela média simples dos ordenamentos apresentados anteriormente, podem ser visualizados na Tabela 4.25. As amostras que têm melhor comportamento quando envelhecidas a longo prazo estão ordenadas com base nos menores aumento de $\mathrm{G}^{*}$ e as maiores reduções de $\delta$.

Tabela 4.25 - Ordenamentos finais da sensibilidade ao envelhecimento nos três níveis de envelhecimento a longo prazo e ordenamento geral da sensibilidade ao envelhecimento, à luz dos valores de $\mathrm{G}^{*}$ e $\delta$ a $25^{\circ} \mathrm{C}$

Ordenamento por procedimento de envelhecimento

\begin{tabular}{|c|c|c|c|c|c|c|c|}
\hline \multicolumn{2}{|l|}{ PAV } & \multicolumn{2}{|c|}{ UV $0,68 \mathrm{~W} / \mathrm{m}^{2}$} & \multicolumn{2}{|c|}{ UV $1,00 \mathrm{~W} / \mathrm{m}^{2}$} & \multirow[b]{2}{*}{$50 / 70$} & \multirow[b]{2}{*}{4,73} \\
\hline SBR-PPA & 3,70 & $50 / 70$ & 2,77 & SBR-PPA & 5,51 & & \\
\hline SBS-PPA & 5,03 & EVA-PPA & 4,77 & SBS & 5,66 & SBR-PPA & 5,51 \\
\hline PE & 5,34 & PE & 5,58 & $50 / 70$ & 5,69 & PE & 5,60 \\
\hline borracha & 5,56 & PPA & 5,79 & EVA-PPA & 5,87 & SBS & 6,01 \\
\hline $50 / 70$ & 5,73 & SBS & 6,09 & PE & 5,88 & EVA-PPA & 6,07 \\
\hline PE-PPA & 6,28 & borracha & 6,20 & PPA & 6,27 & borracha & 6,17 \\
\hline SBS & 6,29 & SBR & 6,56 & SBS-PPA & 6,41 & SBS-PPA & 6,38 \\
\hline borracha-PPA & 6,41 & borracha-PPA & 6,82 & borracha & 6,76 & PPA & 6,73 \\
\hline EVA-PPA & 7,58 & SBR-PPA & 7,33 & borracha-PPA & 7,23 & borracha-PPA & 6,82 \\
\hline PPA & 8,14 & SBS-PPA & 7,70 & EVA & 7,48 & PE-PPA & 7,68 \\
\hline EVA & 8,83 & PE-PPA & 9,16 & PE-PPA & 7,61 & SBR & $\mathbf{7 , 7 6}$ \\
\hline SBR & 9,11 & EVA & 9,24 & SBR & 7,62 & EVA & 8,52 \\
\hline
\end{tabular}

Destacam-se, no ordenamento geral, as formulações CAP 50/70 puro e o $\mathrm{CAP}+\mathrm{SBR}+\mathrm{PPA}$ por apresentarem menor aumento de rigidez e maior aumento de elasticidade, quando expostas aos diferentes níveis de envelhecimento a longo prazo, e o CAP+EVA e o 
$\mathrm{CAP}+\mathrm{SBR}$ por serem os ligantes asfálticos mais sensíveis ao envelhecimento (registraram maiores aumentos de rigidez e menores ganhos de elasticidade). Verifica-se que o acréscimo de PPA foi positivo somente para as amostras contendo EVA e SBR, tendo em vista que as mesmas obtiveram menores aumentos de rigidez e maiores aumentos de elasticidades, do que as amostras sem o PPA.

\subsubsection{Efeitos dos componentes dos níveis de envelhecimento sobre o comportamento termossensível dos ligantes asfálticos}

A Tabela 4.26 mostra quantas vezes os valores de $\mathrm{G}^{*}$ dos ligantes asfálticos modificados aumentaram ou diminuíram em relação ao CAP 50/70 puro, quantos graus o ângulo de fase dos ligantes asfálticos modificados aumentou ou diminuiu e quantas vezes os valores de $\mathrm{G}^{*} / \operatorname{sen} \delta$ e $\mathrm{G}^{*}$.sen $\delta$ dos ligantes asfálticos modificados aumentaram ou diminuíram em relação ao CAP 50/70 puro, a $10 \mathrm{rad} / \mathrm{s}$, em função da temperatura, na condição PAV. A Tabela 4.27 traz tais resultados na condição UV a $0,68 \mathrm{~W} / \mathrm{m}^{2}$ e a Tabela 4.28 traz tais resultados na condição UV a $1,00 \mathrm{~W} / \mathrm{m}^{2}$. Valores de relação de rigidez inferiores a 1 indicam que houve redução da rigidez e valores superiores indicam que houve enrijecimento do CAP 50/70 puro em função da adição dos modificadores. Valores positivos de $\delta$ indicam que o ligante asfáltico modificado é menos elástico que o puro e valores negativos indicam que o ligante asfáltico modificado é mais elástico que o puro. Na linha "50/70 puro" estão indicados os valores originais e nas demais as relações. 
Tabela 4.26 - Variações de $\mathbf{G}^{*}, \delta$, $\mathbf{G}^{*} / \operatorname{sen} \delta$ e $\mathbf{G}^{*}$.sen $\delta$ dos ligantes asfálticos modificados em relação aos valores do 50/70 puro, a $10 \mathrm{rad} / \mathrm{s}$, em função da temperatura, na condição PAV

\begin{tabular}{|c|c|c|c|c|c|c|c|c|}
\hline \multirow{2}{*}{ amostras } & \multicolumn{8}{|c|}{ temperatura $\left({ }^{\circ} \mathbf{C}\right)$} \\
\hline & 4 & 16 & 28 & 40 & 52 & 64 & 76 & 88 \\
\hline \multicolumn{9}{|c|}{$\mathrm{G}^{*}[$ quantas vezes aumentou ou diminuiu] } \\
\hline $50 / 70$ puro & 114755,3 & 24346,4 & 3410,6 & 397,8 & 47,3 & 8,3 & 1,6 & 0,4 \\
\hline 50/70-PPA & 0,9 & 1,0 & 1,3 & 1,9 & 3,0 & 4,2 & 5,6 & 6,5 \\
\hline 50/70-borracha & 0,5 & 0,5 & 0,5 & 0,6 & 1,1 & 1,8 & 3,0 & 4,4 \\
\hline 50/70-borracha- & 0,6 & 0,6 & 0,7 & 0,9 & 1,6 & 2,7 & 4,3 & 6,2 \\
\hline 50/70-SBS & 0,8 & 0,9 & 1,1 & 1,3 & 1,6 & 2,1 & 2,6 & 2,9 \\
\hline 50/70-SBS-PPA & 0,9 & 1,0 & 1,3 & 1,9 & 2,9 & 4,1 & 5,4 & 6,4 \\
\hline 50/70-EVA & 0,7 & 0,6 & 0,8 & 1,4 & 2,9 & 5,4 & 9,3 & 8,9 \\
\hline 50/70-EVA-PPA & 0,9 & 0,9 & 1,2 & 2,0 & 3,1 & 6,3 & 10,8 & 14,4 \\
\hline 50/70-PE & 1,0 & 1,1 & 1,4 & 1,9 & 2,9 & 2,9 & 2,8 & 3,0 \\
\hline 50/70-PE-PPA & 1,0 & 1,0 & 1,3 & 2,1 & 3,2 & 3,8 & 4,2 & 4,5 \\
\hline 50/70-SBR & 0,9 & 1,0 & 1,2 & 1,5 & 2,1 & 2,8 & 3,7 & 4,5 \\
\hline 50/70-SBR-PPA & 0,7 & 0,7 & 0,9 & 1,3 & 2,6 & 3,8 & 5,1 & 6,4 \\
\hline \multicolumn{9}{|c|}{$\delta$ [quantos graus aumentou ou diminuiu] } \\
\hline $50 / 70$ puro & 27,8 & 40,0 & 54,2 & 65,8 & 73,3 & 79,5 & 84,2 & 87,6 \\
\hline 50/70-PPA & $-0,4$ & $-4,3$ & $-10,2$ & $-14,7$ & $-18,4$ & $-20,9$ & $-20,3$ & $-16,6$ \\
\hline 50/70-borracha & 2,8 & 0,7 & $-3,2$ & $-10,5$ & $-17,1$ & $-20,8$ & $-20,0$ & $-17,0$ \\
\hline 50/70-borracha- & 1,0 & $-2,1$ & $-6,6$ & $-12,8$ & $-18,9$ & $-23,4$ & $-23,8$ & $-21,0$ \\
\hline 50/70-SBS & $-2,4$ & $-3,3$ & $-5,0$ & $-7,1$ & $-11,2$ & $-12,2$ & $-8,3$ & $-5,4$ \\
\hline 50/70-SBS-PPA & $-2,5$ & $-5,2$ & $-9,4$ & $-12,9$ & $-17,1$ & $-20,0$ & $-18,0$ & $-13,4$ \\
\hline 50/70-EVA & 1,1 & $-2,5$ & $-10,9$ & $-18,8$ & $-20,0$ & $-21,0$ & $-20,8$ & $-15,5$ \\
\hline 50/70-EVA-PPA & $-0,9$ & $-4,4$ & $-11,3$ & $-16,5$ & $-18,2$ & $-22,4$ & $-24,0$ & $-22,2$ \\
\hline 50/70-PE & $-2,5$ & $-3,8$ & $-6,3$ & $-7,7$ & $-8,0$ & $-6,6$ & $-4,8$ & $-4,8$ \\
\hline 50/70-PE-PPA & $-1,8$ & $-3,9$ & $-8,9$ & $-13,1$ & $-14,2$ & $-14,8$ & $-12,7$ & $-10,0$ \\
\hline 50/70-SBR & $-3,2$ & $-4,9$ & $-7,5$ & $-9,5$ & $-12,2$ & $-13,3$ & $-13,5$ & $-12,5$ \\
\hline 50/70-SBR-PPA & $-2,7$ & $-4,6$ & $-9,2$ & $-12,5$ & $-15,5$ & $-17,6$ & $-17,6$ & $-16,4$ \\
\hline & \multicolumn{4}{|c|}{$\mathrm{G}^{*} \cdot \operatorname{sen} \delta$} & \multicolumn{4}{|c|}{$\mathrm{G}^{*} / \operatorname{sen} \delta$} \\
\hline $50 / 70$ puro & 53554,3 & 15645,9 & 2766,9 & 362,8 & 49,4 & 8,4 & 1,6 & 0,4 \\
\hline 50/70-PPA & 0,9 & 0,9 & 1,1 & 1,6 & 3,5 & 4,9 & 6,2 & 6,8 \\
\hline 50/70-borracha & 0,4 & 0,5 & 0,6 & 1,2 & 3,8 & 5,6 & 6,7 & 8,3 \\
\hline 50/70-borracha- & 0,6 & 0,6 & 0,6 & 0,8 & 1,9 & 3,2 & 5,0 & 6,8 \\
\hline 50/70-SBS & 0,8 & 0,9 & 1,0 & 1,2 & 1,7 & 2,3 & 2,7 & 3,0 \\
\hline 50/70-SBS-PPA & 0,8 & 0,9 & 1,2 & 1,7 & 3,4 & 4,6 & 5,9 & 6,6 \\
\hline 50/70-EVA & 0,6 & 0,8 & 1,5 & 3,7 & 9,9 & 17,2 & 26,5 & 20,1 \\
\hline 50/70-EVA-PPA & 0,9 & 1,2 & 2,2 & 4,7 & 11,2 & 22,2 & 33,0 & 33,1 \\
\hline 50/70-PE & 0,9 & 1,0 & 1,3 & 1,8 & 3,1 & 3,0 & 2,9 & 3,0 \\
\hline 50/70-PE-PPA & 0,9 & 0,9 & 1,2 & 1,9 & 3,5 & 4,1 & 4,4 & 4,6 \\
\hline 50/70-SBR & 0,8 & 0,9 & 1,1 & 1,3 & 2,3 & 3,1 & 3,9 & 4,7 \\
\hline 50/70-SBR-PPA & 0,6 & 0,6 & 0,8 & 1,1 & 3,0 & 4,2 & 5,6 & 6,7 \\
\hline
\end{tabular}


Tabela 4.27 - Variações de $G^{*}, \delta, G * / \operatorname{sen} \delta$ e $G^{*}$.sen $\delta$ dos ligantes asfálticos modificados em relação aos valores do 50/70 puro, a $10 \mathrm{rad} / \mathrm{s}$, em função da temperatura, na condição UV a $0,68 \mathrm{~W} / \mathrm{m}^{2}$

\begin{tabular}{|c|c|c|c|c|c|c|c|c|}
\hline \multirow{2}{*}{ amostras } & \multicolumn{8}{|c|}{ temperatura $\left({ }^{\circ} \mathrm{C}\right)$} \\
\hline & 4 & 16 & 28 & 40 & 52 & 64 & 76 & 88 \\
\hline \multicolumn{9}{|c|}{$\mathrm{G}^{*}$ [quantas vezes aumentou ou diminuiu] } \\
\hline $50 / 70$ puro & 108648,1 & 23630,9 & 3407,6 & 404,1 & 54,4 & 9,8 & 1,9 & 0,4 \\
\hline 50/70-PPA & 1,0 & 1,0 & 1,3 & 1,7 & 2,7 & 3,5 & 4,6 & 5,2 \\
\hline $50 / 70-$ & 0,5 & 0,6 & 0,7 & 1,0 & 1,9 & 3,3 & 5,9 & 9,4 \\
\hline $50 / 70-$ & 0,6 & 0,6 & 0,8 & 1,1 & 1,7 & 2,9 & 4,9 & 6,9 \\
\hline 50/70-SBS & 0,9 & 1,0 & 1,1 & 1,3 & 1,7 & 2,2 & 2,7 & 2,9 \\
\hline 50/70-SBS- & 0,9 & 1,0 & 1,3 & 1,9 & 2,6 & 3,6 & 4,9 & 5,6 \\
\hline 50/70-EVA & 0,7 & 0,6 & 0,8 & 1,4 & 2,5 & 4,0 & 8,5 & 15,4 \\
\hline 50/70-EVA- & 0,8 & 0,8 & 0,9 & 1,4 & 2,5 & 3,9 & 5,9 & 7,2 \\
\hline 50/70-PE & 1,0 & 1,1 & 1,5 & 2,1 & 2,6 & 2,4 & 2,3 & 2,1 \\
\hline 50/70-PE- & 1,1 & 1,3 & 1,7 & 2,6 & 3,6 & 4,1 & 4,3 & 4,2 \\
\hline 50/70-SBR & 0,8 & 0,8 & 0,9 & 1,1 & 1,4 & 1,8 & 2,4 & 2,9 \\
\hline 50/70-SBR- & 0,9 & 0,9 & 1,1 & 1,4 & 2,0 & 2,8 & 4,2 & 5,1 \\
\hline \multicolumn{9}{|c|}{$\delta$ [quantos graus aumentou ou diminuiu] } \\
\hline $50 / 70$ puro & 26,9 & 38,9 & 53,4 & 65,5 & 73,0 & 79,5 & 84,2 & 87,3 \\
\hline 50/70-PPA & 0,4 & $-2,9$ & $-8,3$ & $-13,0$ & $-16,9$ & $-19,5$ & $-18,6$ & $-14,7$ \\
\hline 50/70- & 1,2 & $-2,9$ & $-8,7$ & $-16,3$ & $-22,0$ & $-27,0$ & $-28,3$ & $-25,6$ \\
\hline $50 / 70-$ & 1,5 & $-2,0$ & $-7,0$ & $-13,9$ & $-20,0$ & $-24,2$ & $-24,1$ & $-19,3$ \\
\hline 50/70-SBS & $-2,0$ & $-3,0$ & $-4,9$ & $-6,4$ & $-10,1$ & $-13,6$ & $-10,8$ & $-6,5$ \\
\hline 50/70-SBS- & $-1,3$ & $-3,7$ & $-8,3$ & $-11,4$ & $-15,8$ & $-19,0$ & $-17,1$ & $-12,8$ \\
\hline 50/70-EVA & 2,1 & $-1,4$ & $-11,1$ & $-21,2$ & $-25,6$ & $-23,9$ & $-22,7$ & $-21,5$ \\
\hline 50/70-EVA- & 1,5 & $-1,0$ & $-6,6$ & $-12,1$ & $-16,6$ & $-18,7$ & $-18,3$ & $-15,1$ \\
\hline 50/70-PE & $-1,8$ & $-3,9$ & $-7,3$ & $-8,3$ & $-6,4$ & $-4,5$ & $-2,8$ & $-2,3$ \\
\hline 50/70-PE- & $-1,8$ & $-3,8$ & $-8,1$ & $-11,1$ & $-12,2$ & $-12,3$ & $-10,2$ & $-7,2$ \\
\hline 50/70-SBR & $-0,9$ & $-1,2$ & $-3,0$ & $-5,5$ & $-8,6$ & $-10,1$ & $-10,7$ & $-9,9$ \\
\hline 50/70-SBR- & $-0,7$ & $-2,8$ & $-7,0$ & $-10,2$ & $-14,0$ & $-16,2$ & $-17,0$ & $-15,7$ \\
\hline & \multicolumn{4}{|c|}{$\mathrm{G}^{*} \cdot \operatorname{sen} \delta$} & \multicolumn{4}{|c|}{$\mathrm{G}^{*} / \operatorname{sen} \delta$} \\
\hline $50 / 70$ puro & 49171,7 & 14838,9 & 2736,7 & 367,6 & 56,9 & 10,0 & 1,9 & 0,4 \\
\hline 50/70-PPA & 1,0 & 1,0 & 1,1 & 1,5 & 3,1 & 4,0 & 5,1 & 5,4 \\
\hline 50/70- & 0,6 & 0,5 & 0,6 & 0,9 & 2,3 & 4,1 & 7,1 & 10,7 \\
\hline 50/70- & 0,6 & 0,6 & 0,7 & 0,9 & 2,1 & 3,5 & 5,6 & 7,4 \\
\hline 50/70-SBS & 0,8 & 0,9 & 1,1 & 1,3 & 1,8 & 2,3 & 2,8 & 3,0 \\
\hline 50/70-SBS- & 0,9 & 1,0 & 1,2 & 1,7 & 2,9 & 4,1 & 5,3 & 5,8 \\
\hline 50/70-EVA & 0,8 & 0,6 & 0,7 & 1,1 & 3,3 & 4,8 & 9,6 & 16,9 \\
\hline 50/70-EVA- & 0,9 & 0,8 & 0,8 & 1,2 & 2,9 & 4,4 & 6,4 & 7,5 \\
\hline 50/70-PE & 1,0 & 1,0 & 1,3 & 1,9 & 2,7 & 2,4 & 2,3 & 2,2 \\
\hline 50/70-PE- & 1,1 & 1,2 & 1,5 & 2,3 & 3,9 & 4,4 & 4,4 & 4,3 \\
\hline 50/70-SBR & 0,8 & 0,8 & 0,8 & 1,0 & 1,5 & 1,8 & 2,5 & 2,9 \\
\hline 50/70-SBR- & 0,8 & 0,9 & 1,0 & 1,3 & 2,3 & 3,1 & 4,5 & 5,4 \\
\hline
\end{tabular}


Tabela 4.28 - Variações de $G^{*}, \delta, G^{*} / \operatorname{sen} \delta$ e $G^{*}$.sen $\delta$ dos ligantes asfálticos modificados em relação aos valores do 50/70 puro, a $10 \mathrm{rad} / \mathrm{s}$, em função da temperatura, na condição de envelhecimento a longo prazo na estufa UV a $1,00 \mathrm{~W} / \mathrm{m}^{2}$

\begin{tabular}{|c|c|c|c|c|c|c|c|c|}
\hline \multirow{2}{*}{ amostras } & \multicolumn{8}{|c|}{ temperatura $\left({ }^{\circ} \mathbf{C}\right)$} \\
\hline & 4 & 16 & 28 & 40 & 52 & 64 & 76 & 88 \\
\hline \multicolumn{9}{|c|}{$\mathrm{G}^{*}$ [quantas vezes aumentou ou diminuiu] } \\
\hline $50 / 70$ puro & 104883,0 & 21942,1 & 3000,1 & 338,4 & 51,1 & 8,9 & 1,7 & 0,4 \\
\hline 50/70-PPA & 0,9 & 1,1 & 1,5 & 2,4 & 3,4 & 5,3 & 7,4 & 8,7 \\
\hline 50/70- & 0,7 & 0,8 & 1,3 & 2,3 & 3,5 & 6,6 & 12,8 & 22,5 \\
\hline $50 / 70-$ & 0,8 & 1,1 & 2,0 & 4,4 & 9,4 & 19,6 & 41,7 & 81,6 \\
\hline 50/70-SBS & 1,1 & 1,4 & 2,2 & 3,7 & 4,3 & 6,0 & 8,1 & 9,6 \\
\hline 50/70-SBS- & 1,3 & 2,4 & 6,7 & 21,9 & 53,7 & 119,8 & 248,2 & 452,6 \\
\hline 50/70-EVA & 0,8 & 1,0 & 1,9 & 5,0 & 11,3 & 24,0 & 53,6 & 102,1 \\
\hline 50/70-EVA- & 0,9 & 1,0 & 1,5 & 2,9 & 3,7 & 6,9 & 11,8 & 16,8 \\
\hline 50/70-PE & 1,1 & 1,3 & 1,9 & 3,2 & 3,3 & 3,3 & 3,0 & 2,7 \\
\hline 50/70-PE- & 1,3 & 1,5 & 2,1 & 3,5 & 4,4 & 4,7 & 5,0 & 4,7 \\
\hline 50/70-SBR & 0,9 & 1,0 & 1,2 & 1,5 & 1,3 & 1,8 & 2,5 & 3,0 \\
\hline 50/70-SBR- & 0,9 & 1,1 & 1,5 & 2,3 & 3,2 & 5,4 & 8,7 & 11,2 \\
\hline \multicolumn{9}{|c|}{$\delta$ [quantos graus aumentou ou diminuiu] } \\
\hline $50 / 70$ puro & 28,0 & 40,2 & 54,7 & 66,6 & 73,4 & 79,8 & 84,4 & 87,3 \\
\hline 50/70-PPA & $-0,9$ & $-4,6$ & $-11,1$ & $-16,3$ & $-20,1$ & $-23,5$ & $-23,7$ & $-20,2$ \\
\hline $50 / 70-$ & $-1,3$ & $-7,1$ & $-14,7$ & $-21,8$ & $-27,1$ & $-33,7$ & $-37,6$ & $-38,1$ \\
\hline $50 / 70-$ & $-2,8$ & $-10,1$ & $-19,9$ & $-28,0$ & $-34,6$ & $-41,7$ & $-47,0$ & $-49,9$ \\
\hline 50/70-SBS & $-4,8$ & $-9,0$ & $-14,5$ & $-17,7$ & $-18,9$ & $-21,3$ & $-22,2$ & $-20,0$ \\
\hline 50/70-SBS- & $-9,3$ & $-18,7$ & $-30,7$ & $-39,6$ & $-42,9$ & $-49,1$ & $-53,2$ & $-55,3$ \\
\hline 50/70-EVA & $-2,2$ & $-10,2$ & $-23,2$ & $-33,2$ & $-33,0$ & $-34,7$ & $-36,6$ & $-36,9$ \\
\hline 50/70-EVA- & $-1,6$ & $-6,1$ & $-13,6$ & $-19,9$ & $-19,9$ & $-23,2$ & $-24,7$ & $-22,5$ \\
\hline 50/70-PE & $-3,4$ & $-6,3$ & $-10,8$ & $-12,3$ & $-8,6$ & $-6,5$ & $-4,2$ & $-2,7$ \\
\hline 50/70-PE- & $-3,2$ & $-5,5$ & $-9,7$ & $-12,3$ & $-12,4$ & $-12,1$ & $-9,8$ & $-6,6$ \\
\hline 50/70-SBR & $-2,7$ & $-3,8$ & $-5,6$ & $-7,2$ & $-8,9$ & $-10,6$ & $-11,2$ & $-9,9$ \\
\hline 50/70-SBR- & $-3,3$ & $-7,1$ & $-12,4$ & $-16,6$ & $-20,5$ & $-23,5$ & $-24,2$ & $-22,6$ \\
\hline & \multicolumn{4}{|c|}{$\mathrm{G}^{*} \cdot \operatorname{sen} \delta$} & \multicolumn{4}{|c|}{$\mathrm{G}^{*} / \operatorname{sen} \delta$} \\
\hline $50 / 70$ puro & 49270,6 & 14147,7 & 2449,4 & 310,6 & 53,3 & 9,0 & 1,8 & 0,4 \\
\hline 50/70-PPA & 0,9 & 1,0 & 1,3 & 2,0 & 4,1 & 6,3 & 8,5 & 9,5 \\
\hline 50/70- & 0,6 & 0,7 & 1,0 & 1,8 & 4,7 & 9,0 & 17,5 & 29,8 \\
\hline 50/70- & 0,7 & 0,9 & 1,4 & 3,0 & 14,4 & 31,4 & 68,3 & 134,2 \\
\hline 50/70-SBS & 0,9 & 1,1 & 1,8 & 3,0 & 5,0 & 7,0 & 9,2 & 10,4 \\
\hline 50/70-SBS- & 0,9 & 1,4 & 3,3 & 10,8 & 101,5 & 231,1 & 475,9 & 854,8 \\
\hline 50/70-EVA & 0,8 & 0,8 & 1,2 & 3,0 & 16,7 & 33,4 & 72,0 & 132,5 \\
\hline 50/70-EVA- & 0,8 & 0,9 & 1,2 & 2,3 & 4,4 & 8,1 & 13,6 & 18,6 \\
\hline 50/70-PE & 1,0 & 1,2 & 1,6 & 2,8 & 3,5 & 3,4 & 3,1 & 2,7 \\
\hline 50/70-PE- & 1,1 & 1,3 & 1,8 & 3,1 & 4,8 & 5,0 & 5,1 & 4,7 \\
\hline 50/70-SBR & 0,8 & 1,0 & 1,1 & 1,4 & 1,4 & 1,9 & 2,6 & 3,1 \\
\hline 50/70-SBR- & 0,8 & 0,9 & 1,2 & 1,9 & 3,8 & 6,4 & 10,0 & 12,3 \\
\hline
\end{tabular}


Um ordenamento das formulações em função do efeito das modificações testadas foi efetuado com base nos índices de modificação apresentados nas Tabelas de 4.26 a 4.28, em cada condição de envelhecimento. Foi feito, primeiramente, um ordenamento dos ligantes asfálticos em cada temperatura e uma média simples final foi obtida com base nos ordenamentos médios. Este ordenamento foi feito utilizando apenas os índices calculados com base nos valores de $\mathrm{G}^{*}$.sen $\delta$, tendo em vista que este parâmetro está associado à fadiga, defeito que o pavimento está sujeito durante o processo de envelhecimento a longo prazo. Não foi realizado o ordenamento dos ligantes asfálticos em função do parâmetro $\mathrm{G}^{*} / \operatorname{sen} \delta$, já que o mesmo está associado à deformação permanente, defeito que se manifesta no início da vida útil do pavimento e não a longo prazo.

Do ponto de vista do parâmetro $\mathrm{G}^{*}$.sen $\delta$, admitiu-se como melhores, os menores incrementos, já que nas temperaturas intermediárias do pavimento, ligantes asfálticos menos rígidos proporcionam misturas asfálticas com maiores resistências à fadiga por deformação controlada. Foram utilizados para esta análise os dados referentes apenas aos ligantes asfálticos envelhecidos a longo prazo, nas temperaturas de 40, 28, 16 e $4^{\circ} \mathrm{C}$. Já que a frequência de carregamento afeta os valores de fadiga, foi arbitrada a de $10 \mathrm{rad} / \mathrm{s}$, representativa do tráfego rápido. O posicionamento final das formulações foi o seguinte (da melhor para a pior):

- efeito da modificação à luz dos incrementos de $\mathrm{G}^{*} . \operatorname{sen} \delta \mathrm{PAV}$ a $10 \mathrm{rad} / \mathrm{s}$ (menores incrementos, melhor): CAP+borracha+PPA (1,50), CAP+borracha $(2,00)$, $\mathrm{CAP}+\mathrm{SBR}+\mathrm{PPA}(3,00), \mathrm{CAP}+\mathrm{SBS}(5,00), \mathrm{CAP}+\mathrm{SBR}(6,00), \mathrm{CAP} 50 / 70$ puro $(6,75)$, CAP+EVA $(7,00), C A P+S B S+P P A(7,25), C A P+P E+P P A(8,50), C A P+P E(9,50)$, $\mathrm{CAP}+\mathrm{PPA}(10,50)$ e CAP+EVA+PPA $(11,00)$;

- efeito da modificação à luz dos incrementos de $\mathrm{G}^{*}$.sen $\delta \mathrm{UV}$ a $0,68 \mathrm{~W} / \mathrm{m}^{2}$ a $10 \mathrm{rad} / \mathrm{s}$ (menores incrementos, melhor): CAP+borracha $(1,00)$, CAP+borracha+PPA $(2,50)$, CAP+EVA (3,00), CAP+SBR (4,50), CAP+EVA+PPA (5,25), CAP+SBS $(6,75)$, $\mathrm{CAP}+\mathrm{SBR}+\mathrm{PPA}(6,75), \mathrm{CAP} 50 / 70$ puro $(7,50), \mathrm{CAP}+\mathrm{PPA}(9,00), \mathrm{CAP}+\mathrm{SBS}+\mathrm{PPA}$ $(9,00), \mathrm{CAP}+\mathrm{PE}(10,75), \mathrm{CAP}+\mathrm{PE}+\mathrm{PPA}(12,00) ; \mathrm{e}$

- efeito da modificação à luz dos incrementos de $\mathrm{G}^{*} \cdot \operatorname{sen} \delta \mathrm{UV}$ a $1,00 \mathrm{~W} / \mathrm{m}^{2}$ a $10 \mathrm{rad} / \mathrm{s}$ (menores incrementos, melhor): CAP+borracha (1,75), CAP+SBR $(4,50)$, 
$\mathrm{CAP}+\mathrm{EVA}+\mathrm{PPA}(4,75), \mathrm{CAP}+\mathrm{SBR}+\mathrm{PPA}(4,75), \mathrm{CAP}+\mathrm{EVA}(5,00), \mathrm{CAP} 50 / 70$ puro $(5,25), \mathrm{CAP}+$ borracha+PPA $(5,25), \mathrm{CAP}+\mathrm{PPA}(6,75), \mathrm{CAP}+\mathrm{SBS}(8,75), \mathrm{CAP}+\mathrm{PE}$ $(9,00), \mathrm{CAP}+\mathrm{SBS}+\mathrm{PPA}(11,00), \mathrm{CAP}+\mathrm{PE}+\mathrm{PPA}(11,25)$.

O ordenamento final, obtido pela média simples dos ordenamentos apresentados anteriormente, aponta as seguintes formulações (do melhor para o pior grau de modificação): CAP+borracha (1,58), CAP+borracha+PPA $(3,08), \mathrm{CAP}+\mathrm{SBR}+\mathrm{PPA}(4,83), \mathrm{CAP}+\mathrm{EVA}(5,00)$, $\mathrm{CAP}+\mathrm{SBR}$ (5,00), CAP 50/70 puro (6,50), CAP+SBS (6,83), CAP+EVA+PPA (7,00), CAP+PPA $(8,75), \mathrm{CAP}+\mathrm{SBS}+\mathrm{PPA}(9,08), \mathrm{CAP}+\mathrm{PE}(9,75)$ e CAP+PE+PPA $(10,58)$, sendo os níveis de sensibilidade ao envelhecimento eleitos com base nos menores aumentos de $\mathrm{G}^{*}$.sen $\delta$.

Destaca-se, portanto, o CAP+borracha, por ser a formulação com a menor sensibilidade ao envelhecimento, e o CAP+PE+PPA, por ser a formulação com a maior sensibilidade ao envelhecimento, ao longo da faixa de temperaturas que engloba a manifestação do trincamento por fadiga. No ordenamento final de sensibilidade ao envelhecimento, observase que a adição de PPA aos ligantes asfálticos modificados com polímero (incluindo a borracha) tornou os ligantes asfálticos mais sensíveis ao envelhecimento, à exceção da formulação com SBR.

A Tabela 4.29 mostra quantas vezes os valores de $\mathrm{G}^{*}$ do CAP 50/70 puro aumentaram ou diminuíram, quantos graus o ângulo de fase do CAP 50/70 puro aumentou ou diminuiu e quantas vezes os valores de $\mathrm{G}^{*} / \operatorname{sen} \delta$ e $\mathrm{G}^{*}$.sen $\delta$ do CAP 50/70 puro aumentaram ou diminuíram, por conta dos envelhecimentos a longo prazo, comparativamente ao CAP 50/70 puro envelhecido a curto prazo, em função da temperatura, na frequência de $10 \mathrm{rad} / \mathrm{s}$. No caso da variação de $\mathrm{G}^{*}, \mathrm{G}^{*} / \operatorname{sen} \delta$ e $\mathrm{G}^{*}$.sen $\delta$, valores acima de 1,0 indicam enrijecimento em relação ao ligante asfáltico envelhecido a curto prazo e valores inferiores a 1,0 indicam que o ligante asfáltico envelhecido é menos rígido que envelhecido a curto prazo. No caso da variação de $\delta$, valores negativos indicam que o ligante asfáltico envelhecido é mais elástico que o envelhecido a curto prazo e valores positivos indicam que o ligante asfáltico envelhecido é menos elástico que o envelhecido a curto prazo. As Tabelas de 4.30 a 4.40 apresentam estas mesmas variações para os ligantes asfálticos modificados, na frequência de $10 \mathrm{rad} / \mathrm{s}$. Por meio das médias, observa-se quanto $\mathrm{G}^{*}, \delta, \mathrm{G}^{*} / \mathrm{sen} \delta$ e $\mathrm{G}^{*}$.sen $\delta$ dos CAPs 
envelhecidos a longo prazo aumentaram ou diminuíram quando comparados aos CAPs envelhecidos a curto prazo.

Tabela 4.29 - Variações de $G^{*}, \delta$, G*/sen $\delta$ e $G^{*}$.sen $\delta$ do CAP 50/70 puro nas condições PAV e UV em relação aos valores do material envelhecido a curto prazo, a $10 \mathrm{rad} / \mathrm{s}$, em função da temperatura

\begin{tabular}{|c|c|c|c|c|c|c|c|c|c|c|}
\hline \multirow{2}{*}{$\begin{array}{c}\text { nível de } \\
\text { envelhecimento }\end{array}$} & \multicolumn{8}{|c|}{ temperatura $\left({ }^{\circ} \mathbf{C}\right)$} & \multirow{2}{*}{\multicolumn{2}{|c|}{ média }} \\
\hline & 4 & 16 & 28 & 40 & 52 & 64 & 76 & 88 & & \\
\hline \multicolumn{11}{|c|}{$\mathrm{G}^{*}$ [quantas vezes aumentou ou diminuiu] } \\
\hline RTFOT & $1,0.10^{5}$ & $1,7.10^{4}$ & $1,7.10^{3}$ & $1,8.10^{2}$ & 17,7 & 3,2 & 0,7 & 0,2 & & \\
\hline PAV & 1,1 & 1,4 & 2,0 & 2,2 & 2,7 & 2,6 & 2,4 & 2,1 & \multicolumn{2}{|c|}{2,1} \\
\hline UV $0,68 \mathrm{~W} / \mathrm{m}^{2}$ & 1,0 & 1,3 & 1,7 & 1,9 & 2,9 & 2,8 & 2,6 & 2,4 & \multicolumn{2}{|c|}{2,1} \\
\hline $\mathrm{UV} 1,00 \mathrm{~W} / \mathrm{m}^{2}$ & 1,0 & 1,4 & 2,0 & 2,2 & 3,1 & 3,1 & 2,8 & 2,5 & \multicolumn{2}{|c|}{2,3} \\
\hline \multicolumn{11}{|c|}{$\delta$ [quantos graus aumentou ou diminuiu] } \\
\hline RTFOT & 31,4 & 46,7 & 63,4 & 73,4 & 80,0 & 84,2 & 87,2 & 88,9 & & \\
\hline PAV & $-3,6$ & $-6,7$ & $-9,2$ & $-7,6$ & $-6,7$ & $-4,8$ & $-3,0$ & $-1,2$ & \multicolumn{2}{|c|}{$-5,35$} \\
\hline $\mathrm{UV} 0,68 \mathrm{~W} / \mathrm{m}^{2}$ & $-3,4$ & $-6,5$ & $-8,7$ & $-6,8$ & $-6,6$ & $-4,5$ & $-2,7$ & $-1,6$ & \multicolumn{2}{|c|}{$-5,1$} \\
\hline $\mathrm{UV} 1,00 \mathrm{~W} / \mathrm{m}^{2}$ & $-4,5$ & $-7,8$ & $-10,0$ & $-7,9$ & $-6,9$ & $-4,8$ & $-3,0$ & $-1,6$ & \multicolumn{2}{|c|}{$-5,8$} \\
\hline \multicolumn{11}{|c|}{$\mathrm{G}^{*} / \operatorname{sen} \delta$ e $\mathrm{G}^{*} . \operatorname{sen} \delta$ [quantas vezes aumentou ou diminuiu] } \\
\hline & \multicolumn{4}{|c|}{$\mathrm{G}^{*} \cdot \operatorname{sen} \delta$} & \multicolumn{4}{|c|}{$\mathrm{G} * / \operatorname{sen} \delta$} & $G^{*} \cdot \operatorname{sen} \delta$ & $\mathrm{G}^{*} / \operatorname{sen} \delta$ \\
\hline RTFOT & $5,4.10^{4}$ & $1,3.10^{4}$ & $1,6.10^{3}$ & $1,7.10^{2}$ & 18,0 & 3,2 & 0,7 & 0,2 & & \\
\hline PAV & 1,0 & 1,2 & 1,8 & 2,1 & 2,8 & 2,7 & 2,4 & 2,1 & 1,5 & 2,5 \\
\hline $\mathrm{UV} 0,68 \mathrm{~W} / \mathrm{m}^{2}$ & 0,9 & 1,1 & 1,6 & 1,8 & 3,0 & 2,8 & 2,6 & 2,4 & 1,4 & 2,7 \\
\hline $\mathrm{UV} 1,00 \mathrm{~W} / \mathrm{m}^{2}$ & 0,9 & 1,2 & 1,8 & 2,1 & 3,2 & 3,1 & 2,8 & 2,5 & 1,5 & 2,9 \\
\hline
\end{tabular}


Tabela 4.30 - Variações de $G^{*}, \delta, G * / \operatorname{sen} \delta$ e $G^{*}$.sen $\delta$ do CAP 50/70-PPA nas condições PAV e UV em relação aos valores do material envelhecido a curto prazo, a $10 \mathrm{rad} / \mathrm{s}$, em função da temperatura

\begin{tabular}{|c|c|c|c|c|c|c|c|c|c|c|}
\hline \multirow{2}{*}{$\begin{array}{c}\text { nível de } \\
\text { envelhecimento }\end{array}$} & \multicolumn{8}{|c|}{ temperatura $\left({ }^{\circ} \mathbf{C}\right)$} & \multirow{2}{*}{\multicolumn{2}{|c|}{ média }} \\
\hline & 4 & 16 & 28 & 40 & 52 & 64 & 76 & 88 & & \\
\hline \multicolumn{11}{|c|}{$\mathrm{G}^{*}$ [quantas vezes aumentou ou diminuiu] } \\
\hline RTFOT & $8,6.10^{4}$ & $1,6.10^{4}$ & $2,3.10^{3}$ & 332,4 & 53,8 & 12,5 & 3,1 & 0,8 & & \\
\hline PAV & 1,2 & 1,4 & 1,9 & 2,3 & 2,6 & 2,8 & 2,9 & 2,8 & \multicolumn{2}{|c|}{2,2} \\
\hline $\mathrm{UV} 0,68 \mathrm{~W} / \mathrm{m}^{2}$ & 1,2 & 1,5 & 1,8 & 2,1 & 2,7 & 2,8 & 2,8 & 2,7 & \multicolumn{2}{|c|}{2,2} \\
\hline $\mathrm{UV} 1,00 \mathrm{~W} / \mathrm{m}^{2}$ & 1,1 & 1,4 & 1,9 & 2,5 & 3,3 & 3,8 & 4,1 & 4,3 & \multicolumn{2}{|c|}{2,8} \\
\hline \multicolumn{11}{|c|}{$\delta$ [quantos graus aumentou ou diminuiu] } \\
\hline RTFOT & 31,2 & 41,8 & 51,8 & 58,7 & 63,0 & 67,1 & 72,7 & 78,5 & & \\
\hline PAV & $-3,8$ & $-6,1$ & $-7,8$ & $-7,7$ & $-8,1$ & $-8,6$ & $-8,7$ & $-7,4$ & \multicolumn{2}{|c|}{$-7,3$} \\
\hline UV $0,68 \mathrm{~W} / \mathrm{m}^{2}$ & $-3,9$ & $-5,8$ & $-6,7$ & $-6,3$ & $-6,8$ & $-7,2$ & $-7,1$ & $-5,9$ & \multicolumn{2}{|c|}{$-6,2$} \\
\hline $\mathrm{UV} 1,00 \mathrm{~W} / \mathrm{m}^{2}$ & $-4,0$ & $-6,2$ & $-8,2$ & $-8,4$ & $-9,7$ & $-10,8$ & $-11,9$ & $-11,4$ & \multicolumn{2}{|c|}{$-8,8$} \\
\hline \multicolumn{11}{|c|}{$\mathrm{G}^{*} / \operatorname{sen} \delta$ e $\mathrm{G}^{*} \cdot \operatorname{sen} \delta$ [quantas vezes aumentou ou diminuiu] } \\
\hline & \multicolumn{4}{|c|}{$\mathrm{G}^{*} \cdot \operatorname{sen} \delta$} & \multicolumn{4}{|c|}{$\mathrm{G} * / \operatorname{sen} \delta$} & $\begin{array}{l}\mathrm{G}^{*} . \\
\text { sen } \delta\end{array}$ & $\begin{array}{c}\mathrm{G}^{* /} \\
\operatorname{sen} \delta\end{array}$ \\
\hline RTFOT & $4,5.10^{4}$ & $1,1.10^{4}$ & $1,8.10^{3}$ & 284,1 & 60,3 & 13,5 & 3,3 & 0,8 & & \\
\hline PAV & 1,0 & 1,2 & 1,7 & 2,1 & 2,9 & 3,0 & 3,1 & 2,9 & 1,5 & 3,0 \\
\hline $\mathrm{UV} 0,68 \mathrm{~W} / \mathrm{m}^{2}$ & 1,1 & 1,3 & 1,7 & 2,0 & 2,9 & 2,9 & 2,9 & 2,8 & 1,5 & 2,9 \\
\hline UV $1,00 \mathrm{~W} / \mathrm{m}^{2}$ & 1,0 & 1,2 & 1,7 & 2,2 & 3,6 & 4,2 & 4,5 & 4,6 & 1,5 & 4,2 \\
\hline
\end{tabular}


Tabela 4.31 - Variações de $G^{*}, \delta$, $G^{*} / \operatorname{sen} \delta$ e $G^{*} \cdot \operatorname{sen} \delta$ do CAP 50/70-borracha nas condições PAV e UV em relação aos valores do material envelhecido a curto prazo, a $10 \mathrm{rad} / \mathrm{s}$, em função da temperatura

\begin{tabular}{|c|c|c|c|c|c|c|c|c|c|c|}
\hline \multirow{2}{*}{$\begin{array}{c}\text { nível de } \\
\text { envelhecimento }\end{array}$} & \multicolumn{8}{|c|}{ temperatura $\left({ }^{\circ} \mathbf{C}\right)$} & \multirow{2}{*}{\multicolumn{2}{|c|}{ média }} \\
\hline & 4 & 16 & 28 & 40 & 52 & 64 & 76 & 88 & & \\
\hline \multicolumn{11}{|c|}{$\mathrm{G}^{*}$ [quantas vezes aumentou ou diminuiu] } \\
\hline RTFOT & $6,1.10^{4}$ & $1,2.10^{4}$ & $1,5.10^{3}$ & 204,7 & 36,7 & 10,2 & 3,0 & 0,9 & & \\
\hline PAV & 0,9 & 1,0 & 1,1 & 1,2 & 1,4 & 1,5 & 1,6 & 1,8 & \multicolumn{2}{|c|}{1,3} \\
\hline UV $0,68 \mathrm{~W} / \mathrm{m}^{2}$ & 0,9 & 1,2 & 1,7 & 2,1 & 2,8 & 3,1 & 3,8 & 4,5 & \multicolumn{2}{|c|}{2,5} \\
\hline $\mathrm{UV} 1,00 \mathrm{~W} / \mathrm{m}^{2}$ & 1,2 & 1,6 & 2,7 & 3,8 & 4,9 & 5,8 & 7,6 & 10,3 & \multicolumn{2}{|c|}{4,7} \\
\hline \multicolumn{11}{|c|}{$\delta$ [quantos graus aumentou ou diminuiu] } \\
\hline RTFOT & 31,0 & 42,7 & 53,9 & 57,6 & 59,8 & 64,8 & 71,9 & 78,3 & & \\
\hline PAV & $-0,4$ & $-2,0$ & $-2,9$ & $-2,3$ & $-3,6$ & $-6,1$ & $-7,8$ & $-7,6$ & \multicolumn{2}{|c|}{$-4,1$} \\
\hline UV $0,68 \mathrm{~W} / \mathrm{m}^{2}$ & $-2,9$ & $-6,7$ & $-9,2$ & $-8,5$ & $-8,8$ & $-12,4$ & $-16,0$ & $-16,6$ & \multicolumn{2}{|c|}{$-10,1$} \\
\hline $\mathrm{UV} 1,00 \mathrm{~W} / \mathrm{m}^{2}$ & $-4,3$ & $-9,6$ & $-13,9$ & $-12,8$ & $-13,5$ & $-18,7$ & $-25,1$ & $-29,1$ & \multicolumn{2}{|c|}{$-15,9$} \\
\hline \multicolumn{11}{|c|}{$\mathrm{G}^{*} / \operatorname{sen} \delta$ e $\mathrm{G}^{*} \cdot \operatorname{sen} \delta$ [quantas vezes aumentou ou diminuiu] } \\
\hline & \multicolumn{4}{|c|}{$\mathrm{G}^{*} \cdot \operatorname{sen} \delta$} & \multicolumn{4}{|c|}{$\mathrm{G}^{*} / \operatorname{sen} \delta$} & $\begin{array}{l}\mathrm{G}^{*} . \\
\text { sen } \delta\end{array}$ & $\begin{array}{c}\mathrm{G}^{* /} \\
\operatorname{sen} \delta\end{array}$ \\
\hline RTFOT & $3,1.10^{4}$ & $7,9.10^{3}$ & $1,2.10^{3}$ & 172,9 & 42,4 & 11,3 & 3,1 & 0,9 & & \\
\hline PAV & 0,9 & 0,9 & 1,0 & 1,2 & 1,5 & 1,6 & 1,7 & 1,9 & 1,0 & 1,7 \\
\hline $\mathrm{UV} 0,68 \mathrm{~W} / \mathrm{m}^{2}$ & 0,9 & 1,0 & 1,4 & 1,8 & 3,1 & 3,6 & 4,3 & 5,0 & 1,3 & 4,0 \\
\hline UV $1,00 \mathrm{~W} / \mathrm{m}^{2}$ & 1,0 & 1,3 & 2,1 & 3,2 & 5,9 & 7,2 & 9,9 & 13,3 & 1,9 & 9,1 \\
\hline
\end{tabular}


Tabela 4.32 - Variações de $G^{*}, \delta, G^{*} / \operatorname{sen} \delta$ e $G^{*}$.sen $\delta$ do CAP 50/70-borracha-PPA nas condições PAV e UV em relação aos valores do material envelhecido a curto $\mathrm{prazo}$, a $10 \mathrm{rad} / \mathrm{s}$, em função da temperatura

\begin{tabular}{|c|c|c|c|c|c|c|c|c|c|c|}
\hline \multirow{2}{*}{$\begin{array}{c}\text { nível de } \\
\text { envelhecimento }\end{array}$} & \multicolumn{8}{|c|}{ temperatura $\left({ }^{\circ} \mathbf{C}\right)$} & \multirow{2}{*}{\multicolumn{2}{|c|}{ média }} \\
\hline & 4 & 16 & 28 & 40 & 52 & 64 & 76 & 88 & & \\
\hline \multicolumn{11}{|c|}{$\mathrm{G}^{*}$ [quantas vezes aumentou ou diminuiu] } \\
\hline RTFOT & $6,1.10^{4}$ & $1,1.10^{4}$ & $1,5.10^{3}$ & 204,9 & 42,8 & 11,9 & 3,5 & 1,0 & & \\
\hline PAV & 1,1 & 1,3 & 1,6 & 1,8 & 1,8 & 1,9 & 2,0 & 2,2 & \multicolumn{2}{|c|}{1,7} \\
\hline UV $0,68 \mathrm{~W} / \mathrm{m}^{2}$ & 1,1 & 1,4 & 1,7 & 2,1 & 2,2 & 2,4 & 2,7 & 2,9 & \multicolumn{2}{|c|}{2,0} \\
\hline $\mathrm{UV} 1,00 \mathrm{~W} / \mathrm{m}^{2}$ & 1,4 & 2,2 & 4,1 & 7,3 & 11,3 & 14,6 & 20,9 & 32,4 & \multicolumn{2}{|c|}{11,8} \\
\hline \multicolumn{11}{|c|}{$\delta$ [quantos graus aumentou ou diminuiu] } \\
\hline RTFOT & 30,2 & 41,9 & 52,5 & 57,1 & 58,9 & 63,3 & 70,2 & 76,9 & \multirow{2}{*}{\multicolumn{2}{|c|}{$-5,8$}} \\
\hline PAV & $-1,4$ & $-4,0$ & $-4,9$ & $-4,1$ & $-4,5$ & $-7,2$ & $-9,8$ & $-10,3$ & & \\
\hline $\mathrm{UV} 0,68 \mathrm{~W} / \mathrm{m}^{2}$ & $-1,8$ & $-5,0$ & $-6,1$ & $-5,6$ & $-5,9$ & $-8,0$ & $-10,1$ & $-8,9$ & \multicolumn{2}{|c|}{$-6,4$} \\
\hline $\mathrm{UV} 1,00 \mathrm{~W} / \mathrm{m}^{2}$ & $-5,0$ & $-11,8$ & $-17,6$ & $-18,6$ & $-20,0$ & $-25,2$ & $-32,7$ & $-39,5$ & \multicolumn{2}{|c|}{$-21,3$} \\
\hline \multicolumn{11}{|c|}{$\mathrm{G}^{*} / \operatorname{sen} \delta$ e $\mathrm{G}^{*} . \operatorname{sen} \delta$ [quantas vezes aumentou ou diminuiu] } \\
\hline & \multicolumn{4}{|c|}{$\mathrm{G}^{*} \cdot \operatorname{sen} \delta$} & \multicolumn{4}{|c|}{$\mathrm{G}^{*} / \operatorname{sen} \delta$} & $\begin{array}{l}\mathrm{G}^{*} . \\
\text { sen } \delta\end{array}$ & $\begin{array}{l}\mathrm{G}^{* /} \\
\text { sen } \delta\end{array}$ \\
\hline RTFOT & $3,1.10^{4}$ & $7,4 \cdot 10^{3}$ & $1,2.10^{3}$ & 172,1 & 50,0 & 13,4 & 3,7 & 1,1 & & \\
\hline PAV & 1,1 & 1,2 & 1,5 & 1,7 & 1,9 & 2,0 & 2,2 & 2,3 & 1,4 & 2,1 \\
\hline UV $0,68 \mathrm{~W} / \mathrm{m}^{2}$ & 1,0 & 1,2 & 1,6 & 1,9 & 2,4 & 2,6 & 2,9 & 3,0 & 1,4 & 2,7 \\
\hline $\mathrm{UV} 1,00 \mathrm{~W} / \mathrm{m}^{2}$ & 1,2 & 1,7 & 2,9 & 5,4 & 15,4 & 21,2 & 32,4 & 51,9 & 2,8 & 30,2 \\
\hline
\end{tabular}


Tabela 4.33 - Variações de $G^{*}$, $\delta$, $G^{*} / \operatorname{sen} \delta$ e $G^{*}$.sen $\delta$ do CAP 50/70-SBS nas condições PAV e UV em relação aos valores do material envelhecido a curto prazo, a $10 \mathrm{rad} / \mathrm{s}$, em função da temperatura

\begin{tabular}{|c|c|c|c|c|c|c|c|c|c|c|}
\hline \multirow{2}{*}{$\begin{array}{c}\text { nível de } \\
\text { envelhecimento }\end{array}$} & \multicolumn{8}{|c|}{ temperatura $\left({ }^{\circ} \mathbf{C}\right)$} & \multirow{2}{*}{\multicolumn{2}{|c|}{ média }} \\
\hline & 4 & 16 & 28 & 40 & 52 & 64 & 76 & 88 & & \\
\hline \multicolumn{11}{|c|}{$\mathrm{G}^{*}$ [quantas vezes aumentou ou diminuiu] } \\
\hline RTFOT & $8,8.10^{4}$ & $1,7.10^{4}$ & $2,2.10^{3}$ & 249,2 & 40,2 & 9,6 & 2,3 & 0,6 & & \\
\hline PAV & 1,1 & 1,3 & 1,7 & 2,1 & 1,9 & 1,8 & 1,9 & 1,9 & \multicolumn{2}{|c|}{1,7} \\
\hline UV $0,68 \mathrm{~W} / \mathrm{m}^{2}$ & 1,1 & 1,3 & 1,8 & 2,2 & 2,3 & 2,2 & 2,2 & 2,2 & \multicolumn{2}{|c|}{1,9} \\
\hline $\mathrm{UV} 1,00 \mathrm{~W} / \mathrm{m}^{2}$ & 1,3 & 1,8 & 3,0 & 5,0 & 5,4 & 5,6 & 6,2 & 6,8 & \multicolumn{2}{|c|}{4,4} \\
\hline \multicolumn{11}{|c|}{$\delta$ [quantos graus aumentou ou diminuiu] } \\
\hline RTFOT & 28,2 & 41,8 & 56,2 & 63,8 & 64,1 & 71,1 & 79,4 & 84,6 & & \\
\hline PAV & $-2,7$ & $-5,1$ & $-7,1$ & $-5,1$ & $-2,0$ & $-3,8$ & $-3,5$ & $-2,4$ & \multicolumn{2}{|c|}{$-4,0$} \\
\hline UV $0,68 \mathrm{~W} / \mathrm{m}^{2}$ & $-3,3$ & $-5,9$ & $-7,7$ & $-4,7$ & $-1,2$ & $-5,2$ & $-6,0$ & $-3,9$ & \multicolumn{2}{|c|}{$-4,7$} \\
\hline $\mathrm{UV} 1,00 \mathrm{~W} / \mathrm{m}^{2}$ & $-5,0$ & $-10,6$ & $-16,0$ & $-14,9$ & $-9,6$ & $-12,6$ & $-17,1$ & $-17,3$ & \multicolumn{2}{|c|}{$-12,9$} \\
\hline \multicolumn{11}{|c|}{$\mathrm{G}^{*} / \operatorname{sen} \delta$ e $\mathrm{G}^{*} \cdot \operatorname{sen} \delta$ [quantas vezes aumentou ou diminuiu] } \\
\hline & \multicolumn{4}{|c|}{$\mathrm{G}^{*} \cdot \operatorname{sen} \delta$} & \multicolumn{4}{|c|}{$\mathrm{G}^{*} / \operatorname{sen} \delta$} & $\begin{array}{l}\mathrm{G}^{*} . \\
\text { sen } \delta\end{array}$ & $\begin{array}{c}\mathrm{G}^{* /} \\
\operatorname{sen} \delta\end{array}$ \\
\hline RTFOT & $4,1.10^{4}$ & $1,2.10^{4}$ & $1,8.10^{3}$ & 223,6 & 44,7 & 10,1 & 2,3 & 0,6 & & \\
\hline PAV & 1,0 & 1,2 & 1,5 & 2,0 & 1,9 & 1,9 & 1,9 & 1,9 & 1,4 & 1,9 \\
\hline $\mathrm{UV} 0,68 \mathrm{~W} / \mathrm{m}^{2}$ & 1,0 & 1,2 & 1,6 & 2,1 & 2,3 & 2,3 & 2,3 & 2,2 & 1,4 & 2,3 \\
\hline $\mathrm{UV} 1,00 \mathrm{~W} / \mathrm{m}^{2}$ & 1,1 & 1,4 & 2,4 & 4,2 & 6,0 & 6,2 & 6,9 & 7,3 & 2,2 & 6,6 \\
\hline
\end{tabular}


Tabela 4.34 - Variações de $G^{*}, \delta$, $G * / \operatorname{sen} \delta$ e $G^{*}$.sen $\delta$ do CAP 50/70-SBS-PPA nas condições PAV e UV em relação aos valores do material envelhecido a curto $\mathrm{prazo}$, a $10 \mathrm{rad} / \mathrm{s}$, em função da temperatura

\begin{tabular}{|c|c|c|c|c|c|c|c|c|c|c|}
\hline \multirow{2}{*}{$\begin{array}{c}\text { nível de } \\
\text { envelhecimento }\end{array}$} & \multicolumn{8}{|c|}{ temperatura $\left({ }^{\circ} \mathbf{C}\right)$} & \multirow{2}{*}{\multicolumn{2}{|c|}{ média }} \\
\hline & 4 & 16 & 28 & 40 & 52 & 64 & 76 & 88 & & \\
\hline \multicolumn{11}{|c|}{$\mathrm{G}^{*}[$ quantas vezes aumentou ou diminuiu] } \\
\hline RTFOT & $8,8.10^{4}$ & $1,7.10^{4}$ & $2,4.10^{3}$ & 315,6 & 50,8 & 12,9 & 3,3 & 0,8 & & \\
\hline PAV & 1,2 & 1,4 & 1,9 & 2,4 & 2,7 & 2,6 & 2,7 & 2,8 & \multicolumn{2}{|c|}{2,2} \\
\hline UV $0,68 \mathrm{~W} / \mathrm{m}^{2}$ & 1,1 & 1,4 & 1,9 & 2,4 & 2,8 & 2,7 & 2,8 & 2,9 & \multicolumn{2}{|c|}{2,3} \\
\hline $\mathrm{UV} 1,00 \mathrm{~W} / \mathrm{m}^{2}$ & 1,6 & 3,1 & 8,3 & 23,5 & 54,1 & 82,9 & 132,3 & 218,6 & \multicolumn{2}{|c|}{65,5} \\
\hline \multicolumn{11}{|c|}{$\delta$ [quantos graus aumentou ou diminuiu] } \\
\hline RTFOT & 29,2 & 41,1 & 53,1 & 60,4 & 61,2 & 65,8 & 74,6 & 81,0 & & \\
\hline PAV & $-3,9$ & $-6,4$ & $-8,3$ & $-7,5$ & $-5,1$ & $-6,4$ & $-8,4$ & $-6,8$ & \multicolumn{2}{|c|}{$-6,6$} \\
\hline UV $0,68 \mathrm{~W} / \mathrm{m}^{2}$ & $-3,6$ & $-5,9$ & $-8,0$ & $-6,4$ & $-4,0$ & $-5,4$ & $-7,5$ & $-6,5$ & \multicolumn{2}{|c|}{$-5,9$} \\
\hline $\mathrm{UV} 1,00 \mathrm{~W} / \mathrm{m}^{2}$ & $-10,5$ & $-19,7$ & $-29,0$ & $-33,4$ & $-30,7$ & $-35,1$ & $-43,3$ & $-49,1$ & \multicolumn{2}{|c|}{$-31,3$} \\
\hline \multicolumn{11}{|c|}{$\mathrm{G}^{*} / \operatorname{sen} \delta$ e $\mathrm{G}^{*} . \operatorname{sen} \delta$ [quantas vezes aumentou ou diminuiu] } \\
\hline & \multicolumn{4}{|c|}{$\mathrm{G}^{*} \cdot \operatorname{sen} \delta$} & \multicolumn{4}{|c|}{$\mathrm{G}^{*} / \operatorname{sen} \delta$} & $\begin{array}{l}\mathrm{G}^{*} \\
\text { sen } \delta\end{array}$ & $\begin{array}{r}\mathrm{G}^{*} / \\
\operatorname{sen} \delta\end{array}$ \\
\hline RTFOT & $4,3.10^{4}$ & $1,1.10^{4}$ & $1,9.10^{3}$ & 274,4 & 57,9 & 14,1 & 3,4 & 0,9 & & \\
\hline PAV & 1,0 & 1,2 & 1,7 & 2,2 & 2,9 & 2,8 & 2,8 & 2,8 & 1,5 & 2,8 \\
\hline $\mathrm{UV} 0,68 \mathrm{~W} / \mathrm{m}^{2}$ & 1,0 & 1,2 & 1,7 & 2,3 & 2,9 & 2,9 & 2,9 & 2,9 & 1,5 & 2,9 \\
\hline UV $1,00 \mathrm{~W} / \mathrm{m}^{2}$ & 1,0 & 1,7 & 4,3 & 12,3 & 93,4 & 148,3 & 245,6 & 408,2 & 4,8 & 223,9 \\
\hline
\end{tabular}


Tabela 4.35 - Variações de $G^{*}, \delta$, $G^{*} / \operatorname{sen} \delta$ e $G^{*}$.sen $\delta$ do CAP 50/70-EVA nas condições PAV e UV em relação aos valores do material envelhecido a curto prazo, a $10 \mathrm{rad} / \mathrm{s}$, em função da temperatura

\begin{tabular}{|c|c|c|c|c|c|c|c|c|c|c|}
\hline \multirow{2}{*}{$\begin{array}{c}\text { nível de } \\
\text { envelhecimento }\end{array}$} & \multicolumn{8}{|c|}{ temperatura $\left({ }^{\circ} \mathbf{C}\right)$} & \multirow{2}{*}{\multicolumn{2}{|c|}{ média }} \\
\hline & 4 & 16 & 28 & 40 & 52 & 64 & 76 & 88 & & \\
\hline \multicolumn{11}{|c|}{$\mathrm{G}^{*}$ [quantas vezes aumentou ou diminuiu] } \\
\hline RTFOT & $8,1.10^{4}$ & $1,3.10^{4}$ & $1,9.10^{3}$ & 344,3 & 29,6 & 7,9 & 2,7 & 0,8 & & \\
\hline PAV & 0,9 & 1,1 & 1,4 & 1,6 & 4,6 & 5,7 & 5,7 & 4,0 & \multicolumn{2}{|c|}{3,2} \\
\hline UV $0,68 \mathrm{~W} / \mathrm{m}^{2}$ & 0,9 & 1,1 & 1,4 & 1,7 & 4,6 & 5,0 & 6,0 & 8,2 & \multicolumn{2}{|c|}{3,6} \\
\hline $\mathrm{UV} 1,00 \mathrm{~W} / \mathrm{m}^{2}$ & 1,0 & 1,6 & 3,0 & 5,0 & 19,5 & 27,0 & 35,3 & 51,6 & \multicolumn{2}{|c|}{18,0} \\
\hline \multicolumn{11}{|c|}{$\delta$ [quantos graus aumentou ou diminuiu] } \\
\hline RTFOT & 31,6 & 43,0 & 49,0 & 49,1 & 59,5 & 66,3 & 73,7 & 80,9 & & \\
\hline PAV & $-2,7$ & $-5,5$ & $-5,7$ & $-2,1$ & $-6,2$ & $-7,8$ & $-10,3$ & $-8,8$ & \multicolumn{2}{|c|}{$-6,1$} \\
\hline UV $0,68 \mathrm{~W} / \mathrm{m}^{2}$ & $-2,5$ & $-5,5$ & $-6,6$ & $-4,9$ & $-12,1$ & $-10,8$ & $-12,2$ & $-15,2$ & \multicolumn{2}{|c|}{$-8,7$} \\
\hline UV $1,00 \mathrm{~W} / \mathrm{m}^{2}$ & $-5,7$ & $-13,1$ & $-17,5$ & $-15,6$ & $-19,1$ & $-21,3$ & $-25,9$ & $-30,6$ & \multicolumn{2}{|c|}{$-18,6$} \\
\hline \multicolumn{11}{|c|}{$\mathrm{G}^{*} / \operatorname{sen} \delta$ e $\mathrm{G}^{*} \cdot \operatorname{sen} \delta$ [quantas vezes aumentou ou diminuiu] } \\
\hline & \multicolumn{4}{|c|}{$\mathrm{G}^{*} \cdot \operatorname{sen} \delta$} & \multicolumn{4}{|c|}{$\mathrm{G}^{*} / \operatorname{sen} \delta$} & $\begin{array}{l}\mathrm{G}^{*} . \\
\text { sen } \delta\end{array}$ & $\begin{array}{l}* / \\
\text { sen } \delta \\
\end{array}$ \\
\hline RTFOT & $4,3 \cdot 10^{4}$ & $9,0.10^{3}$ & $1,4 \cdot 10^{3}$ & 260,2 & 34,4 & 8,6 & 2,8 & 0,8 & & \\
\hline PAV & 0,9 & 1,0 & 1,3 & 1,6 & 5,0 & 6,1 & 6,2 & 4,2 & 1,2 & 5,4 \\
\hline $\mathrm{UV} 0,68 \mathrm{~W} / \mathrm{m}^{2}$ & 0,9 & 1,0 & 1,3 & 1,6 & 5,4 & 5,5 & 6,6 & 8,9 & 1,2 & 6,6 \\
\hline UV $1,00 \mathrm{~W} / \mathrm{m}^{2}$ & 0,9 & 1,2 & 2,1 & 3,6 & 25,9 & 35,0 & 45,7 & 66,2 & 1,9 & 43,2 \\
\hline
\end{tabular}


Tabela 4.36 - Variações de $G^{*}, \delta$, G*/sen $\delta$ e $G^{*} . \operatorname{sen} \delta$ do CAP 50/70-EVA-PPA nas condições PAV e UV em relação aos valores do material envelhecido a curto $\mathrm{prazo}$, a $10 \mathrm{rad} / \mathrm{s}$, em função da temperatura

\begin{tabular}{|c|c|c|c|c|c|c|c|c|c|c|}
\hline \multirow{2}{*}{$\begin{array}{c}\text { nível de } \\
\text { envelhecimento }\end{array}$} & \multicolumn{8}{|c|}{ temperatura $\left({ }^{\circ} \mathbf{C}\right)$} & \multirow{2}{*}{\multicolumn{2}{|c|}{ média }} \\
\hline & 4 & 16 & 28 & 40 & 52 & 64 & 76 & 88 & & \\
\hline \multicolumn{11}{|c|}{$\mathrm{G}^{*}$ [quantas vezes aumentou ou diminuiu] } \\
\hline RTFOT & $8,3.10^{4}$ & $1,4.10^{4}$ & $1,9.10^{3}$ & 290,4 & 68,1 & 19,6 & 5,3 & 1,1 & & \\
\hline PAV & 1,2 & 1,6 & 2,2 & 2,8 & 2,2 & 2,7 & 3,3 & 4,9 & \multicolumn{2}{|c|}{2,6} \\
\hline UV $0,68 \mathrm{~W} / \mathrm{m}^{2}$ & 1,1 & 1,3 & 1,6 & 1,9 & 2,0 & 1,9 & 2,1 & 2,9 & \multicolumn{2}{|c|}{1,8} \\
\hline $\mathrm{UV} 1,00 \mathrm{~W} / \mathrm{m}^{2}$ & 1,1 & 1,6 & 2,3 & 3,3 & 2,8 & 3,1 & 3,9 & 6,4 & \multicolumn{2}{|c|}{3,1} \\
\hline \multicolumn{11}{|c|}{$\delta$ [quantos graus aumentou ou diminuiu] } \\
\hline RTFOT & 31,7 & 42,8 & 51,5 & 57,2 & 59,2 & 62,4 & 67,3 & 76,0 & & \\
\hline PAV & $-4,9$ & $-7,2$ & $-8,5$ & $-7,9$ & $-4,2$ & $-5,4$ & $-7,1$ & $-10,5$ & \multicolumn{2}{|c|}{$-7,0$} \\
\hline UV $0,68 \mathrm{~W} / \mathrm{m}^{2}$ & $-3,3$ & $-4,9$ & $-4,7$ & $-3,9$ & $-2,8$ & $-1,6$ & $-1,5$ & $-3,8$ & \multicolumn{2}{|c|}{$-3,3$} \\
\hline $\mathrm{UV} 1,00 \mathrm{~W} / \mathrm{m}^{2}$ & $-5,3$ & $-8,7$ & $-10,3$ & $-10,5$ & $-5,8$ & $-5,8$ & $-7,6$ & $-11,2$ & \multicolumn{2}{|c|}{$-8,1$} \\
\hline \multicolumn{11}{|c|}{$\mathrm{G}^{*} / \operatorname{sen} \delta$ e $\mathrm{G}^{*} \cdot \operatorname{sen} \delta$ [quantas vezes aumentou ou diminuiu] } \\
\hline & \multicolumn{4}{|c|}{$G^{*} \cdot \operatorname{sen} \delta$} & \multicolumn{4}{|c|}{$\mathrm{G}^{*} / \mathrm{sen} \delta$} & $\begin{array}{l}\mathrm{G}^{*} . \\
\text { sen } \delta\end{array}$ & $\begin{array}{r}\mathrm{G}^{* /} \\
\text { sen } \delta \\
\end{array}$ \\
\hline RTFOT & $4,3.10^{4}$ & $9,5.10^{3}$ & $1,5.10^{3}$ & 244,1 & 79,3 & 22,1 & 5,8 & 1,1 & & \\
\hline PAV & 1,0 & 1,4 & 1,9 & 2,5 & 2,3 & 2,8 & 3,5 & 5,2 & 1,7 & 3,5 \\
\hline UV $0,68 \mathrm{~W} / \mathrm{m}^{2}$ & 1,0 & 1,2 & 1,5 & 1,8 & 2,1 & 2,0 & 2,1 & 2,9 & 1,4 & 2,3 \\
\hline $\mathrm{UV} 1,00 \mathrm{~W} / \mathrm{m}^{2}$ & 1,0 & 1,3 & 2,0 & 2,9 & 2,9 & 3,3 & 4,2 & 6,8 & 1,8 & 4,3 \\
\hline
\end{tabular}


Tabela 4.37 - Variações de $G^{*}, \delta, G^{*} / \operatorname{sen} \delta$ e $G^{*}$.sen $\delta$ do CAP 50/70-PE nas condições PAV e UV em relação aos valores do material envelhecido a curto prazo, a $10 \mathrm{rad} / \mathrm{s}$, em função da temperatura

\begin{tabular}{|c|c|c|c|c|c|c|c|c|c|c|}
\hline \multirow{2}{*}{$\begin{array}{c}\text { nível de } \\
\text { envelhecimento }\end{array}$} & \multicolumn{8}{|c|}{ temperatura $\left({ }^{\circ} \mathbf{C}\right)$} & \multirow{2}{*}{\multicolumn{2}{|c|}{ média }} \\
\hline & 4 & 16 & 28 & 40 & 52 & 64 & 76 & 88 & & \\
\hline \multicolumn{11}{|c|}{$\mathrm{G}^{*}$ [quantas vezes aumentou ou diminuiu] } \\
\hline RTFOT & $1,1.10^{5}$ & $2,2.10^{4}$ & $3,1.10^{3}$ & 416,7 & 54,0 & 10,0 & 2,3 & 0,7 & & \\
\hline PAV & 1,0 & 1,2 & 1,6 & 1,9 & 2,5 & 2,4 & 2,0 & 1,7 & \multicolumn{2}{|c|}{1,8} \\
\hline UV $0,68 \mathrm{~W} / \mathrm{m}^{2}$ & 1,0 & 1,2 & 1,6 & 2,0 & 2,6 & 2,3 & 1,8 & 1,4 & \multicolumn{2}{|c|}{1,8} \\
\hline $\mathrm{UV} 1,00 \mathrm{~W} / \mathrm{m}^{2}$ & 1,0 & 1,3 & 1,9 & 2,6 & 3,1 & 2,9 & 2,3 & 1,7 & \multicolumn{2}{|c|}{2,1} \\
\hline \multicolumn{11}{|c|}{$\delta$ [quantos graus aumentou ou diminuiu] } \\
\hline RTFOT & 28,4 & 41,4 & 55,1 & 65,1 & 71,1 & 77,0 & 80,3 & 81,9 & \multirow{2}{*}{\multicolumn{2}{|c|}{$-4,0$}} \\
\hline PAV & $-3,0$ & $-5,2$ & $-7,2$ & $-7,0$ & $-5,8$ & $-4,1$ & $-0,9$ & 1,0 & & \\
\hline $\mathrm{UV} 0,68 \mathrm{~W} / \mathrm{m}^{2}$ & $-3,3$ & $-6,4$ & $-9,0$ & $-7,9$ & $-4,4$ & $-2,0$ & 1,1 & 3,1 & \multicolumn{2}{|c|}{$-3,6$} \\
\hline $\mathrm{UV} 1,00 \mathrm{~W} / \mathrm{m}^{2}$ & $-3,8$ & $-7,5$ & $-11,1$ & $-10,7$ & $-6,3$ & $-3,7$ & 0,0 & 2,7 & \multicolumn{2}{|c|}{$-5,1$} \\
\hline \multicolumn{11}{|c|}{$\mathrm{G}^{*} / \operatorname{sen} \delta$ e $\mathrm{G}^{*} . \operatorname{sen} \delta$ [quantas vezes aumentou ou diminuiu] } \\
\hline & \multicolumn{4}{|c|}{$\mathrm{G}^{*} \cdot \operatorname{sen} \delta$} & \multicolumn{4}{|c|}{$\mathrm{G}^{*} / \operatorname{sen} \delta$} & $\begin{array}{l}\mathrm{G}^{*} . \\
\text { sen } \delta\end{array}$ & $\begin{array}{l}\mathrm{G}^{* /} \\
\text { sen } \delta\end{array}$ \\
\hline RTFOT & $5,4.10^{4}$ & $1,5.10^{4}$ & $2,5.10^{3}$ & 377,8 & 57,1 & 10,3 & 2,4 & 0,7 & & \\
\hline PAV & 0,9 & 1,1 & 1,4 & 1,7 & 2,6 & 2,5 & 2,0 & 1,7 & 1,3 & 2,2 \\
\hline $\mathrm{UV} 0,68 \mathrm{~W} / \mathrm{m}^{2}$ & 0,9 & 1,0 & 1,4 & 1,9 & 2,7 & 2,3 & 1,8 & 1,4 & 1,3 & 2,1 \\
\hline $\mathrm{UV} 1,00 \mathrm{~W} / \mathrm{m}^{2}$ & 0,9 & 1,1 & 1,6 & 2,3 & 3,3 & 3,0 & 2,3 & 1,7 & 1,5 & 2,6 \\
\hline
\end{tabular}


Tabela 4.38 - Variações de $G^{*}, \delta, G^{*} / \operatorname{sen} \delta$ e $G^{*} \cdot \operatorname{sen} \delta$ do CAP 50/70-PE-PPA nas condições PAV e UV em relação aos valores do material envelhecido a curto $\mathrm{prazo}$, a $10 \mathrm{rad} / \mathrm{s}$, em função da temperatura

\begin{tabular}{|c|c|c|c|c|c|c|c|c|c|c|}
\hline \multirow{2}{*}{$\begin{array}{c}\text { nível de } \\
\text { envelhecimento }\end{array}$} & \multicolumn{8}{|c|}{ temperatura $\left({ }^{\circ} \mathbf{C}\right)$} & \multirow{2}{*}{\multicolumn{2}{|c|}{ média }} \\
\hline & 4 & 16 & 28 & 40 & 52 & 64 & 76 & 88 & & \\
\hline \multicolumn{11}{|c|}{$\mathrm{G}^{*}$ [quantas vezes aumentou ou diminuiu] } \\
\hline RTFOT & $9,5.10^{4}$ & $1,8 \cdot 10^{4}$ & $2,4.10^{3}$ & 358,6 & 57,9 & 12,0 & 2,7 & 0,7 & & \\
\hline PAV & 1,2 & 1,4 & 1,9 & 2,4 & 2,6 & 2,6 & 2,5 & 2,3 & \multicolumn{2}{|c|}{2,1} \\
\hline $\mathrm{UV} 0,68 \mathrm{~W} / \mathrm{m}^{2}$ & 1,3 & 1,7 & 2,4 & 2,9 & 3,4 & 3,3 & 2,9 & 2,6 & \multicolumn{2}{|c|}{2,6} \\
\hline $\mathrm{UV} 1,00 \mathrm{~W} / \mathrm{m}^{2}$ & 1,4 & 1,9 & 2,7 & 3,3 & 3,8 & 3,5 & 3,2 & 2,7 & \multicolumn{2}{|c|}{2,8} \\
\hline \multicolumn{11}{|c|}{$\delta$ [quantos graus aumentou ou diminuiu] } \\
\hline RTFOT & 30,2 & 42,9 & 54,6 & 61,7 & 66,0 & 71,4 & 76,6 & 80,5 & & \\
\hline PAV & $-4,1$ & $-6,8$ & $-9,3$ & $-9,1$ & $-6,9$ & $-6,7$ & $-5,1$ & $-2,9$ & \multicolumn{2}{|c|}{$-6,4$} \\
\hline UV $0,68 \mathrm{~W} / \mathrm{m}^{2}$ & $-5,1$ & $-7,8$ & $-9,3$ & $-7,4$ & $-5,2$ & $-4,2$ & $-2,6$ & $-0,5$ & \multicolumn{2}{|c|}{$-5,3$} \\
\hline $\mathrm{UV} 1,00 \mathrm{~W} / \mathrm{m}^{2}$ & $-5,4$ & $-8,2$ & $-9,5$ & $-7,4$ & $-5,0$ & $-3,7$ & $-1,9$ & 0,2 & \multicolumn{2}{|c|}{$-5,1$} \\
\hline \multicolumn{11}{|c|}{$\mathrm{G}^{*} / \operatorname{sen} \delta$ e $\mathrm{G}^{*}$.sen $\delta$ [quantas vezes aumentou ou diminuiu] } \\
\hline & \multicolumn{4}{|c|}{$\mathrm{G}^{*} \cdot \operatorname{sen} \delta$} & \multicolumn{4}{|c|}{$\mathrm{G} * / \operatorname{sen} \delta$} & $\begin{array}{l}\mathrm{G}^{*} . \\
\operatorname{sen} \delta\end{array}$ & $\begin{array}{l}\mathrm{G}^{* /} \\
\operatorname{sen} \delta\end{array}$ \\
\hline RTFOT & $4,8.10^{4}$ & $1,2.10^{4}$ & $1,9.10^{3}$ & 315,7 & 63,4 & 12,6 & 2,8 & 0,7 & & \\
\hline PAV & 1,0 & 1,2 & 1,7 & 2,1 & 2,8 & 2,8 & 2,6 & 2,3 & 1,5 & 2,6 \\
\hline UV $0,68 \mathrm{~W} / \mathrm{m}^{2}$ & 1,1 & 1,4 & 2,1 & 2,7 & 3,5 & 3,4 & 3,0 & 2,6 & 1,8 & 3,1 \\
\hline $\mathrm{UV} 1,00 \mathrm{~W} / \mathrm{m}^{2}$ & 1,2 & 1,6 & 2,3 & 3,0 & 4,0 & 3,6 & 3,2 & 2,7 & 2,0 & 3,4 \\
\hline
\end{tabular}


Tabela 4.39 - Variações de $G^{*}, \delta, G^{*} / \operatorname{sen} \delta$ e $G^{*}$.sen $\delta$ do CAP 50/70-SBR nas condições PAV e UV em relação aos valores do material envelhecido a curto prazo, a $10 \mathrm{rad} / \mathrm{s}$, em função da temperatura

\begin{tabular}{|c|c|c|c|c|c|c|c|c|c|c|}
\hline \multirow{2}{*}{$\begin{array}{c}\text { nível de } \\
\text { envelhecimento }\end{array}$} & \multicolumn{8}{|c|}{ temperatura $\left({ }^{\circ} \mathbf{C}\right)$} & \multirow{2}{*}{\multicolumn{2}{|c|}{ média }} \\
\hline & 4 & 16 & 28 & 40 & 52 & 64 & 76 & 88 & & \\
\hline \multicolumn{11}{|c|}{$\mathrm{G}^{*}$ [quantas vezes aumentou ou diminuiu] } \\
\hline RTFOT & $7,5.10^{4}$ & $1,5.10^{4}$ & $1,9.10^{3}$ & 239,0 & 39,3 & 9,2 & 2,4 & 0,7 & & \\
\hline PAV & 1,3 & 1,6 & 2,1 & 2,5 & 2,6 & 2,5 & 2,5 & 2,4 & \multicolumn{2}{|c|}{2,2} \\
\hline UV $0,68 \mathrm{~W} / \mathrm{m}^{2}$ & 1,2 & 1,3 & 1,5 & 1,6 & 1,7 & 1,7 & 1,7 & 1,7 & \multicolumn{2}{|c|}{1,6} \\
\hline $\mathrm{UV} 1,00 \mathrm{~W} / \mathrm{m}^{2}$ & 1,1 & 1,3 & 1,5 & 1,8 & 2,0 & 1,9 & 1,8 & 1,8 & \multicolumn{2}{|c|}{1,7} \\
\hline \multicolumn{11}{|c|}{$\delta$ [quantos graus aumentou ou diminuiu] } \\
\hline RTFOT & 27,7 & 40,9 & 54,7 & 63,1 & 68,3 & 72,6 & 76,4 & 80,4 & & \\
\hline PAV & $-3,1$ & $-5,9$ & $-7,9$ & $-6,9$ & $-7,2$ & $-6,4$ & $-5,7$ & $-5,3$ & \multicolumn{2}{|c|}{$-6,0$} \\
\hline UV $0,68 \mathrm{~W} / \mathrm{m}^{2}$ & $-1,5$ & $-3,0$ & $-4,0$ & $-2,7$ & $-4,1$ & $-3,3$ & $-2,9$ & $-3,1$ & \multicolumn{2}{|c|}{$-3,1$} \\
\hline UV $1,00 \mathrm{~W} / \mathrm{m}^{2}$ & $-1,7$ & $-3,2$ & $-4,2$ & $-3,1$ & $-3,9$ & $-3,2$ & $-3,0$ & $-3,0$ & \multicolumn{2}{|c|}{$-3,2$} \\
\hline \multicolumn{11}{|c|}{$\mathrm{G}^{*} / \operatorname{sen} \delta$ e $\mathrm{G}^{*} \cdot \operatorname{sen} \delta$ [quantas vezes aumentou ou diminuiu] } \\
\hline & \multicolumn{4}{|c|}{$\mathrm{G}^{*} \cdot \operatorname{sen} \delta$} & \multicolumn{4}{|c|}{$\mathrm{G}^{*} / \operatorname{sen} \delta$} & $\begin{array}{l}\mathrm{G}^{*} . \\
\text { sen } \delta\end{array}$ & $\begin{array}{c}\mathrm{G}^{* /} \\
\operatorname{sen} \delta \\
\end{array}$ \\
\hline RTFOT & $3,5.10^{4}$ & $9,8.10^{3}$ & $1,6.10^{3}$ & 213,2 & 42,2 & 9,7 & 2,5 & 0,7 & & \\
\hline PAV & 1,2 & 1,4 & 1,9 & 2,3 & 2,7 & 2,7 & 2,6 & 2,5 & 1,7 & 2,6 \\
\hline UV $0,68 \mathrm{~W} / \mathrm{m}^{2}$ & 1,1 & 1,2 & 1,5 & 1,5 & 1,8 & 1,8 & 1,8 & 1,7 & 1,3 & 1,8 \\
\hline UV $1,00 \mathrm{~W} / \mathrm{m}^{2}$ & 1,1 & 1,2 & 1,4 & 1,7 & 2,0 & 1,9 & 1,9 & 1,8 & 1,4 & 1,9 \\
\hline
\end{tabular}


Tabela 4.40 - Variações de $G^{*}, \delta$, $G^{*} / \operatorname{sen} \delta$ e $G^{*}$.sen $\delta$ do CAP 50/70-SBR-PPA nas condições PAV e UV em relação aos valores do material envelhecido a curto prazo, a $10 \mathrm{rad} / \mathrm{s}$, em função da temperatura

\begin{tabular}{|c|c|c|c|c|c|c|c|c|c|c|}
\hline \multirow{2}{*}{$\begin{array}{c}\text { nível de } \\
\text { envelhecimento }\end{array}$} & \multicolumn{8}{|c|}{ temperatura $\left({ }^{\circ} \mathbf{C}\right)$} & \multirow{2}{*}{\multicolumn{2}{|c|}{ média }} \\
\hline & 4 & 16 & 28 & 40 & 52 & 64 & 76 & 88 & & \\
\hline \multicolumn{11}{|c|}{$\mathrm{G}^{*}$ [quantas vezes aumentou ou diminuiu] } \\
\hline RTFOT & $8,7.10^{4}$ & $1,7.10^{4}$ & $2,4.10^{3}$ & 336,9 & 54,6 & 13,3 & 3,5 & 1,0 & & \\
\hline PAV & 0,9 & 1,0 & 1,3 & 1,5 & 2,3 & 2,4 & 2,4 & 2,4 & \multicolumn{2}{|c|}{1,8} \\
\hline UV $0,68 \mathrm{~W} / \mathrm{m}^{2}$ & 1,1 & 1,3 & 1,6 & 1,7 & 2,0 & 2,1 & 2,3 & 2,3 & \multicolumn{2}{|c|}{1,8} \\
\hline $\mathrm{UV} 1,00 \mathrm{~W} / \mathrm{m}^{2}$ & 1,1 & 1,4 & 1,9 & 2,3 & 3,0 & 3,6 & 4,4 & 4,7 & \multicolumn{2}{|c|}{2,8} \\
\hline \multicolumn{11}{|c|}{$\delta$ [quantos graus aumentou ou diminuiu] } \\
\hline RTFOT & 28,9 & 40,7 & 52,5 & 60,3 & 64,6 & 68,6 & 72,6 & 76,9 & & \\
\hline PAV & $-3,8$ & $-5,3$ & $-7,5$ & $-6,9$ & $-6,9$ & $-6,7$ & $-6,1$ & $-5,7$ & \multicolumn{2}{|c|}{$-6,1$} \\
\hline $\mathrm{UV} 0,68 \mathrm{~W} / \mathrm{m}^{2}$ & $-2,7$ & $-4,6$ & $-6,1$ & $-5,0$ & $-5,6$ & $-5,3$ & $-5,5$ & $-5,4$ & \multicolumn{2}{|c|}{$-5,0$} \\
\hline $\mathrm{UV} 1,00 \mathrm{~W} / \mathrm{m}^{2}$ & $-4,2$ & $-7,6$ & $-10,2$ & $-10,2$ & $-11,8$ & $-12,3$ & $-12,4$ & $-12,2$ & \multicolumn{2}{|c|}{$-10,1$} \\
\hline \multicolumn{11}{|c|}{$\mathrm{G}^{*} / \operatorname{sen} \delta$ e $\mathrm{G}^{*} \cdot \operatorname{sen} \delta$ [quantas vezes aumentou ou diminuiu] } \\
\hline & \multicolumn{4}{|c|}{$\mathrm{G}^{*} \cdot \operatorname{sen} \delta$} & \multicolumn{4}{|c|}{$\mathrm{G}^{*} / \operatorname{sen} \delta$} & $\begin{array}{l}\mathrm{G}^{*} . \\
\text { sen } \delta\end{array}$ & $\begin{array}{l}\mathrm{G}^{*} / \\
\operatorname{sen} \delta\end{array}$ \\
\hline RTFOT & $4,2.10^{4}$ & $1,1.10^{4}$ & $1,9.10^{3}$ & 292,5 & 60,4 & 14,3 & 3,6 & 1,0 & & \\
\hline PAV & 0,8 & 0,9 & 1,2 & 1,4 & 2,4 & 2,5 & 2,5 & 2,5 & 1,1 & 2,5 \\
\hline UV $0,68 \mathrm{~W} / \mathrm{m}^{2}$ & 1,0 & 1,2 & 1,5 & 1,6 & 2,1 & 2,2 & 2,4 & 2,3 & 1,3 & 2,3 \\
\hline $\mathrm{UV} 1,00 \mathrm{~W} / \mathrm{m}^{2}$ & 0,9 & 1,2 & 1,6 & 2,1 & 3,4 & 4,1 & 4,8 & 5,1 & 1,4 & 4,3 \\
\hline
\end{tabular}

Um ordenamento das formulações em função do efeito dos envelhecimentos a longo prazo, tendo o CAP envelhecido no RTFOT como referência, foi efetuado com base nos valores de $\mathrm{G}^{*}, \delta$ e $\mathrm{G}^{*}$.sen $\delta$, apresentados nas Tabelas de 4.29 a 4.40 . Os valores de $\mathrm{G}^{*} / \mathrm{sen} \delta$ não foram empregados neste ordenamento, por se tratar de um parâmetro relacionado à deformação permanente, defeito que ocorre durante o envelhecimento a curto prazo.

Foi feito, primeiramente, um ordenamento dos ligantes asfálticos em cada temperatura e uma média simples final foi obtida com base nos ordenamentos médios em cada temperatura. Do ponto de vista de aumento de rigidez indicado pelo aumento dos valores de $\mathrm{G}^{*}$, admitiu-se que, quanto maior o índice, pior, por indicar maior sensibilidade ao envelhecimento. Em relação ao ângulo de fase, quanto maior a diferença entre os valores de $\delta$ 
das amostras envelhecidas a longo prazo e das amostras envelhecidas a curto prazo (RTFO), melhor, pois o envelhecimento provocou ganho de elasticidade.

No ordenamento dos índices de envelhecimento baseados nos valores de $\mathrm{G}^{*}$ e $\delta$, foram utilizados os dados referentes aos ligantes asfálticos envelhecidos a longo prazo, tendo o CAP envelhecido a curto prazo como referência, nas temperaturas de 4, 16, 28, 40, 52, 64, 76 e $88^{\circ} \mathrm{C}$

Do ponto de vista do parâmetro $G^{*}$.sen $\delta$, são melhores os que apresentam menores graus de envelhecimento, já que nas temperaturas intermediárias, ligantes asfálticos menos rígidos proporcionam misturas asfálticas mais resistentes à fadiga por deformação controlada. Foram utilizados para esta análise os dados referentes apenas aos ligantes asfálticos envelhecidos a longo prazo, nas temperaturas de $40,28,16$ e $4^{\circ} \mathrm{C}$. Já que a frequência afeta os valores dos parâmetros de envelhecimento, foi utilizada a frequência de $10 \mathrm{rad} / \mathrm{s}$ para esta análise, representativa de tráfego rápido.

O posicionamento das formulações é o indicado na Tabela 4.41. Nesta Tabela, são apresentadas as médias dos ordenamentos, por procedimento de envelhecimento. Na Tabela 4.42 é apresentado o ordenamento final das formulações em relação à sensibilidade ao envelhecimento a longo prazo na estufa PAV, da melhor para a pior. Na Tabela 4.43 é apresentado o ordenamento final das formulações em relação à sensibilidade ao envelhecimento a longo prazo na estufa UV a $0,68 \mathrm{~W} / \mathrm{m}^{2}$, da melhor para pior. Na Tabela 4.44 é apresentado o ordenamento final das formulações em relação à sensibilidade ao envelhecimento a longo prazo na estufa UV a $1,00 \mathrm{~W} / \mathrm{m}^{2}$, da melhor para a pior. E finalmente, na Tabela 4.45 é apresentado o ordenamento das amostras, considerando todos os envelhecimentos aos quais foram submetidas, da melhor para a pior. 
Tabela 4.41 - Ordenamento baseado nos índices de envelhecimento das Tabelas de 4.29 a 4.40

\begin{tabular}{|c|c|c|c|c|c|c|c|c|c|c|c|c|c|}
\hline índice de envelhecimento & CAP & PPA & borracha & $\begin{array}{c}\text { borracha } \\
\text { +PPA }\end{array}$ & SBS & $\begin{array}{r}\text { SBS } \\
+ \text { PPA }\end{array}$ & EVA & $\begin{array}{r}\text { EVA } \\
+ \text { PPA }\end{array}$ & $\mathbf{P E}$ & $\begin{array}{r}\text { PE } \\
+ \text { PPA }\end{array}$ & SBR & $\begin{array}{r}\text { SBR } \\
+ \text { PPA }\end{array}$ & critério \\
\hline $\mathrm{G}^{*}(\mathrm{PAV} / \mathrm{RTFOT})$ & 7,1 & 9,0 & 1,1 & 4,4 & 4,0 & 9,3 & 7,4 & 10,4 & 4,1 & 8,1 & 9,4 & 3,8 & maior, pior \\
\hline$\delta(\mathrm{PAV} / \mathrm{RTFOT})$ & 6,5 & 9,3 & 3,6 & 5,5 & 2,9 & 7,9 & 6,5 & 8,9 & 3,9 & 8,9 & 6,6 & 6,8 & maior, melhor \\
\hline $\mathrm{G}^{*} \cdot \operatorname{sen} \delta(\mathrm{PAV} / \mathrm{RTFOT})$ & 8,0 & 8,3 & 1,8 & 6,8 & 2,8 & 11,3 & 4,3 & 7,3 & 5,5 & 9,3 & 11,5 & 1,5 & maior, pior \\
\hline média & 7,2 & 8,9 & 2,2 & 5,6 & 3,2 & 9,5 & 6,1 & 8,9 & 4,5 & 8,8 & 9,2 & 4,0 & menor, melhor \\
\hline $\mathrm{G}^{*}$ (UV 0,68 W/m²/RTFOT) & 6,3 & 8,9 & 7,3 & 7,4 & 6,3 & 9,3 & 6,6 & 4,4 & 3,9 & 10,8 & 3,1 & 4,0 & maior, pior \\
\hline$\delta\left(\mathrm{UV} 0,68 \mathrm{~W} / \mathrm{m}^{2} / \mathrm{RTFOT}\right)$ & 7,3 & 8,1 & 10,8 & 6,8 & 5,5 & 7,9 & 7,8 & 3,1 & 5,6 & 7,6 & 2,5 & 5,1 & maior, melhor \\
\hline $\mathrm{G}^{*} \cdot \operatorname{sen} \delta\left(\mathrm{UV} 0,68 \mathrm{~W} / \mathrm{m}^{2} / \mathrm{RTFOT}\right)$ & 5,0 & 10,0 & 2,8 & 8,5 & 1,5 & 6,0 & 4,0 & 11,8 & 7,3 & 9,8 & 6,3 & 5,3 & maior, pior \\
\hline média & 6,2 & 9,0 & 7,0 & 7,6 & 4,4 & 7,7 & 6,1 & 6,4 & 5,6 & 9,4 & 4,0 & 4,8 & menor, melhor \\
\hline $\mathrm{G}^{*}\left(\mathrm{UV} 1,00 \mathrm{~W} / \mathrm{m}^{2} / \mathrm{RTFOT}\right)$ & 3,1 & 5,3 & 8,1 & 10,5 & 8,9 & 12,0 & 9,1 & 5,4 & 2,6 & 6,8 & 1,9 & 4,4 & maior, pior \\
\hline$\delta\left(\mathrm{UV} 1,00 \mathrm{~W} / \mathrm{m}^{2} / \mathrm{RTFOT}\right)$ & 4,1 & 4,4 & 8,0 & 10,4 & 7,9 & 11,9 & 10,1 & 5,6 & 3,4 & 3,6 & 1,6 & 5,8 & maior, melhor \\
\hline $\mathrm{G}^{*} \cdot \operatorname{sen} \delta\left(\mathrm{UV} 1,00 \mathrm{~W} / \mathrm{m}^{2} / \mathrm{RTFOT}\right)$ & 3,3 & 5,0 & 7,5 & 11,3 & 5,3 & 6,3 & 2,5 & 9,3 & 9,5 & 11,0 & 4,3 & 3,0 & maior, pior \\
\hline média & 3,5 & 4,9 & 7,9 & 10,7 & 7,4 & 10,1 & 7,2 & 6,8 & 5,2 & 7,1 & 2,6 & 4,4 & menor, melhor \\
\hline
\end{tabular}


Tabela 4.42 - Ordenamento baseado nos índices de envelhecimento PAV das Tabelas de 4.29 a 4.40

\begin{tabular}{|c|c|c|c|c|c|c|c|c|c|c|c|}
\hline borracha & SBS & SBR+PPA & PE & borracha+PPA & EVA & CAP & PE+PPA & PPA & EVA+PPA & SBR & SBS+PPA \\
\hline 2,2 & 3,2 & 4,0 & 4,5 & 5,6 & 6,1 & 7,2 & 8,8 & 8,8 & 8,8 & 9,2 & 9,5 \\
\hline
\end{tabular}

Tabela 4.43 - Ordenamento final baseado nos índices de envelhecimento UV a $0,68 \mathrm{~W} / \mathrm{m}^{2}$ das Tabelas de 4.29 a 4.40

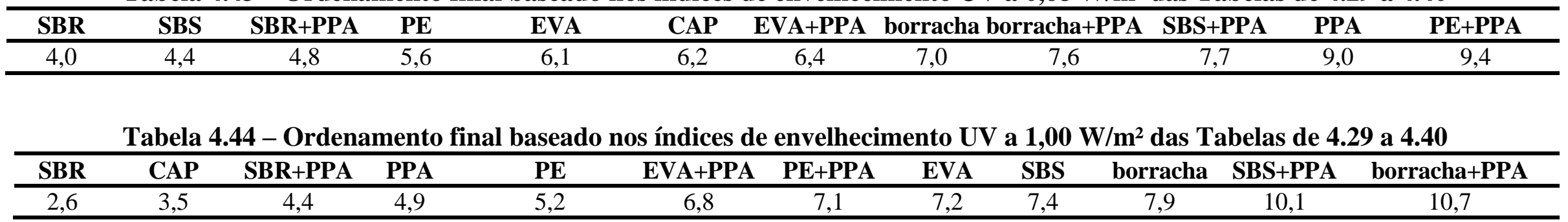

Tabela 4.45 - Ordenamento final baseado nos índices de envelhecimento PAV, UV a 0,68 W/m² e UV a 1,00 W/m² das Tabelas de 4.29 a 4.40

\begin{tabular}{cccccccccccc}
\hline SBR+PPA & SBS & PE & SBR & CAP & borracha & EVA & EVA+PPA & PPA & borracha+PPA & PE+PPA & SBS+PPA \\
\hline 4,4 & 5,0 & 5,1 & 5,2 & 5,6 & 5,7 & 6,5 & 7,4 & 7,6 & 8,0 & 8,4 & 9,1 \\
\hline
\end{tabular}


Destacam-se o CAP+borracha, no caso do envelhecimento PAV, e o CAP+SBR, no caso dos envelhecimentos na estufa UV, como os ligantes asfálticos que apresentaram a menor sensibilidade ao envelhecimento a longo prazo. Por outro lado, as amostras que apresentaram maior sensibilidade ao envelhecimento a longo prazo foram o $\mathrm{CAP}+\mathrm{SBS}+\mathrm{PPA}$ (PAV), CAP+PE+PPA (UV 0,68 W/m²) e o CAP+borracha+PPA (UV 1,00 W/m²). Considerando o ordenamento geral (todos os envelhecimentos juntos), destacou-se positivamente o $\mathrm{CAP}+\mathrm{SBR}+\mathrm{PPA}$ e negativamente o $\mathrm{CAP}+\mathrm{SBS}+\mathrm{PPA}$.

Ao se compararem os ordenamentos médios de sensibilidade ao envelhecimento a longo prazo (PAV, UV a $0,68 \mathrm{~W} / \mathrm{m}^{2}$ e UV a 1,00 W/m²), observa-se que a adição de PPA aos ligantes asfálticos modificados com polímero (incluindo a borracha) piora a sensibilidade ao envelhecimento, à exceção da formulação com SBR. No caso do envelhecimento UV a 1,00 W/m², o CAP+EVA também é exceção. 


\subsection{Ensaio de varredura de amplitude linear (LAS)}

Neste item serão apresentados os resultados das duas análises realizadas com base nos dados obtidos do ensaio de varredura de amplitude linear (LAS):

1)análise do índice de tolerância ao dano pelo parâmetro $\mathrm{a}_{\mathrm{f}}, \mathrm{e}$

2) análise baseada na teoria de dano contínuo viscoelástico (VECD).

Os resultados obtidos com os materiais envelhecidos a curto prazo na estufa RTFO e depois sob radiação UV foram comparados com os resultados obtidos por Nuñez (2013), que utilizou as mesmas amostras, porém envelhecidas a curto prazo na estufa RTFO e a longo prazo apenas na estufa PAV.

\subsubsection{Análise do índice de tolerância ao dano pelo parâmetro $a_{f}$}

$\mathrm{Na}$ análise do índice de tolerância ao dano pelo parâmetro $\mathrm{a}_{\mathrm{f}}$, verifica-se no gráfico da taxa de crescimento da fissura ( $\mathrm{mm} /$ ciclo) em função do comprimento de fissura $(\mathrm{mm}), \mathrm{o}$ menor valor que a curva apresenta antes do rápido aumento na taxa de crescimento da fissura. Neste critério, proposto por Hintz (2012), quanto maior o comprimento da trinca $\left(\mathrm{a}_{\mathrm{f}}\right)$ na falha, maior a tolerância à fadiga, pois indica que o ligante asfáltico pode resistir a um fissuramento maior antes da rápida ruptura. Como exemplo, observa-se, na Figura 4.34, o ponto indicado pela seta vermelha, que corresponde ao parâmetro $a_{\mathrm{f}}$ de uma das duas réplicas do CAP 50/70 puro envelhecido na estufa UV a $0,68 \mathrm{~W} / \mathrm{m}^{2}$.

Os resultados apresentados correspondem à média de duas réplicas de cada amostra, admitindo-se uma variabilidade de no máximo 15\%. Variabilidades maiores exigiriam que novas amostras fossem refeitas, até se obterem valores dentro deste limite. Os resultados dos comprimentos das trincas $\left(\mathrm{a}_{\mathrm{f}}\right)$ na falha para todas as amostras e nos quatro níveis de envelhecimento estudados são apresentados na Tabela 4.46. Os resultados das colunas 
referentes aos envelhecimentos RTFOT e PAV foram obtidos por Nuñez (2013). Na Tabela 4.47 são apresentados os ordenamentos das amostras por condição envelhecida.

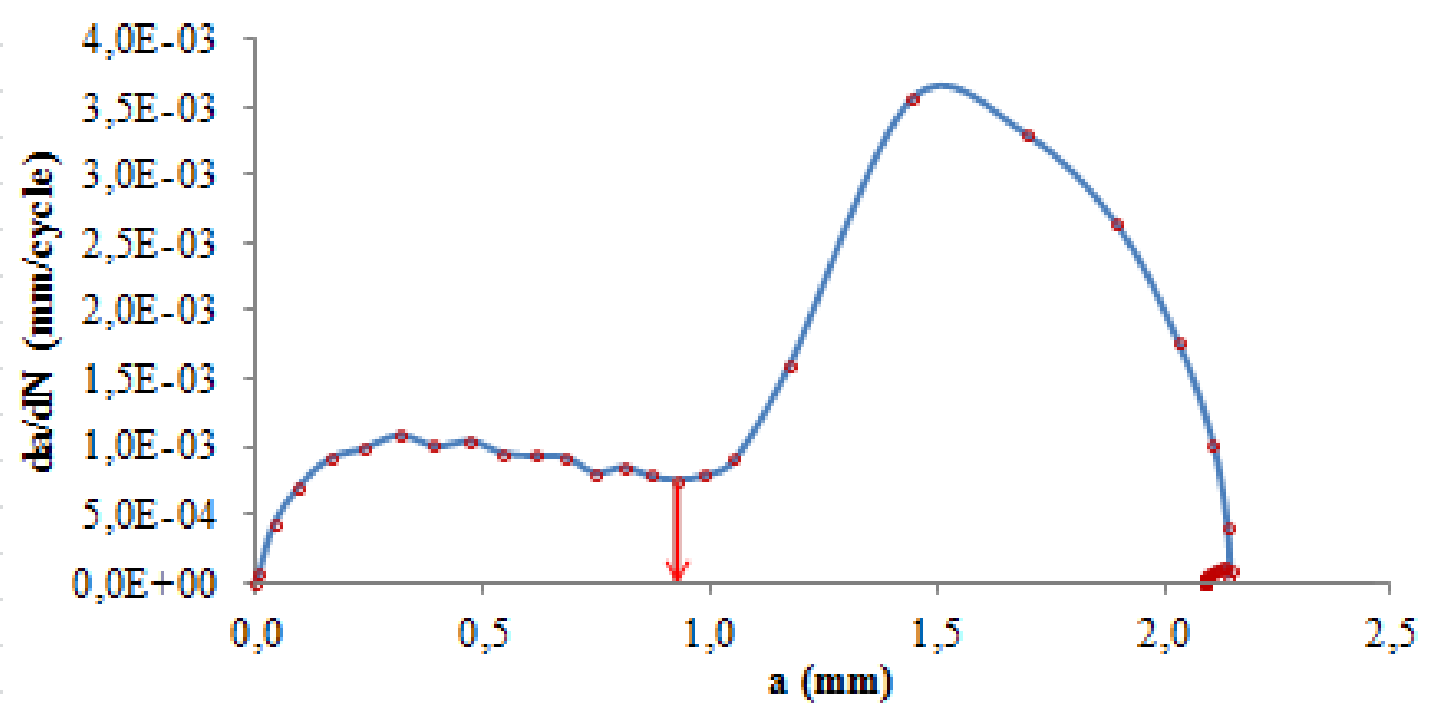

Figura 4.34 - Determinação do valor do parâmetro a na temperatura de $25^{\circ} \mathrm{C}$ para o CAP 50/70 puro envelhecido na estufa UV a $0,68 \mathrm{~W} / \mathrm{m}^{2}$

Tabela 4.46 - Parâmetro de tolerância ao dano $\mathrm{a}_{\mathrm{f}}(\mathrm{mm})$ no ensaio LAS a $25^{\circ} \mathrm{C}$ - os dados referentes às condições RTFOT e PAV foram obtidos de Nuñez (2013)

\begin{tabular}{ccccc}
\hline Ligante asfáltico & RTFOT & PAV & UV a 0,68 W/m & UV a 1,00 W/m \\
\hline $50 / 70$ & $\mathbf{0 , 7 1 1}$ & 1,080 & $\mathbf{0 , 9 5 2}$ & $\mathbf{0 , 9 5 9}$ \\
PPA & 0,971 & 1,225 & 1,157 & 1,082 \\
Borracha & 1,041 & $\mathbf{1 , 0 5 1}$ & 1,313 & 1,427 \\
Borracha+PPA & 0,929 & 1,171 & 0,979 & 1,450 \\
SBS & 0,888 & 1,130 & 1,168 & $\mathbf{1 , 6 0 0}$ \\
SBS+PPA & 0,955 & 1,276 & 1,184 & n.d \\
EVA & n.d & n.d & $\mathbf{1 , 3 9 8}$ & 1,480 \\
EVA+PPA & 1,185 & 1,377 & 1,301 & 1,351 \\
PE & 0,923 & 1,114 & 1,018 & 1,070 \\
PE+PPA & 0,930 & 1,203 & 1,131 & 1,112 \\
SBR & $\mathbf{1 , 5 4 5}$ & $\mathbf{1 , 7 1 4}$ & 1,393 & 1,313 \\
SBR+PPA & 1,374 & 1,497 & 1,350 & 1,433 \\
\hline
\end{tabular}


Tabela 4.47 - Ordenamento do parâmetro de tolerância ao dano a $(\mathrm{mm})$ no ensaio LAS a $25^{\circ} \mathrm{C}$, por condição envelhecida - os dados referentes às condições RTFOT e PAV foram obtidos de Nuñez (2013)

\begin{tabular}{ccccc}
\hline Posição & RTFOT & PAV & UV a 0,68 W/m & UV a 1,00 W/m \\
\hline 1 & SBR & SBR & EVA & SBS \\
2 & SBR+PPA & SBR+PPA & SBR & EVA \\
3 & EVA+PPA & EVA+PPA & SBR+PPA & Borracha+PPA \\
4 & Borracha & SBS+PPA & Borracha & SBR+PPA \\
5 & PPA & PPA & EVA+PPA & Borracha \\
6 & SBS+PPA & PE+PPA & SBS+PPA & EVA+PPA \\
7 & PE+PPA & Borracha+PPA & SBS & SBR \\
8 & Borracha+PPA & SBS & PPA & PE+PPA \\
9 & PE & PE & PE+PPA & PPA \\
10 & SBS & $50 / 70$ & PE & PE \\
11 & $\mathbf{5 0 / 7 0}$ & Borracha & Borracha+PPA & $\mathbf{5 0 / 7 0}$ \\
12 & - & - & $\mathbf{5 0 / 7 0}$ & - \\
\hline
\end{tabular}

Considerando cada um dos procedimentos de envelhecimento, pode-se perceber que:

- condição RTFOT: todos os ligantes asfálticos modificados apresentaram comprimento de trinca $\left(\mathrm{a}_{\mathrm{f}}\right)$ maior que o do CAP puro, o que indica a vantagem da adição dos modificadores; neste nível de envelhecimento, destacam-se o CAP+SBR e o CAP+SBR+PPA como os mais tolerantes ao dano por fadiga e o CAP 50/70 puro e o CAP+SBS como os menos tolerantes;

- condição PAV: todos os ligantes asfálticos modificados apresentaram comprimento de trinca $\left(\mathrm{a}_{\mathrm{f}}\right)$ maior que o do CAP puro, exceto o CAP+borracha; neste nível de envelhecimento, destacam-se também o $\mathrm{CAP}+\mathrm{SBR}$ e o $\mathrm{CAP}+\mathrm{SBR}+\mathrm{PPA}$ como os mais tolerantes ao dano por fadiga; quanto aos menos tolerantes, destacam-se o CAP+borracha e o CAP 50/70 puro;

- condição UV a $\mathbf{0 , 6 8} \mathbf{W} / \mathbf{m}^{2}$ : todos os ligantes asfálticos modificados apresentaram comprimento de trinca $\left(\mathrm{a}_{\mathrm{f}}\right)$ maiores que o do CAP puro; neste nível de envelhecimento, destacam-se o CAP+EVA (que não pôde ter o parâmetro $a_{\mathrm{f}}$ medido nas condições anteriores) e o $\mathrm{CAP}+\mathrm{SBR}$ como os mais tolerantes ao dano por fadiga; quanto aos menos tolerantes, destacam-se o CAP 50/70 puro e o CAP+borracha+PPA; e

- condição UV a $\mathbf{1 , 0 0} \mathbf{W} / \mathbf{m}^{2}$ : todos os ligantes asfálticos modificados apresentaram comprimento de trinca $\left(a_{\mathrm{f}}\right)$ maiores que o do CAP puro; neste nível de 
envelhecimento, destacam-se o $\mathrm{CAP}+\mathrm{SBS}$ e o $\mathrm{CAP}+\mathrm{EVA}$ como os mais tolerantes ao dano por fadiga e o CAP 50/70 puro e o CAP+PE como aos menos tolerantes.

Quando se comparam os comprimentos das trincas $\left(a_{\mathrm{f}}\right)$ dos asfaltos envelhecidos a curto prazo com os dos asfaltos envelhecidos a longo prazo, observa-se que, para todas as amostras, houve aumento dos comprimentos das trincas ao se envelhecer a longo prazo, exceto no caso do $\mathrm{CAP}+\mathrm{SBR}+\mathrm{PPA}$ na condição $\mathrm{UV}$ a $0,68 \mathrm{~W} / \mathrm{m}^{2}$ e no caso do $\mathrm{CAP}+\mathrm{SBR}$ nas condições UV a $0,68 \mathrm{~W} / \mathrm{m}^{2}$ e $\mathrm{UV}$ a $1,00 \mathrm{~W} / \mathrm{m}^{2}$. Isso demonstra que, para a maioria das condições e materiais, o envelhecimento a longo prazo aumenta a tolerância ao dano, em comparação ao estágio de envelhecimento a curto prazo.

Quando se comparam os resultados do parâmetro $a_{\mathrm{f}}$ entre os procedimentos PAV e UV a $0,68 \mathrm{~W} / \mathrm{m}^{2}$, observa-se que todas as amostras envelhecidas no PAV apresentaram maior tolerância ao dano, exceto no caso do CAP+borracha e do CAP+SBS. Quando se comparam as condições PAV e UV a $1,00 \mathrm{~W} / \mathrm{m}^{2}$, os resultados mostram que os CAPs com borracha, borracha+PPA e SBS tiveram maiores comprimentos de trinca na falha na condição UV a $1,00 \mathrm{~W} / \mathrm{m}^{2}$ e o restante das amostras tiveram menores comprimentos de trinca na falha. . Ou seja, tanto no nível de irradiação mais baixo, quanto no mais alto, a tolerância ao dano da amostras envelhecidas no UV são menores que as das amostras envelhecidas no PAV. Os resultados obtidos no nível de irradiação maior se devem, provavelmente, ao alto nível de severidade imposto aos materiais durante o condicionamento à irradiação ultravioleta, ainda que alguns materiais (CAP+borracha, $\mathrm{CAP}+$ borracha+PPA e CAP+SBS) tenham apresentado resultados positivos neste nível de irradiação.

E finalmente, quando se comparam os dois procedimentos de envelhecimento na estufa UV, verifica-se que no nível de irradiação mais intenso $\left(1,00 \mathrm{~W} / \mathrm{m}^{2}\right)$, a tolerância ao dano foi maior para todas as amostras, exceto para o CAP+PPA, o CAP+PE+PPA e o $\mathrm{CAP}+\mathrm{SBR}$. Tais resultados indicam que, dada a severidade do condicionamento a altos níveis de irradiação, alguns materiais têm seu comportamento à fadiga prejudicado, à luz da lógica associada ao parâmetro $\mathrm{a}_{\mathrm{f}}$

Nestas análises, o CAP+EVA e CAP+SBS+PPA não puderam ser comparados em algumas situações, tendo em vista que em determinados procedimentos de envelhecimento o 
168

parâmetro $a_{\mathrm{f}}$ não pôde ser medido, pois os gráficos gerados com os resultados do ensaio LAS não apresentaram condições de se localizar o menor ponto que a curva apresentou antes do rápido aumento na taxa de crescimento da fissura. Uma possível explicação para este fato é a ocorrência de problemas de adesão entre a amostra e a placa metálica ou a predominância de fluxo sobre a fratura coesiva por fadiga, conforme comentam Safaei e Hintz (2014). Aqueles autores comentam que possivelmente haja uma faixa de valores de módulo complexo dentro da qual o procedimento atual do ensaio LAS se aplique ou, em outras palavras, que amostras com valores de módulo fora desta faixa não proporcionariam resultados plausíveis neste ensaio. Segundo Safaei e Hintz (2014), esta faixa vai de 10 a 50 MPa e amostras com valores de módulo superiores a $50 \mathrm{MPa}$ estariam sujeitas a problemas de adesão, assim como amostras com valores de módulo inferiores a $10 \mathrm{MPa}$ teriam a ruptura provocada mais por fluxo viscoso que por fratura coesiva.

$\mathrm{Na}$ maioria das condições de envelhecimento das amostras CAP+EVA e CAP+SBS+PPA, observam-se valores de $\mathrm{G}^{*}$ abaixo de $10 \mathrm{MPa}$, a $25^{\circ} \mathrm{C}$, de maneira que a hipótese de ruptura por fluxo viria a ser plausível. No entanto, todas as demais amostras, nas quais o procedimento de obtenção do parâmetro $a_{\mathrm{f}}$ foi aplicado com sucesso, também apresentaram valores de módulo complexo a $25^{\circ} \mathrm{C}$ menores que $10 \mathrm{MPa}$. Isto obviamente vai de encontro à hipótese apontada por Safaei e Hintz (2014) e também suscita questionamentos a respeito da ocorrência de algum outro fenômeno ainda não identificado que também prejudica a aplicação do procedimento de obtenção do parâmetro $\mathrm{a}_{\mathrm{f}}$.

\subsubsection{Análise baseada na teoria de dano contínuo viscoelástico (VECD)}

Por meio do modelo proposto por Johnson (2010), $\mathrm{N}_{\mathrm{f}}=\mathrm{A}_{35} \cdot \gamma^{\mathrm{B}}$, para análise dos dados obtidos no ensaio LAS, é possível prever o comportamento à fadiga de materiais expostos a diferentes níveis de deformação. No modelo, $\mathrm{N}_{\mathrm{f}}$ representa a vida de fadiga, ou seja, o número de ciclos necessários para levar o material à fissura, e $\gamma$ representa a deformação cisalhante aplicada. 
$\mathrm{A}_{35}$ é o parâmetro que corresponde ao critério de ruptura adotado por Johnson (2010), em que o módulo inicial das amostras reduz em 35\%. Este parâmetro depende da variação da integridade do material em função do dano acumulado (curva integridade versus dano) e também do módulo complexo inicial (quando o material ainda não possui dano). Assim, $\mathrm{A}_{35}$ possui um valor elevado quando o ligante asfáltico mantém a integridade elevada, medida por meio do parâmetro $\left|\mathrm{G}^{*}\right|$.sen $\delta$, o que é positivo. Ocorrendo queda rápida nos valores de $\left|G^{*}\right|$.sen $\delta$, o parâmetro $A_{35}$ será baixo. $\mathrm{O}$ parâmetro $\mathrm{B}$ está relacionado à sensibilidade do ligante asfáltico ao nível de deformação. Quando este parâmetro diminui, a declividade da curva de fadiga aumenta, indicando que o material é mais sensível às variações nos níveis de deformação do pavimento (NUÑEZ, 2013; PAMPLONA, 2013).

As Tabelas de 4.48 e 4.49 apresentam os parâmetros $\mathrm{A}_{35}$ e B obtidos dos modelos de fadiga das amostras nas quatro condições de envelhecimento. Os coeficientes $\mathrm{A}_{35}$ e $\mathrm{B}$ foram obtidos por meio da média das duas réplicas ensaiadas.

$\mathrm{O}$ parâmetro $\mathrm{A}_{35}$, apresentado na Tabela 4.48, está relacionado à integridade do material (sua rigidez inicial), assim, maiores valores de $\mathrm{A}_{35}$ representam maior integridade. $\mathrm{O}$ que se percebe é que os envelhecimentos a longo prazo aumentam a integridade dos ligantes asfálticos, tendo como destaque, com os maiores valores de $\mathrm{A}_{35}$, o $\mathrm{CAP}+\mathrm{EVA}$ em todos os níveis de envelhecimento. As seguintes amostras se destacam como melhores em cada um dos níveis de envelhecimento:

- RTFOT: CAP+EVA e CAP+EVA+PPA;

- PAV: CAP+EVA e CAP+EVA+PPA;

- UV a 0,68 W/m²: CAP+EVA e CAP+EVA+PPA; e

- UV a 1,00 W/m²: CAP+EVA e CAP+borracha+PPA

Dentre os materiais que apresentaram menores valores de $A_{35}$ (menor integridade) o CAP puro se destaca em todos os níveis de envelhecimento. As seguintes amostras se destacam como piores em cada um dos níveis de envelhecimento:

- RTFOT: CAP puro e CAP+SBR+PPA;

- PAV: CAP puro e CAP+SBR;

- UV a 0,68 W/m²: CAP puro e CAP+SBR; e 
Tabela 4.48 - Valores do coeficiente $A_{35}$ dos modelos de fadiga a $25^{\circ} \mathrm{C}$ - os dados referentes às condições RTFOT e PAV foram obtidos de Nuñez (2013)

\begin{tabular}{ccccc}
\hline $\begin{array}{c}\text { Ligante } \\
\text { asfáltico }\end{array}$ & RTFOT & PAV & UV 0,68 W/m² & UV $1,00 \mathrm{~W} / \mathrm{m}^{2}$ \\
\hline 50/70 & 100.853 & 213.831 & 177.341 & 325.981 \\
PPA & 545.802 & 2.534 .063 & 1.964 .787 & 1.493 .248 \\
Borracha & 521.934 & 776.670 & 2.093 .975 & 4.083 .290 \\
Borracha+PPA & 698.004 & 1.277 .314 & 2.006 .220 & 17.755 .743 \\
SBS & 264.062 & 572.959 & 683.732 & 2.883 .076 \\
SBS+PPA & 315.613 & 1.253 .486 & 1.188 .335 & n.d \\
EVA & 4.179 .057 & 10.532 .290 & 16.372 .917 & 42.379 .725 \\
EVA+PPA & 1.125 .304 & 3.177 .270 & 2.234 .832 & 5.365 .822 \\
PE & 314.606 & 1.395 .468 & 555.079 & 793.899 \\
PE+PPA & 351.764 & 1.363 .456 & 888.453 & 910.543 \\
SBR & 177.585 & 408.682 & 369.793 & 429.461 \\
SBR+PPA & 129.041 & 1.005 .090 & 994.200 & 1.386 .367 \\
\hline
\end{tabular}

Considerando o parâmetro B, apresentado na Tabela 4.49, quanto maior o seu valor em módulo, maior a redução da vida de fadiga para um incremento unitário de deformação. $\mathrm{O}$ que se percebe é que os envelhecimentos a longo prazo contribuem para o aumento da sensibilidade à deformação dos ligantes asfálticos, quando comparados com o envelhecimento a curto prazo (RTFOT). Dentre os materiais mais sensíveis tem-se:

- RTFOT: CAP+EVA e CAP+EVA+PPA;

- PAV: CAP+PPA e CAP+EVA;

- UV a 0,68 W/m²: CAP+EVA, CAP+PPA e CAP+EVA+PPA; e

- UV a 1,00 W/m²: CAP+EVA e CAP+borracha+PPA

Em todos os níveis de envelhecimento, o CAP+EVA encontra-se entre os materiais mais sensíveis à deformação. Quando se considera aqueles materiais que tiveram menos sensibilidade à deformação, é o CAP puro que se destaca em todos os níveis de envelhecimento, como pode ser observado abaixo:

- RTFOT: CAP puro e CAP+SBR+PPA;

- PAV: CAP puro e CAP+borracha; 
- UV a 0,68 W/m²: CAP puro e CAP+SBR; e

- UV a $1,00 \mathrm{~W} / \mathrm{m}^{2}$ : CAP puro e CAP+SBR

Tabela 4.49 - Valores do coeficiente $B$ dos modelos de fadiga - os dados referentes às condições RTFOT e PAV foram obtidos de Nuñez (2013)

\begin{tabular}{ccccc}
\hline $\begin{array}{c}\text { Ligante } \\
\text { asfáltico }\end{array}$ & RTFOT & PAV & UV $0,68 \mathrm{~W} / \mathrm{m}^{2}$ & UV $1,00 \mathrm{~W} / \mathrm{m}^{2}$ \\
\hline 50/70 & $-2,81$ & $-3,28$ & $-3,21$ & $-3,36$ \\
PPA & $-3,60$ & $-4,28$ & $-4,14$ & $-4,19$ \\
Borracha & $-3,36$ & $-3,59$ & $-4,00$ & $-4,45$ \\
Borracha+PPA & $-3,42$ & $-3,91$ & $-3,97$ & $-5,24$ \\
SBS & $-3,22$ & $-3,70$ & $-3,65$ & $-4,55$ \\
SBS+PPA & $-3,33$ & $-4,18$ & $-3,96$ & - \\
EVA & $-3,96$ & $-4,20$ & $-4,61$ & $-5,69$ \\
EVA+PPA & $-3,81$ & $-4,14$ & $-4,14$ & $-4,66$ \\
PE & $-3,26$ & $-4,06$ & $-3,60$ & $-3,81$ \\
PE+PPA & $-3,45$ & $-4,10$ & $-3,94$ & $-3,92$ \\
SBR & $-3,31$ & $-3,84$ & $-3,56$ & $-3,49$ \\
SBR+PPA & $-3,17$ & $-4,08$ & $-4,00$ & $-4,34$ \\
\hline
\end{tabular}

A Tabela 4.50 apresenta os modelos de fadiga que geraram as curvas de fadiga obtidas nas análises do dano contínuo viscoelástico (VECD) em todos os níveis de envelhecimentos estudados e na temperatura de $25^{\circ}$. Nas Figuras de 4.35 a 4.38 , podem ser visualizadas as curvas de fadiga dos materiais juntos e, nas Figuras de 4.39 a 4.50 , os materiais separados. Os gráficos referentes ao envelhecimento a curto prazo (RTFOT) e a longo prazo (PAV) foram elaborados por Nuñez (2013). 
Tabela 4.50 - Modelos de fadiga dos ligantes asfálticos - os modelos referentes às condições RTFOT e PAV foram obtidos de Nuñez (2013)

\begin{tabular}{ccccc}
\hline $\begin{array}{c}\text { Ligante } \\
\text { asfáltico }\end{array}$ & RTFOT & PAV & UV 0,68 W/m & UV 1,00 W/m \\
\hline 50/70 & $\mathrm{N}_{\mathrm{f}}=100.853 \cdot \gamma^{-2,81}$ & $\mathrm{~N}_{\mathrm{f}}=213.831 \cdot \gamma^{-3,28}$ & $\mathrm{~N}_{\mathrm{f}}=177.341 \cdot \gamma^{-3,21}$ & $\mathrm{~N}_{\mathrm{f}}=325.981 \cdot \gamma^{-3,36}$ \\
PPA & $\mathrm{N}_{\mathrm{f}}=545.802 \cdot \gamma^{-3,60}$ & $\mathrm{~N}_{\mathrm{f}}=2.534 .063 \cdot \gamma^{-4,28}$ & $\mathrm{~N}_{\mathrm{f}}=1.964 .787 \cdot \gamma^{-4,14}$ & $\mathrm{~N}_{\mathrm{f}}=1.493 .248 \cdot \gamma^{-4,19}$ \\
Borracha & $\mathrm{N}_{\mathrm{f}}=521.934 \cdot \gamma^{-3,36}$ & $\mathrm{~N}_{\mathrm{f}}=776.670 \cdot \gamma^{-3,59}$ & $\mathrm{~N}_{\mathrm{f}}=2.093 .975 \cdot \gamma^{-4,00}$ & $\mathrm{~N}_{\mathrm{f}}=4.083 .290 \cdot \gamma^{-4,45}$ \\
Borracha+PPA & $\mathrm{N}_{\mathrm{f}}=698.004 \cdot \gamma^{-3,42}$ & $\mathrm{~N}_{\mathrm{f}}=1.277 .314 \cdot \gamma^{-3,91}$ & $\mathrm{~N}_{\mathrm{f}}=2.006 .220 . \gamma^{-3,97}$ & $\mathrm{~N}_{\mathrm{f}}=17.755 .743 \cdot \gamma^{-5,24}$ \\
SBS & $\mathrm{N}_{\mathrm{f}}=264.062 \cdot \gamma^{-3,22}$ & $\mathrm{~N}_{\mathrm{f}}=572.959 \cdot \gamma^{-3,70}$ & $\mathrm{~N}_{\mathrm{f}}=683.732 \cdot \gamma^{-3,65}$ & $\mathrm{~N}_{\mathrm{f}}=2.883 .076 \cdot \gamma^{-4,55}$ \\
SBS+PPA & $\mathrm{N}_{\mathrm{f}}=315.613 \cdot \gamma^{-3,33}$ & $\mathrm{~N}_{\mathrm{f}}=1.253 .486 \cdot \gamma^{-4,18}$ & $\mathrm{~N}_{\mathrm{f}}=1.188 .335 \cdot \gamma^{-3,96}$ & - \\
EVA & $\mathrm{N}_{\mathrm{f}}=4.179 .057 \cdot \gamma^{-3,96}$ & $\mathrm{~N}_{\mathrm{f}}=10.532 .290 \cdot \gamma^{-4,20}$ & $\mathrm{~N}_{\mathrm{f}}=16.372 .917 \cdot \gamma^{-4,61}$ & $\mathrm{~N}_{\mathrm{f}}=42.379 .725 \cdot \gamma^{-5,69}$ \\
EVA+PPA & $\mathrm{N}_{\mathrm{f}}=1.125 .304 \cdot \gamma^{-3,81}$ & $\mathrm{~N}_{\mathrm{f}}=3.177 .270 \cdot \gamma^{-4,14}$ & $\mathrm{~N}_{\mathrm{f}}=2.234 .832 \cdot \gamma^{-4,14}$ & $\mathrm{~N}_{\mathrm{f}}=5.365 .822 \cdot \gamma^{-4,66}$ \\
PE & $\mathrm{N}_{\mathrm{f}}=314.606 \cdot \gamma^{-3,26}$ & $\mathrm{~N}_{\mathrm{f}}=1.395 .468 \cdot \gamma^{-4,06}$ & $\mathrm{~N}_{\mathrm{f}}=555.079 \cdot \gamma^{-3,60}$ & $\mathrm{~N}_{\mathrm{f}}=793.899 \cdot \gamma^{-3,81}$ \\
PE+PPA & $\mathrm{N}_{\mathrm{f}}=351.764 \cdot \gamma^{-3,45}$ & $\mathrm{~N}_{\mathrm{f}}=1.363 .456 \cdot \gamma^{-4,10}$ & $\mathrm{~N}_{\mathrm{f}}=888.453 \cdot \gamma^{-3,94}$ & $\mathrm{~N}_{\mathrm{f}}=910.543 \cdot \gamma^{-3,92}$ \\
SBR & $\mathrm{N}_{\mathrm{f}}=177.585 \cdot \gamma^{-3,31}$ & $\mathrm{~N}_{\mathrm{f}}=408.682 \cdot \gamma^{-3,84}$ & $\mathrm{~N}_{\mathrm{f}}=369.793 \cdot \gamma^{-3,56}$ & $\mathrm{~N}_{\mathrm{f}}=429.461 \cdot \gamma^{-3,49}$ \\
SBR+PPA & $\mathrm{N}_{\mathrm{f}}=129.041 \cdot \gamma^{-3,17}$ & $\mathrm{~N}_{\mathrm{f}}=1.005 .090 \cdot \gamma^{-4,08}$ & $\mathrm{~N}_{\mathrm{f}}=100.853 \cdot \gamma^{-4,00}$ & $\mathrm{~N}_{\mathrm{f}}=1.386 .367 \cdot \gamma^{-4,34}$ \\
\hline
\end{tabular}


RTFOT $-25^{\circ} \mathrm{C}$

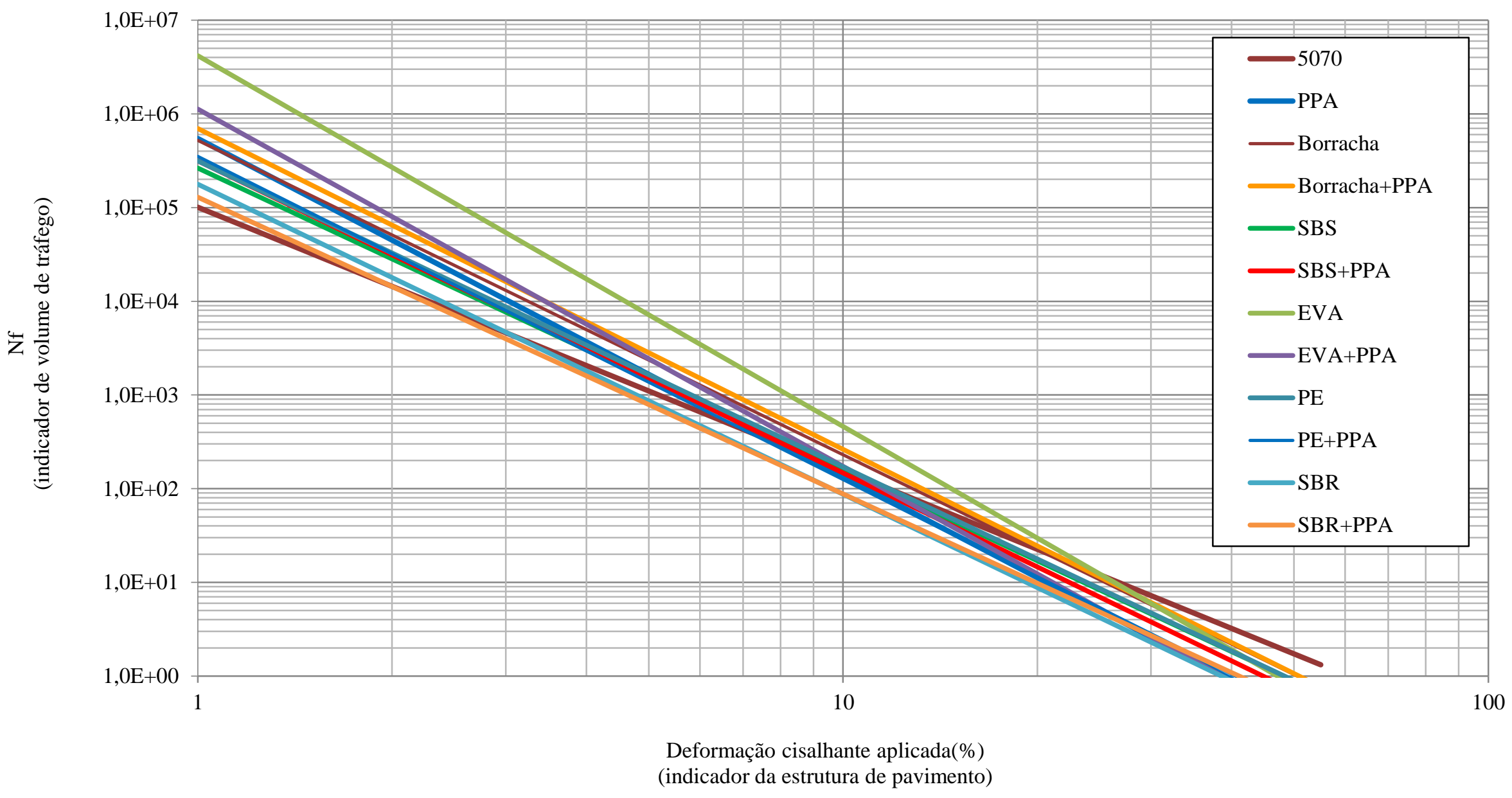

Figura 4.35 - Estimativa da vida de fadiga em função da deformação na condição de envelhecimento a curto prazo e temperatura de $25^{\circ} \mathrm{C}$ - dados fornecidos por Nuñez (2013) 
$\mathrm{PAV}-25^{\circ} \mathrm{C}$

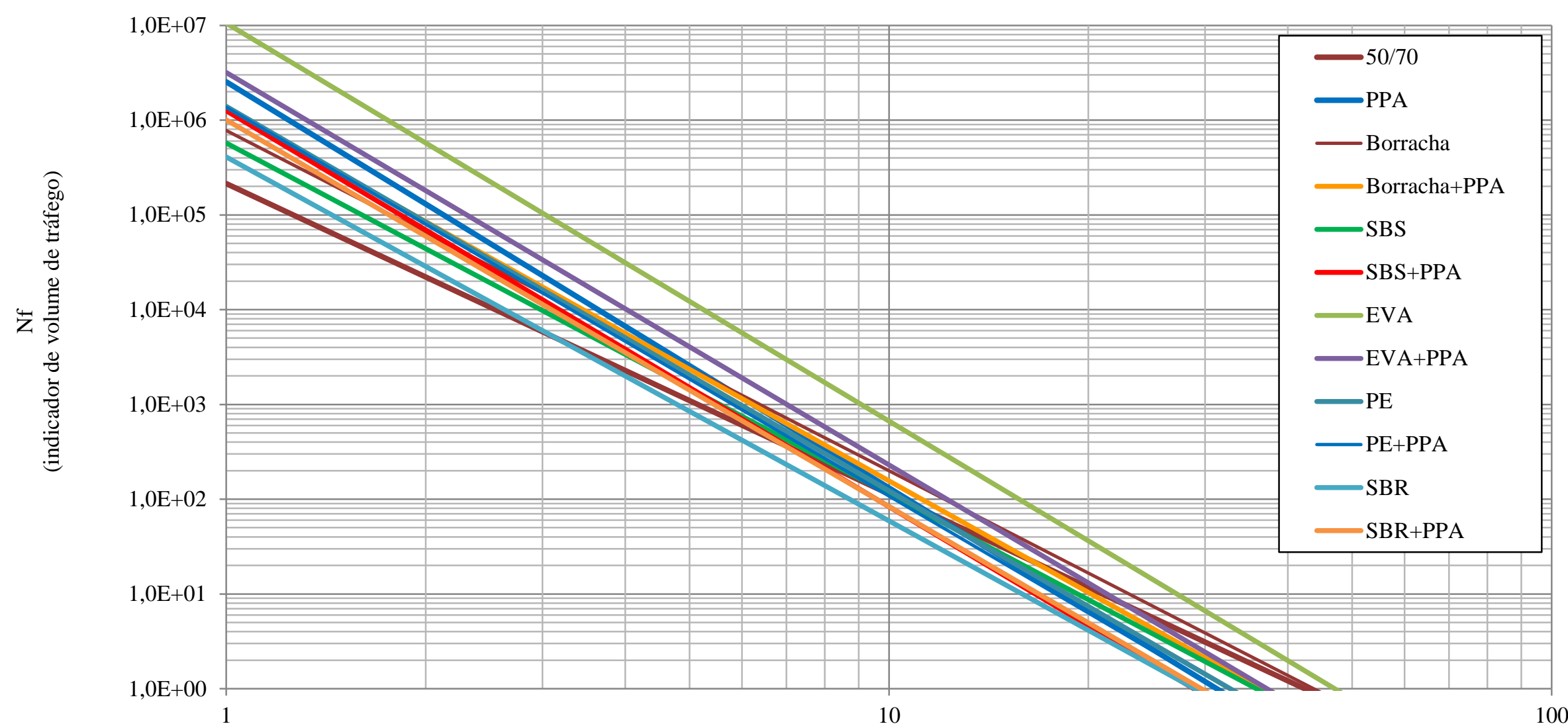

Deformação cisalhante aplicada $(\%)$

(indicador da estrutura de pavimento)

Figura 4.36 - Estimativa da vida de fadiga em função da deformação na condição de envelhecimento a longo prazo PAV e temperatura de $25^{\circ} \mathrm{C}$ - dados fornecidos por Nuñez (2013) 
UV a $0,68 \mathrm{~W} / \mathrm{m}^{2}-25^{\circ} \mathrm{C}$

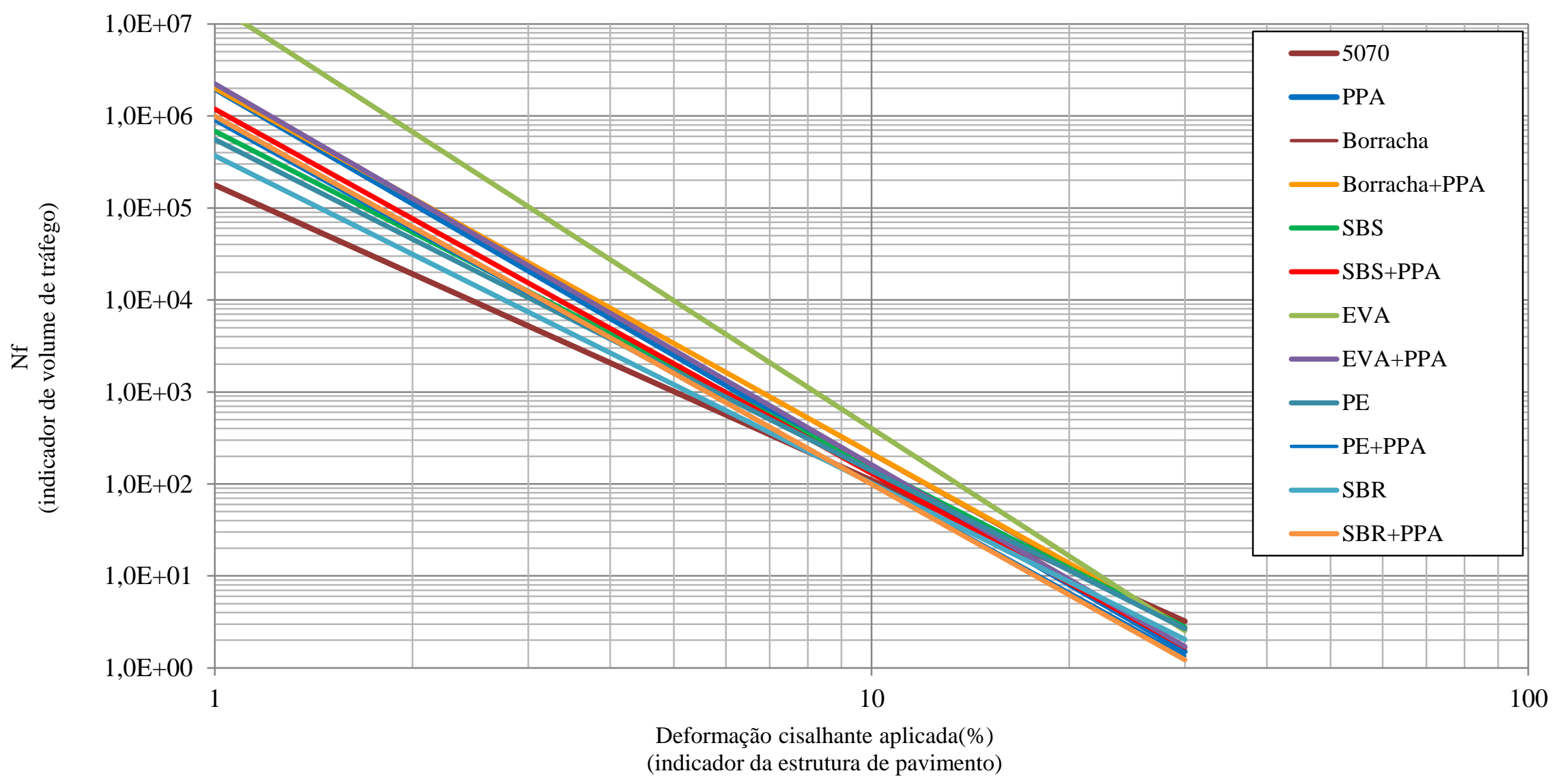

Figura 4.37 - Estimativa da vida de fadiga em função da deformação na condição de envelhecimento a longo prazo UV a 0,68 W/m² e temperatura de $25^{\circ} \mathrm{C}$ 
$\mathrm{UV}$ a $1,00 \mathrm{~W} / \mathrm{m}^{2}-25^{\circ} \mathrm{C}$

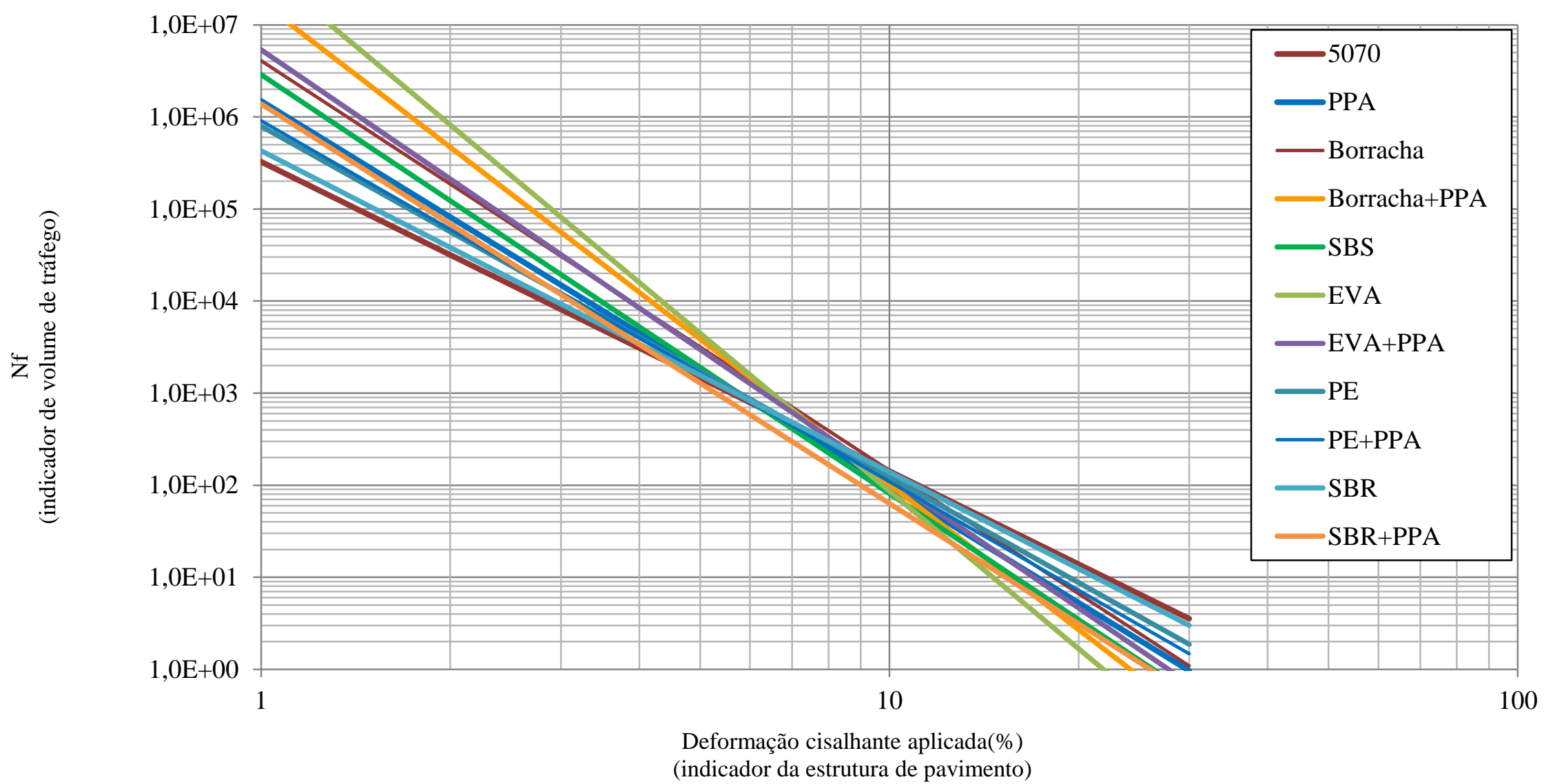

Figura 4.38 - Estimativa da vida de fadiga em função da deformação na condição de envelhecimento a longo prazo UV a $1,00 \mathrm{~W} / \mathrm{m}^{2}$ e temperatura de $25^{\circ} \mathrm{C}$ 


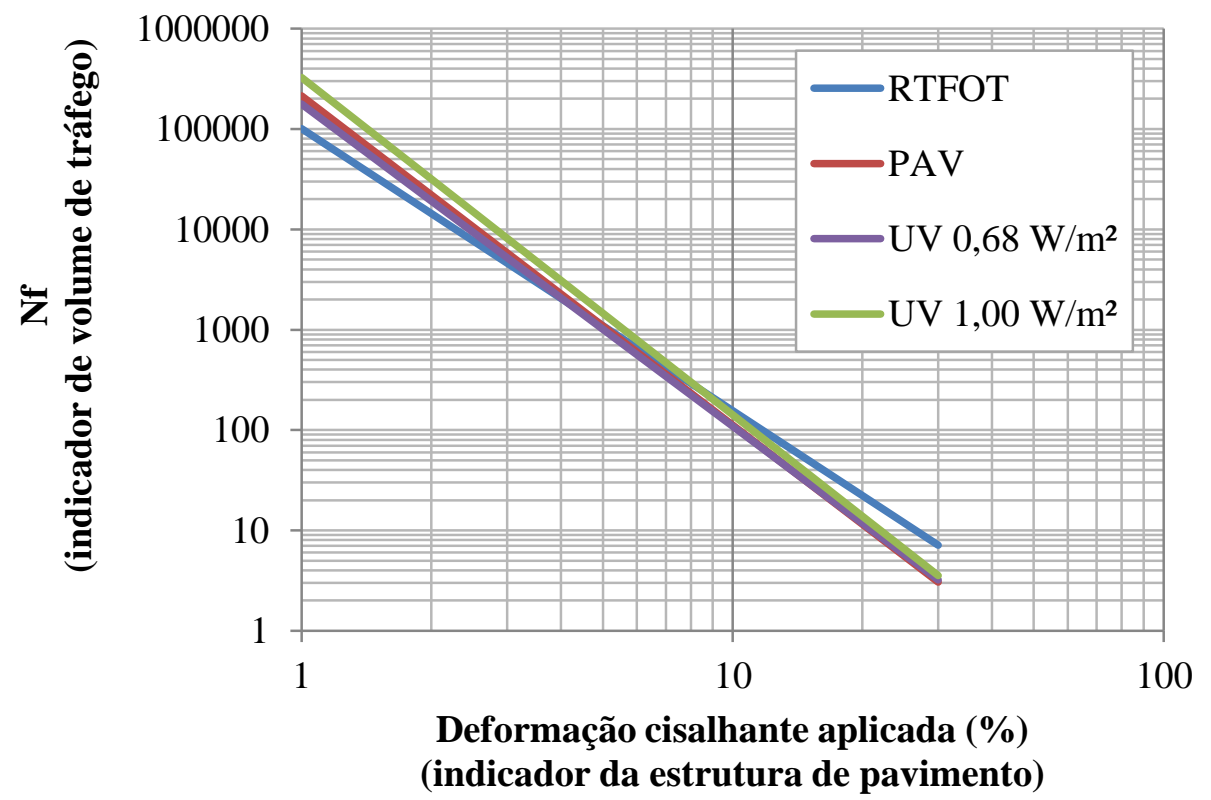

Figura 4.39 - Estimativa de vida de fadiga - CAP 50/70 puro [dados referentes aos materiais nas condições RTFOT e PAV obtidos de Nuñez (2013]

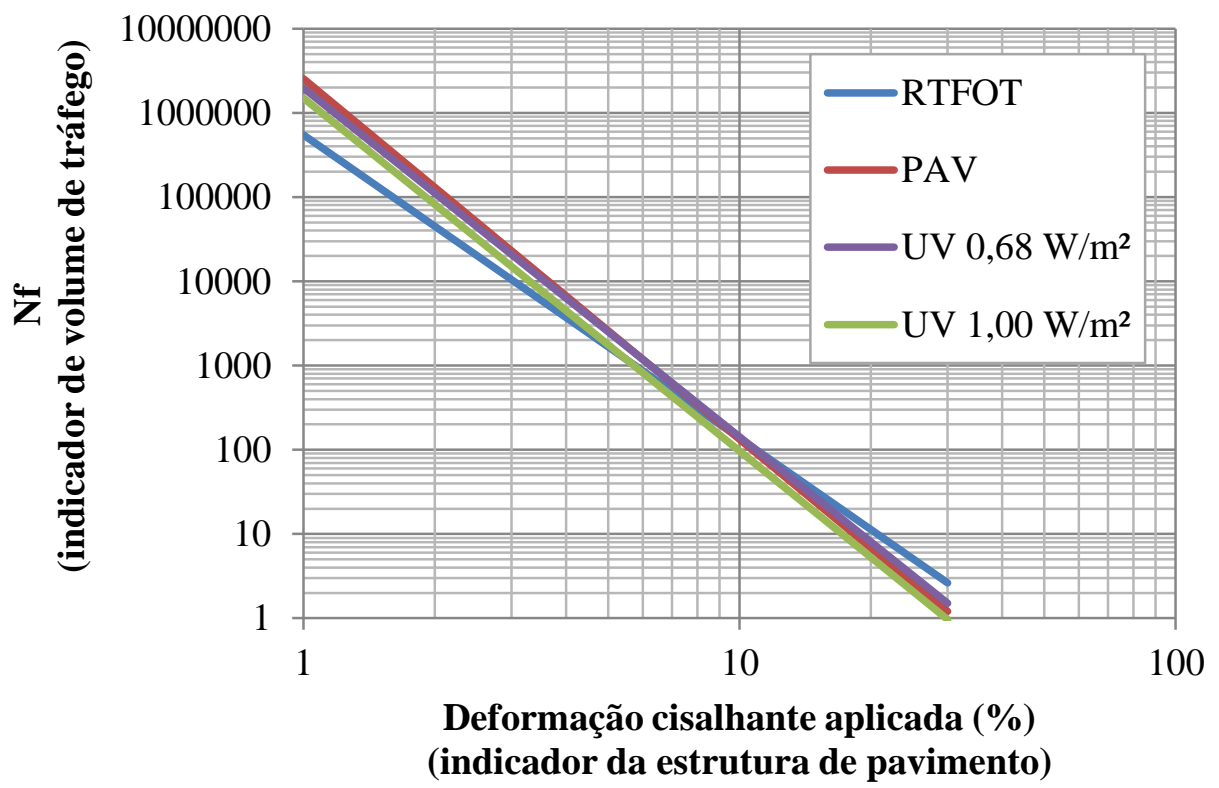

Figura 4.40 - Estimativa de vida de fadiga - CAP+PPA [dados referentes aos materiais nas condições RTFOT e PAV obtidos de Nuñez (2013] 


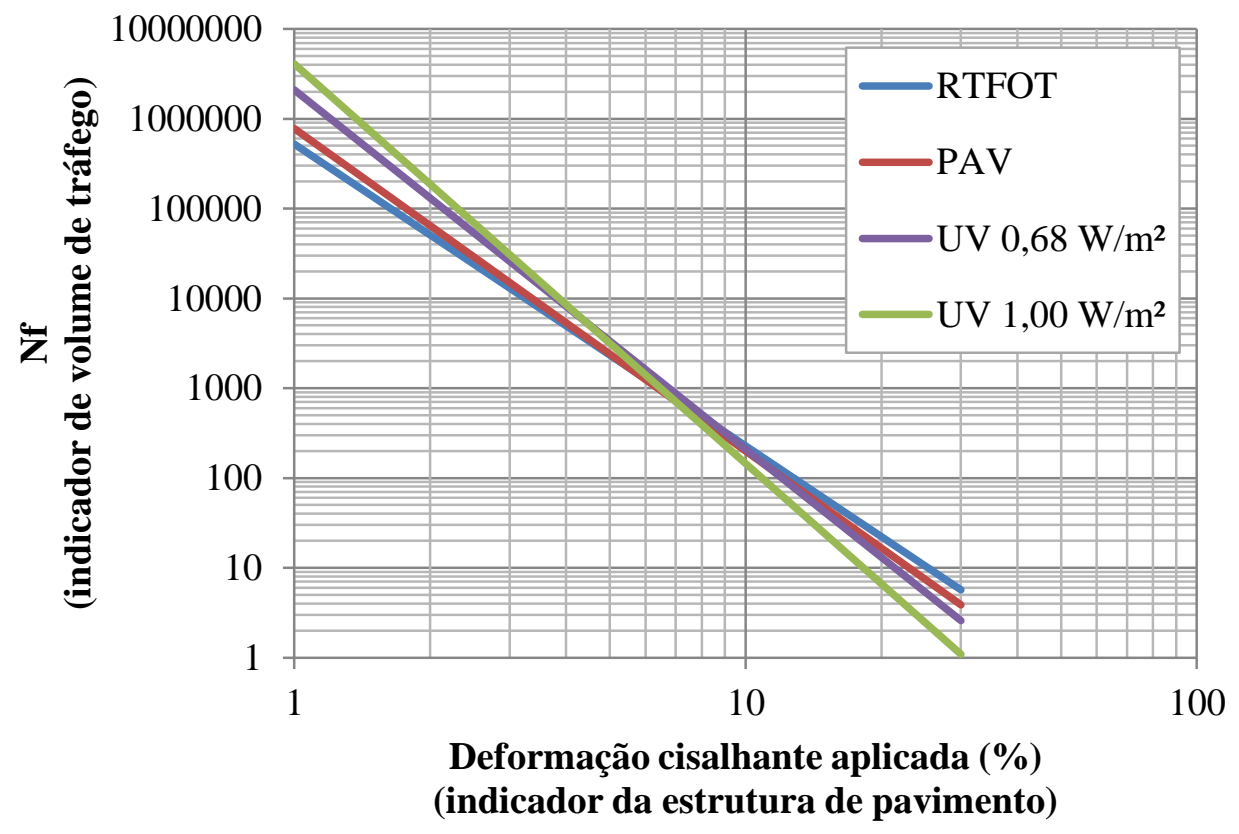

Figura 4.41 - Estimativa de vida de fadiga - CAP+borracha [dados referentes aos materiais nas condições RTFOT e PAV obtidos de Nuñez (2013]

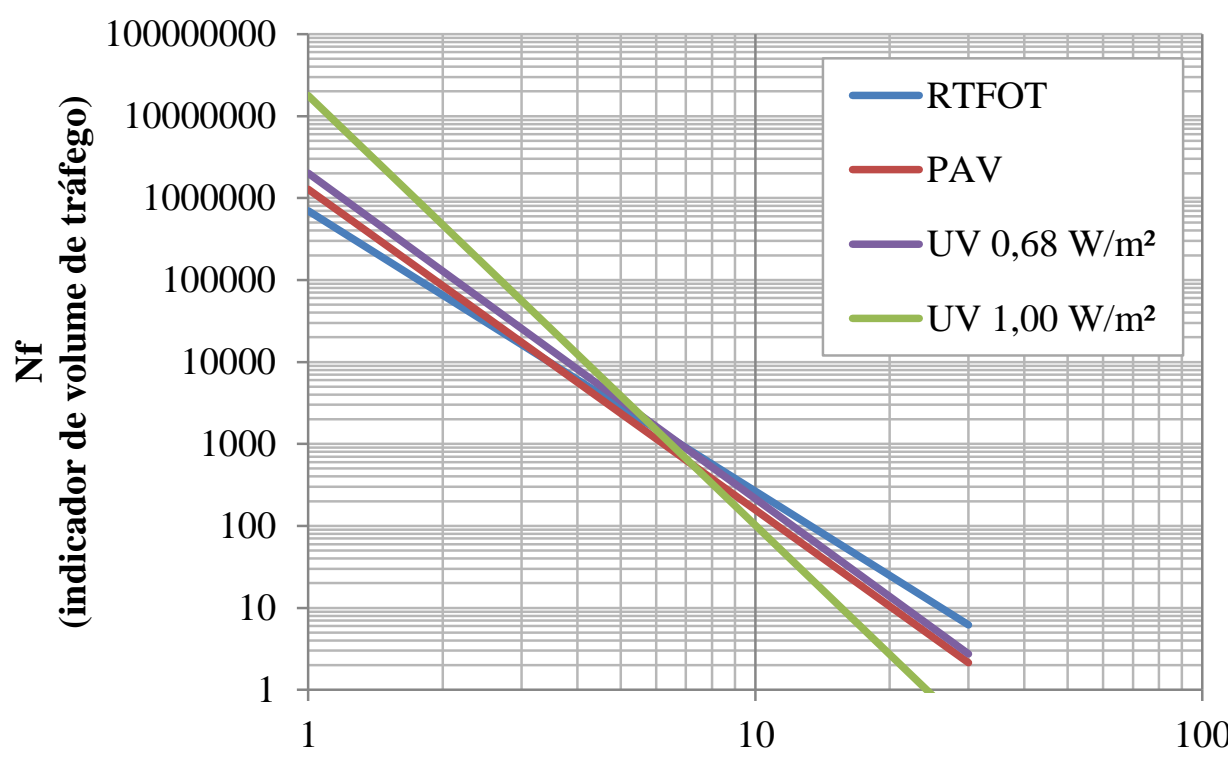

Deformação cisalhante aplicada (\%) (indicador da estrutura de pavimento)

Figura 4.42 - Estimativa de vida de fadiga - CAP+borracha+PPA [dados referentes aos materiais nas condições RTFOT e PAV obtidos de Nuñez (2013] 


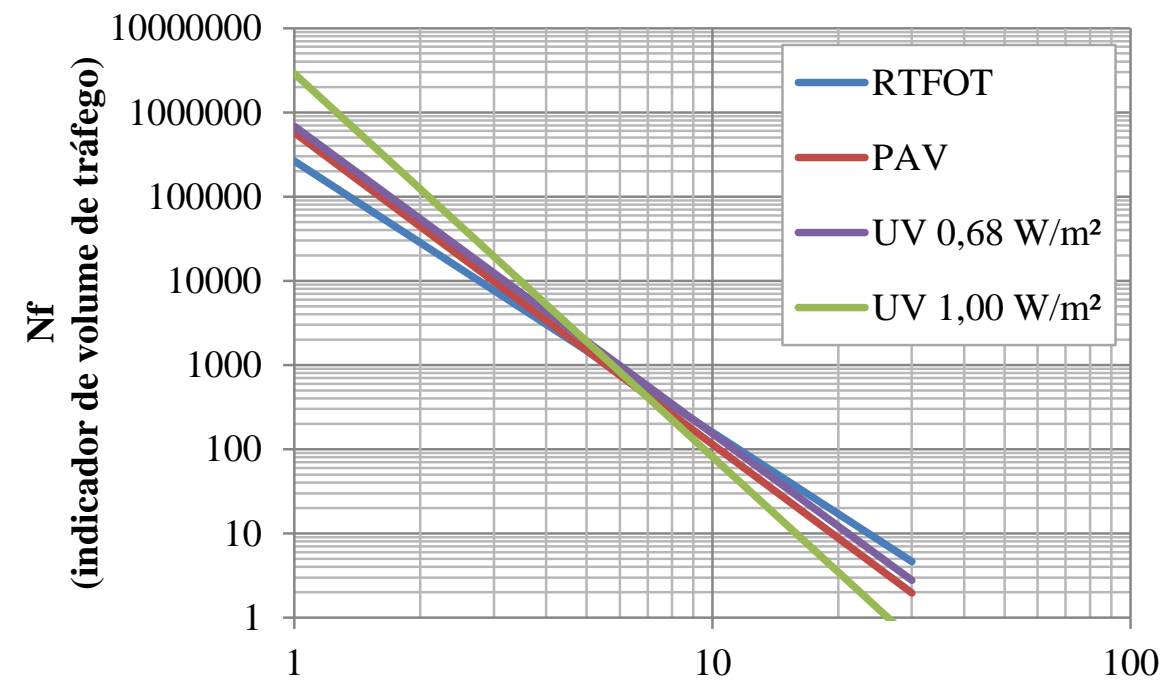

Deformação cisalhante aplicada (\%)

(indicador da estrutura de pavimento)

Figura 4.43 - Estimativa de vida de fadiga - CAP+SBS [dados referentes aos materiaisnas condições RTFOT e PAV obtidos de Nuñez (2013]

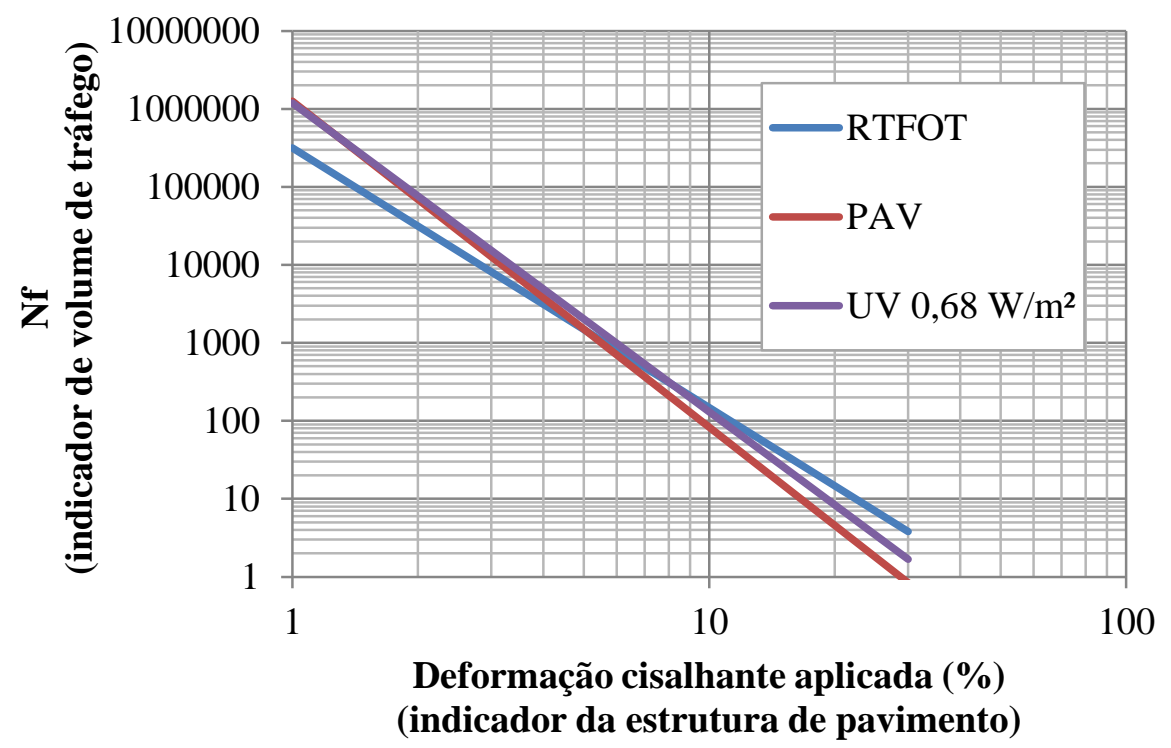

Figura 4.44 - Estimativa de vida de fadiga - CAP+SBS+PPA [dados referentes aos materiais nas condições RTFOT e PAV obtidos de Nuñez (2013] 
180

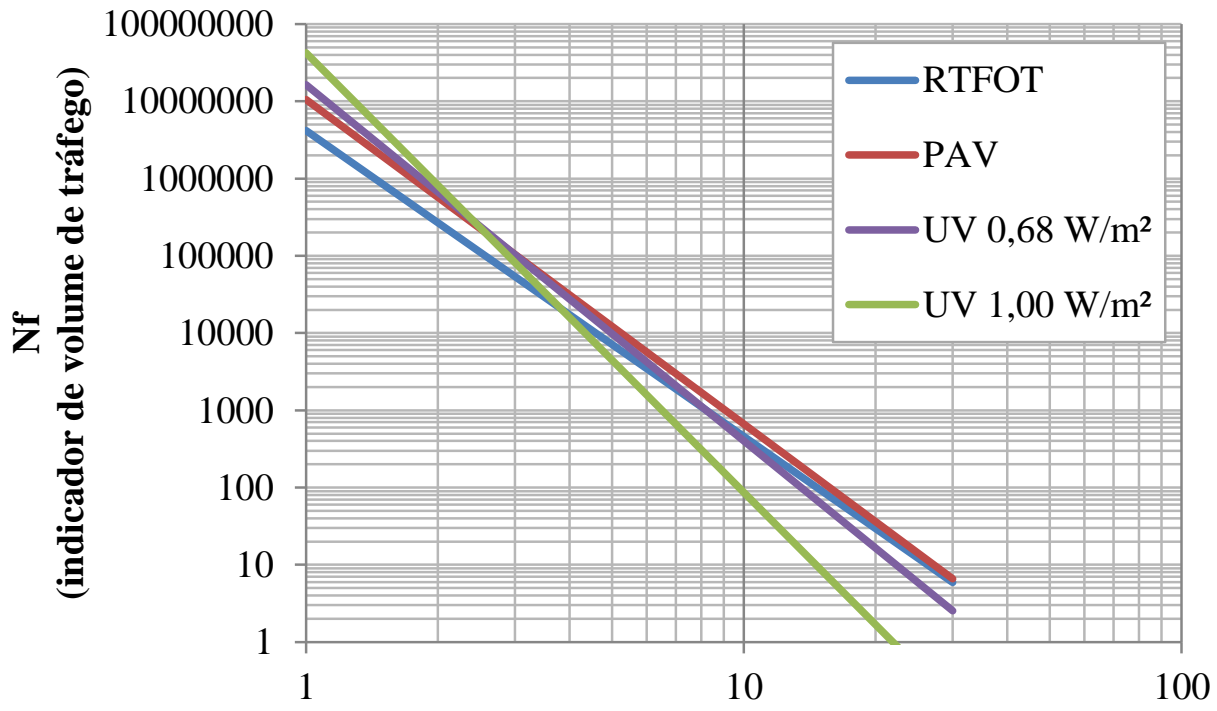

Deformação cisalhante aplicada (\%)

(indicador da estrutura de pavimento)

Figura 4.45 - Estimativa de vida de fadiga - CAP+EVA [dados referentes aos materiais nas condições RTFOT e PAV obtidos de Nuñez (2013]

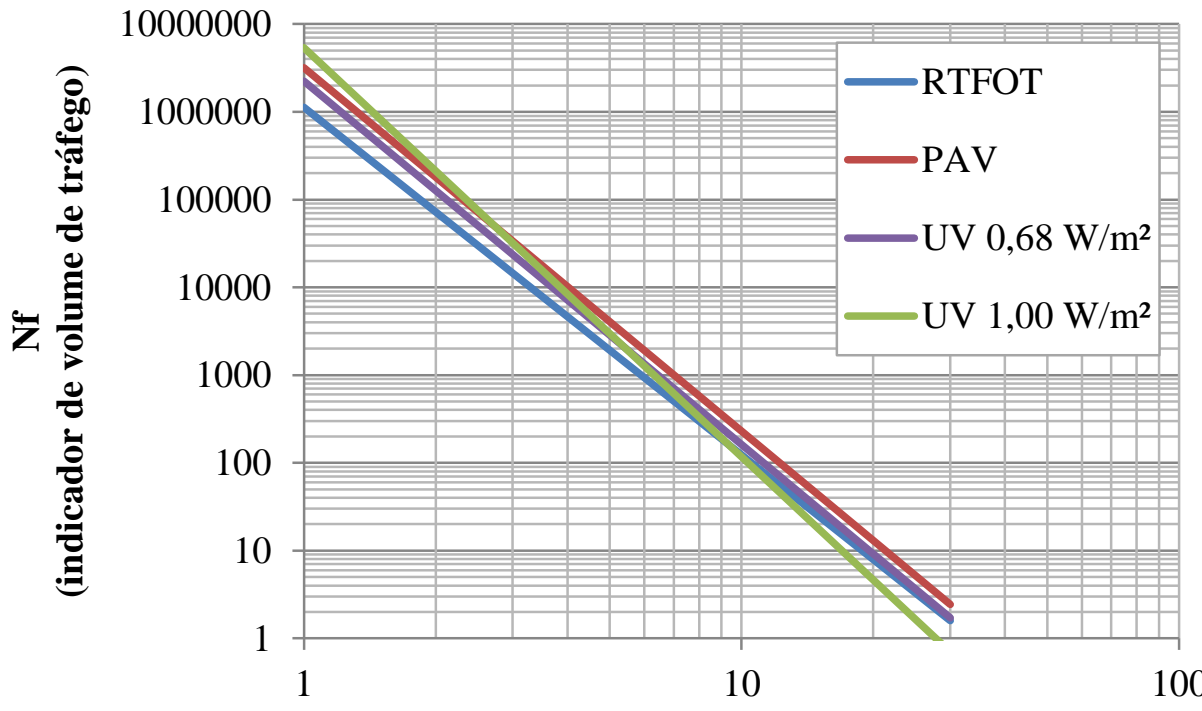

Deformação cisalhante aplicada (\%)

(indicador da estrutura de pavimento)

Figura 4.46 - Estimativa de vida de fadiga - CAP+EVA+PPA [dados referentes aos materiais nas condições RTFOT e PAV obtidos de Nuñez (2013] 


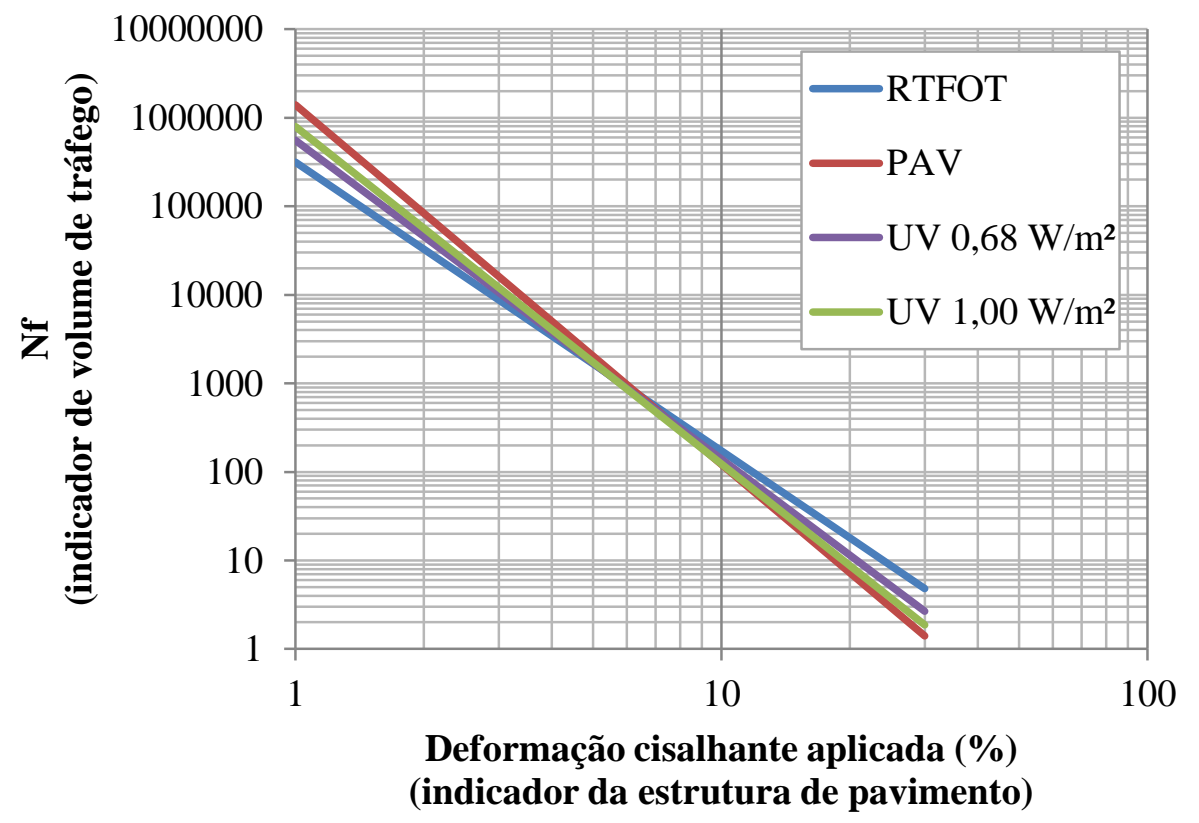

Figura 4.47 - Estimativa de vida de fadiga - CAP+PE [dados referentes aos materiais nas condições RTFOT e PAV obtidos de Nuñez (2013]

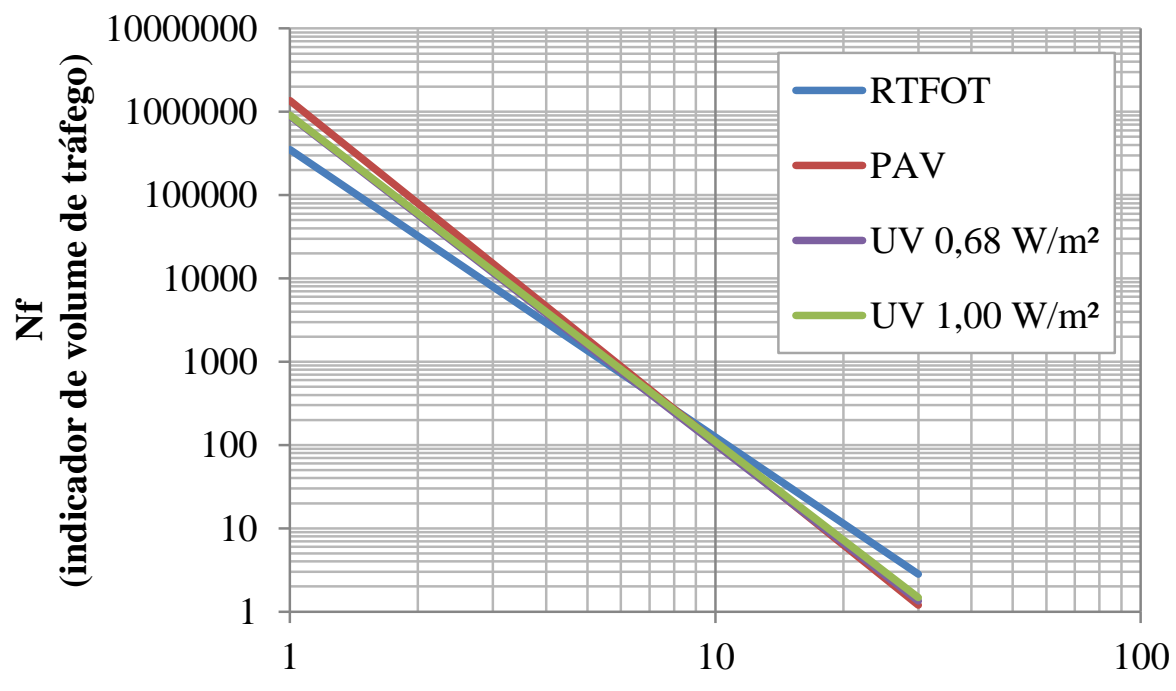

Deformação cisalhante aplicada $(\%)$

(indicador da estrutura de pavimento)

Figura 4.48 - Estimativa de vida de fadiga - CAP+PE+PPA [dados referentes aos materiais nas condições RTFOT e PAV obtidos de Nuñez (2013] 
182

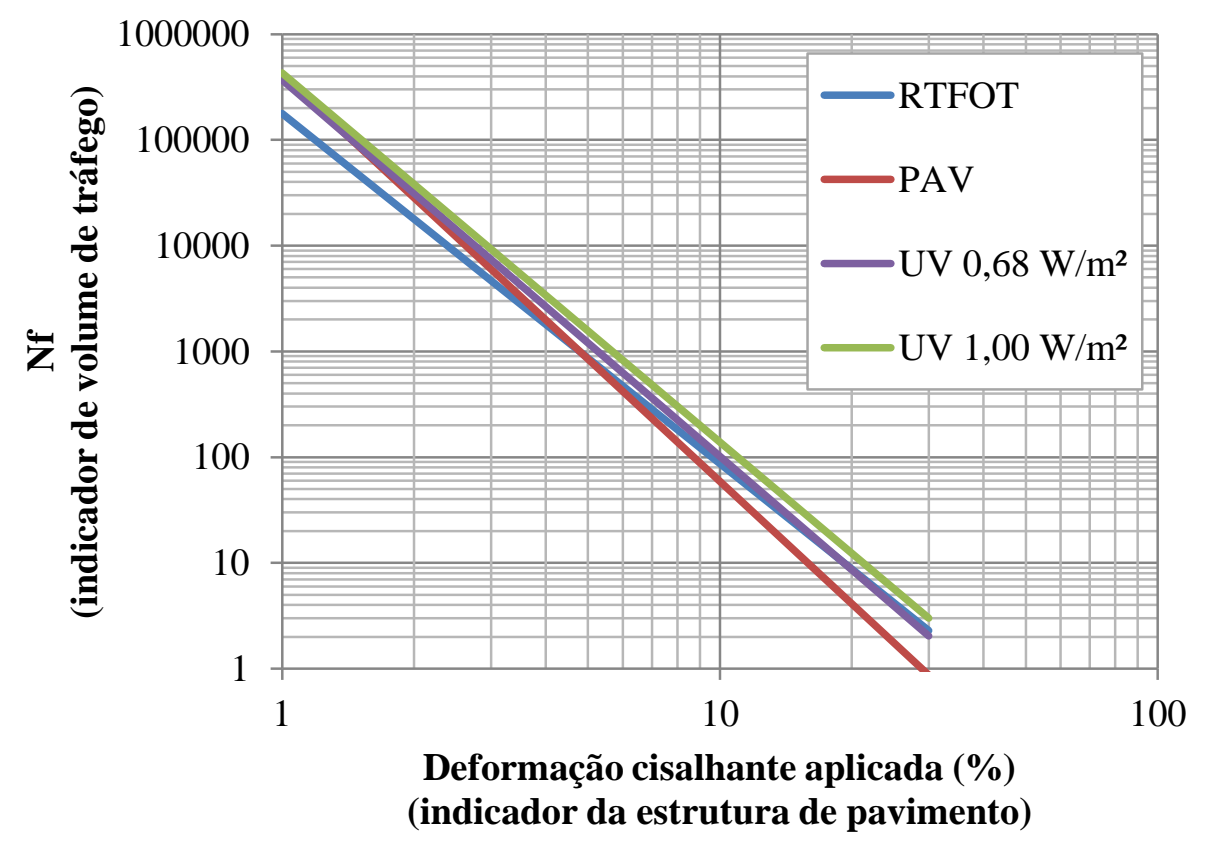

Figura 4.49 - Estimativa de vida de fadiga - CAP+SBR [dados referentes aos materiais nas condições RTFOT e PAV obtidos de Nuñez (2013]

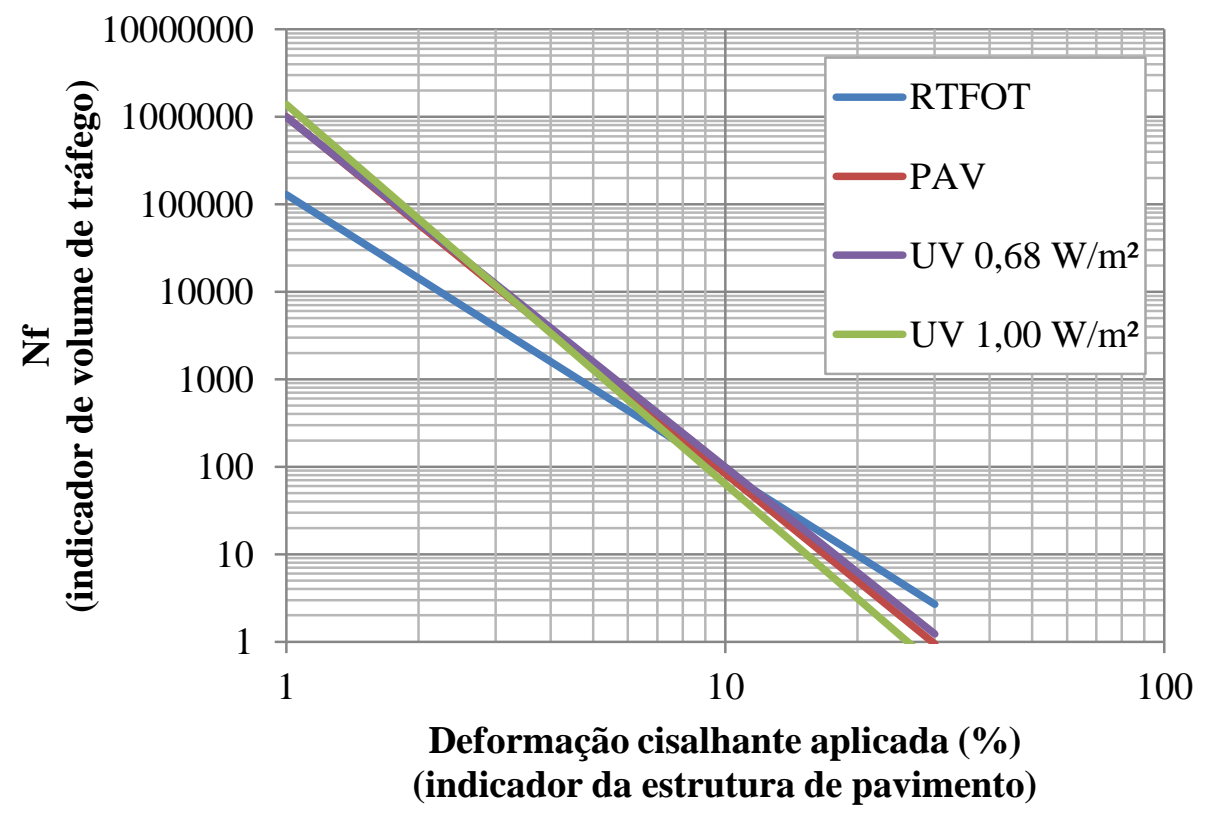

Figura 4.50 - Estimativa de vida de fadiga - CAP+SBR+PPA [dados referentes aos materiais nas condições RTFOT e PAV obtidos de Nuñez (2013] 
As Tabelas de 4.51 a 4.54 apresentam a estimativa de vida de fadiga $\left(\mathrm{N}_{\mathrm{f}}\right)$ dos materiais, considerando dois níveis de deformação: um baixo (3\%), representativo de pavimentos com baixos níveis deflectométricos, cujo comportamento deflectométrico se assemelha ao de um pavimento rígido, e um alto (30\%), representativo de um pavimento com altos níveis deflectométricos, cujo comportamento defectométrico se assemelha ao de um pavimento flexível. As Figuras 4.51 e 4.52 apresentam os ordenamentos realizados para estes dois níveis de deformação.

Tabela 4.51 - Estimativa do número de repetições do eixo padrão para $3 \%$ e $30 \%$ de deformação, com base no modelo de fadiga, das amostras na condição RTFOT a $25^{\circ} \mathrm{C}$ (NUÑEZ, 2013)

\begin{tabular}{ccc}
\hline Ligante asfáltico & $\mathbf{N}_{\mathbf{f}}(\mathbf{3 \%})$ & $\mathbf{N}_{\mathbf{f}}(\mathbf{3 0 \%})$ \\
\hline 50/70 & 4.624 & 7 \\
PPA & 10.433 & 3 \\
Borracha & 13.082 & 6 \\
Borracha+PPA & 16.226 & 6 \\
SBS & 7.672 & 5 \\
SBS+PPA & 8.127 & 4 \\
EVA & 54.104 & 6 \\
EVA+PPA & 17.072 & 3 \\
PE & 8.711 & 5 \\
PE+PPA & 7.962 & 3 \\
SBR & 4.685 & 2 \\
SBR+PPA & 3.980 & 3 \\
\hline
\end{tabular}

Tabela 4.52 - Estimativa do número de repetições do eixo padrão para $3 \%$ e $30 \%$ de deformação, com base no modelo de fadiga, das amostras na condição PAV a $25^{\circ} \mathrm{C}$ (NUÑEZ, 2013)

\begin{tabular}{ccc}
\hline Ligante asfáltico & $\mathbf{N}_{\mathbf{f}}(\mathbf{3 \%})$ & $\mathbf{N}_{\mathbf{f}}(\mathbf{3 0 \%})$ \\
\hline $50 / 70$ & 5.852 & 3 \\
PPA & 22.887 & 1 \\
Borracha & 15.048 & 4 \\
Borracha+PPA & 17.352 & 2 \\
SBS & 9.788 & 2 \\
SBS+PPA & 12.742 & 1 \\
EVA & 104.551 & 7 \\
EVA+PPA & 33.625 & 2 \\
PE & 16.203 & 1 \\
PE+PPA & 15.059 & 1 \\
SBR & 6.018 & 1 \\
SBR+PPA & 11.373 & 1 \\
\hline
\end{tabular}


184

Tabela 4.53 - Estimativa do número de repetições do eixo padrão para $3 \%$ e $30 \%$ de deformação, com base no modelo de fadiga, das amostras na condição UV a $0,68 \mathrm{~W} / \mathrm{m}^{2}$ a $25^{\circ} \mathrm{C}$ (NUNEZ, 2013)

\begin{tabular}{ccc}
\hline Ligante asfáltico & $\mathbf{N}_{\mathbf{f}}(\mathbf{3 \%})$ & $\mathbf{N}_{\mathbf{f}} \mathbf{( 3 0 \% )}$ \\
\hline $50 / 70$ & 5.215 & 3 \\
PPA & 20.799 & 2 \\
Borracha & 25.852 & 3 \\
Borracha+PPA & 25.598 & 3 \\
SBS & 12.399 & 3 \\
SBS+PPA & 15.330 & 2 \\
EVA & 103.418 & 3 \\
EVA+PPA & 23.657 & 2 \\
PE & 10.635 & 3 \\
PE+PPA & 11.716 & 1 \\
SBR & 7.403 & 2 \\
SBR+PPA & 12.274 & 1 \\
\hline
\end{tabular}

Tabela 4.54 - Estimativa do número de repetições do eixo padrão para $3 \%$ e $30 \%$ de deformação, com base no modelo de fadiga, das amostras na condição UV a $1,0 \mathrm{~W} / \mathrm{m}^{2}$ a $25^{\circ} \mathrm{C}$ (NUÑEZ, 2013)

\begin{tabular}{ccc}
\hline Ligante asfáltico & $\mathbf{N}_{\mathbf{f}} \mathbf{( 3 \% )}$ & $\mathbf{N}_{\mathbf{f}} \mathbf{( 3 0 \% )}$ \\
\hline $50 / 70$ & 8.130 & 4 \\
PPA & 14.962 & 1 \\
Borracha & 30.748 & 1 \\
Borracha+PPA & 56.134 & 0 \\
SBS & 19.452 & 1 \\
SBS+PPA & n.d & n.d \\
EVA & 81.722 & 0 \\
EVA+PPA & 32.081 & 1 \\
PE & 12.076 & 2 \\
PE+PPA & 12.274 & 1 \\
SBR & 9.285 & 3 \\
SBR+PPA & 11.781 & 1 \\
\hline
\end{tabular}



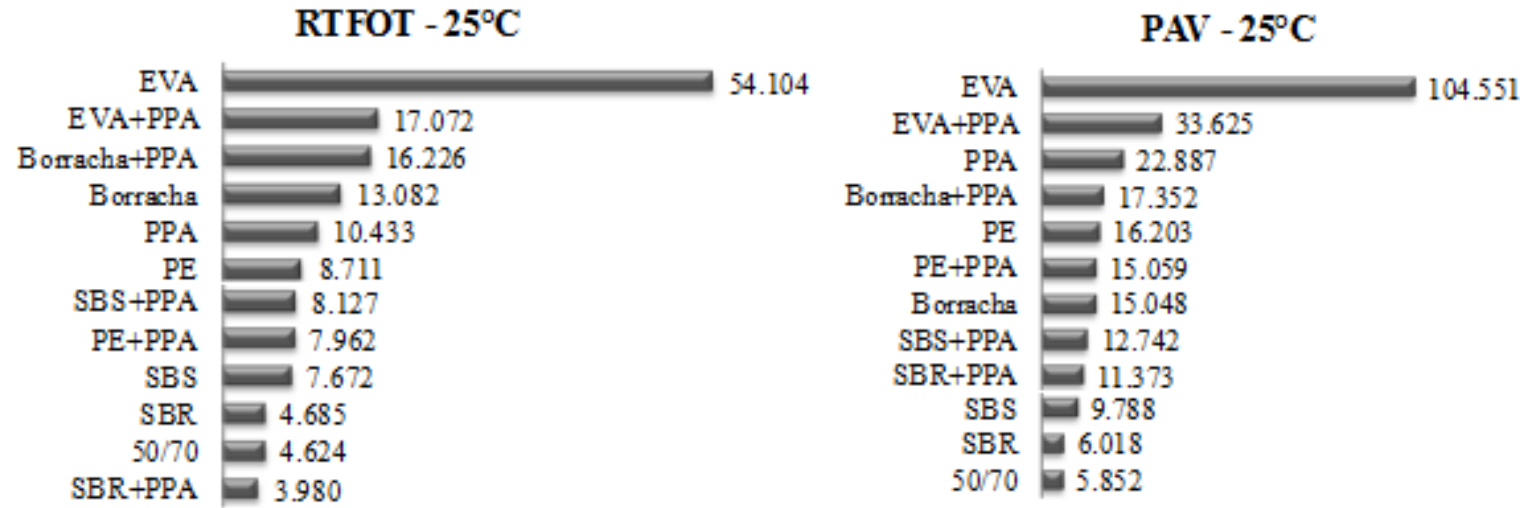

UV $0,68 \mathrm{~W} / \mathrm{m}^{2}-25^{\circ} \mathrm{C}$

UV $1,00 \mathrm{~W} / \mathrm{m}^{2}-25^{\circ} \mathrm{C}$
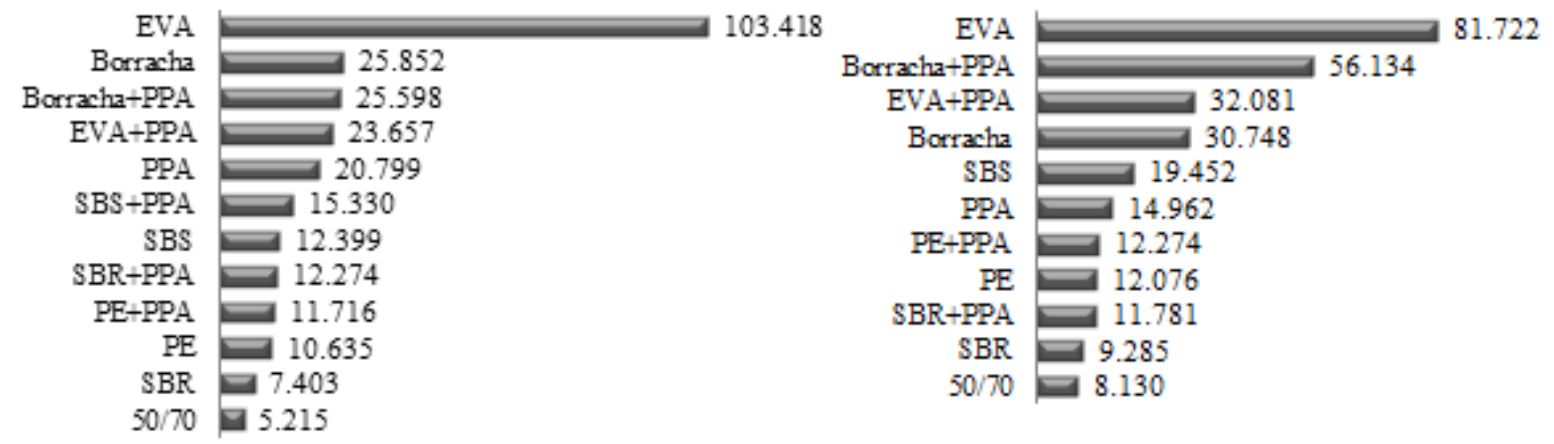

Figura 4.51 - Ordenamento dos valores de $\mathbf{N}_{\mathrm{f}}$ obtidos do ensaio LAS para baixos níveis de deformação (3\%) [dados nas condições RTFOT e PAV obtidos de Nuñez (2013)]

Para baixos níveis de deformação (3\%), o que pode se observar, de acordo com a Figura 4.51, é que o material que apresenta maior vida de fadiga é o CAP+EVA, o que pode ser observado para todos os níveis de envelhecimento. Ainda sob baixos níveis de deformação, o CAP puro apresenta a pior vida de fadiga em todos os níveis de envelhecimento, exceto na condição RTFOT, na qual o CAP+SBR+PPA apresenta a menor vida de fadiga. Tais resultados mostram que para baixas deformações, no geral, o efeito das modificações é positivo. 
RTFOT $-25^{\circ} \mathrm{C}$

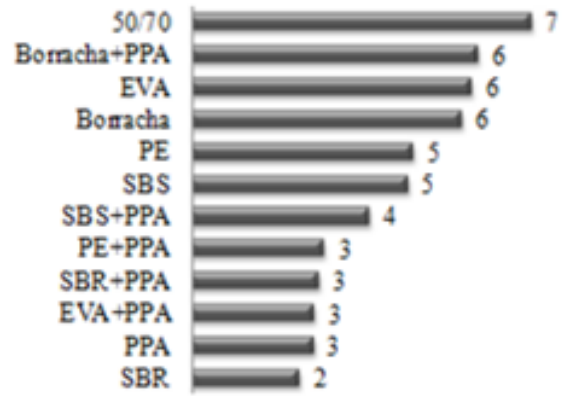

UV $0,68 \mathrm{~W} / \mathrm{m}^{2}-25^{\circ} \mathrm{C}$

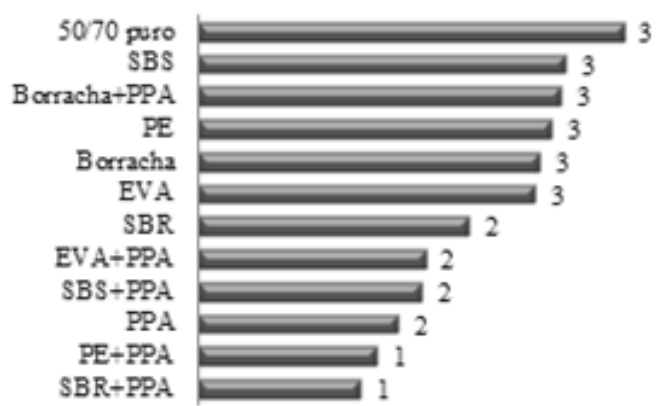

$\mathrm{PAV}-25^{\circ} \mathrm{C}$

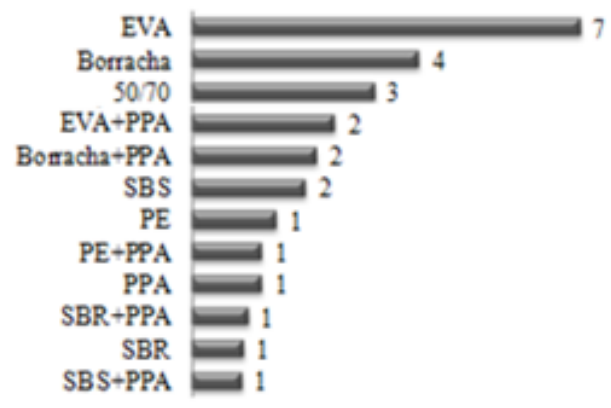

UV $1,00 \mathrm{~W} / \mathrm{m}^{2}-25^{\circ} \mathrm{C}$

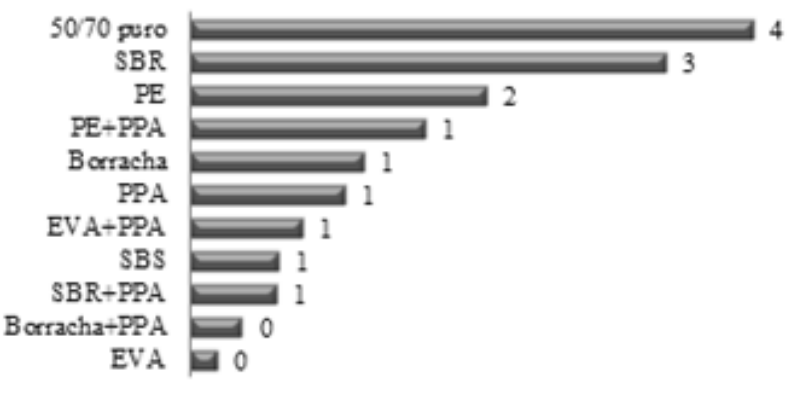

Figura 4.52 - Ordenamento dos valores de $\mathbf{N}_{\mathrm{f}}$ obtidos do ensaio LAS para altos níveis de deformação (30\%) [dados nas condições RTFOT e PAV obtidos de Nuñez (2013)]

Ao se analisar a Figura 4.52, observa-se que o comportamento dos materiais é bastante distinto do apresentado na Figura 4.51. O CAP 50/70 puro, que na deformação de 3\% apresentou as menores vidas de fadiga, se destaca, sob altas deformações, como o melhor em todas as condições de envelhecimento, exceto na condição PAV, embora ainda bem posicionado ( $3^{\circ}$ lugar). Sob altas deformações, verifica-se que as modificações não contribuem para o aumento da vida de fadiga dos materiais. 


\subsection{Análises Químicas}

\subsubsection{Caracterização estrutural por FTIR}

Nas Figuras de 4.53 a 4.55 podem ser observados os cortes feitos no eixo x dos espectros completos, para melhor visualização das bandas de absorbância de interesse nesta análise. Os CAPs analisados foram o 50/70 puro e o 50/70+PPA, envelhecidos no RTFOT, PAV, UV 0,68 W/m² e UV 1,00 W/m² e o CAP 50/70+SBS, envelhecido no RTFOT, PAV e $\mathrm{UV} 1,00 \mathrm{~W} / \mathrm{m}^{2}$.

De acordo com Qin et al. (2014), a absorbância dos grupos funcionais das carbonilas e sulfóxidos aumenta com o nível de severidade do envelhecimento. Neste sentido, para cada amostra envelhecida, foram calculadas as áreas de absorbância da carbonila (entre as bandas 1720 e $1674 \mathrm{~cm}^{-1}$ ) e do sulfóxido (entre as bandas 1053 e $1008 \mathrm{~cm}^{-1}$ ) e comparadas (Tabela $4.55)$.

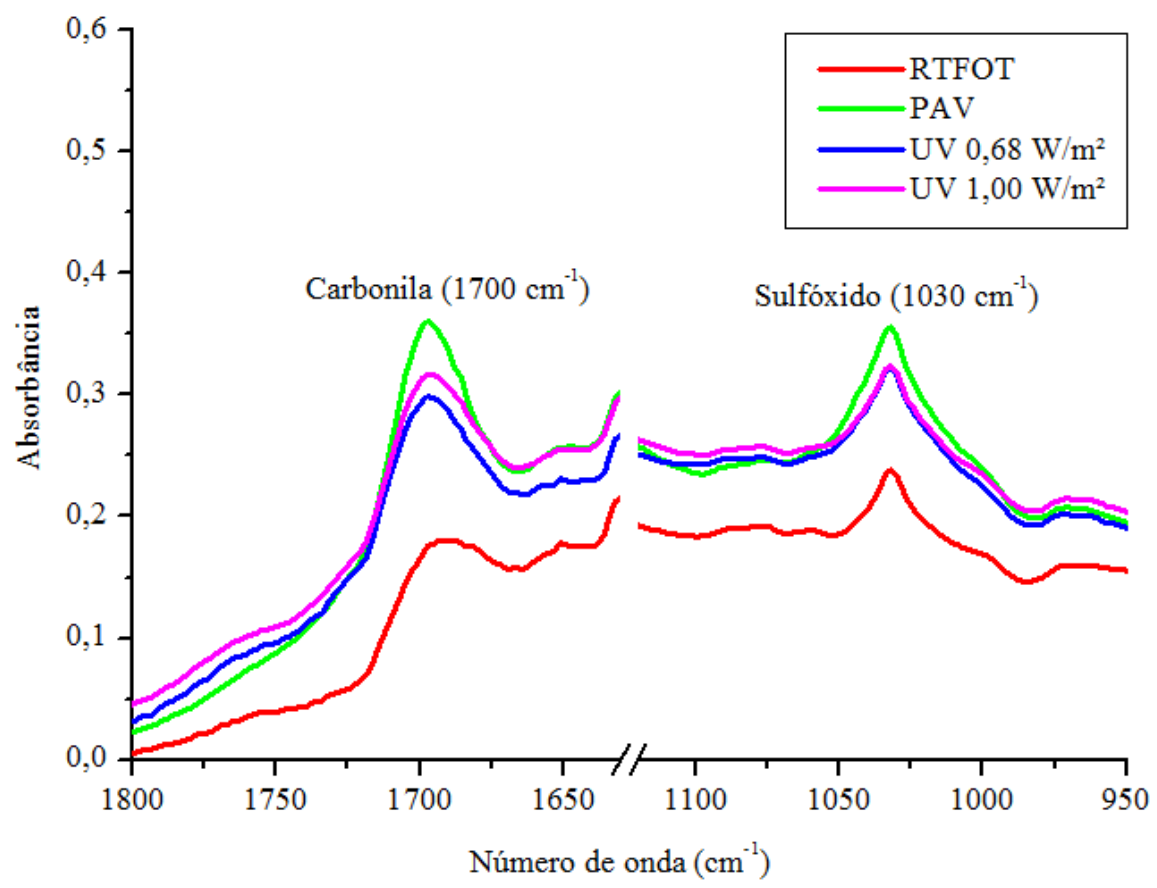

Figura 4.53 - Espectro do FTIR do CAP puro nas condições de envelhecimentos a curto prazo (RTFOT) e a longo prazos (PAV, UV 0,68 W/m² e UV 1,00 W/m²) 
188

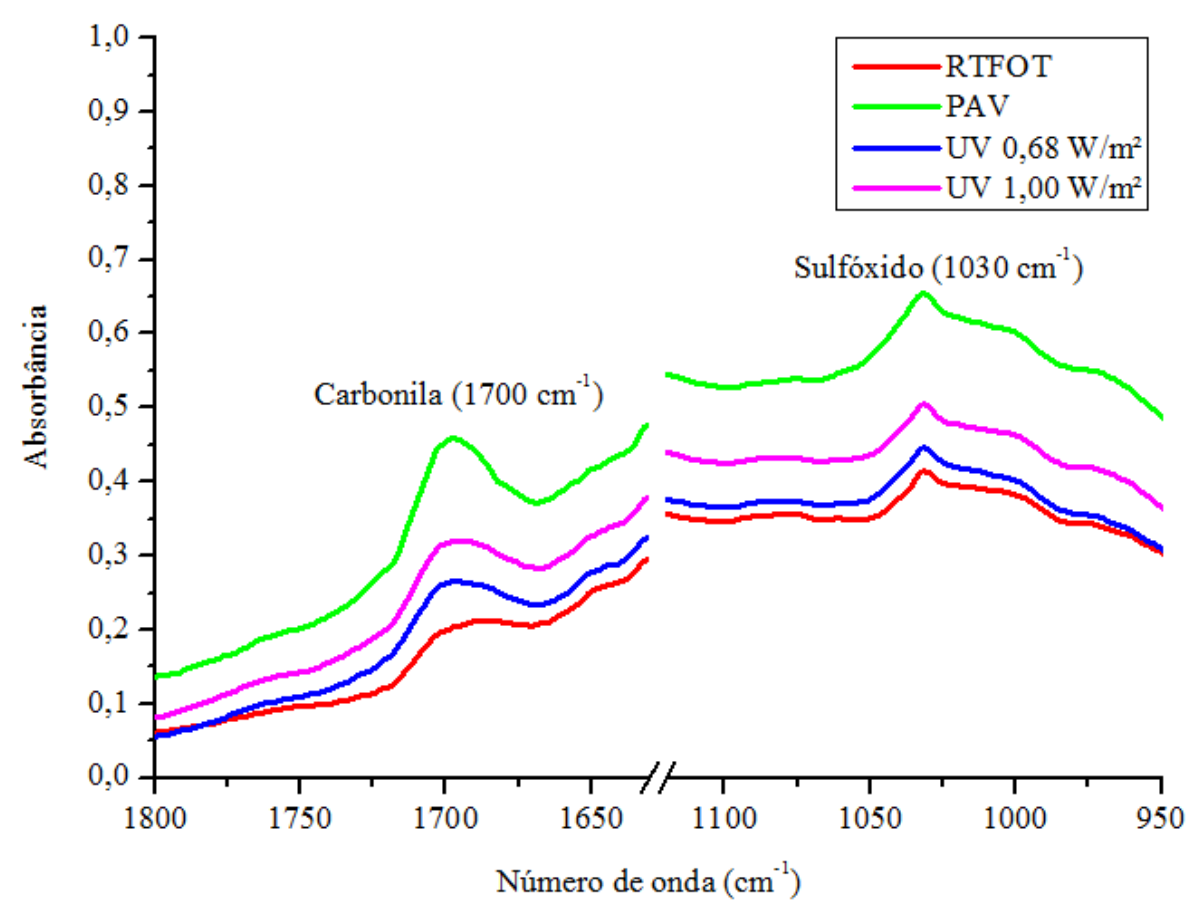

Figura 4.54 - Espectro do FTIR do CAP+PPA nas condições de envelhecimentos a curto prazo (RTFOT) e a longo prazos (PAV, UV 0,68 W/m² e UV 1,00 W/m²)

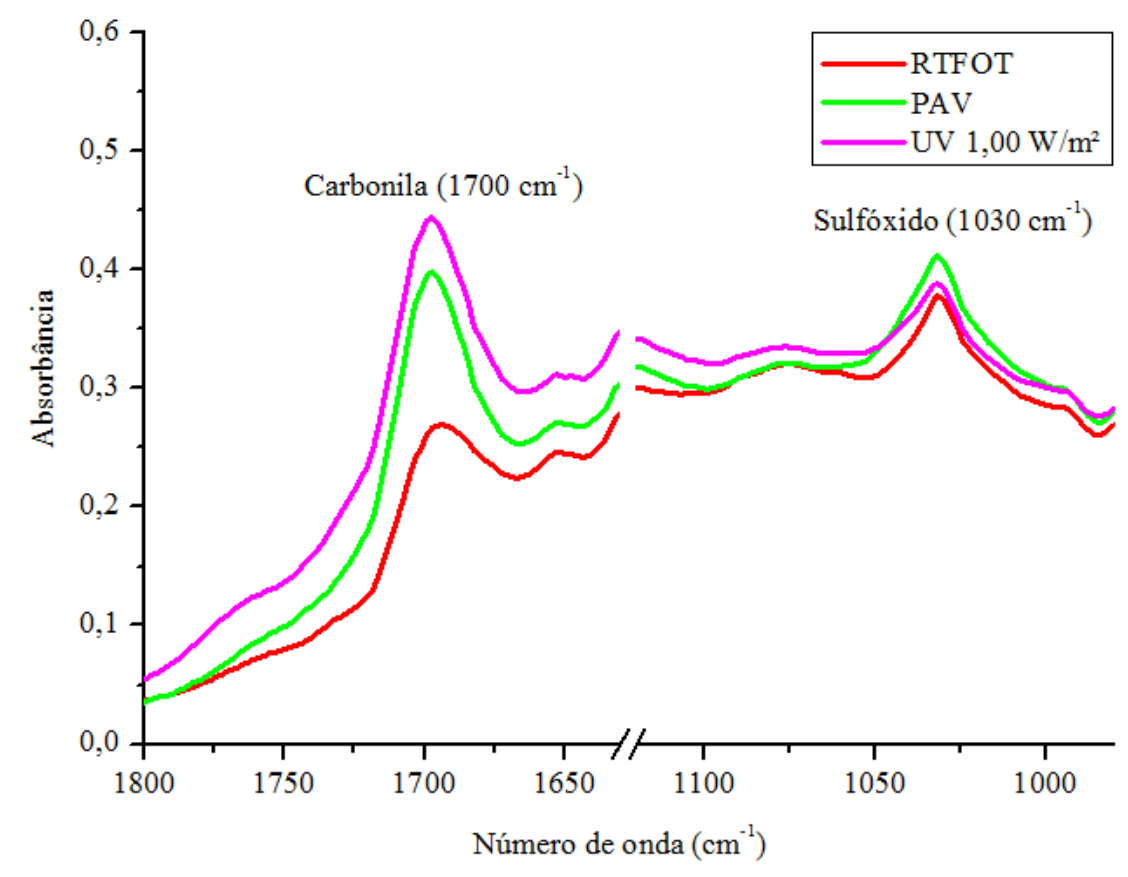

Figura 4.55 - Espectro do FTIR do CAP+SBS nas condições de envelhecimentos a curto prazo (RTFOT) e a longo prazos (PAV, UV 0,68 W/m² e UV 1,00 W/m²) 
Tabela 4.55 - Áreas de absorbância de carbonila e sulfóxido dos CAPs analisados nas condições envelhecidas

\begin{tabular}{ccccc}
\hline \multirow{2}{*}{ Ligante asfáltico } & $\begin{array}{c}\text { Nível de } \\
\text { envelhecimento }\end{array}$ & $\begin{array}{c}\text { Área } \\
\text { carbonila } \\
(\mathbf{C}=\mathbf{O})\end{array}$ & $\begin{array}{c}\text { Área } \\
\text { sulfóxido } \\
(\mathbf{S}=\mathbf{O})\end{array}$ & Soma \\
\hline \multirow{3}{*}{ CAP puro } & RTFOT & 1,58 & 0,98 & 2,56 \\
& PAV & 3,71 & 1,92 & 5,63 \\
& UV $0,68 \mathrm{~W} / \mathrm{m}^{2}$ & 2,64 & 1,49 & 4,13 \\
& $\mathrm{UV} 1,00 \mathrm{~W} / \mathrm{m}^{2}$ & 2,75 & 1,54 & 4,29 \\
\hline \multirow{3}{*}{$\mathrm{CAP}+\mathrm{PPA}$} & $\mathrm{RTFOT}$ & 1,08 & 0,75 & 1,83 \\
& $\mathrm{PAV}$ & 3,21 & 1,36 & 4,57 \\
& $\mathrm{UV} 0,68 \mathrm{~W} / \mathrm{m}^{2}$ & 1,78 & 0,91 & 2,69 \\
& $\mathrm{UV} 1,00 \mathrm{~W} / \mathrm{m}^{2}$ & 1,97 & 0,95 & 2,92 \\
\hline \multirow{2}{*}{$\mathrm{CAP}+\mathrm{SBS}$} & $\mathrm{RTFOT}$ & 2,19 & 1,24 & 3,43 \\
& $\mathrm{PAV}$ & 4,21 & 1,80 & 6,01 \\
& $\mathrm{UV} 1,00 \mathrm{~W} / \mathrm{m}^{2}$ & 4,15 & 1,28 & 5,43 \\
\hline
\end{tabular}

Para uma melhor visualização dos resultados obtidos, a Figura 4.56 apresenta o gráfico das somas das áreas de absorbância de carbonila $(\mathrm{C}=\mathrm{O})$ e sufóxido $(\mathrm{S}=\mathrm{O})$. Maiores áreas representam uma concentração maior desses grupos funcionais, indicando a extensão do envelhecimento oxidativo (OLIVEIRA, 2014). As menores áreas obtidas nos resultados das três amostras, ou seja, as menores concentrações de carbonilas e sulfóxidos, se deram para os CAPs envelhecidos a curto prazo no RTFOT, o que já era esperado. O objetivo maior era descobrir, dentre os três tipos de envelhecimentos a longo prazo, qual se destacava com as maiores concentrações dos grupos funcionais mencionados, o que se deu (para todas as amostras) no envelhecimento PAV, seguido do UV 1,00 W/m² e UV 0,68 W/m² (nas amostras CAP puro e CAP+PPA). Esses resultados indicam, que para as três amostras testadas no FTIR o envelhecimento PAV foi mais severo do que o envelhecimento UV (independente da intesidade da radiação). 
190

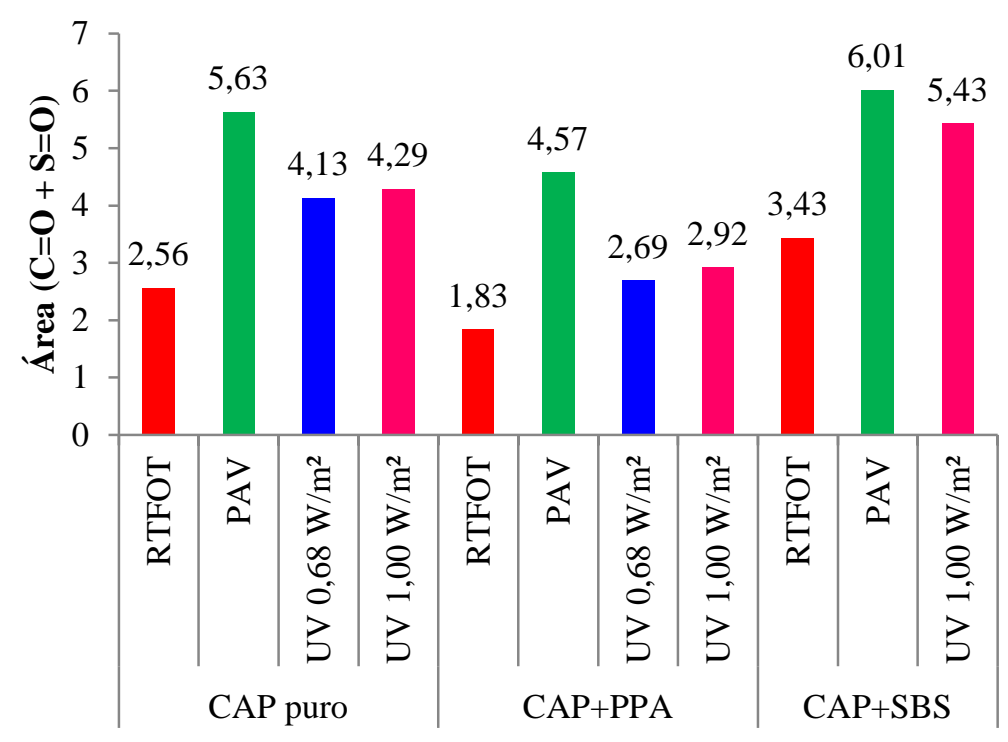

Figura 4.56 - Soma das áreas de carbonila e sulfóxido dos CAPs analisados envelhecidos

\subsubsection{Cromatografia por Permeação em Gel (GPC)}

A técnica de cromatografia por permeação em gel consiste em separar moléculas de acordo com o seu tamanho, passando uma solução da amostra do ligante (ou de outra macromolécula, como polímeros) por uma coluna cromatográfica (de matriz porosa). Durante o experimento, as moléculas maiores "escapam" antes, pois não ficam retidas na coluna cromatográfica, enquanto as moléculas menores ficam retidas nos poros da coluna por um tempo, até serem eluídas, para "escaparem” depois. As Figuras 4.57 e 4.58 apresentam os resultados obtidos nos ensaios de cromatografia por permeação em gel do CAP 50/70 puro e do CAP 50/70+PPA, ambos na condição virgem e envelhecidos (a curto prazo no RTFOT e a longo prazo no PAV; UV 0,68 W/m² e UV 1,00 W/m²). Para o cálculo das massas molares que estão na Tabela 4.56 foi realizada uma média, na qual se incluem os maltenos e os asfaltenos. 


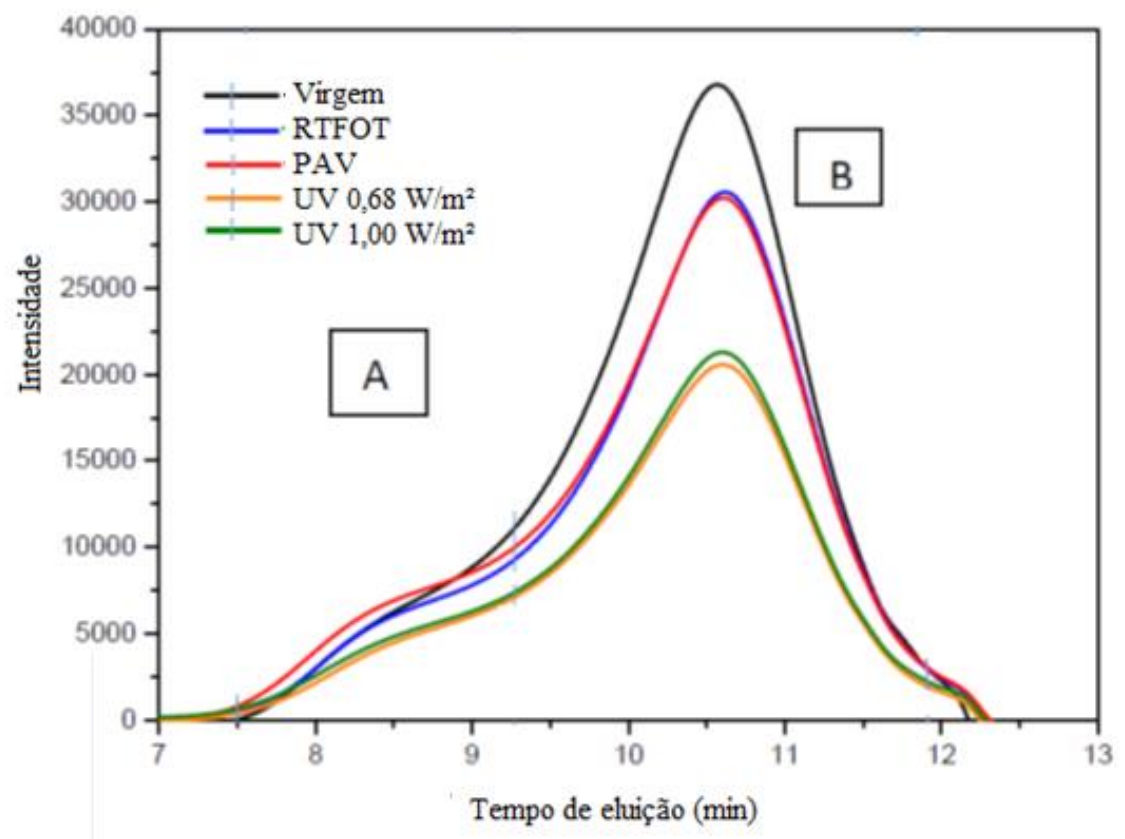

Figura 4.57 - Cromatograma do CAP 50/70 virgem e envelhecido a curto e a longo prazos

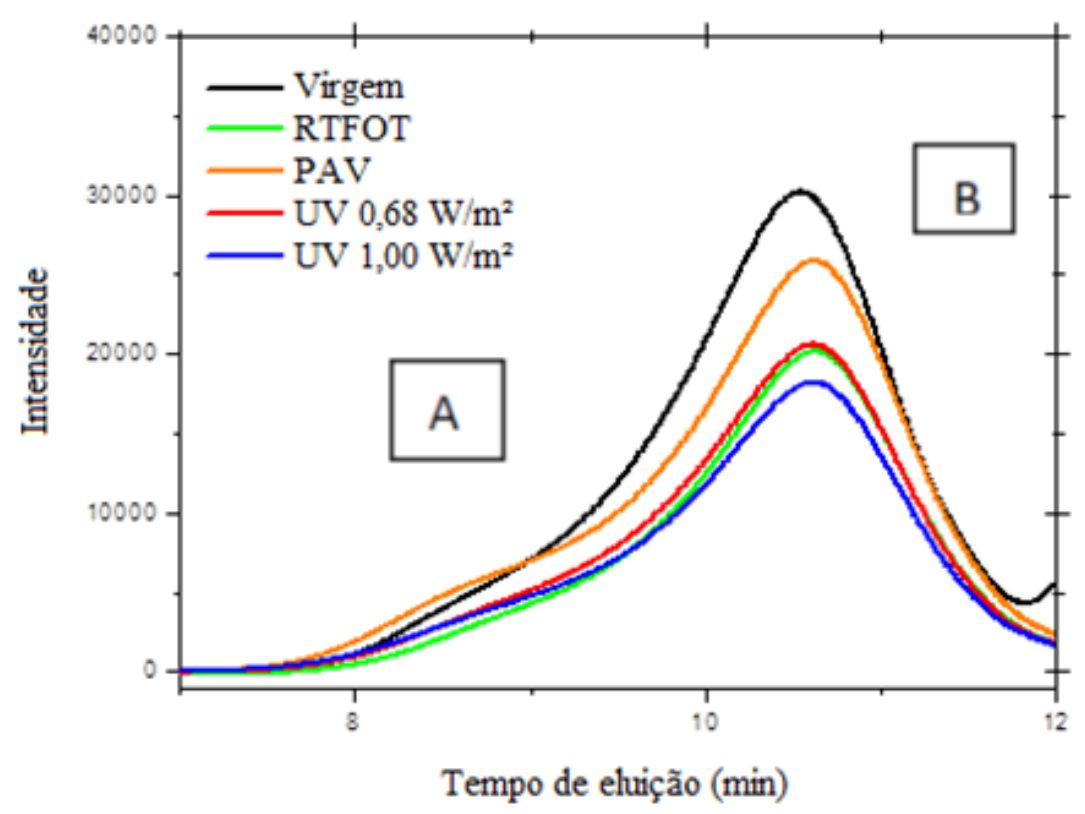

Figura 4.58 - Cromatograma do CAP 50/70+PPA virgem e envelhecido a curto e a longo prazos 
Tabela 4.56 - Resultados GPC dos CAP puro e CAP+PPA virgens e envelhecidos a curto e a longo prazos

\begin{tabular}{|c|c|}
\hline Amostra & Massa molar (Mw) (g/mol) \\
\hline \multicolumn{2}{|c|}{ 50/70 puro } \\
\hline Virgem & 3556 \\
\hline RTFOT & 3675 \\
\hline PAV & 4077 \\
\hline $\mathrm{UV} 0,68 \mathrm{~W} / \mathrm{m}^{2}$ & 4004 \\
\hline $\mathrm{UV} 1,00 \mathrm{~W} / \mathrm{m}^{2}$ & 4010 \\
\hline \multicolumn{2}{|c|}{ 50/70+PPA } \\
\hline Virgem & 3065 \\
\hline RTFOT & 3107 \\
\hline PAV & 3671 \\
\hline $\mathrm{UV} 0,68 \mathrm{~W} / \mathrm{m}^{2}$ & 3400 \\
\hline $\mathrm{UV} 1,00 \mathrm{~W} / \mathrm{m}^{2}$ & 3511 \\
\hline
\end{tabular}

A curva do GPC é representada pela relação da resposta do detector (intensidade) em relação ao tempo de eluição. Para interpretação dos gráficos das Figuras 4.57 e 4.58, deve-se levar em consideração que a intensidade da absorção (eixo y) não está relacionada com a massa molar. A massa molar está relacionada, sim, com a posição no gráfico. A intensidade está relacionada com a presença dos compostos em maior ou menor concentração. Teoricamente, com o envelhecimento, o que deveria acontecer é um aumento da porcentagem de asfaltenos (representada pelo movimento da curva para a esquerda) - logo, a de maior massa). Por outro lado, se espera uma redução das frações de maltenos de menor massa molar, posicionados na região B dos gráficos.

Considerando os resultados do CAP puro (Figura 4.57), observa-se que o grupo da região A (asfaltenos) possui maior massa molar que o grupo da região B (maltenos), deixando claro o aumento dos asfaltenos e a redução dos maltenos. $O$ fato da absorção do grupo da região A começar a ficar mais intensa, com o envelhecimento, significa que existe uma concentração maior de asfaltenos na ordem da intensidade de absorção. E ao que parece, o envelhecimento mais pronunciado ocorreu no PAV, mostrando a maior alteração, mas o comportamento não foi proporcional à intensidade do envelhecimento, pois o CAP virgem parece ter o mesmo teor de asfaltenos que o CAP envelhecido no RTFOT. O fato do pico mais intenso está mais para a esquerda do gráfico (maior massa molar), pode significar que os asfaltenos formaram micelas de agregados maiores (caso PAV). Na região B do gráfico, notase que houve uma redução da fração dos maltenos (óleos aromáticos e saturados) com o 
envelhecimento. Os resultados deixam claro que praticamente não ocorreu mudança entre os envelhecimentos UV $\left(0,68\right.$ e $\left.1,00 \mathrm{~W} / \mathrm{m}^{2}\right)$, já que as curvas estão praticamente sobrepostas, e que nos dois envelhecimentos UV, os maltenos sofreram maiores reduções. No CAP virgem, envelhecido no RTFOT e no PAV, também não ocorreu grandes diferenças na região B (dos maltenos).

Quando se observa a Figura 4.58, que representa o resultado do CAP+PPA verificase que o grupo da região A (asfaltenos) também possui maior massa molar que o grupo da região B (maltenos), deixando claro o aumento dos asfaltenos e a redução dos maltenos. $\mathrm{Na}$ região $\mathrm{A}$, o envelhecimento mais pronunciado também ocorreu no $\mathrm{PAV}$, mostrando maior aumento de asfaltenos, mas o comportamento não foi proporcional à intensidade do envelhecimento, pois o CAP virgem também aparenta estar envelhecido. Na região $\mathbf{B}$ do gráfico, nota-se que houve uma redução da fração dos maltenos com o envelhecimento. Os resultados mostram que também praticamente não ocorreu mudança entre os envelhecimentos $\mathrm{UV}\left(0,68\right.$ e $\left.1,00 \mathrm{~W} / \mathrm{m}^{2}\right)$. As curvas indicam que foi no UV que os maltenos sofreram maior redução.

\subsubsection{Fracionamento SARA (Saturados, Aromáticos, Resinas e Asfaltenos)}

De acordo com Bernucci et al. (2008), algumas variáveis como a origem e o processo de produção dos CAPs influenciam nas proporções das frações SARA presentes nos ligantes asfálticos e durante a vida de serviço há variação dessas proporções. Tonial (2001) explica que, no processo de envelhecimento do ligante asfáltico, seja a curto ou a longo prazo, geralmente há redução do teor de aromáticos, que se transformam em resinas e estas, por sua vez, se transformam (em parte) em asfaltenos. Assim, ao final do processo, o teor de saturados e resinas sofre pequena ou nenhuma variação, o teor de aromáticos diminui e o de asfaltenos aumenta.

As Tabelas 4.57 e 4.58 , bem como as Figuras 4.59 e 4.60, apresentam os resultados dos fracionamentos SARA para os diferentes níveis de envelhecimento do CAP puro e do $\mathrm{CAP}+\mathrm{PPA}$. Considerando o teor de asfaltenos, no geral, houve aumento conforme a intensidade do envelhecimento, obtendo-se maiores valores na condição UV 1,00 W/m², no 
194

caso do CAP puro, e na condição PAV e UV 1,00 W/m², no caso do CAP+PPA. De acordo com a literatura, as frações de aromáticos tendem a diminuir com o envelhecimento, o que pode ser comprovado no caso do CAP+PPA. No caso do CAP puro, não se observou uma tendência clara. As frações de saturados se mantêm praticamente iguais no CAP puro e sofrem uma pequena redução nos envelhecimentos a longo prazo do CAP+PPA. E finalmente, as frações de resinas também não seguem uma tendência clara, sofrendo variações ao longo dos procedimentos de envelhecimento.

Tabela 4.57 - Principais frações SARA (\%) do CAP 50/70 puro na condição virgem e envelhecidos a curto e a longo prazos

\begin{tabular}{cccccc}
\hline $\begin{array}{c}\text { Frações } \\
(\mathbf{\%})\end{array}$ & Virgem & RTFOT & PAV & UV 0,68 W/m & UV 1,00 W/m \\
\hline Saturados & 15,7 & 15,7 & 16,4 & 14,9 & 14,9 \\
Aromáticos & 16,0 & 22,7 & 17,8 & 17,0 & 20,0 \\
Resinas & 43,2 & 37,6 & 39,5 & 40,6 & 37,0 \\
Asfaltenos & 25,1 & 24,0 & 26,1 & 27,4 & 28,1 \\
\hline
\end{tabular}

Tabela 4.58 - Principais frações SARA (\%) do CAP 50/70+PPA na condição virgem e envelhecidos a curto e a longo prazos

\begin{tabular}{cccccc}
\hline $\begin{array}{c}\text { Frações } \\
(\boldsymbol{\%})\end{array}$ & Virgem & RTFOT & PAV & UV 0,68 W/m² & UV 1,00 W/m² \\
\hline Saturados & 16,2 & 16,1 & 13,0 & 11,8 & 12,5 \\
Aromáticos & 29,0 & 28,1 & 16,7 & 21,6 & 17,3 \\
Resinas & 29,2 & 28,8 & 37,1 & 37,0 & 36,6 \\
Asfaltenos & 25,7 & 26,9 & 33,0 & 30,7 & 33,1 \\
\hline
\end{tabular}

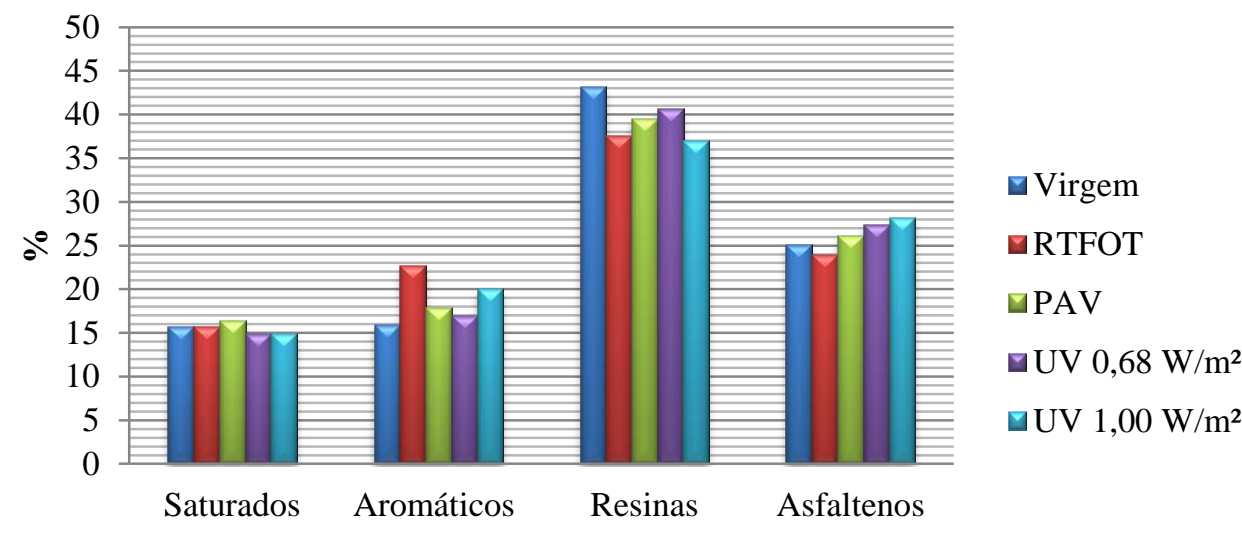

Frações SARA

Figura 4.59 - Variação das frações SARA do CAP puro virgem e envelhecidos a curto e a longos prazos 


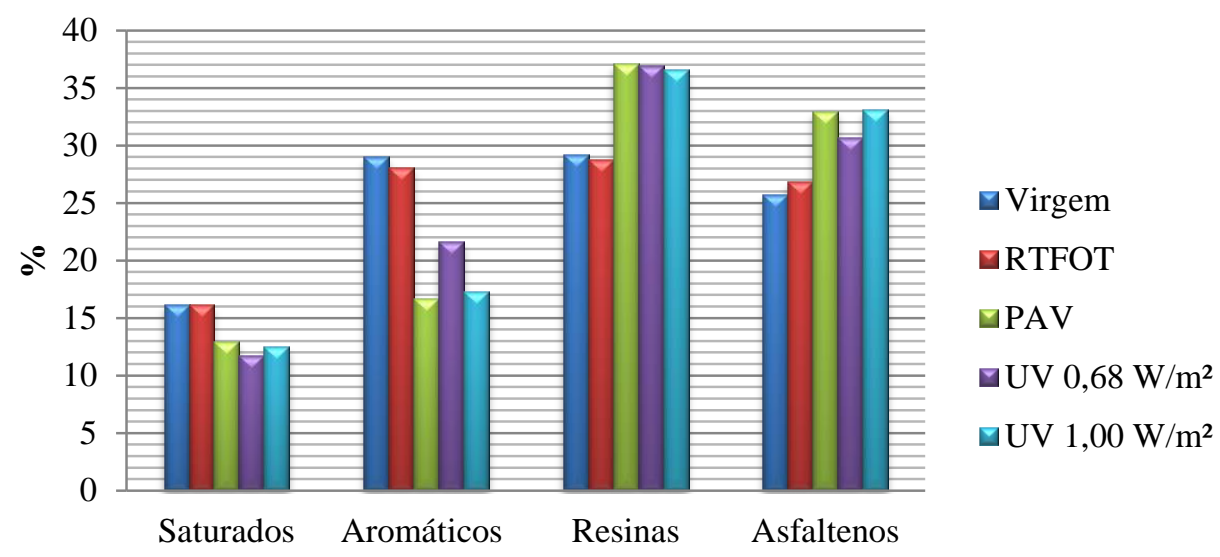

Frações SARA

\section{Figura 4.60 - Variação das frações SARA do CAP+PPA virgem e envelhecidos a curto e a longos prazos}

Como foi abordado no Capítulo 3 (Materiais e Métodos), os resultados do fracionamento SARA permitem o cálculo do índice de instabilidade coloidal $\left(\mathrm{I}_{\mathrm{C}}\right)$, com o objetivo de averiguar se o ligante asfáltico possui comportamento, SOL, GEL ou intermediário. Para Ramos et al. (1995) ${ }^{5}$ apud Bernucci et al. (2008), os ligantes asfálticos com comportamento SOL tendem a apresentar maior susceptibilidade térmica, ficando mais moles e menos resistentes à aplicação de cargas, porém com maior capacidade de recuperação de sua condição original, quando a carga é cessada. Os CAPs com comportamento GEL, por sua vez, são mais resistentes à aplicação de cargas e possuem menor capacidade de recuperação quando esta se cessa, tornando-os mais propensos ao trincamento. Entretanto, não se deve esquecer que as propriedades dos asfaltos variam bastante com a temperatura.

A Tabela 4.59 apresenta os resultados do Índice de Instabilidade Coloidal $\left(\mathrm{I}_{\mathrm{C}}\right)$ do CAP puro e do CAP+PPA nas condições virgem e envelhecida a curto e a longo prazos. Os resultados mostram que os dois ligantes asfálticos virgens e em todas as condições de envelhecimento apresentaram o comportamento GEL $\left(\mathrm{I}_{\mathrm{C}}>0,5\right)$, ou seja, mais estruturados, mais resistentes à aplicação de cargas e com menos capacidade de recuperação. No caso do CAP puro, o maior $\mathrm{I}_{\mathrm{C}}$ foi obtido na condição de envelhecimento UV $1,00 \mathrm{~W} / \mathrm{m}^{2}$, e no caso do CAP+PPA, no envelhecimento PAV. Os menores índices foram obtidos na condição virgem, para o CAP+PPA e na condição RTFOT, para o CAP puro. O que se percebe é que o

\footnotetext{
${ }^{5}$ Ramos, C.R et al. (1995). Curso de ligantes asfálticos. IBP, 114
} 
196

envelhecimento leva os CAPs do estado SOL para o estado GEL, o que é favorável, em partes, pois se tornam mais resistentes à aplicação de cargas, porém menos suscetível ao retorno, podendo facilitar o trincamento.

Tabela 4.59-Índice de instabilidade coloidal do CAP puro e do CAP+PPA, nas condições virgem e envelhecida a curto e a longo prazos (PAV e UV)

\begin{tabular}{cccccc}
\hline Ic & Virgem & RTFOT & PAV & UV 0,68 W/m & UV $\mathbf{1 , 0 0 ~ W / \mathbf { m } ^ { 2 }}$ \\
\hline CAP puro & 0,69 & 0,66 & 0,74 & 0,73 & 0,75 \\
CAP+PPA & 0,72 & 0,76 & 0,86 & 0,73 & 0,85 \\
\hline
\end{tabular}




\subsection{Introdução}

O presente trabalho teve como objetivo principal quantificar o efeito da radiação ultravioleta sobre as propriedades reológicas de ligantes asfálticos modificados, previamente envelhecidos a curto prazo em estufa RTFO. Para isto, 12 ligantes asfálticos, sendo 1 puro e 11 modificados, foram envelhecidos sob dois níveis de radiação ultravioleta $\left(0,68 \mathrm{~W} / \mathrm{m}^{2}\right.$ e $1,00 \mathrm{~W} / \mathrm{m}^{2}$ ). Para efeito de comparação, as mesmas amostras foram envelhecidas a longo prazo na estufa PAV. Considera-se envelhecimento a curto prazo o envelhecimento realizado na estufa RTFO, e envelhecimento a longo prazo o envelhecimento realizado nas estufas PAV e UV $\left(0,68 \mathrm{~W} / \mathrm{m}^{2}\right.$ e UV a $\left.1,00 \mathrm{~W} / \mathrm{m}^{2}\right)$. Foram realizados ensaios de caracterização reológica em todas as amostras e ensaios de caracterização química em apenas algumas delas. As principais conclusões deste experimento são apresentadas a seguir, separadas por assunto.

\subsection{Efeitos dos envelhecimentos a curto a longo prazos com base nas curvas- mestre}

- O envelhecimento é responsável por alterações significativas do comportamento reológico dos materiais, com maior ou menor intensidade, dependendo da formulação;

- os envelhecimentos a curto e a longo prazos provocaram, em linhas gerais, aumento da rigidez (aumento dos valores de $\mathrm{G}^{*}$ ) e da elasticidade (redução dos valores de $\delta$ ) dos ligantes asfálticos avaliados, sendo tais variações particulares para cada tipo de ligante asfáltico, o que afeta diferentemente as propriedades mecânicas das misturas asfálticas: a resistência à deformação permanente é favorecida pelo enrijecimento e pelo aumento de elasticidade provocados pelo envelhecimento a curto prazo, porém, 
as resistências à fadiga por deformação controlada e ao trincamento de origem térmica são prejudicadas pelo enrijecimento provocado pelo envelhecimento a longo prazo;

- o aumento de elasticidade provocado pelo envelhecimento, por sua vez, ameniza o efeito negativo que o envelhecimento tem sobre a rigidez nas temperaturas de fadiga e de trincamento térmico;

- considerando os ordenamentos médios de todas as frequências, a $25^{\circ} \mathrm{C}$, obtidos para cada procedimento de envelhecimento a longo prazo, por amostra, verificou-se que em 10 das 12 amostras, o procedimento de envelhecimento a longo prazo que mais proporcionou o aumento da rigidez do ligante asfáltico foi o UV a 1,00 W/m²; o CAP 50/70 puro e o CAP+SBR obtiveram maior incremento da rigidez após envelhecimento na estufa PAV;

- analisando os ordenamentos médios de todas as frequências, a $25^{\circ} \mathrm{C}$, obtidos para cada procedimento de envelhecimento a longo prazo, por amostra, com relação ao ângulo de fase, observa-se que 10 das 12 amostras apresentaram maior sensibilidade ao envelhecimento UV a $1,00 \mathrm{~W} / \mathrm{m}^{2}$, isto é, os ligantes asfálticos ganharam mais elasticidade neste procedimento de envelhecimento e, por este ser um ponto positivo, no que se refere à resistência à deformação permanente e à fadiga, estas amostras ficaram com a melhor posição do ordenamento; o $\mathrm{CAP}+\mathrm{PE}+\mathrm{PPA}$ e o $\mathrm{CAP}+\mathrm{SBR}$ apresentaram maior ganho de elasticidade quando submetidas ao envelhecimento na estufa PAV;

- considerando os ordenamentos médios de todas as frequências, a $25^{\circ} \mathrm{C}$, obtidos para cada procedimento de envelhecimento a longo prazo, por amostra, verificou-se que, dentre os procedimentos que menos afetaram a rigidez, está o PAV para 50\% das amostras (CAP+borracha, CAP+borracha+PPA, CAP+EVA, CAP+polietileno, $\mathrm{CAP}+$ polietileno+PPA e $\mathrm{CAP}+\mathrm{SBR}+\mathrm{PPA}$ ) e o $\mathrm{UV}$ a $0,68 \mathrm{~W} / \mathrm{m}^{2}$ para as demais amostras (CAP 50/70 puro, CAP+PPA, CAP+SBS, CAP+SBS+PPA, CAP+EVA+PPA e CAP+SBR);

- do ponto de vista do menor incremento na elasticidade (piores posições nos ordenamentos, considerando todas as frequências, a $25^{\circ} \mathrm{C}$ ) foi obtida a seguinte distribuição: 58,33\% das amostras (CAP 50/70 puro, CAP+borracha+PPA, 
$\mathrm{CAP}+\mathrm{SBS}+\mathrm{PPA}, \mathrm{CAP}+\mathrm{EVA}, \mathrm{CAP}+\mathrm{EVA}+\mathrm{PPA}, \mathrm{CAP}+\mathrm{SBR}$ e $\mathrm{CAP}+\mathrm{SBR}+\mathrm{PPA})$ envelhecidas no UV a $0,68 \mathrm{~W} / \mathrm{m}^{2} ; 33,33 \%$ das amostras (CAP+PPA, CAP+borracha, $\mathrm{CAP}+\mathrm{SBS}$ e CAP+PE) envelhecidas no PAV e 8,33\% (1 amostra) apresentou ordenamento médio igual para os dois níveis de envelhecimento UV (CAP+PE+PPA);

- os resultados, no geral, indicaram que os procedimentos PAV e UV a 0,68 W/m² apresentam certa equivalência em termos da capacidade de alterar as propriedades analisadas $\left(\mathrm{G}^{*}\right.$ e $\left.\delta\right)$;

- os resultados indicaram que, para a maior parte das amostras, o procedimento UV a $1,00 \mathrm{~W} / \mathrm{m}^{2}$ foi o que provocou maiores alterações nos valores de $\mathrm{G}^{*} \mathrm{e} \delta$, isto é, foi o procedimento ao qual as amostras se mostraram mais sensíveis;

- considerando o critério da rigidez e da elasticidade (juntos), o ordenamento geral (todas as amostras, em todos os níveis de envelhecimento, apresentado na Tabela $4.25)$, a $25^{\circ} \mathrm{C}$, em que as melhores posições são indicadas por aquelas que tiveram os menores aumentos de $\mathrm{G}^{*}$ e os maiores aumentos de $\delta$ (em módulo), destacam-se as formulações CAP 50/70 puro e $\mathrm{CAP}+\mathrm{SBR}+\mathrm{PPA}$, nas melhores posições, e o $\mathrm{CAP}+\mathrm{EVA}$ e o $\mathrm{CAP}+\mathrm{SBR}$ nas piores (registraram maiores aumentos de rigidez e menores ganhos de elasticidade);

- o ordenamento final (Tabela 4.45) com base nas variações de $\mathrm{G}^{*}, \delta$ e $\mathrm{G}^{*}$.sen $\delta$ devidas aos envelhecimentos a longo prazo, na frequência de $10 \mathrm{rad} / \mathrm{s}$, aponta as seguintes formulações (da menos para a mais sensível ao envelhecimento): $\mathrm{CAP}+\mathrm{SBR}+\mathrm{PPA}$ $(4,4), \mathrm{CAP}+\mathrm{SBS}(5,0), \mathrm{CAP}+\mathrm{PE}(5,1), \mathrm{CAP}+\mathrm{SBR}(5,2), \mathrm{CAP}$ puro $(5,6)$, CAP+borracha (5,7), CAP+EVA (6,5), CAP+EVA+PPA (7,4), CAP+PPA (7,6), CAP+borracha+PPA $(8,0), \mathrm{CAP}+\mathrm{PE}+\mathrm{PPA}(8,4)$ e CAP+SBS+PPA $(9,1)$; destacandose, portanto, o $\mathrm{CAP}+\mathrm{SBR}+\mathrm{PPA}$ como o menos sensível ao envelhecimento a longo prazo e o $\mathrm{CAP}+\mathrm{SBS}+\mathrm{PPA}$ como o mais sensível;

- ao se compararem os ordenamentos médios da sensibilidade aos envelhecimentos a longo prazo com base nas variações de $\mathrm{G}^{*}, \delta$ e $\mathrm{G}^{*}$.sen $\delta$, na frequência de $10 \mathrm{rad} / \mathrm{s}$, observa-se que a adição de PPA aos ligantes asfálticos modificados com polímero (incluindo a borracha) reduz a sensibilidade ao envelhecimento, à exceção do $\mathrm{CAP}+\mathrm{SBR}$, no caso do PAV, e do CAP+EVA, no caso do UV a 1,0 W/m². 
- No geral, os envelhecimentos a longo prazo (PAV, UV a 0,68 W/m² e UV a 1,00 $\mathrm{W} / \mathrm{m}^{2}$ ) aumentam a tolerância ao dano por fadiga avaliado à luz do parâmetro $\mathrm{a}_{\mathrm{f}}$, quando comparado ao envelhecimento a curto prazo; as exceções são o CAP+SBR+PPA (UV a $0,68 \mathrm{~W} / \mathrm{m}^{2}$ ) e o CAP+SBR (UV a $0,68 \mathrm{~W} / \mathrm{m}^{2}$ e $\mathrm{UV}$ a 1,00 $\left.\mathrm{W} / \mathrm{m}^{2}\right)$;

- todas as amostras envelhecidas na estufa PAV apresentaram maior tolerância ao dano por fadiga quando comparadas às envelhecidas no $\mathrm{UV}$ a $0,68 \mathrm{~W} / \mathrm{m}^{2}$, exceto o CAP+borracha e o CAP+SBS;

- todas as amostras envelhecidas na estufa PAV apresentaram maior tolerância ao dano por fadiga quando comparadas às envelhecidas no $\mathrm{UV}$ a $1,00 \mathrm{~W} / \mathrm{m}^{2}$, exceto o CAP+borracha, o CAP+borracha+PPA e o CAP+SBS;

- todas as amostras envelhecidas no UV a $1,00 \mathrm{~W} / \mathrm{m}^{2}$ tiveram maior tolerância ao dano por fadiga do que as amostras envelhecidas no UV a $0,68 \mathrm{~W} / \mathrm{m}^{2}$, exceto para o $\mathrm{CAP}+\mathrm{PPA}$, o $\mathrm{CAP}+\mathrm{PE}+\mathrm{PPA}$ e o $\mathrm{CAP}+\mathrm{SBR}$; tais resultados indicam que, dada a severidade do condicionamento a altos níveis de irradiação, alguns materiais têm seu comportamento à fadiga prejudicado, à luz da lógica associada ao parâmetro $\mathrm{a}_{\mathrm{f}}$;

- as modificações foram positivas para o aumento da tolerância ao dano por fadiga; todos os ligantes asfálticos modificados apresentaram maiores comprimentos de trinca $\left(\mathrm{a}_{\mathrm{f}}\right)$, quando comparados ao CAP puro, exceto a formulação com borracha no envelhecimento PAV; nas condições RTFOT e PAV, o melhor desempenho foi observado para o CAP+SBR; na condição UV a 0,68 W/m², o melhor desempenho foi do CAP+EVA e na condição UV a $1,00 \mathrm{~W} / \mathrm{m}^{2}$, destaca-se o CAP+SBS;

- os envelhecimentos a longo prazo aumentam a integridade (coeficiente $\mathrm{A}_{35}$ ) dos ligantes asfálticos, especialmente nos materiais envelhecidos no UV a $1,00 \mathrm{~W} / \mathrm{m}^{2}$; a amostra que mais se destacou mantendo uma integridade elevada em todos os níveis de envelhecimento foi o CAP+EVA; o CAP puro apresentou a menor integridade;

- os envelhecimentos a longo prazo contribuem para o aumento da sensibilidade ao nível de deformação (parâmetro B) dos ligantes asfálticos, quando comparados com o envelhecimento a curto prazo (RTFOT); em todos os níveis de envelhecimento, o 
CAP+EVA encontra-se entre os materiais mais sensíveis ao nível de deformação e o CAP puro entre os menos sensíveis;

- para baixos níveis de deformação, no geral, o efeito das modificações é positivo; a amostra que apresentou maior vida de fadiga foi o CAP+EVA, o que pode ser observado para todos os níveis de envelhecimento; ainda sob baixos níveis de deformação, o CAP puro apresenta a pior vida de fadiga em todos os níveis de envelhecimento, exceto na condição RTFOT, na qual o CAP+SBR+PPA apresenta a menor vida de fadiga;

- o CAP 50/70 puro, que sob baixos níveis de deformação apresentou as menores vidas de fadiga, se destaca, sob altas deformações, como o melhor em todas as condições de envelhecimento, exceto na condição PAV, embora ainda bem posicionado ( $3^{\circ}$ lugar); sob altos níveis de deformação, verifica-se que as modificações não contribuem para o aumento da vida de fadiga dos materiais.

\subsection{Caracterização química dos ligantes asfálticos}

- Para o CAP puro, CAP+PPA e CAP+SBS, submetidos ao FTIR, o envelhecimento na estufa PAV foi mais severo que os demais, pois apresentou maiores áreas de absorbância do grupo funcional carbonila e dos sulfóxidos; para o CAP puro e o CAP+PPA, o envelhecimento UV a $1,00 \mathrm{~W} / \mathrm{m}^{2}$ apresentou maior nível de severidade que o envelhecimento UV a $0,68 \mathrm{~W} / \mathrm{m}^{2}$;

- para o CAP puro e o CAP+PPA, a análise por GPC indicou aumento das frações de asfaltenos com os envelhecimentos, sendo mais acentuada no envelhecimento PAV, em ambos os casos; indicou ainda redução dos maltenos, sendo mais acentuada nos envelhecimentos UV, no dois níveis de radiação;

- por meio do francionamento SARA, constatou o aumento nos teores de asfaltenos dos CAP puro e CAP+PPA envelhecidos que, no geral, foram maiores conforme a intensidade do envelhecimento, obtendo-se maiores valores na condição UV a 1,00 $\mathrm{W} / \mathrm{m}^{2}$, no caso do CAP puro, e nas condições PAV e UV a $1,00 \mathrm{~W} / \mathrm{m}^{2}$, no caso do 
CAP+PPA; as frações de aromáticos diminuíram com o envelhecimento, no caso do CAP+PPA e no CAP puro não se observou uma tendência clara;

- o Índice de Instabilidade Coloidal apontou que o CAP puro e o CAP+PPA em todas as condições de envelhecimento apresentaram o comportamento GEL; no caso do CAP puro, o maior $I_{C}$ foi obtido na condição de envelhecimento UV a 1,00 W/m² e, no caso do CAP+PPA, no envelhecimento PAV; o que se percebe é que o envelhecimento leva os CAPs do estado SOL para o estado GEL, o que é favorável, em partes, pois se tornam mais resistentes à aplicação de cargas, porém menos suscetível ao retorno elástico, podendo favorecer o trincamento por fadiga.

\subsection{Considerações Finais}

Levando em consideração os objetivos iniciais deste trabalho, tem-se que:

- Foi possível quantificar, por meio das curvas-mestres, os efeitos da radiação ultravioleta sobre as propriedades reológicas dos ligantes asfálticos modificados, em termos de quantas vezes houve aumento ou diminuição dos parâmetros relacionados à rigidez, elasticidade e fadiga, quando comparados ao CAP envelhecido a curto prazo na estufa RTFO;

- foi também possível comparar, por meio das curvas-mestre e dos resultados do ensaio LAS, os efeitos do envelhecimento foto-oxidativo e termo-oxidativo e constatar que para a maioria das amostras os procedimentos PAV e UV a $0,68 \mathrm{~W} / \mathrm{m}^{2}$ apresentam certa equivalência, em termos da capacidade de alterar as propriedades reológicas analisadas, e que, para a maioria das amostras analisadas, o procedimento UV a $1,00 \mathrm{~W} / \mathrm{m}^{2}$ foi mais severo que o PAV e o UV $0,68 \mathrm{~W} / \mathrm{m}^{2}$, pois provocou aumento da sensibilidade ao envelhecimento;

- ao se compararem as melhores e as piores amostras, à luz dos ordenamentos baseados nos do parâmetros de fadiga $\mathrm{a}_{\mathrm{f}}, \mathrm{N}_{\mathrm{f}} \mathrm{e} \mathrm{G}^{*}$.sen $\delta$, constatou-se que, em alguns casos, os ligantes asfálticos em destaque são os mesmos, mas em outros não há nenhuma correspondência (Tabela 5.2); 
- foi possível, por meio das análises químicas, verificar evidências do envelhecimento oxidativo das amostras testadas em maior severidade nos ligantes asfálticos envelhecidos no PAV e no UV a $1,00 \mathrm{~W} / \mathrm{m}^{2}$; nestes ensaios, as amostras virgens do CAP puro e do CAP+PPA apresentaram indícios de envelhecimento, decorrente, possivelmente, do aquecimento repetido destes materiais para moldagem de amostras;

- este estudo comprovou que as propriedades reológicas e as características químicas dos ligantes asfálticos são afetadas pelo envelhecimento ultravioleta e de diferentes maneiras, conforme a intensidade da irradiação;

- o ligante asfáltico que mostrou ser menos sensível ao envelhecimento PAV, considerando os requisitos de interesse apresentados na Tabela 5.1, foi o CAP+SBR, como pode ser visualizado na Figura 5.1, o que demonstrou ser menos sensível ao envelhecimento UV a $0,68 \mathrm{~W} / \mathrm{m}^{2}$ foi o CAP+EVA (Figura 5.2), e o que demonstrou menor sensibilidade ao envelhecimento UV a 1,00 W/m² foi o CAP+SBS (Figura 5.3);

- o CAP+SBS+PPA foi a amostra que apresentou maior sensibilidade ao envelhecimento PAV e UV a $1,00 \mathrm{~W} / \mathrm{m}^{2}$;

- considerando a classificação constante na Figura 5.4, em que foram considerados todos os requisitos de interesse, o ligante asfáltico que apresentou melhor desempenho geral foi o CAP+EVA; tal amostra apresentou maior ganho de elasticidade e maiores vida de fadiga (nas amplitudes de deformação baixa e alta) no envelhecimento PAV; maiores vida de fadiga, nas deformações altas, nos envelhecimentos UV a $0,68 \mathrm{~W} / \mathrm{m}^{2}$ e UV a $1,00 \mathrm{~W} / \mathrm{m}^{2}$ e melhor posicionamento no parâmetro de fadiga $\mathrm{G}^{*}$.sen $\delta$ na condição UV a $1,00 \mathrm{~W} / \mathrm{m}^{2}$;

- a adição de PPA aos ligantes asfálticos contribui para o aumento da sensibilidade aos envelhecimentos UV (nos dois níveis de radiação); no envelhecimento PAV a adição de PPA contribui para o aumento da sensibilidade ao envelhecimento apenas nas modificações com SBR e SBS; na classificação geral o efeito da adição de PPA é negativo;.

- o Apêndice B apresenta uma proposta de procedimento de envelhecimento de ligantes asfálticos puros e modificados em estufa UV, bem como uma proposta de procedimento de análise dos efeitos do envelhecimento UV por meio de curvasmestre, tendo por base uma das técnicas que foram desenvolvidas neste estudo. 
5.6 Sugestões para trabalhos futuros

Para uma abordagem mais profunda e abrangente dos efeitos da radiação ultravioleta sobre os ligantes asfálticos modificados, seguem algumas sugestões para trabalhos futuros:

- realizar os ensaios químicos no restante das amostras;

- testar novas condições de ensaio, variando a intensidade da radiação UV, bem como o tempo de exposição na câmara e as temperaturas de ensaio;

- simular o efeito da água submetendo as amostras a ciclos intercalados com e sem aspersão de água;

- aplicar o procedimento proposto neste trabalho com ligantes asfálticos procedentes de outras fontes e de outras classes, incluindo modificados. 
Tabela 5.1 - Posições médias dos ligantes asfálticos por requisitos de interesse, incluindo todas as condições de envelhecimento - longo prazo na estufa PAV e longo prazo na estufa UV $\left(0,68\right.$ e $\left.1,00 \mathrm{~W} / \mathrm{m}^{2}\right)$

\begin{tabular}{|c|c|c|c|c|c|c|c|c|c|c|c|c|c|}
\hline requisito de interesse & CAP & PPA & borracha & $\begin{array}{c}\text { borracha } \\
\text { +PPA }\end{array}$ & SBS & $\begin{array}{c}\text { SBS+ } \\
\text { PPA }\end{array}$ & EVA & EVA+PPA & $\mathbf{P E}$ & PE+PPA & SBR & $\begin{array}{c}\text { SBR+ } \\
\text { PPA }\end{array}$ & critério \\
\hline $\begin{array}{l}\text { sensibilidade ao envelhecimento } \\
\mathrm{PAV}\left(25^{\circ} \mathrm{C} \text {, várias frequências }\right)\end{array}$ & 5,73 & 8,14 & 5,56 & 6,41 & 6,29 & 5,03 & 8,83 & 7,58 & 5,34 & 6,28 & 9,11 & 3,70 & $\begin{array}{l}\text { pior: aumento de } \mathrm{G}^{*} \text {; } \\
\text { melhor: redução de } \delta\end{array}$ \\
\hline $\begin{array}{c}\text { sensibilidade ao envelhecimento } \\
\mathrm{UV} \text { a } 0,68 \mathrm{~W} / \mathrm{m}^{2}\left(25^{\circ} \mathrm{C} \text {, várias }\right. \\
\text { frequências })\end{array}$ & 2,77 & 5,79 & 6,20 & 6,82 & 6,09 & 7,70 & 9,24 & 4,77 & 5,58 & 9,16 & 6,56 & 7,33 & $\begin{array}{l}\text { pior: aumento de } \mathrm{G}^{*} \text {; } \\
\text { melhor: redução de } \delta\end{array}$ \\
\hline $\begin{array}{c}\text { sensibilidade ao envelhecimento } \\
\mathrm{UV} \text { a } 1,00 \mathrm{~W} / \mathrm{m}^{2}\left(25^{\circ} \mathrm{C} \text {, várias }\right. \\
\text { frequências })\end{array}$ & 5,69 & 6,27 & 6,76 & 7,23 & 5,66 & 6,41 & 7,48 & 5,87 & 5,88 & 7,61 & 7,62 & 5,51 & $\begin{array}{l}\text { pior: aumento de } \mathrm{G}^{*} \text {; } \\
\text { melhor: redução de } \delta\end{array}$ \\
\hline $\begin{array}{c}\text { sensibilidade ao envelhecimento a } \\
\text { longo prazo PAV (10 rad/s, várias } \\
\text { temperaturas) }\end{array}$ & 7,20 & 8,87 & 2,17 & 5,57 & 3,23 & 9,50 & 6,07 & 8,87 & 4,50 & 8,77 & 9,17 & 4,03 & $\begin{array}{c}\text { pior: aumentar } \mathrm{G}^{*} \text {; } \\
\text { melhor: reduzir } \delta \text { e } \mathrm{G}^{*} . \operatorname{sen} \delta\end{array}$ \\
\hline $\begin{array}{c}\text { sensibilidade ao envelhecimento a } \\
\text { longo prazo UV a } 0,68 \mathrm{~W} / \mathrm{m}^{2}(10 \\
\text { rad/s, várias temperaturas) }\end{array}$ & 6,20 & 9,00 & 6,97 & 7,57 & 4,43 & 7,73 & 6,13 & 6,43 & 5,60 & 9,40 & 3,97 & 4,80 & $\begin{array}{c}\text { pior: aumentar } \mathrm{G}^{*} \text {; } \\
\text { melhor: reduzir } \delta \text { e } \mathrm{G}^{*} \text {.sen } \delta\end{array}$ \\
\hline $\begin{array}{c}\text { sensibilidade ao envelhecimento a } \\
\text { longo prazo } 1,00 \mathrm{~W} / \mathrm{m}^{2}(10 \mathrm{rad} / \mathrm{s}, \\
\text { várias temperaturas })\end{array}$ & 3,50 & 4,90 & 7,87 & 10,73 & 7,37 & 10,07 & 7,23 & 6,77 & 5,17 & 7,13 & 2,60 & 4,40 & $\begin{array}{c}\text { pior: aumentar } \mathrm{G}^{*} \text {; } \\
\text { melhor: reduzir } \delta \text { e } \mathrm{G}^{*} . \operatorname{sen} \delta\end{array}$ \\
\hline $\mathrm{a}_{\mathrm{f}}$ PAV $25^{\circ} \mathrm{C}$ & 10,00 & 5,00 & 11,00 & 7,00 & 8,00 & 4,00 & & 3,00 & 9,00 & 6,00 & 1,00 & 2,00 & maior, melhor \\
\hline $\mathrm{a}_{\mathrm{f}} \mathrm{UV}$ a $0,68 \mathrm{~W} / \mathrm{m}^{2} 25^{\circ} \mathrm{C}$ & 12,00 & 8,00 & 4,00 & 11,00 & 7,00 & 6,00 & 1,00 & 5,00 & 10,00 & 9,00 & 2,00 & 3,00 & maior, melhor \\
\hline $\mathrm{a}_{\mathrm{f}} \mathrm{UV}$ a $1,00 \mathrm{~W} / \mathrm{m}^{2} 25^{\circ} \mathrm{C}$ & 11,00 & 9,00 & 5,00 & 3,00 & 1,00 & & 2,00 & 7,00 & 10,00 & 8,00 & 7,00 & 4,00 & maior, melhor \\
\hline $\mathrm{N}_{\mathrm{f}}(3 \%)$ PAV & 12,00 & 3,00 & 7,00 & 4,00 & 10,00 & 8,00 & 1,00 & 2,00 & 5,00 & 6,00 & 11,00 & 9,00 & maior, melhor \\
\hline $\mathrm{N}_{\mathrm{f}}(3 \%)$ UV a $0,68 \mathrm{~W} / \mathrm{m}^{2}$ & 12,00 & 5,00 & 2,00 & 3,00 & 7,00 & 6,00 & 1,00 & 4,00 & 10,00 & 9,00 & 11,00 & 8,00 & maior, melhor \\
\hline $\mathrm{N}_{\mathrm{f}}(3 \%)$ UV a $1,00 \mathrm{~W} / \mathrm{m}^{2}$ & 11,00 & 6,00 & 4,00 & 2,00 & 5,00 & & 1,00 & 3,00 & 8,00 & 7,00 & 10,00 & 9,00 & maior, melhor \\
\hline $\mathrm{N}_{\mathrm{f}}(30 \%)$ PAV & 3,00 & 9,00 & 2,00 & 5,00 & 6,00 & 12,00 & 1,00 & 4,00 & 7,00 & 8,00 & 11,00 & 10,00 & maior, melhor \\
\hline $\mathrm{N}_{\mathrm{f}}(30 \%)$ UV a $0,68 \mathrm{~W} / \mathrm{m}^{2}$ & 1,00 & 10,00 & 5,00 & 3,00 & 2,00 & 9,00 & 6,00 & 8,00 & 4,00 & 11,00 & 7,00 & 12,00 & maior, melhor \\
\hline $\mathrm{N}_{\mathrm{f}}(30 \%) \mathrm{UV}$ a $1,00 \mathrm{~W} / \mathrm{m}^{2}$ & 1,00 & 6,00 & 5,00 & 10,00 & 8,00 & & 11,00 & 7,00 & 3,00 & 4,00 & 2,00 & 9,00 & maior, melhor \\
\hline
\end{tabular}


Tabela 5.2 - Parâmetros de fadiga por condição de envelhecimento - destaques

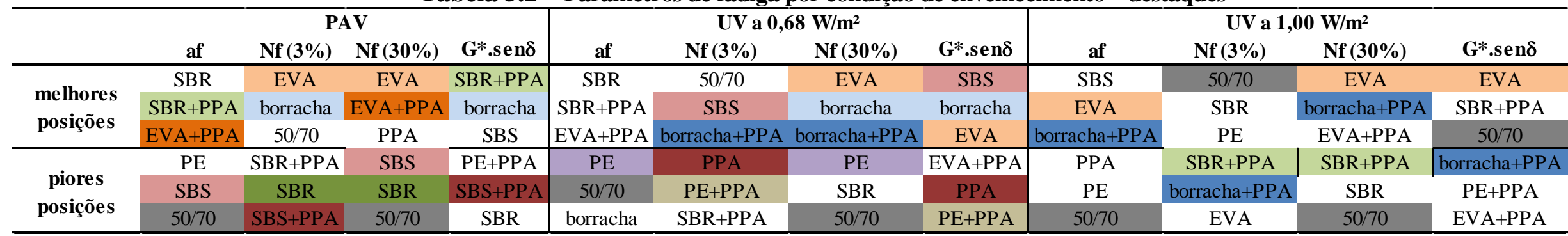

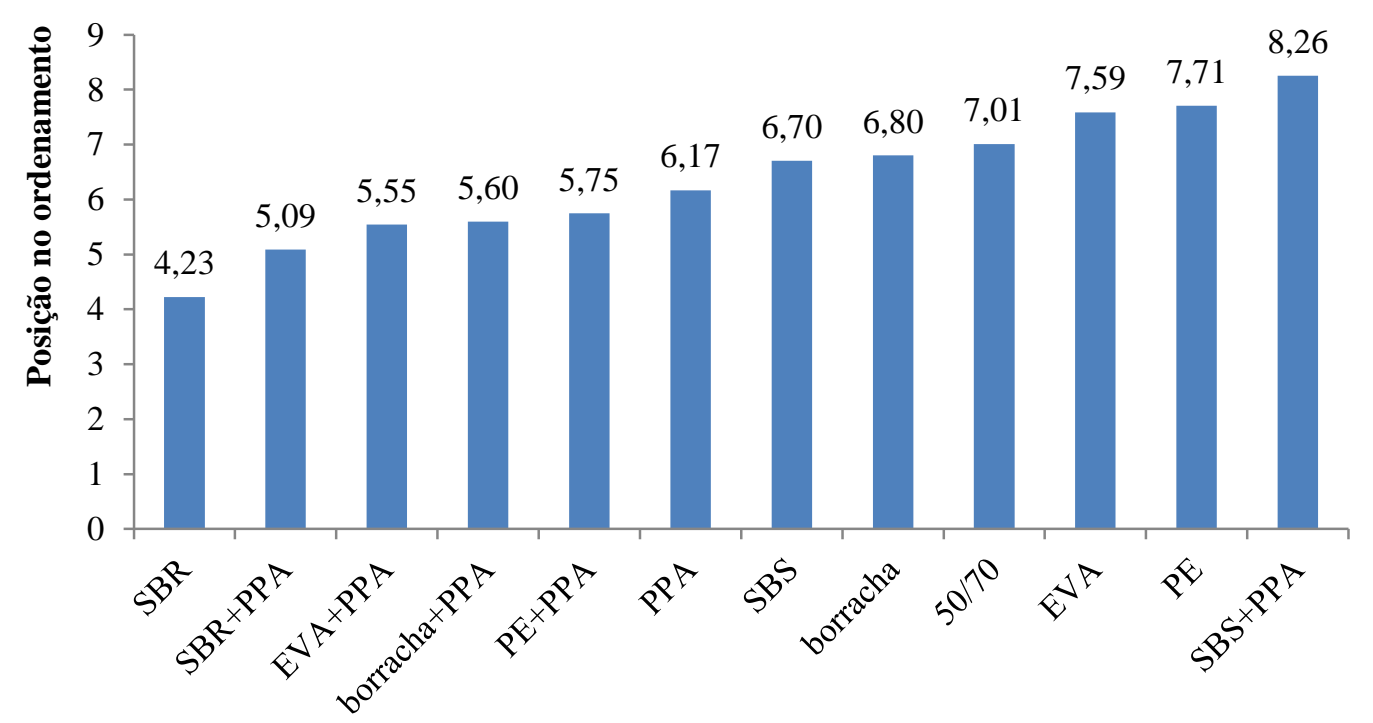

Figura 5.1 - Ordenamento final da sensibilidade à radiação PAV - posição média mais baixa indicando material menos sensível 


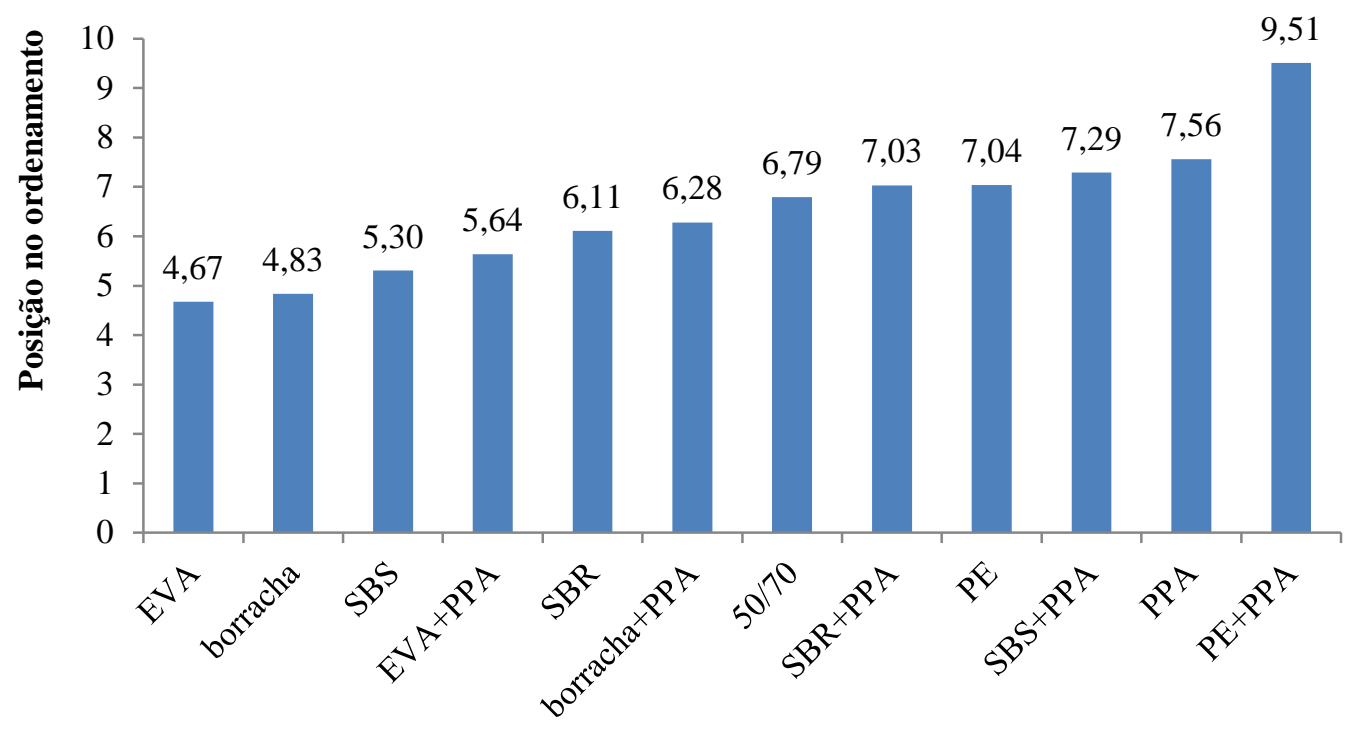

Figura 5.2 - Ordenamento final da sensibilidade à radiação UV $\left(0,68 \mathrm{~W} / \mathrm{m}^{2}\right)$ - posição média mais baixa indicando material menos sensível

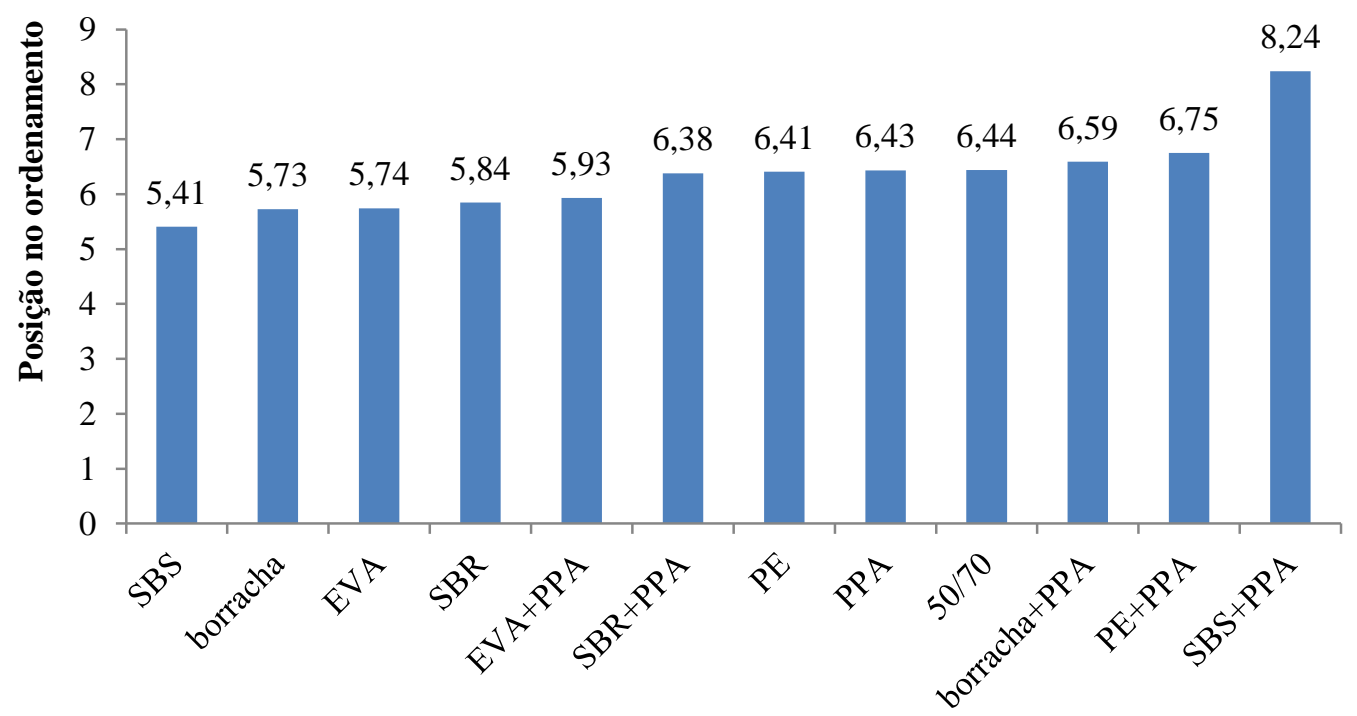

Figura 5.3 - Ordenamento final da sensibilidade à radiação UV $\left(1,00 \mathrm{~W} / \mathrm{m}^{2}\right)$ - posição média mais baixa indicando material menos sensível 


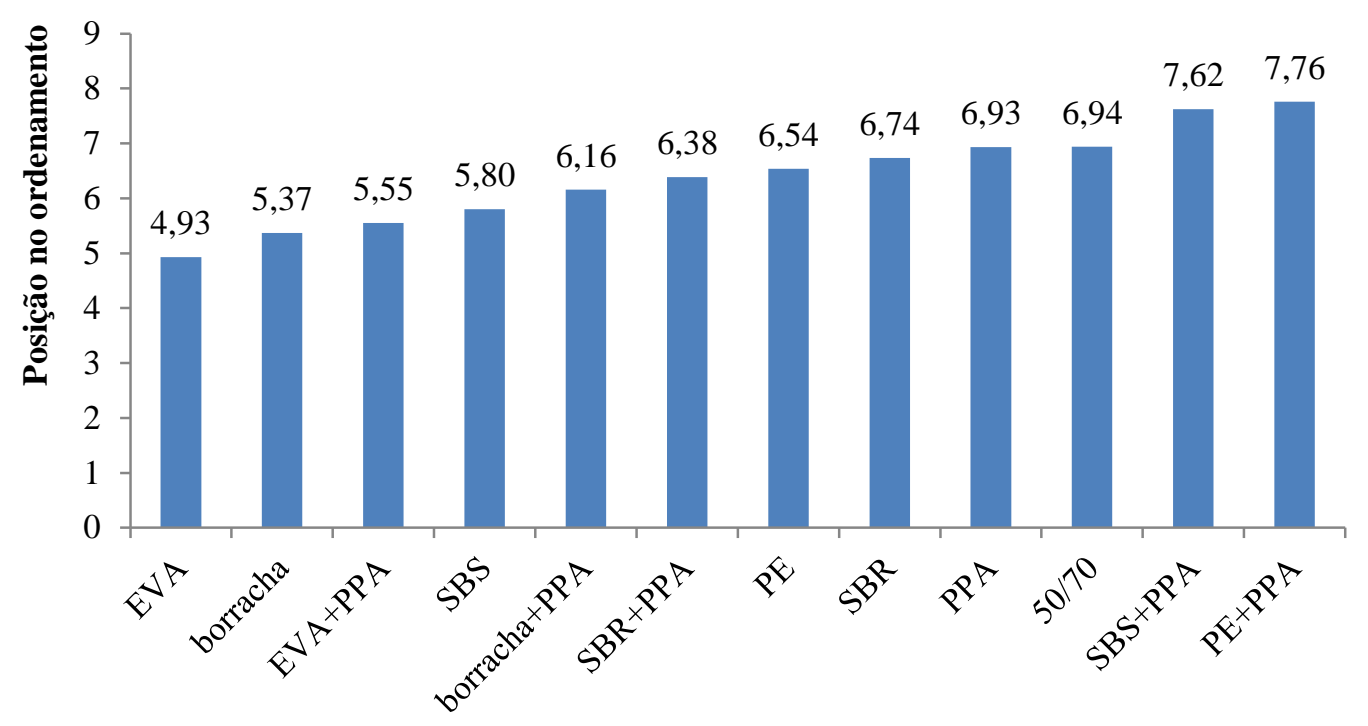

Figura 5.4 - Ordenamento final da sensibilidade aos envelhecimentos PAV, UV a 0,68 $\mathrm{W} / \mathrm{m}^{2}$ e UV $1,00 \mathrm{~W} / \mathrm{m}^{2}$ 
ABBAS, A. et al. (2002) The influence of laboratory aging method on the rheological properties of asphalt binders. Journal of Testing and Evaluation, v.30, n.2, p.171-176.

AIREY, G. D. (2003). State of the art report on aging test methods for bituminous pavement materials. Internation Journal of Pavement Engineering, v. 4, n. 3, p. 165-176.

ANDERSON, D.A. et al. (1994). Binder characterization and evaluation: physical characterization. Washington: Strategic Highway Research Program, National Research Council. Report SHRP-A369.

ABDELRAHMAN, M.A.; CARPENTER, S.H. (1999). Mechanism of interaction of asphalt cement with crumb rubber modifier. Transportation Research Record, n.1661, p.106-113.

BAHIA, H. U.; ZHAI, H.; BONNETTI, K.; KOSE, S. (1999). Non-linear viscoelastic and fatigue properties of asphalt binders. Association of Asphalt Paving Technologists, v. 68, p. 1-34.

BAHIA, H. U.; ZHAI, H.; ZENG, M.; HU, Y.; TURNER, P. (2001). Development Of Binder Specification Parameters Based On Characterization Of Damage Behavior (With Discussion). Journal of the Association of Asphalt Paving Technologists, v. 70.

BECHARA, M. F.; FAXINA, A. L.; FABBRI, G. T. P. (2008). Avaliação do comportamento reológico de mástiques asfálticos por meio de curvas-mestre. In: $22^{\circ}$. CONGRESSO DA ASSOCIAÇÃO NACIONAL DE PESQUISA E ENSINO EM TRANSPORTES, 2008, Fortaleza.

BELL, C. A. (1989). Aging of asphalt-aggregate systems. Summary report SHRP A-305, 121 p.

BELL, C. A.; SOSNOVSKE, D. (1994). Aging: binder validation. SHRP-A-384, 85 p.

BERNUCCI, L. B.; MOTTA, L. M. G.; CERATI, J. A. P.; SOARES, J. B. (2008). Pavimentação asfáltica: formação básica para engenheiros. Rio de Janeiro: PETROBRÁS: ABEDA.

BUTTON, J. et al. (1993). Evaluation and development of a pressure aging vessel for asphalt cement. Transportation Research Record, n. 1391, p. 11-19.

DIFFEY, B. L. (1977). The calculation of the spectral distribution of natural ultraviolet radiation under clear day conditions. Physics in Medicine and Biology, v. 22, n. 2, p. 309-316.

. (2002). Sources and measurement of ultraviolet radiation. Methods, v. 28, p. 4-13.

DOW, A.W. (1903). Asphalt experiments at Washington. Engineering Record, v. 47, n. 18. 
210

DURAND, G.; GUEIT, C.; MARTIN, H. (2012) Assessment of bitumens for emulsions and modified binders: characterization by gel permeation chromatography. In: $5^{\text {th }}$ EURASPHALT \& EUROBITUME CONGRESS, 2012, Instanbul, 10 p.

DURRIEU, F.; FARCAS, F.; MOUILLET, V. (2007). The influence of UV aging of a Styrenebutadine-styrene modified bitumen: comparison between laboratory and on site aging. Fuel, v. 86, p. 1446-1451.

EDLER, A.C.; HATTINGH, M. M.; SERVAS, V. P.; MARAIS, C. P. (1985). Use of aging tests to determine the efficacy of hydrated lime additions to asphalt in retarding its oxidative hardening. Association of Asphalt Paving Technologists, v. 54, p. 118-139.

FAXINA, A. L.; SALOMON, D. (2010). Envelhecimento a curto e longo prazos de asfaltos-borracha compostos com resíduo de óleo de xisto e ácido polifosfórico. In: $25^{\circ}$ CONGRESSO DE PESQUISA E ENSINO EM TRANSPORTES, ASSOCIAÇÃO NACIONAL DE PESQUISA E ENSINO EM TRANSPORTES, Belo Horizonte.

FREDERICK, J. E.; SNELL, H. E.; HAYWOOD, E. K. (1989). Solar ultraviolet radiation at the earth's surface. Photochemistry and Photobiology, v. 50, n. 8, p. 443-450.

GAESTEL, C.; SMADJA R.; LAMMINAN K.A. (1971). Contribution à la connaissance des proprietés des bitumes routiers. Bull. Laboratoire des Ponts e Chausées, v. 466, p. 85-97.

GARRICK, N. W. (1995). Nonlinear differential equation for modeling asphalt aging. Journal of Materials in Civil Engineering, v.7, n.4, p.265-268.

GIAVARINI, C. et al. (2000). Macrostructure and rheological properties of chemically modified residues and bitumens. Energy and Fuels, v.14, p.495-502.

GRIFFIN, R.L.; MILES, T.K.; PENTHER, C.J. (1955). Microfilm durability test for asphalt. Association of Asphalt Paving Technologists, v. 24, p. 31-62.

HALSTEAD, W. J. (1985). Relation of asphalt chemistry to physical properties and specifications. Association of Asphalt Paving Technologists, v. 54, p .91-117.

HERRINGTON, P.; JAMES, B.; HENNING, T. F. P. (2014). Model for long term bitumen oxidation. In: $26^{\text {th }}$ ARRB Conference - Research driving efficiency, 2014, Sydney.

HINTZ, C. (2012). Understanding Mechanisms Leading to Asphalt Binder Fatigue. Dissertation (Doctorate) - University of Wisconsin, Madison.

HUANG, S-C.; TIA, M.; RUTH, B. E. (1996). Laboratory aging methods for simulation of field aging of asphalts. Journal of Materials in Civil Engineering, v. 8, n. 3, p. 147-152. 
HUH, J. D.; ROBERTSON, R. (1996). Modeling of oxidative aging behavior of asphalts from shortterm, high temperature data as a step toward prediction of pavement aging. Transportation Research Record, n.1535, p.91-97.

HVEEM, F. N.; ZUBE, E.; SKOG, J. (1963). Proposed new tests and specifications for paving grade asphalts. Association of Asphalt Paving Technologists, v. 32, p. 247-327.

JONES, D.R. (1992). Understanding How the Origin and Composition of Paving-Grade Asphalt Cements Affect Their Performance - SHRP Asphalt Research Program Technical Memorandum \#4.

JOHNSON, C. M. (2010). Estimating asphalt binder fatigue resistance using na accelerated test method. Dissertation (Doctorate) - University of Wisconsin, Madison.

KEMP, G.R.; PREDOEHL, N.H. (1981). A comparison of field and laboratory environments on asphalt durability. Association of Asphalt Paving Technologists, v. 50, p. 492-537.

KIM, O-K.; BELL, C.A.; WILSON, J.; BOYLE, G. (1986). Effect of moisture and aging on asphalt pavement life, part 2 - effect of aging. FHWA-OR-RD-86-01-2, Final Report to Oregon Department of Transportation and the Federal Highway Administration.

KIRCHHOFF, V. W. J. H.; ECHER, E.; LEME, N. P. (2000). A variação sazonal da radiação ultravioleta solar biologicamente ativa. Brazilian Journal of Geophysics, v. 18, n. 1, p. 64-74.

LAMONTAGNE, J.; DUMAS, P.; MOUILLET, V.; KISTER, J. (2001). Comparison by Fourier transform infrared (FTIR) spectroscopy of different ageing techniques: application to road bitumens. Fuel, v. 80, p. 483-488.

LEE, D.Y. (1973). Aspahlt durability correlation in Iowa. Highway Research Record, n. 468, p. 4360.

LEE, S-J.; AMIRKHANIAN, S. N.; SHATANAWI, K.; KIM, K. W. (2008). Short-term aging characterization of asphalt binders using gel permeation chromatography and selected Superpave binder tests. Construction and Building Materials, v. 22, p. 2220-2227.

LEE, S-J.; AMIRKHANIAN, S. N.; KIM, K. W. (2009). Laboratory evaluation of the effects of shortterm oven aging on asphalt binders in asphalt mixtures using HP-GPC. Construction and Building Materials, v. 23, p. 3087-3093.

LEITE, L. F. M. (1999). Estudos de preparo e caracterização de asfaltos modificados por polímero. Tese (Doutorado) - Universidade Federal do Rio de Janeiro, Rio de Janeiro.

LESUEUR, D. (2002). La Rhéologie des Bitumes : Principes et Modification. Rhéologie, v. 2, p. 1-30. 
212

LEWIS, R. H.; WELBORN, J. Y. (1940). Report on the properties of the residues of 50-60 and 85-100 penetration asphalts from oven tests and exposure. Association of Asphalt Paving Technologists, v. 11, p. $86-157$.

LIAO, G-Y.; HUANG, X.; BA SANG, D-Z. (2008). Antiultraviolet aging and antithermal-oxygen aging tests of asphalts adapting to environment of Tibetan Plateau of China. In: TRANSPORTATION RESEARCH BOARD ANNUAL MEETING 2008, Transportation Research Board, paper number 08-0308.

LIN, M. S.; CHAFFIN, J. M.; LIU, M.; GLOVER, C. J.; DAVISON, R. R.; BULLIN, J. A. (1996). The effect of asphalt composition of the formation of asphaltenes and their contribution to asphalt viscosity. Fuel Science and Technology International, v. 14, n. 1/2, p. 139-162.

LIU, X.; WU, S.; PANG, L.; XIAO, Y.; PAN, P. (2014). Fatigue properties of Layered Double Hydroxides modified asphalt and its mixture. Advances in Materials Science and Engineering, v. 2014, 6 p.

LU, X.; ISACSSON, U. (1998). Chemical and rheological evaluation of ageing properties of SBS polymer modified bitumens. Fuel, v. 77, n. 9/10, p. 961-972.

. (2002). Effect of ageing on bitumen chemistry and rheology. Construction and Building Materials, v. 16, p. 15-22.

LU, X.; TALON, Y.; REDELIUS, P. (2008). Aging of bituminous binders - laboratory tests and field data. In: $4^{\text {th }}$ EURASPHALT AND EUROBITUME CONGRESS HELD MAY 2008, Proceedings... Copenhagen, $12 \mathrm{p}$.

MA, L. X.; WU, S. P.; HUANG, F. J.; LI, N. (2008). Effect of UV ageing on components, structure and properties of asphalt. In: $2^{\text {nd }}$ INTERNATIONAL CONFERENCE ON HETEROGENEOUS MATERIALS MECHANICS, Huangshan, China, p. 415-418.

MARTONO, W.; BAHIA, H. U.; D'ANGELO, J. (2007). Effect of testing geometry on measuring fatigue of asphalt binders and mastics. Journal of Materials in Civil Engineering, v. 19, n. 9, p. 746-752.

MCHATTIE, R.L. (1983). Estimating the durability of chem-crete modified paving asphalt. Alaska Department of Transportation.

MOUILLET, V.; FARCAS, F.; CHAILLEUX, E.; SAUGER, L. (2014). Evolution of bituminous mix behaviour submitted to UV rays in laboratory compared to field exposure. Materials and Structures, v. 47 , p. $1287-1299$.

NICHOLSON, V. (1937). A laboratory oxidation test for asphaltic bitumens. Association of Asphalt Paving Technologists, v. 9, p. 208-214. 
NUÑEZ, J. Y. M. (2013). Caracterização à fadiga de ligantes asfálticos modificados envelhecidos a curto e a longo prazo. Dissertação (Mestrado) - Escola de Engenharia de São Carlos da Universidade de São Paulo, São Carlos.

OKUNO, E.; VILELA M. A. C. (2005). Radiação Ultravioleta: Características e Efeitos. 1.ed. São Paulo: Livraria da Física: Sociedade Brasileira de Física. ISBN 85-88325-31-4.

OLIVEIRA, A. H. (2015). Avaliação do potencial anti oxidante do líquido da castanha de caju (LCC) para materiais asfálticos através de diferentes métodos de envelhecimento. Dissertação (Mestrado) - Universidade Federal do Ceará, Fortaleza.

PAMPLONA, T. F. (2013). Efeito da adição de ácido polifosfórico em ligantes asfálticos de diferentes fontes. Dissertação (Mestrado) - Escola de Engenharia de São Carlos da Universidade de São Paulo, São Carlos.

PETERSEN, J.C. (1984). Chemical composition of asphalt as related to asphalt durability: state of the art. Transportation Research Record, n. 999, p. 13-30.

. (1989). A thin-film accelerated aging test for evaluating asphalt oxidative aging. Association of Asphalt Paving Technologists, p. 220-237.

PETERSEN, J. C.; BRANTHAVER, J. F.; ROBERTSON, R. E.; HARNSBERGER, P. M; DUVALL, J. J.; ENSLEY, E. K. (1993). Effects of physicochemical factors on asphalt oxidation kinetics. Transportation Research Record, n. 1391, p. 1-10.

PETERSEN, J. C.; GLASER, R. (2011). Asphalt oxidation mechanisms and the role of oxidation products on age hardening revisited. Road Materials and Pavement Design, v. 12, n. 4, p. 795-819.

QIN, Q.; SCHABRON, J. F.; BOYSEN, R. B.; FARRAR, M. J. (2014). Field aging effect on chemistry and rheology of asphalt binders and rheological predictions for field aging. Fuel, v. 121, p. 86-94.

RASCHING, F.L.; DOYLE, P.C. (1937). A laboratory oxidation test. Association of Asphalt Paving Technologists, v. 9, p. 215-217.

READ, J.; WHITEOAK, D. (2003). The Shell Bitumen Handbook. $5^{\text {th }}$ ed. Inglaterra, Shell Bitumen. ISBN 072773220X.

SAFAEI, F.; HINTZ, C. (2014). Investigation of the effect of temperature on asphalt binder fatigue. In Asphalt Pavements - Proceedings of the Internacional Conference on Asphalt pavements, ISAP 2014, v.2, p.1491-1500.

SCHMIDT, R.J.; SANTUCCI, L.E. (1969). The effect of asphalt properties on the fatigue cracking of asphalt concrete on the Zaca-Wigmore Test Project. Association of Asphalt Paving Technologists, v. 38 , p. 39-64. 
214

SCHRAMM, G. (2006). Reologia e reometria: fundamentos teóricos e práticos. São Paulo: Artliber. $240 \mathrm{p}$.

SHENOY, A. (2002). Fatigue testing and evaluation of asphalt binders using the dynamic shear rheometer. Journal of testing and evaluation, v. 30, n. 4, p. 303-312.

SILVA, L. S. (2005). Contribuição ao estudo do envelhecimento de ligantes asfálticos. Influência da adição de polímeros e comportamento frente a radiação uv. Tese (Doutorado) - Escola de Engenharia da Universidade Federal do Rio Grande do Sul, Porto Alegre.

SILVA, L. S.; FORTE, M. M. C.; BARTOlOMEO, P.; FARCAS, F.; DURRIEU, F. (2005). Envelhecimento UV de ligantes asfálticos. Revista Transportes. v. XIII, n. 2, p. 5-20.

SUN, S.; WANG, Y.; ZHANG, A. (2011). Study on anti-ultraviolet radiation aging property of $\mathrm{TiO}_{2}$ modified Asphalt. Advanced Materials Research, v. 306-307, p. 951-955.

TRAXLER, R.N. (1961). Relation between asphalt composition and hardening by volatilization and oxidation. Association of Asphalt Paving Technologists, v. 30, p. 359-377. p. $44-58$.

(1963). Durability of asphalt cements. Association of Asphalt Paving Technologists, v. 32,

TONIAL, I. A. (2001). Influência do envelhecimento do revestimento asfáltico na vida de fadiga de pavimentos. Dissertação (Mestrado) - Universidade Federal do Rio de Janeiro, Rio de Janeiro.

VALLERGA, B. A.; MONISMITH, C. L.; GRANTHEM, K. (1957).A study of some factors influencing the weathering of paving asphalts. Association of Asphalt Paving Technologists, v. 26, p. $126-150$.

WELBORN, J. Y. (1979). Relationship of asphalt cement properties to pavement durability. NCHRP Synthesis 59, Washington.

WHITEOAK, D. (1991). The SHELL Bitumen Handbook. 1 ed. reprinted - Inglaterra, SHELL.

WOO, W. J.; CHOWDHURY, A.; GLOVER, C. J. (2008). Field aging of unmodified asphalt binder in three Texas Long-Term Performance Pavements. Transportation Research Record, n. 2051, p. $15-22$.

WU, S.; PANG, L.; LIU, G.; ZHU, J. (2010). Laboratory study on ultraviolet radiation aging of bitumen. Journal of Materials in Civil Engineering, v. 22, n. 8, p. 767-772.

WU, S.; PANG, L.; MO, L.; QIU, J.; ZHU, G.; XIAO, Y. (2008b). UV and thermal aging of purê bitumen-comparison between laboratory simulation and natural exposure aging. Road Materials and Pavement Design, EATA 2008, p. 103-113. 
WU, S.; PANG, L.; ZHU, G. (2008a). The effect of ageing on rheological properties and chemical conversions of asphalts. Key Engineering Materials, v. 385-387, p. 481-484.

XU, S.; LI, L.; YU, J.; ZHANG, C.; ZHOU, J.; SUN, Y. (2015). Investigation of the ultraviolet aging resistance of organic layered double hydroxides modified bitumen. Construction and Building Materials, v. 96, p. 127-134.

YAMAGUCHI, K.; SASAKI, I.; MEIARASHI, S. (2004). Mechanism of asphalt binder aging by ultraviolet irradiation and aging resistance by adding carbon black. Journal of Japan Petroleum Institute, v. 47, n. 4, p. 266-273.

YAMAGUCHI, K.; SASAKI, I.; NISHIZAKI, I.; MEIARASHI, S.; MORIYOSHI, A. (2005). Effects of film thickness, wavelength, and carbon black on photodegradation of asphalt. Journal of the Japan Petroleum Institute, v. 48, n. 3, p. 150-155.

YE, F.; YANG, J; HUANG, P. (2006). Performance of modified asphalt aging under ultravioleta radiation. Pavement Mechanics and Performance, p. 102-109.

YI-QIU, T.; JIA-NI, W.; ZHONG-LIANG, F.; XING-YE, Z. (2007a). Influence and mechanism of ultraviolet aging on bitumen performance. In: $26^{\text {th }}$ SOUTHERN AFRICAN TRANSPORT CONFERENCE, 2007, PRETORIA. Proceedings...: Pretoria: Document Transformation Technologies cc, 2007, p. 726-735.

YI-QIU, T.; JIA-NI, W.; ZHONGJUN, X.; ZHONG-LIANG, F.; HUINING, X. (2007b). Laboratory study on ultraviolet aging behavior of asphalt binder and mixture. In: PLAN, BUILD, AND MANAGE TRANSPORTATION INFRASTRUCTURES IN CHINA CONGRESS, 2007, China: p. 752-759.

YU, J-Y.; FENG, P-C.; ZHANG, H-L.; WU, S-P. (2009). Effect of organo-montomorillonite on aging properties of asphalt. Construction and Building Materials, n. 23, p. 2636-2640.

YU, M.; WU, S.P.; HAN, J.; LIU, X. (2010). Research on UV aging characteristics of inorganic powder modified asphalt binders. Journal of Wuhan University of Technology, v. 32, n. 17, p. 7682.

ZHANG, F.; YU, J.; HAN, J. (2011a). Effects of thermal oxidative ageing on dynamic viscosity, TG/DTG, DTA and FTIR of SBS- and SBS/sulfur-modified asphalts. Construction and Building Materials, v. 25, p. 129-137.

ZHANG, H.; YU, J.; WANG, H.; XU, L. (2011b). Investigation of microstructures and ultraviolet aging properties of organo-montmorilonite/SBS modified bitumen. Materials Chemistry and Physics, v. 129, p. 769-776.

ZHAO, S.; BOWERS, B.; HUANG, B.; SHU, X. (2014). Characterizing rheological properties of binder and blending efficiency of asphalt paving mixtures containing RAS through GPC. Journal of Materials in Civil Engineering, v. 26, p. 941-946. 
ZENG, W.; WU, S.; WEN, J.; CHEN, Z. (2015). The temperature effects in aging index of asphalt during UV aging process. Construction and Building Materials, v. 93, p. 1125-1131. 
No Apêndice A são apresentadas as curvas-mestre de $G^{*}$, seguidas das curvas-mestre de $\delta$, dos ligantes asfálticos modificados em comparação com a curva-mestre do ligante asfáltico de base, nas diversas condições de envelhecimento (virgem, curto prazo, longo prazo no PAV e longo prazo na estufa UV), respectivamente, e cujas análises foram feitas no item 4.2.1 do Capítulo 4 - Resultados e Discussão.

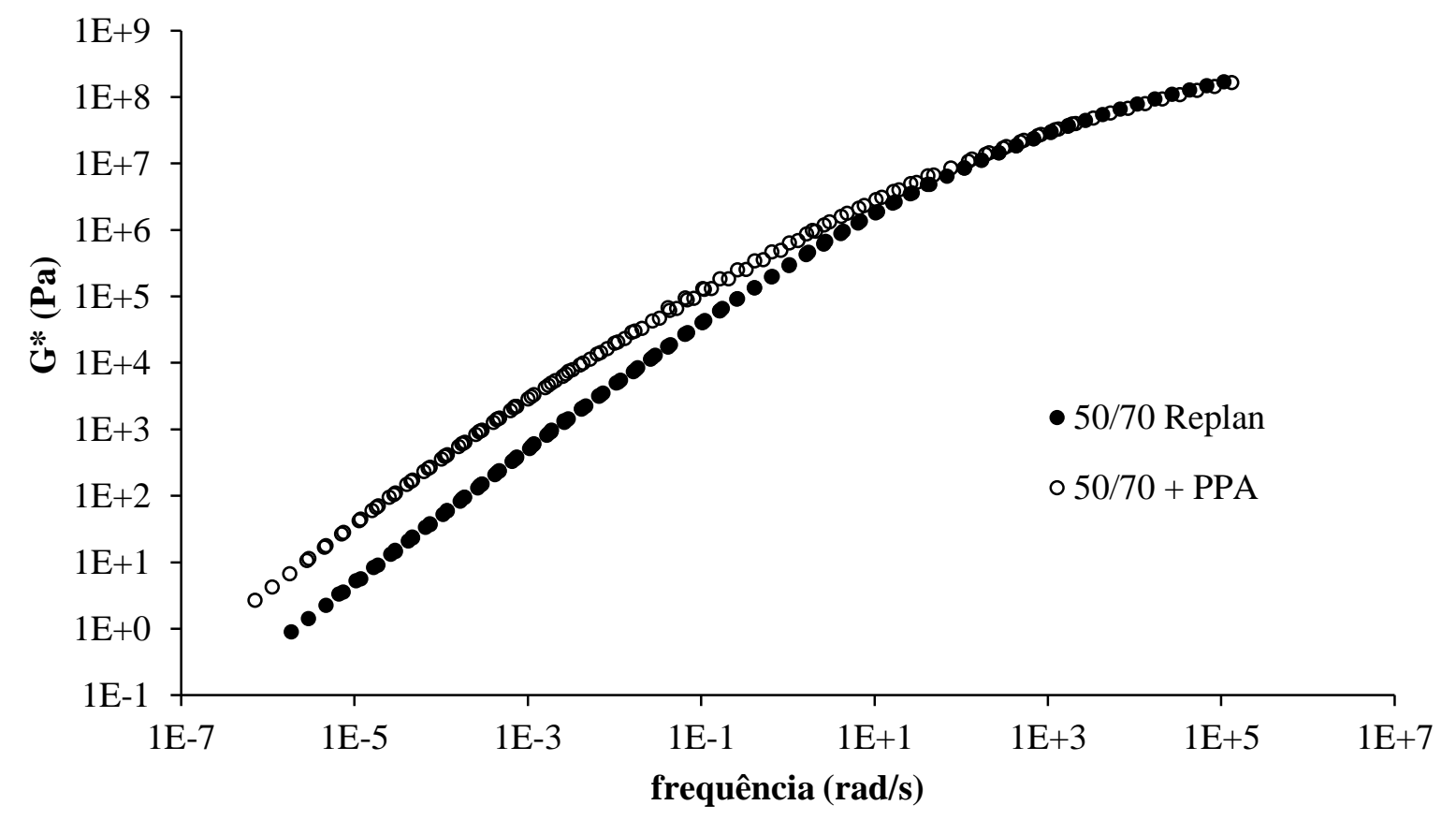

Figura A. 1-Curva-mestre de $G^{*}$ da mistura 50/70-PPA em relação ao CAP puro: condição virgem 


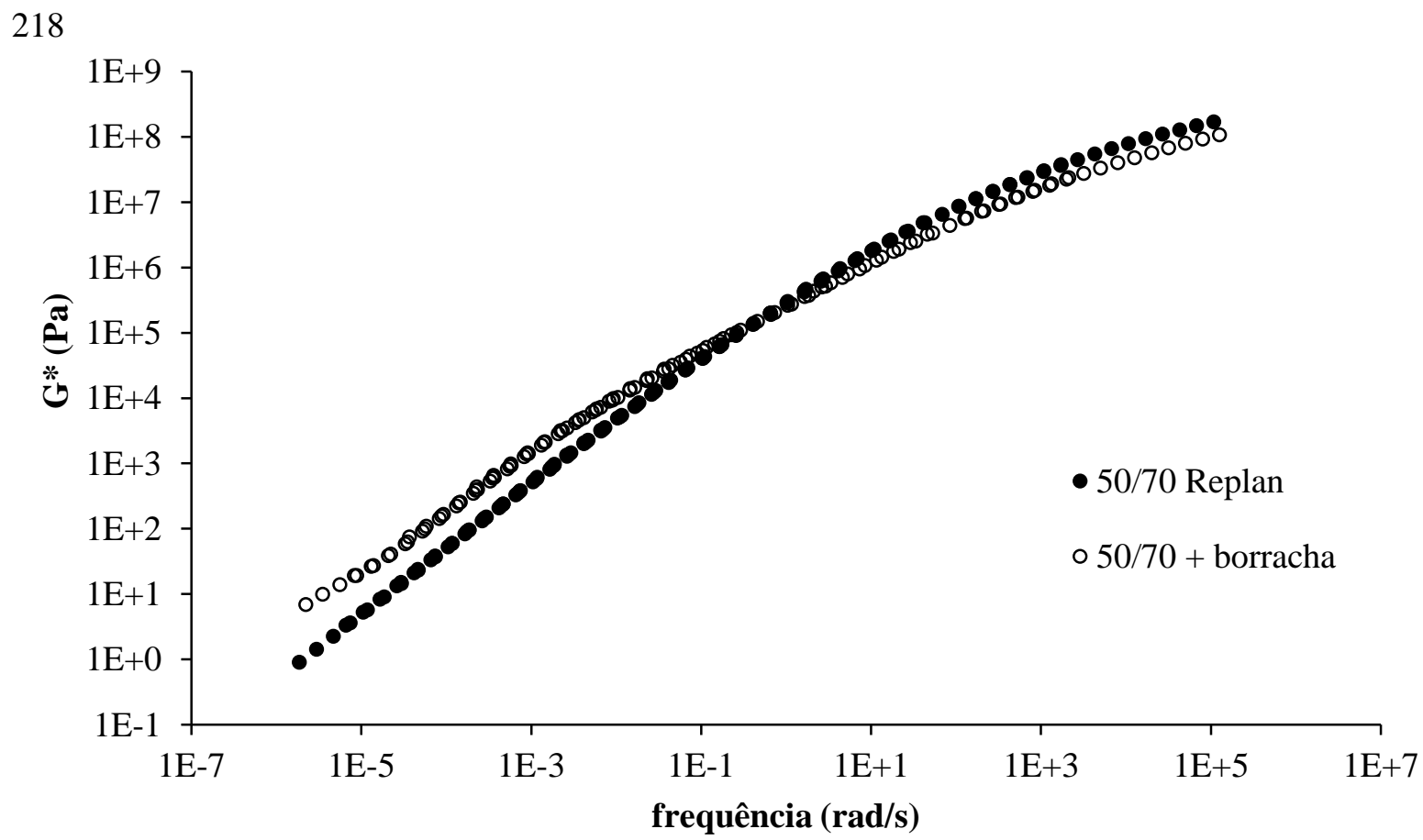

Figura A. 2 - Curva-mestre de $G^{*}$ da mistura 50/70-borracha em relação ao CAP puro: condição virgem

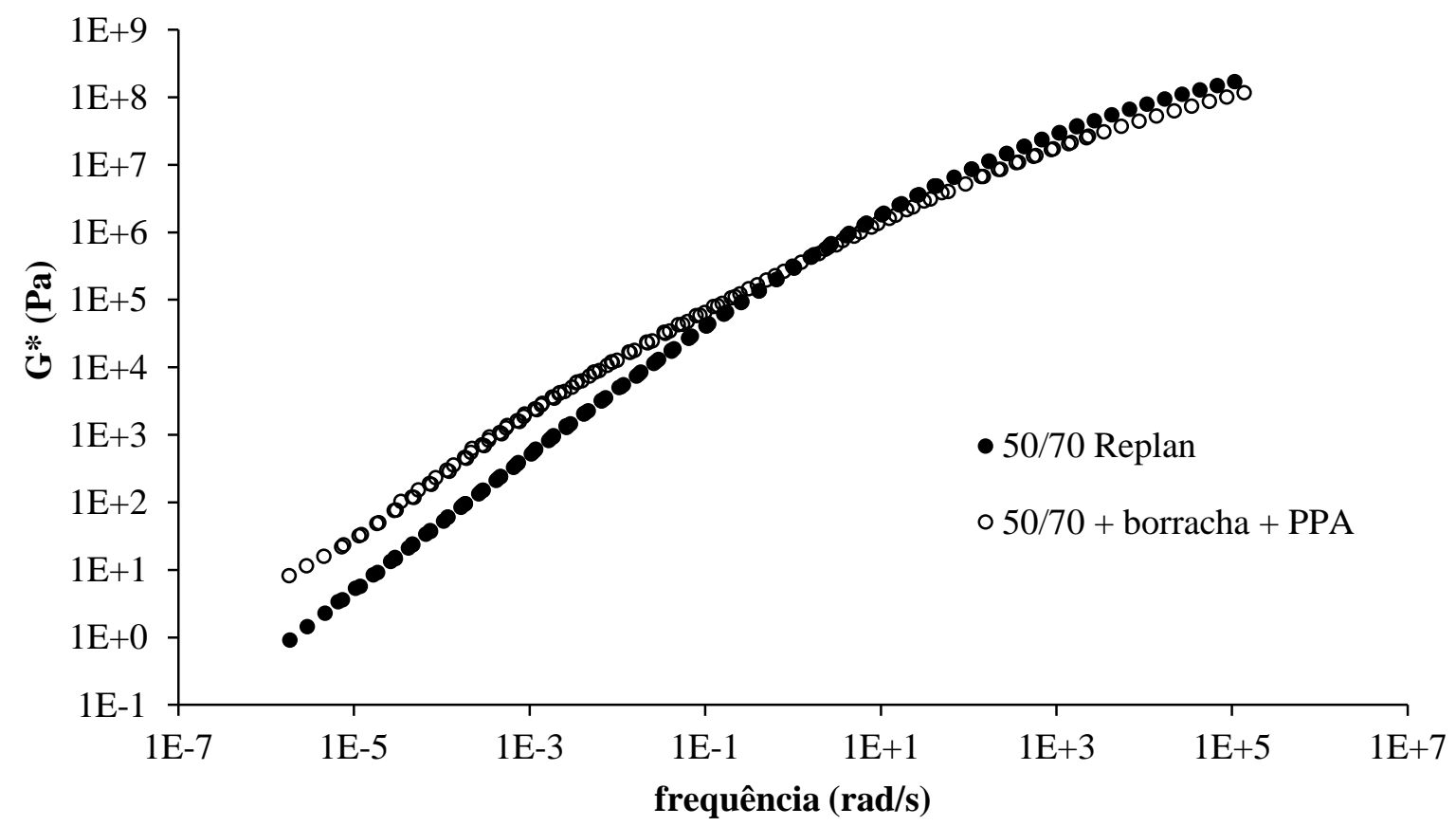

Figura A. 3 - Curva-mestre de G* da mistura 50/70-borracha-PPA em relação ao CAP puro: condição virgem 


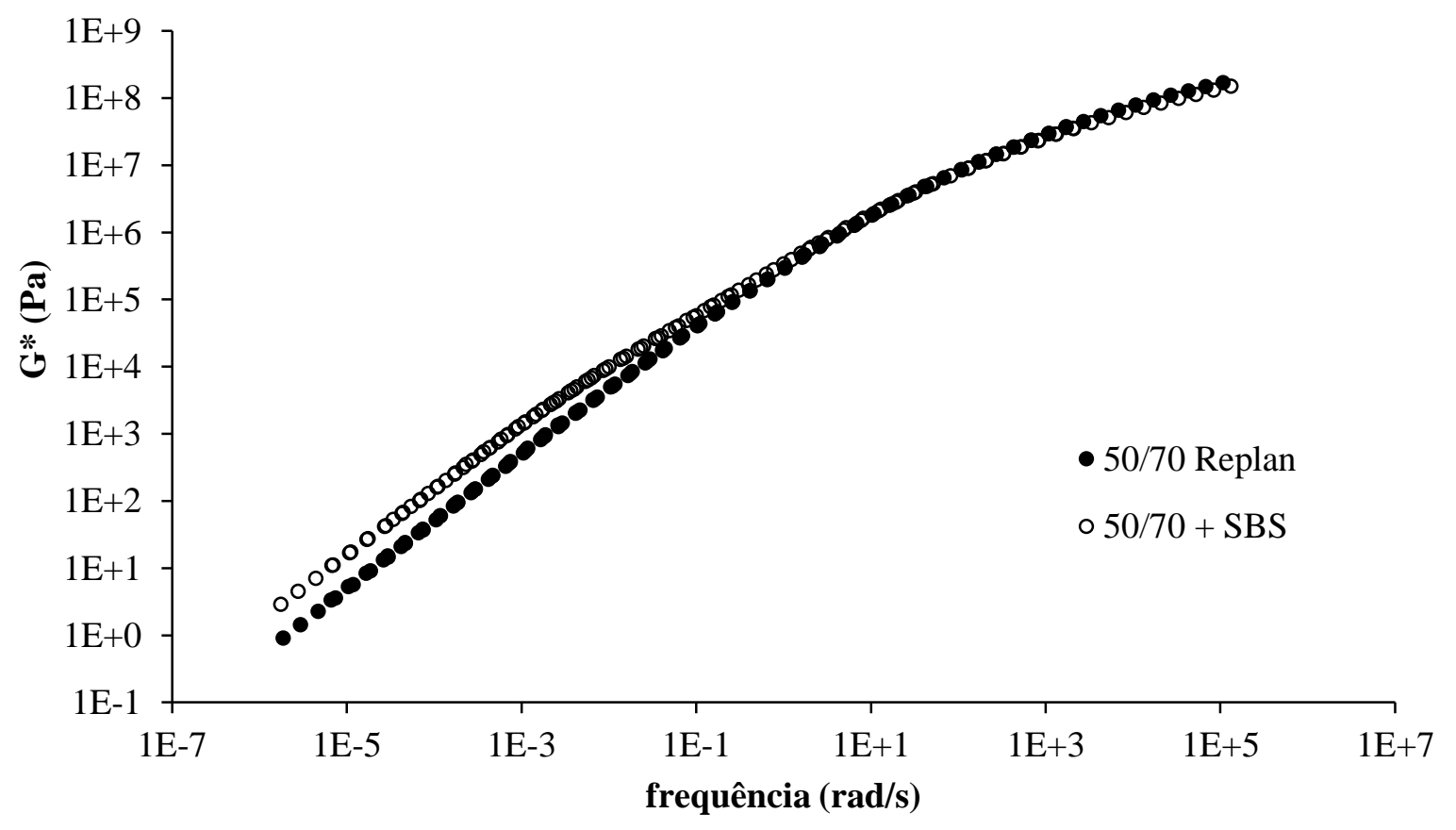

Figura A. 4 - Curva-mestre de $G^{*}$ da mistura 50/70-SBS em relação ao CAP puro: condição virgem

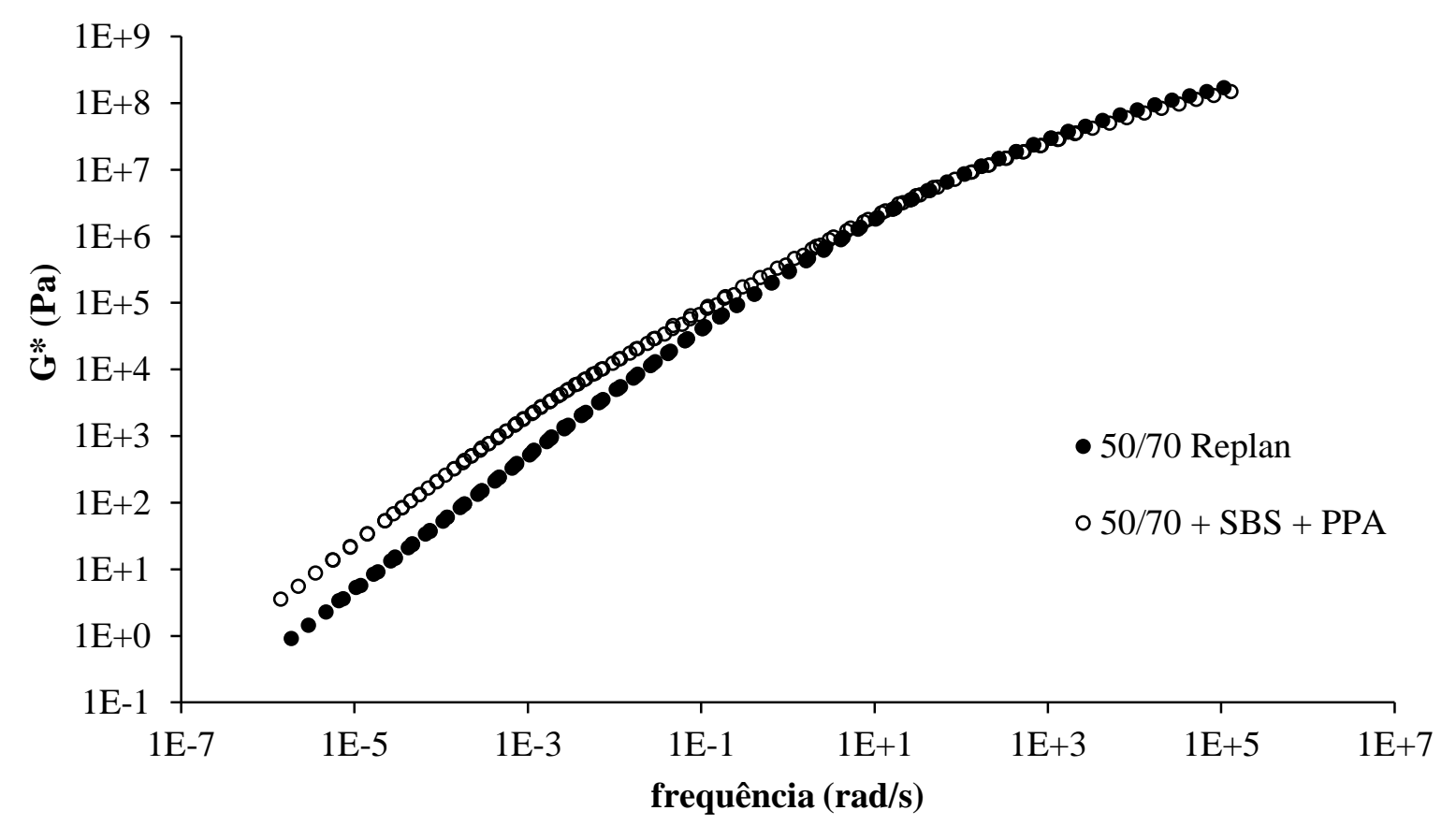

Figura A. 5 - Curva-mestre de G* da mistura 50/70-SBS-PPA em relação ao CAP puro: condição virgem 


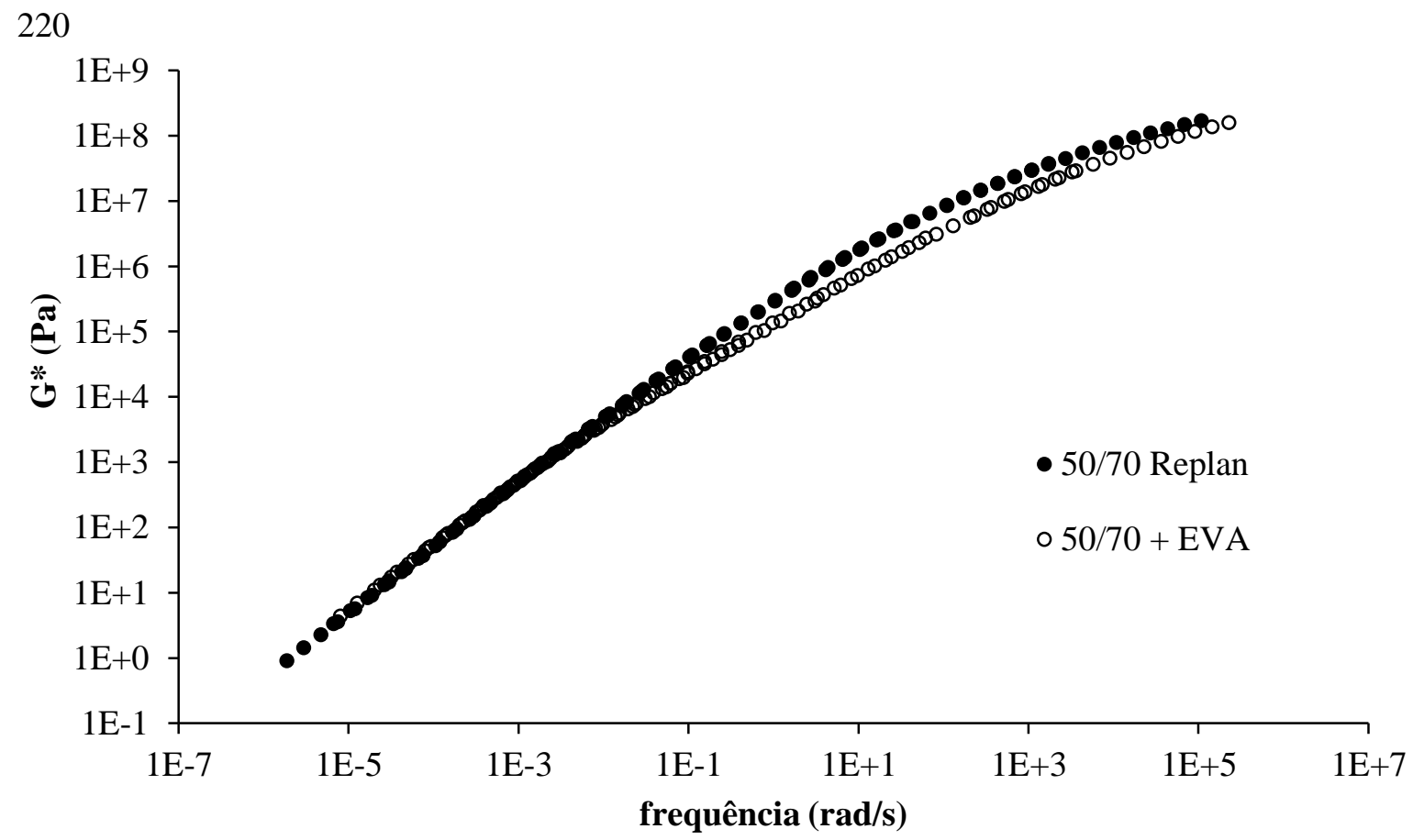

Figura A. 6 - Curva-mestre de $G^{*}$ da mistura 50/70-EVA em relação ao CAP puro: condição virgem

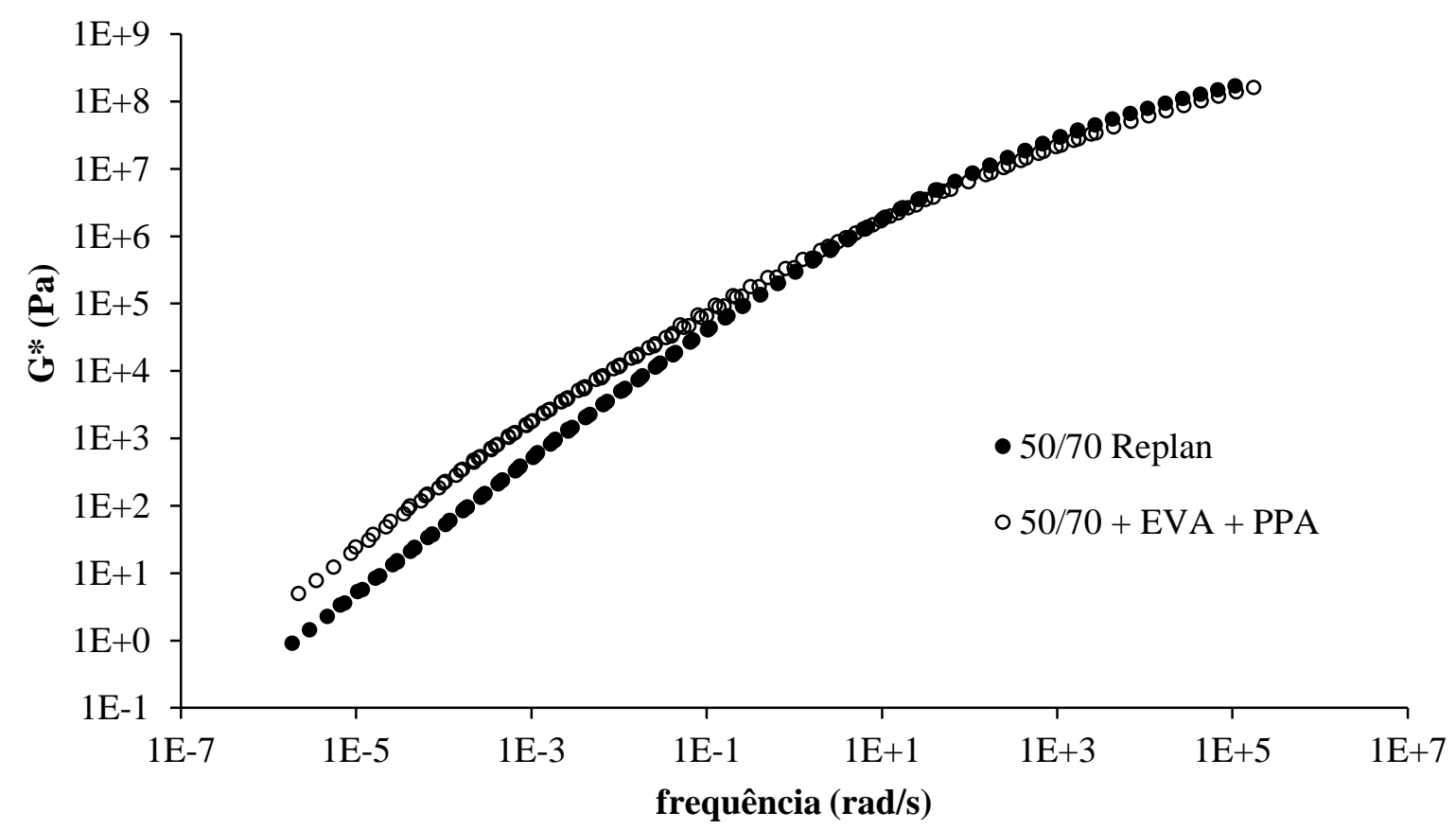

Figura A. 7 - Curva-mestre de G* da mistura 50/70-EVA-PPA em relação ao CAP puro: condição virgem 


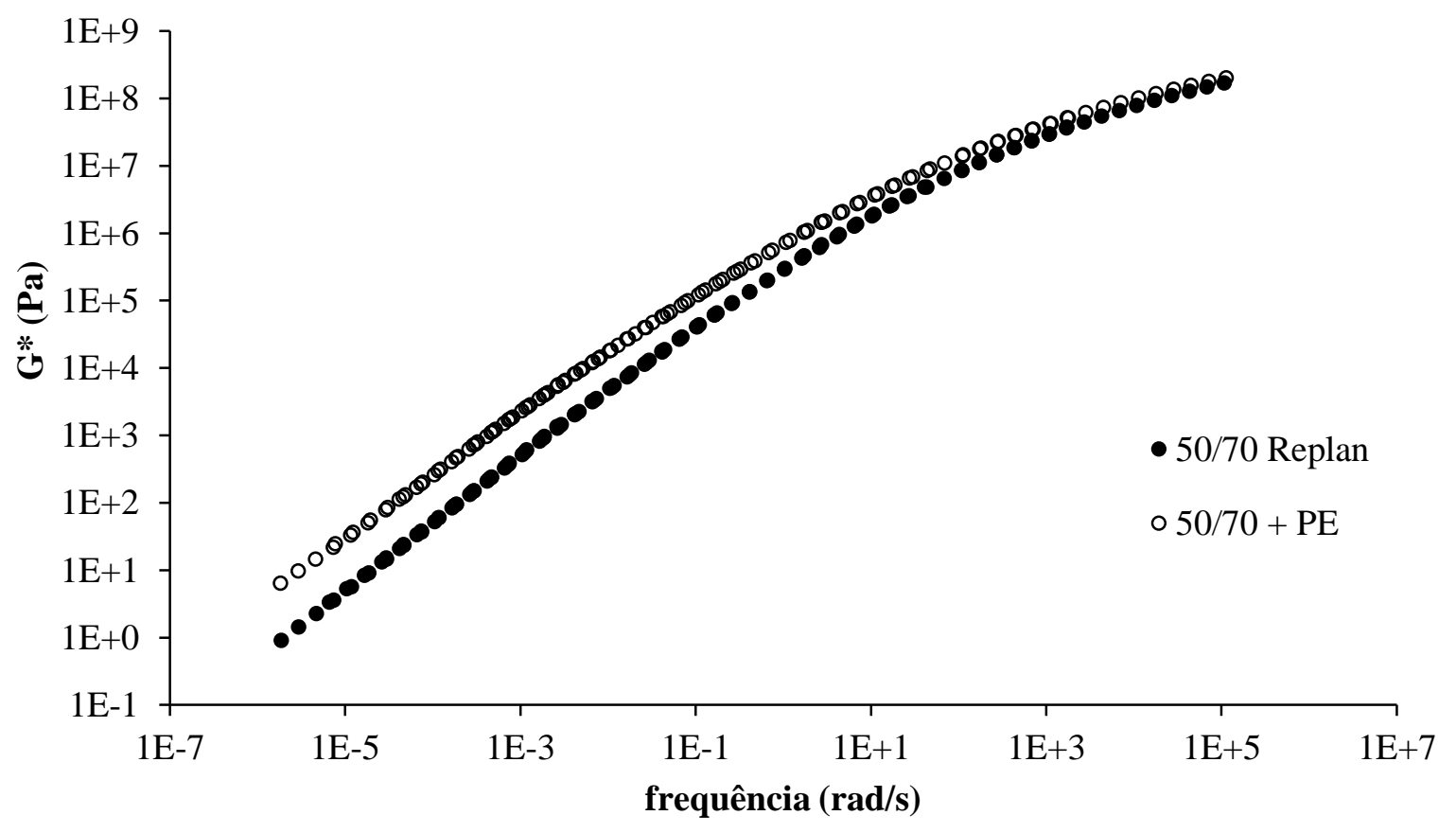

Figura A. 8 - Curva-mestre de $G^{*}$ da mistura 50/70-PE em relação ao CAP puro: condição virgem

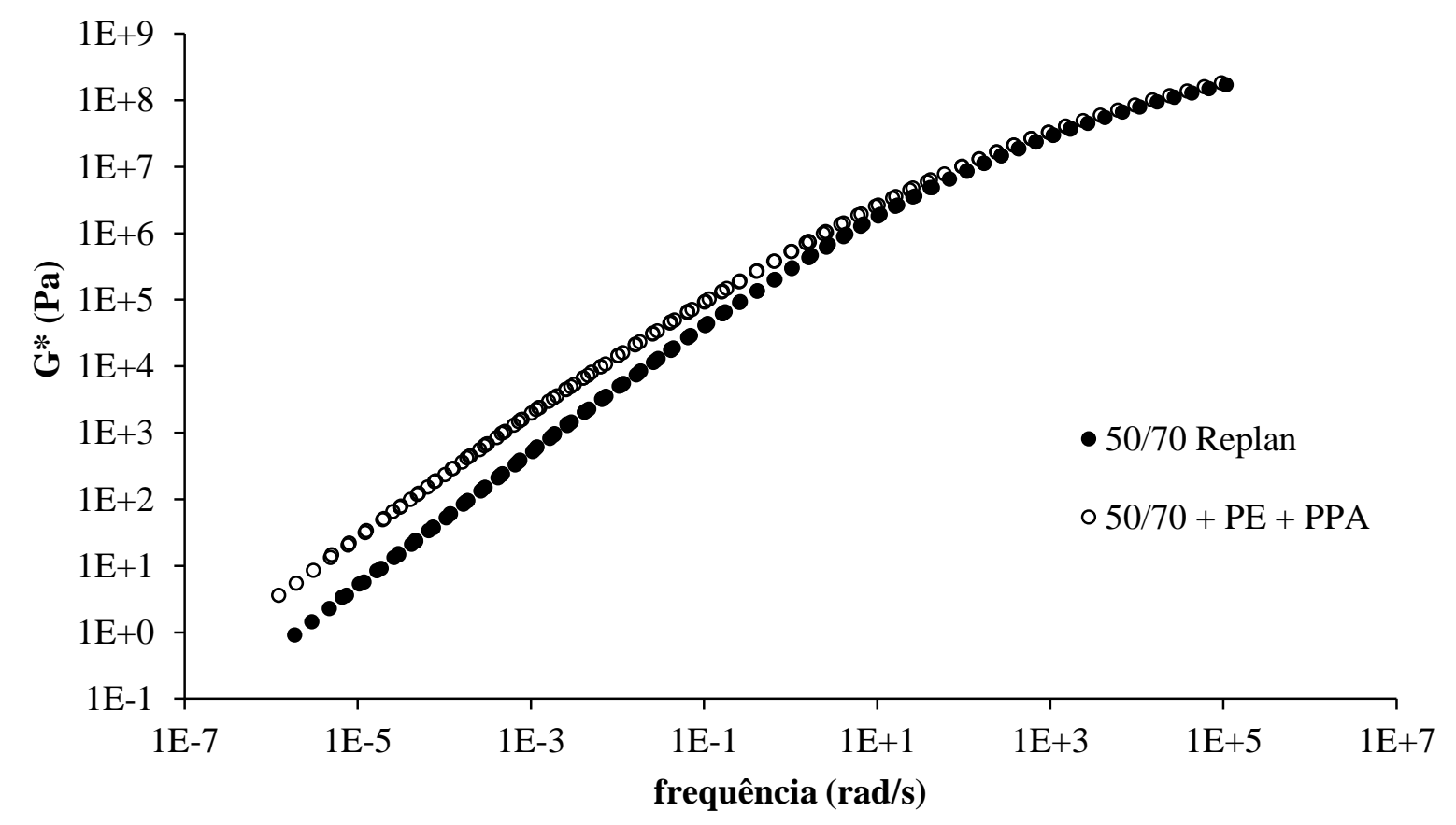

Figura A. 9 - Curva-mestre de G* da mistura 50/70-PE-PPA em relação ao CAP puro: condição virgem 


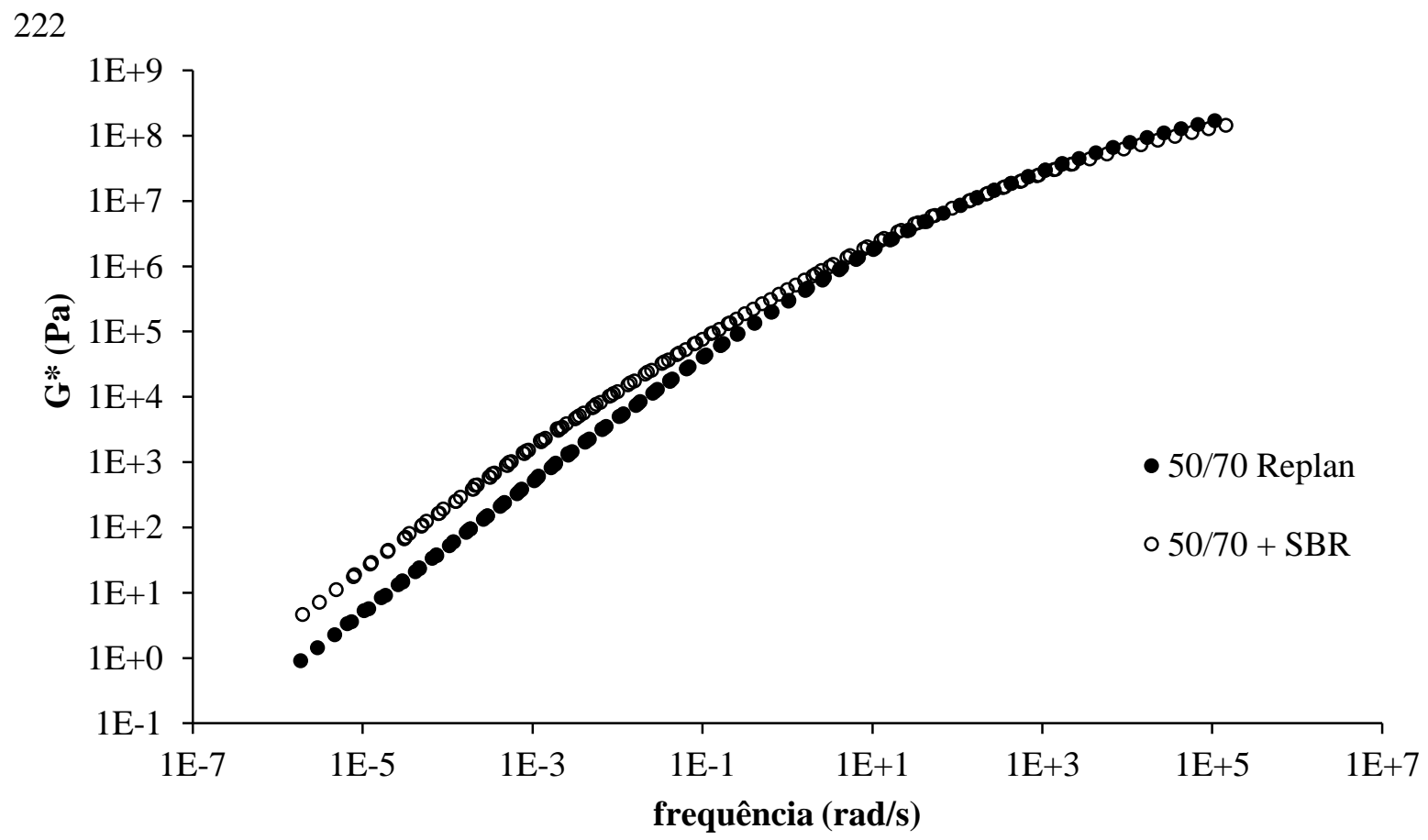

Figura A. 10 - Curva-mestre de G* da mistura 50/70-SBR em relação ao CAP puro: condição virgem

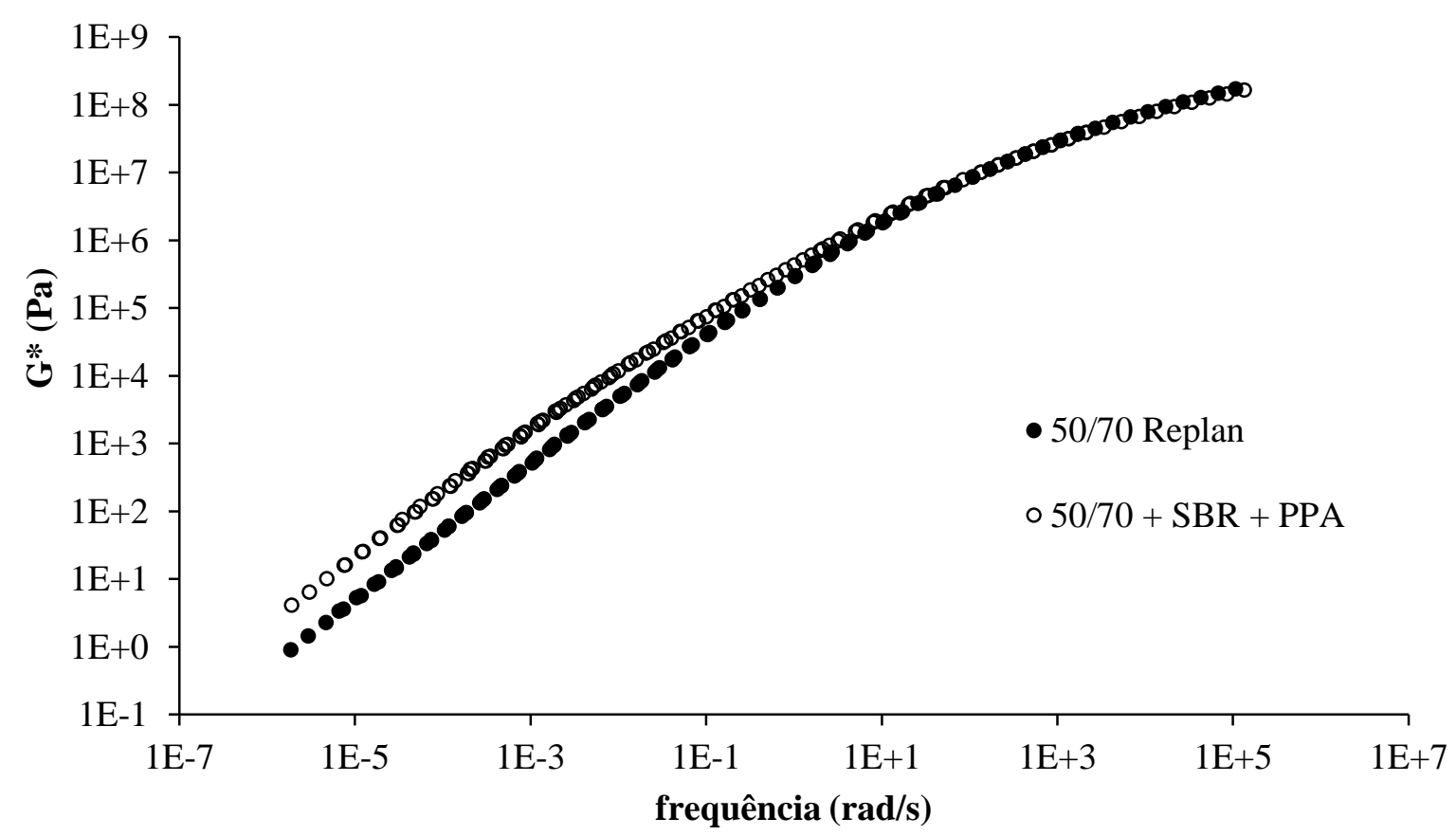

Figura A. 11 - Curva-mestre de G* da mistura 50/70-SBR-PPA em relação ao CAP puro: condição virgem 


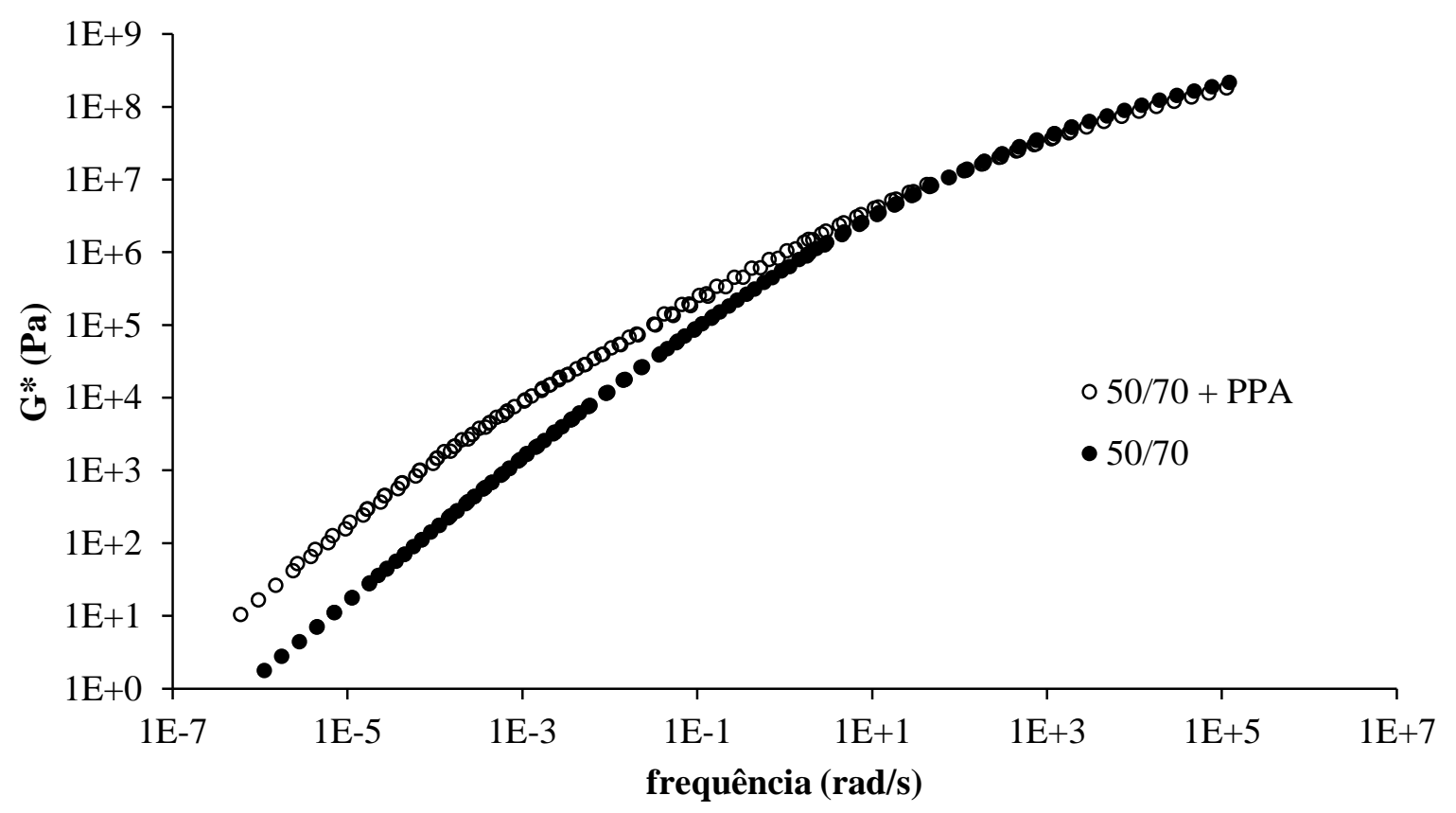

Figura A. 12 - Curva-mestre de G* da mistura 50/70-PPA em relação ao CAP puro: condição RTFOT

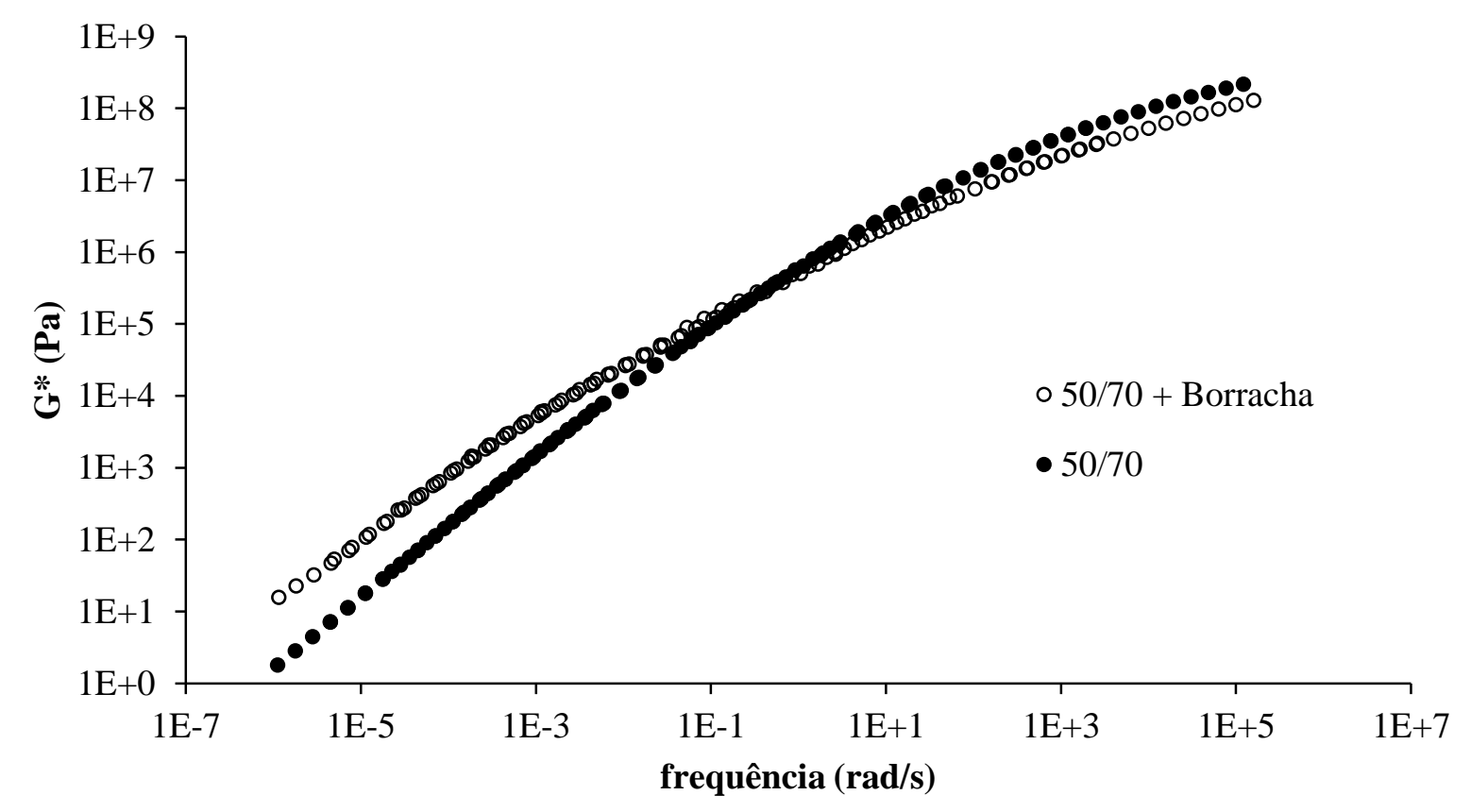

Figura A. 13 - Curva-mestre de $G^{*}$ da mistura 50/70-borracha em relação ao CAP puro: condição RTFOT 


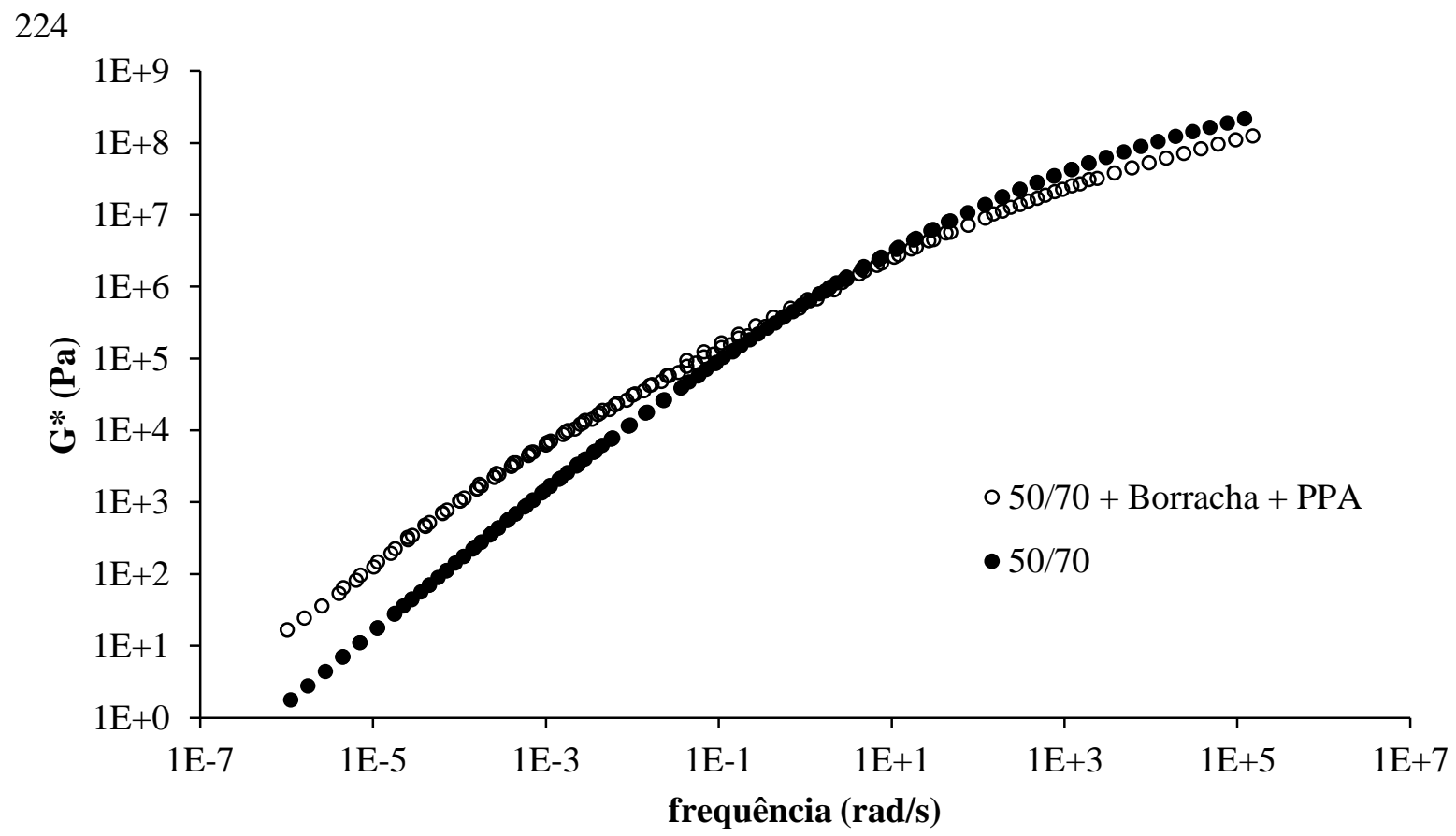

Figura A. 14 - Curva-mestre de $G^{*}$ da mistura 50/70-borracha-PPA em relação ao CAP puro: condição RTFOT

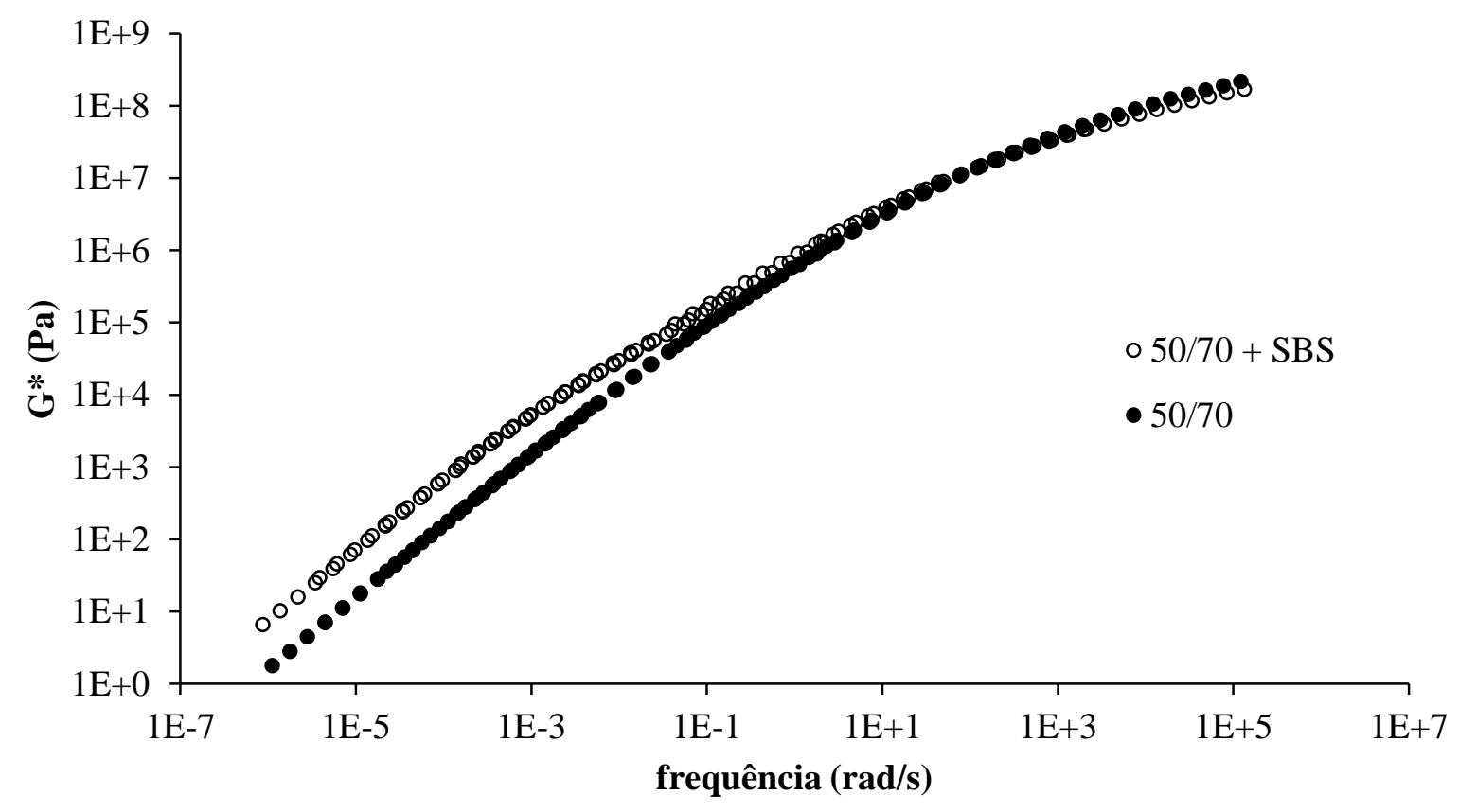

Figura A. 15 - Curva-mestre de G* da mistura 50/70-SBS em relação ao CAP puro: condição RTFOT 


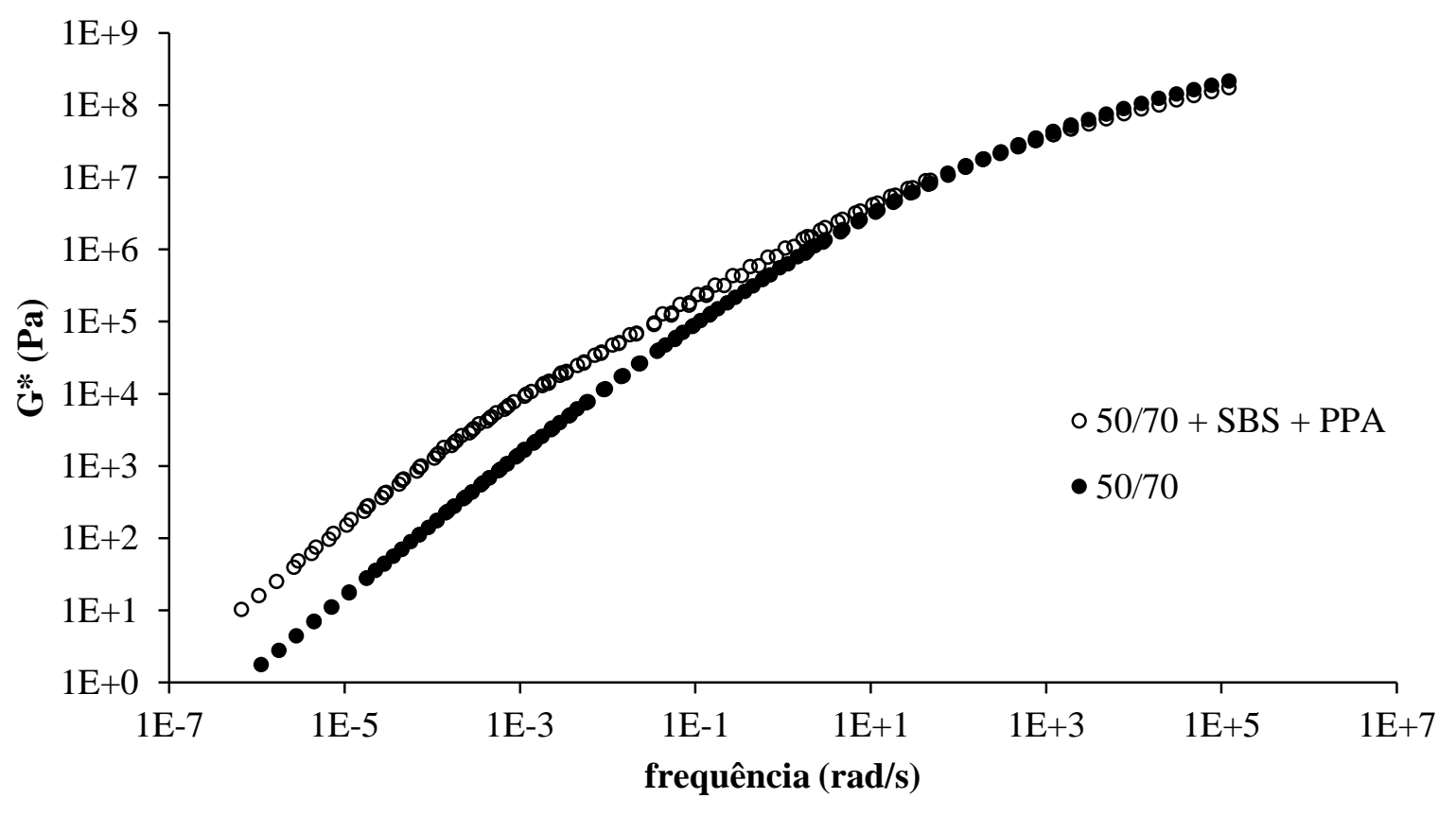

Figura A. 16 - Curva-mestre de $G^{*}$ da mistura 50/70-SBS-PPA em relação ao CAP puro: condição RTFOT

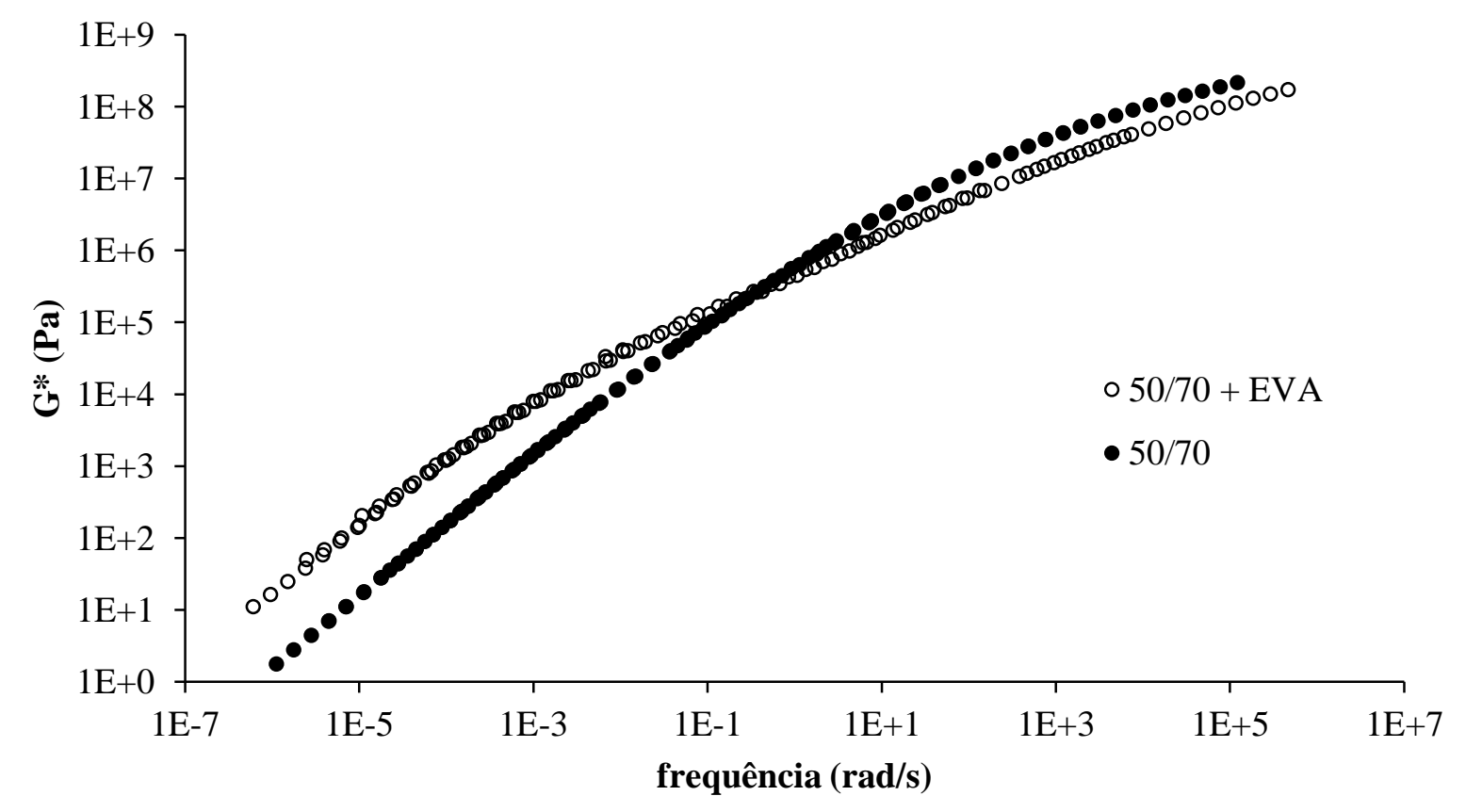

Figura A. 17 - Curva-mestre de G* da mistura 50/70-EVA em relação ao CAP puro: condição RTFOT 


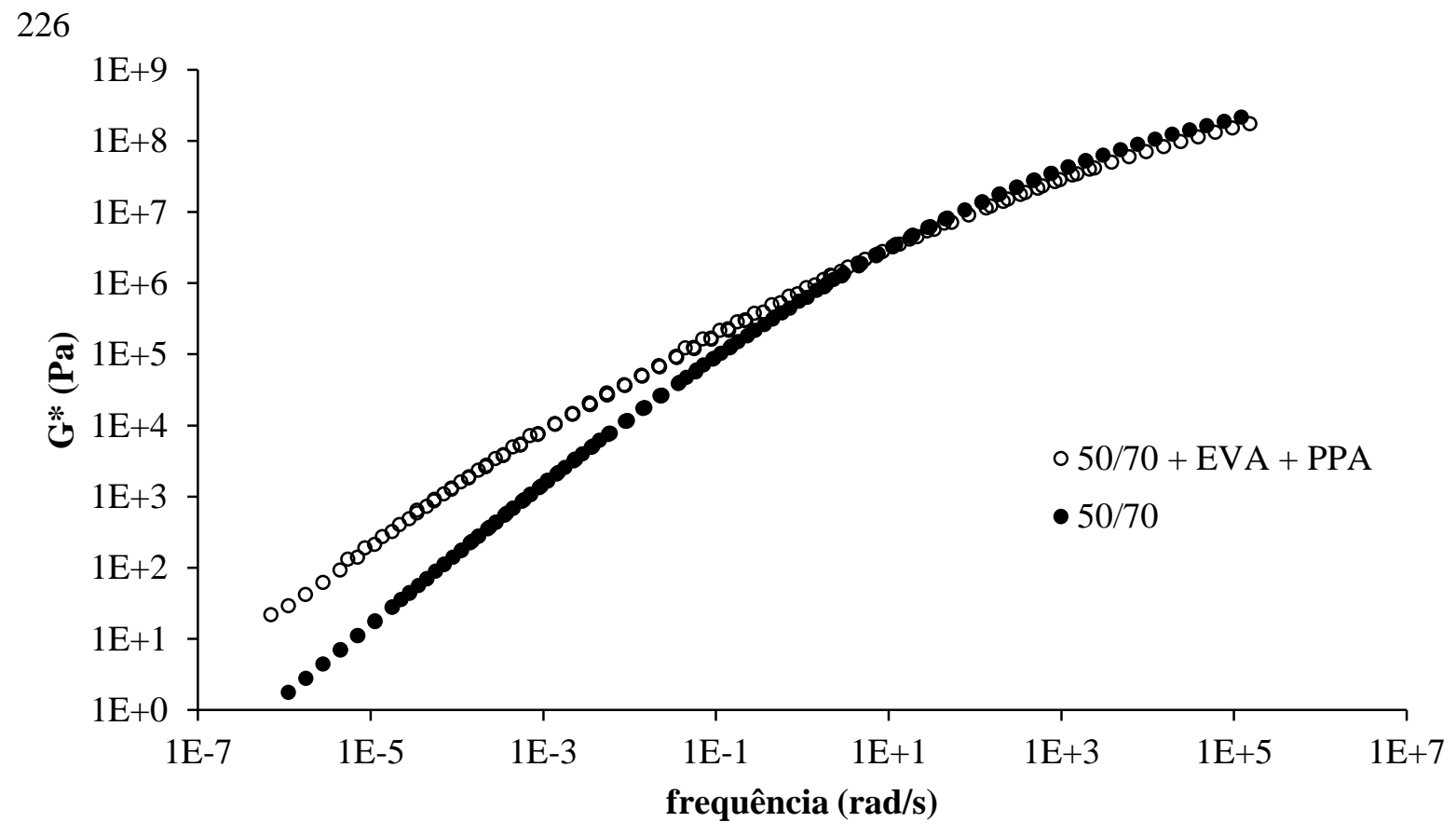

Figura A. 18 - Curva-mestre de $G^{*}$ da mistura 50/70-EVA-PPA em relação ao CAP puro: condição RTFOT

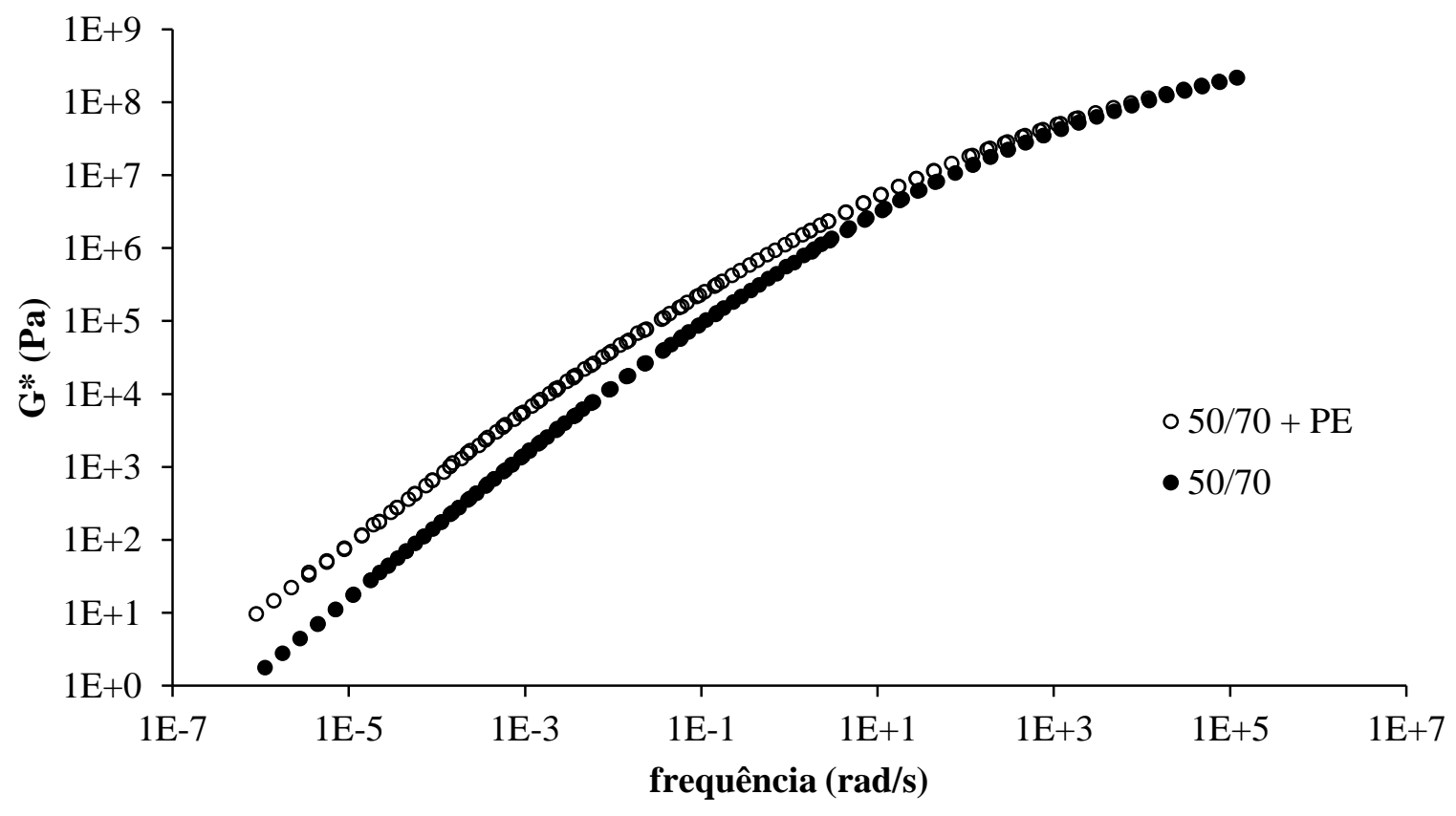

Figura A. 19 - Curva-mestre de $G^{*}$ da mistura 50/70-PE em relação ao CAP puro: condição RTFOT 


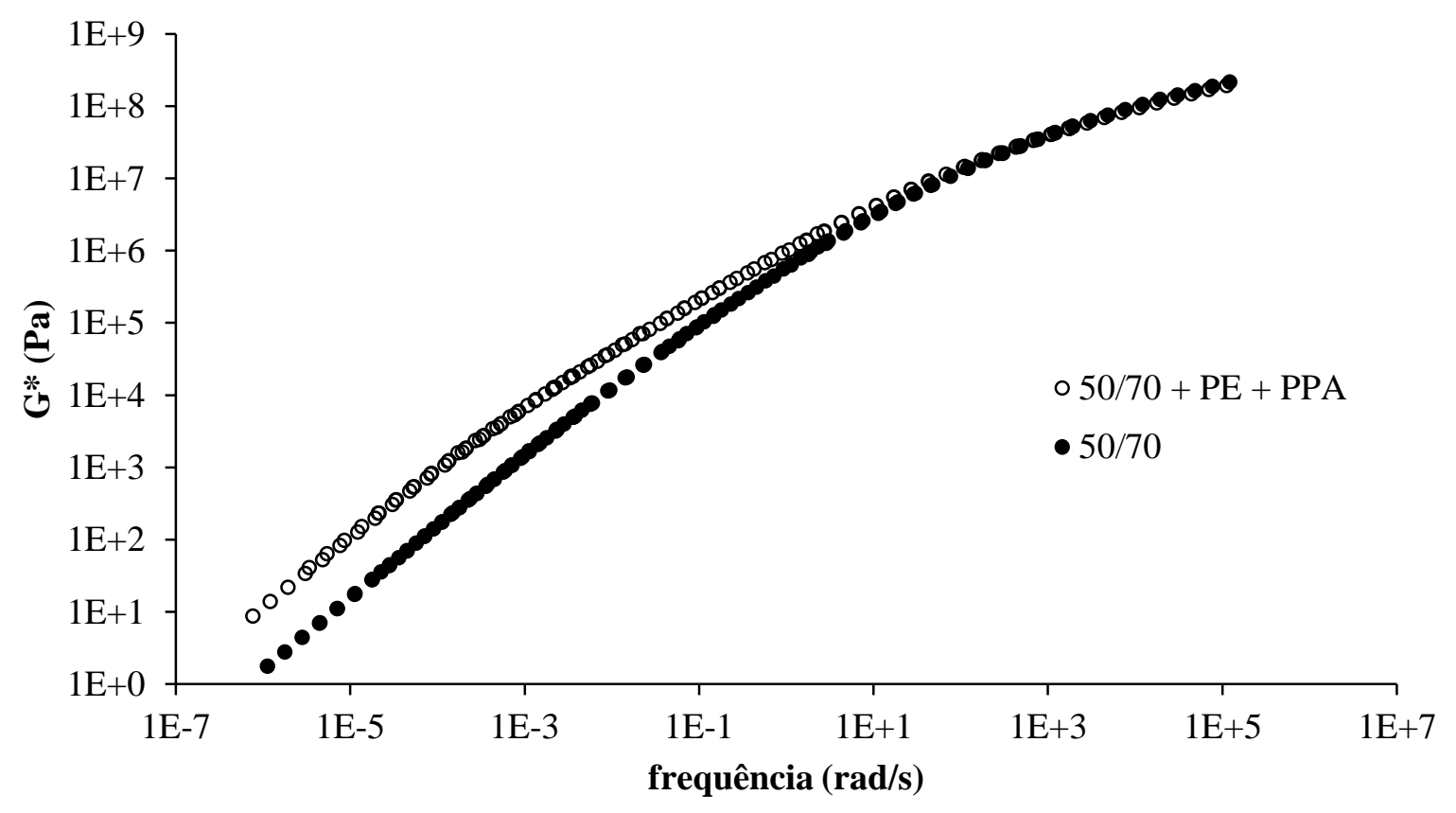

Figura A. 20 - Curva-mestre de $G^{*}$ da mistura 50/70-PE-PPA em relação ao CAP puro: condição RTFOT

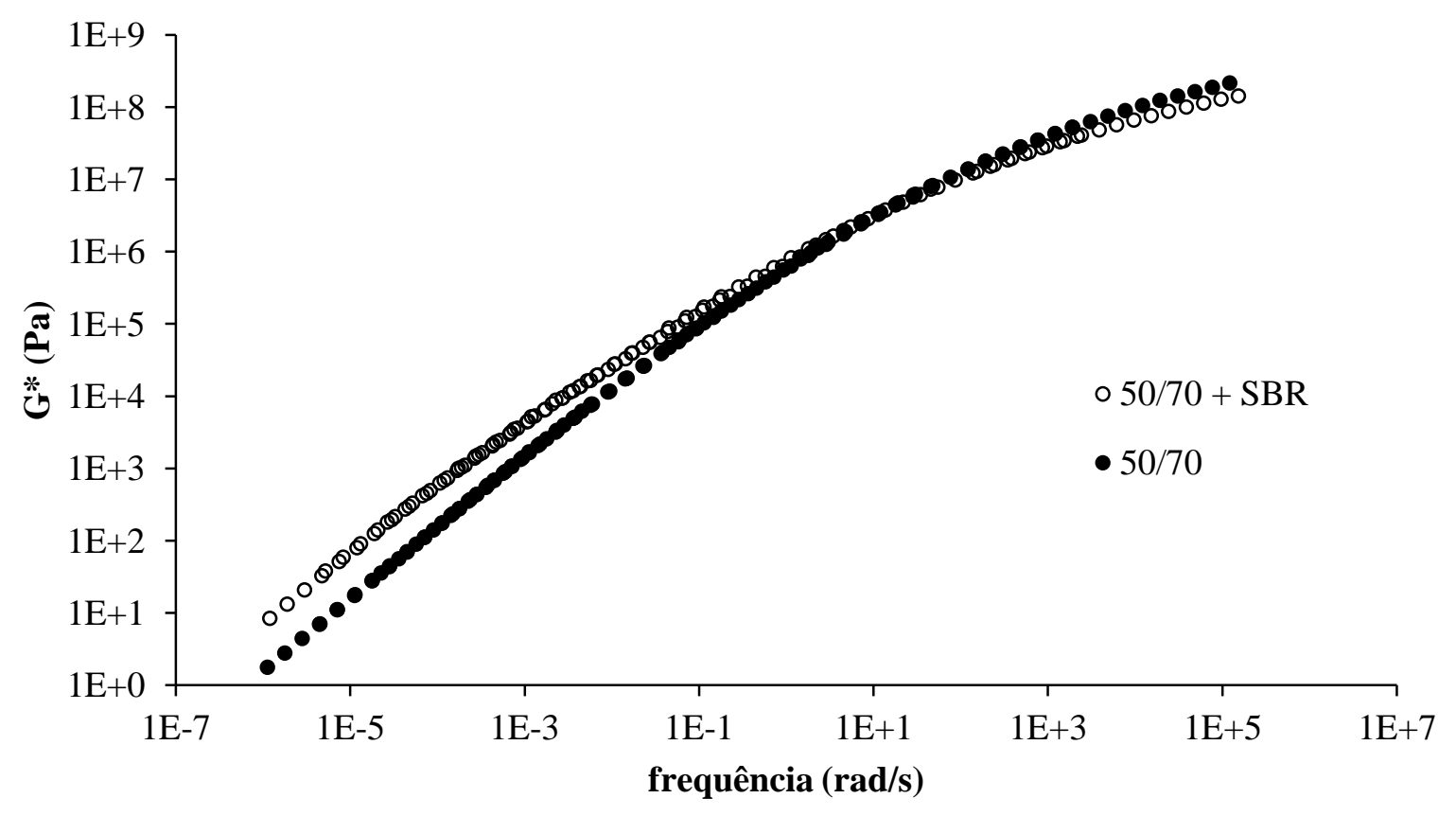

Figura A. 21 - Curva-mestre de G* da mistura 50/70-SBR em relação ao CAP puro: condição RTFOT 


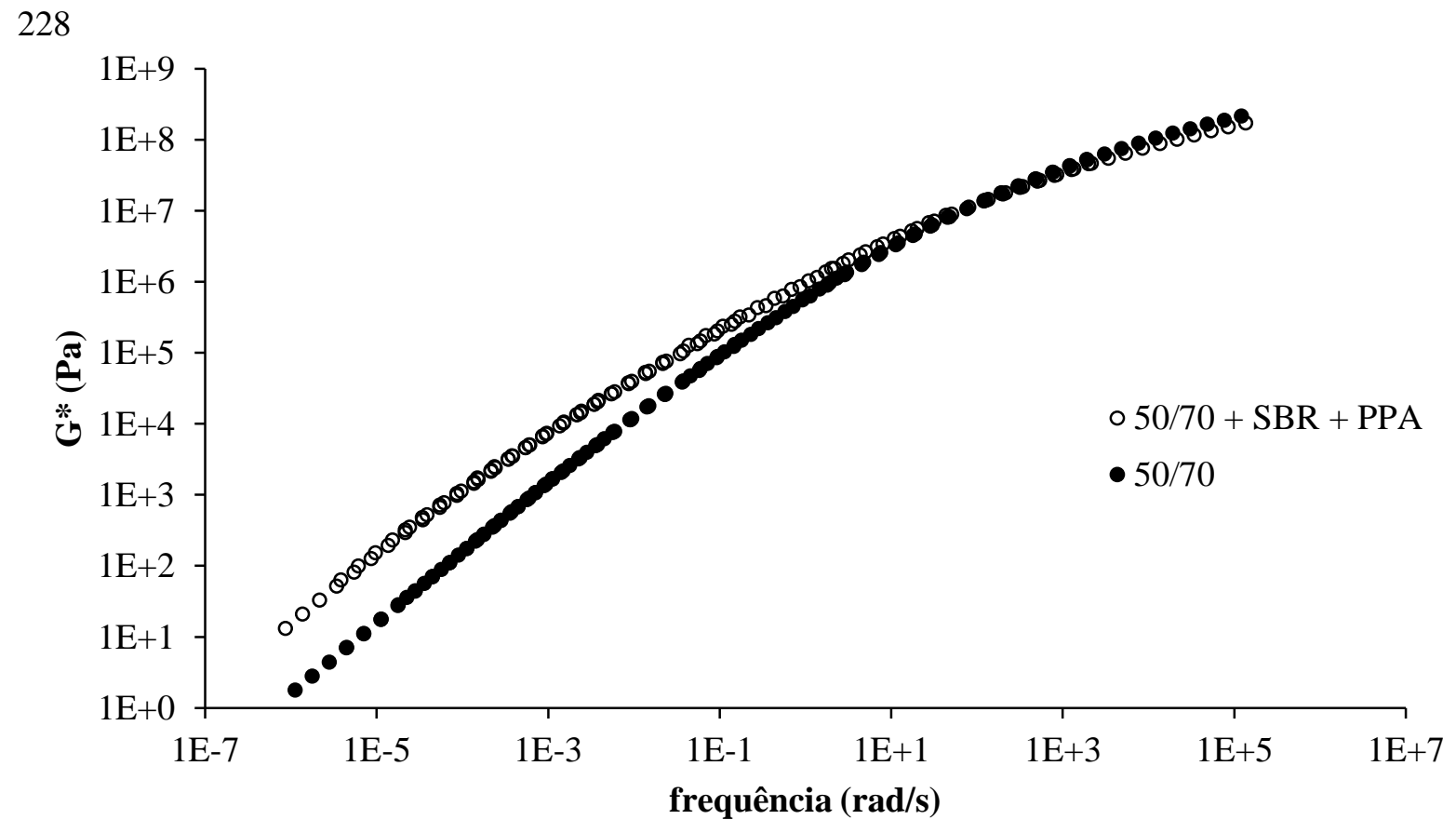

Figura A. 22 - Curva-mestre de $G^{*}$ da mistura 50/70-SBR-PPA em relação ao CAP puro: condição RTFOT

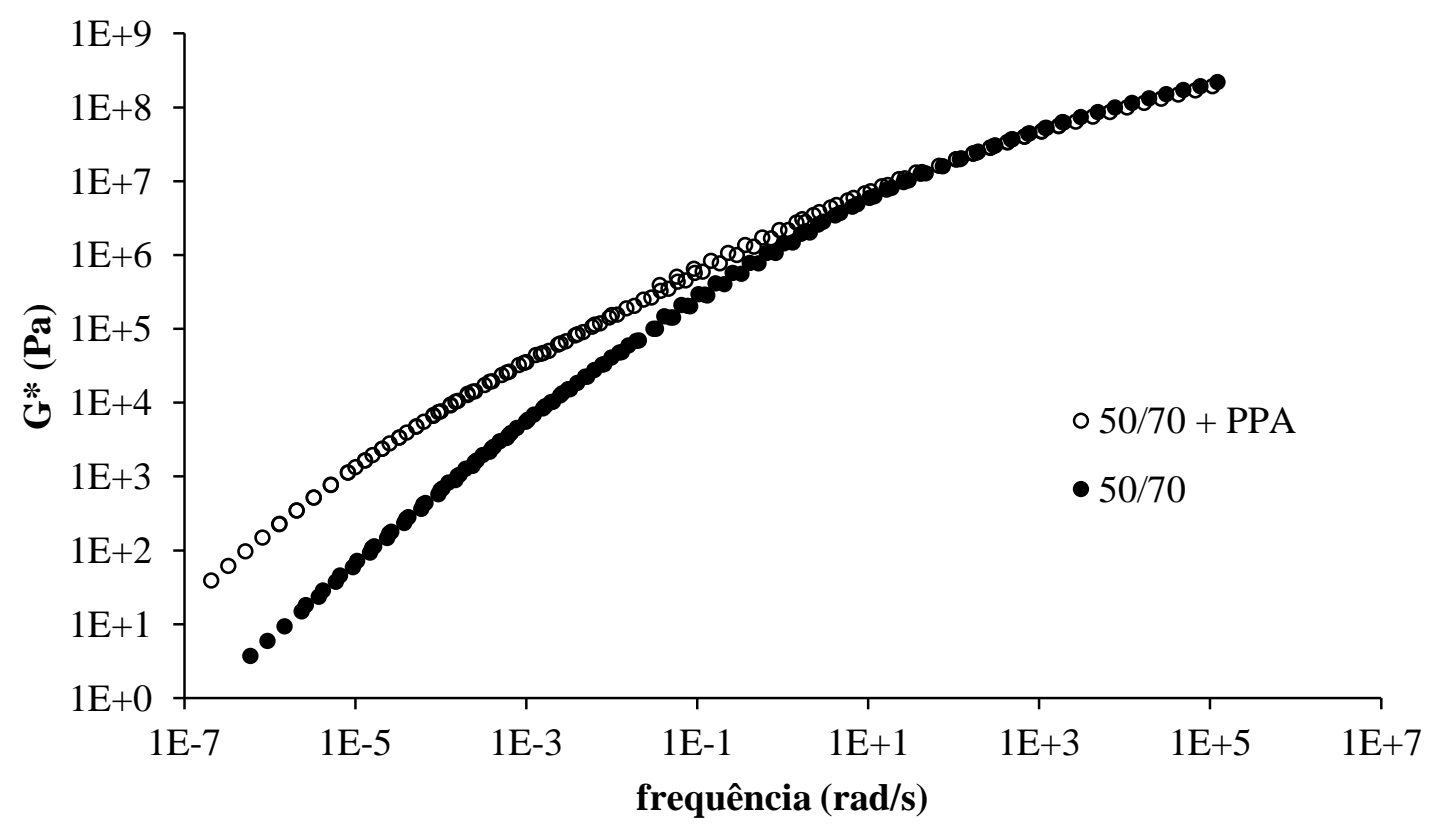

Figura A. 23 - Curva-mestre de $G^{*}$ da mistura 50/70-PPA em relação ao CAP puro: condição PAV 


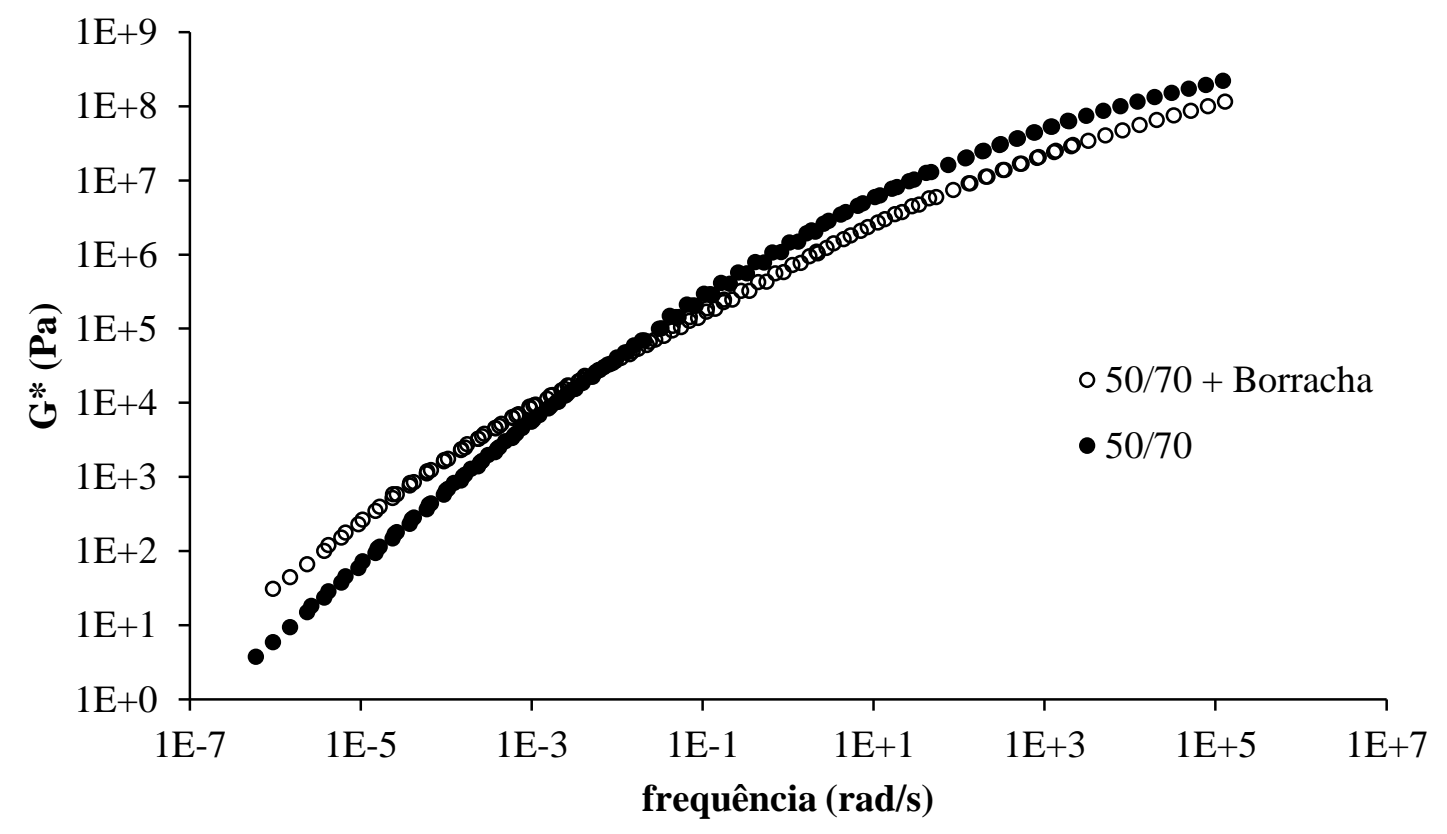

Figura A. 24 - Curva-mestre de $G^{*}$ da mistura 50/70-borracha em relação ao CAP puro: condição PAV

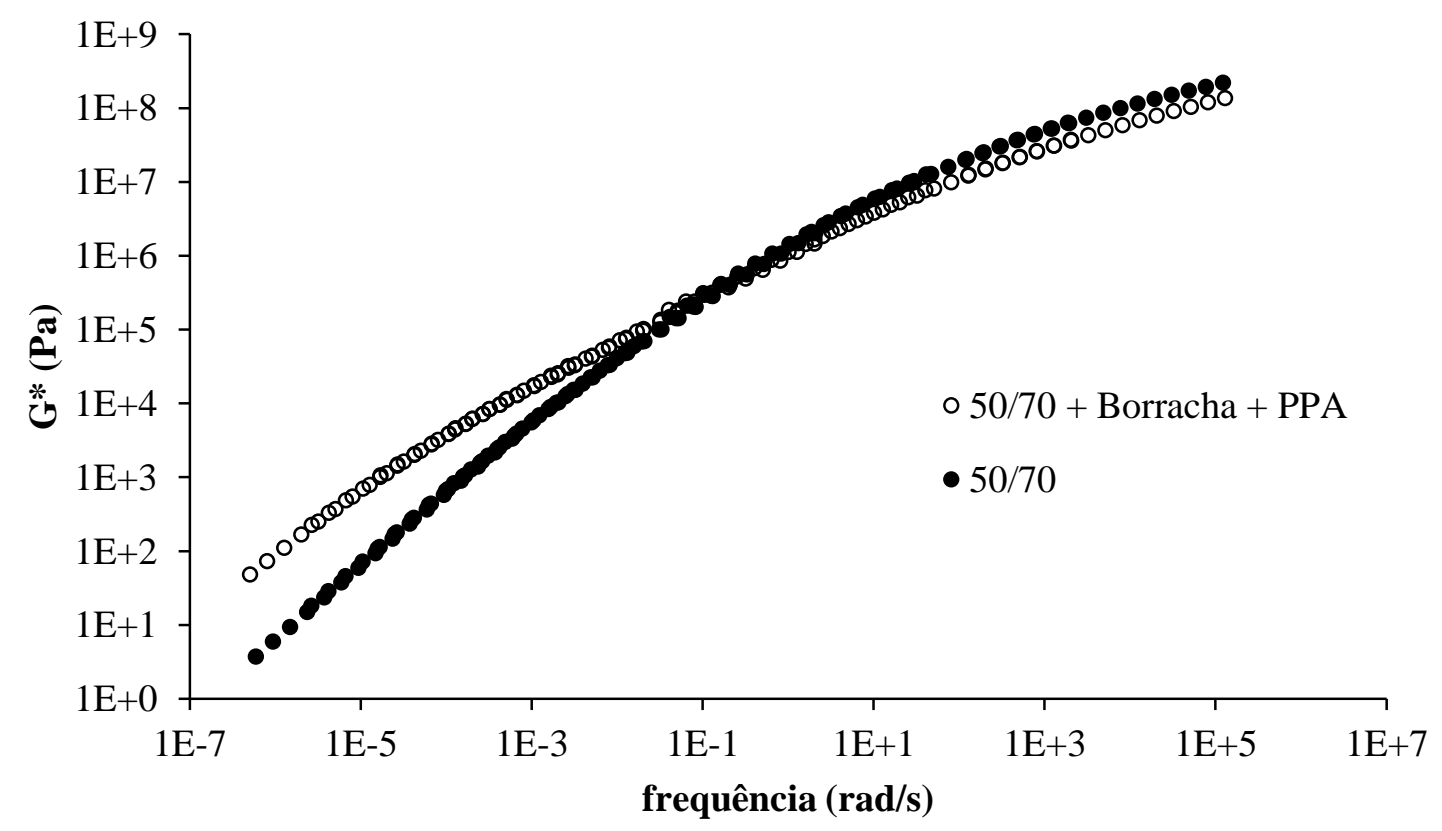

Figura A. 25 - Curva-mestre de $G^{*}$ da mistura 50/70-borracha-PPA em relação ao CAP puro: condição PAV 


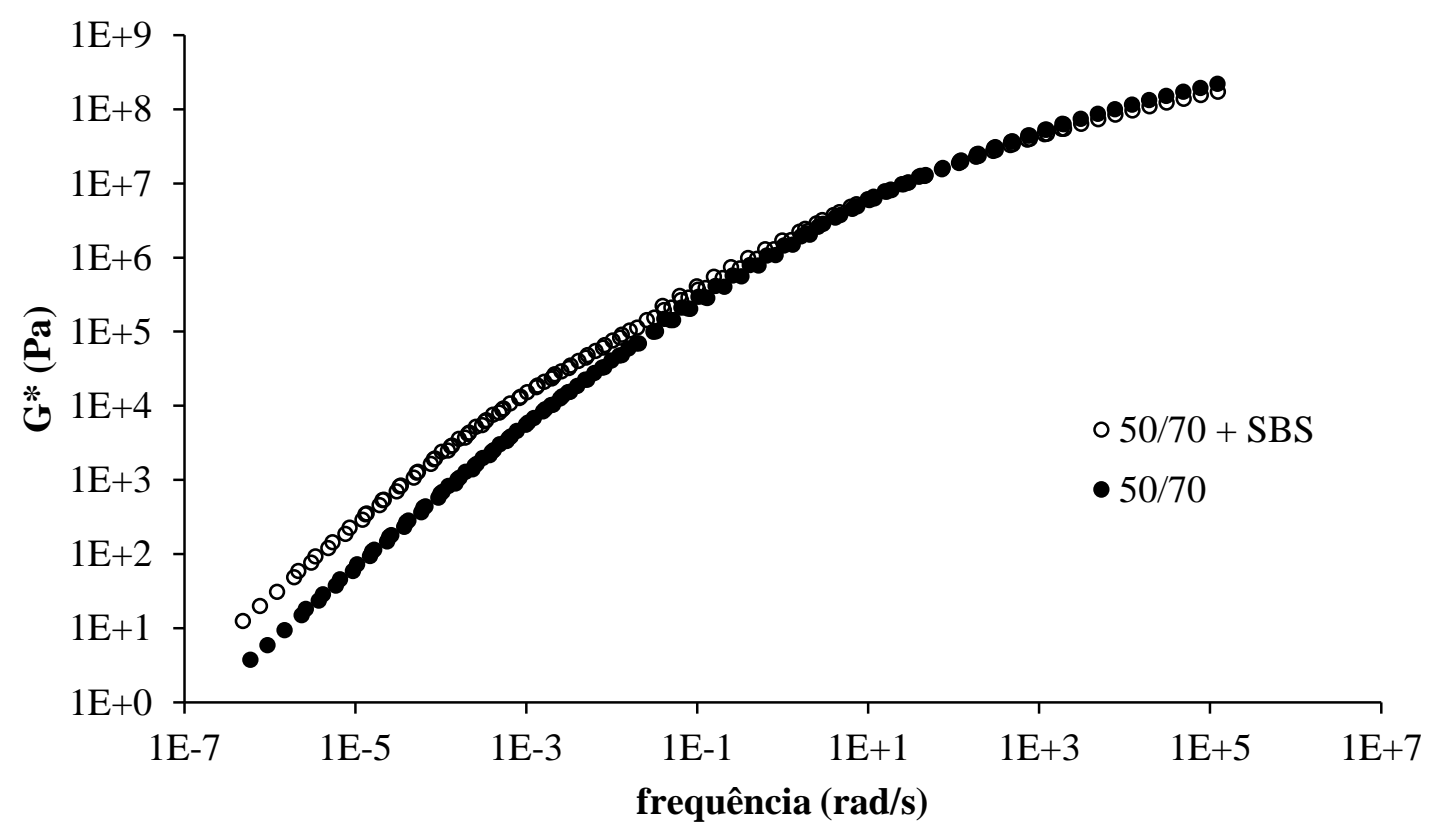

Figura A. 26 - Curva-mestre de G* da mistura 50/70-SBS em relação ao CAP puro: condição PAV

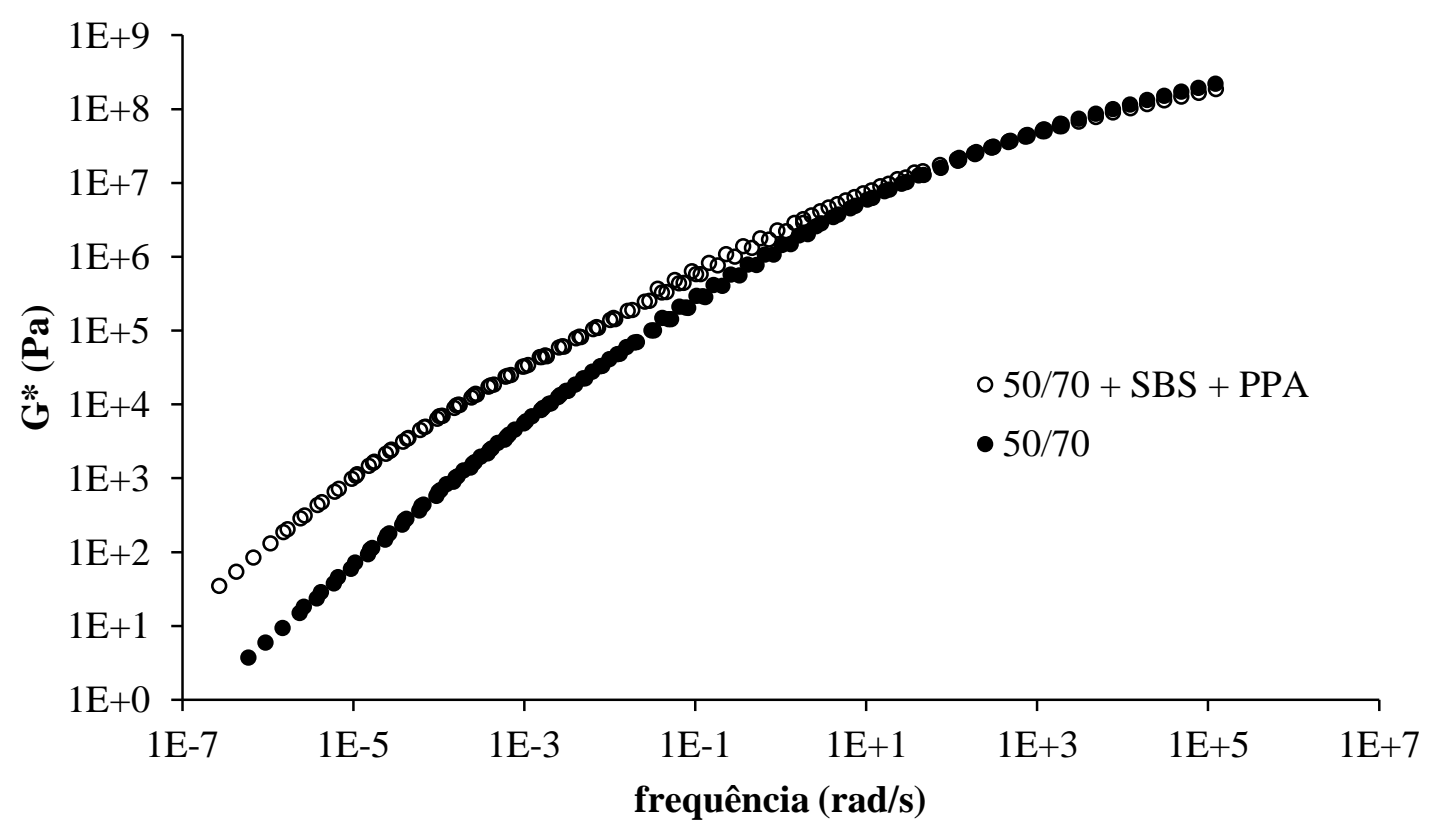

Figura A. 27 - Curva-mestre de $G^{*}$ da mistura 50/70-SBS-PPA em relação ao CAP puro: condição PAV 


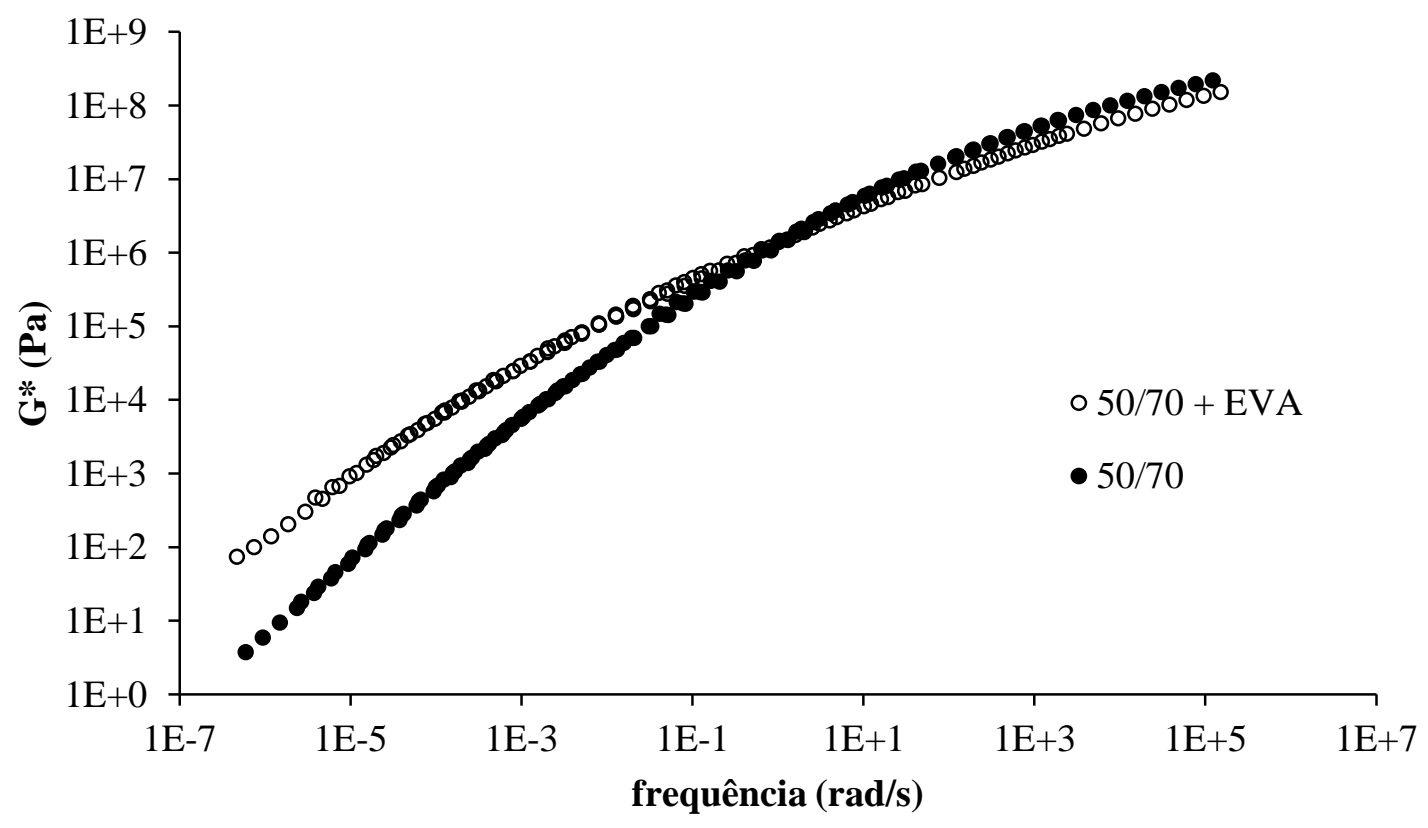

Figura A. 28 - Curva-mestre de G* da mistura 50/70-EVA em relação ao CAP puro: condição PAV

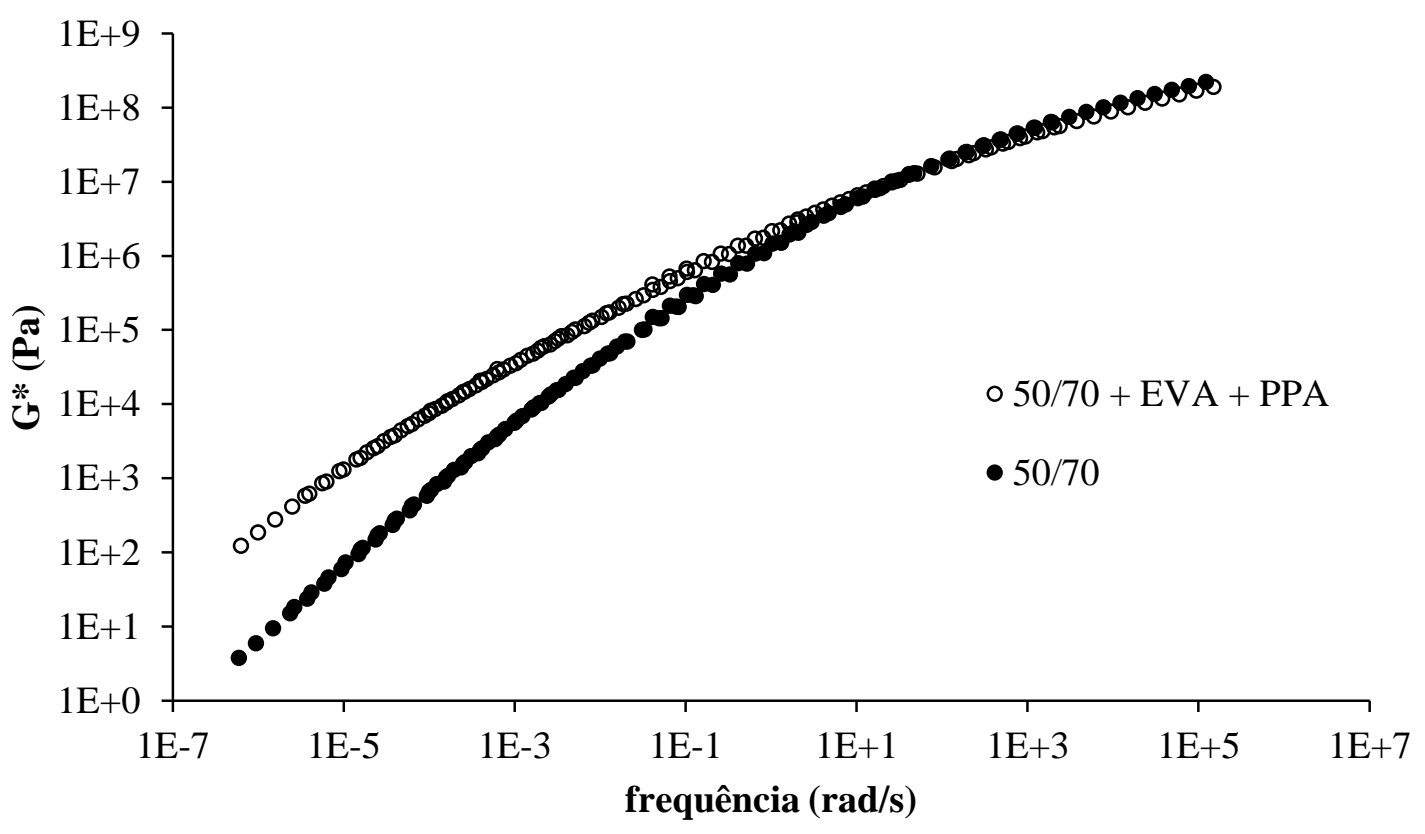

Figura A. 29 - Curva-mestre de G* da mistura 50/70-EVA-PPA em relação ao CAP puro: condição PAV 


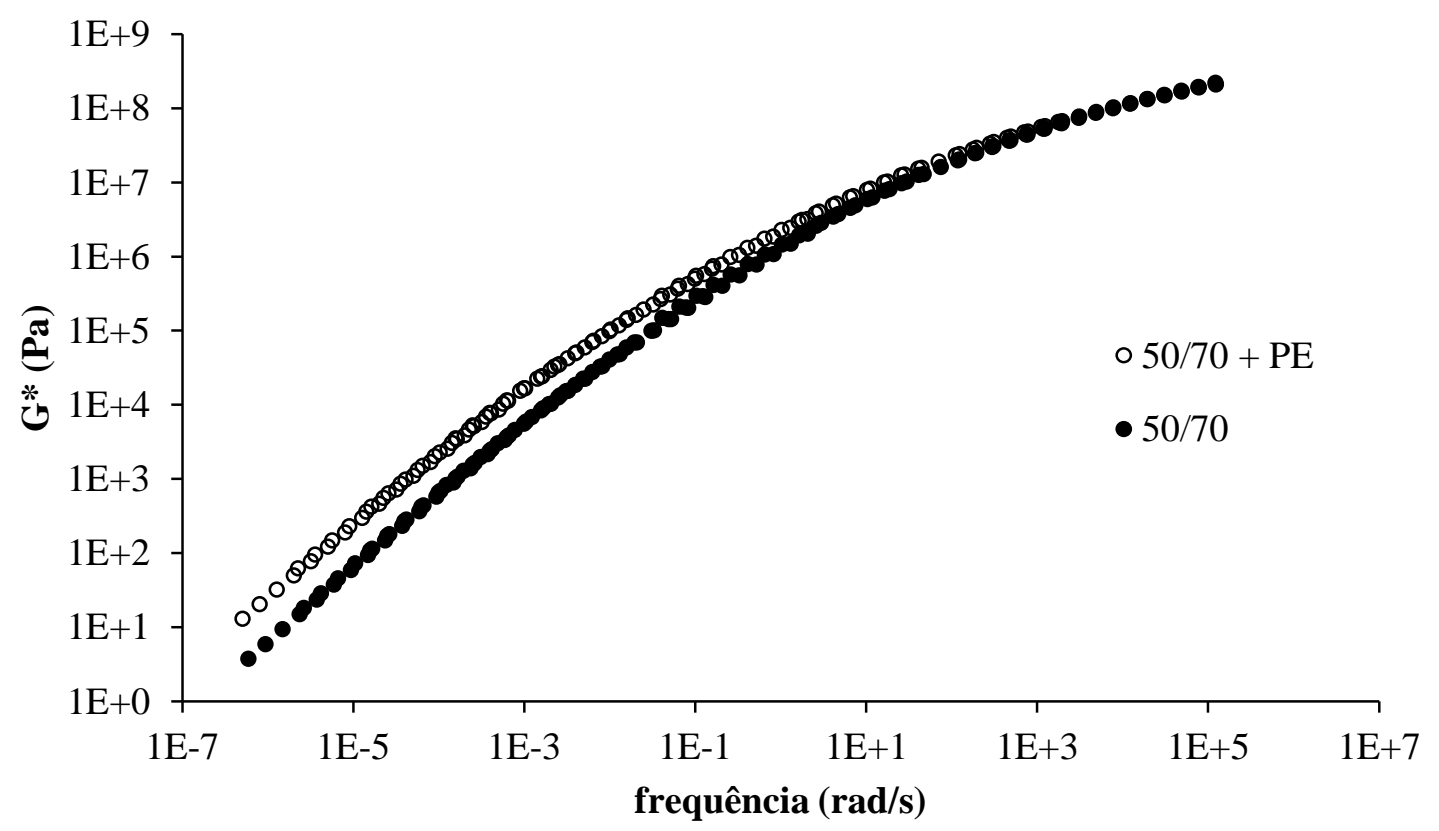

Figura A. 30 - Curva-mestre de $G^{*}$ da mistura 50/70-PE em relação ao CAP puro: condição PAV

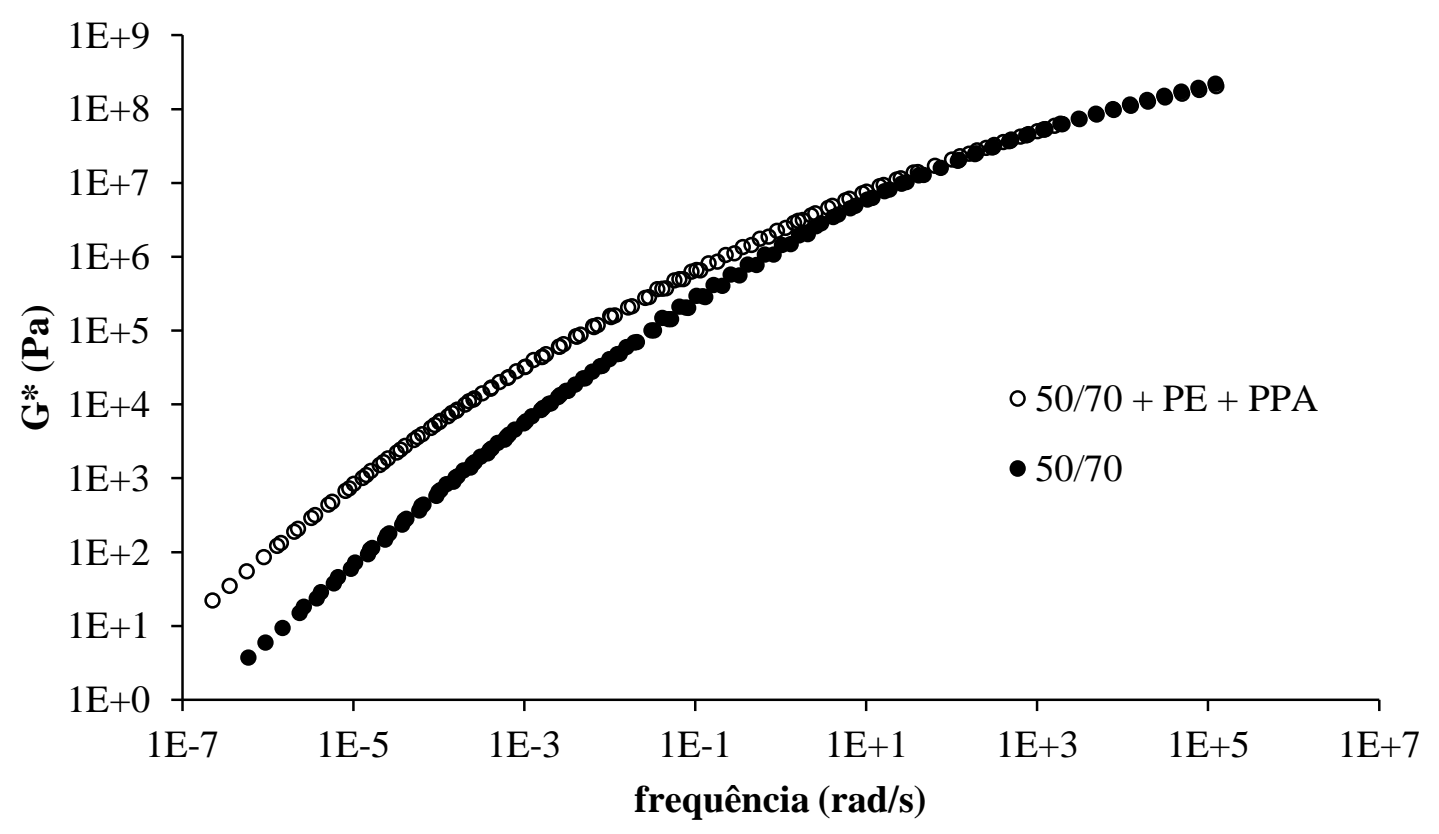

Figura A. 31 - Curva-mestre de $G^{*}$ da mistura 50/70-PE-PPA em relação ao CAP puro: condição PAV 


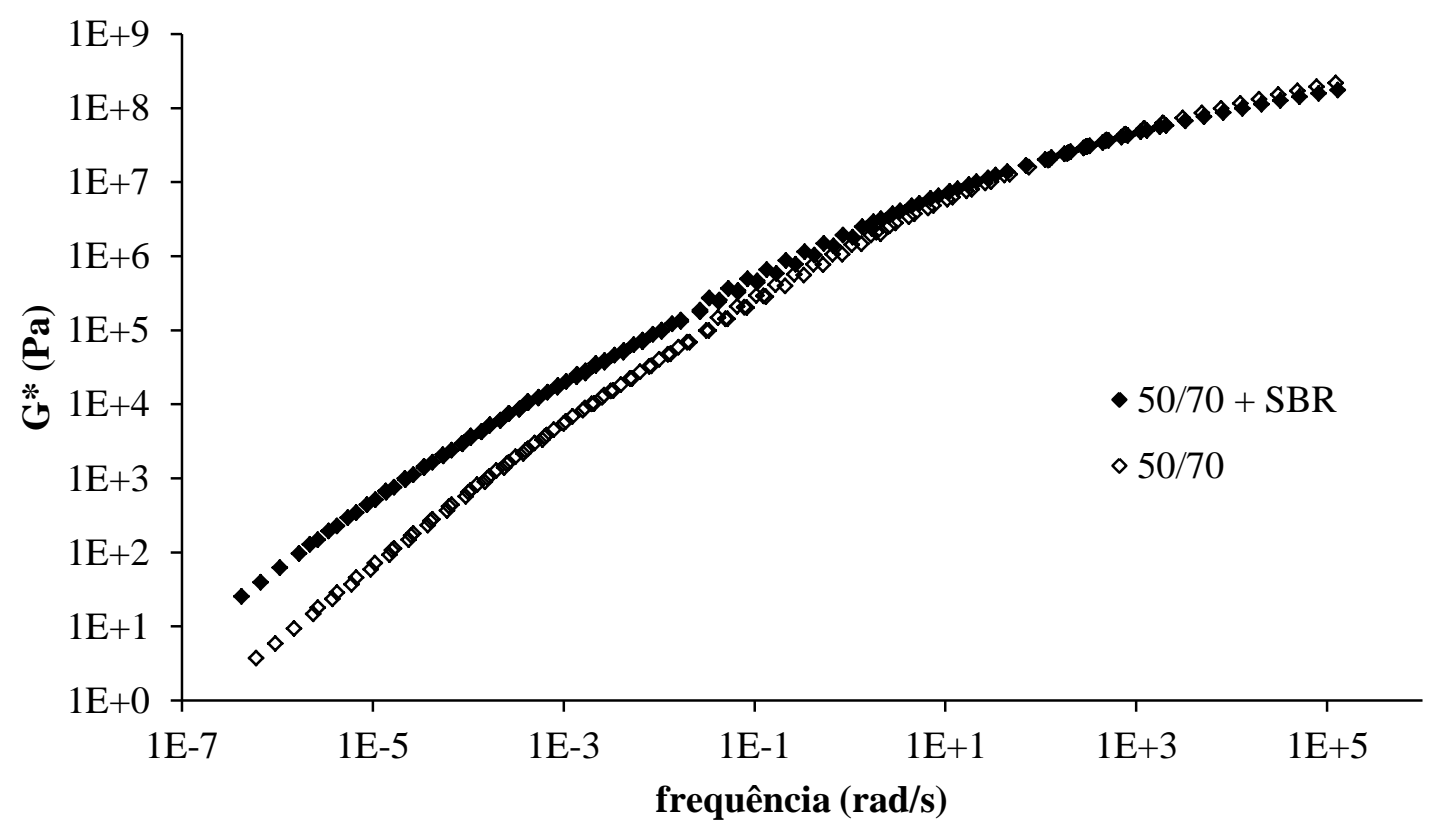

Figura A. 32 - Curva-mestre de $G^{*}$ da mistura 50/70-SBR em relação ao CAP puro: condição PAV

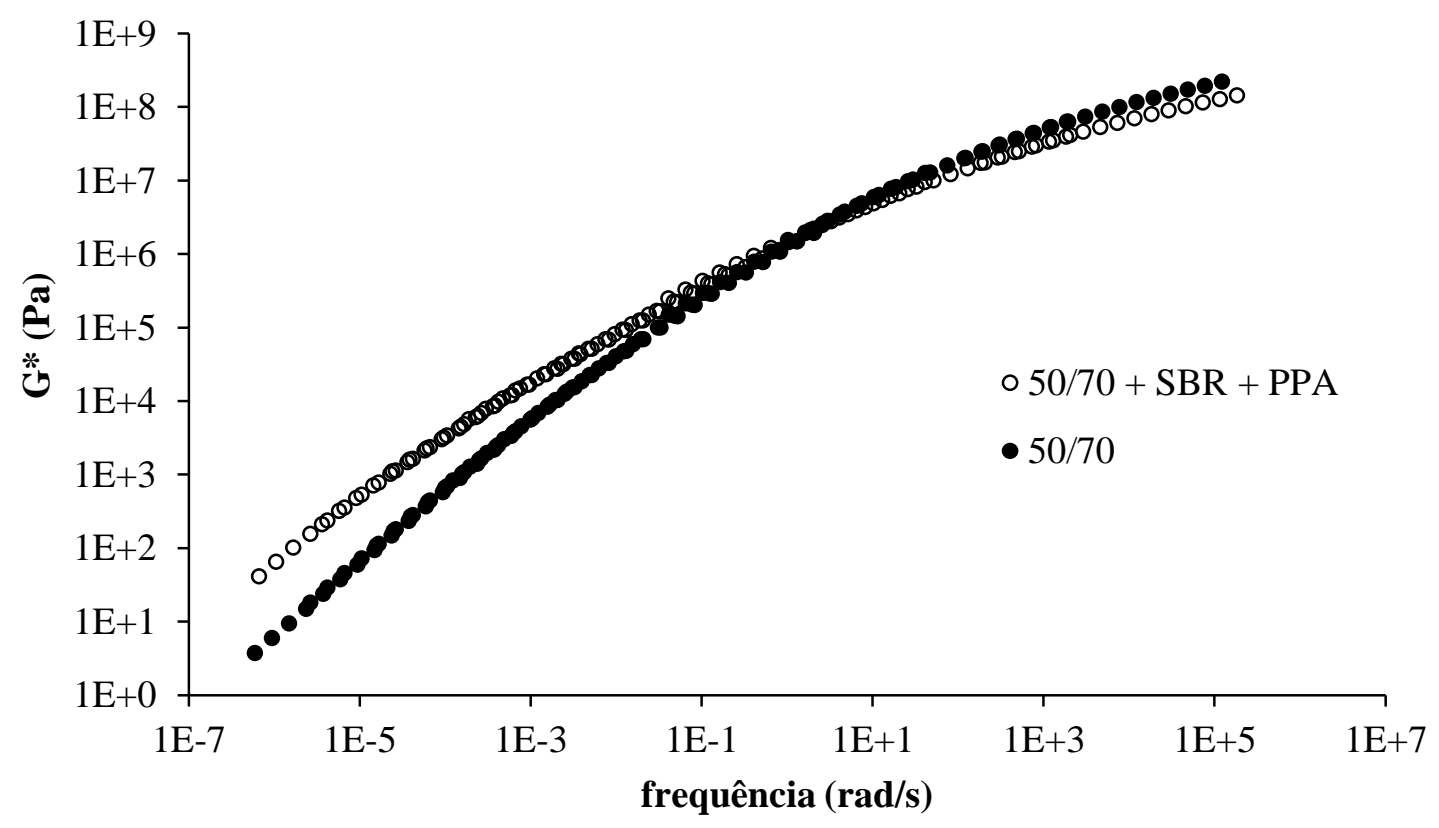

Figura A. 33 - Curva-mestre de $G^{*}$ da mistura 50/70-SBR-PPA em relação ao CAP puro: condição PAV 


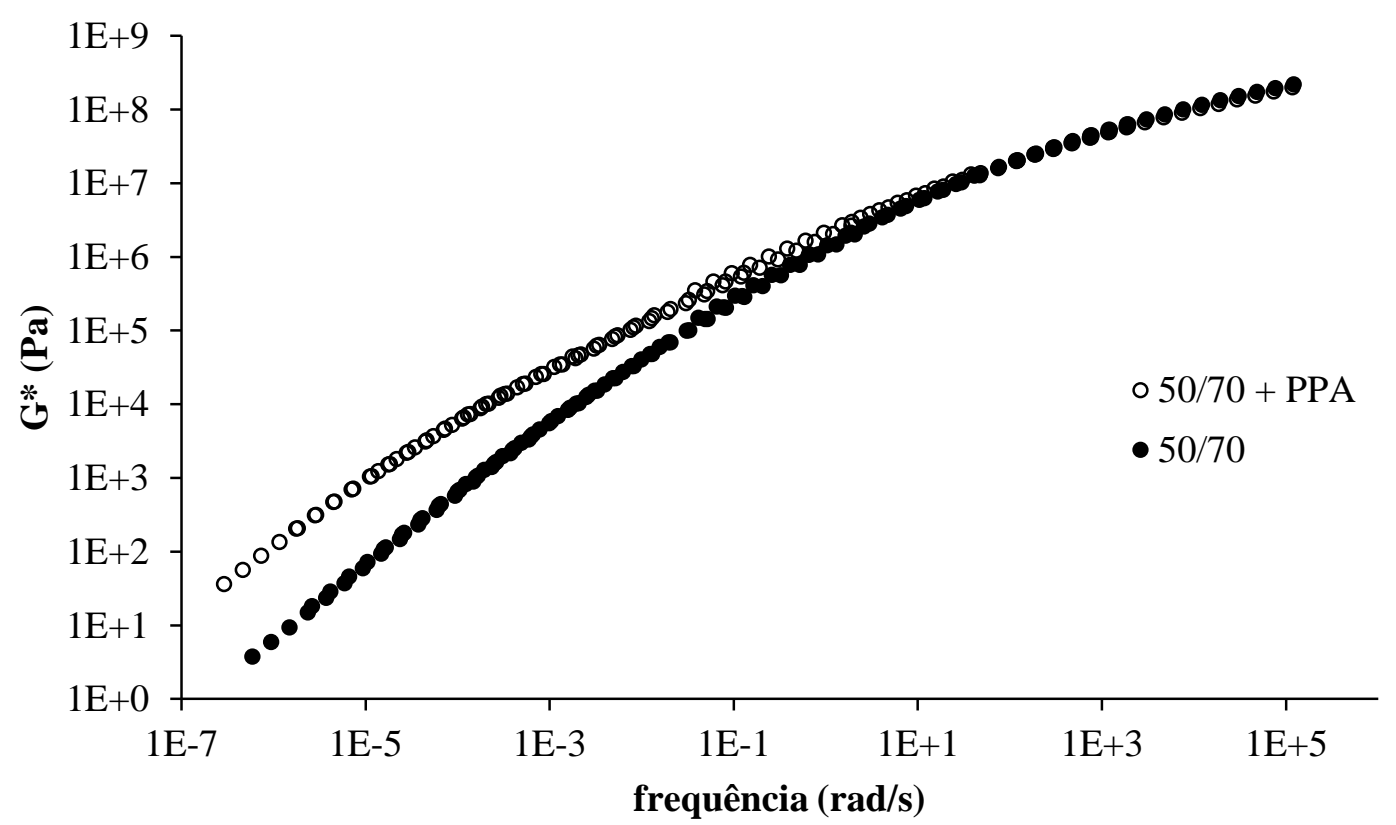

Figura A. 34 - Curva-mestre de $G^{*}$ da mistura 50/70-PPA em relação ao CAP puro: UV a $0,68 \mathrm{~W} / \mathrm{m}^{2}$

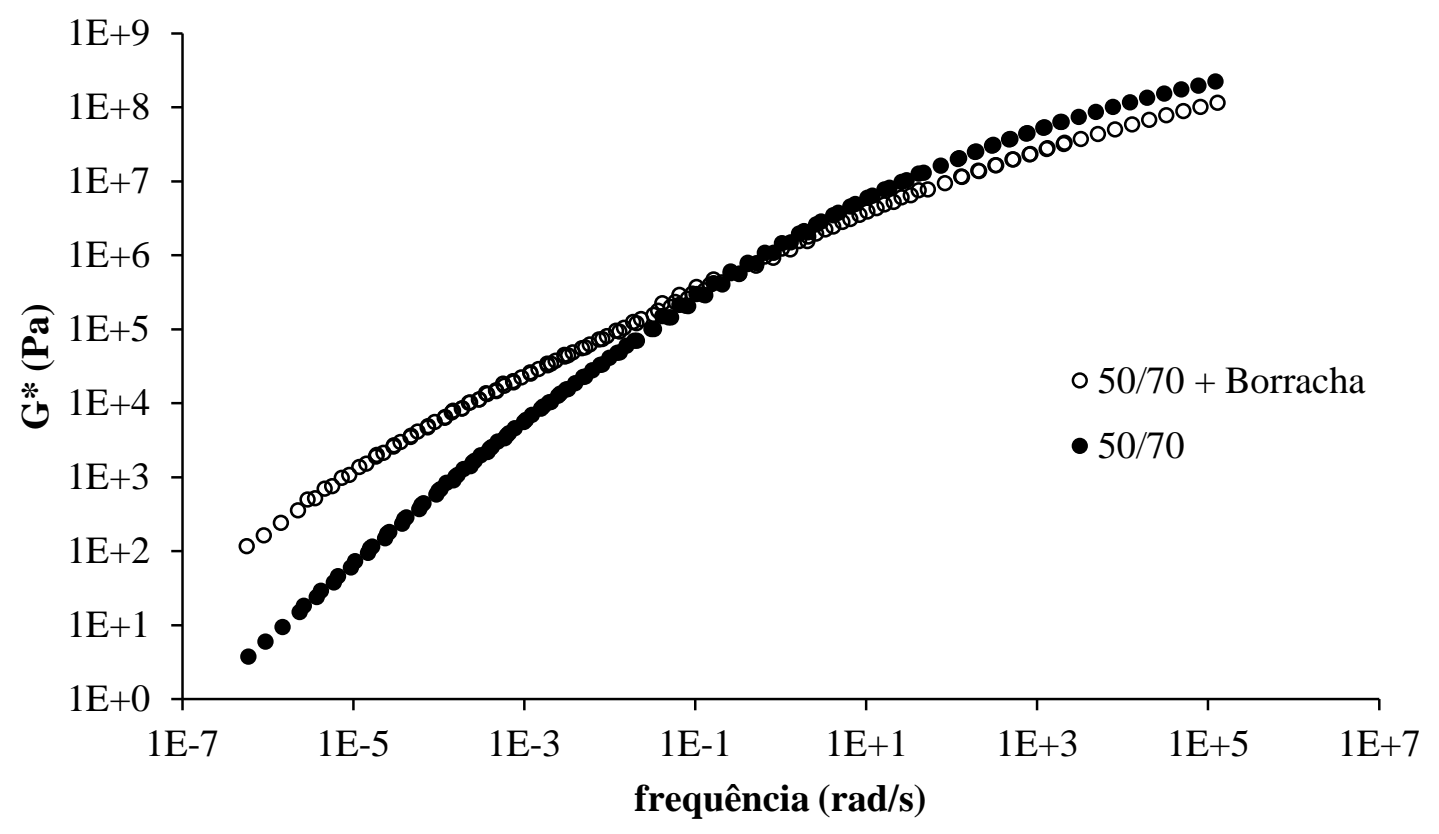

Figura A. 35 - Curva-mestre de $G^{*}$ da mistura 50/70-borracha em relação ao CAP puro: condição UV a $0,68 \mathrm{~W} / \mathrm{m}^{2}$ 


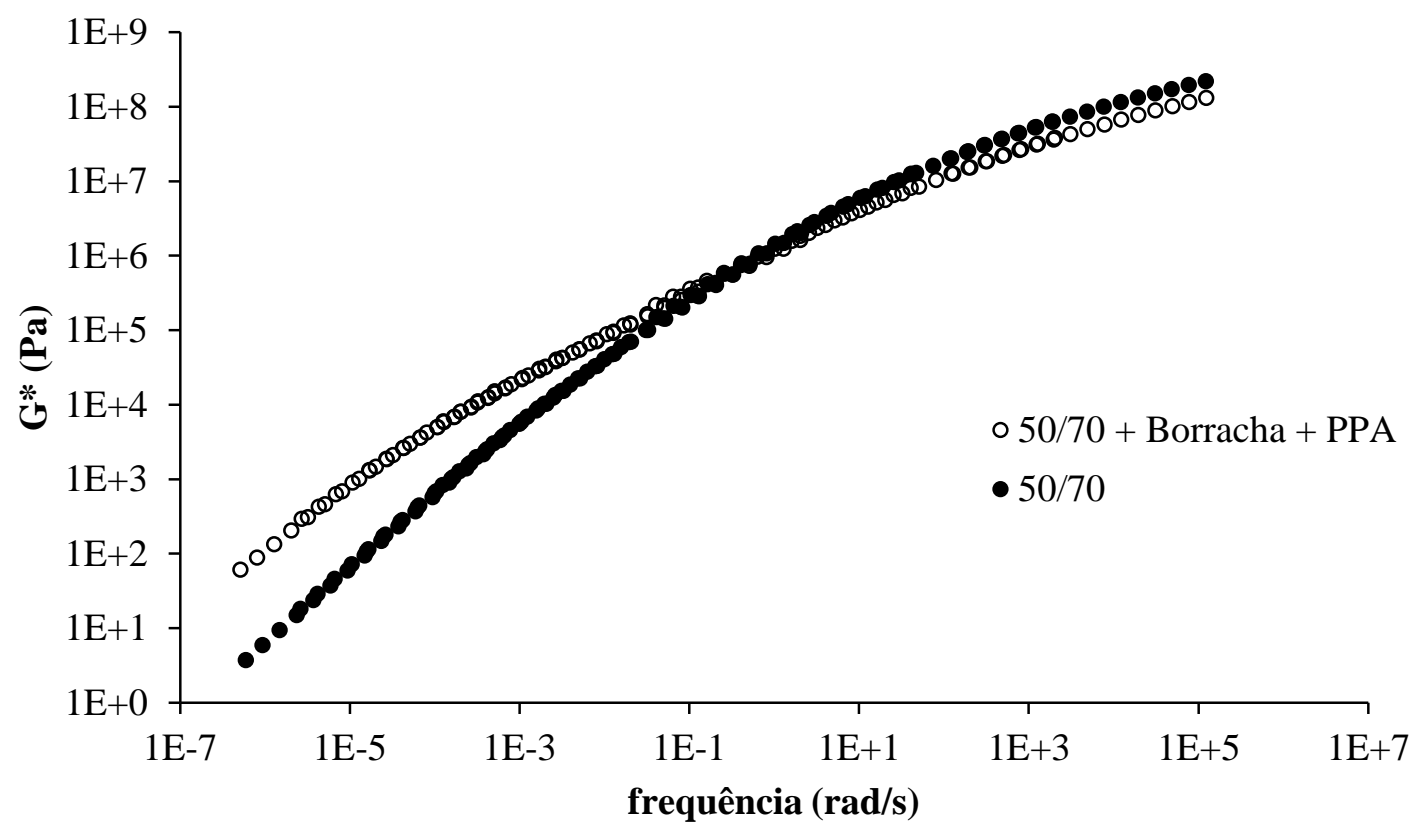

Figura A. 36 - Curva-mestre de $G^{*}$ da mistura 50/70-borracha-PPA em relação ao CAP puro: condição UV a $0,68 \mathrm{~W} / \mathrm{m}^{2}$

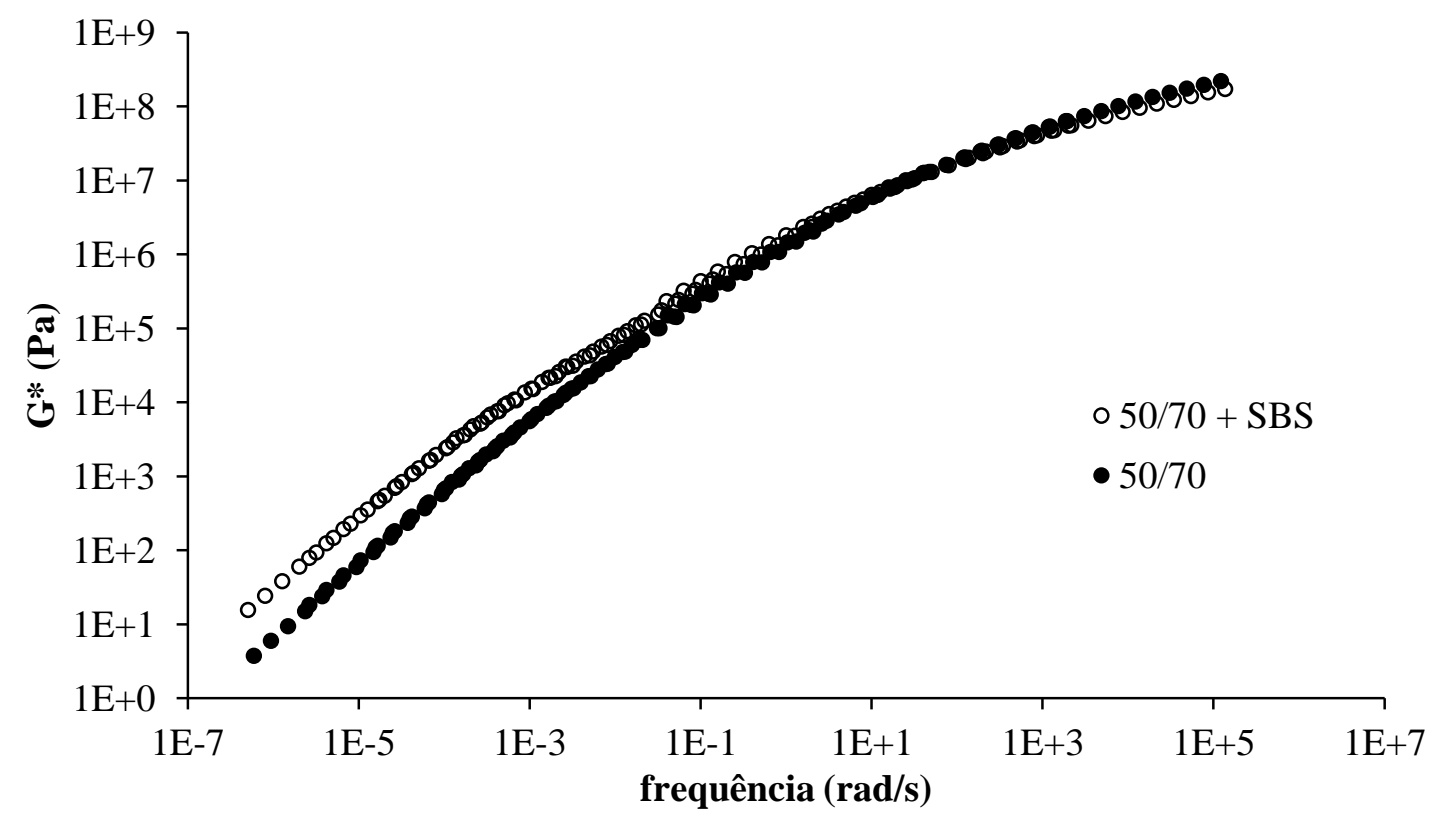

Figura A. 37 - Curva-mestre de $G^{*}$ da mistura 50/70-SBS em relação ao CAP puro: condição UV a $0,68 \mathrm{~W} / \mathrm{m}^{2}$ 


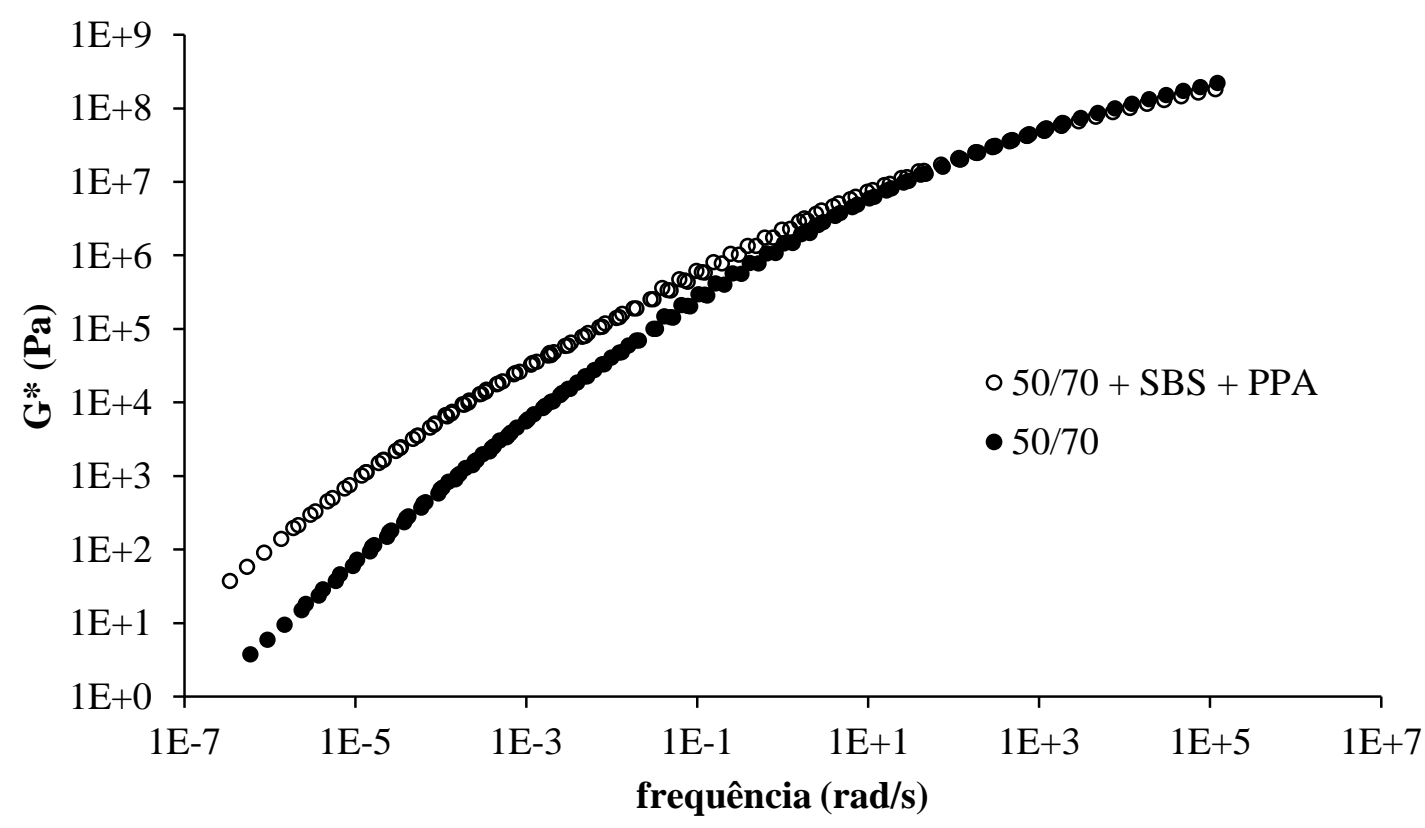

Figura A. 38 - Curva-mestre de $G^{*}$ da mistura 50/70-SBS-PPA em relação ao CAP puro: condição UV a $0,68 \mathrm{~W} / \mathrm{m}^{2}$

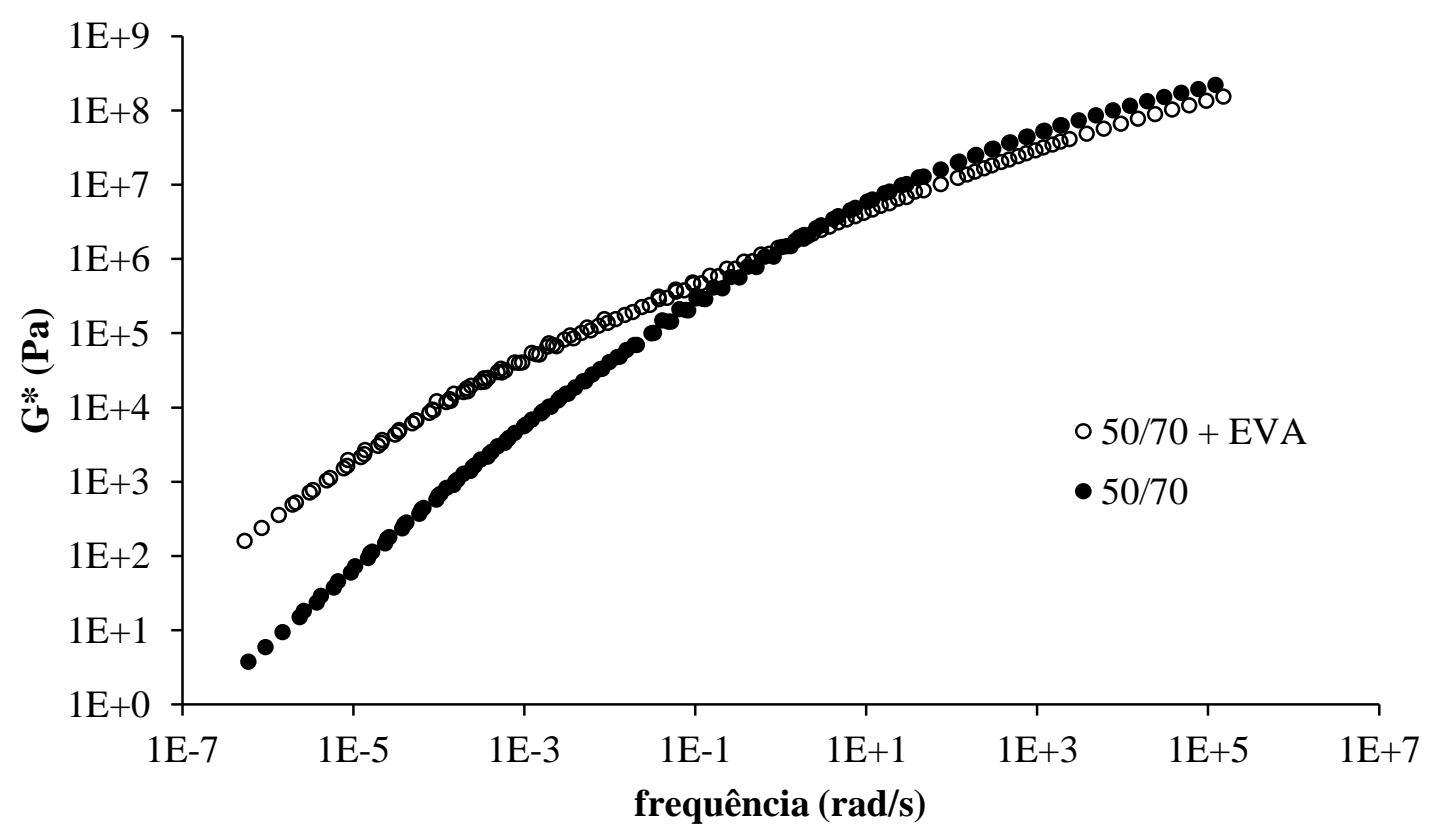

Figura A. 39 - Curva-mestre de G* da mistura 50/70-EVA em relação ao CAP puro: condição UV a $0,68 \mathrm{~W} / \mathrm{m}^{2}$ 


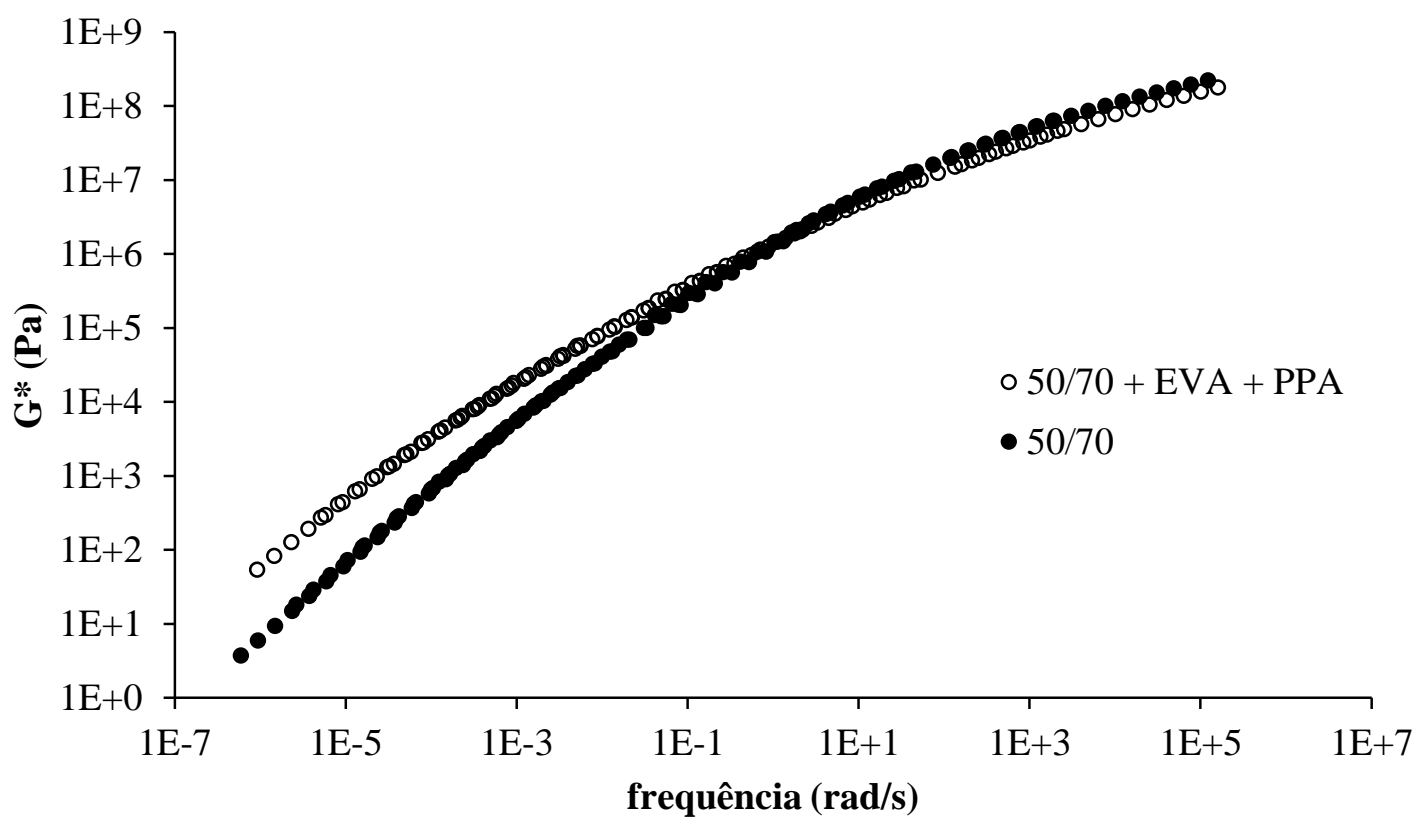

Figura A. 40 - Curva-mestre de G* da mistura 50/70-EVA-PPA em relação ao CAP puro: condição UV a $0,68 \mathrm{~W} / \mathrm{m}^{2}$

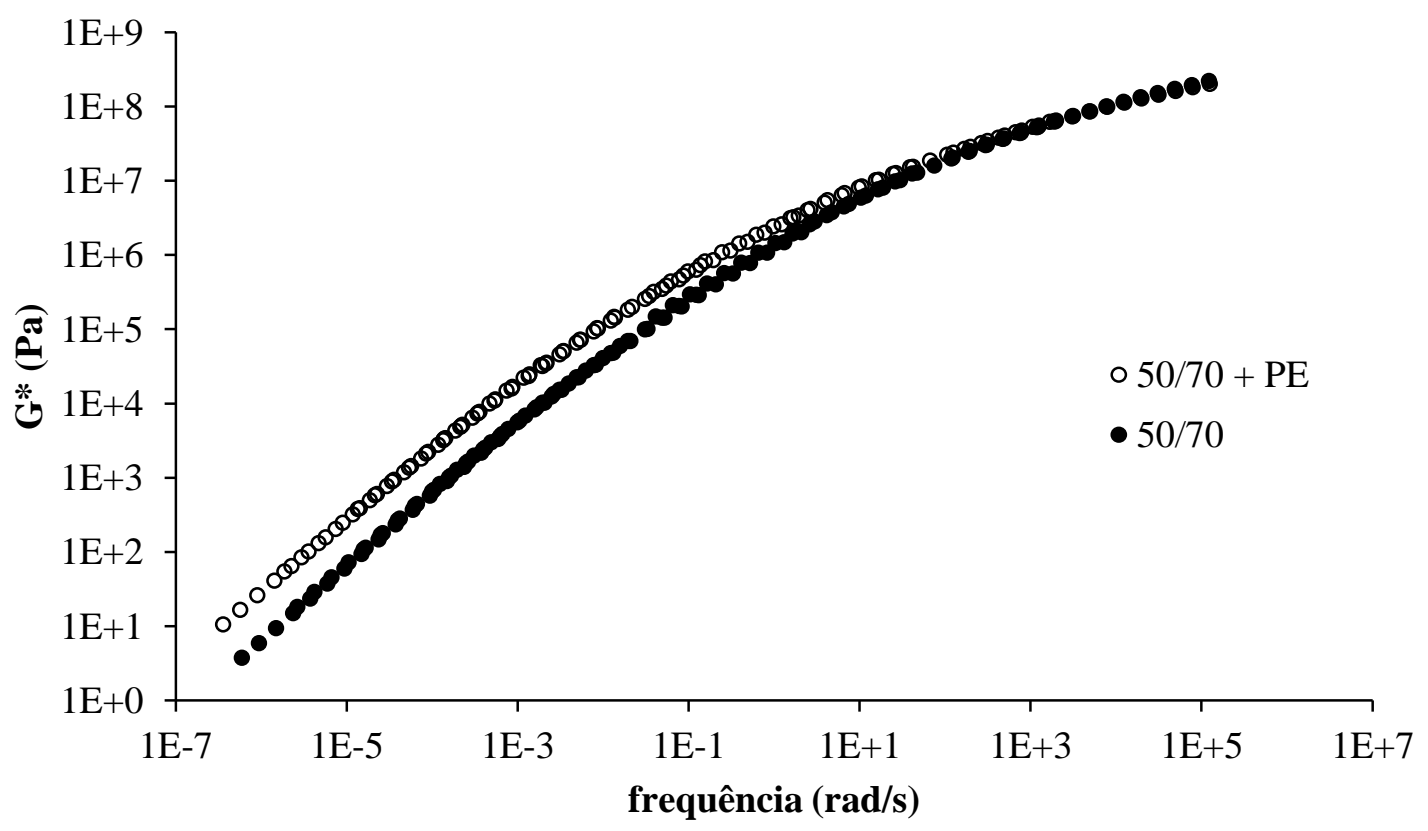

Figura A. 41 - Curva-mestre de $G^{*}$ da mistura 50/70-PE em relação ao CAP puro: condição UV a $0,68 \mathrm{~W} / \mathrm{m}^{2}$ 


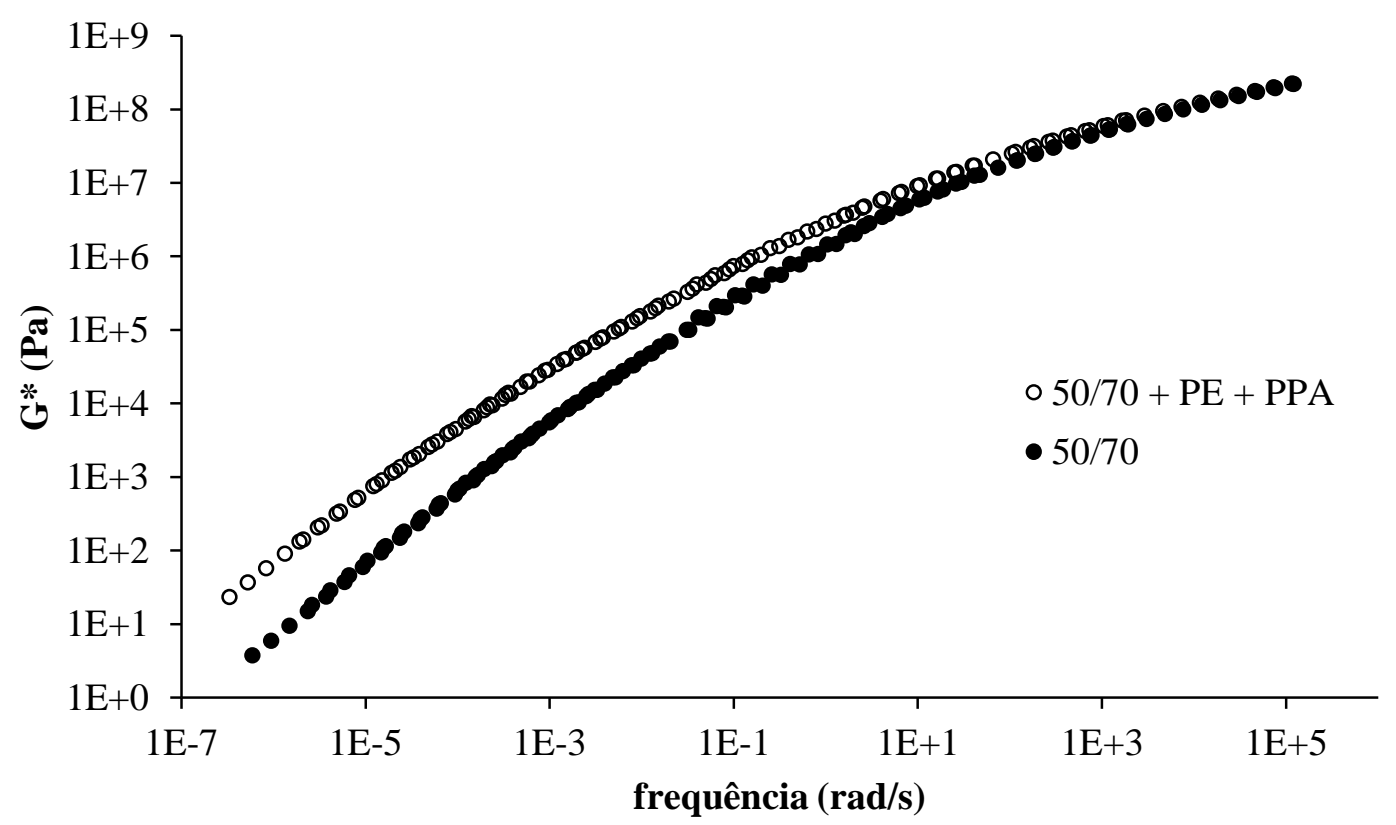

Figura A. 42 - Curva-mestre de $G^{*}$ da mistura 50/70-PE-PPA em relação ao CAP puro: condição UV a $0,68 \mathrm{~W} / \mathrm{m}^{2}$

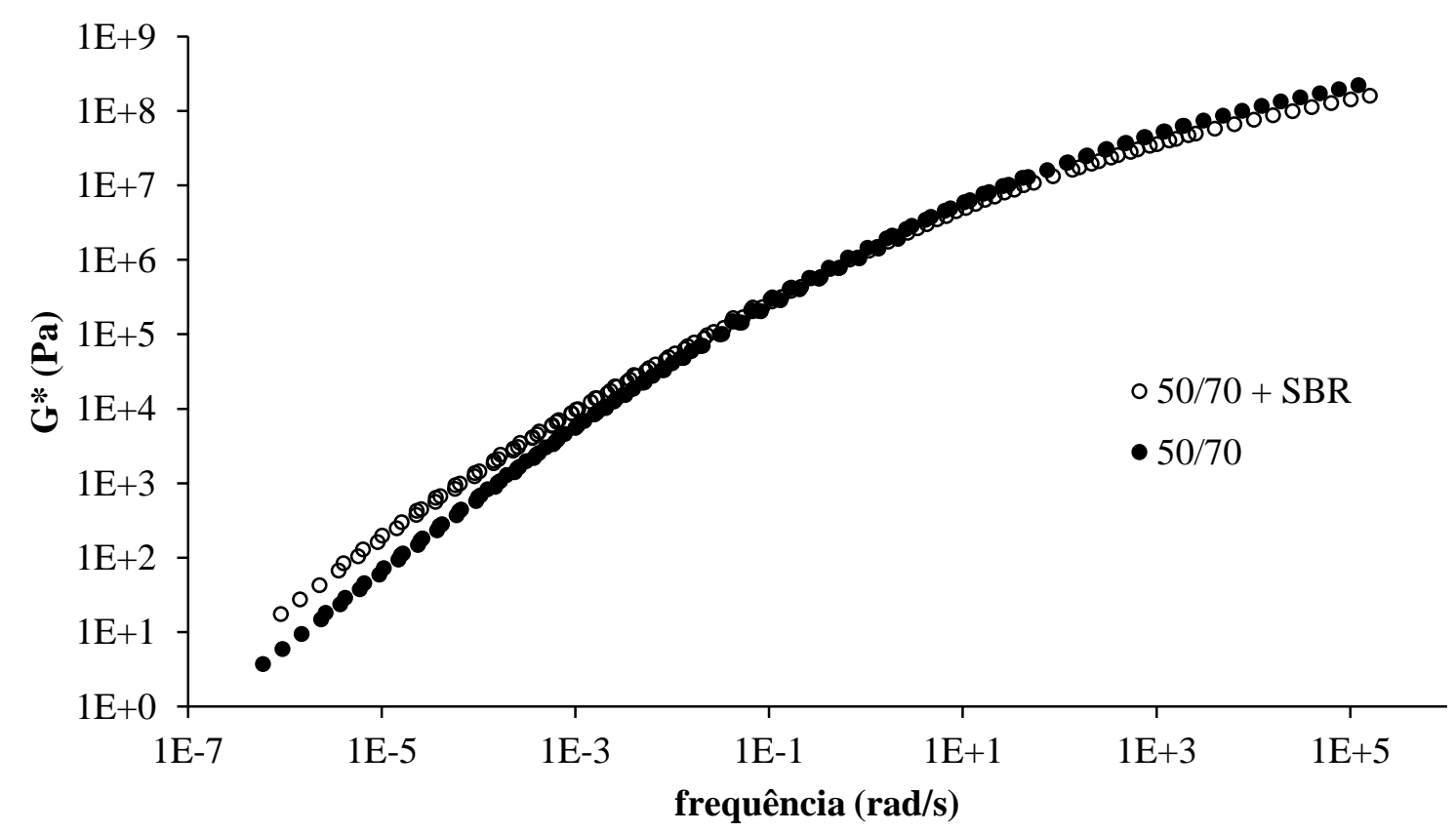

Figura A. 43 - Curva-mestre de $G^{*}$ da mistura 50/70-SBR em relação ao CAP puro: condição UV a $0,68 \mathrm{~W} / \mathrm{m}^{2}$ 


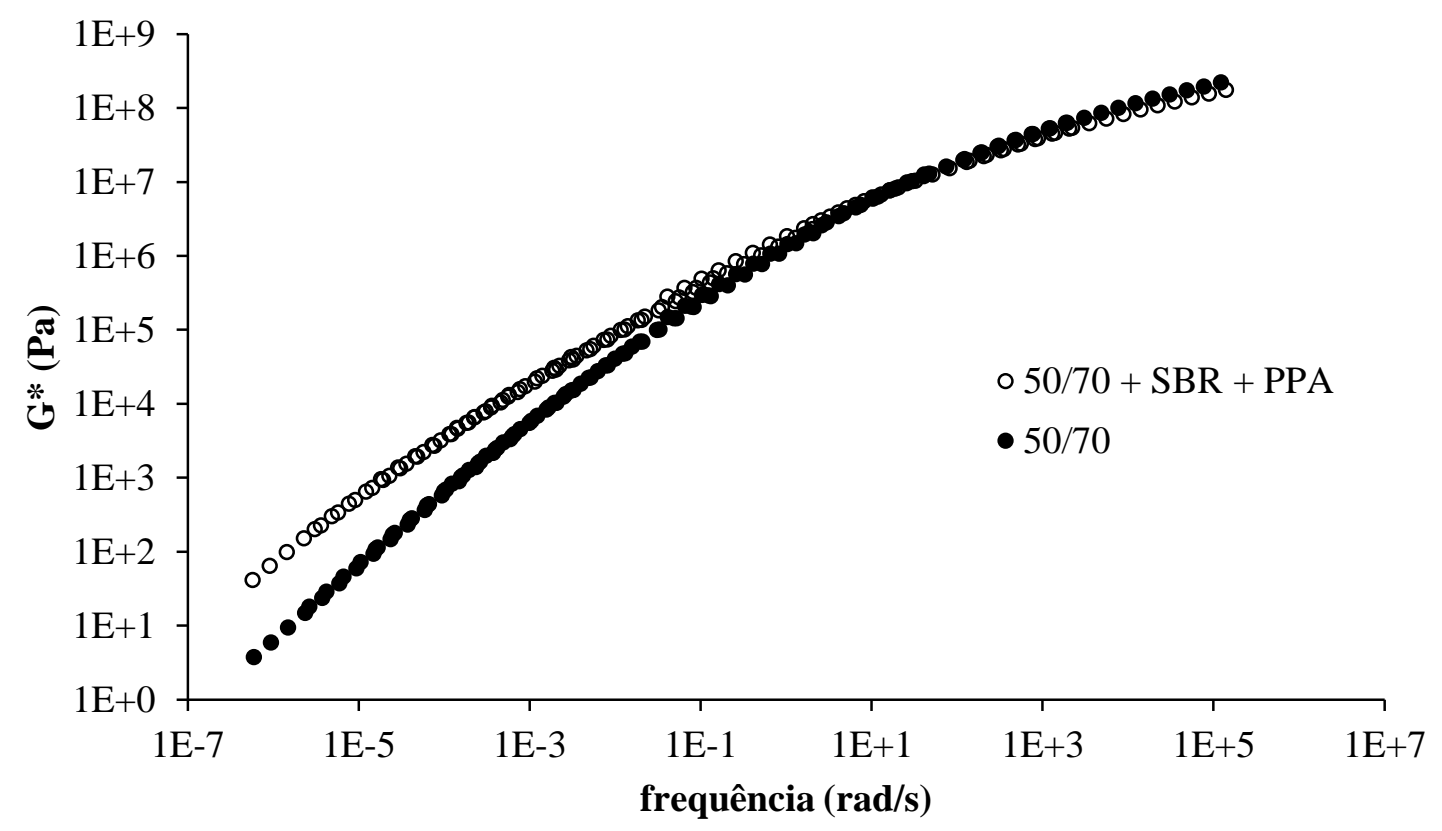

Figura A. 44 - Curva-mestre de $G^{*}$ da mistura 50/70-SBR-PPA em relação ao CAP puro: condição UV a $0,68 \mathrm{~W} / \mathrm{m}^{2}$

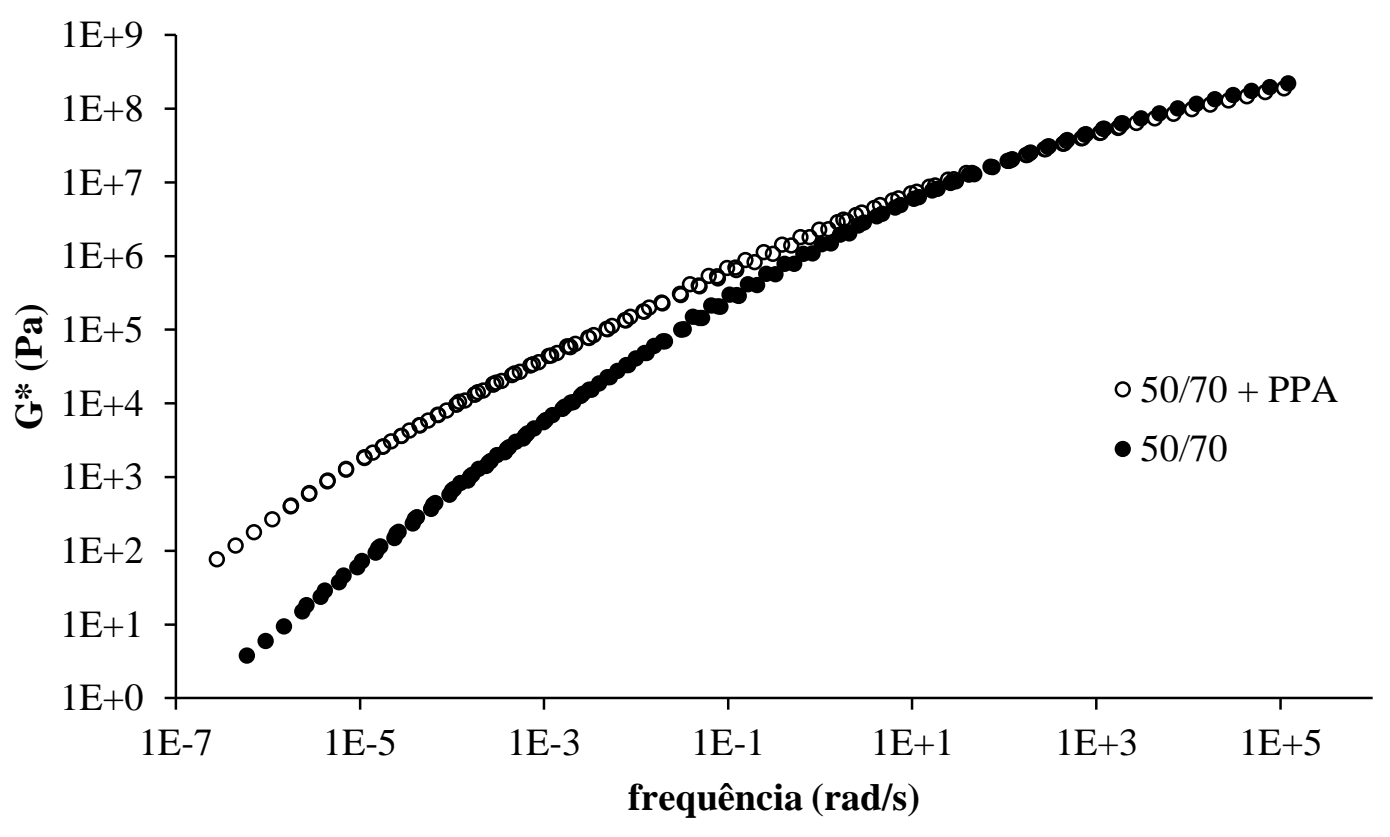

Figura A. 45 - Curva-mestre de G* da mistura 50/70-PPA em relação ao CAP puro: UV a $1,00 \mathrm{~W} / \mathrm{m}^{2}$ 


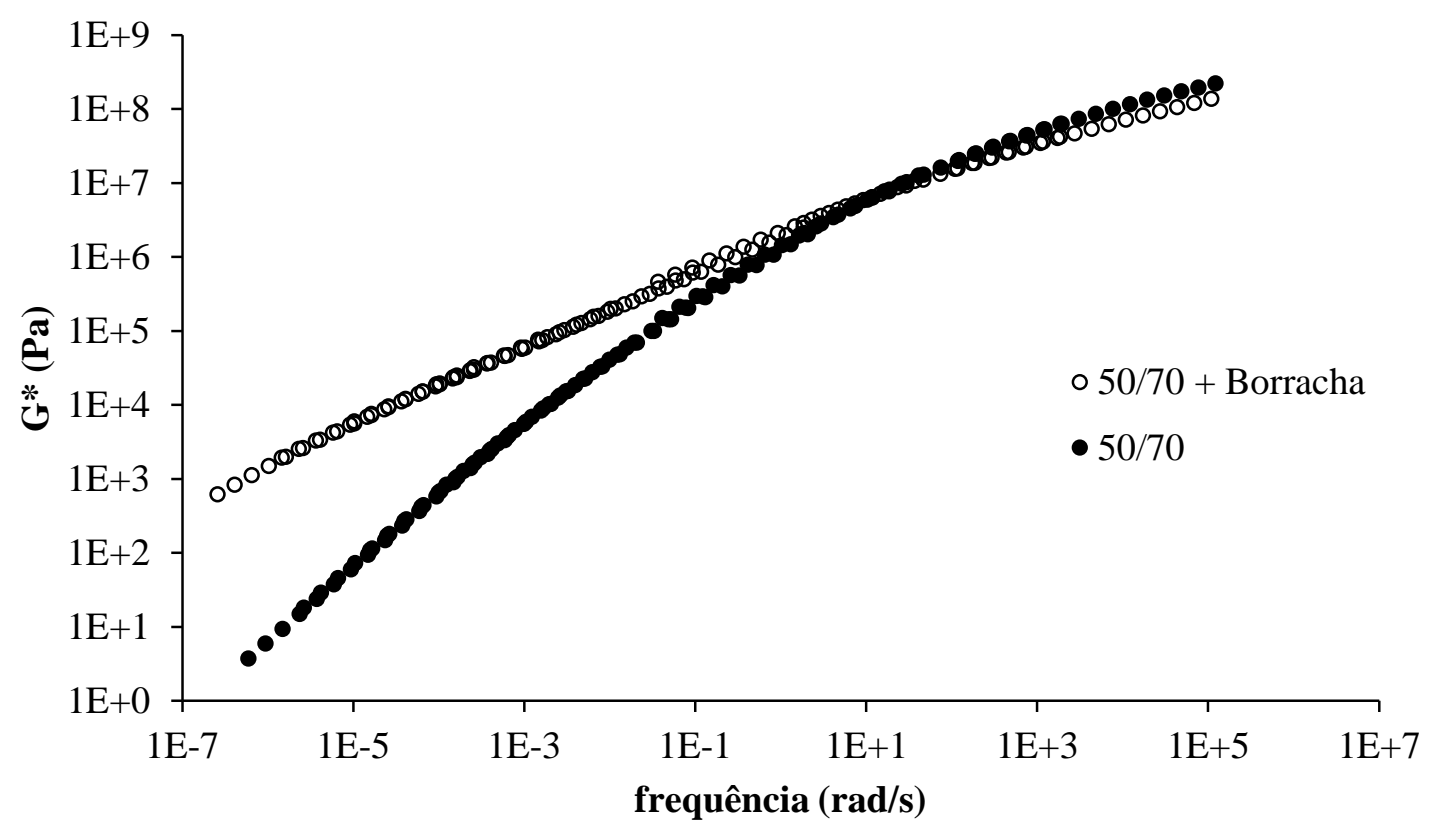

Figura A. 46 - Curva-mestre de G* da mistura 50/70-borracha em relação ao CAP puro: condição UV a $1,00 \mathrm{~W} / \mathrm{m}^{2}$

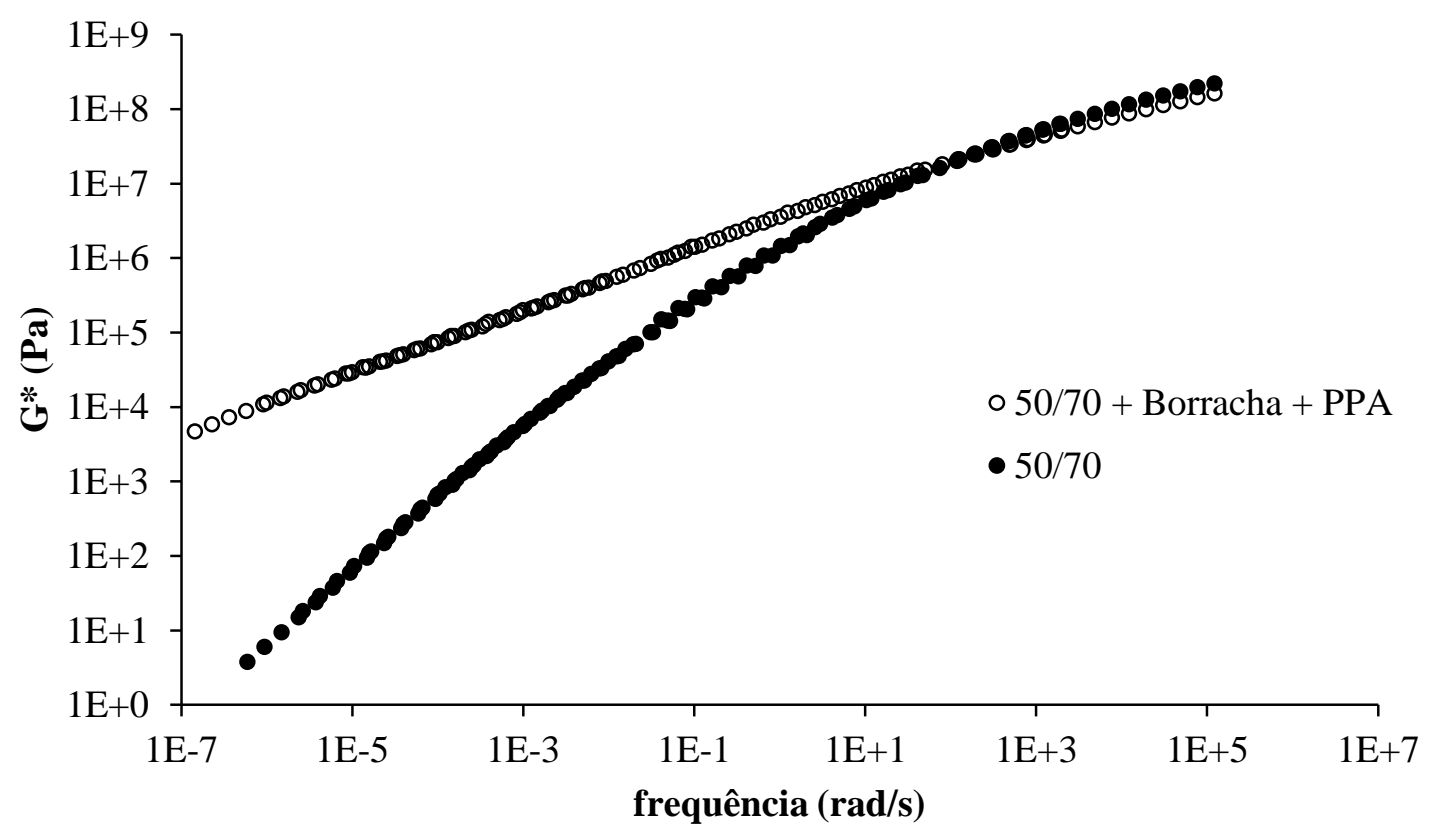

Figura A. 47 - Curva-mestre de $G^{*}$ da mistura 50/70-borracha-PPA em relação ao CAP puro: condição UV a $1,00 \mathrm{~W} / \mathrm{m}^{2}$ 


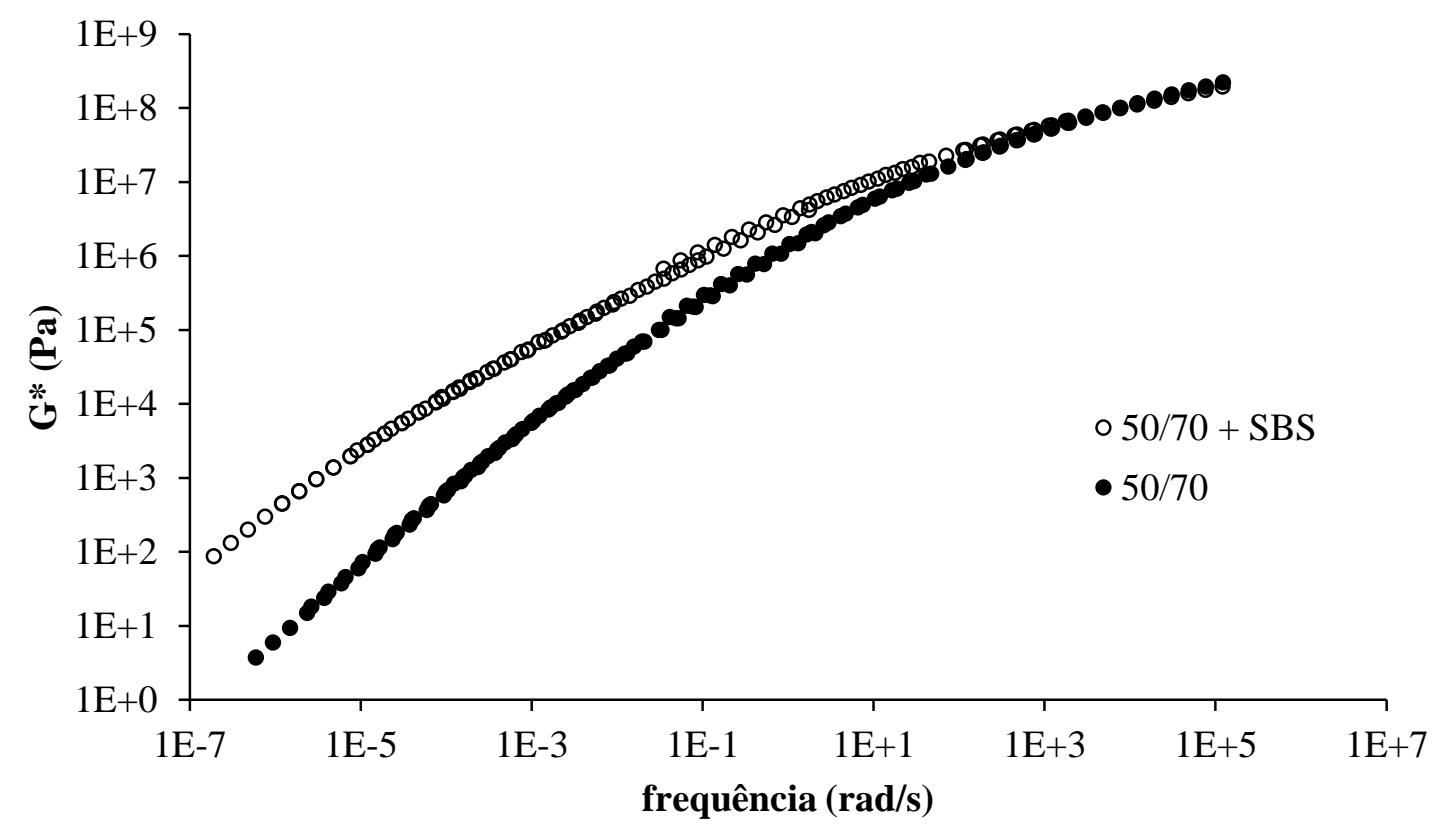

Figura A. 48 - Curva-mestre de $G^{*}$ da mistura 50/70-SBS em relação ao CAP puro: condição UV a $1,00 \mathrm{~W} / \mathrm{m}^{2}$

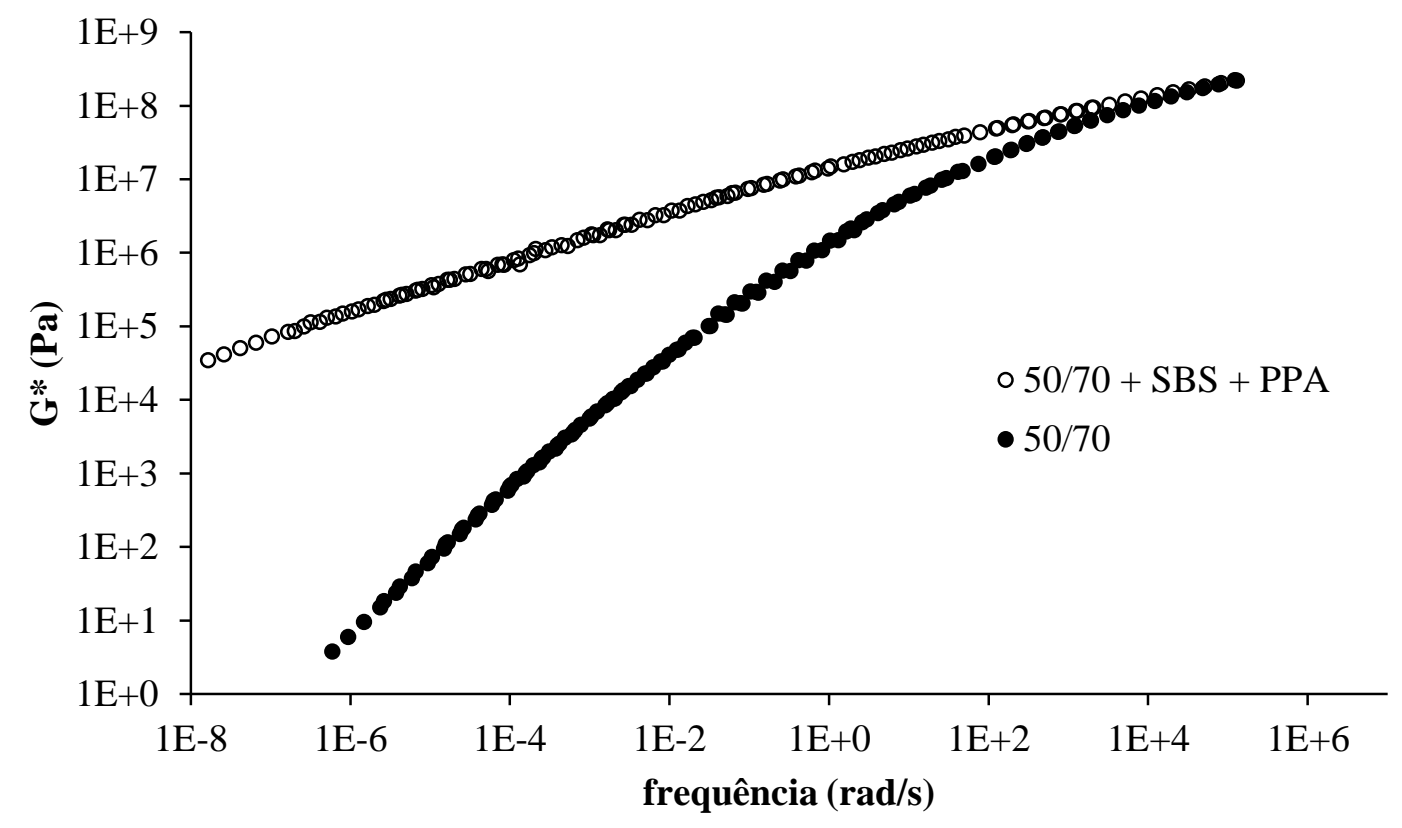

Figura A. 49 - Curva-mestre de G* da mistura 50/70-SBS-PPA em relação ao CAP puro: condição UV a $1,00 \mathrm{~W} / \mathrm{m}^{2}$ 


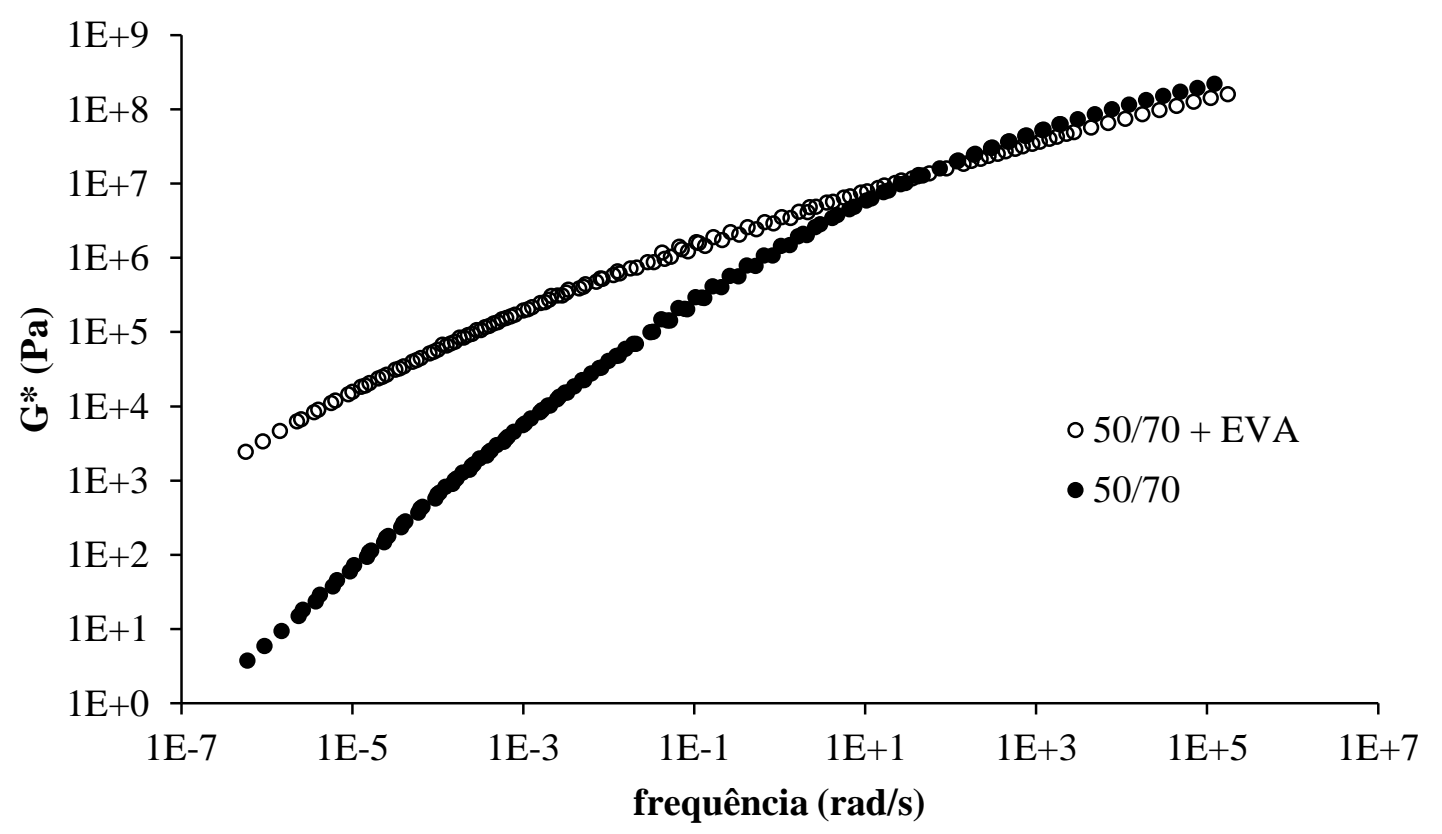

Figura A. 50 - Curva-mestre de $G^{*}$ da mistura 50/70-EVA em relação ao CAP puro: condição UV a $1,00 \mathrm{~W} / \mathrm{m}^{2}$

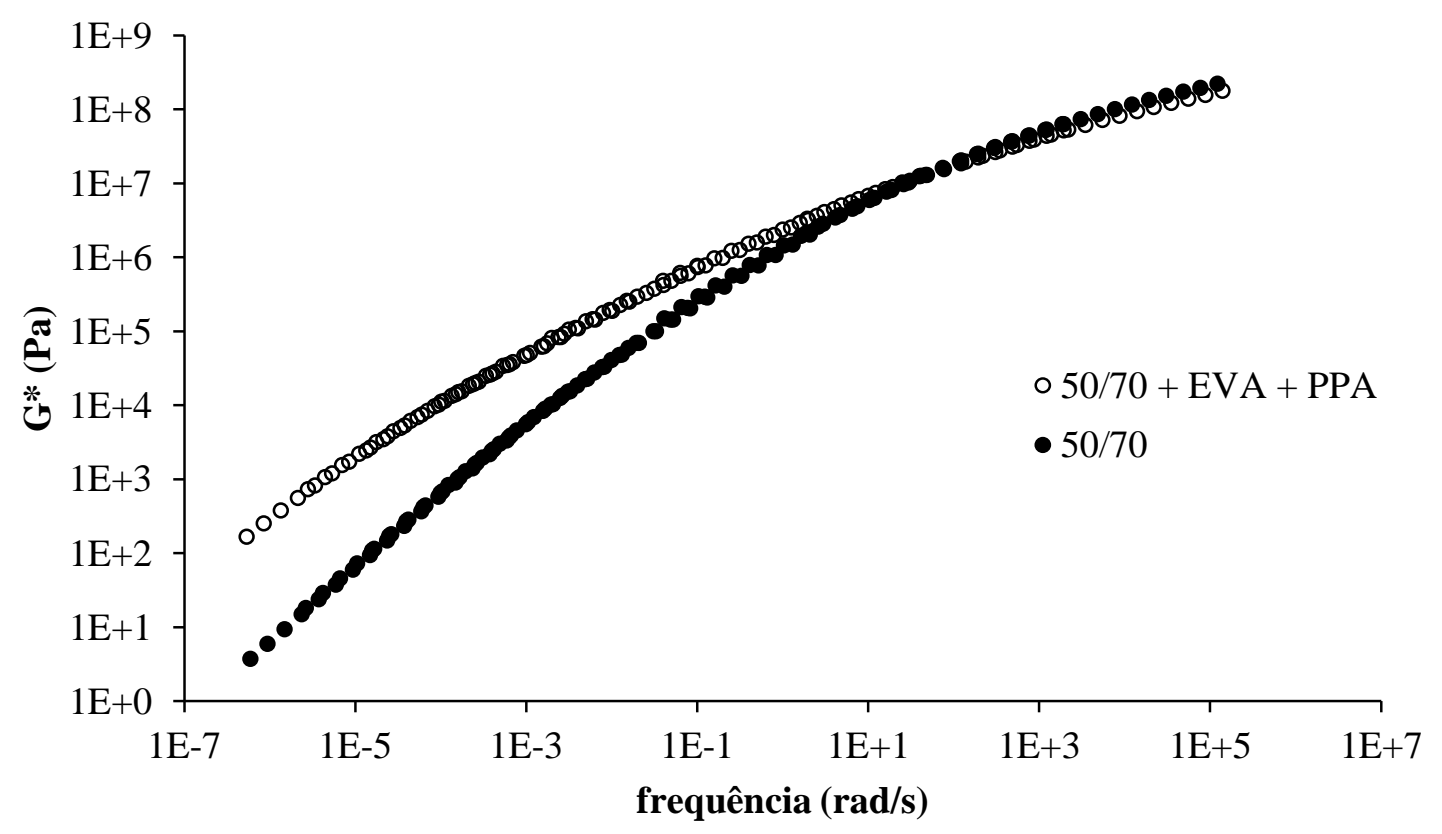

Figura A. 51 - Curva-mestre de G* da mistura 50/70-EVA-PPA em relação ao CAP puro: condição UV a $1,00 \mathrm{~W} / \mathrm{m}^{2}$ 


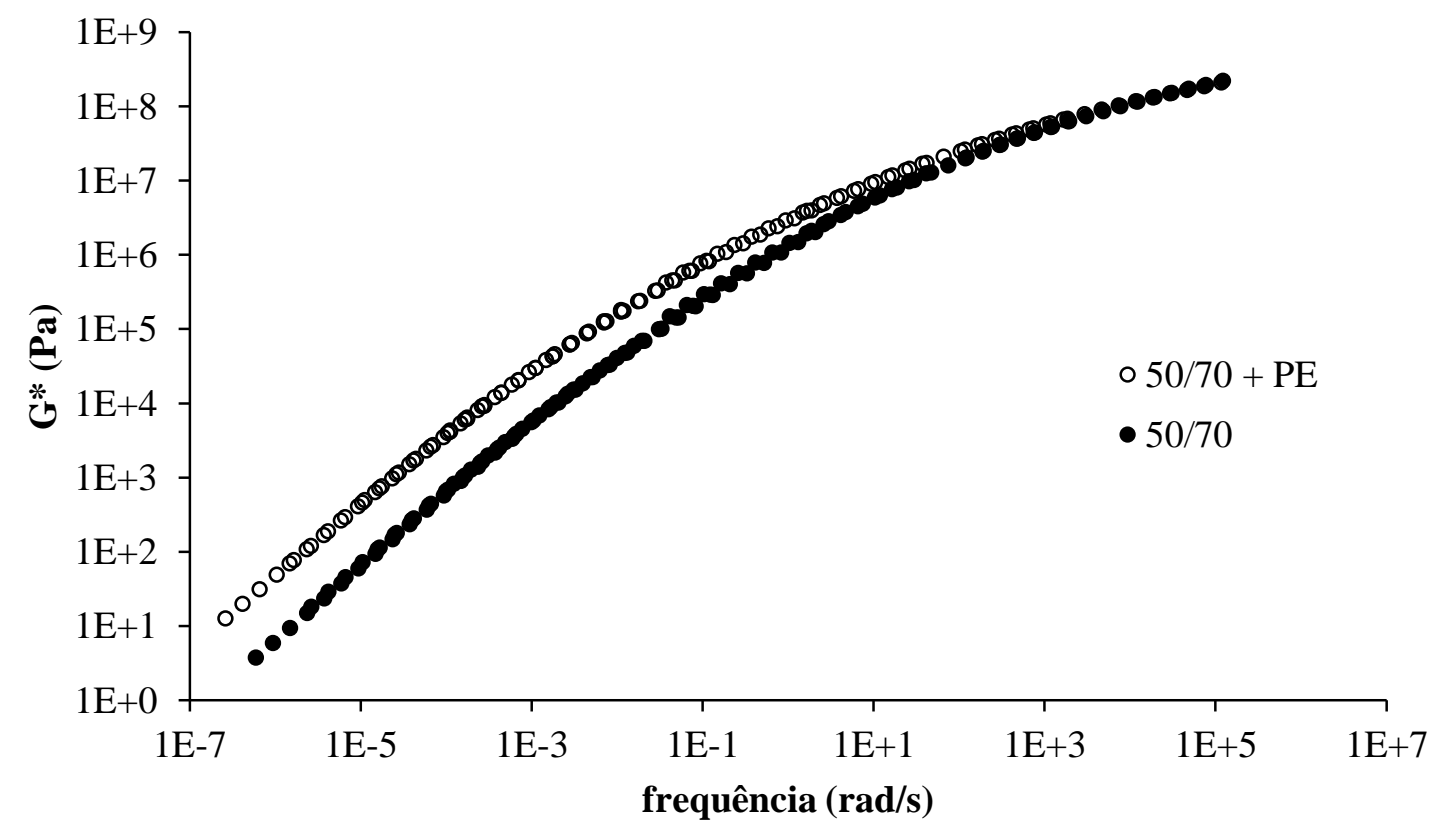

Figura A. 52 - Curva-mestre de $G^{*}$ da mistura 50/70-PE em relação ao CAP puro: condição UV a $1,00 \mathrm{~W} / \mathrm{m}^{2}$

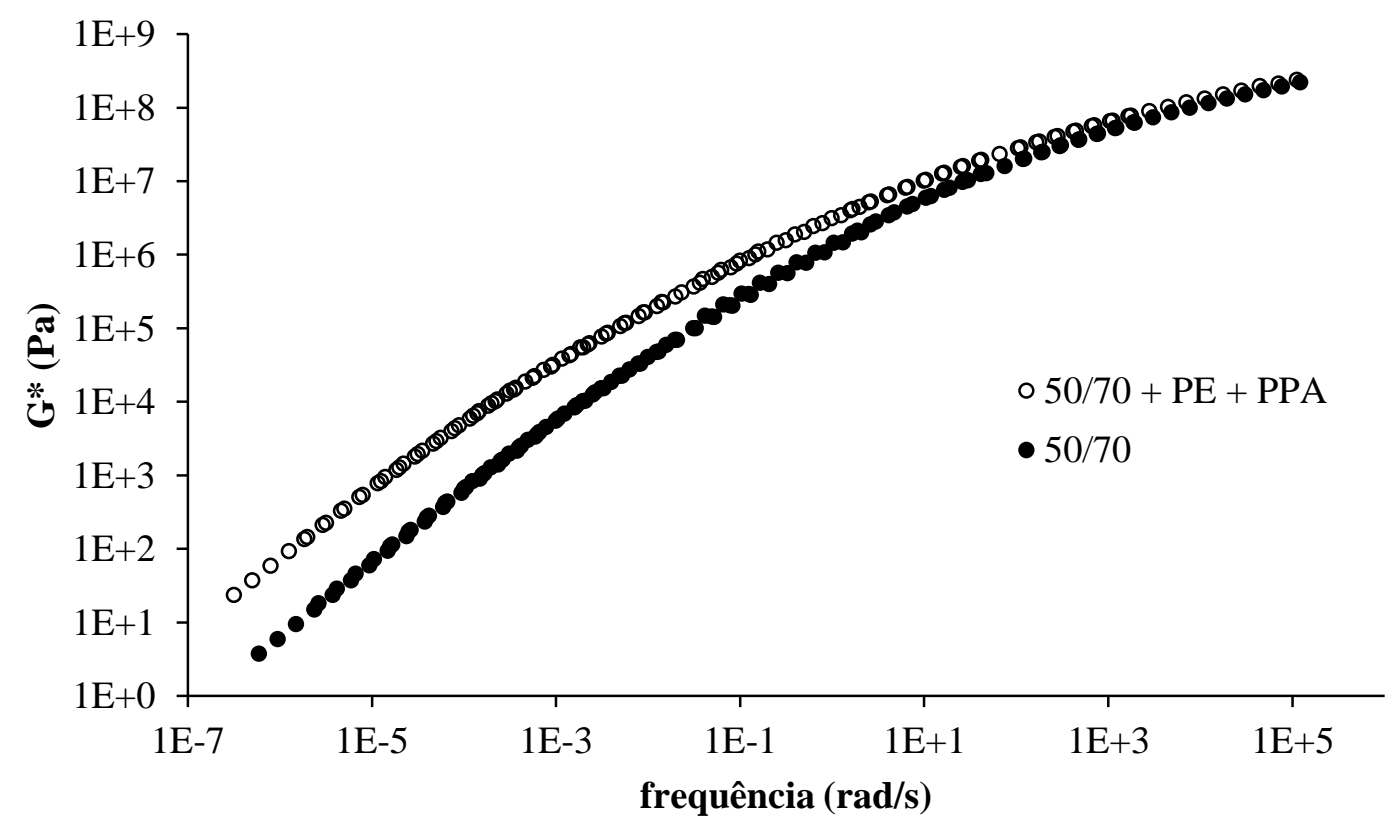

Figura A. 53 - Curva-mestre de G* da mistura 50/70-PE-PPA em relação ao CAP puro: condição UV a $1,00 \mathrm{~W} / \mathrm{m}^{2}$ 


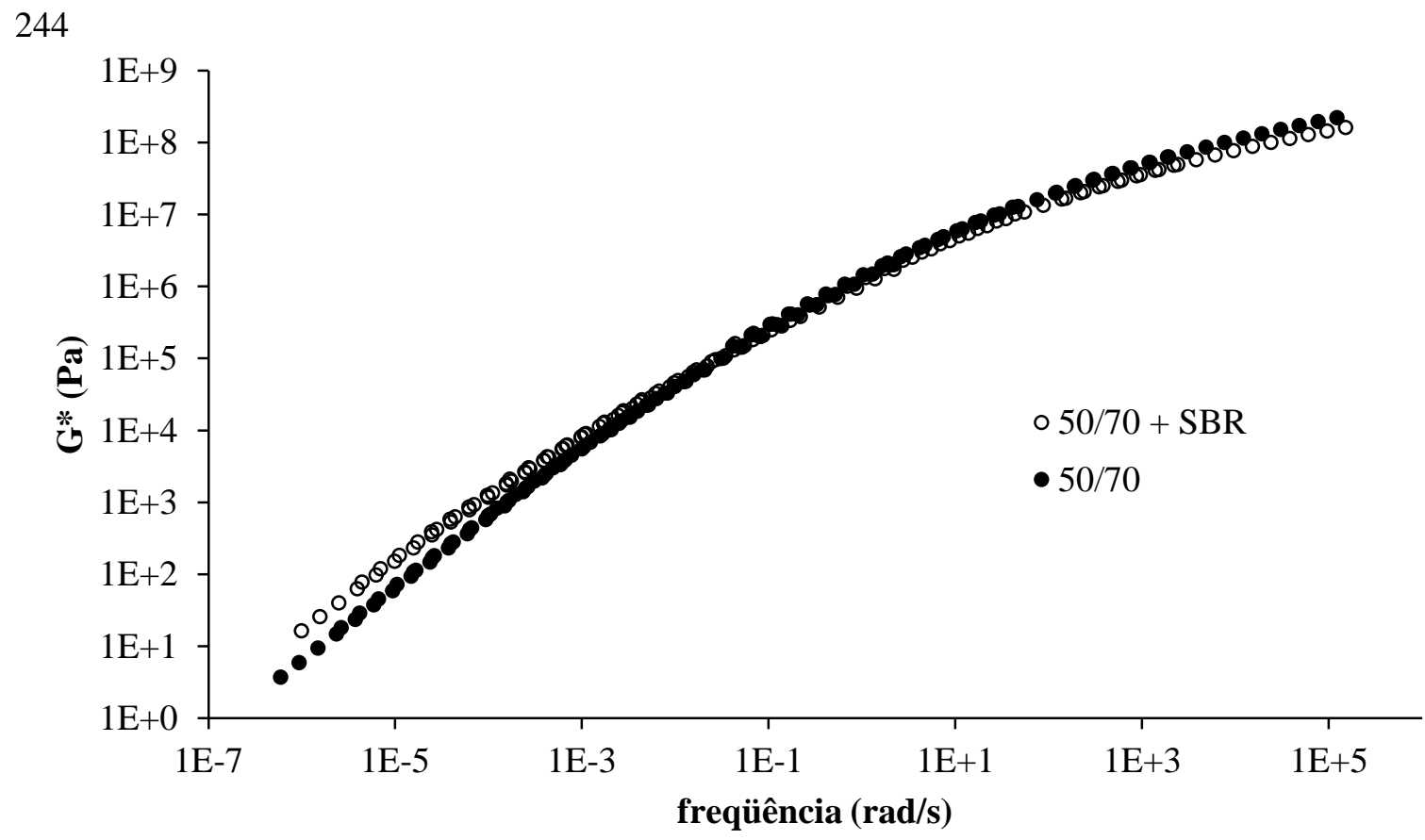

Figura A. 54 - Curva-mestre de $G^{*}$ da mistura 50/70-SBR em relação ao CAP puro: condição UV a $1,00 \mathrm{~W} / \mathrm{m}^{2}$

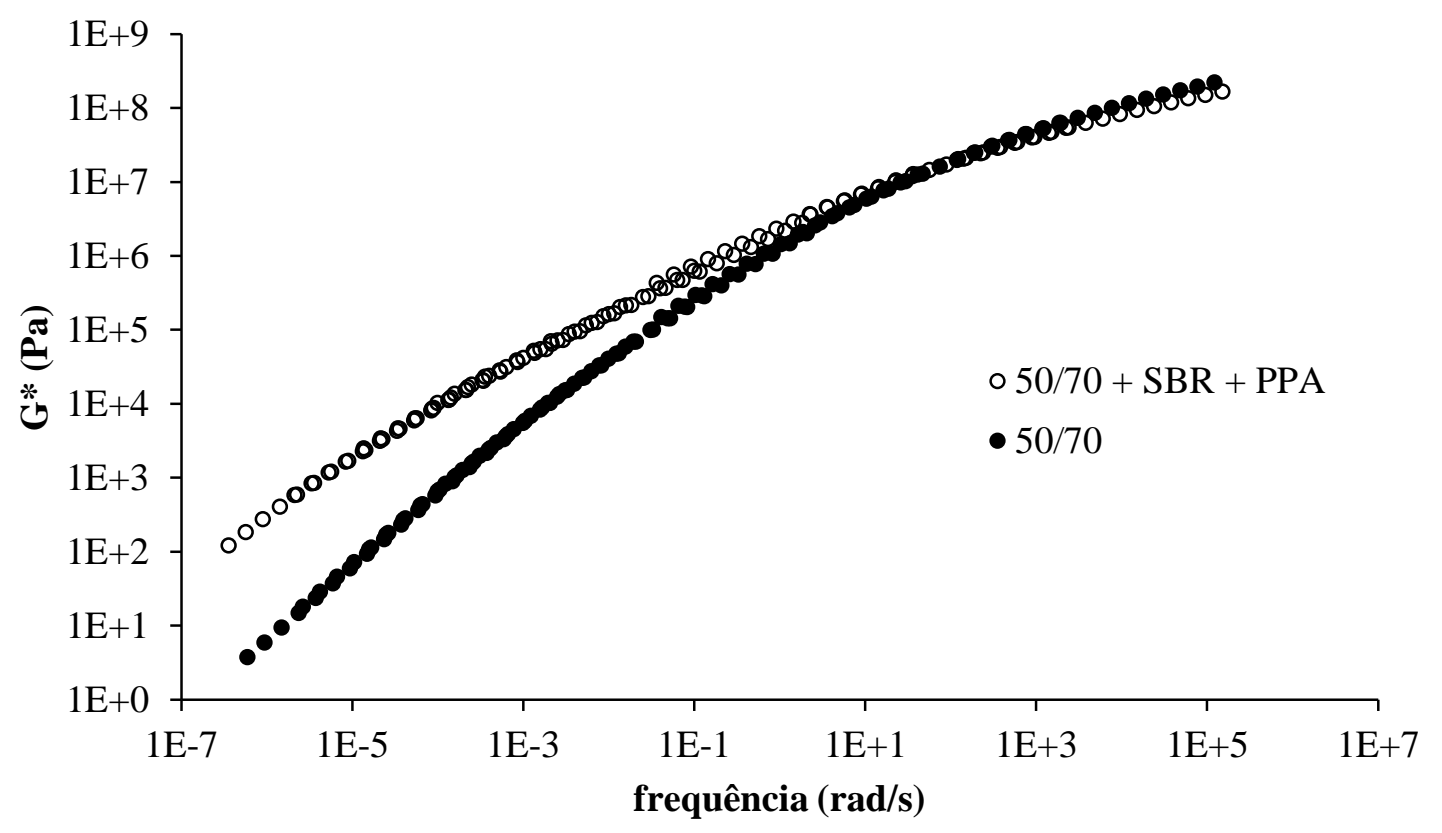

Figura A. 55 - Curva-mestre de G* da mistura 50/70-SBR-PPA em relação ao CAP puro: condição UV a $1,00 \mathrm{~W} / \mathrm{m}^{2}$ 


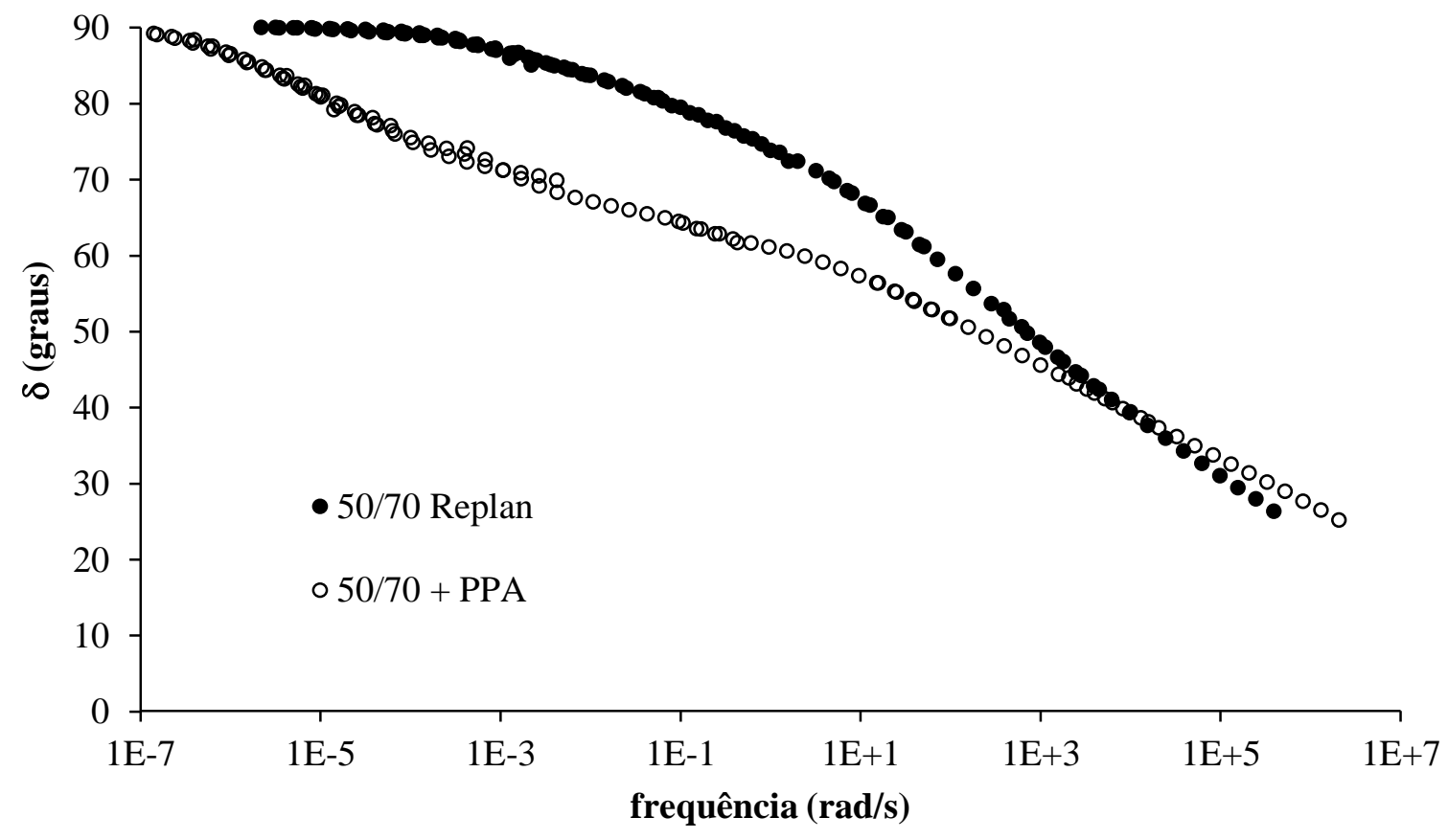

Figura A. 56 - Curva-mestre de $\delta$ do 50/70-PPA em relação ao CAP puro: condição virgem

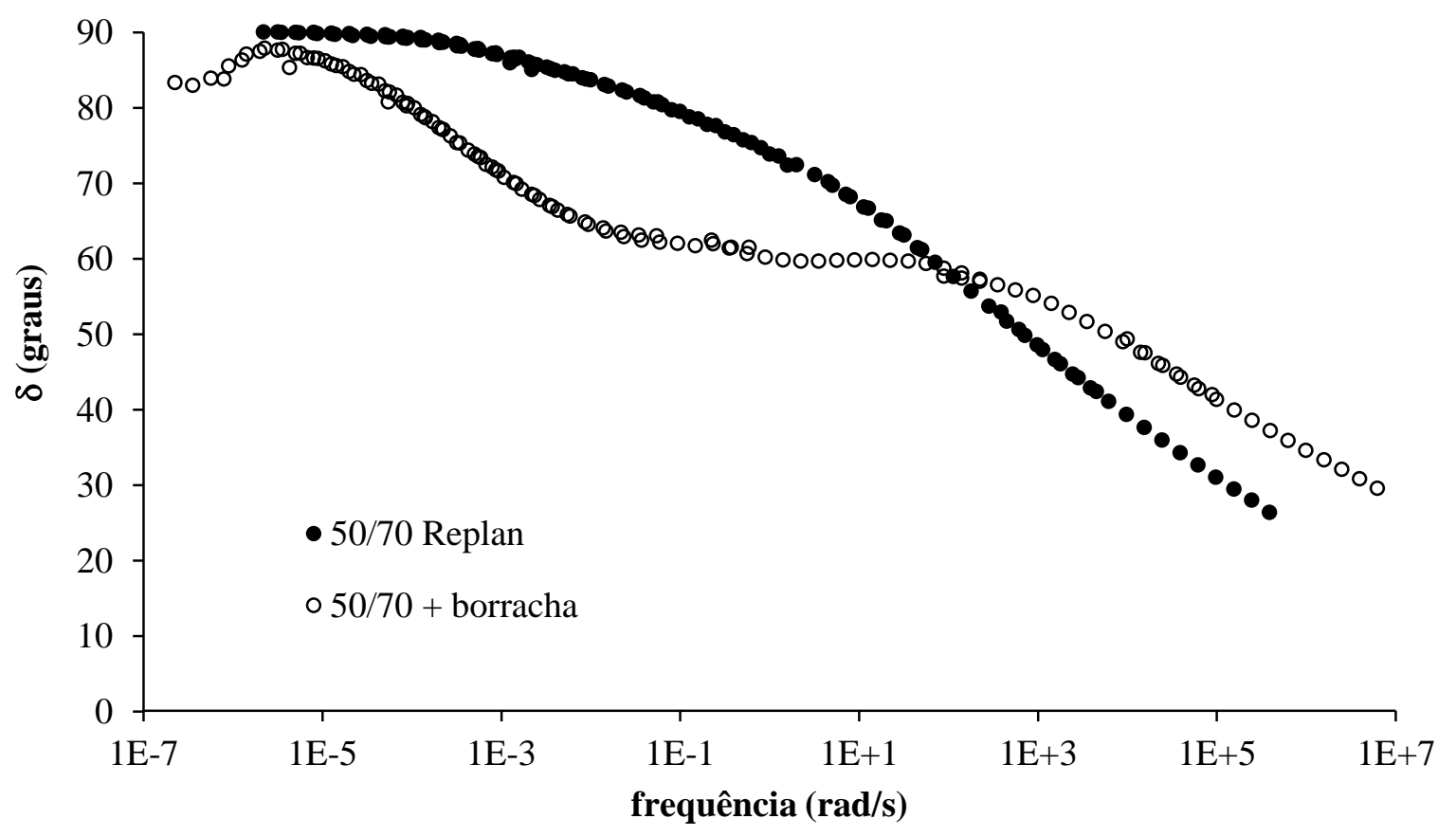

Figura A. 57 - Curva-mestre de $\delta$ da mistura 50/70-borracha em relação ao CAP puro: condição virgem 


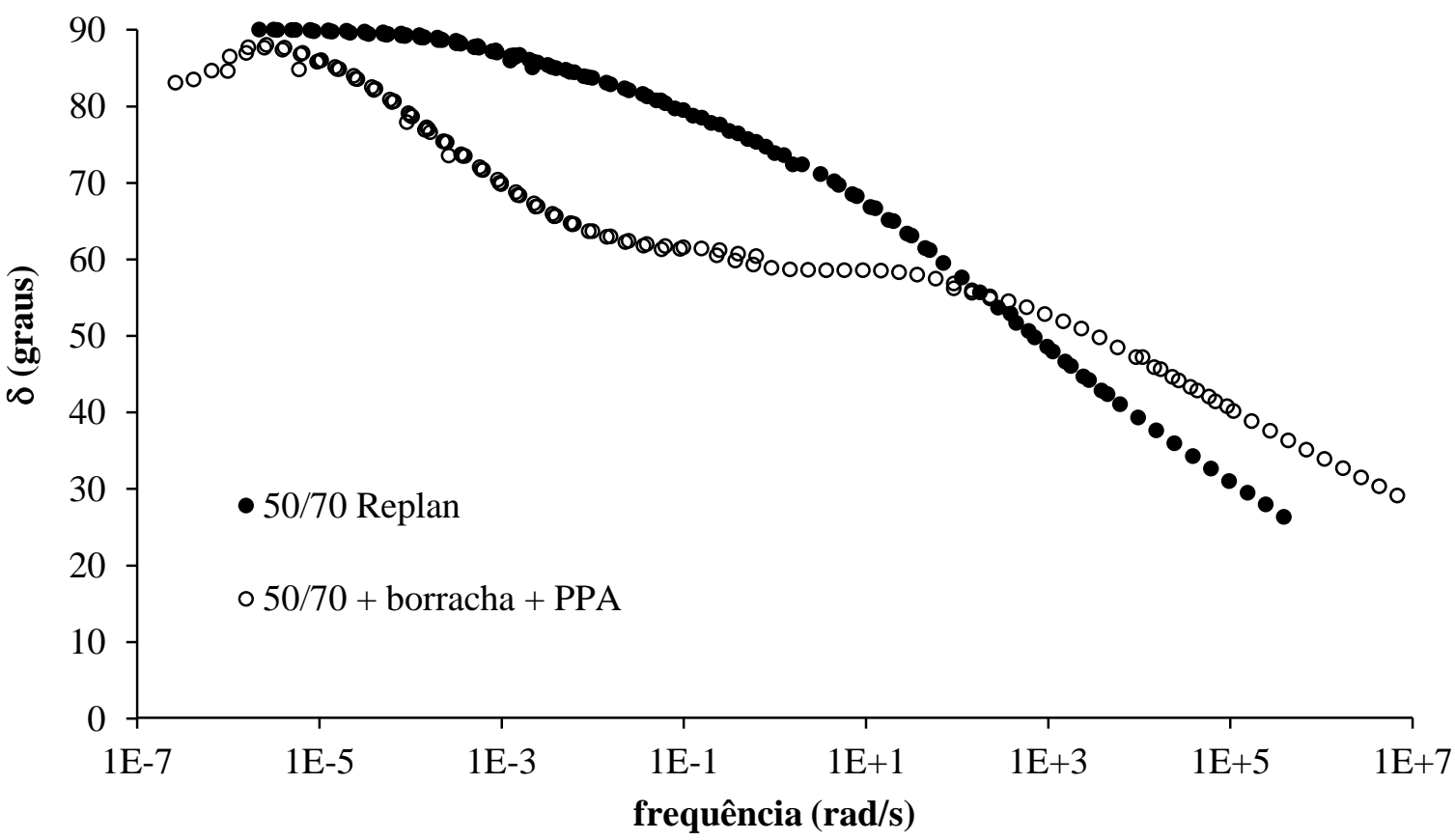

Figura A. 58 - Curva-mestre de $\delta$ da mistura 50/70-borracha-PPA em relação ao CAP puro: condição virgem

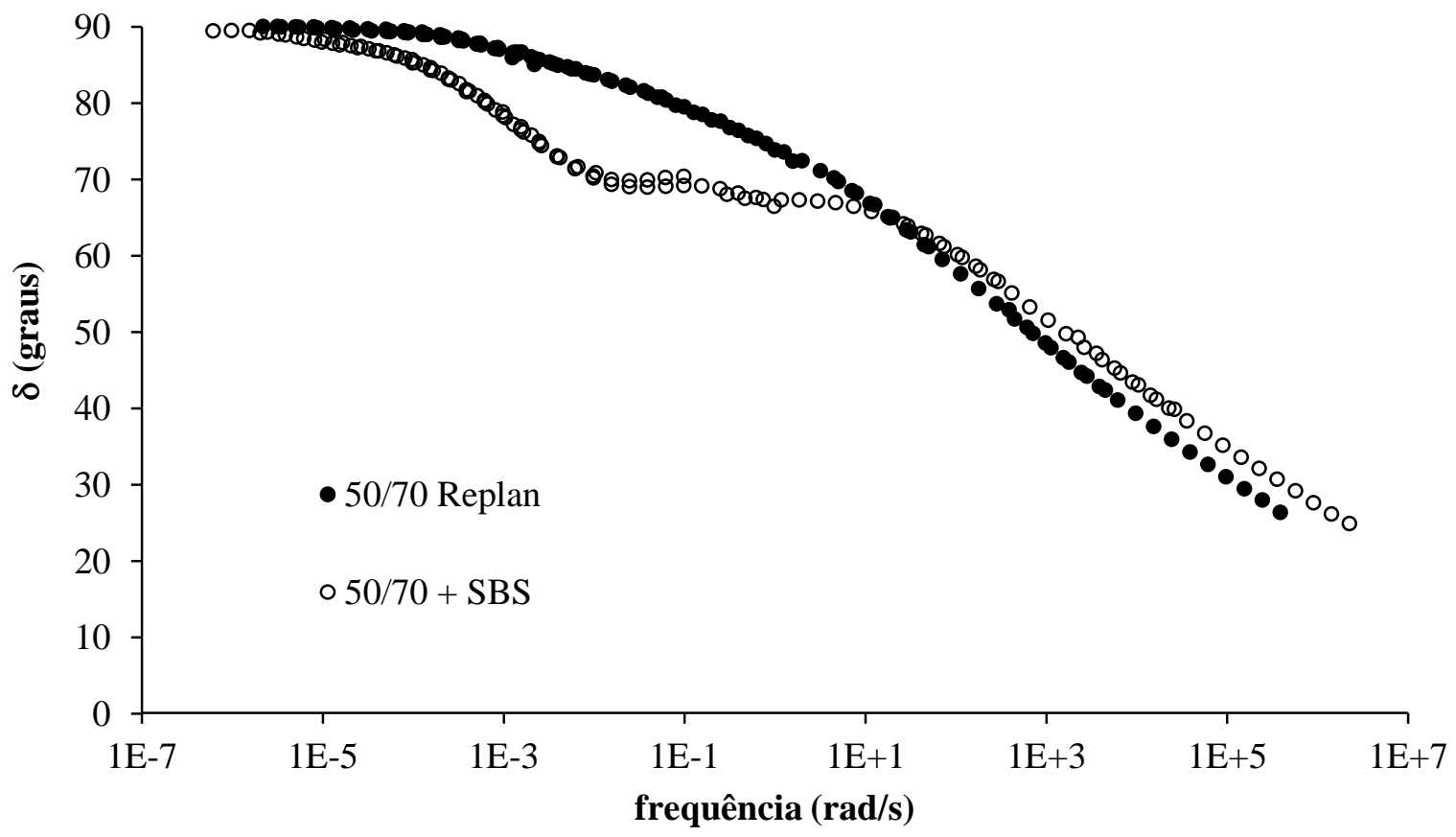

Figura A. 59 - Curva-mestre de $\delta$ da mistura 50/70-SBS em relação ao CAP puro: condição virgem 


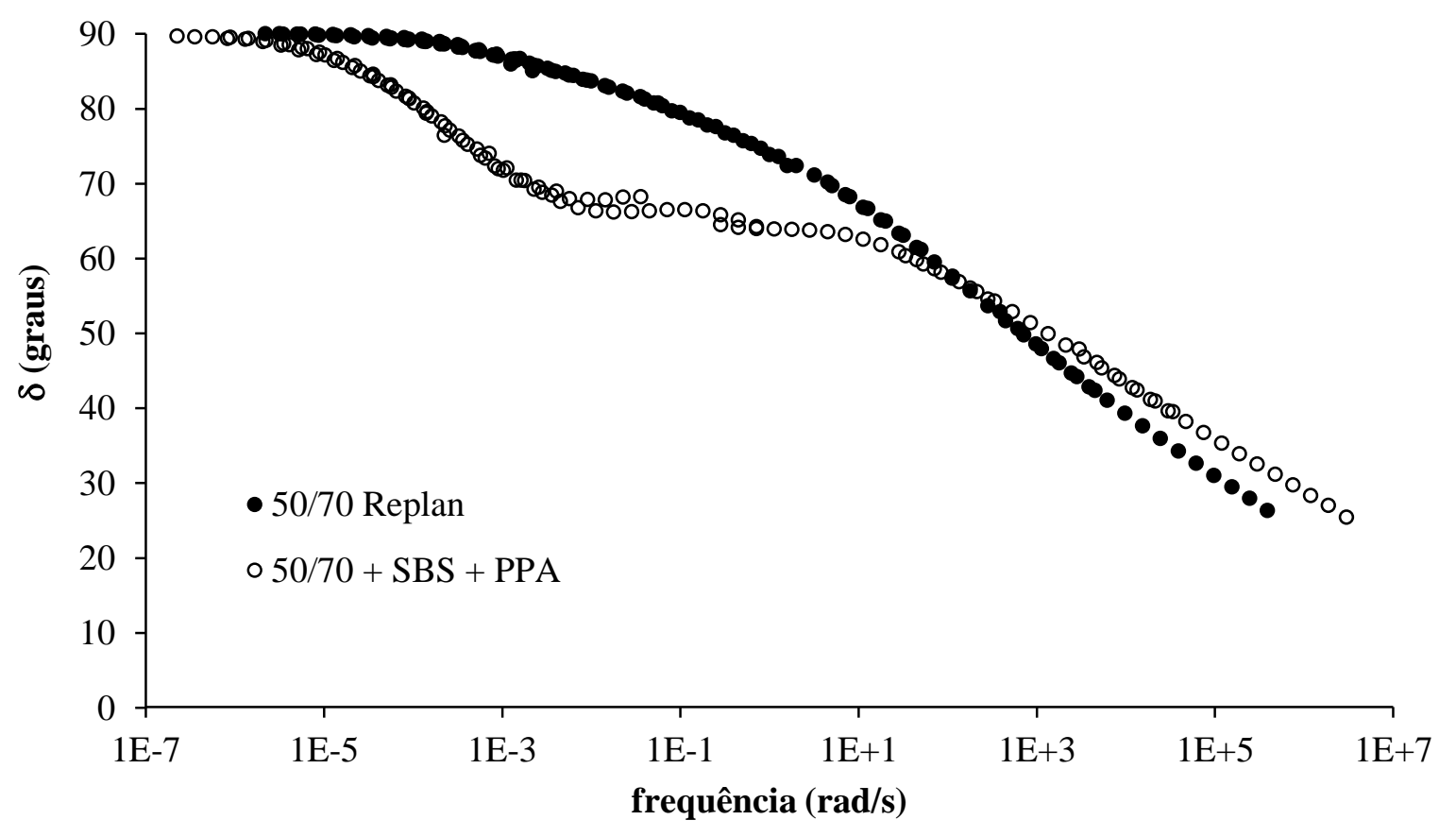

Figura A. 60 - Curva-mestre de $\delta$ da mistura 50/70-SBS-PPA em relação ao CAP puro: condição virgem

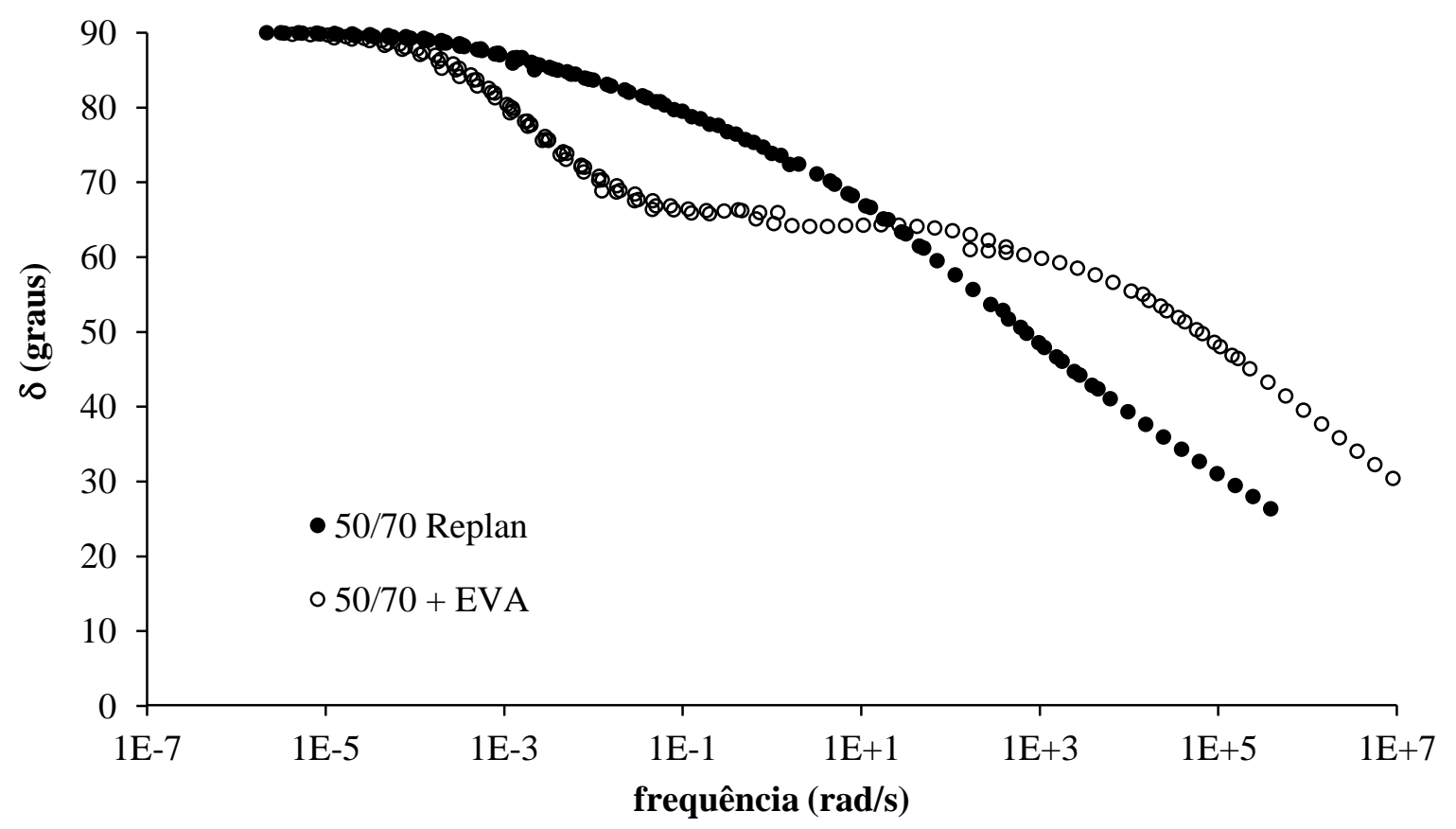

Figura A. 61 - Curva-mestre de $\delta$ da mistura 50/70-EVA em relação ao CAP puro: condição virgem 


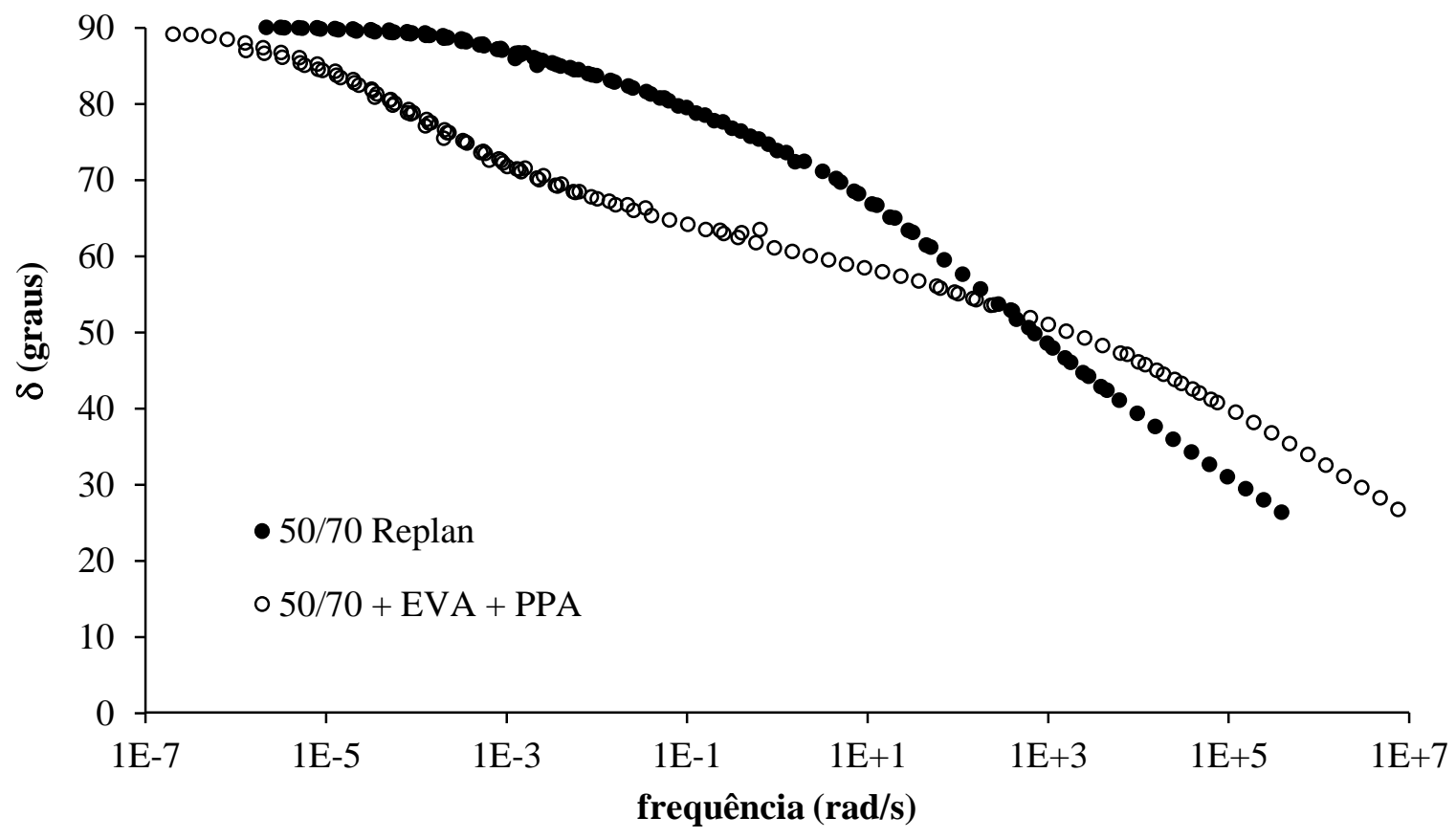

Figura A. 62 - Curva-mestre de $\delta$ da mistura 50/70-EVA-PPA em relação ao CAP puro: condição virgem

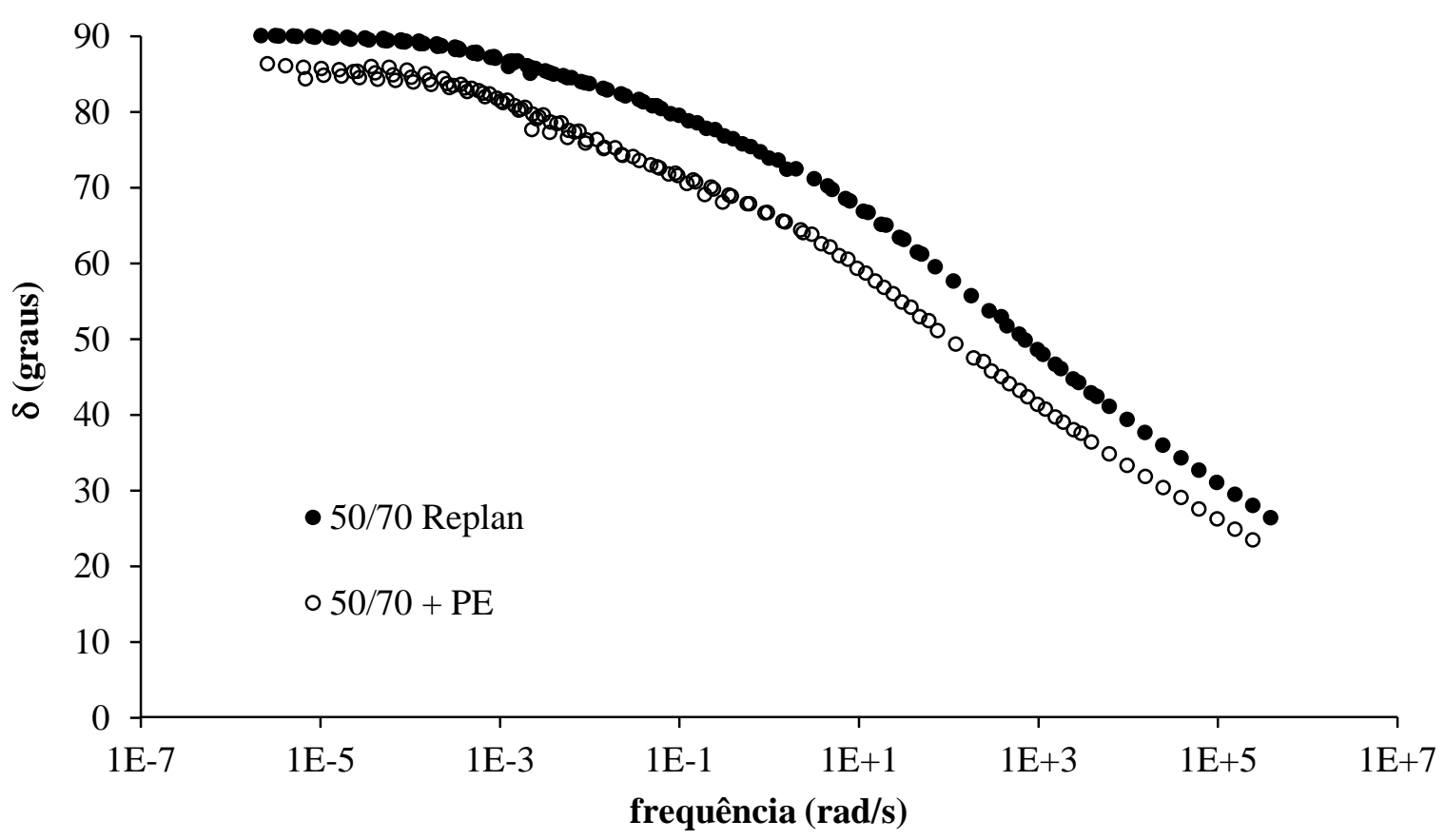

Figura A. 63 - Curva-mestre de $\delta$ da mistura 50/70-PE em relação ao CAP puro: condição virgem 


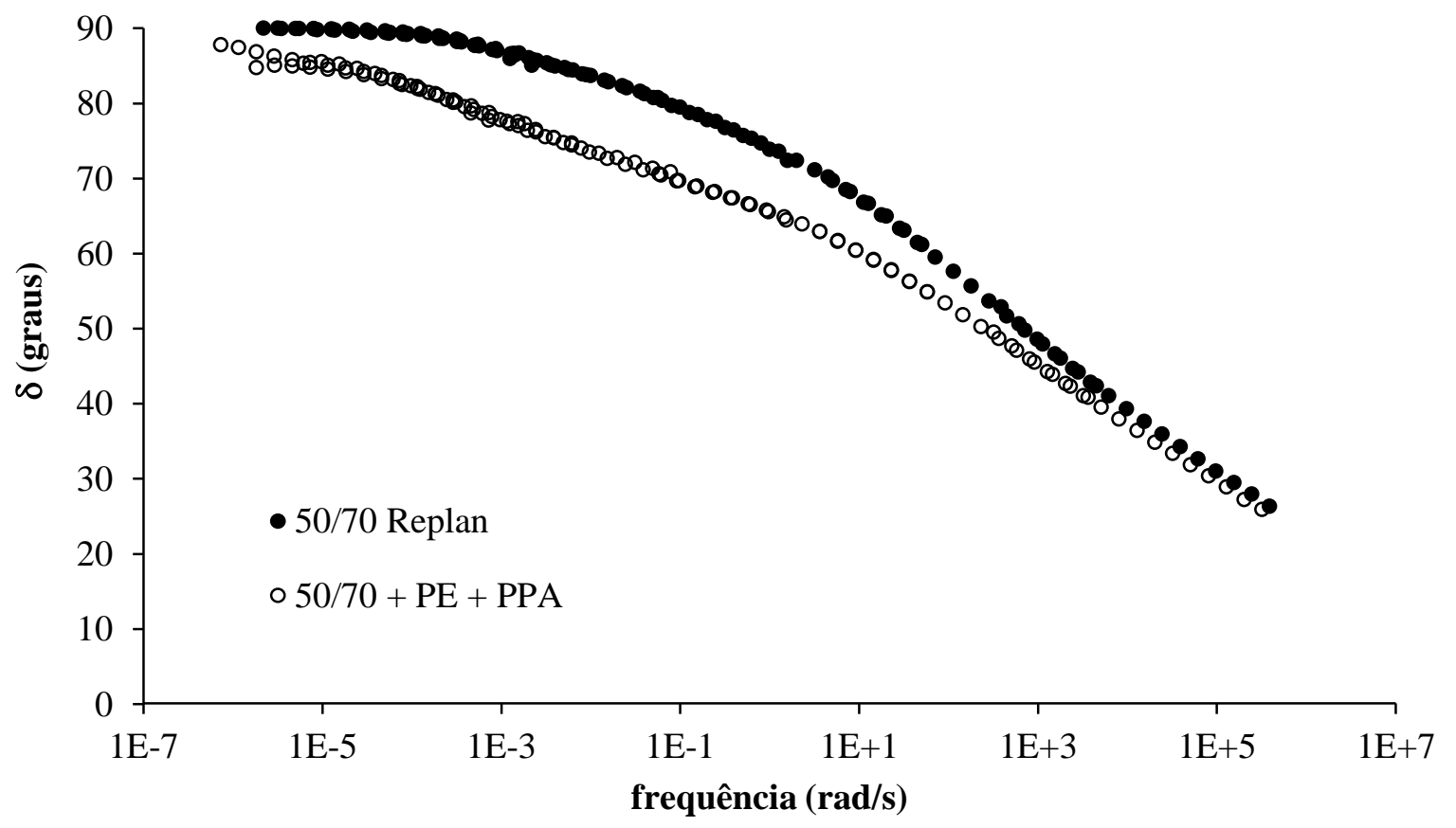

Figura A. 64 - Curva-mestre de $\delta$ da mistura 50/70-PE-PPA em relação ao CAP puro: condição virgem

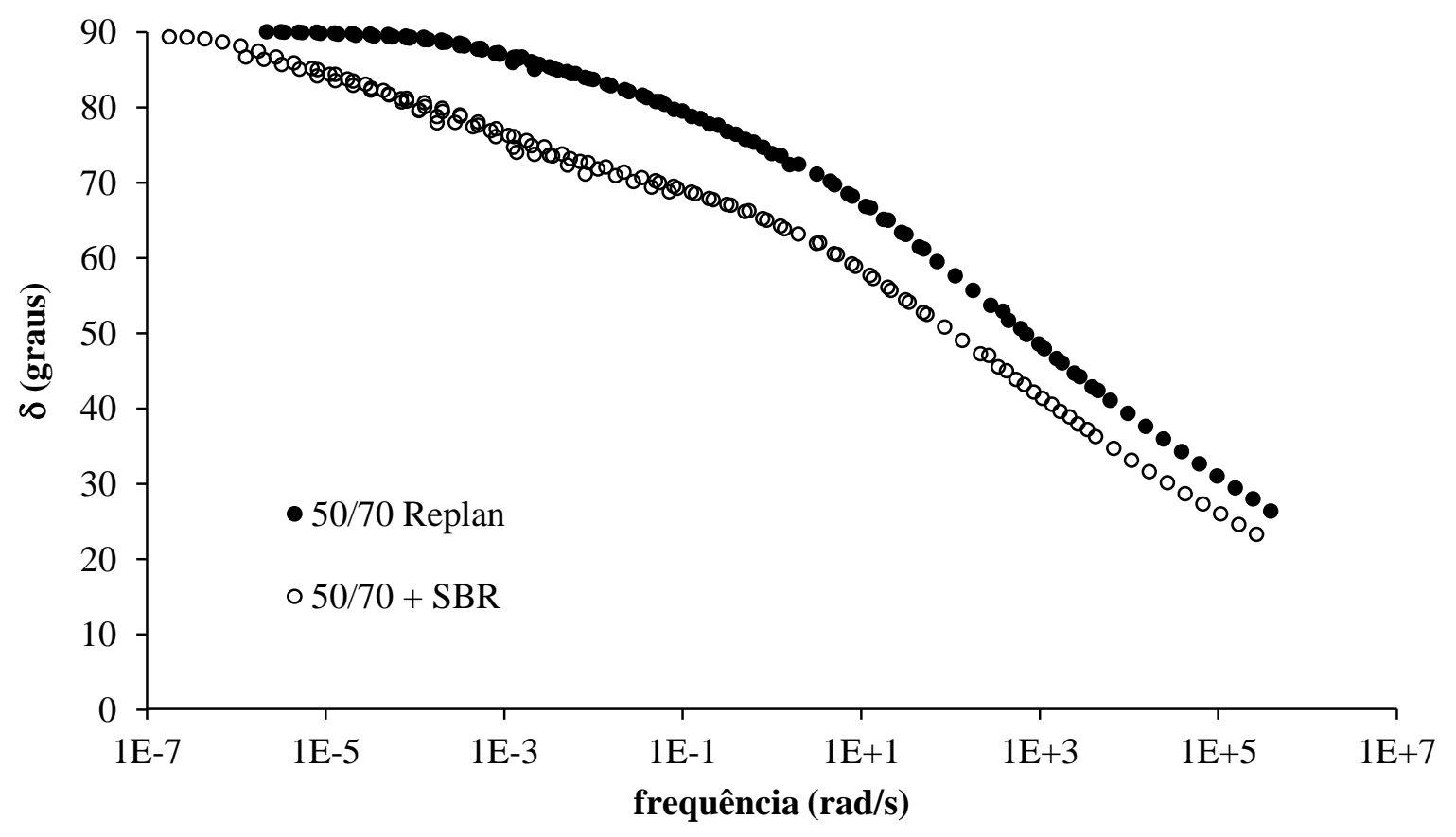

Figura A. 65 - Curva-mestre de $\delta$ da mistura 50/70-SBR em relação ao CAP puro: condição virgem 


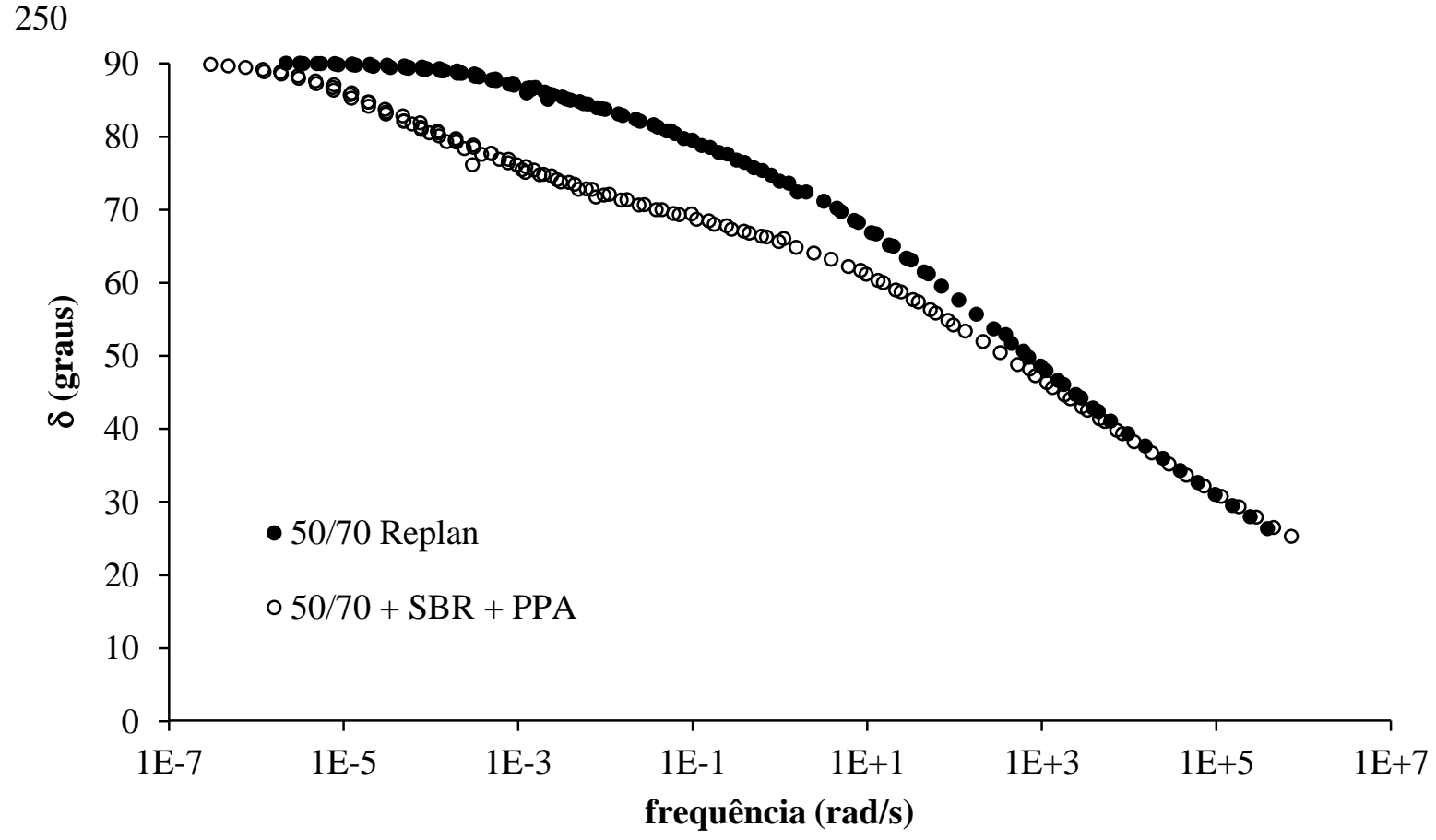

Figura A. 66 - Curva-mestre de $\delta$ da mistura 50/70-SBR-PPA em relação ao CAP puro: condição virgem

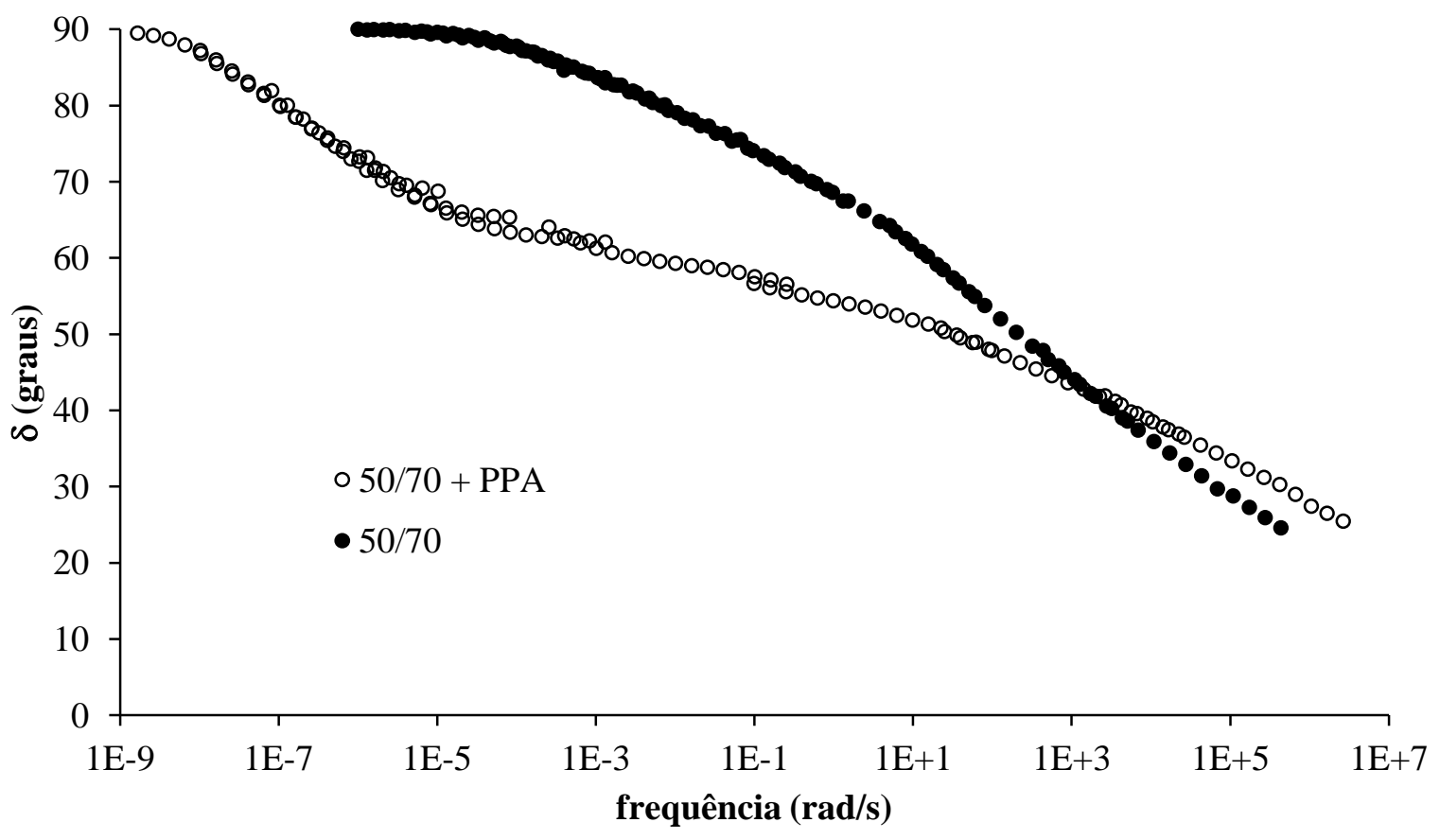

Figura A. 67 - Curva-mestre de $\delta$ da mistura 50/70-PPA em relação ao CAP puro: condição RTFOT 


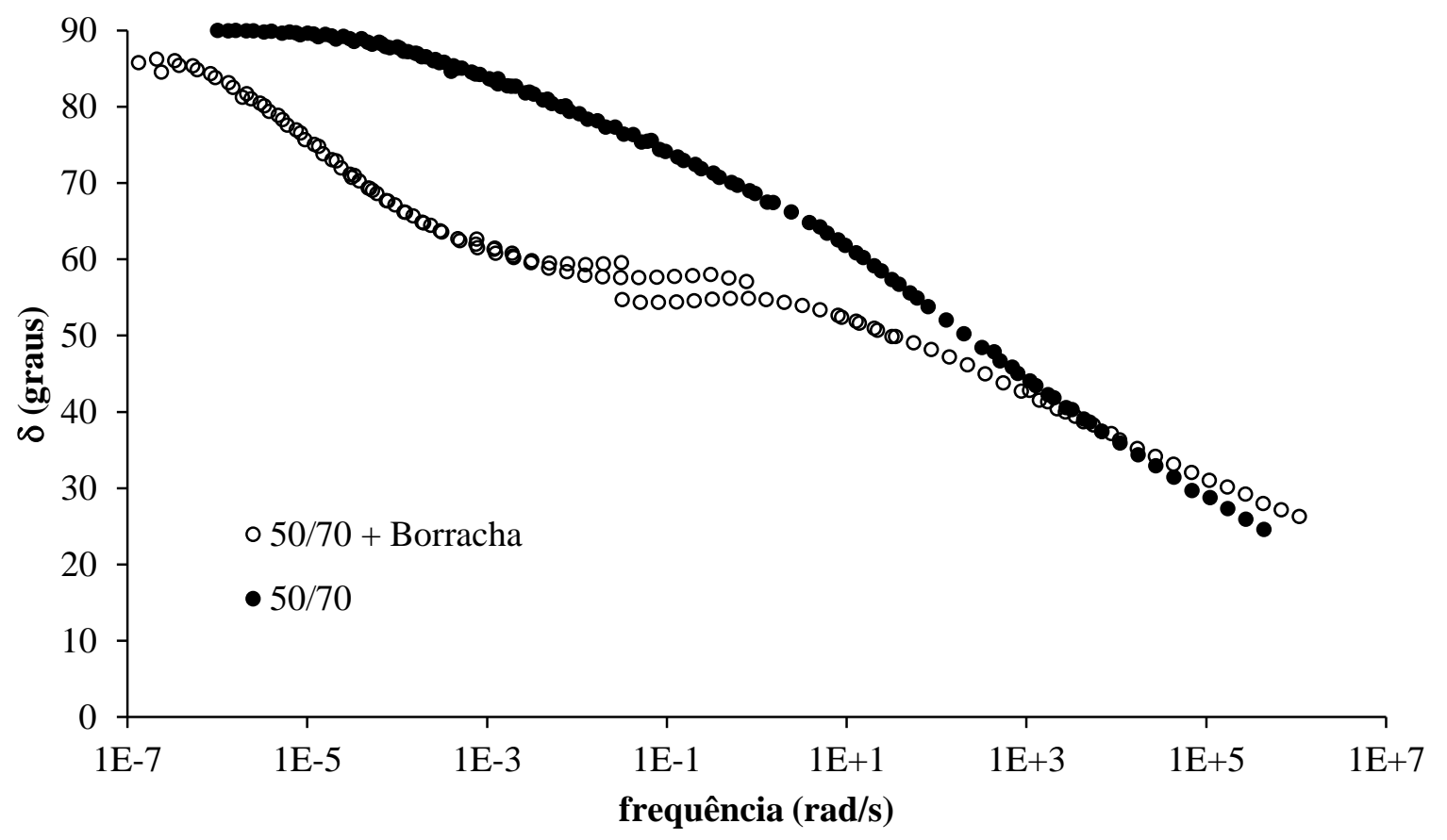

Figura A. 68 - Curva-mestre de $\delta$ da mistura 50/70-borracha em relação ao CAP puro: condição RTFOT

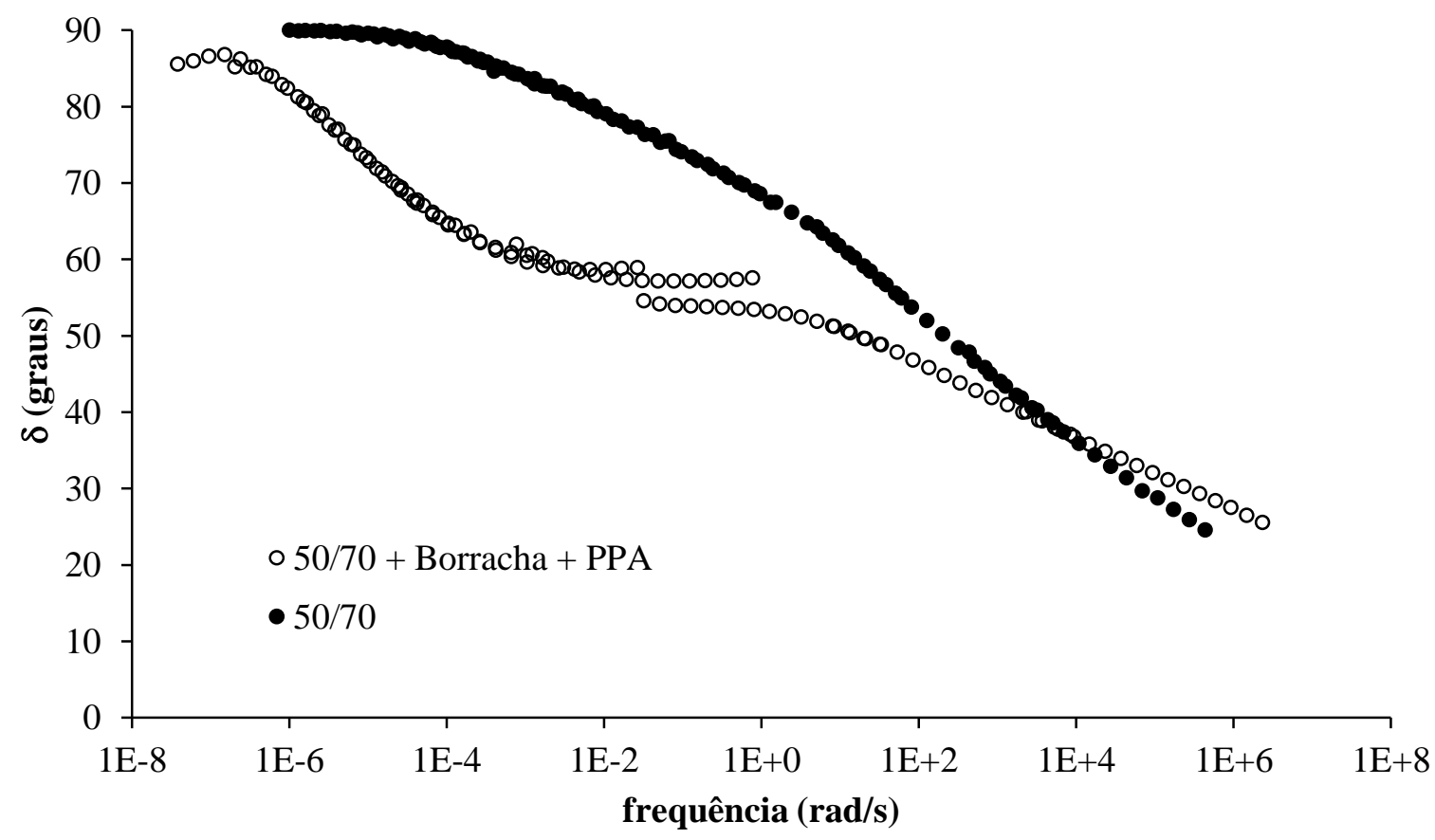

Figura A. 69 - Curva-mestre de $\delta$ da mistura 50/70-borracha-PPA em relação ao CAP puro: condição RTFOT 


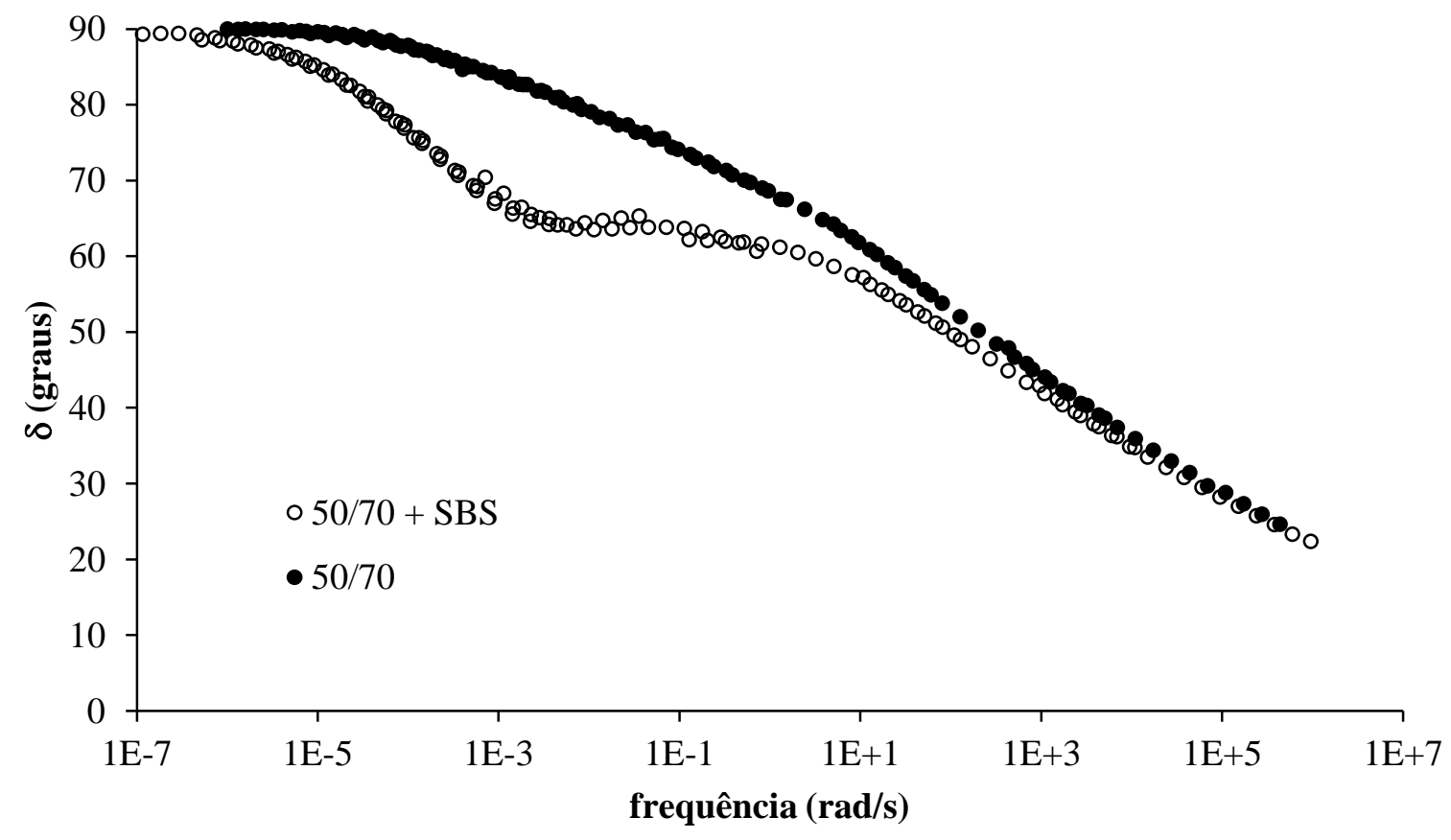

Figura A. 70 - Curva-mestre de $\delta$ da mistura 50/70-SBS em relação ao CAP puro: condição RTFOT

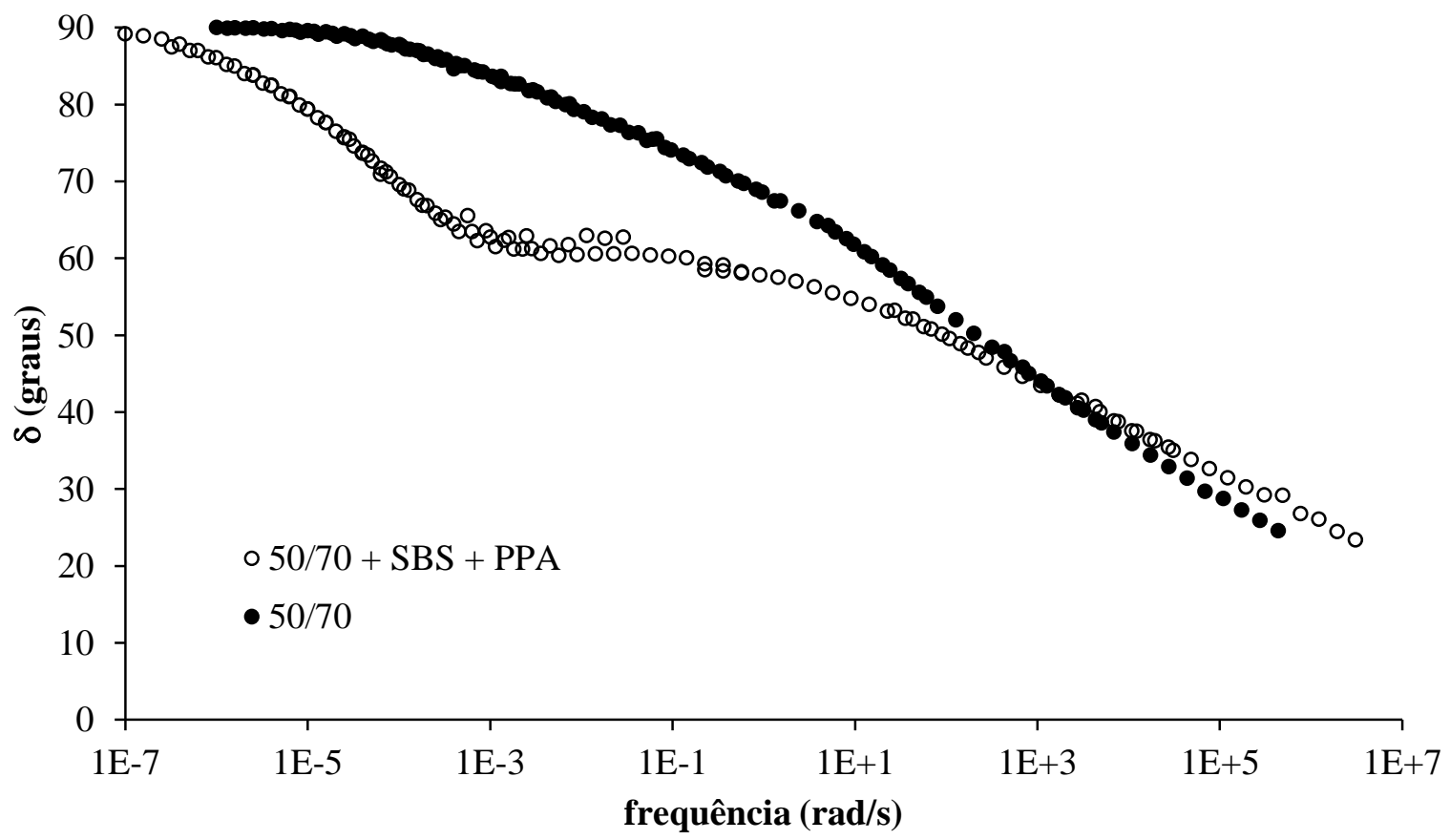

Figura A. 71 - Curva-mestre de $\delta$ da mistura 50/70-SBS-PPA em relação ao CAP puro: condição RTFOT 


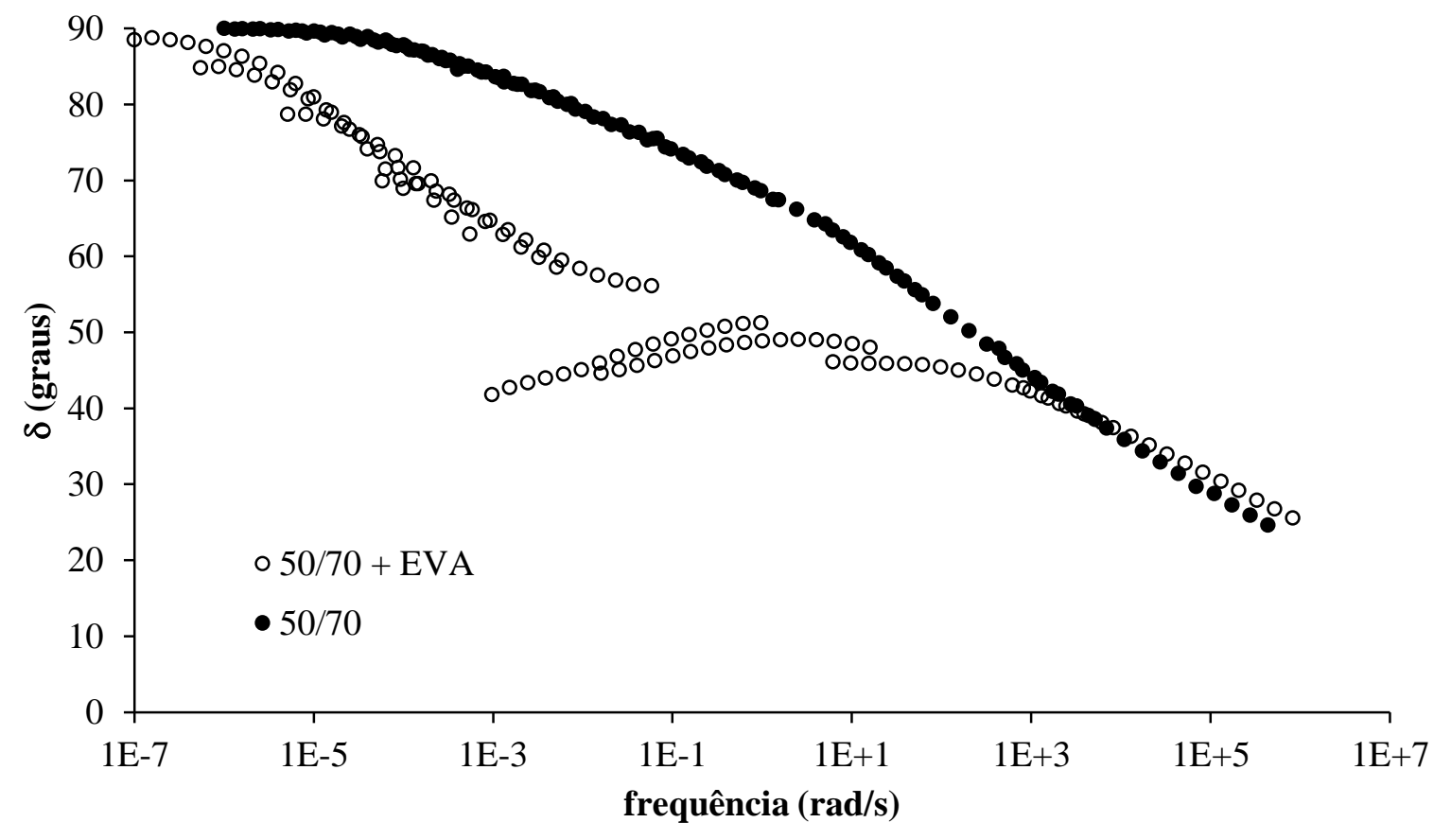

Figura A. 72 - Curva-mestre de $\delta$ da mistura 50/70-EVA em relação ao CAP puro: condição RTFOT

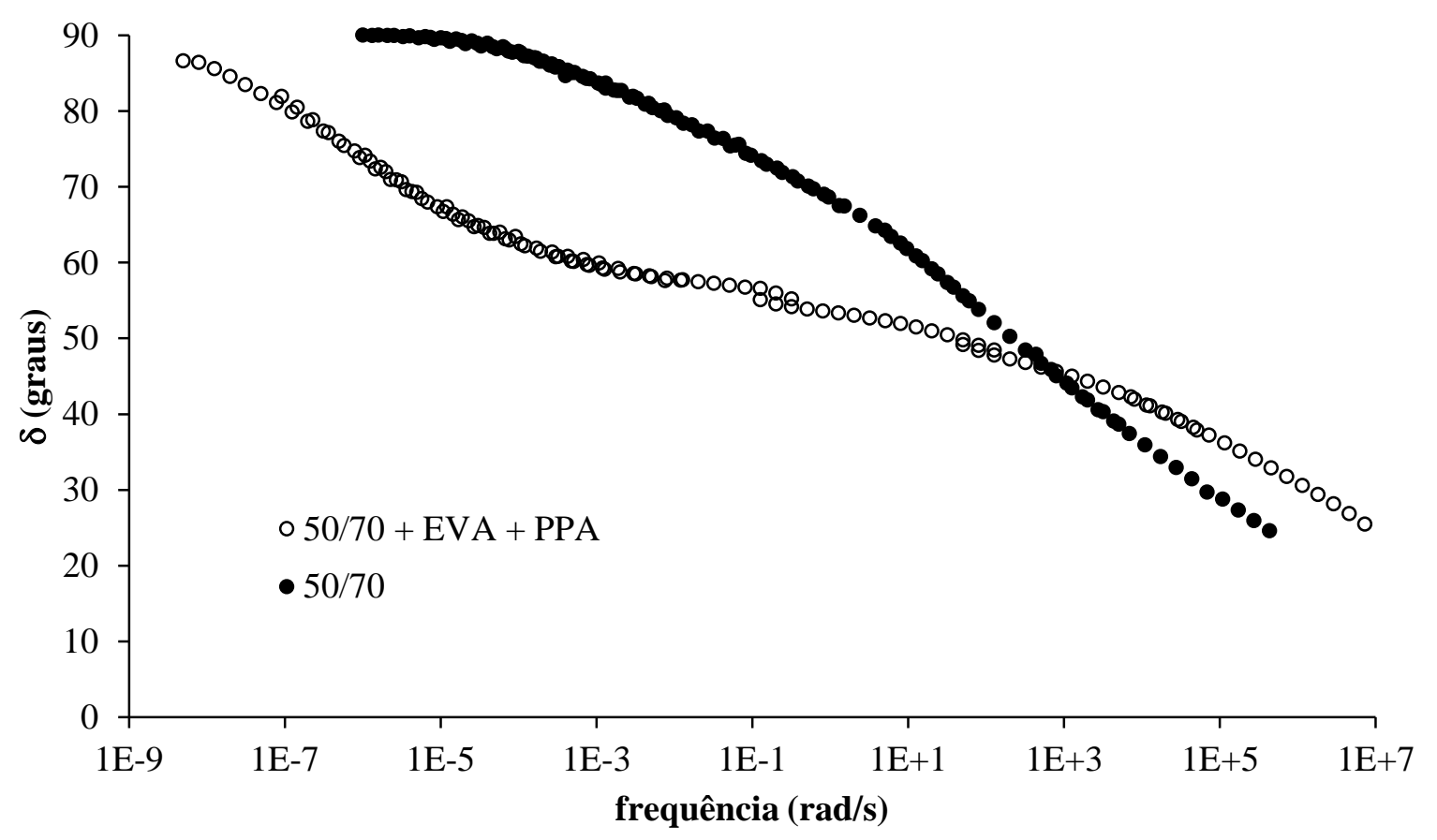

Figura A. 73 - Curva-mestre de $\delta$ da mistura 50/70-EVA-PPA em relação ao CAP puro: condição RTFOT 


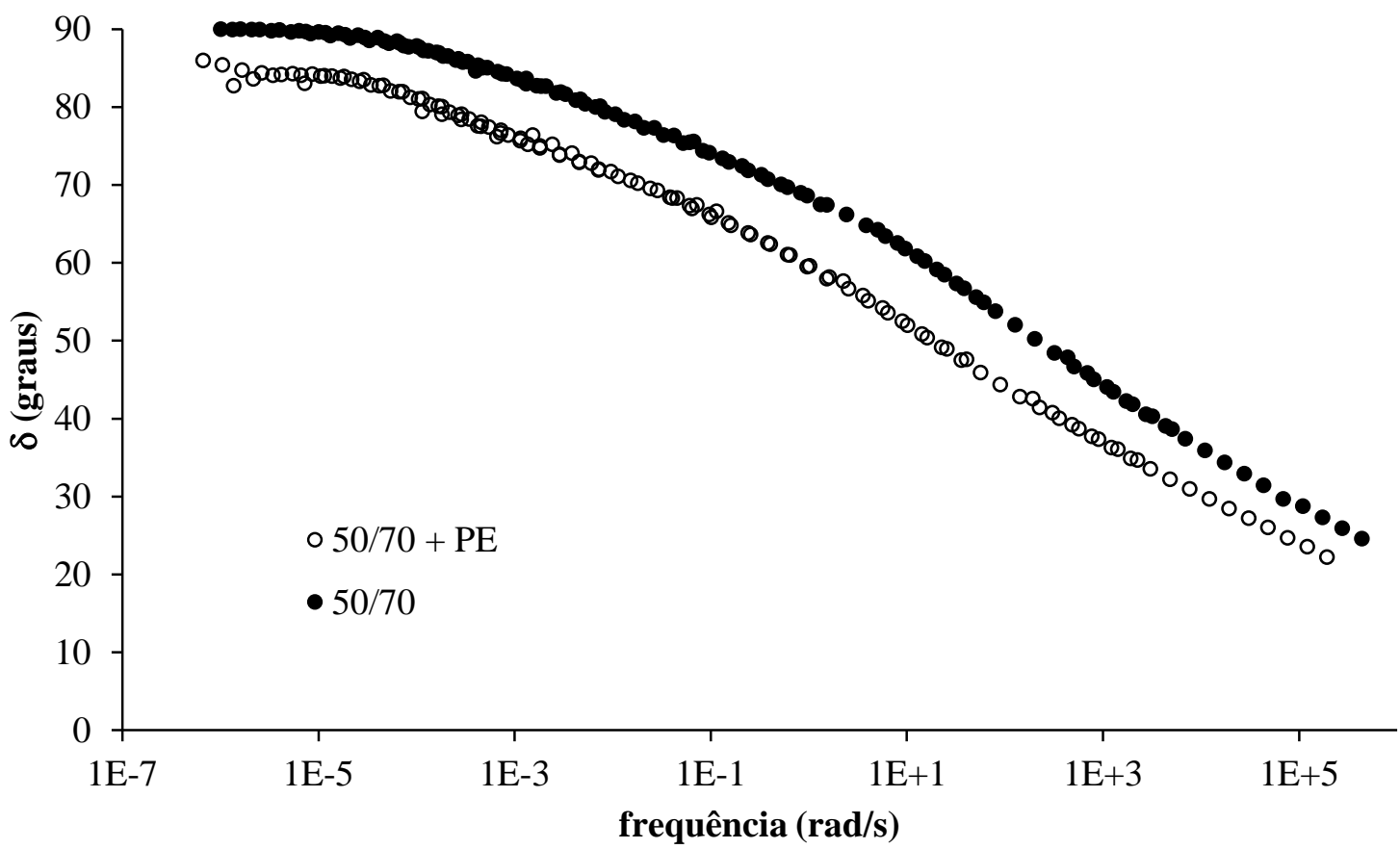

Figura A. 74 - Curva-mestre de $\delta$ da mistura 50/70-PE em relação ao CAP puro: condição RTFOT

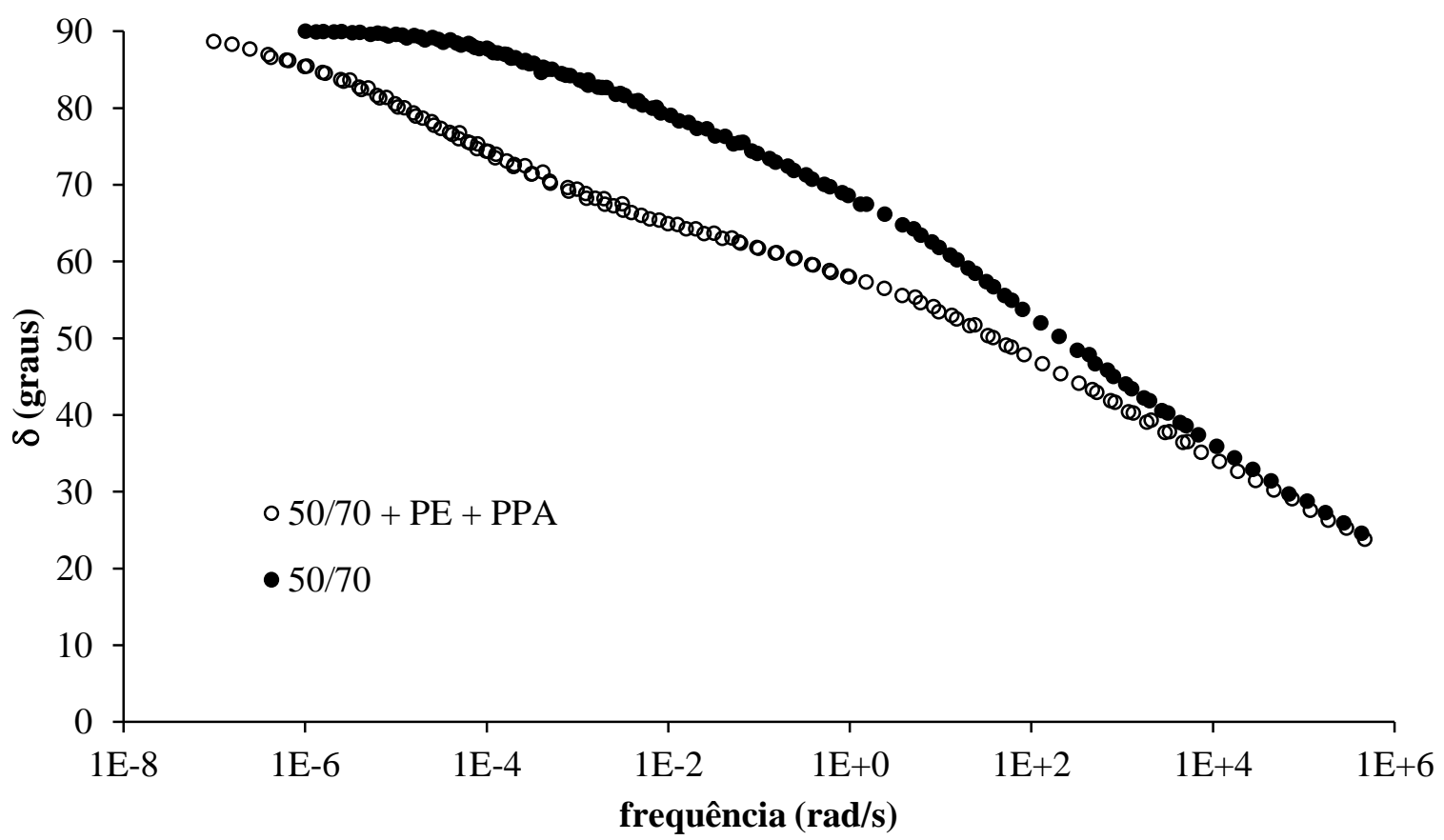

Figura A. 75 - Curva-mestre de $\delta$ da mistura 50/70-PE-PPA em relação ao CAP puro: condição RTFOT 


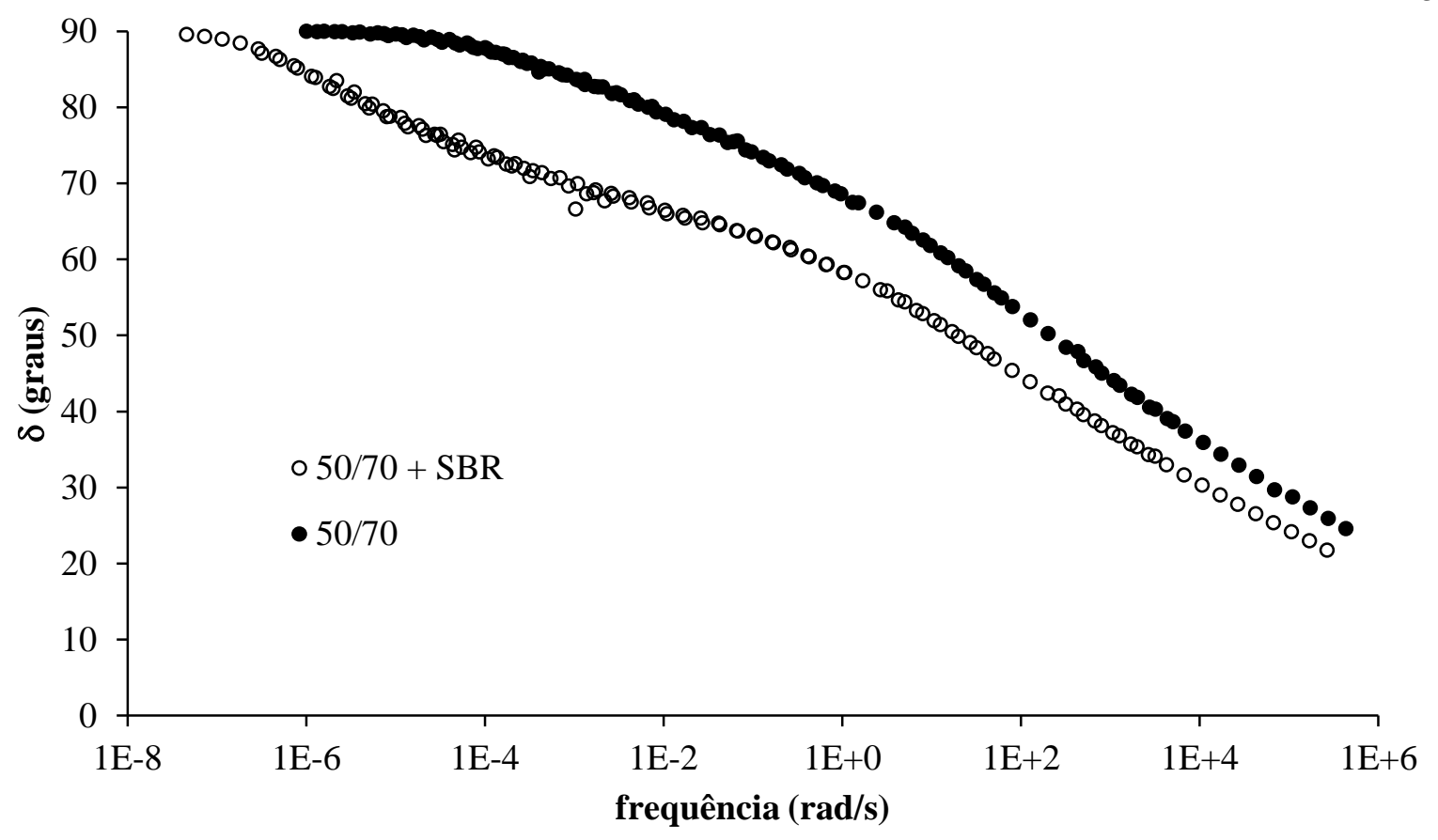

Figura A. 76 - Curva-mestre de $\delta$ da mistura 50/70-SBR em relação ao CAP puro: condição RTFOT

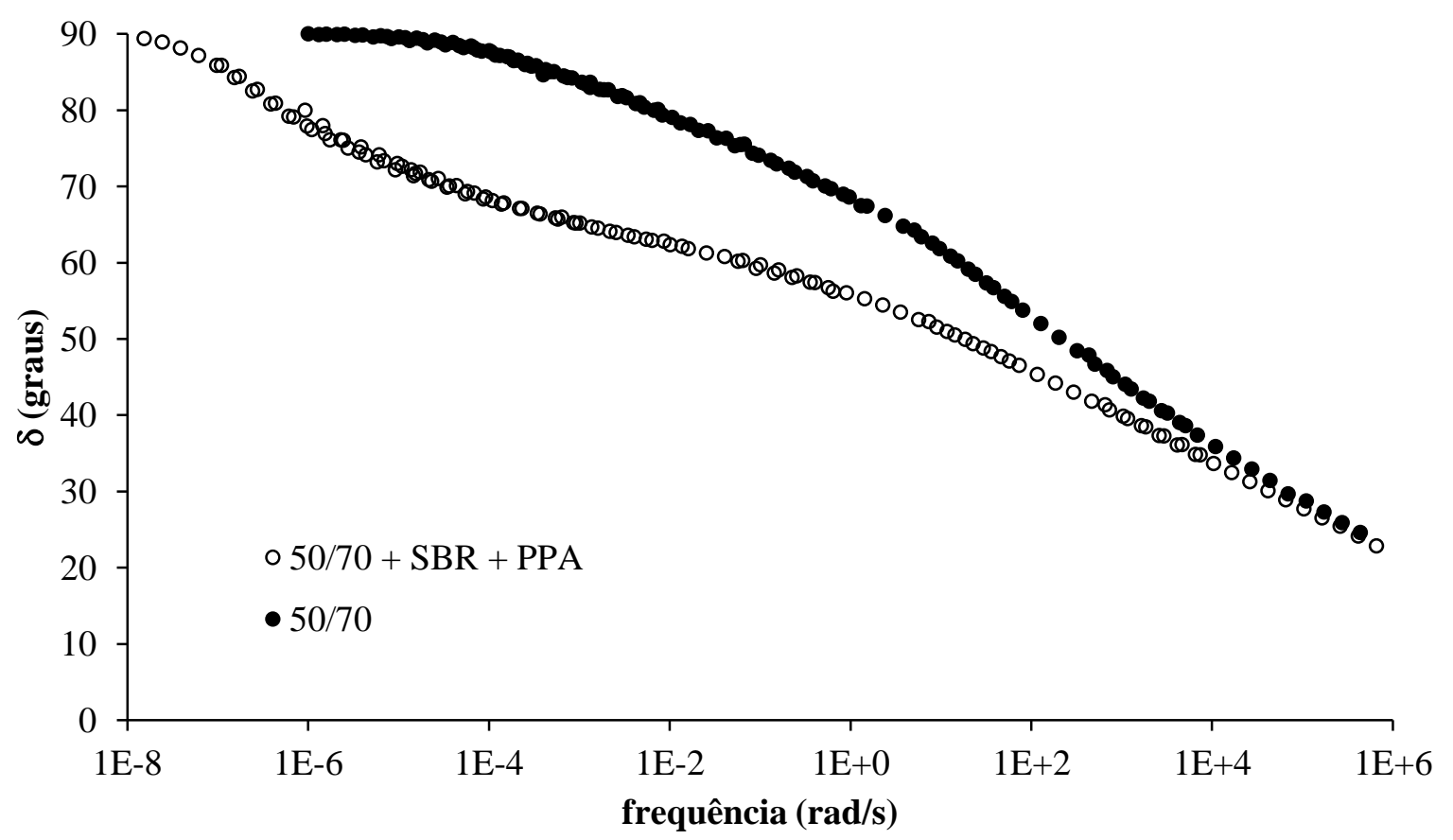

Figura A. 77 - Curva-mestre de $\delta$ da mistura 50/70-SBR-PPA em relação ao CAP puro: condição RTFOT 


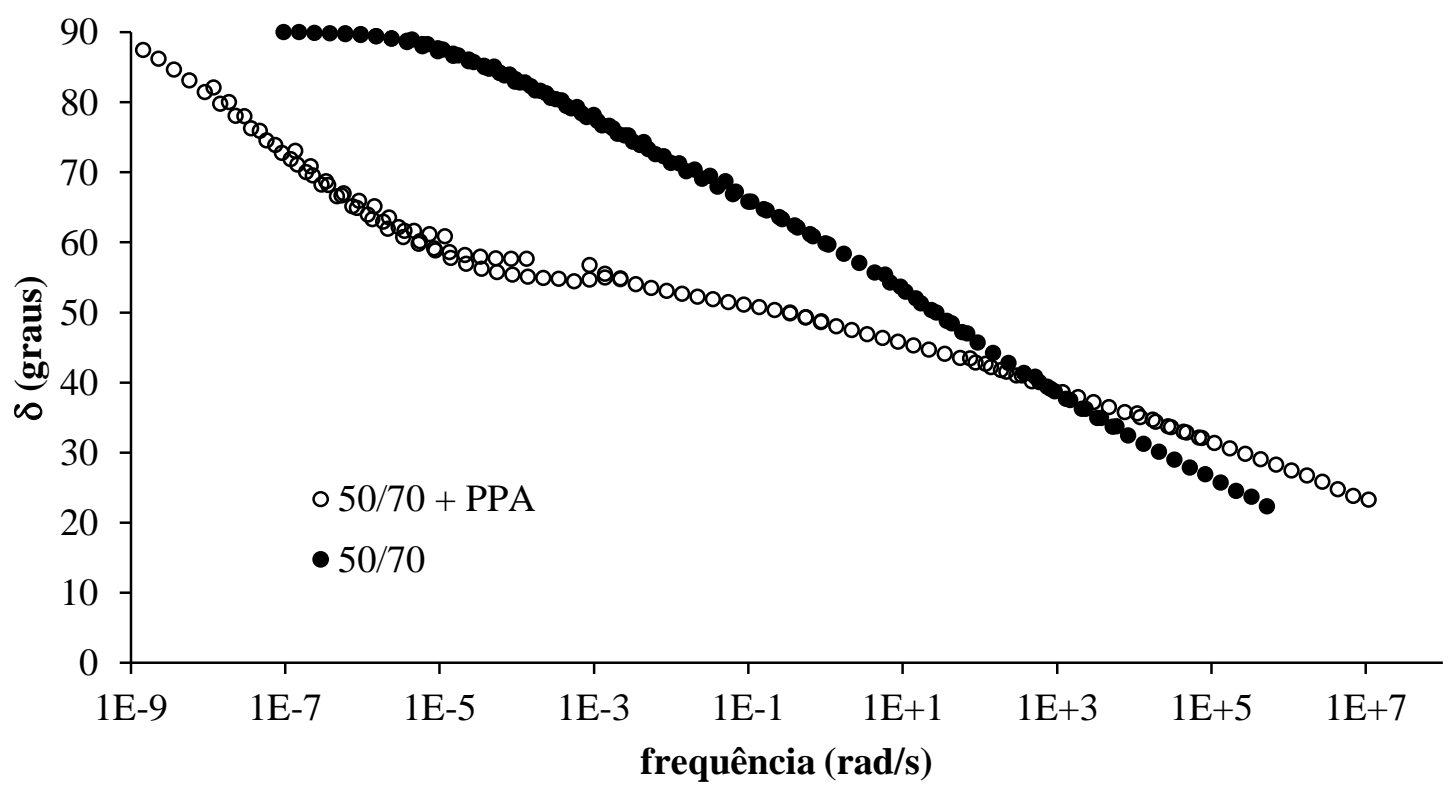

Figura A. 78 - Curva-mestre de $\delta$ da mistura 50/70-PPA em relação ao CAP puro: condição PAV

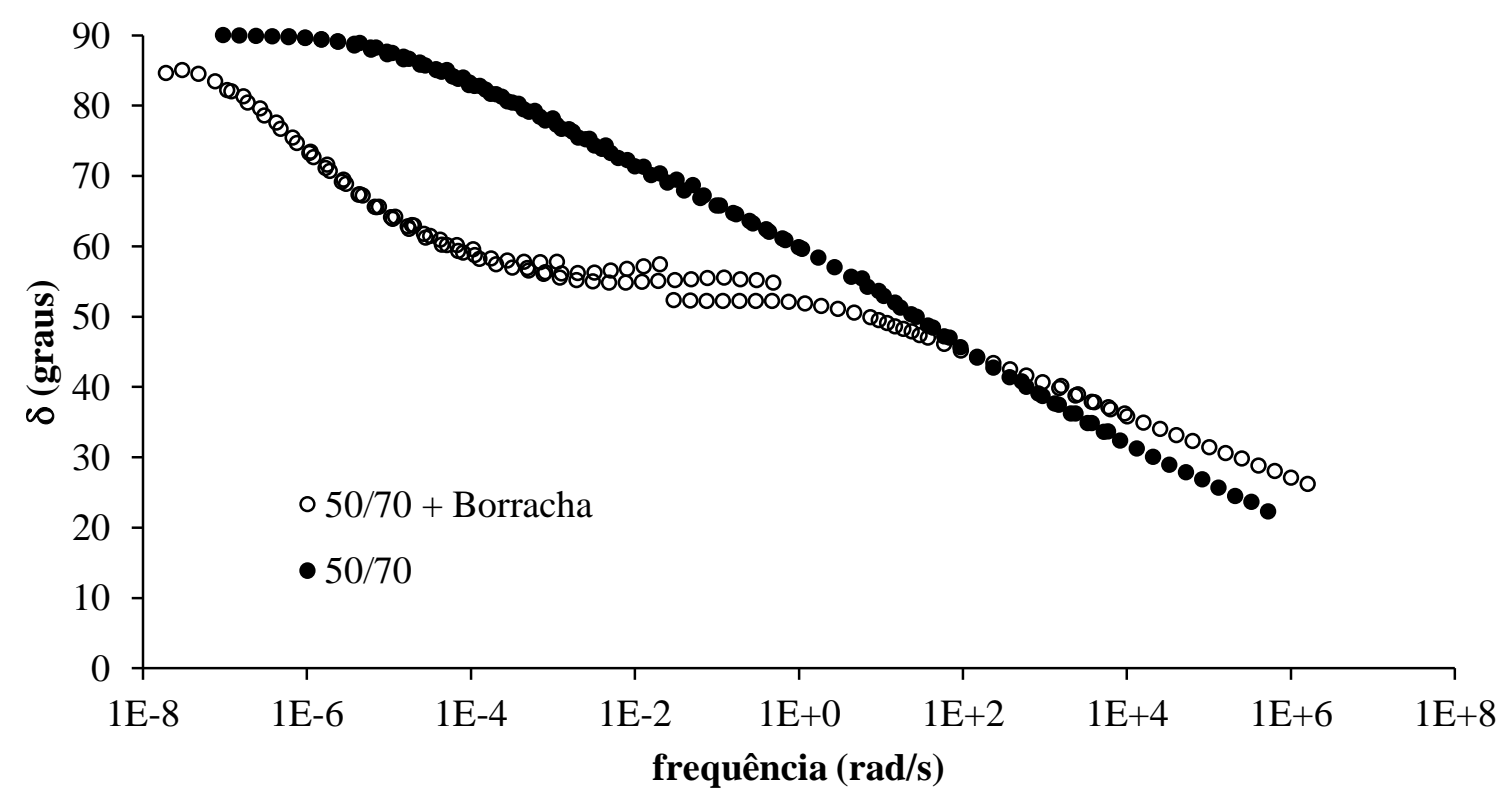

Figura A. 79 - Curva-mestre de $\delta$ da mistura 50/70-borracha em relação ao CAP puro: condição PAV 


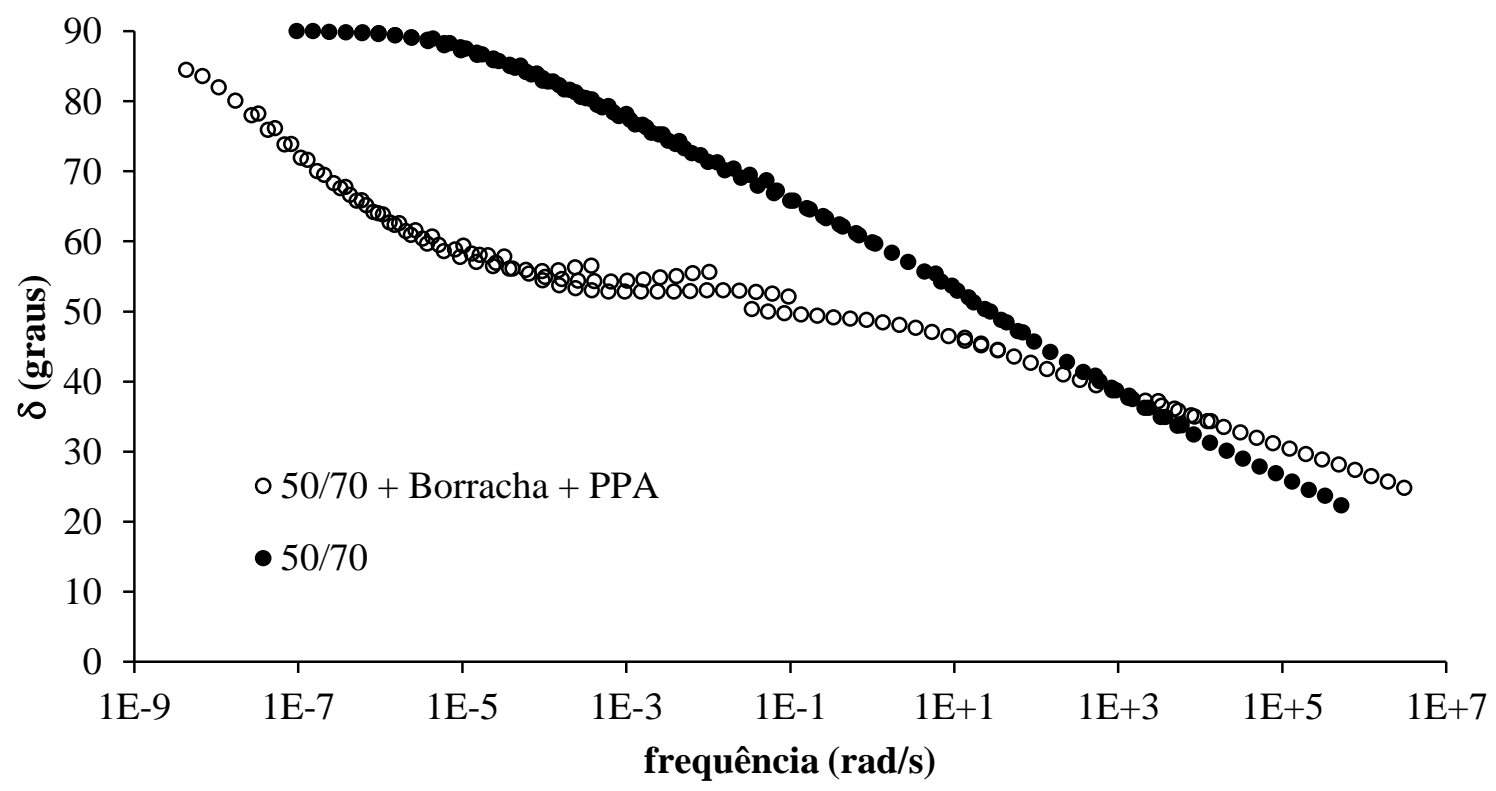

Figura A. 80 - Curva-mestre de $\delta$ da mistura 50/70-borracha-PPA em relação ao CAP puro: condição PAV

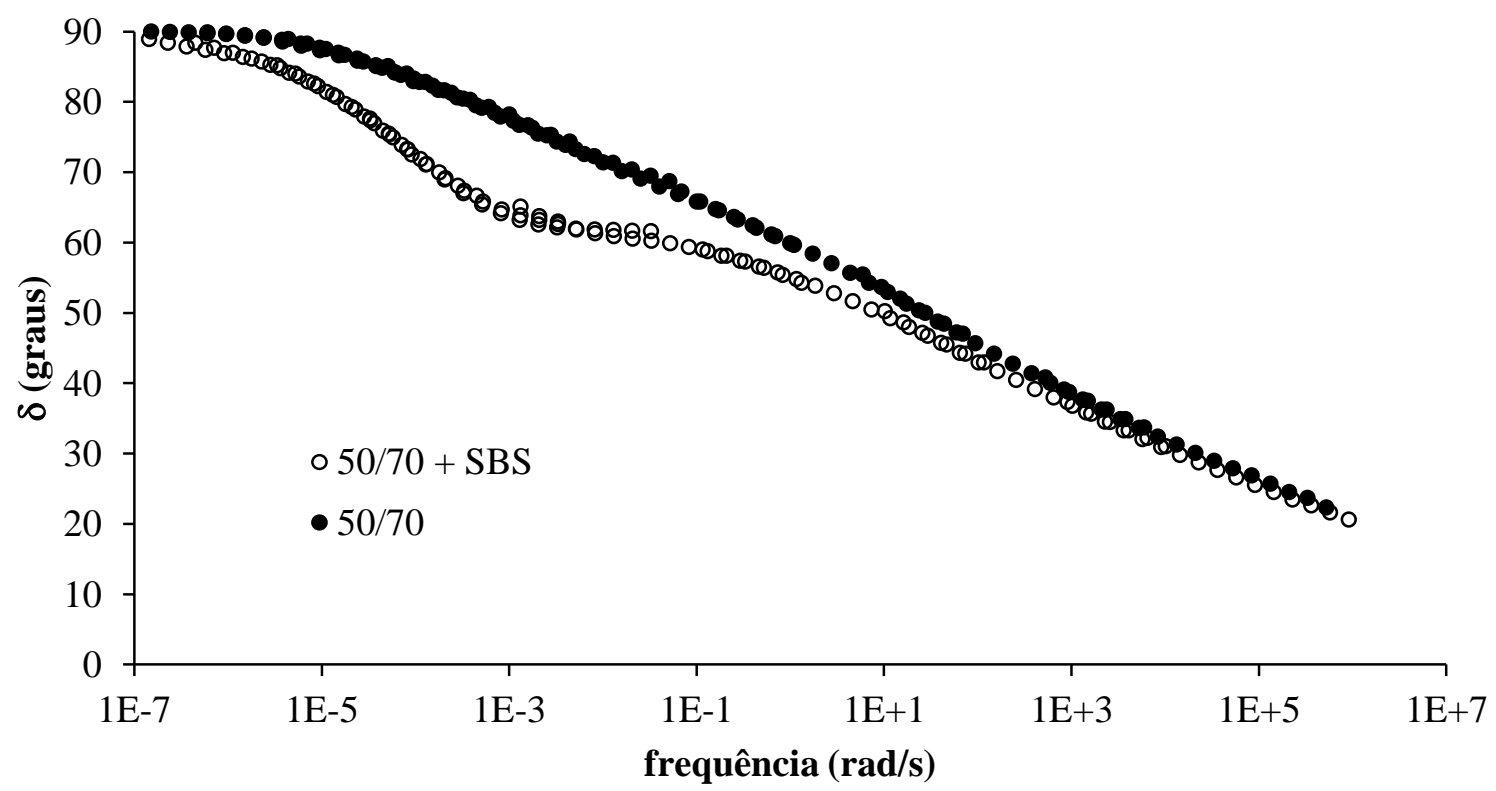

Figura A. 81 - Curva-mestre de $\delta$ da mistura 50/70-SBS em relação ao CAP puro: condição PAV 


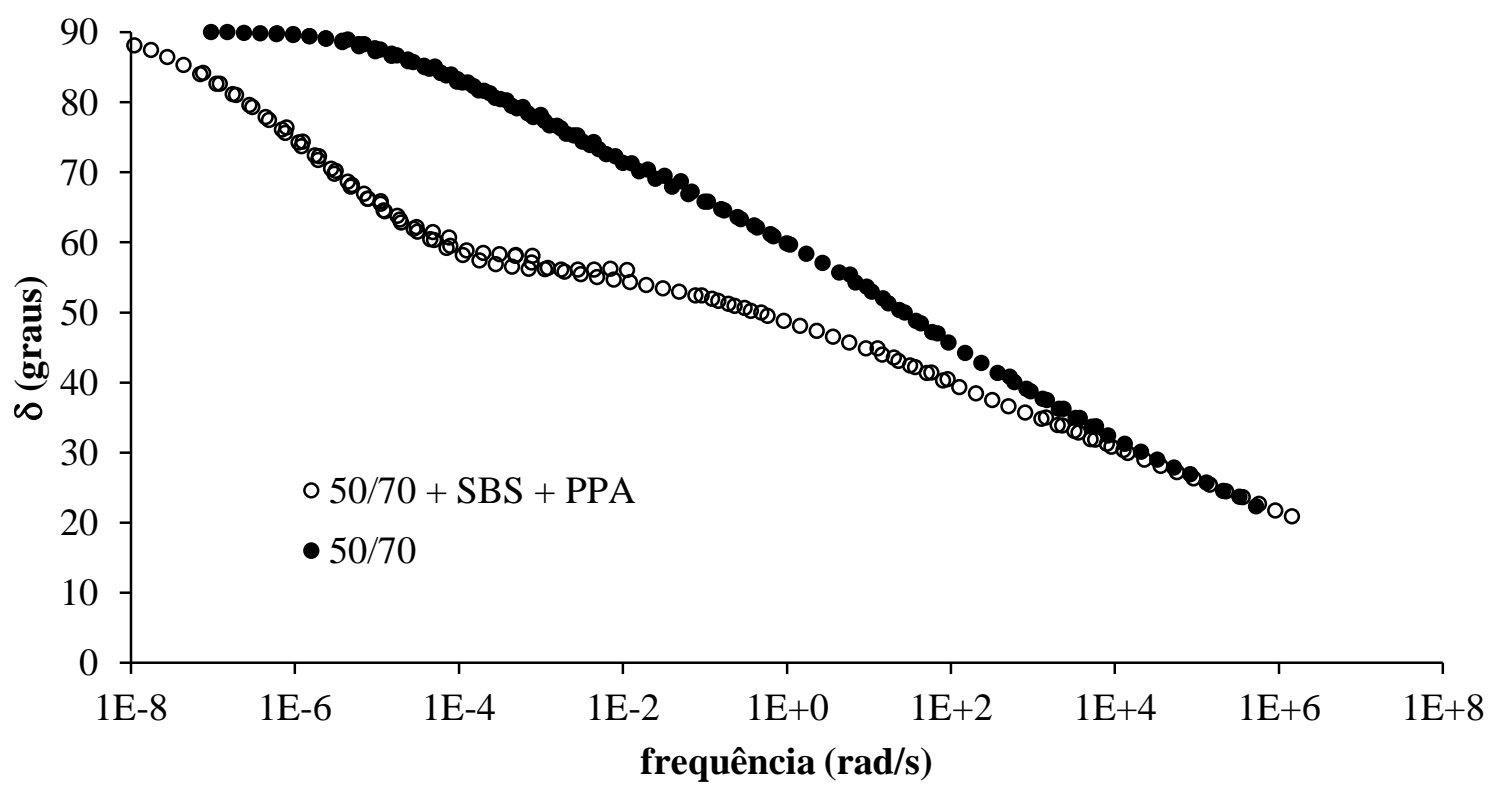

Figura A. 82 - Curva-mestre de $\delta$ da mistura 50/70-SBS-PPA em relação ao CAP puro: condição PAV

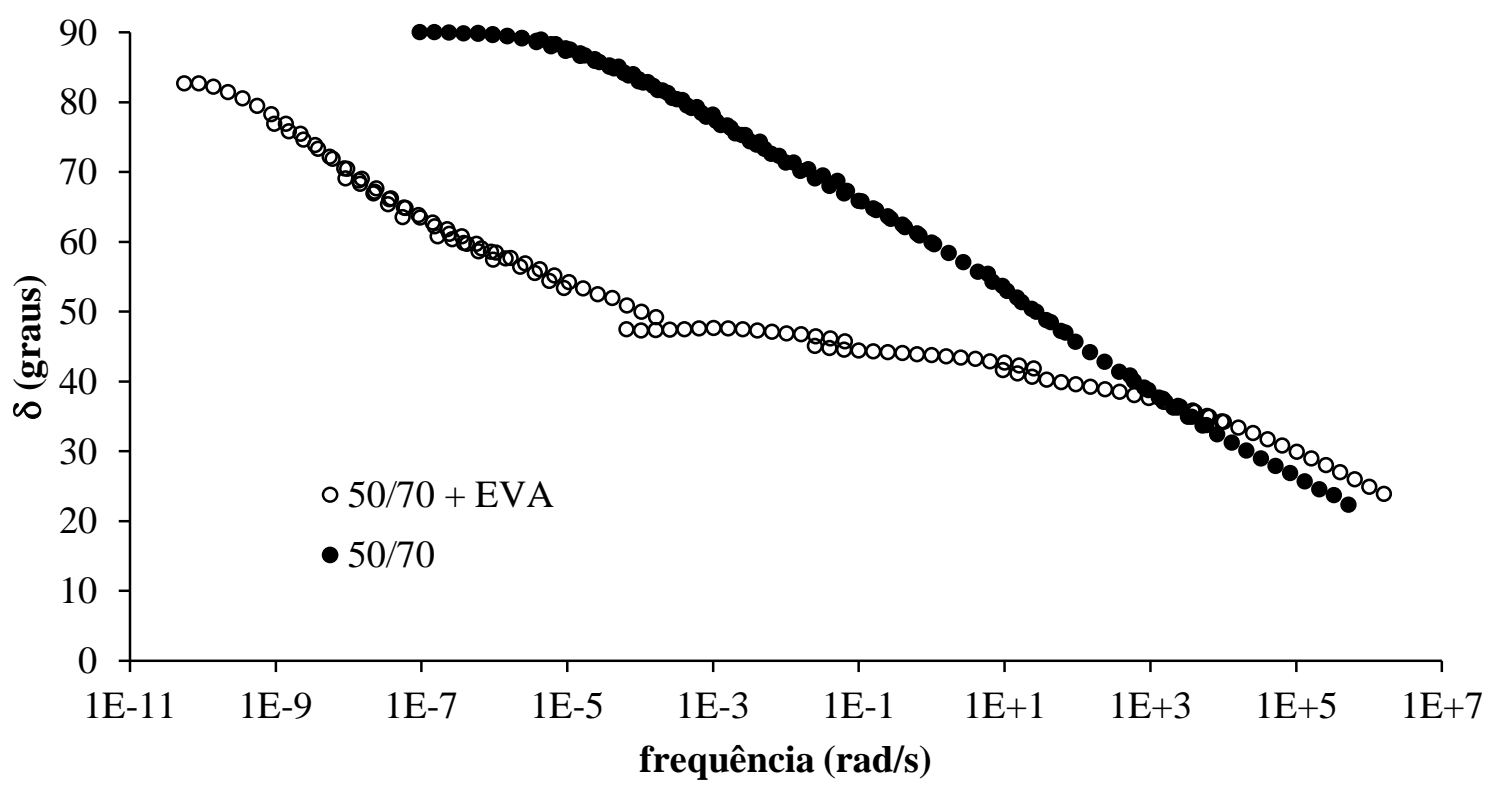

Figura A. 83 - Curva-mestre de $\delta$ da mistura 50/70-EVA em relação ao CAP puro: condição PAV 


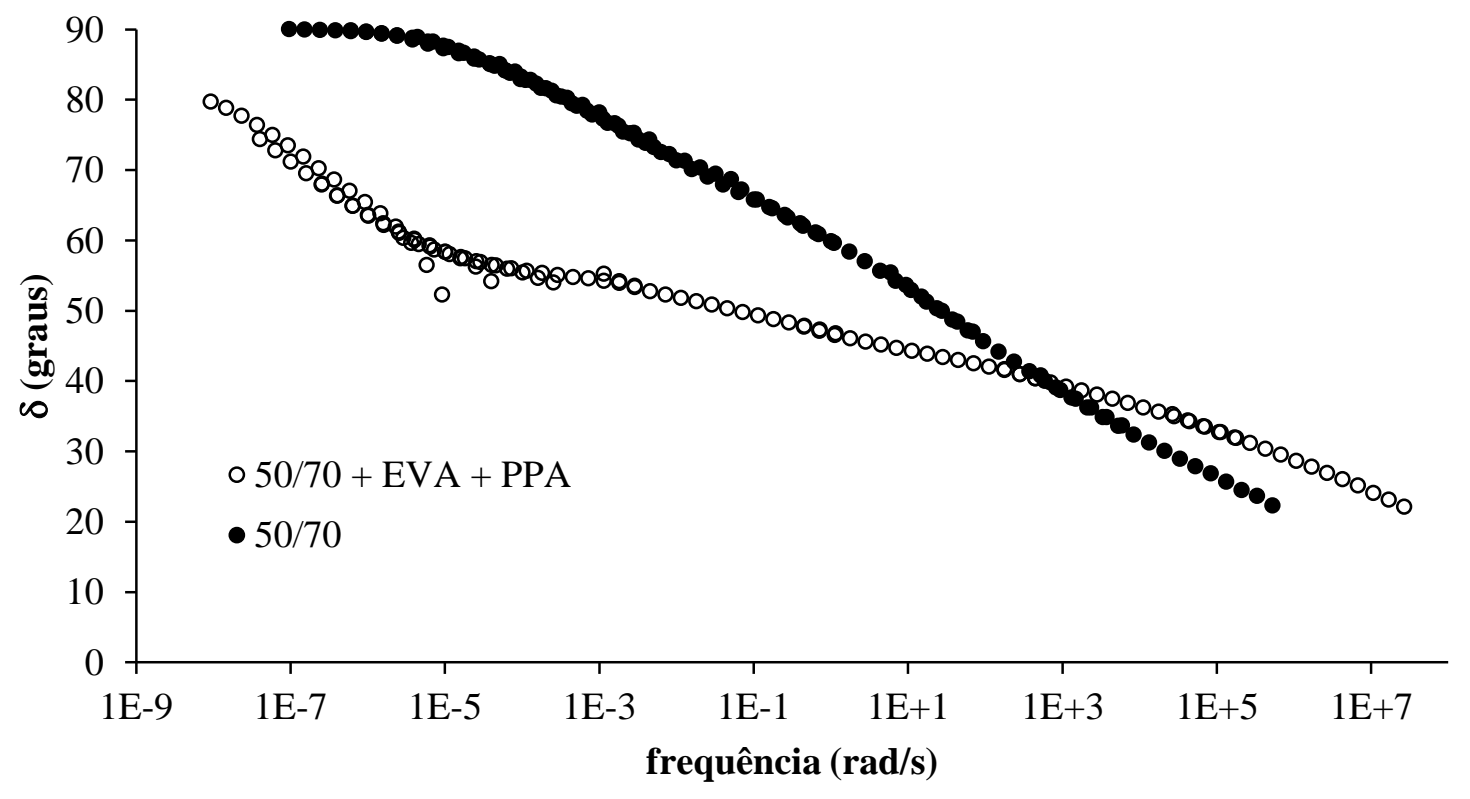

Figura A. 84 - Curva-mestre de $\delta$ da mistura 50/70-EVA-PPA em relação ao CAP puro: condição PAV

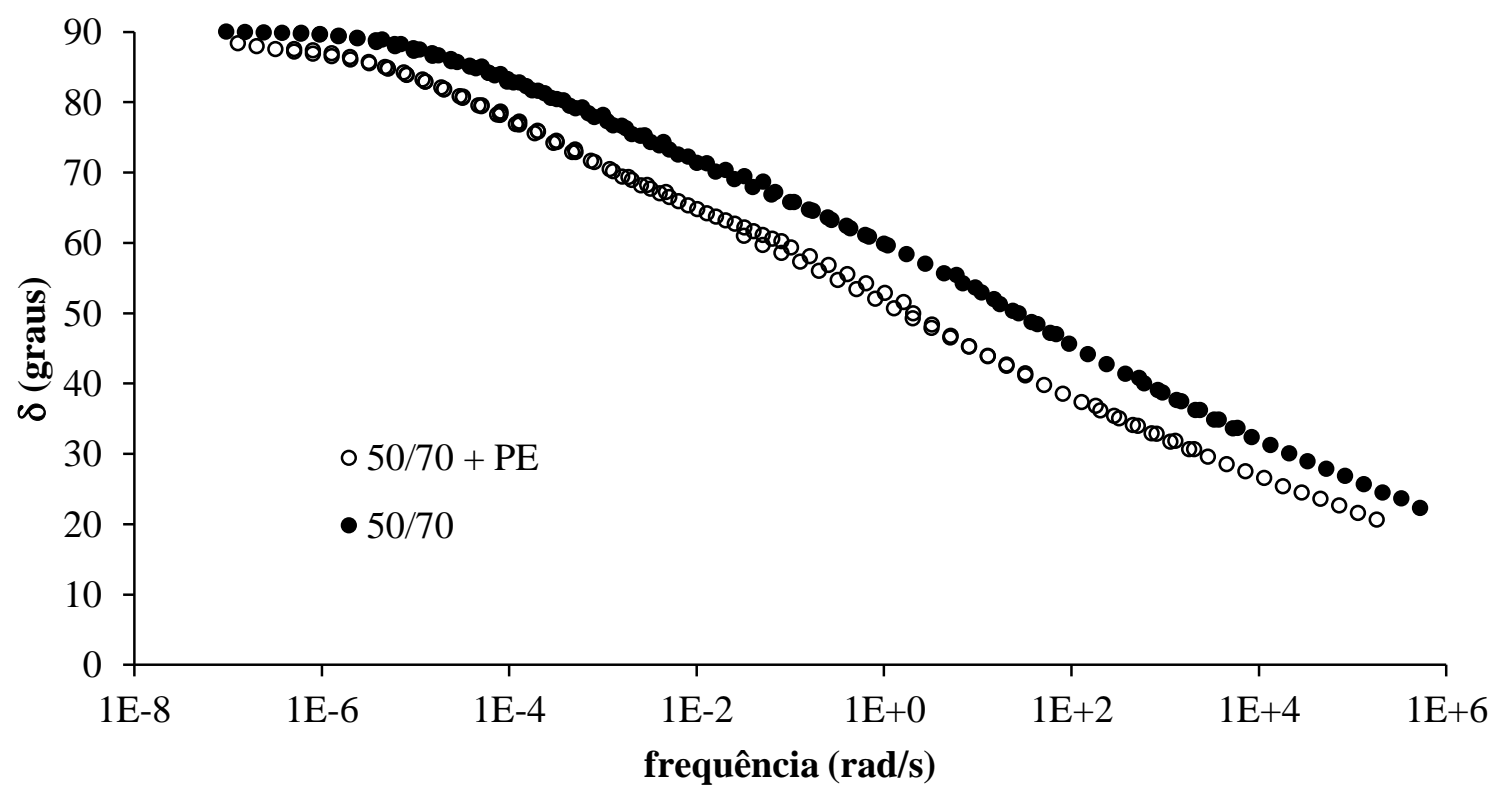

Figura A. 85 - Curva-mestre de $\delta$ da mistura 50/70-PE em relação ao CAP puro: condição PAV 


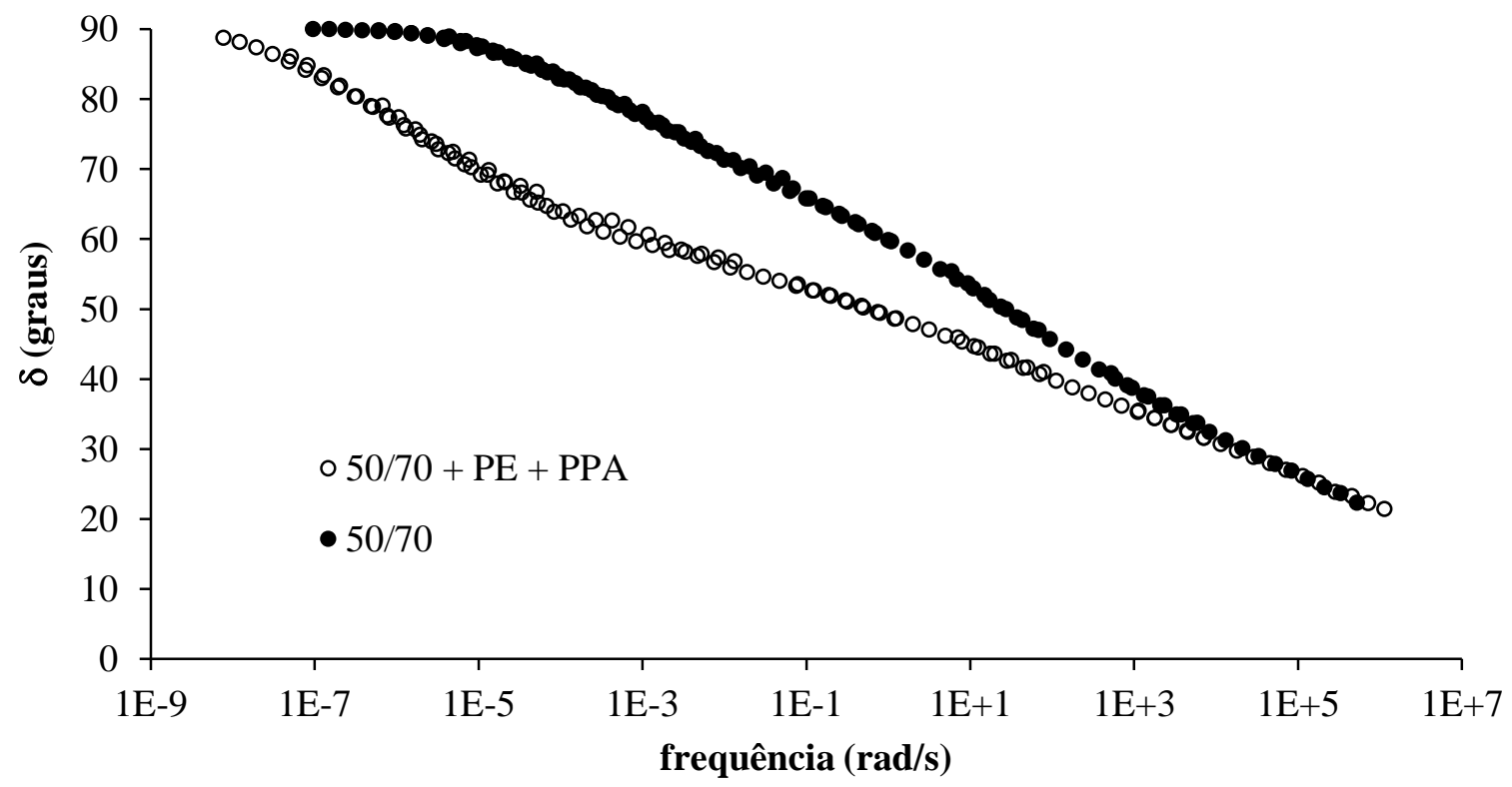

Figura A. 86 - Curva-mestre de $\delta$ da mistura 50/70-PE-PPA em relação ao CAP puro: condição PAV

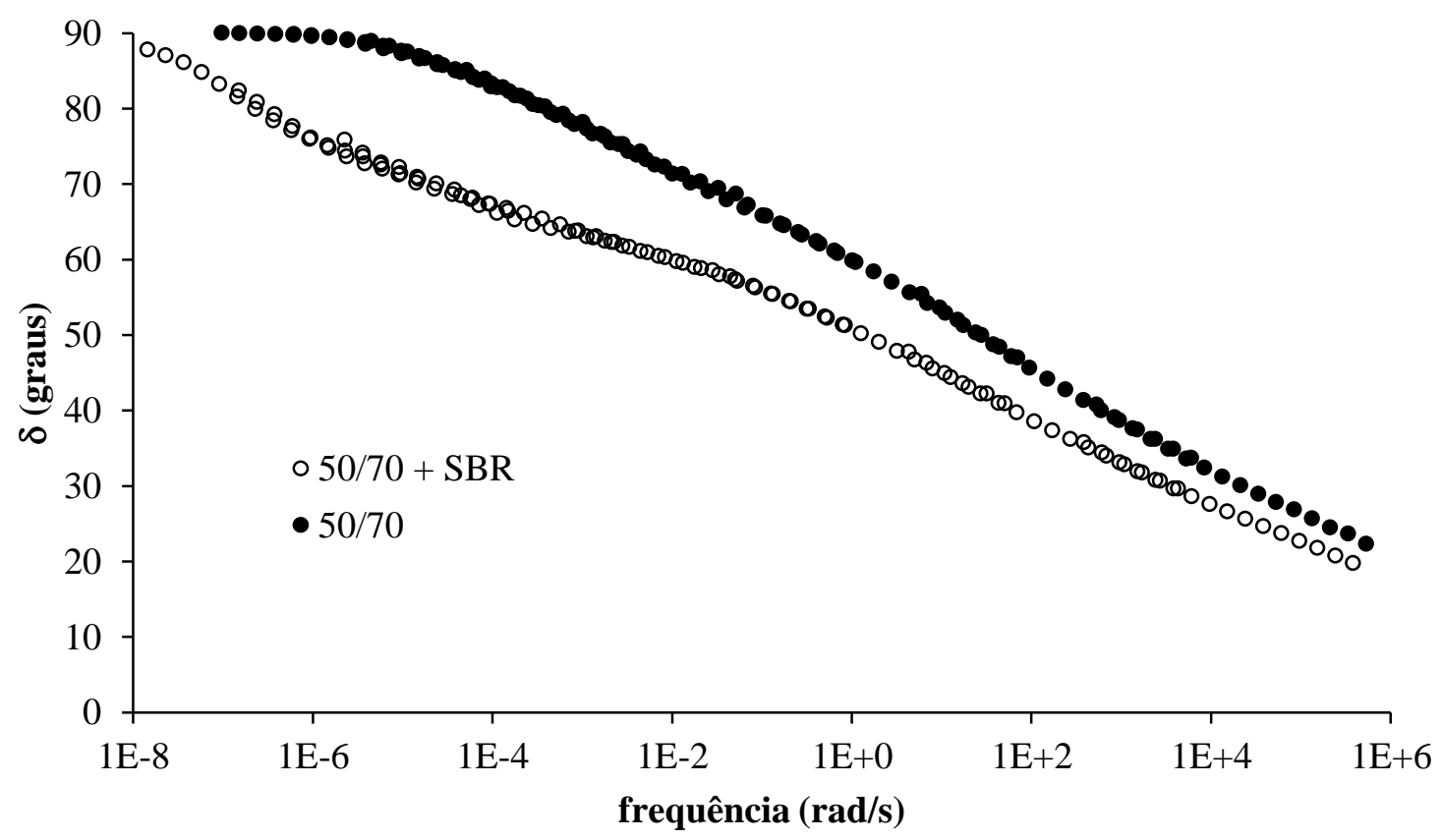

Figura A. 87 - Curva-mestre de $\delta$ da mistura 50/70-SBR em relação ao CAP puro: condição PAV 


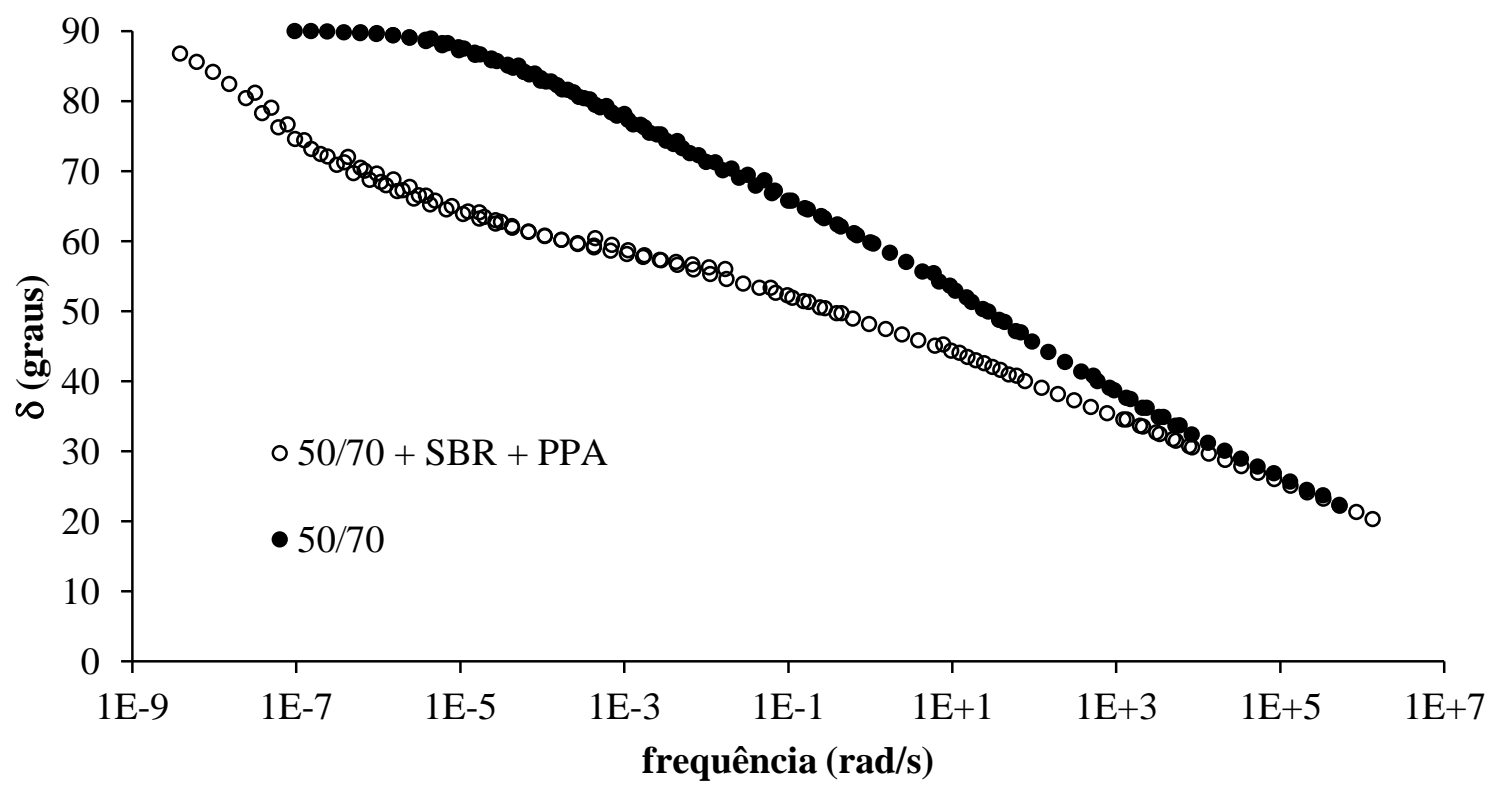

Figura A. 88 - Curva-mestre de $\delta$ da mistura 50/70-SBR-PPA em relação ao CAP puro: condição PAV

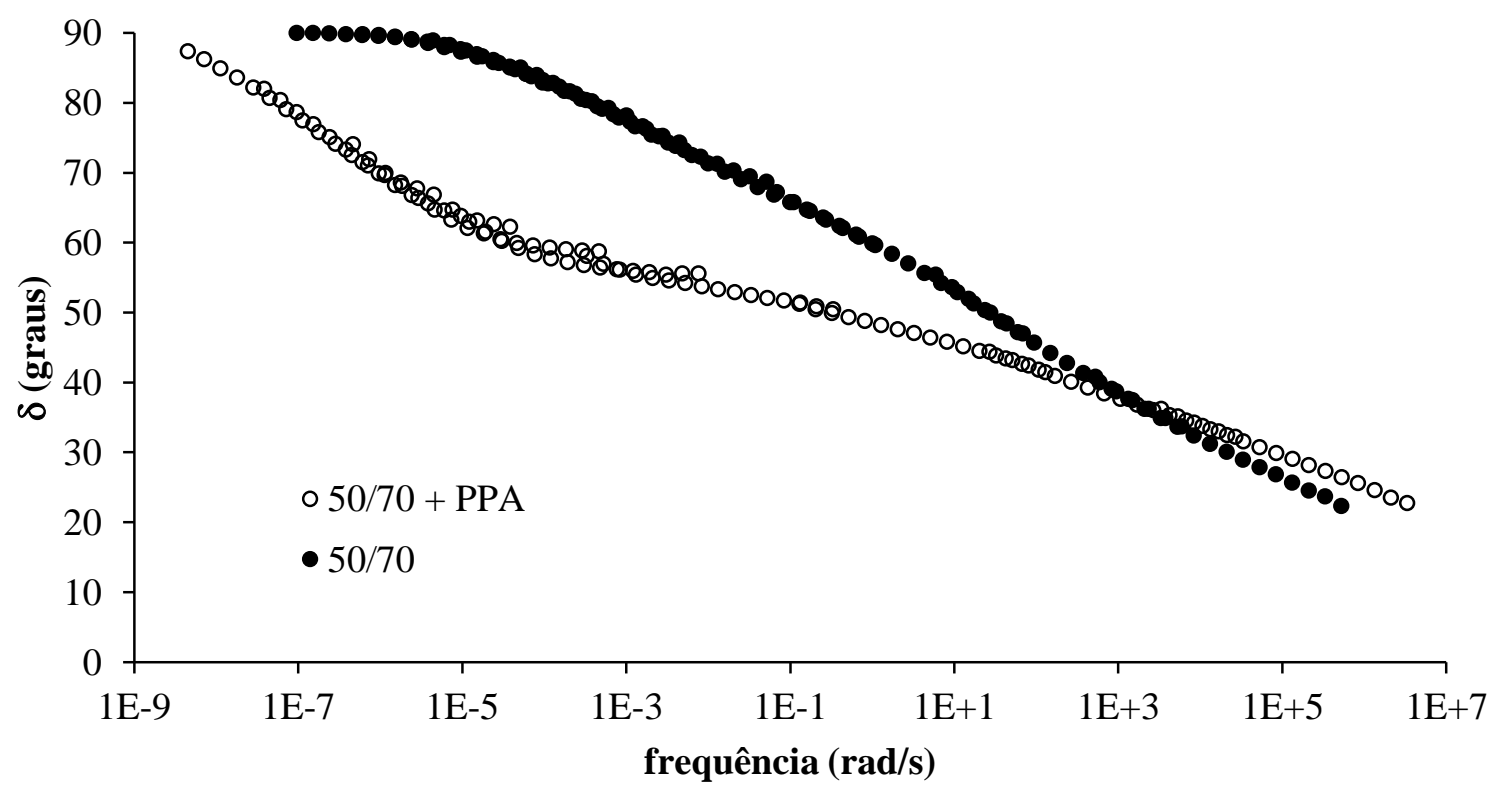

Figura A. 89 - Curva-mestre de $\delta$ da mistura 50/70-PPA em relação ao CAP puro: condição UV a $0,68 \mathrm{~W} / \mathrm{m}^{2}$ 


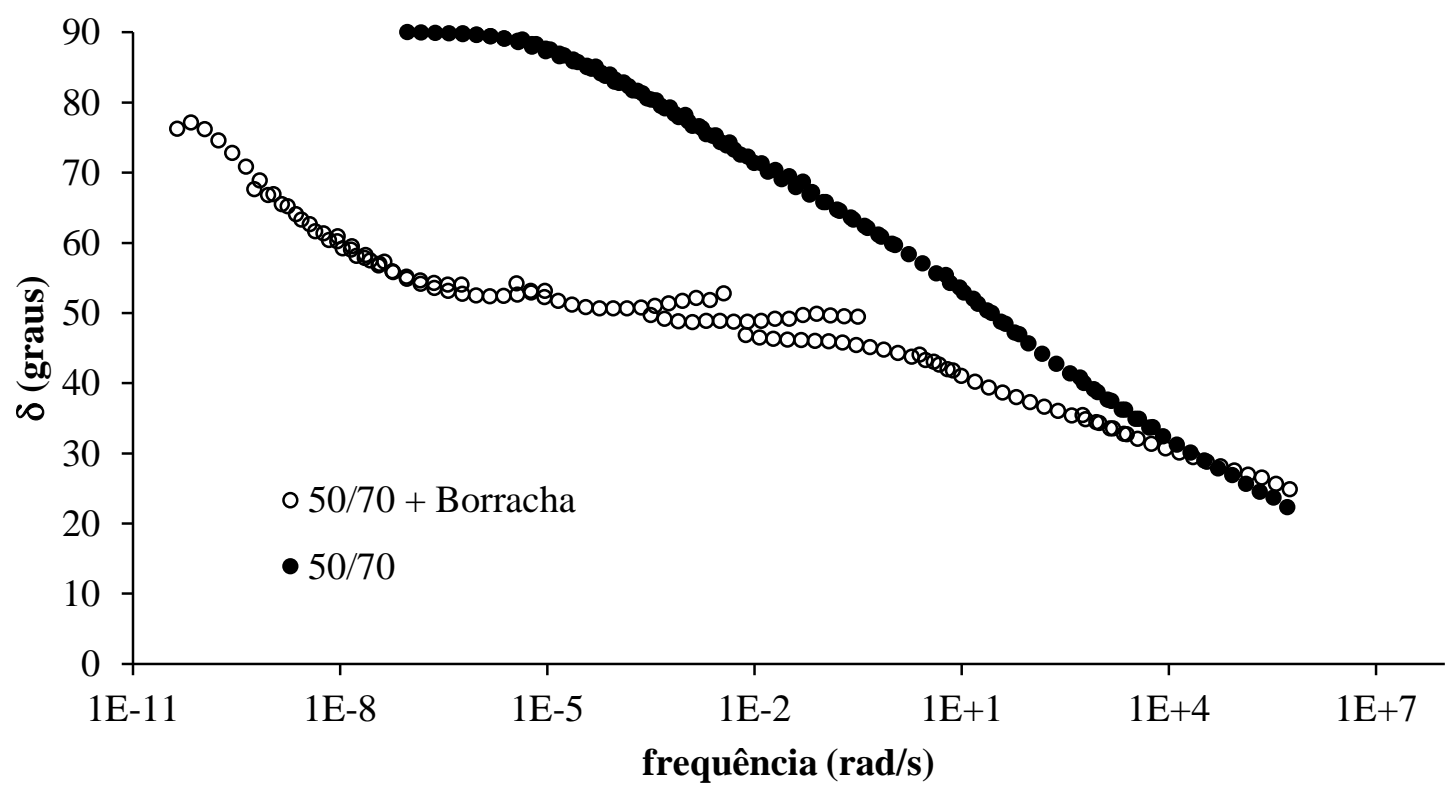

Figura A.90 - Curva-mestre de $\delta$ da mistura 50/70-borracha em relação ao CAP puro: condição UV a $0,68 \mathrm{~W} / \mathrm{m}^{2}$

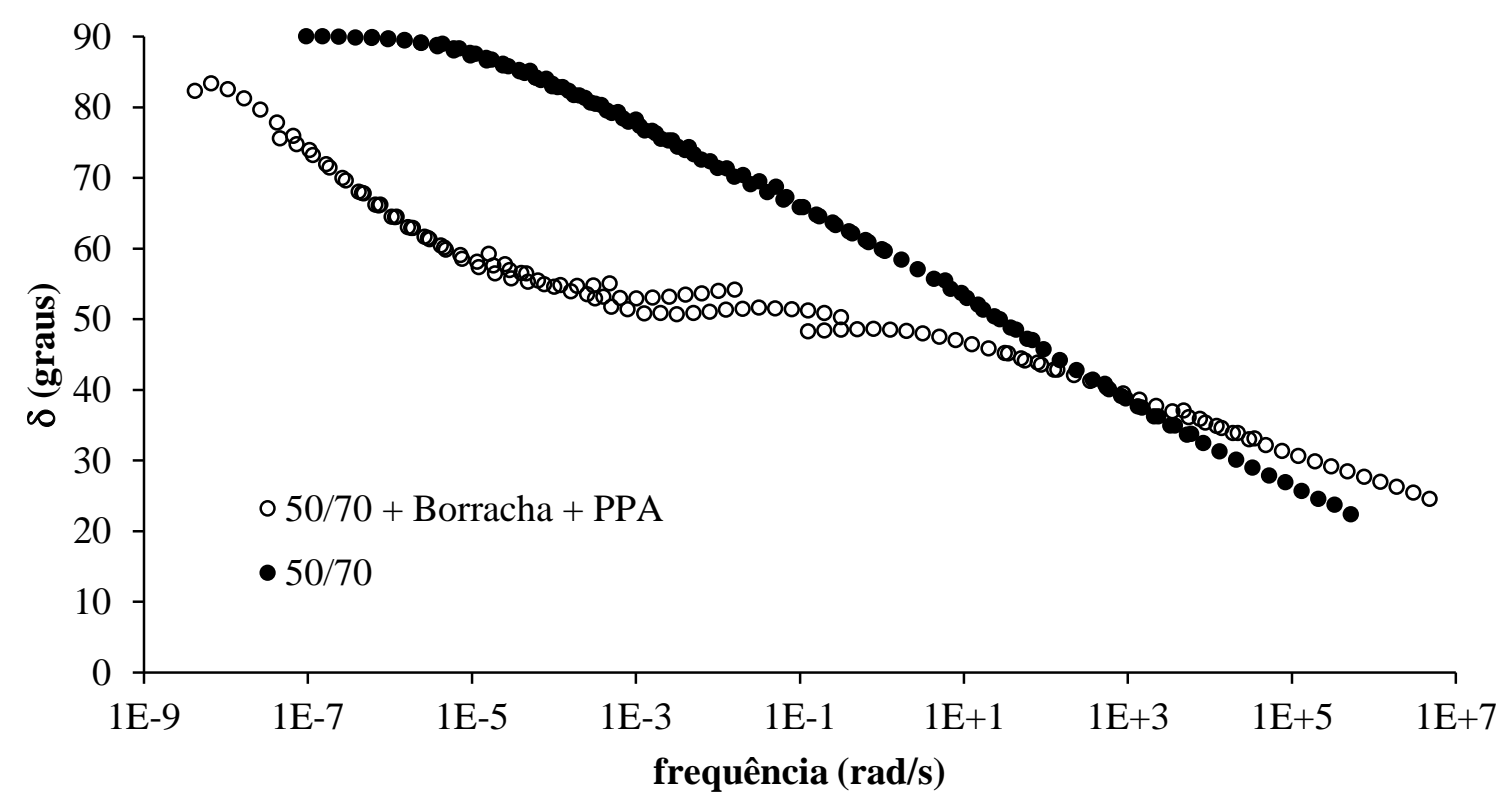

Figura A.91 - Curva-mestre de $\delta$ da mistura 50/70-borracha-PPA em relação ao CAP puro: condição UV a $0,68 \mathrm{~W} / \mathrm{m}^{2}$ 


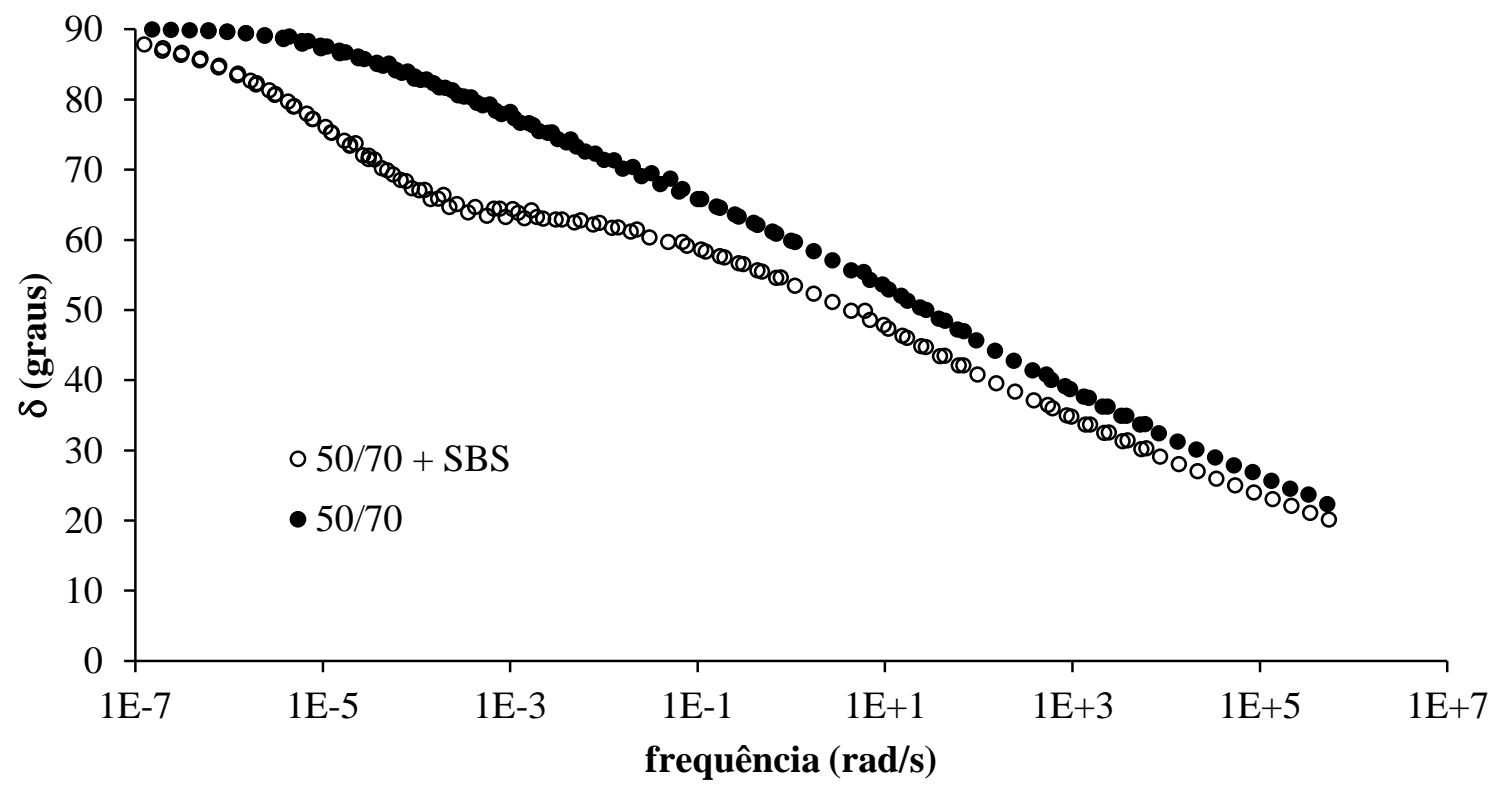

Figura A. 92 - Curva-mestre de $\delta$ da mistura 50/70-SBS em relação ao CAP puro: condição UV a $0,68 \mathrm{~W} / \mathrm{m}^{2}$

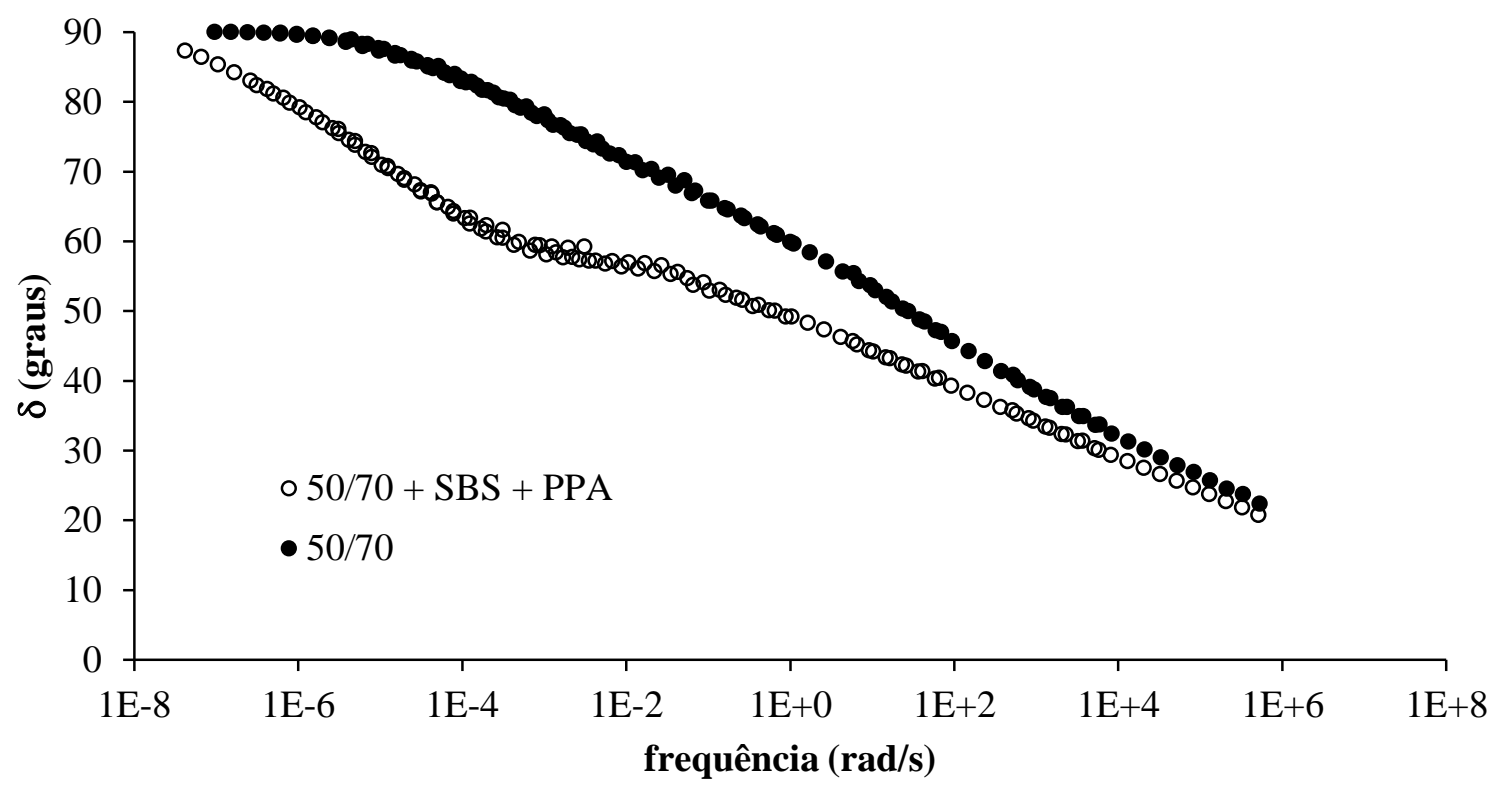

Figura A. 93 - Curva-mestre de $\delta$ da mistura 50/70-SBS-PPA em relação ao CAP puro: condição UV a $0,68 \mathrm{~W} / \mathrm{m}^{2}$ 


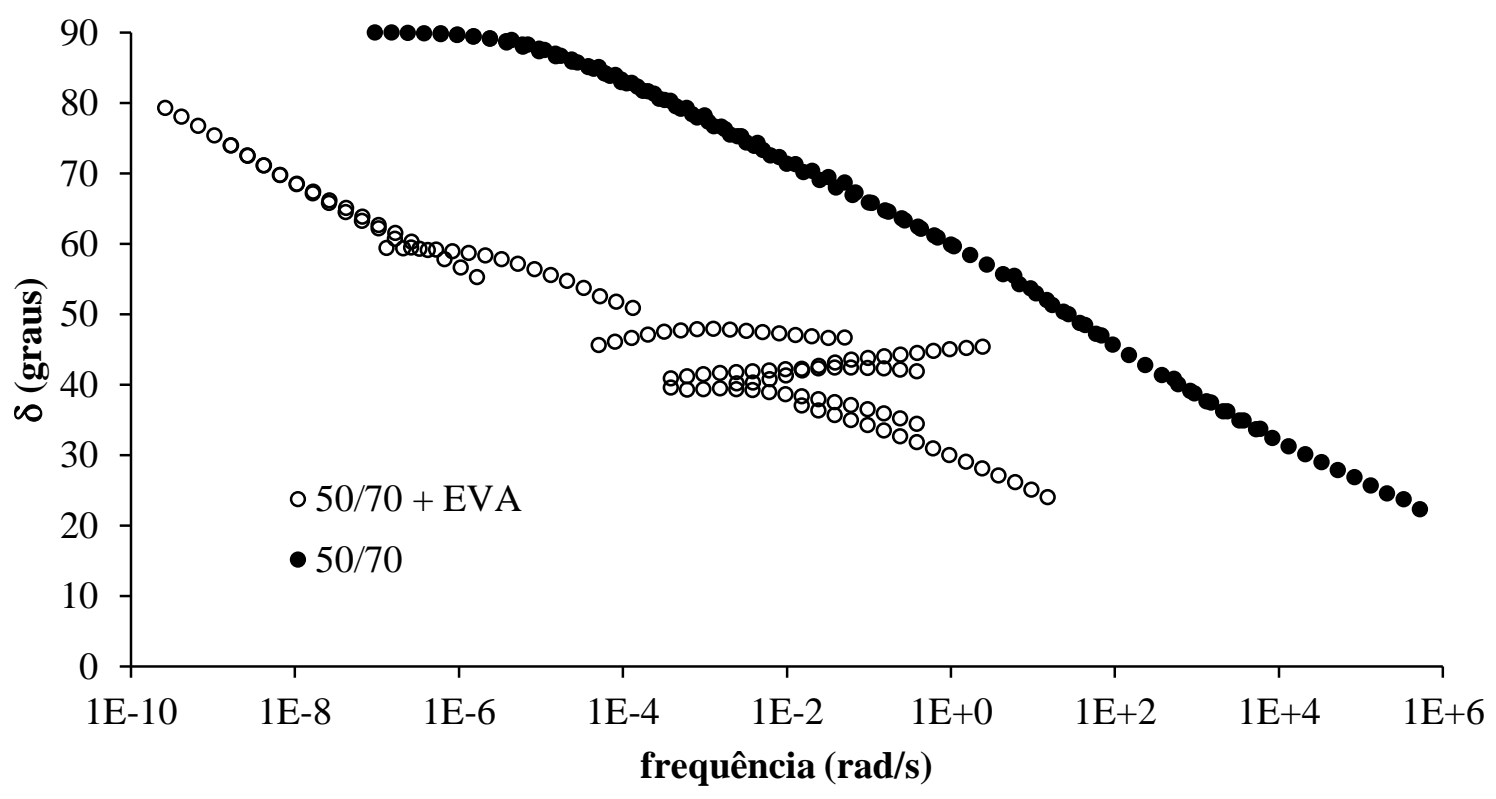

Figura A. 94 - Curva-mestre de $\delta$ da mistura 50/70-EVA em relação ao CAP puro: condição UV a $0,68 \mathrm{~W} / \mathrm{m}^{2}$

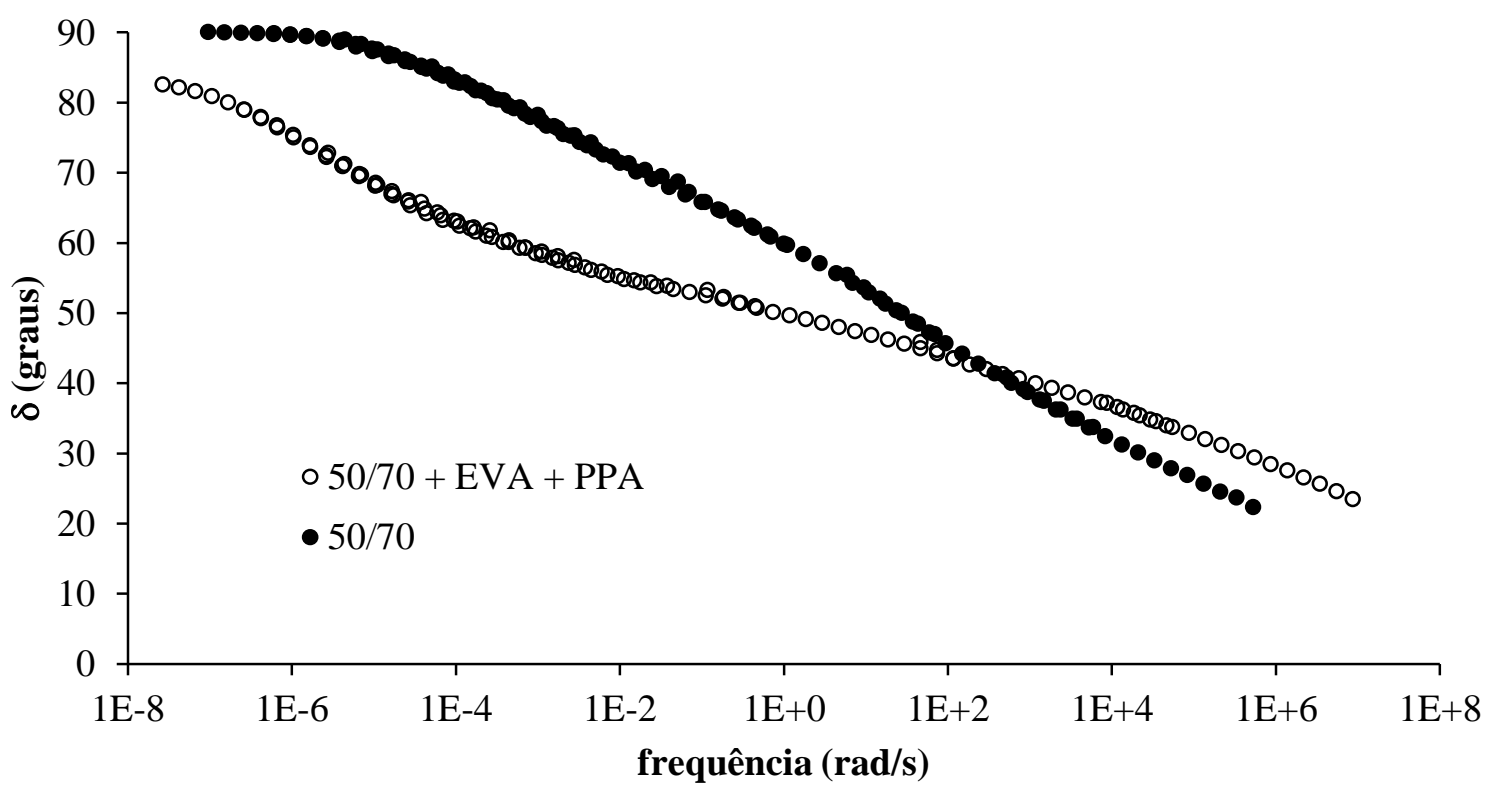

Figura A.95 - Curva-mestre de $\delta$ da mistura 50/70-EVA-PPA em relação ao CAP puro: condição UV a $0,68 \mathrm{~W} / \mathrm{m}^{2}$ 


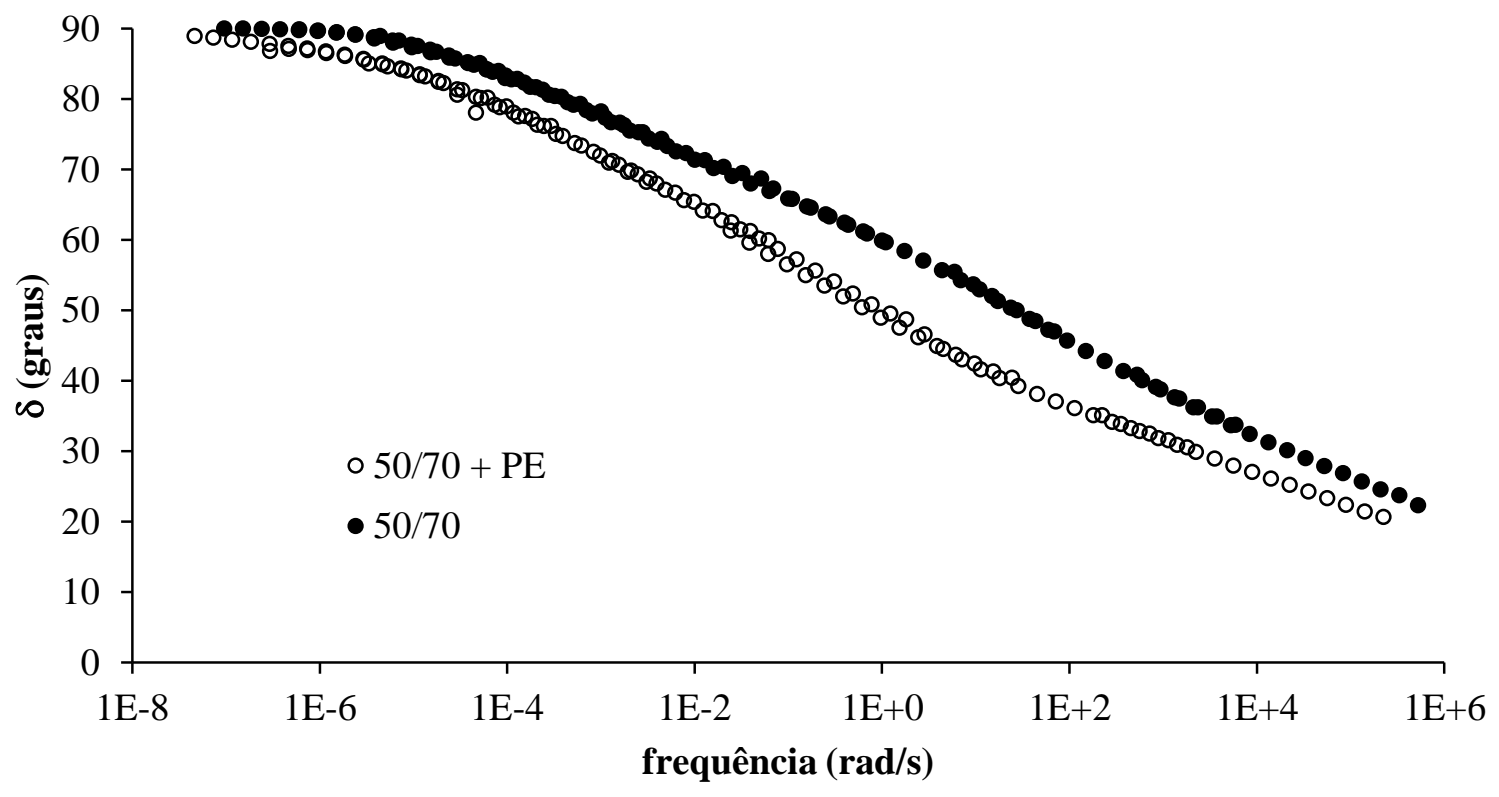

Figura A. 96 - Curva-mestre de $\delta$ da mistura 50/70-PE em relação ao CAP puro: condição UV a $0,68 \mathrm{~W} / \mathrm{m}^{2}$

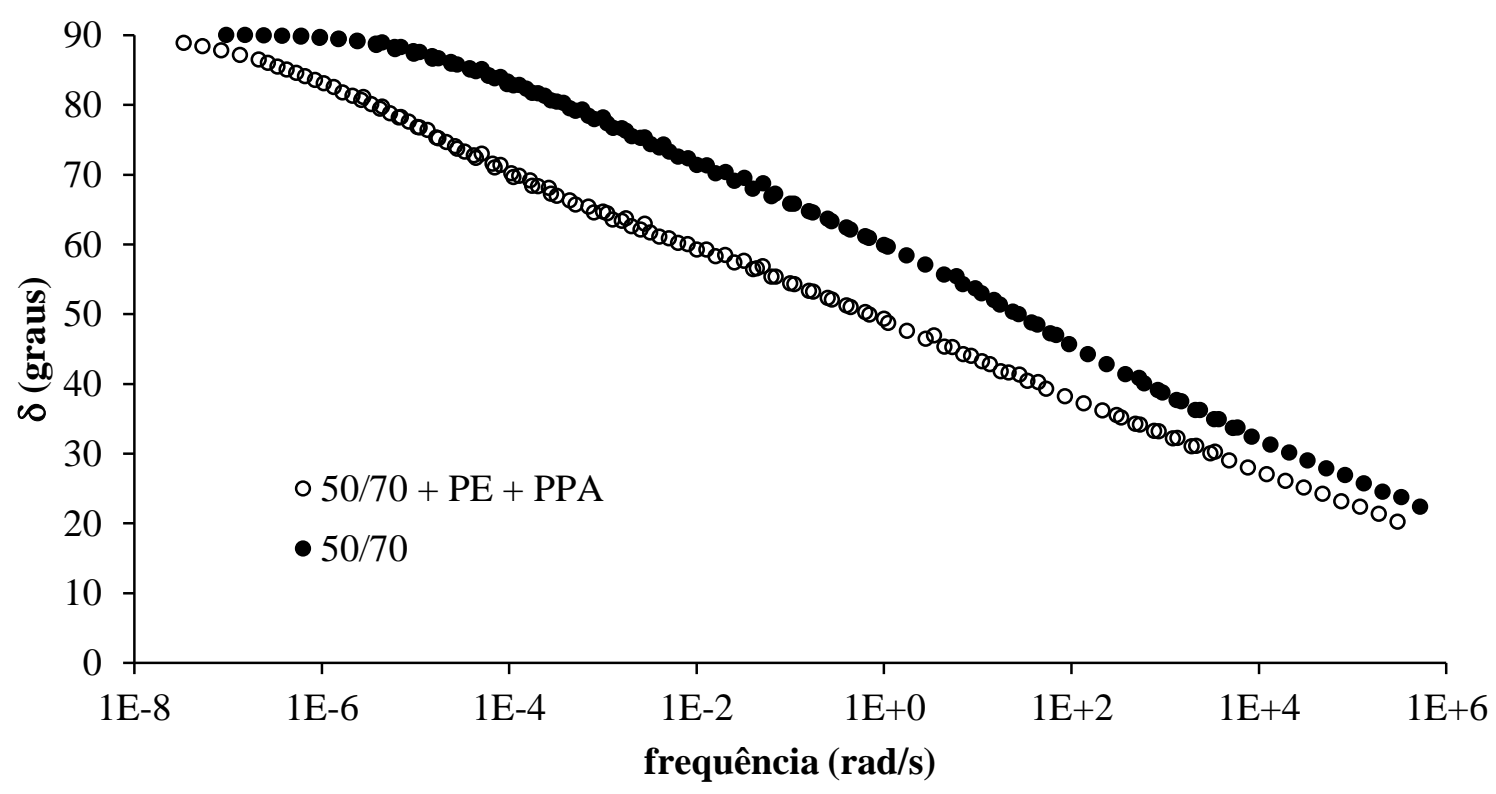

Figura A. 97 - Curva-mestre de $\delta$ da mistura 50/70-PE-PPA em relação ao CAP puro: condição UV a $0,68 \mathrm{~W} / \mathrm{m}^{2}$ 


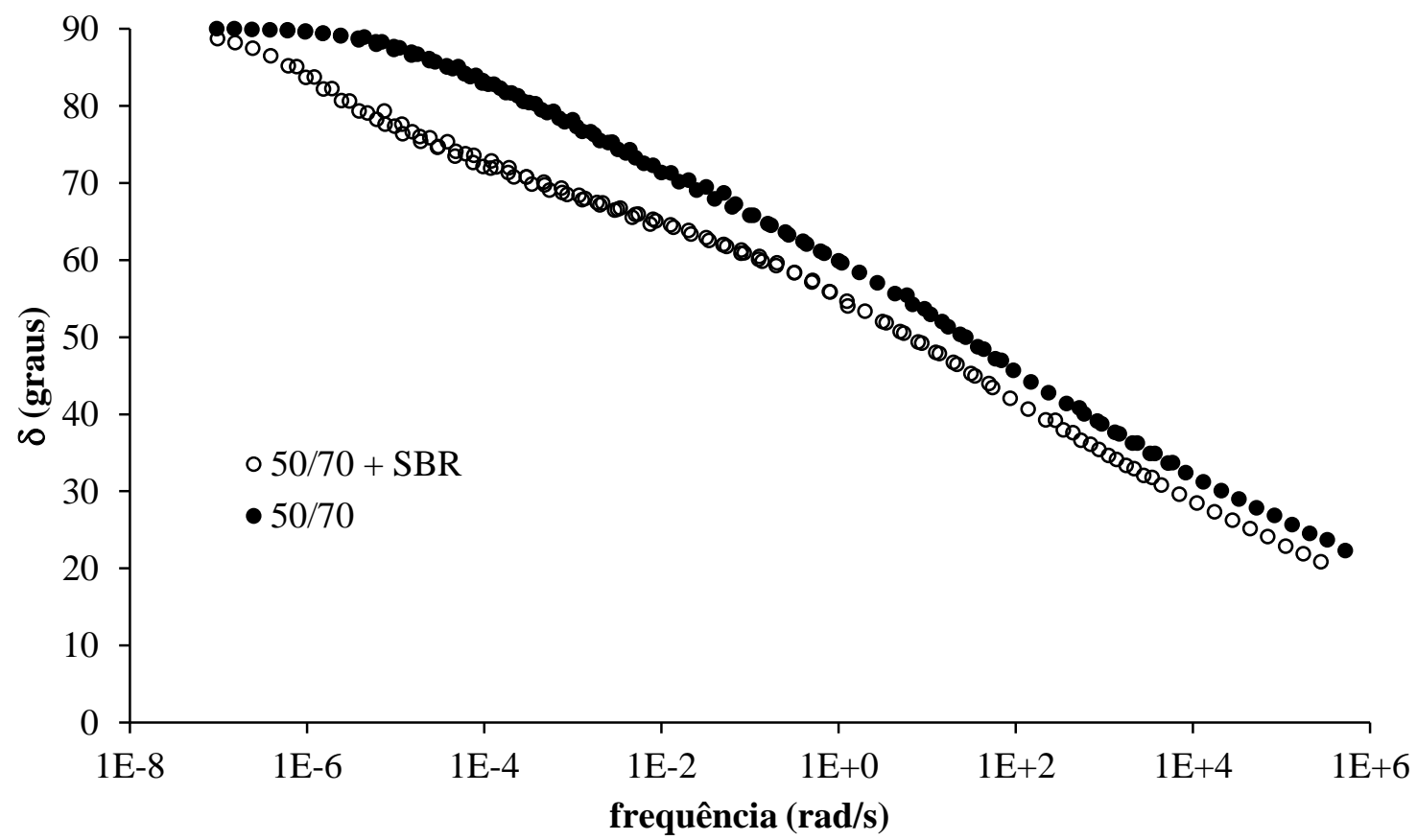

Figura A.98 - Curva-mestre de $\delta$ da mistura 50/70-SBR em relação ao CAP puro: condição UV a $0,68 \mathrm{~W} / \mathrm{m}^{2}$

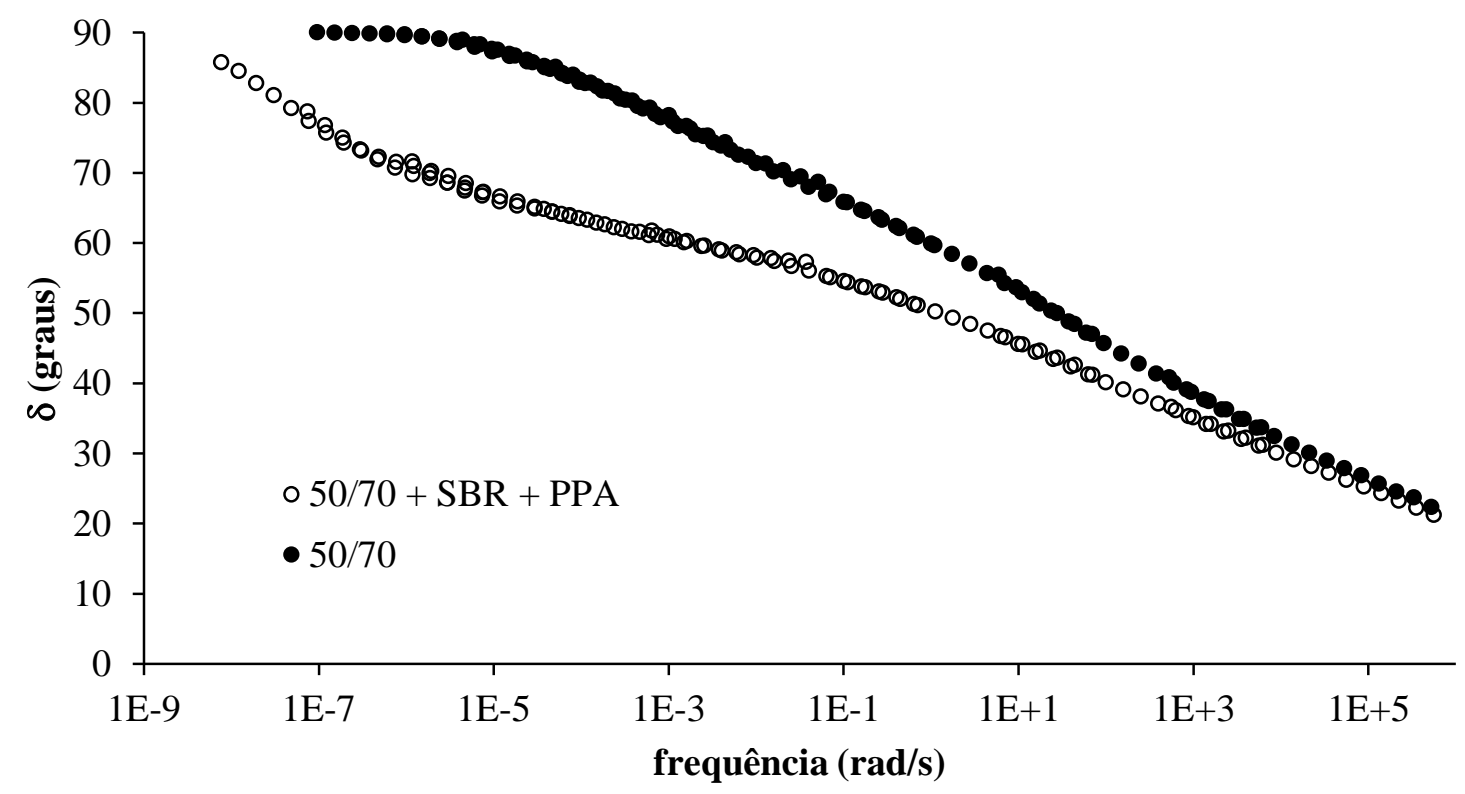

Figura A. 99 - Curva-mestre de $\delta$ da mistura 50/70-SBR-PPA em relação ao CAP puro: condição UV a $0,68 \mathrm{~W} / \mathrm{m}^{2}$ 


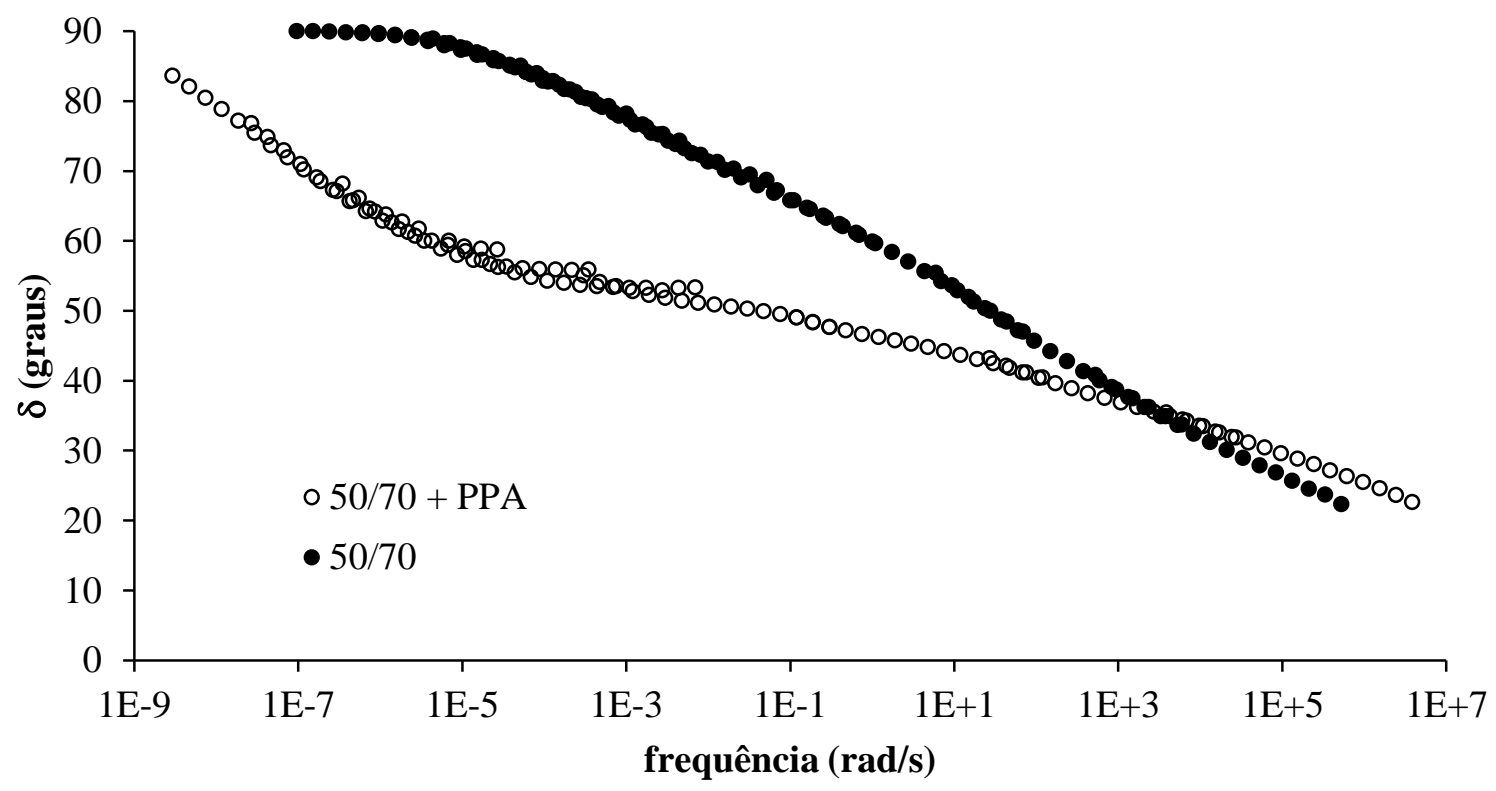

Figura A. 100 - Curva-mestre de $\delta$ da mistura 50/70-PPA em relação ao CAP puro: condição UV a $1,00 \mathrm{~W} / \mathrm{m}^{2}$

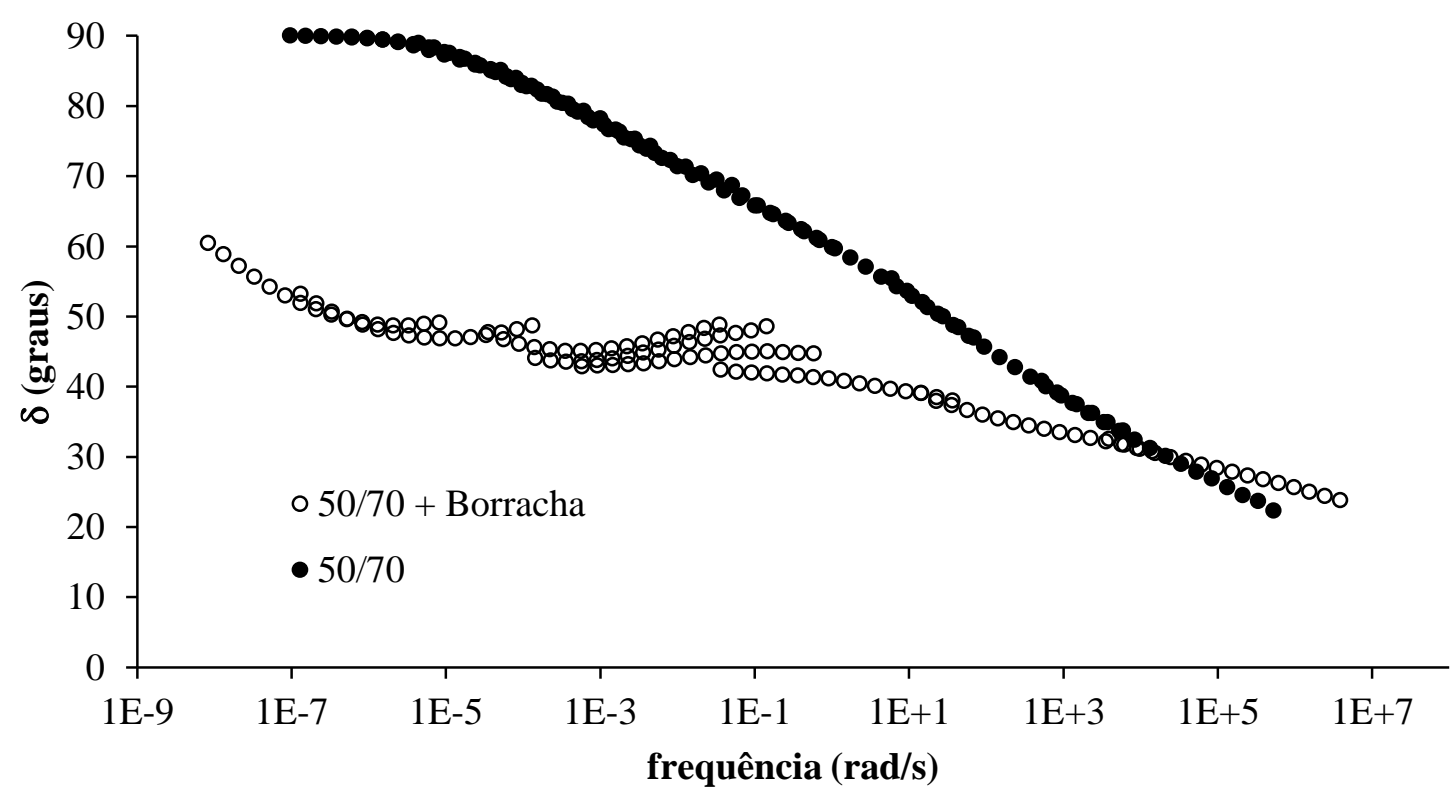

Figura A. 101 - Curva-mestre de $\delta$ da mistura 50/70-borracha em relação ao CAP puro: condição UV a $1,00 \mathrm{~W} / \mathrm{m}^{2}$ 


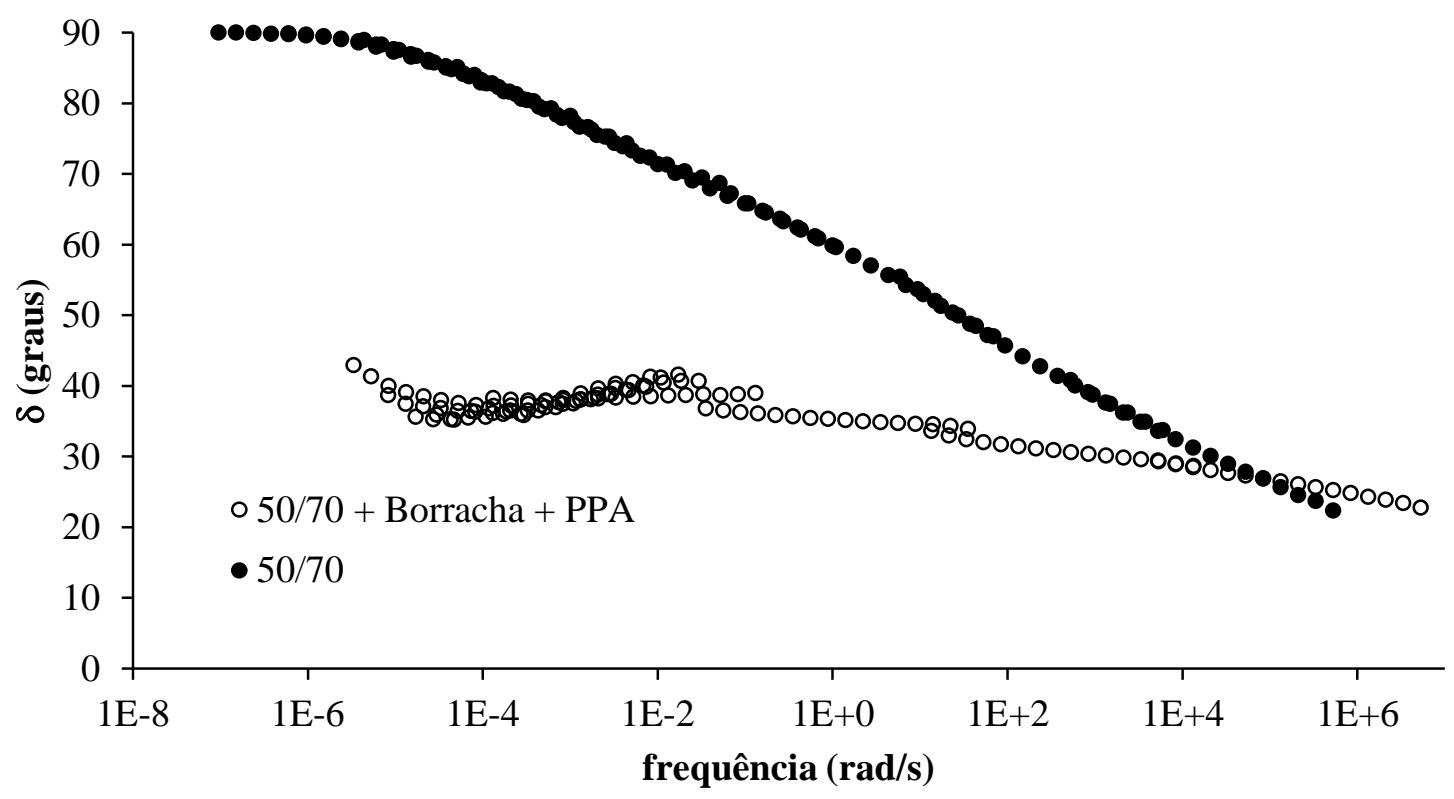

Figura A. 102 - Curva-mestre de $\delta$ da mistura 50/70-borracha-PPA em relação ao CAP puro: condição UV a $1,00 \mathrm{~W} / \mathrm{m}^{2}$

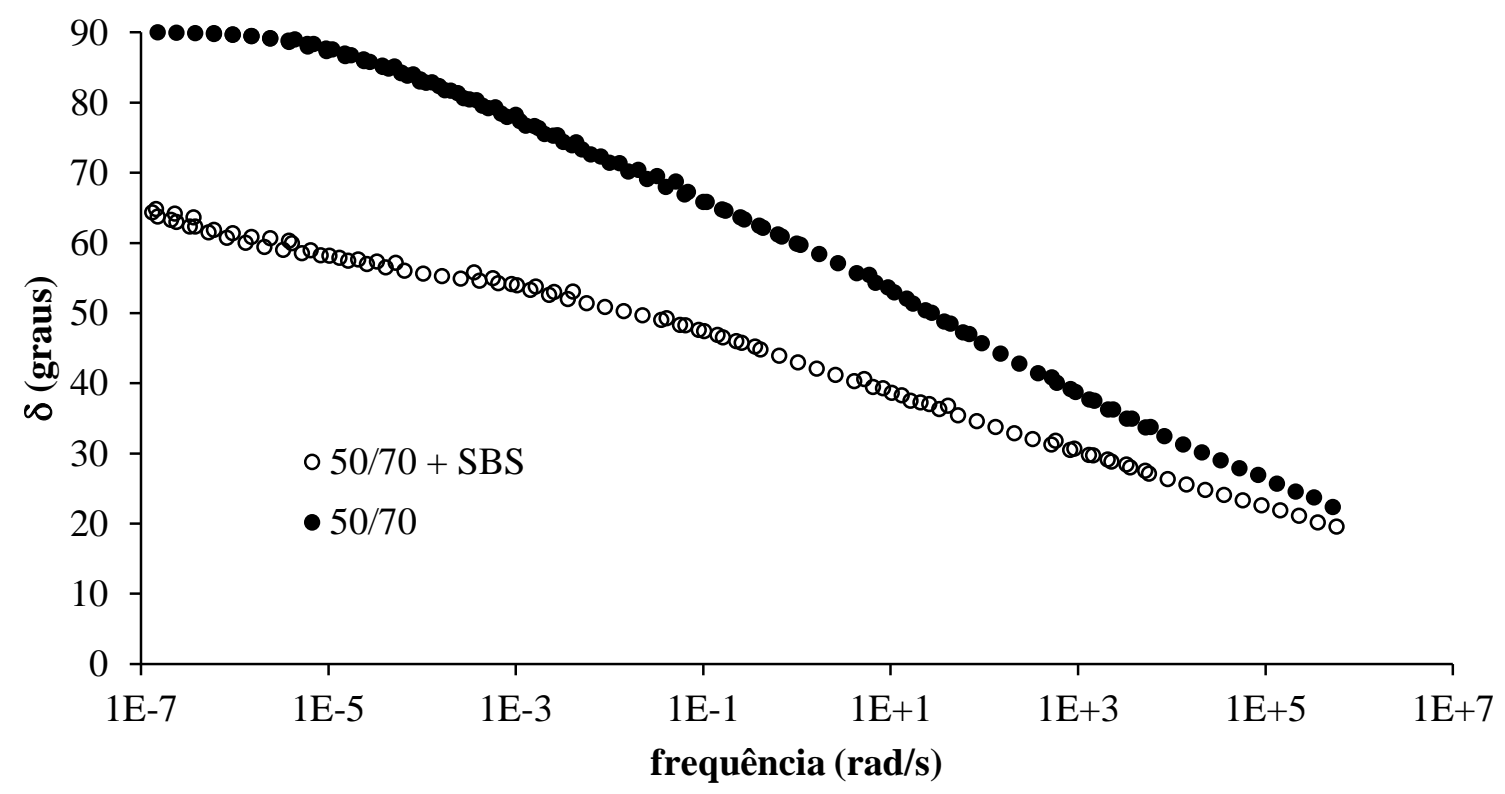

Figura A. 103 - Curva-mestre de $\delta$ da mistura 50/70-SBS em relação ao CAP puro: condição UV a $1,00 \mathrm{~W} / \mathrm{m}^{2}$ 


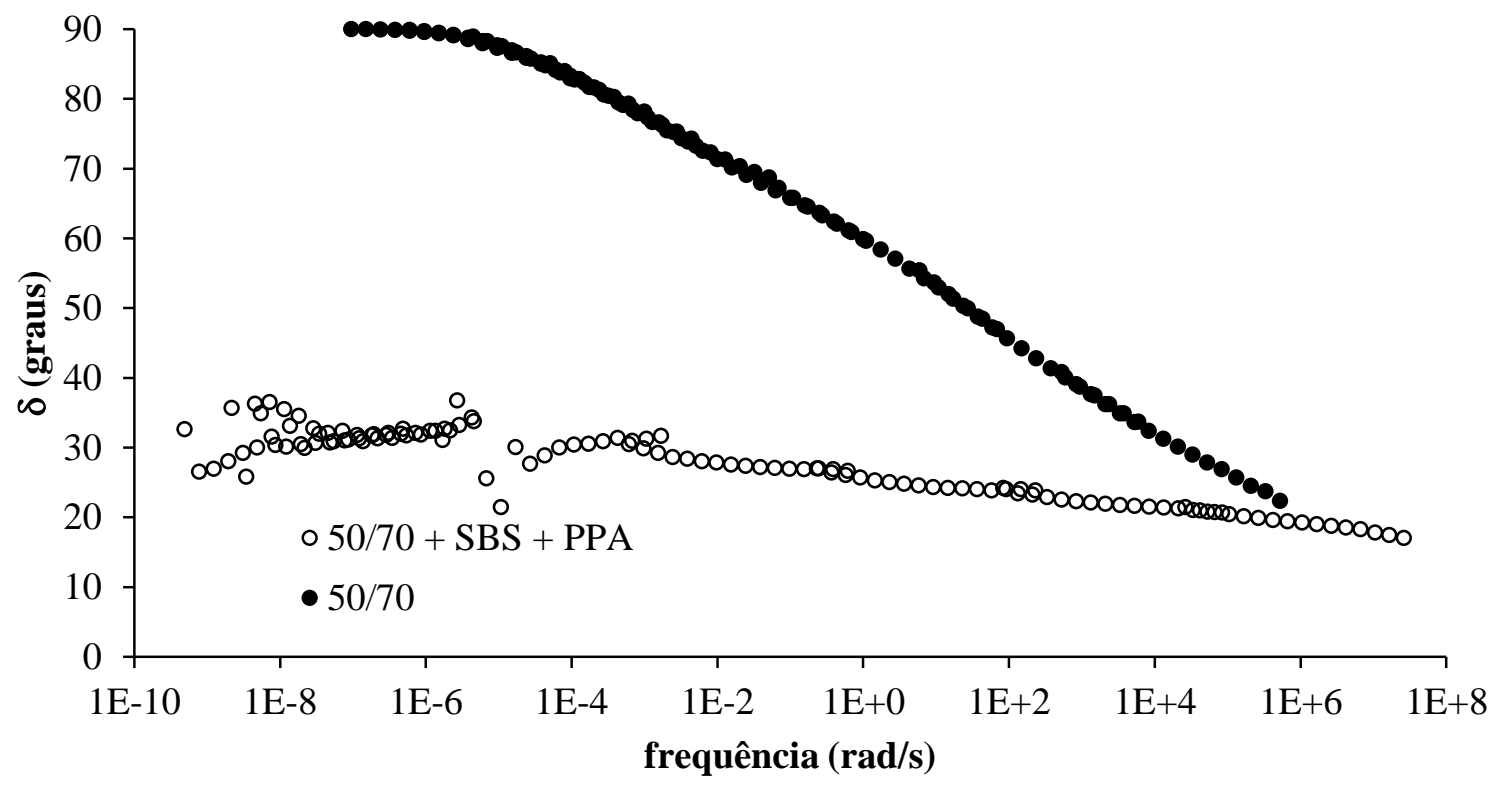

Figura A. 104 - Curva-mestre de $\delta$ da mistura 50/70-SBS-PPA em relação ao CAP puro: condição UV a $1,00 \mathrm{~W} / \mathrm{m}^{2}$

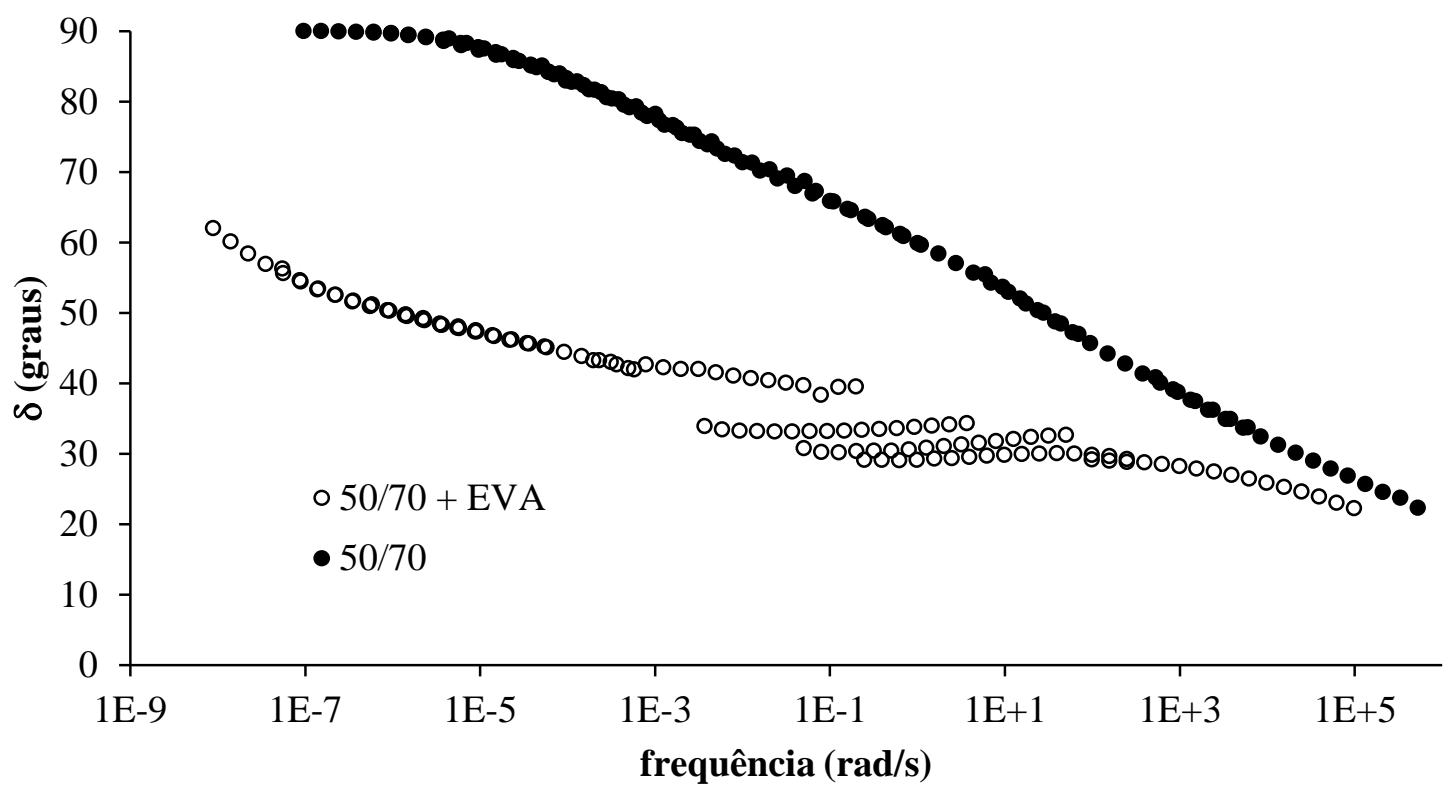

Figura A. 105 - Curva-mestre de $\delta$ da mistura 50/70-EVA em relação ao CAP puro: condição UV a $1,00 \mathrm{~W} / \mathrm{m}^{2}$ 


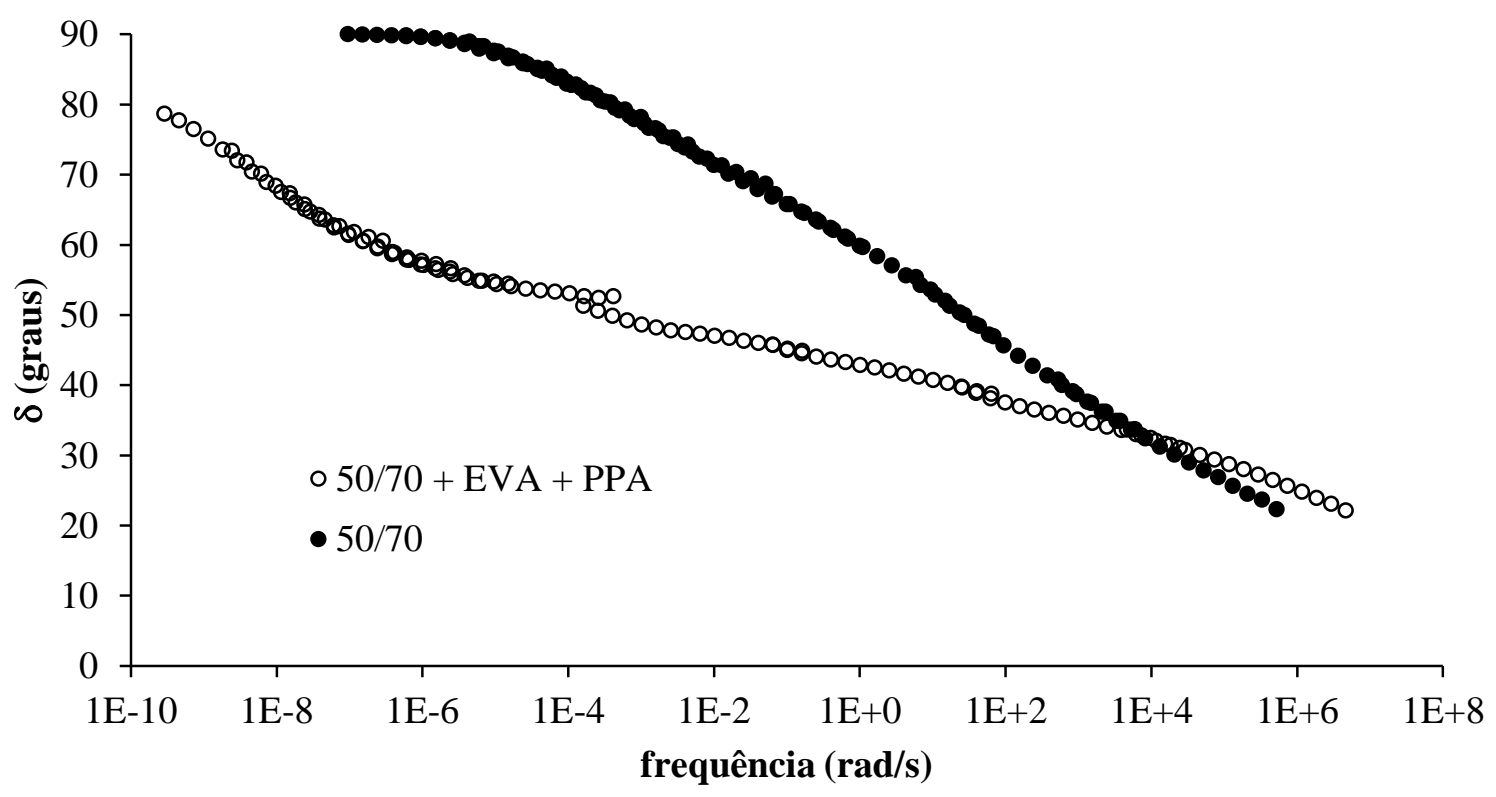

Figura A. 106 - Curva-mestre de $\delta$ da mistura 50/70-EVA-PPA em relação ao CAP puro: condição UV a $1,00 \mathrm{~W} / \mathrm{m}^{2}$

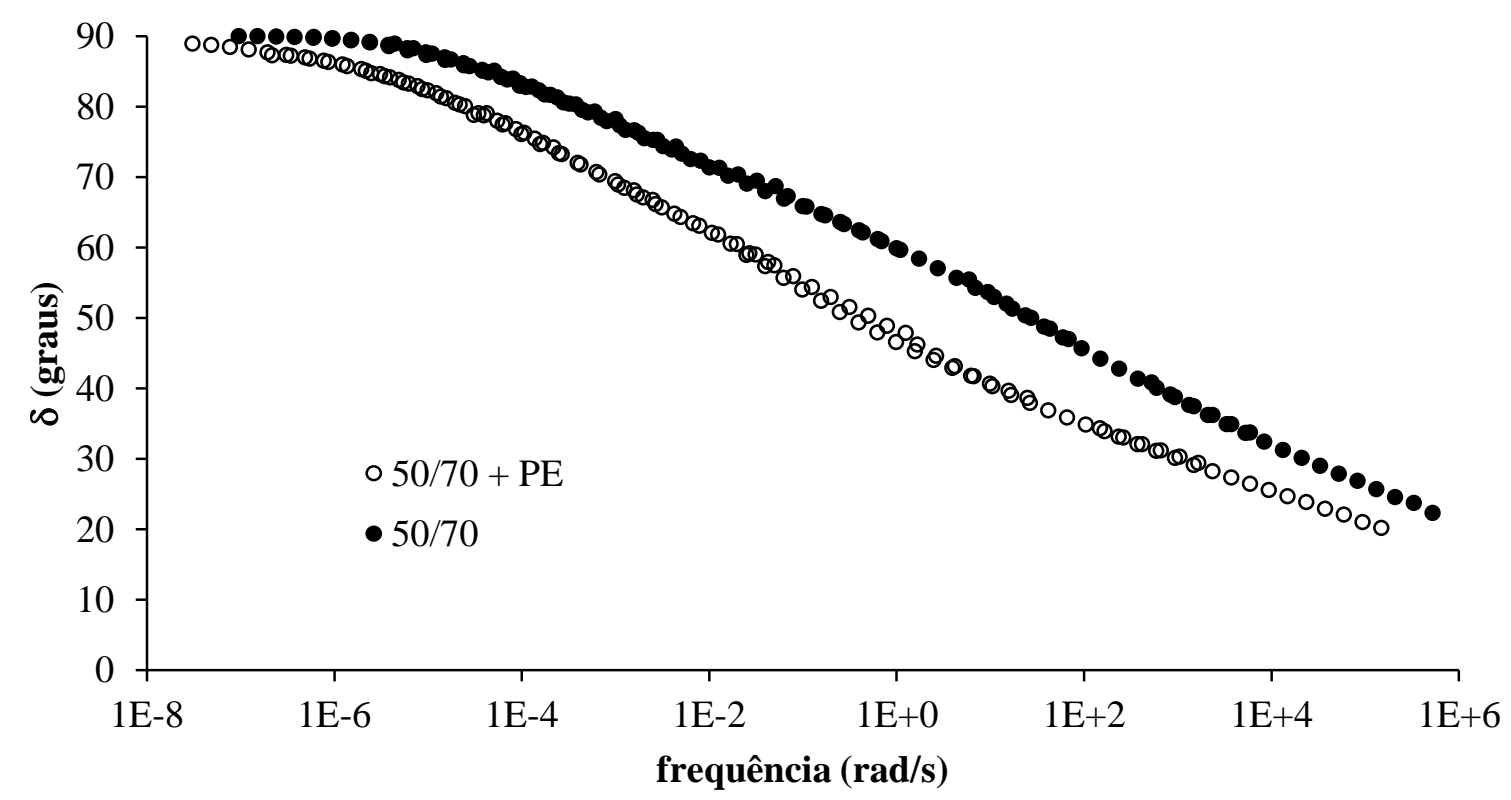

Figura A. 107 - Curva-mestre de $\delta$ da mistura 50/70-PE em relação ao CAP puro: condição UV a $1,00 \mathrm{~W} / \mathrm{m}^{2}$ 


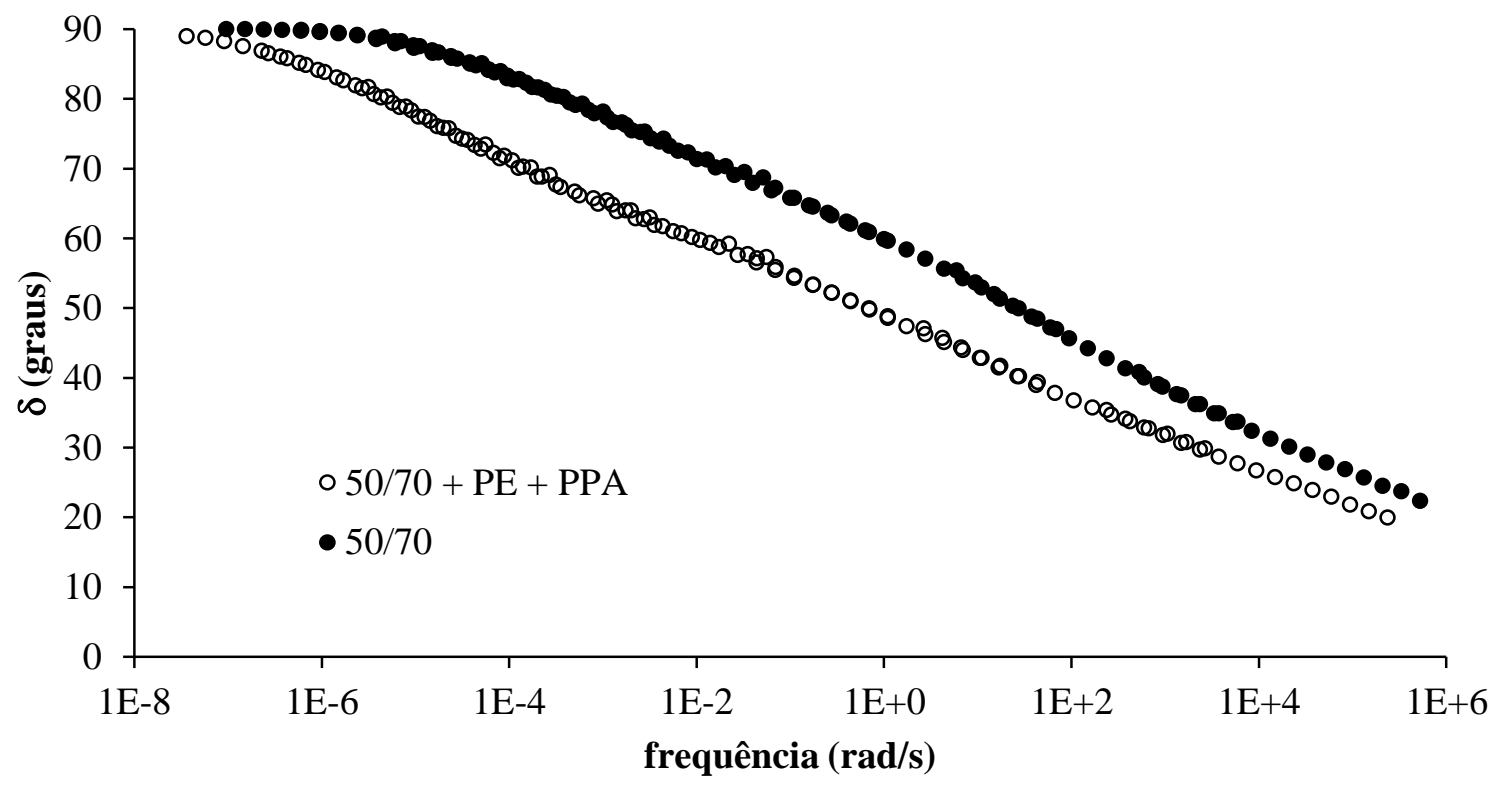

Figura A. 108 - Curva-mestre de $\delta$ da mistura 50/70-PE-PPA em relação ao CAP puro: condição UV a $1,00 \mathrm{~W} / \mathrm{m}^{2}$

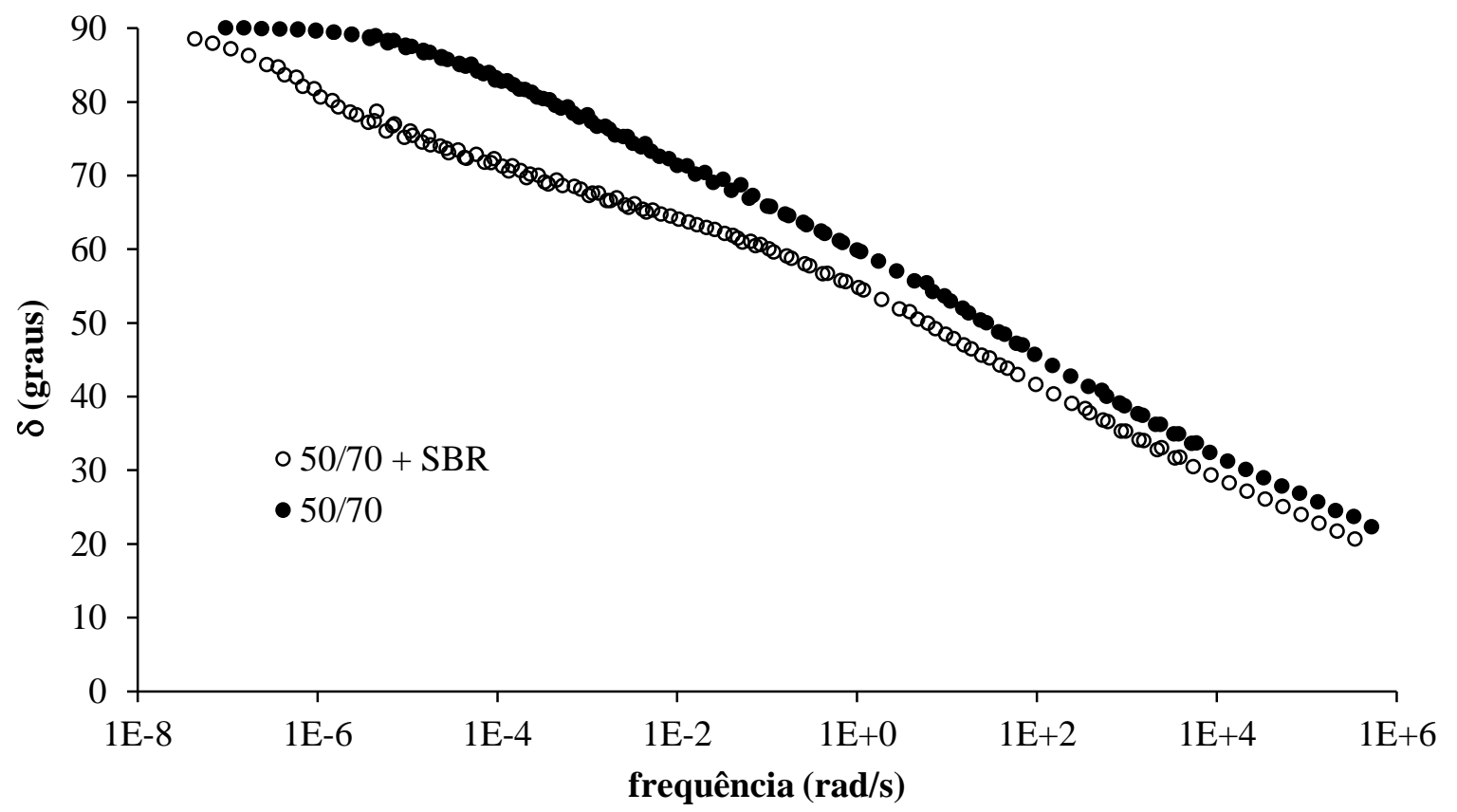

Figura A. 109 - Curva-mestre de $\delta$ da mistura 50/70-SBR em relação ao CAP puro: condição UV a $1,00 \mathrm{~W} / \mathrm{m}^{2}$ 


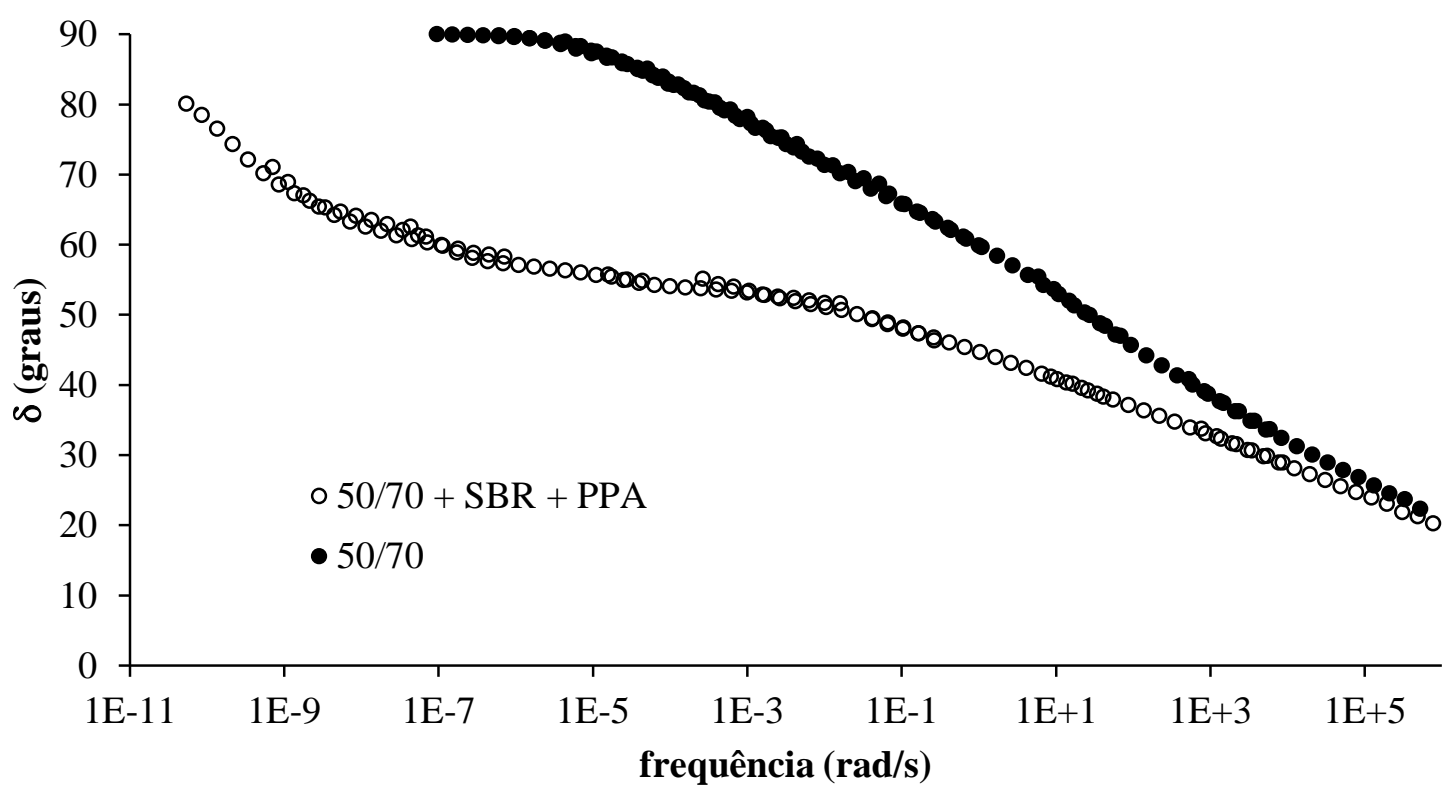

Figura A. 110 - Curva-mestre de $\delta$ da mistura 50/70-SBR-PPA em relação ao CAP puro: condição UV a $1,00 \mathrm{~W} / \mathrm{m}^{2}$ 
Proposta de procedimento para simulação do envelhecimento foto-oxidativo de ligantes asfálticos puros e modificados

\section{INTRODUÇÃO}

O presente procedimento tem por objetivo nortear a simulação do envelhecimento foto-oxidativo que os ligantes asfálticos puros ou modificados, presentes nos revestimentos asfálticos, estão expostos ao longo da vida em serviço. São apresentados os procedimentos de ensaio e de análise desenvolvidos neste estudo.

\section{EQUIPAMENTOS E MATERIAIS}

Os seguintes equipamentos e materiais são necessários:

- 30 g de ligante asfáltico, puro ou modificado, envelhecido previamente a curto prazo na estufa RTFO, conforme método ASTM D2872-97;

- estufa de filme fino rotativo (RTFO) para envelhecer as amostras a curto prazo;

- balança de precisão;

- bandeja metálica com dimensões 21,5 x 32,0 cm;

- equipamento utilizado na simulação de radiação ultravioleta - estufa UV;

- reômetro de cisalhamento dinâmico (DSR) para realização de ensaios reológicos.

\section{PROCEDIMENTO DE ENVELHECIMENTO UV}

Após a retirada do resíduo envelhecido no RTFO, verter 30g na bandeja metálica, distribuindo o ligante asfáltico de forma a recobrir toda a área da bandeja, formando um filme ultradelgado. Quando for necessário, aquecer a amostra para o ligante asfáltico fluir pela superfície da bandeja. Pra isto, utilizar a temperatura de $160^{\circ} \mathrm{C}$ para ligantes asfálticos modificados e de $140^{\circ} \mathrm{C}$ para ligantes asfálticos puros. Após o recobrimento total da 
274

superfície da bandeja, aguardar o resfriamento. Colocar a bandeja na estufa UV calibrado em $0,68 \mathrm{~W} / \mathrm{m}^{2}$. A temperatura do painel onde a bandeja é colocada deve ser de $60^{\circ} \mathrm{C}$ e temperatura do ar interno deve ser de $40^{\circ} \mathrm{C}$. O período de exposição contínua à irradiação deve ser de 240h. Durante este período, faz-se necessário o monitoramento das condições da estufa, para garantir as mesmas condições do início ao fim do ensaio. Após a retirada da bandeja, ao fim das $240 \mathrm{~h}$, aquecê-la em uma estufa (ligante asfáltico modificado a $160^{\circ} \mathrm{C}$ e CAP puro a $140^{\circ} \mathrm{C}$ ) para a retirada do resíduo, que deverá ser armazenado em um recipiente seco e limpo para a posterior realização de ensaios reológicos.

\section{PROCEDIMENTO DE ANÁlISE DOS EFEITOS DO ENVELHECIMENTO - CURVAS-MESTRE}

Um dos procedimentos de análise das propriedades reológicas, utilizando o reômetro de cisalhamento dinâmico, é a composição de curvas-mestre, da seguinte forma: (1) a amostra deve ser submetida à varredura de tensão, nas temperaturas de 52, 64, 76 e $88^{\circ} \mathrm{C}$, na frequência de $10 \mathrm{rad} / \mathrm{s}$, empregando geometria de $25 \mathrm{~mm}$ de diâmetro e distância entre placas de 1,0 mm, a fim de determinar a tensão que solicita o material, em cada temperatura, na faixa de viscoelasticidade linear; (2) a amostra deve ser submetida à varredura de tensão, a 40, 28, 16 e $4{ }^{\circ} \mathrm{C}$, a $10 \mathrm{rad} / \mathrm{s}$, empregando geometria de $8 \mathrm{~mm}$ de diâmetro e distância entre placas de 2,0 mm; (3) a amostra deve ser submetida à varredura de frequência, entre 0,1 e $100 \mathrm{rad} / \mathrm{s}$, a 52, 64, 76 e $88^{\circ} \mathrm{C}$, nas tensões obtidas em (1) com geometria de $25 \mathrm{~mm}$ e distância entre placas de 1,0 mm; (4) outra amostra deve ser submetida à varredura de frequência, entre $0,1 \mathrm{e}$ $100 \mathrm{rad} / \mathrm{s}$, a 40,28, 16 e $4{ }^{\circ} \mathrm{C}$, nas tensões obtidas em (2), com geometria de $8 \mathrm{~mm}$ e distância entre placas de 2,0 mm; e (5) a curva-mestre deve ser composta na temperatura de referência de $25^{\circ} \mathrm{C}$. As análises devem visar a comparação entre os materiais envelhecidos e seus correspondentes, seja na condição virgem, envelhecida a curto prazo no RTFO ou a longo prazo no PAV, em termos de quantas vezes o envelhecimento UV contribuiu para a variação de propriedades como o ângulo de fase $(\delta)$, a rigidez $\left(\mathrm{G}^{*}\right)$ e o parâmetro de fadiga $\mathrm{G}^{*}$.sen $\delta$. 